\title{
Advanced Small Modular Reactor (SMR) Probabilistic Risk Assessment (PRA) Technical Exchange Meeting
}

Curtis Smith

September 2013

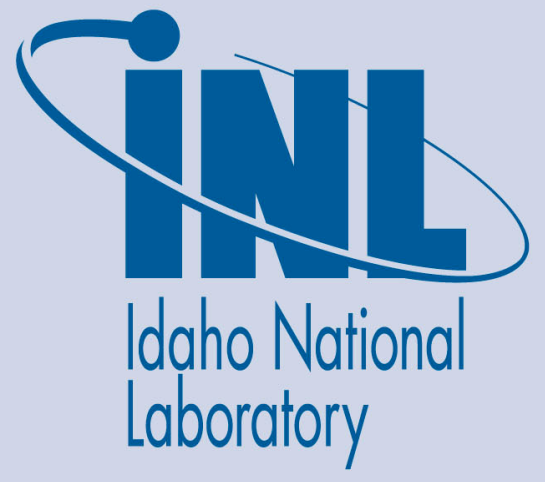

The INL is a U.S. Department of Energy National Laboratory operated by Battelle Energy Alliance 
INL/EXT-13-30170

\title{
Advanced Small Modular Reactor (SMR) Probabilistic Risk Assessment (PRA) Technical Exchange Meeting
}

\author{
Curtis Smith
}

September 2013

\author{
Idaho National Laboratory \\ Idaho Falls, Idaho 83415
}

http://www.inl.gov

Prepared for the

U.S. Department of Energy

Office of Nuclear Energy

Under DOE Idaho Operations Office

Contract DE-AC07-05ID14517 


\section{Chapter}

\section{Introduction}

\subsection{Overview}

A key area of the Advanced Small Modular Reactor (SMR) Probabilistic Risk Assessment (PRA) strategy is the development of methodologies and tools that will be used to predict the safety, security, safeguards, performance, and deployment viability of SMR systems starting in the design process through the operation phase. The goal of the SMR PRA activity will be to develop quantitative methods and tools and the associated analysis framework for assessing a variety of risks. These risks will be focused on SMR designs and operational strategies as they relate to the technical basis behind safety and security characterization.

Development and implementation of SMR-focused safety assessment methods may require new analytic methods or adaptation of traditional methods to the advanced design and operational features of SMRs. We will need to move beyond the current limitations such as static, logic-based models in order to provide more integrated, scenario-based models based upon predictive modeling which are tied to causal factors. The development of SMR-specific safety models for margin determination will provide a safety case that describes potential accidents, design options (including postulated controls), and supports licensing activities by providing a technical basis for the safety envelope.

During FY13, the INL developed an advanced SMR PRA framework which has been described in the report Small Modular Reactor (SMR) Probabilistic Risk Assessment (PRA) Detailed Technical Framework Specification, INL/EXT-13-28974 (April 2013). In this framework, the various areas are considered:

- Probabilistic models to provide information specific to advanced SMRs

- Representation of specific SMR design issues such as having co-located modules and passive safety features

- Use of modern open-source and readily available analysis methods

- Internal and external events resulting in impacts to safety

- All-hazards considerations

- Methods to support the identification of design vulnerabilities

- Mechanistic and probabilistic data needs to support modeling and tools

In order to describe this framework more fully and obtain feedback on the proposed approaches, the INL hosted a technical exchange meeting during August 2013. This report describes the outcomes of that meeting. 


\subsection{Technical Exchange Meeting Structure}

The technical exchange meeting took place on August 21 and 22, 2013. The overall structure, topics, and presenters during the meeting are:

Introduction, Background and Agenda

The purpose of this meeting is to obtain stakeholder feedback on the Small Modular Reactor Probabilistic Risk Assessment Detailed Technical Framework Specification report published by the INL.

aSMR PRA, Safety, and Licensing Activities

Jim Kinsey - Idaho National Laboratory

Overview of the Advanced SMR PRA Framework

Curtis Smith - Idaho National Laboratory

Development of Surrogates for Core Damage Frequency and Large Early Release Frequency for Advanced Small Modular Reactors

George Flanagan - Oak Ridge National Laboratory

Identification of Initiating Events for aSMRs

Mike Muhlheim - Oak Ridge National Laboratory

\section{NGNP Licensing Overview}

Mark Holbrook - Idaho National Laboratory

Advanced PRA Methods for aSMRs

Diego Mandelli - Idaho National Laboratory 
Cloud Technologies for use in Risk Assessment

Curtis Smith - Idaho National Laboratory

Risk-Informing Severe Accident Management Guidelines for aSMRs

Matthew Denman - Sandia National Laboratory

Review of Passive System Reliability Modeling Approaches for aSMRs

Dave Grabaskas - Argonne National Laboratory

3D Representation of Safety Hazards

Steve Prescott - Idaho National Laboratory 


\section{Chapter}

\section{Meeting Discussion}

In addition to the presentations (slides of which are provided in Appendix A), discussion and question/answer sessions were facilitated. Included in the comments are:

- It would be helpful to find industry partners to play a role in the PRA prototype development.

- It was noted that the NRC will be (as part of its proposed NUREG-2150 activities) looking at "Design Enhancements." These are called "Design Extension Conditions" by IAEA.

- Discussion was held related to whether untested passive features would work far in the future (e.g., 59 years later) in the context of aging and degradation mechanisms being present. An issue of inspectability seems to be more pressing for SMRs since they are (1) more integrated and (2) shipped (somewhat) prefabbed.

- It may be needed to make the initiating events list for advanced SMRs a "living document" to accommodate new issues, new ideas, and new modeling techniques as the project progresses. For example, if we move to simulating a variety of loss-ofcoolant-accident (LOCA) break sizes, it may be that we simply have an initiating event called "LOCAs" rather than small LOCAs, medium LOCAS, large LOCAs, etc.

- It was noted for advanced reactors and passive designs that we should be able to find "cliff edge" effects at some (perhaps small in frequency) level in the risk analysis. Otherwise the regulator may not believe the analysis.

- The topic of using the Fukushima accident to benchmark an advanced flooding analysis may be a useful activity since a large quantity of information is available for that specific type of external event.

- Discussions were held concerning the need for a "generic" advanced SMR model that can be used by all of the analysis teams to provide a common-platform for our modeling and tool development.

- A question was asked about who is the primary target audience for the PRA framework? One response to this question was the following figure: 


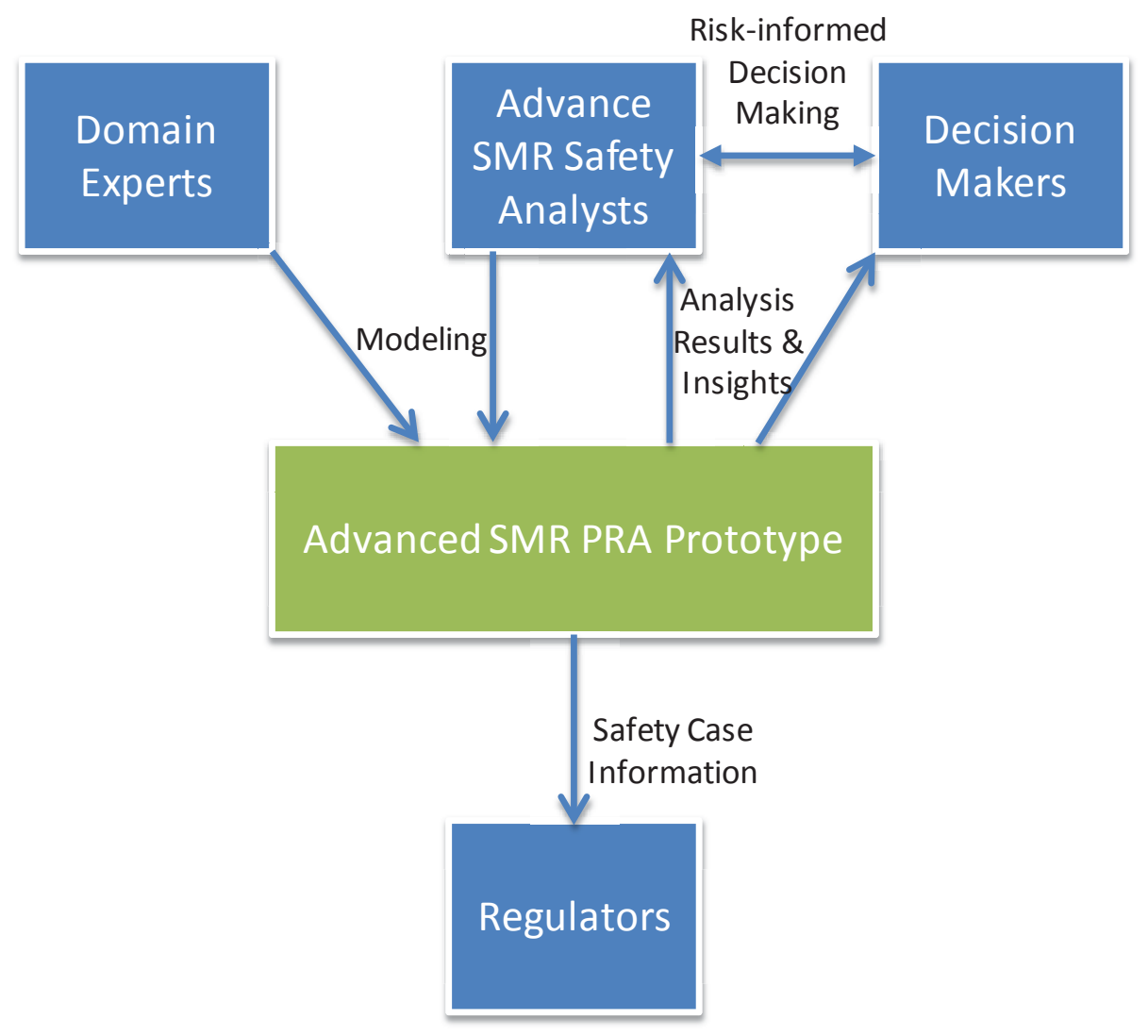

Attendees at the meeting were:

Amos, Willettia DOE-Idaho

Denman, Matthew Sandia National Laboratory

Flanagan, George Oak Ridge National Laboratory

Grabaskas, David Argonne National Laboratory

Holbrook, Mark Idaho National Laboratory

Kinsey, Jim Idaho National Laboratory

Munlheim, Mike Oak Ridge National Laboratory

Prescott, Steve Idaho National Laboratory

Sattison, Martin Idaho National Laboratory

Smith, Curtis Idaho National Laboratory

Sofu, Tanju Argonne National Laboratory

Wheeler, Tim Sandia National Laboratory

Youngblood, Bob Idaho National Laboratory

Unwin, Stephen Pacific Northwest National Laboratory 


\section{Appendix

$$
\Delta
$$$$
\text { Presentation Slides }
$$

The slides that were presented during the technical exchange meeting are listed in this Appendix. 

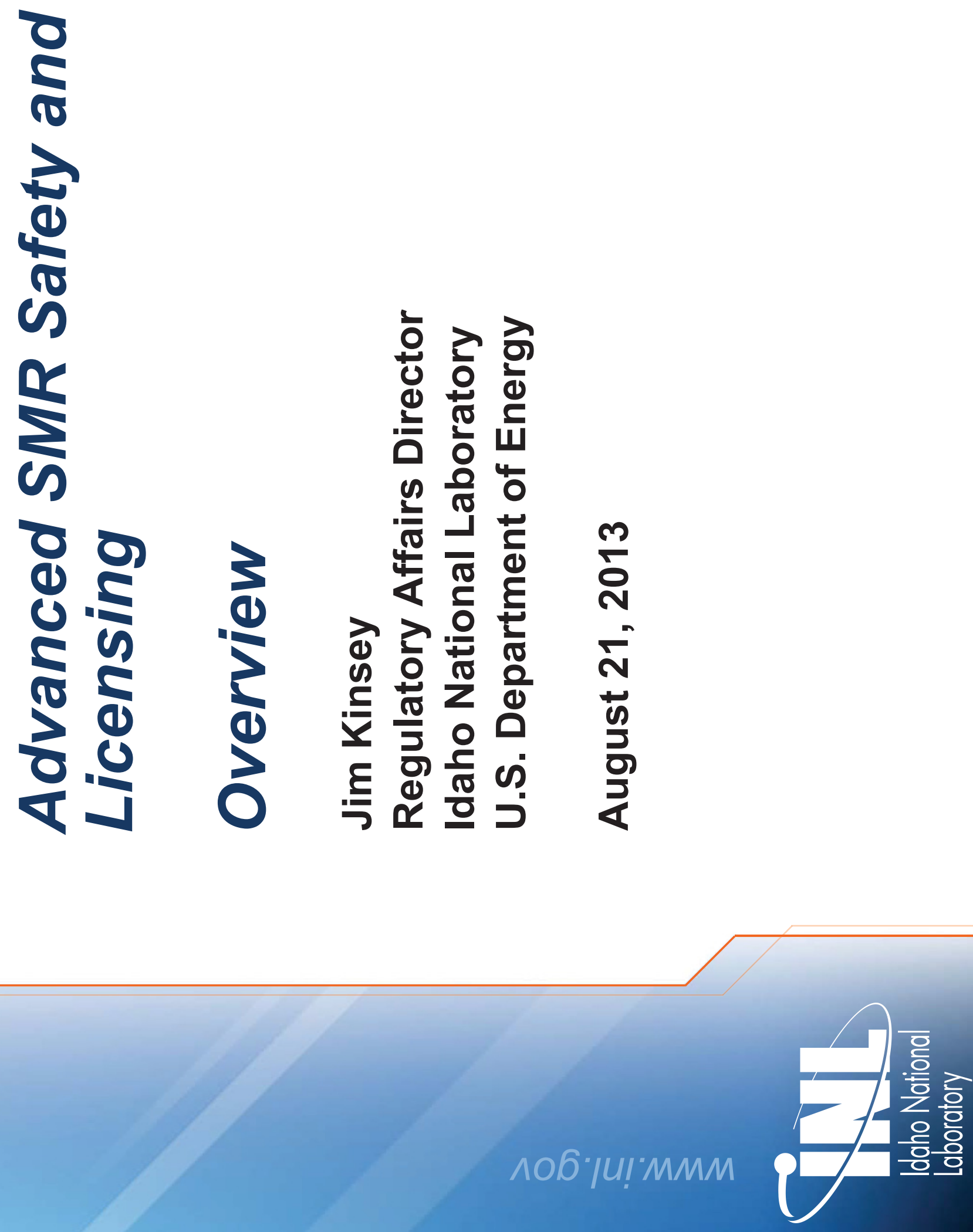


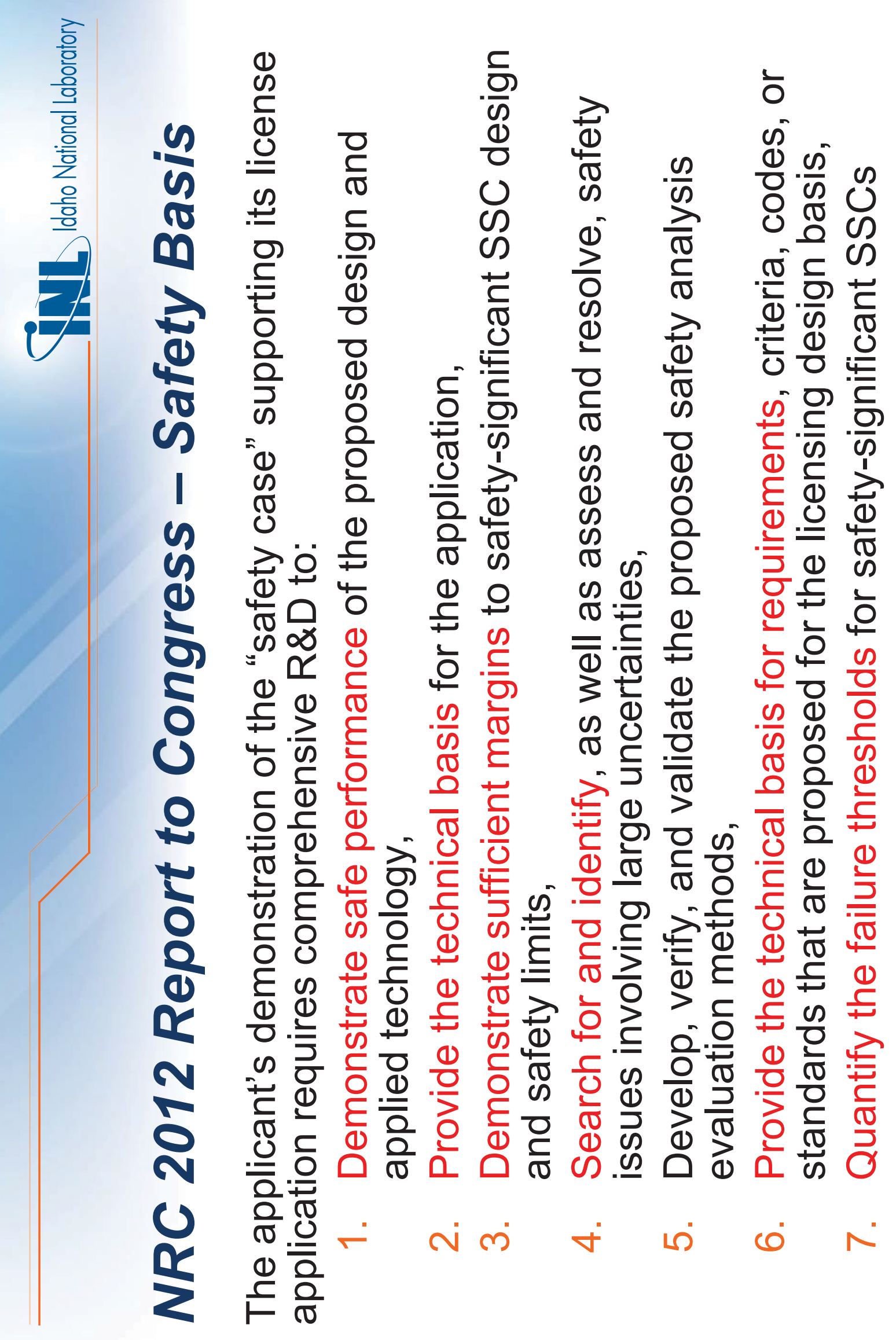




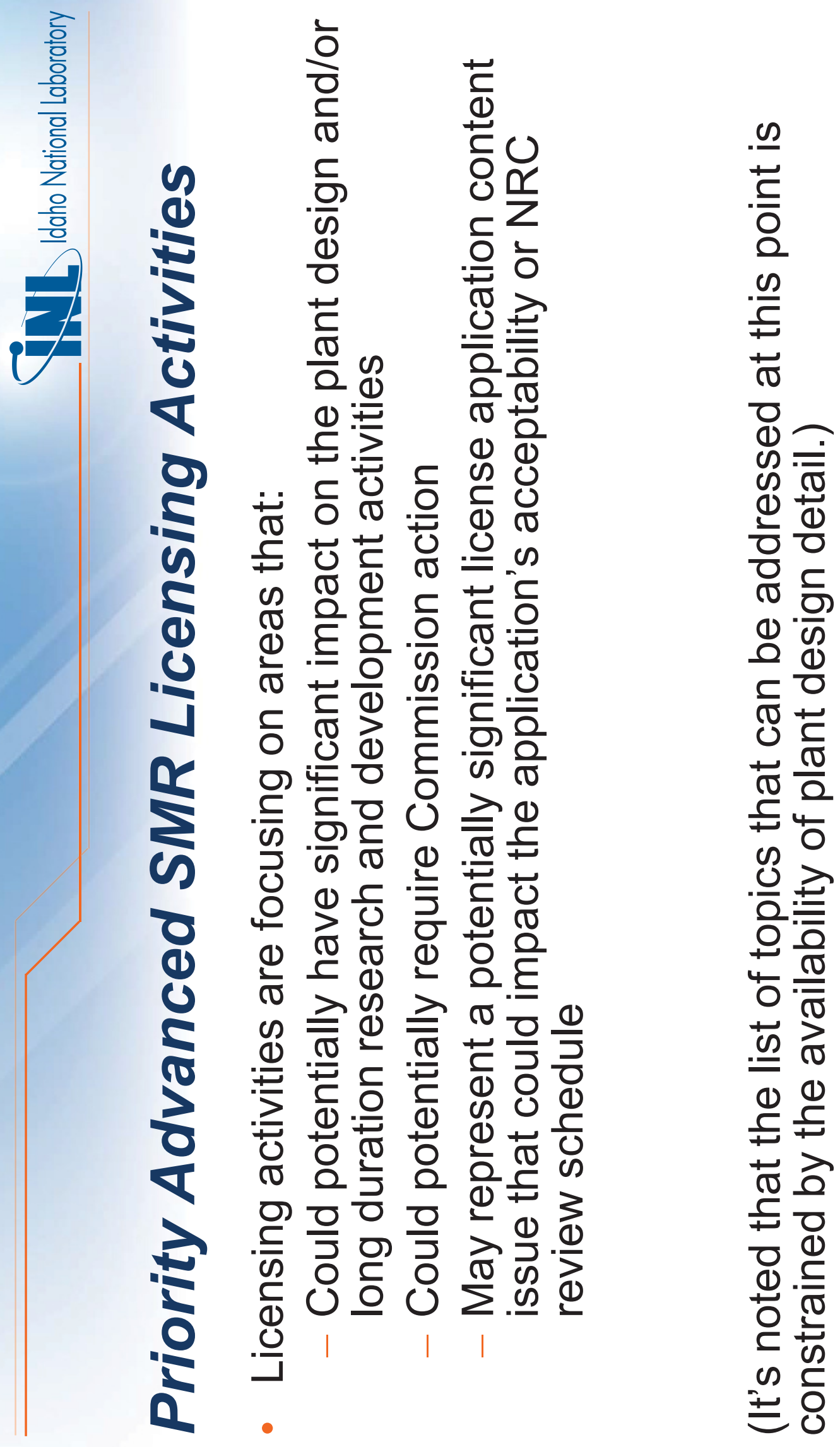



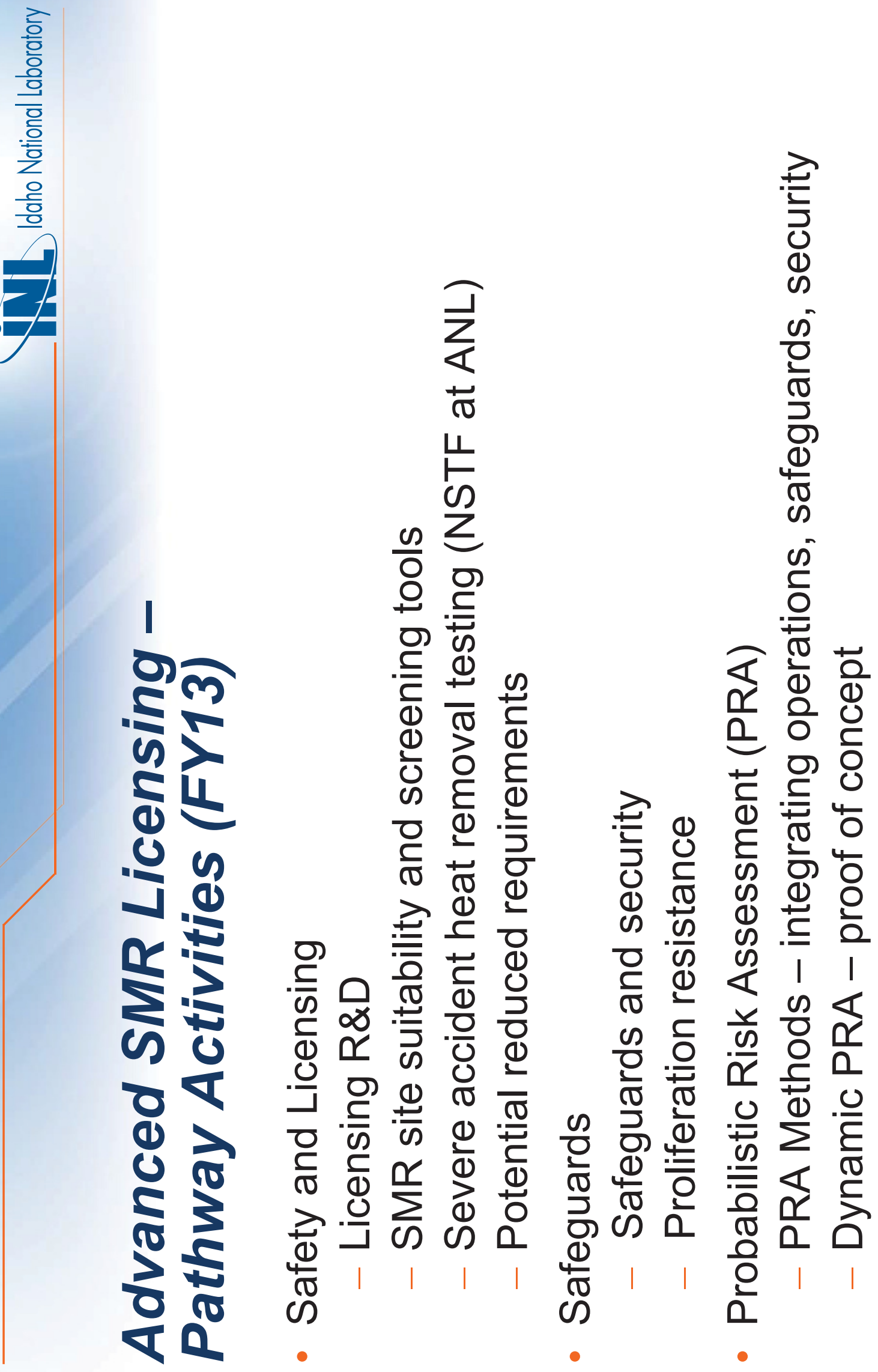


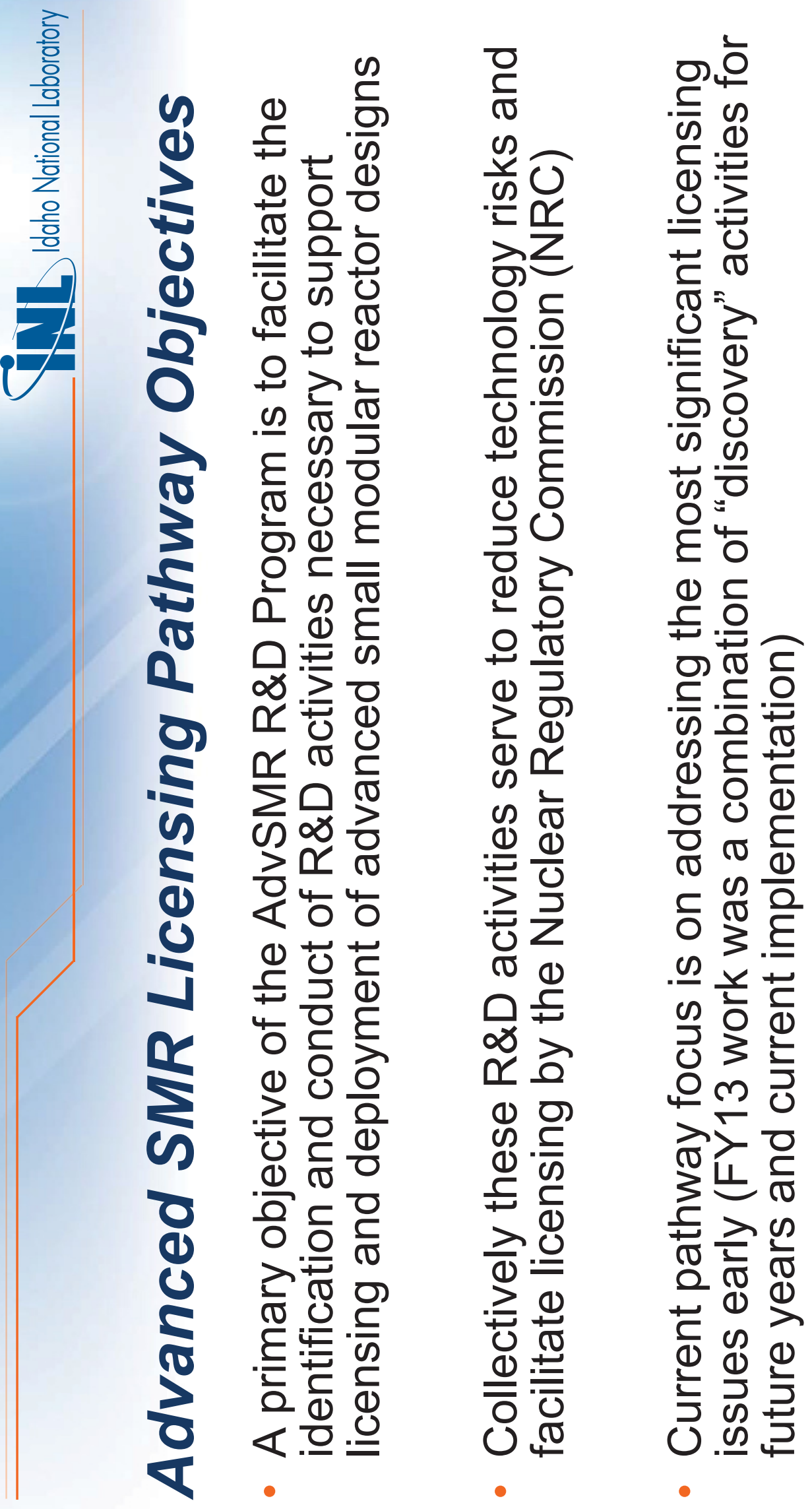



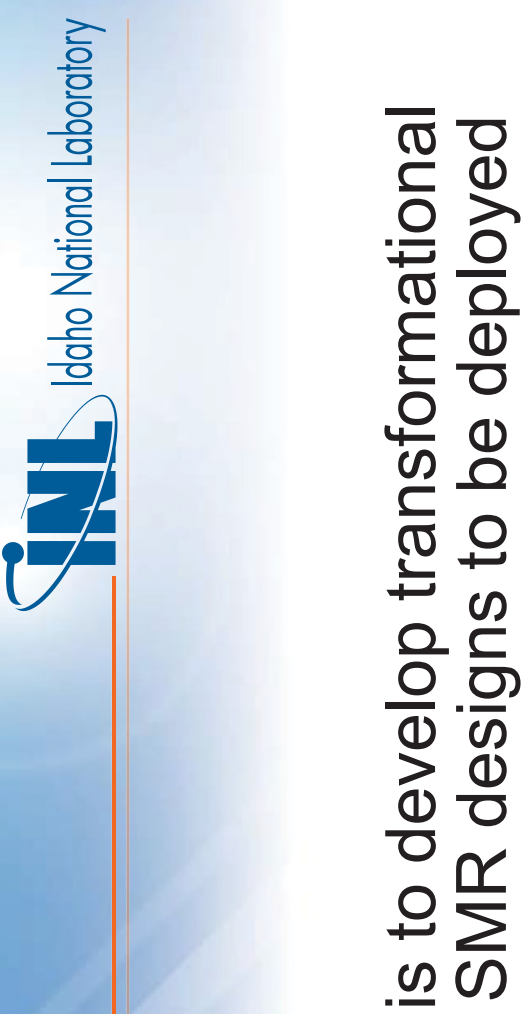

돈 든

ำ

ㄴำ

들

$\alpha$ O

() $\sum x$

(1) 01

$0 \geqslant \frac{1}{6}$

$<\frac{0}{0}$

$10 \frac{0}{\sigma}$

- $\frac{E}{4}$

(1) 0

(1)

(1)

0.10

$\frac{1}{0} \frac{0}{0} \mathrm{~m}$

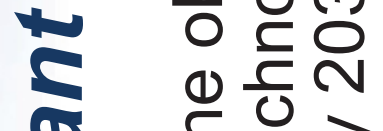

10 뻐

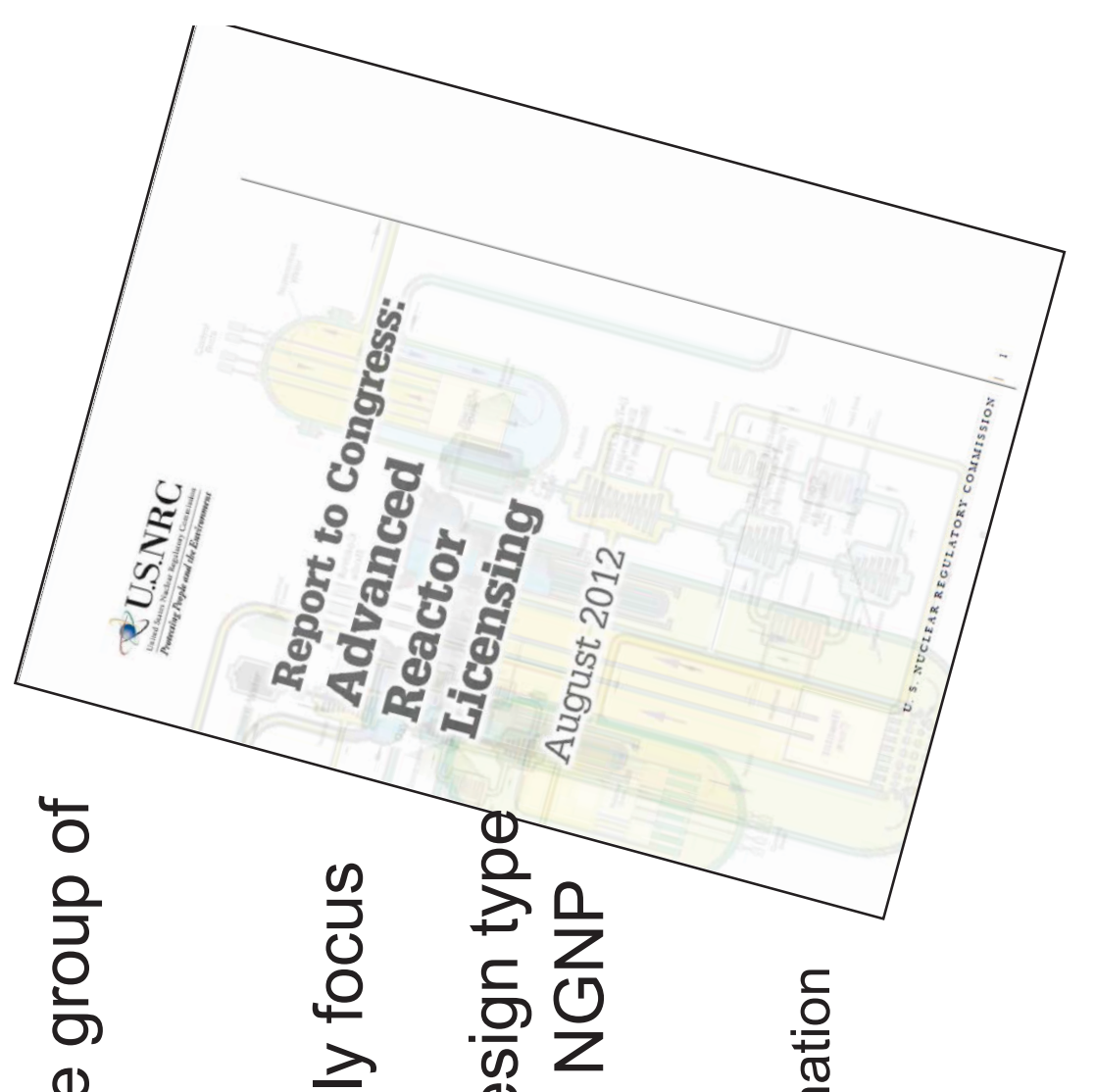

(1)

$\geqq$

(1)

$\frac{1}{10}$

0

(1)

응

논 늘

(ช) $\frac{5}{\sigma}$

든

(으

ป

4

굴

ब.

-

送

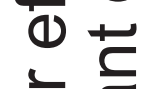

훈흥

$\frac{2}{\sqrt{\sigma}} \quad \frac{0}{0} \quad \frac{\pi}{>}$

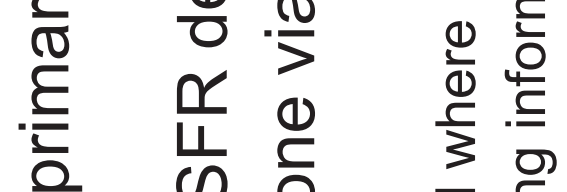

\begin{tabular}{lllll}
$\overline{0}$ & 0 & \multicolumn{1}{c}{} & 3 & 0 \\
& 0 & 0 & 0
\end{tabular}

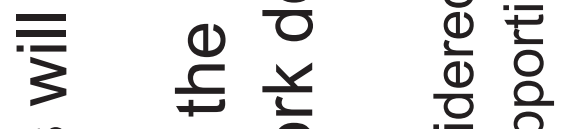

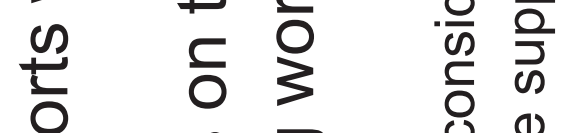

范 ब

(1) : 仓

들

ज

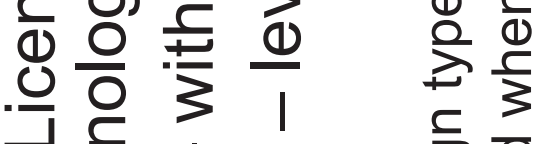

Q 


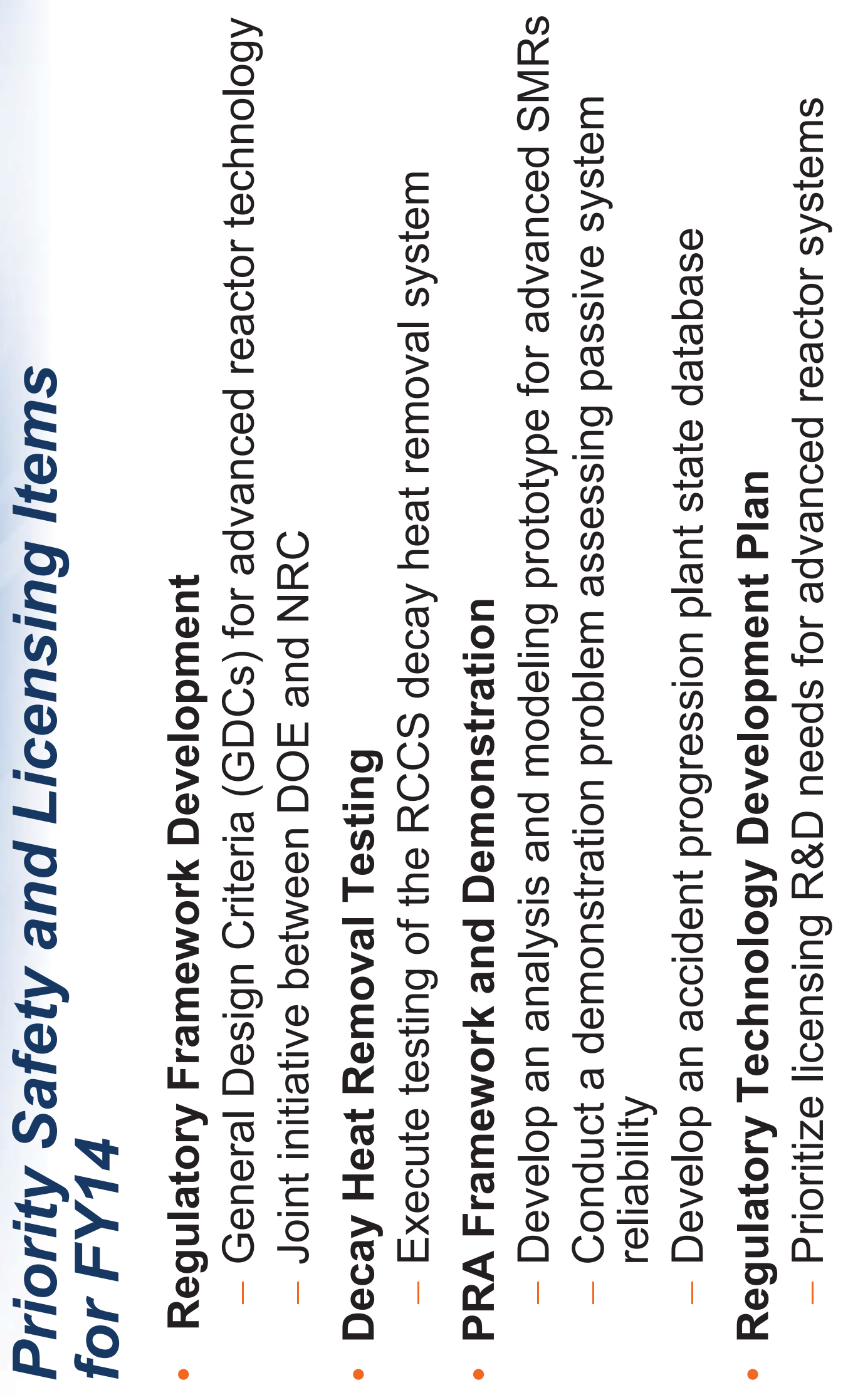




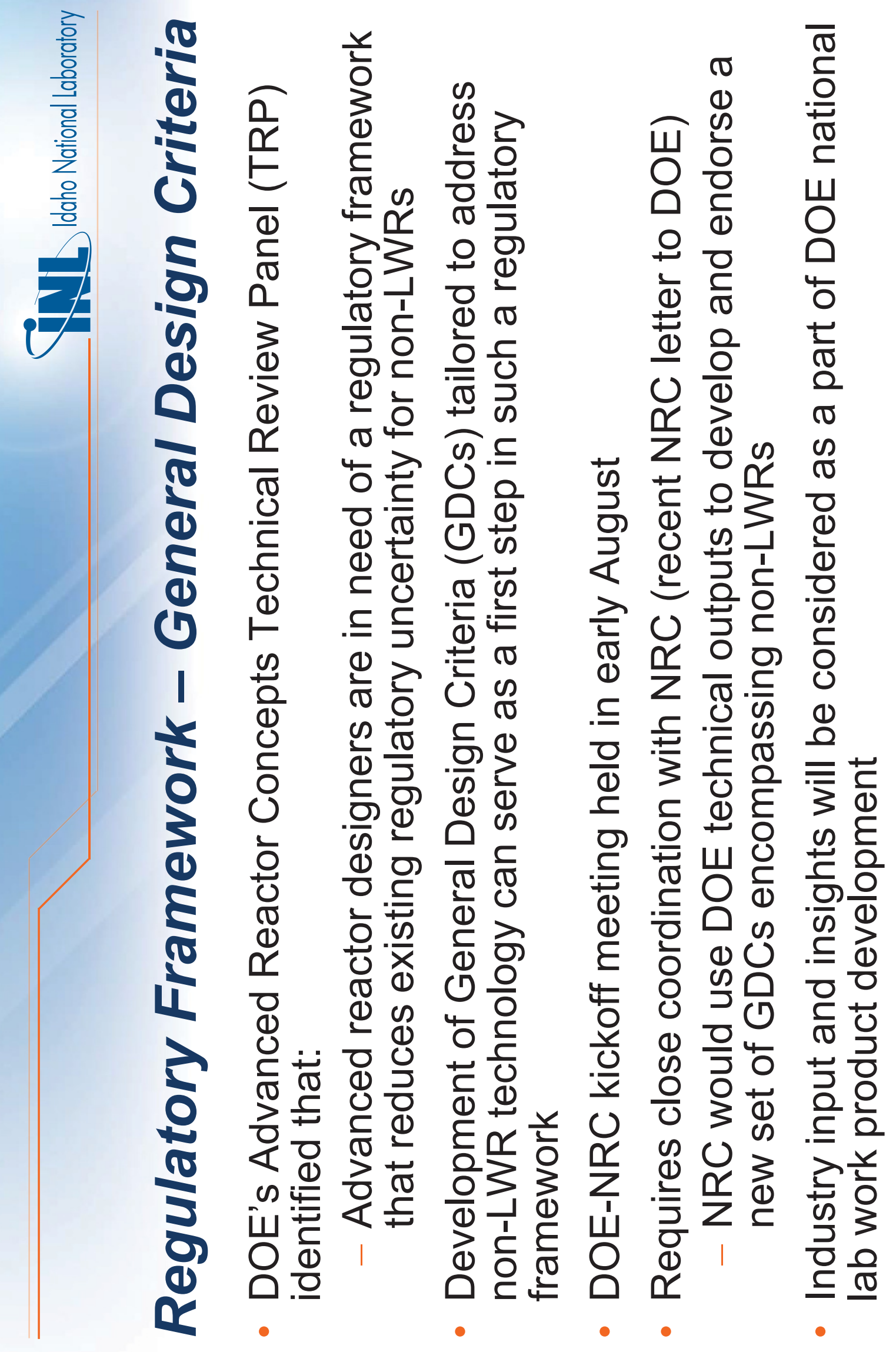




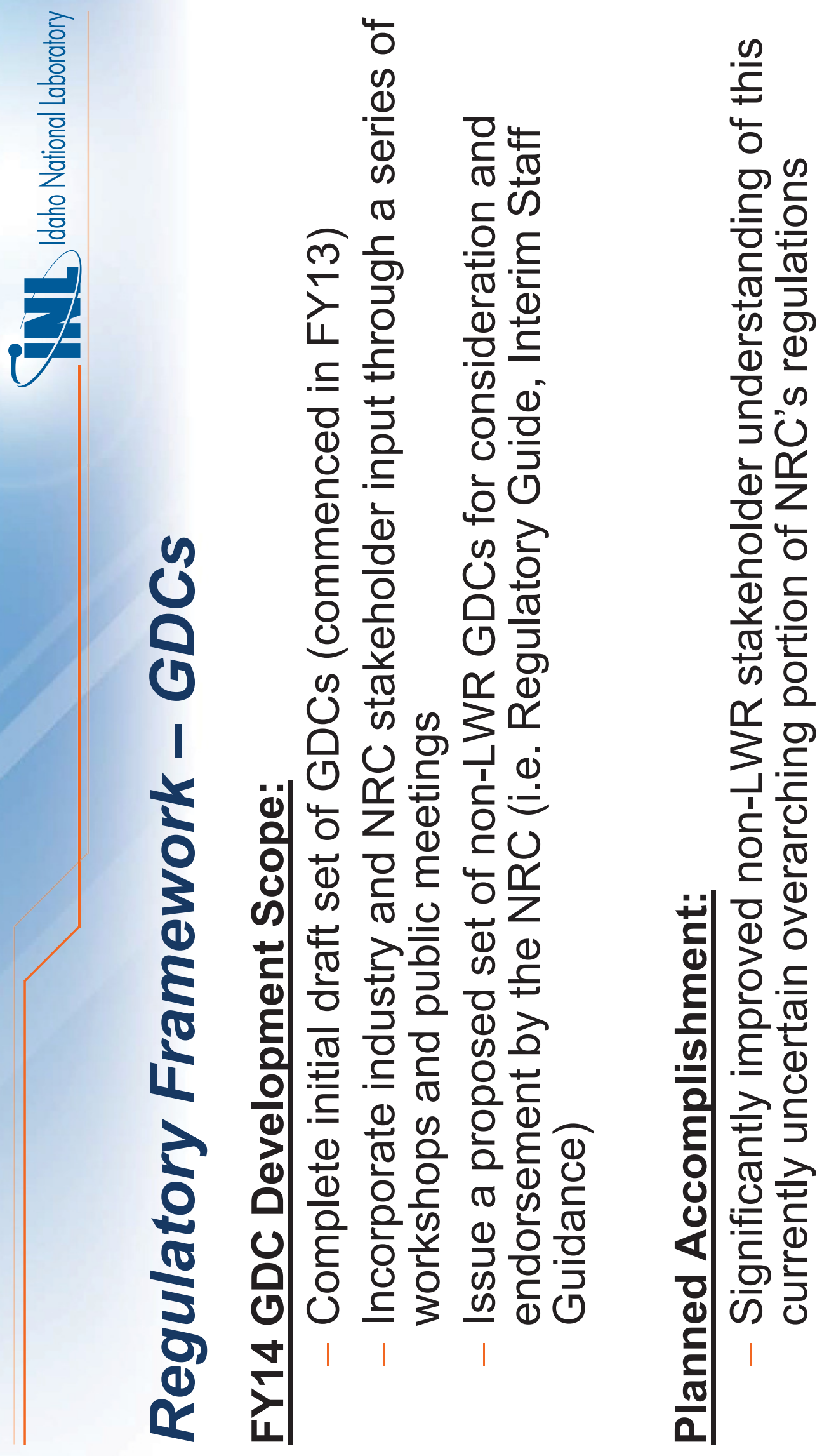



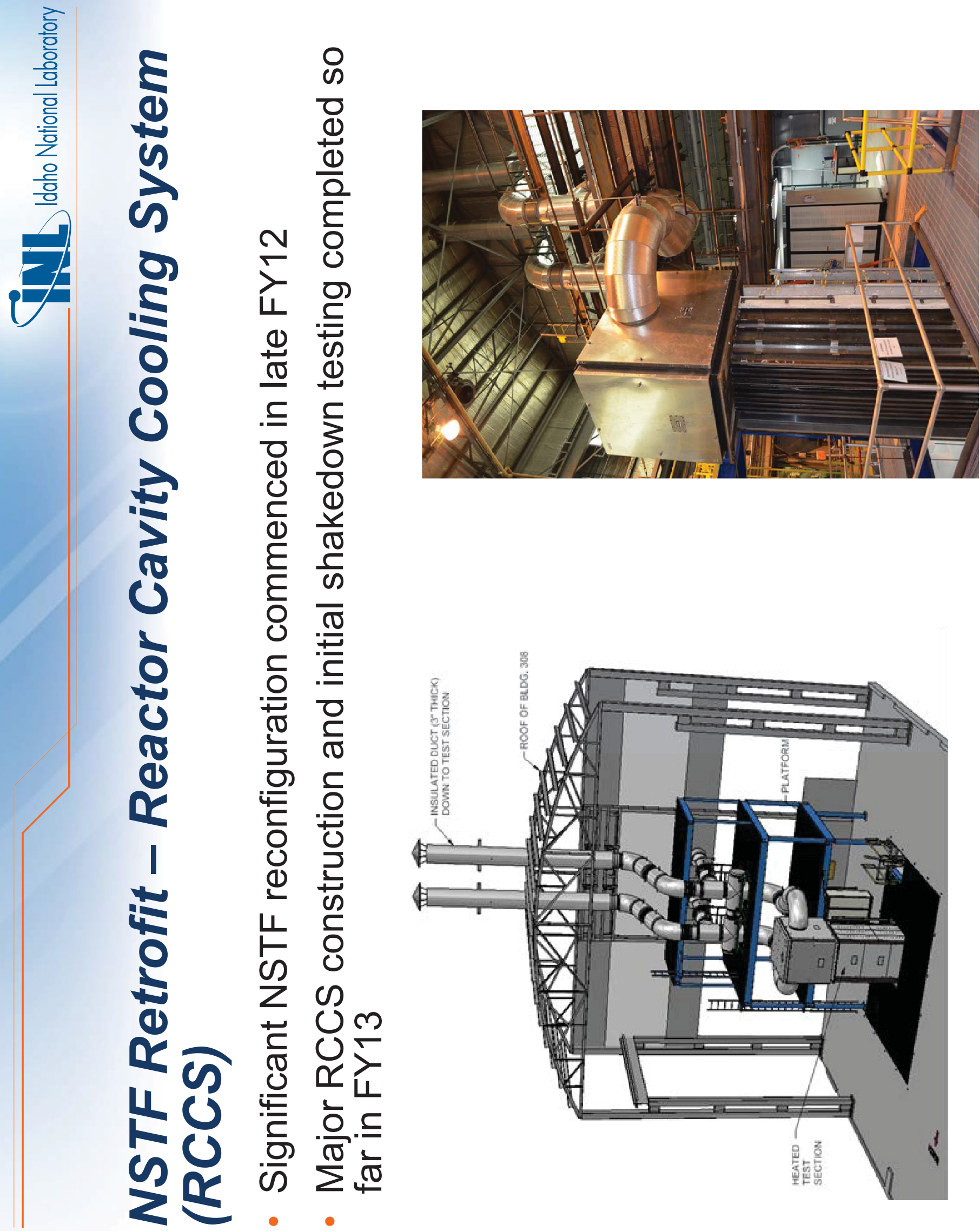


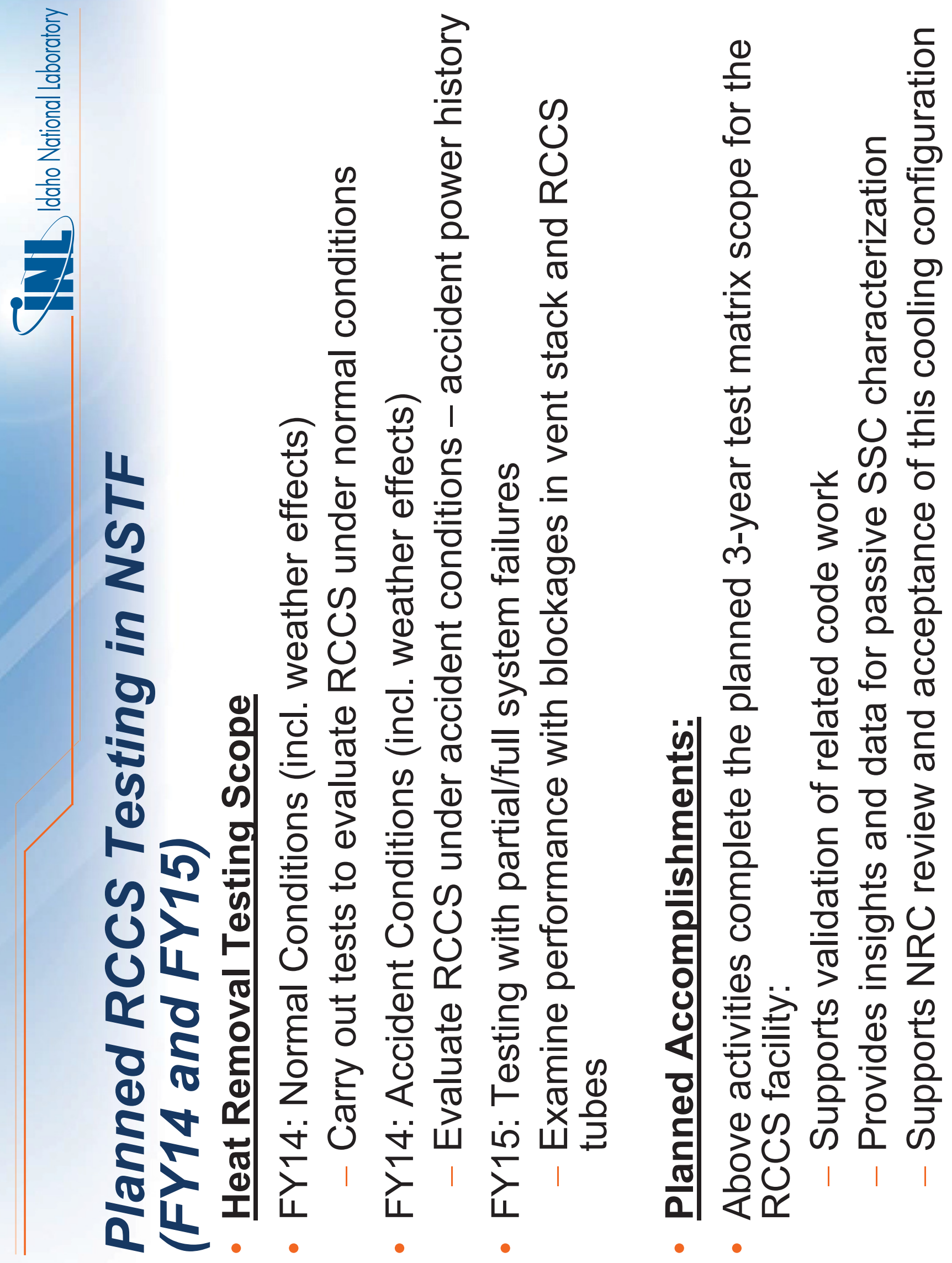




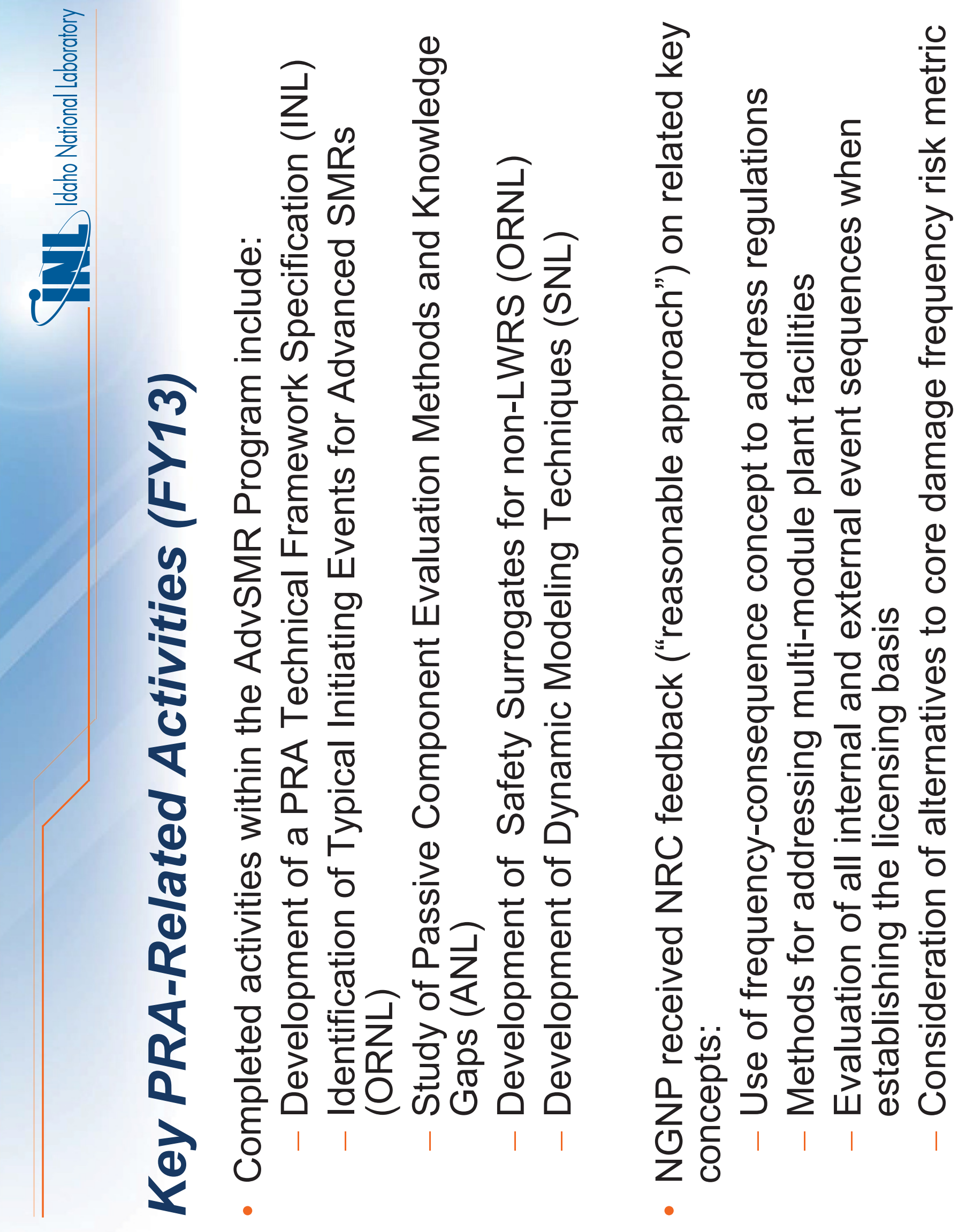


음

高 $\frac{\infty}{5} \stackrel{\infty}{\infty}$

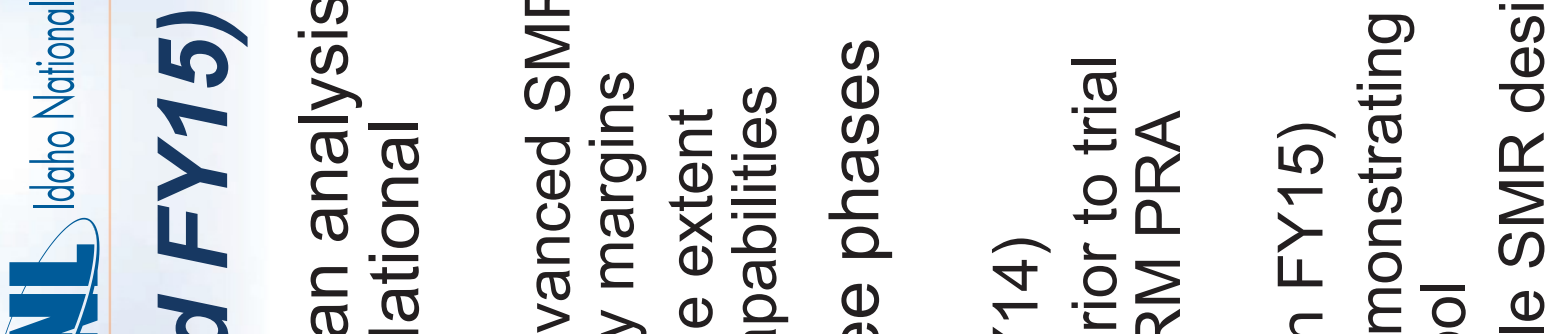

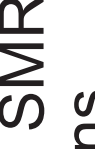

$\stackrel{\frac{0}{ \pm}}{\frac{0}{0}}$

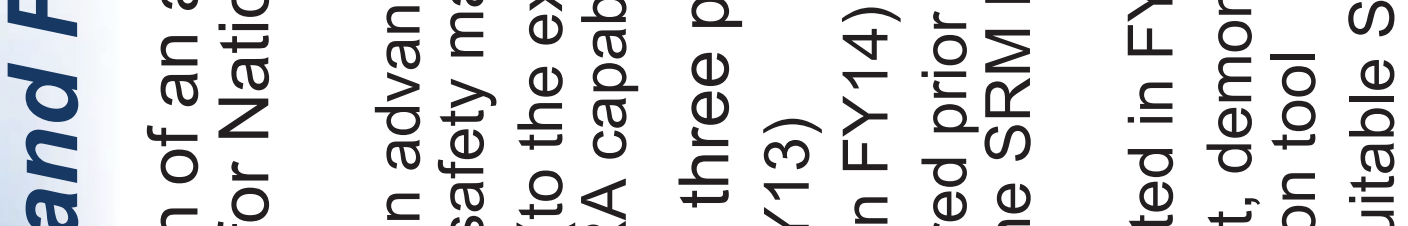

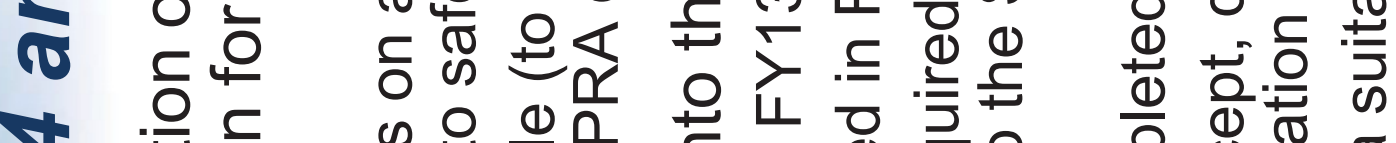

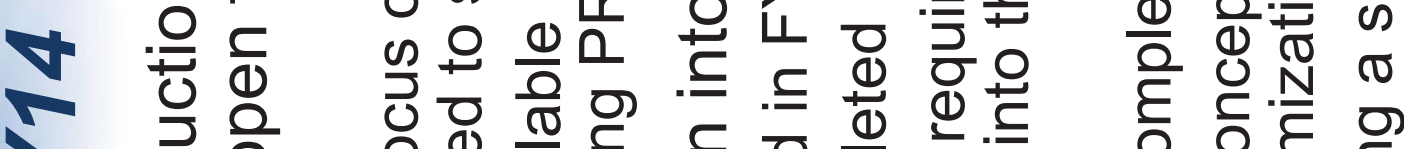

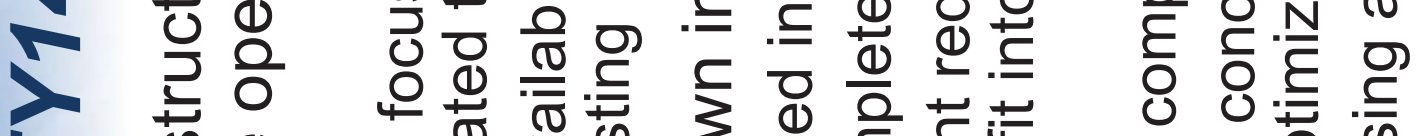

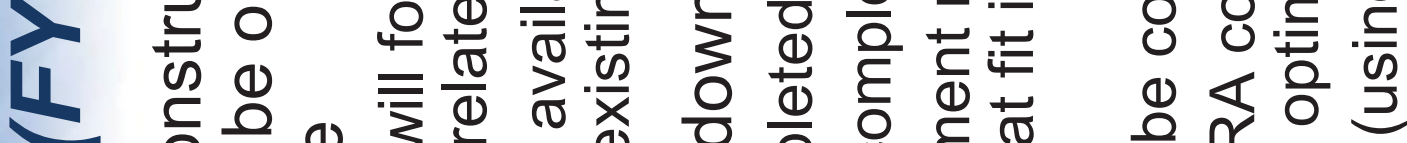

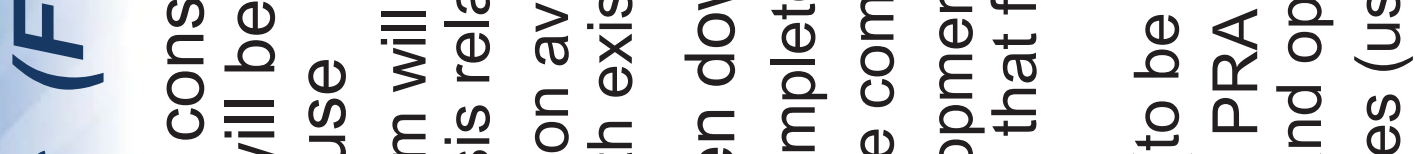

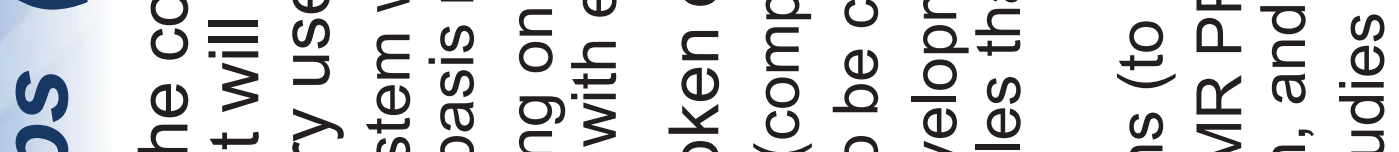

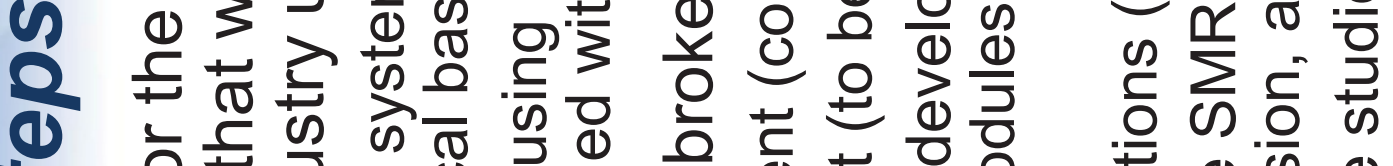

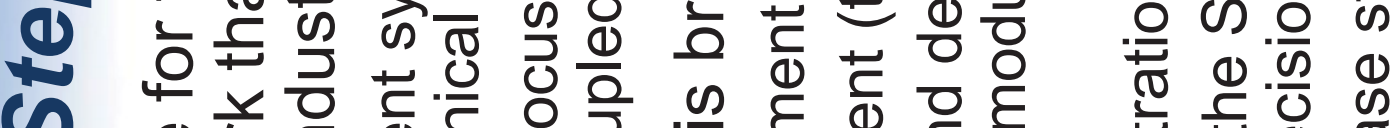

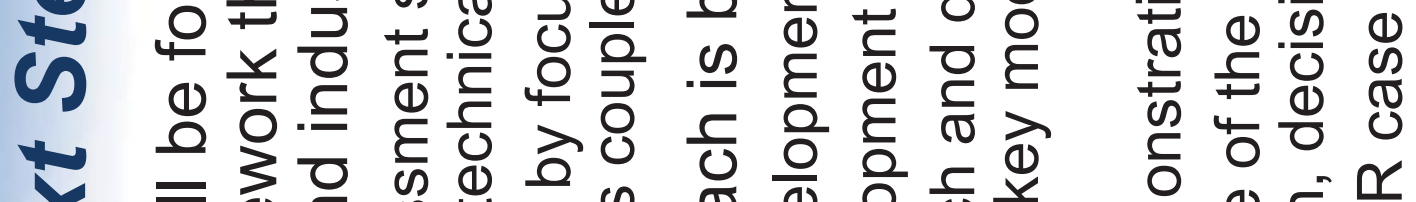

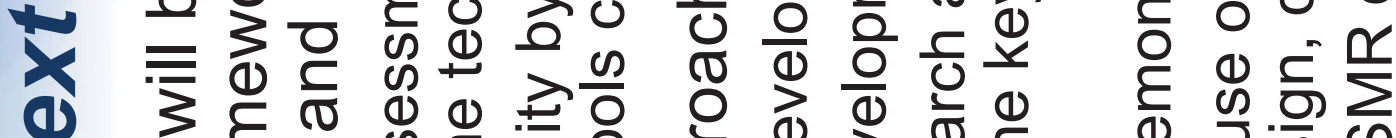

(1) उ宁

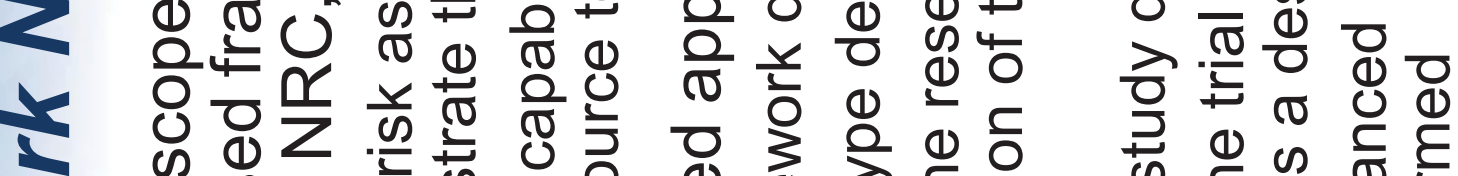

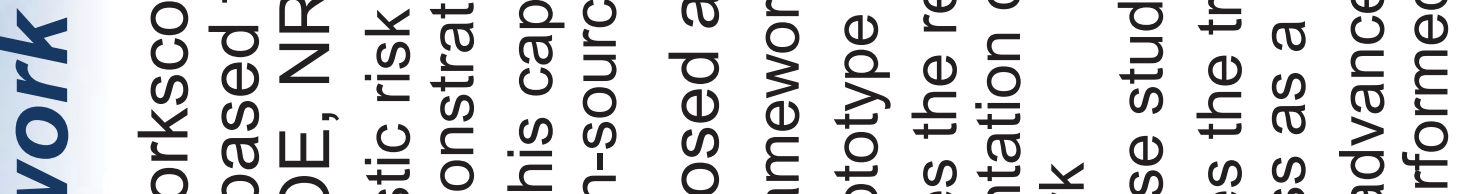

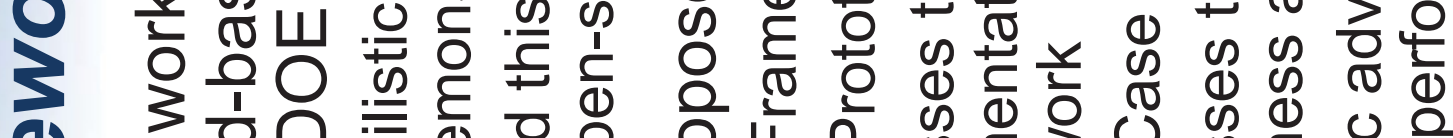

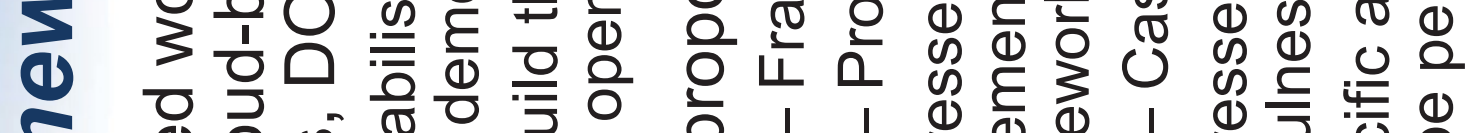

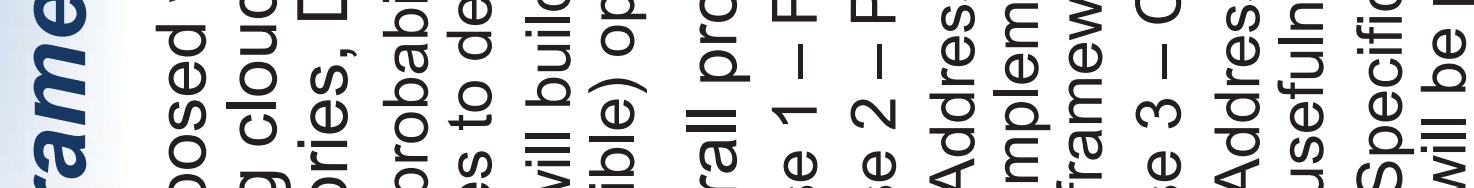

IU D O

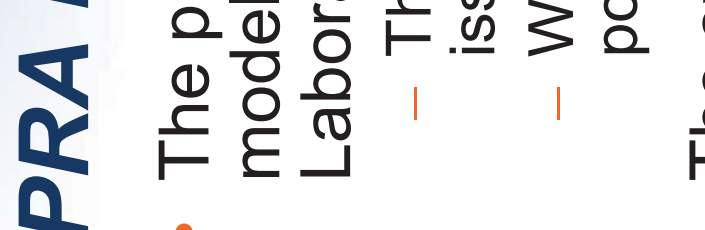




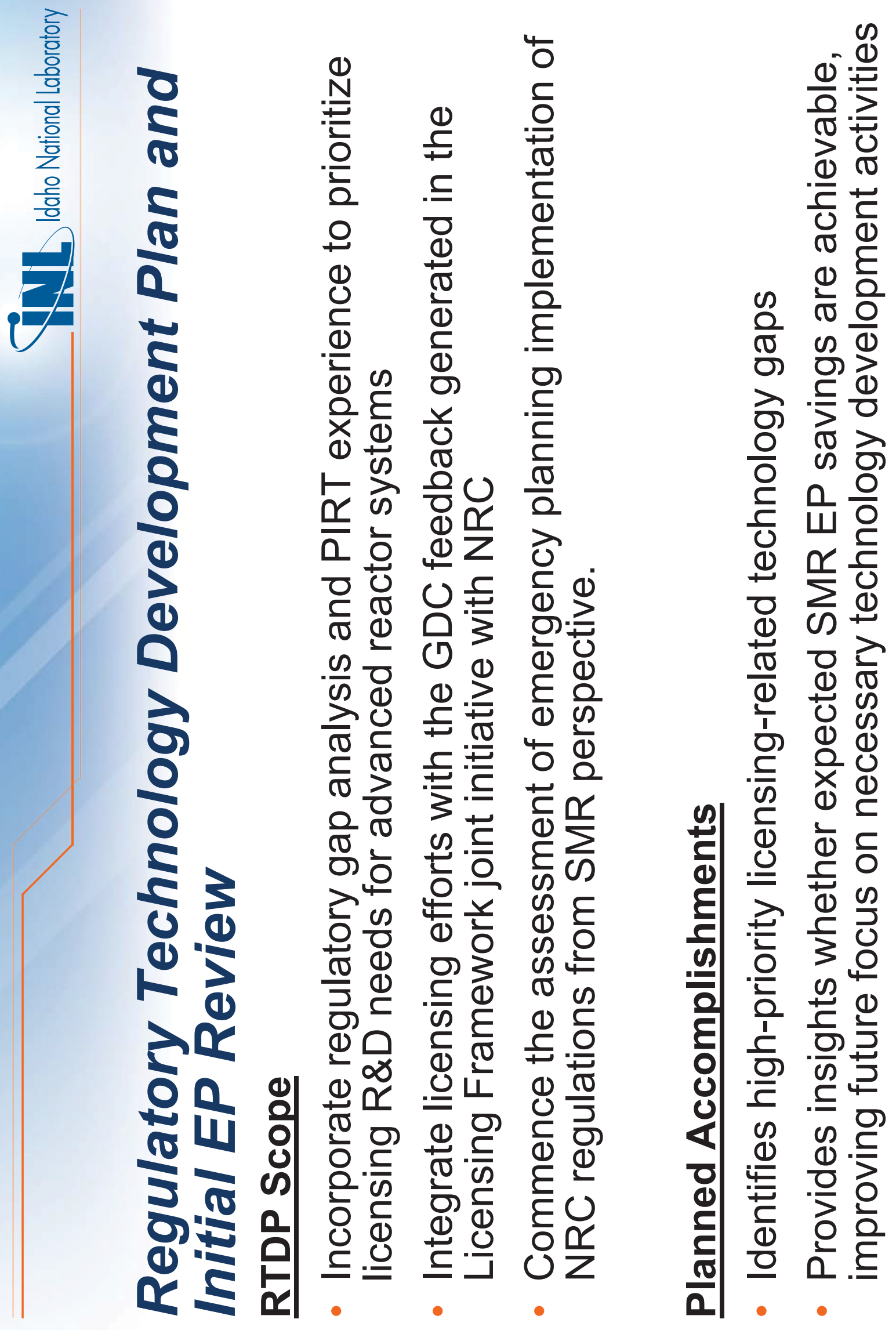




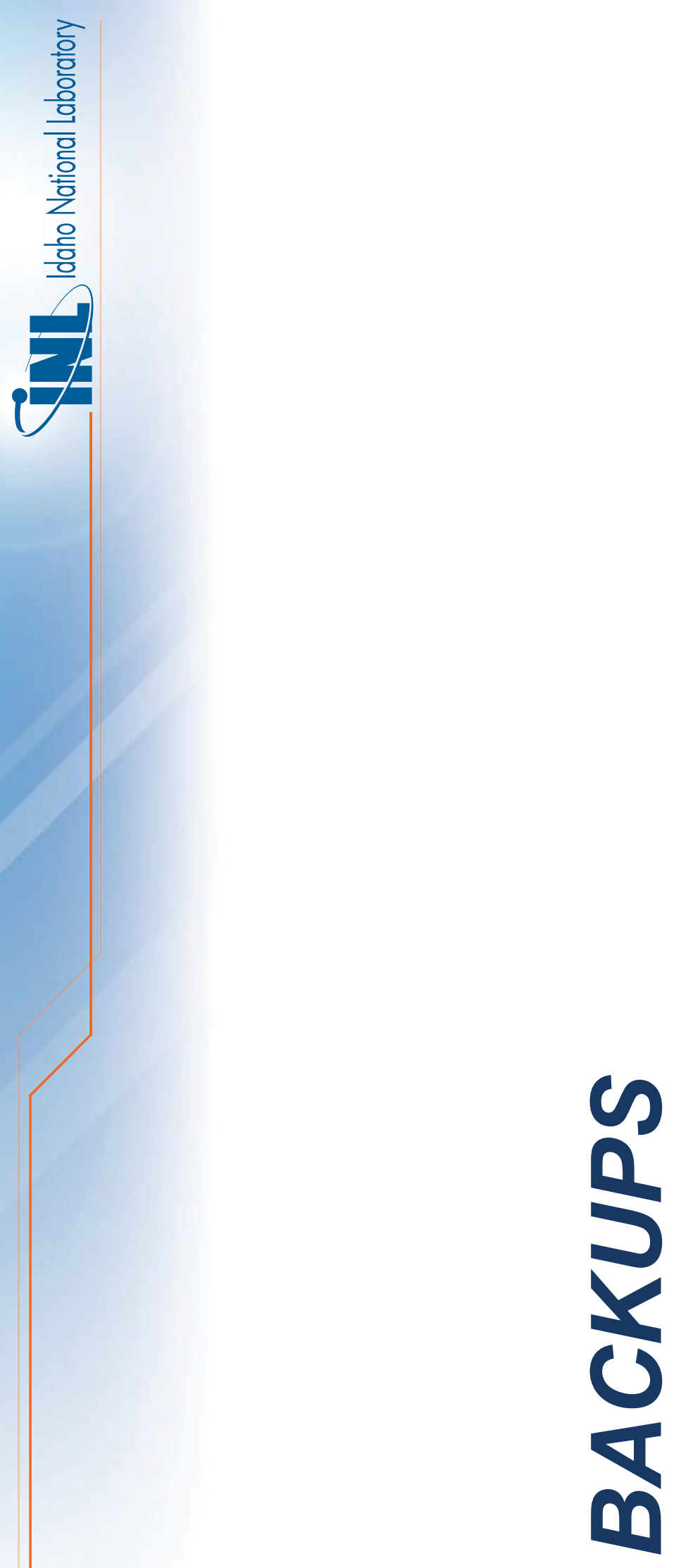



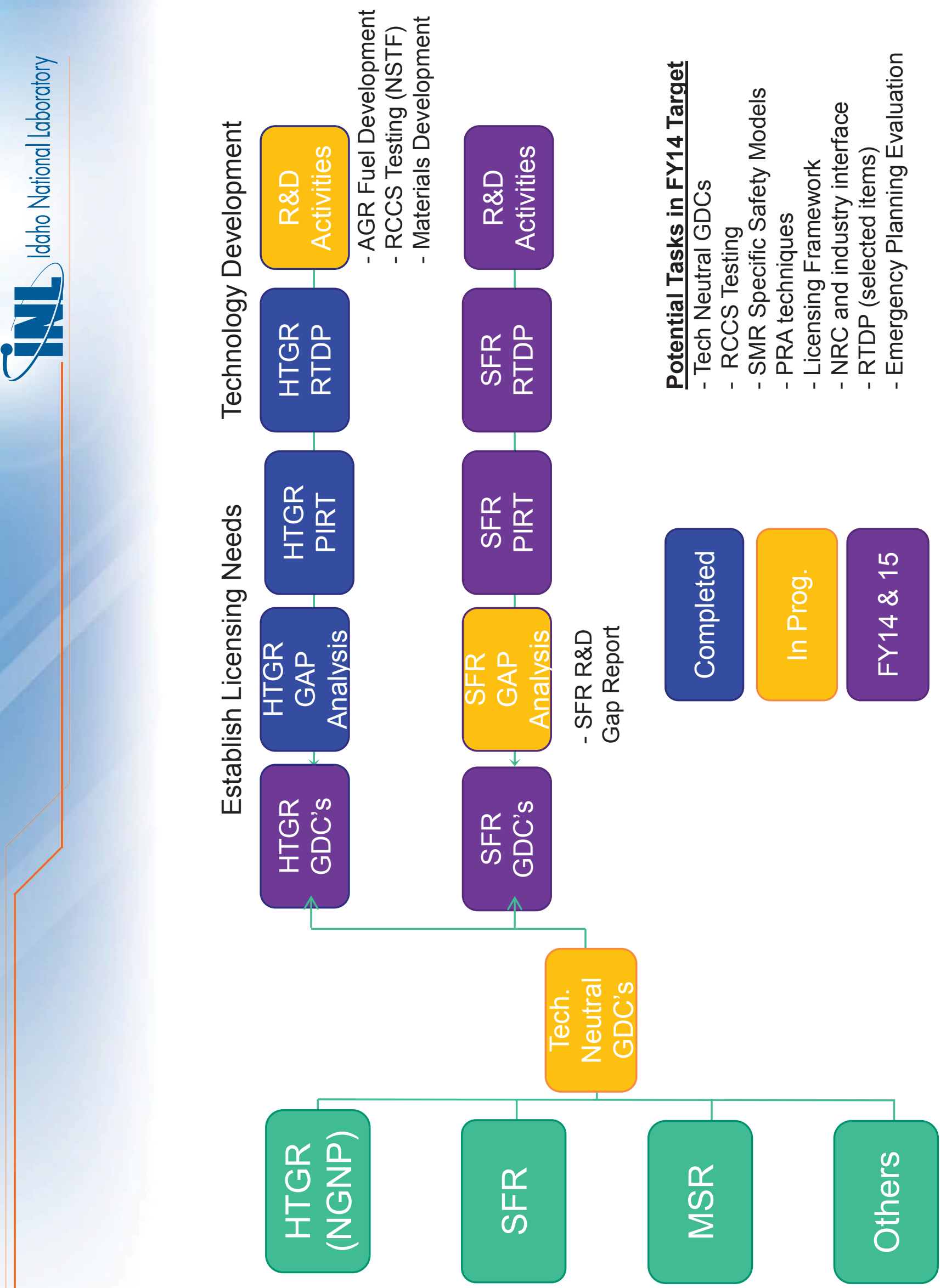

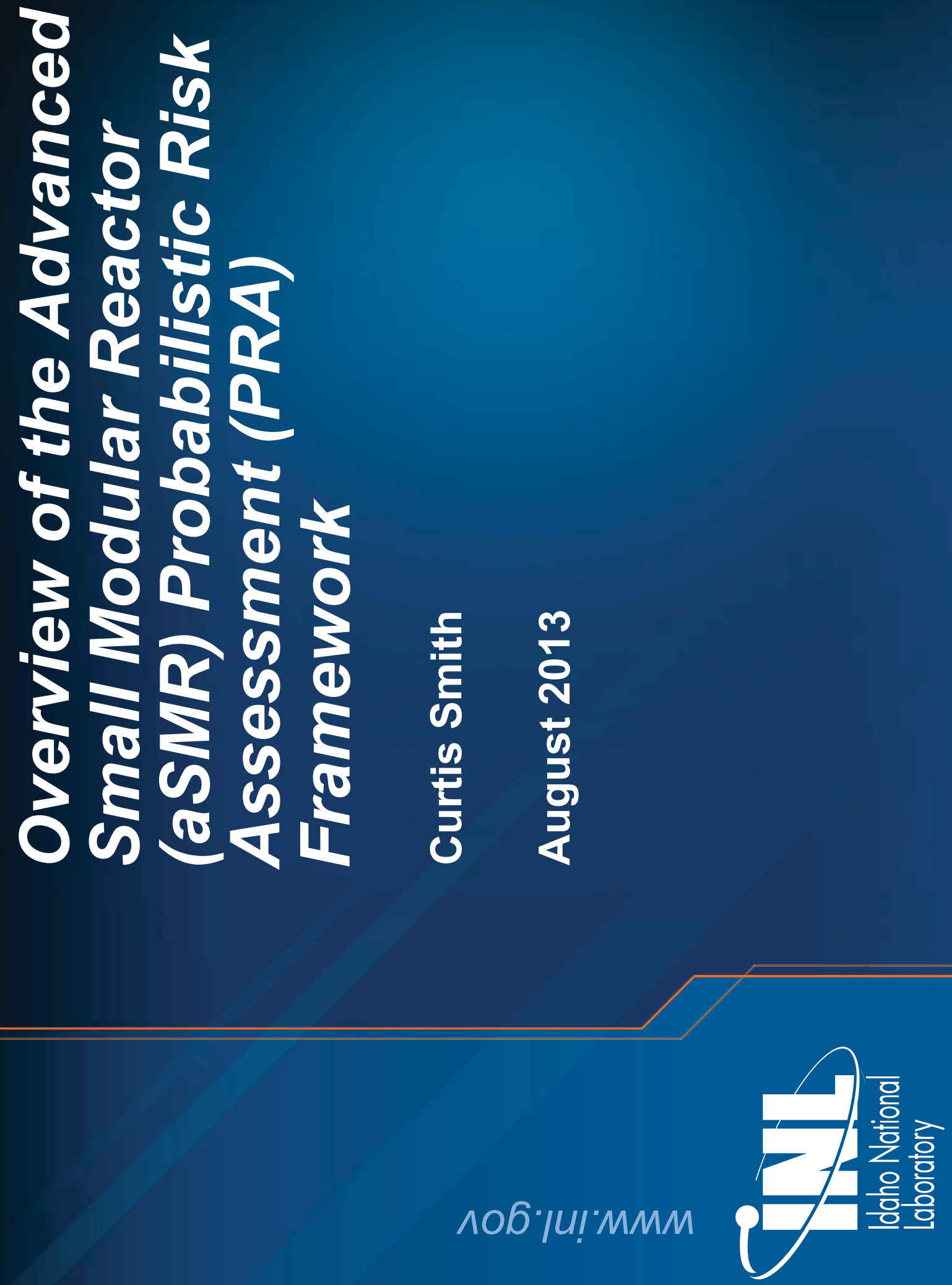

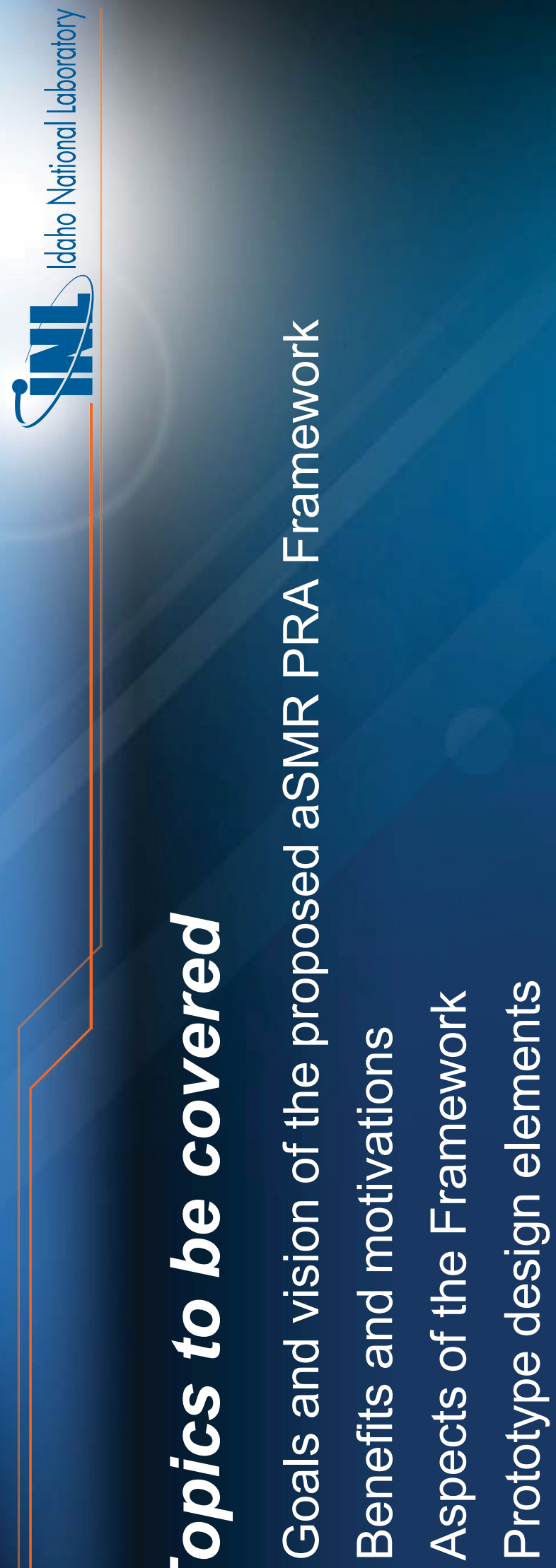


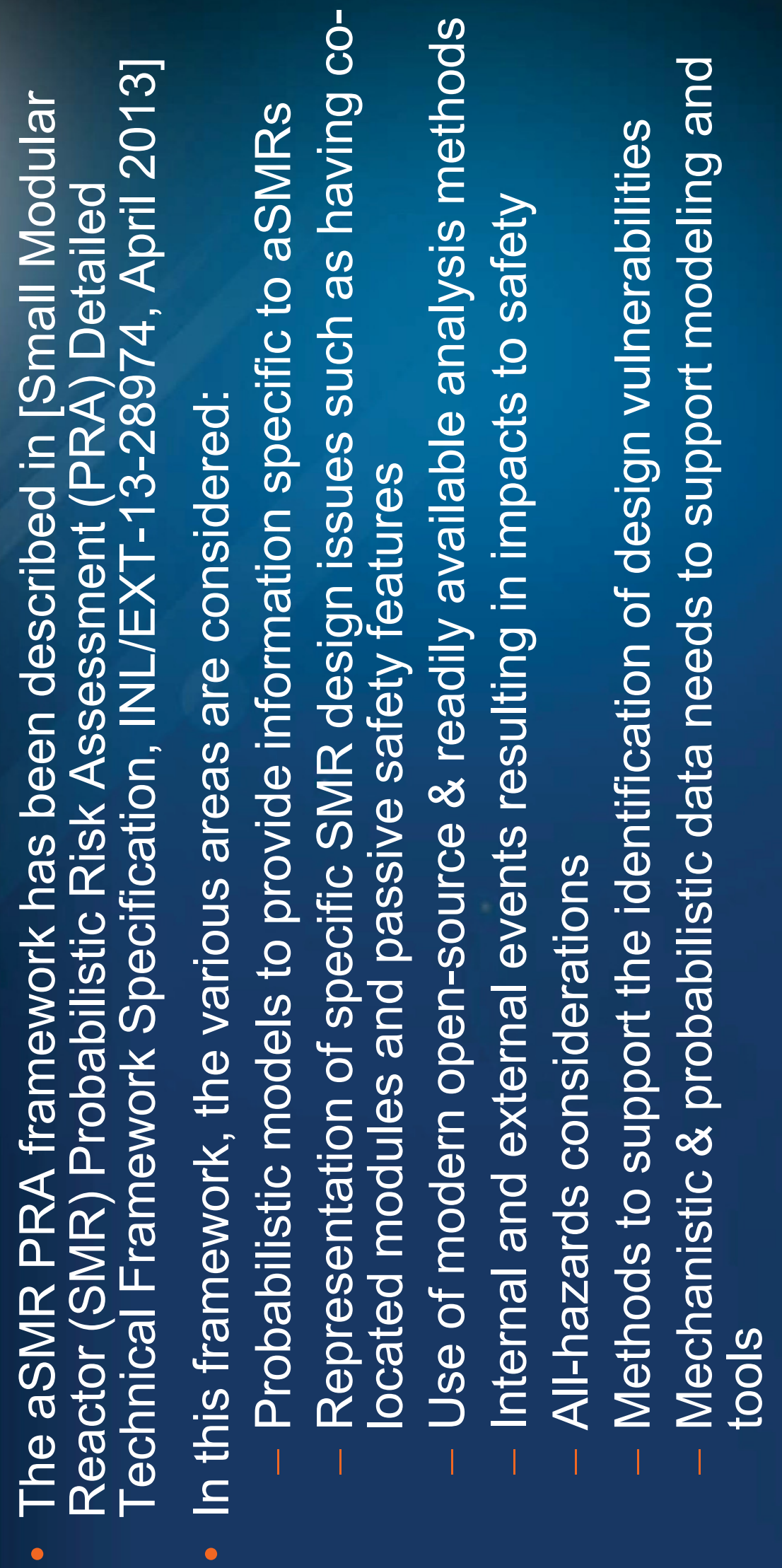




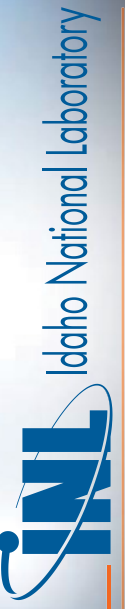

울

$\frac{0}{8}$

임

$+$

$\infty$

엉

की

政

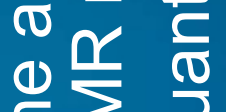

응

平 $\frac{2}{0}$

든

- $\frac{1}{\square}$

잉

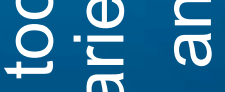

잉

(1)

का

옹 을 $\frac{\omega}{x}$

응

$1 \frac{0}{0} \frac{0}{0}$

$\times \frac{1}{0}$

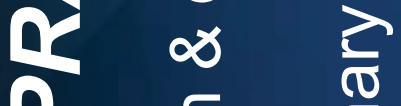

0 들 흥

으동ㅇㅎㅇ

C

이 (1) 은

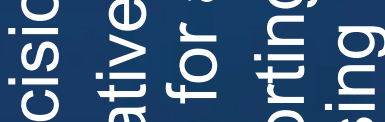

đI

응 한능 응

든학윽

으

क 응

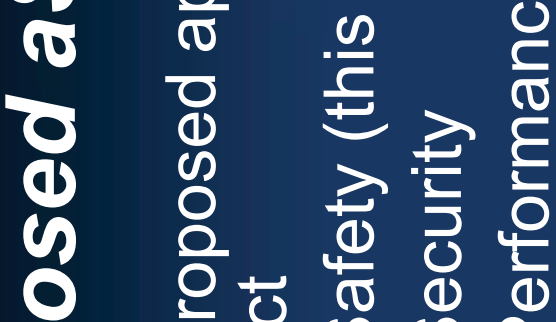

y

- 드응

- $\stackrel{\infty}{\lessgtr} \frac{d}{2}$

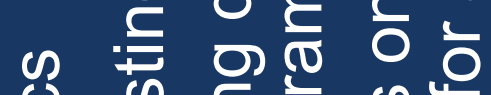

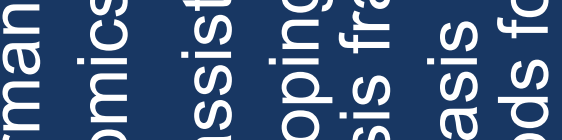

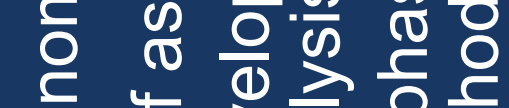

(1) 잉 


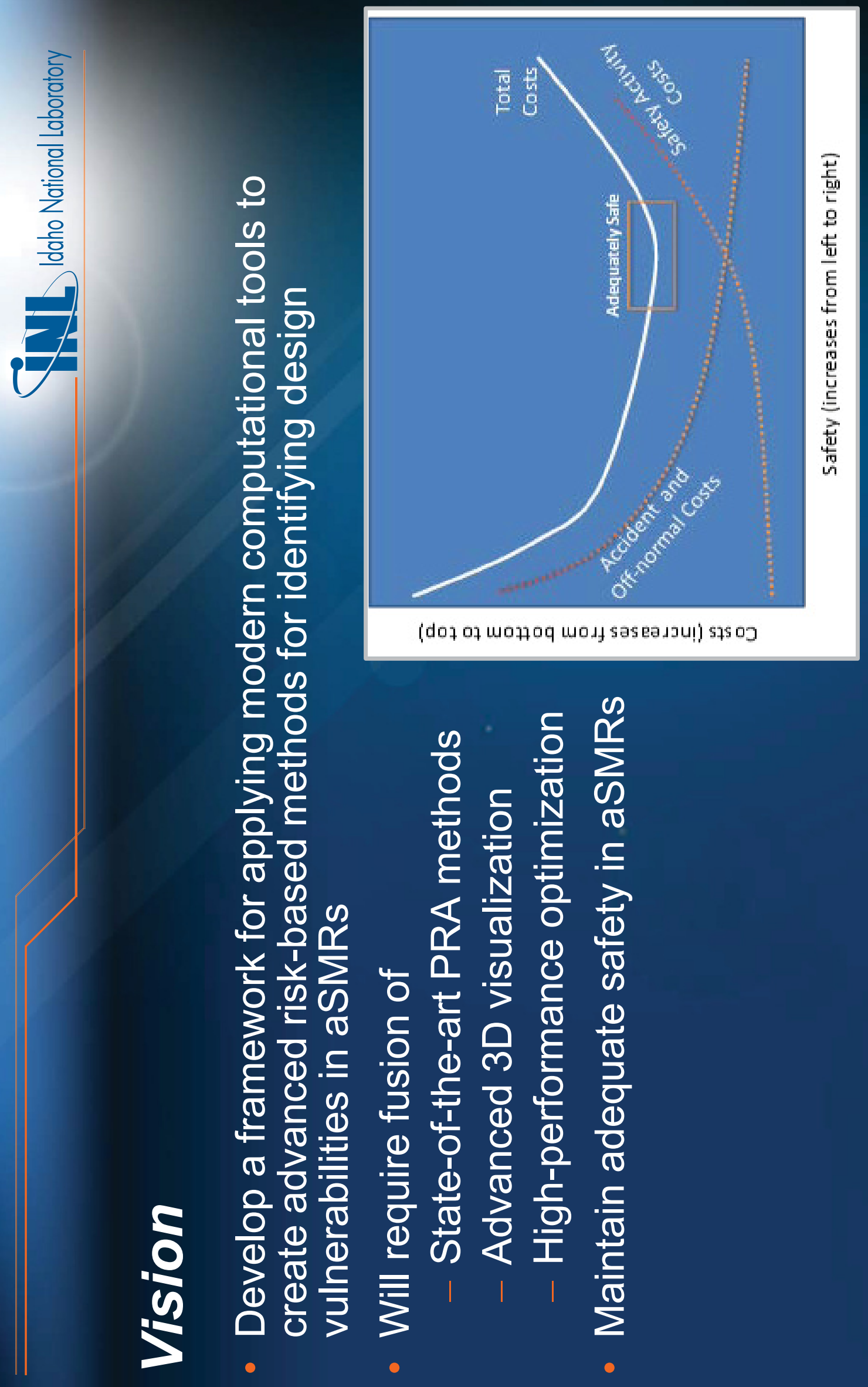



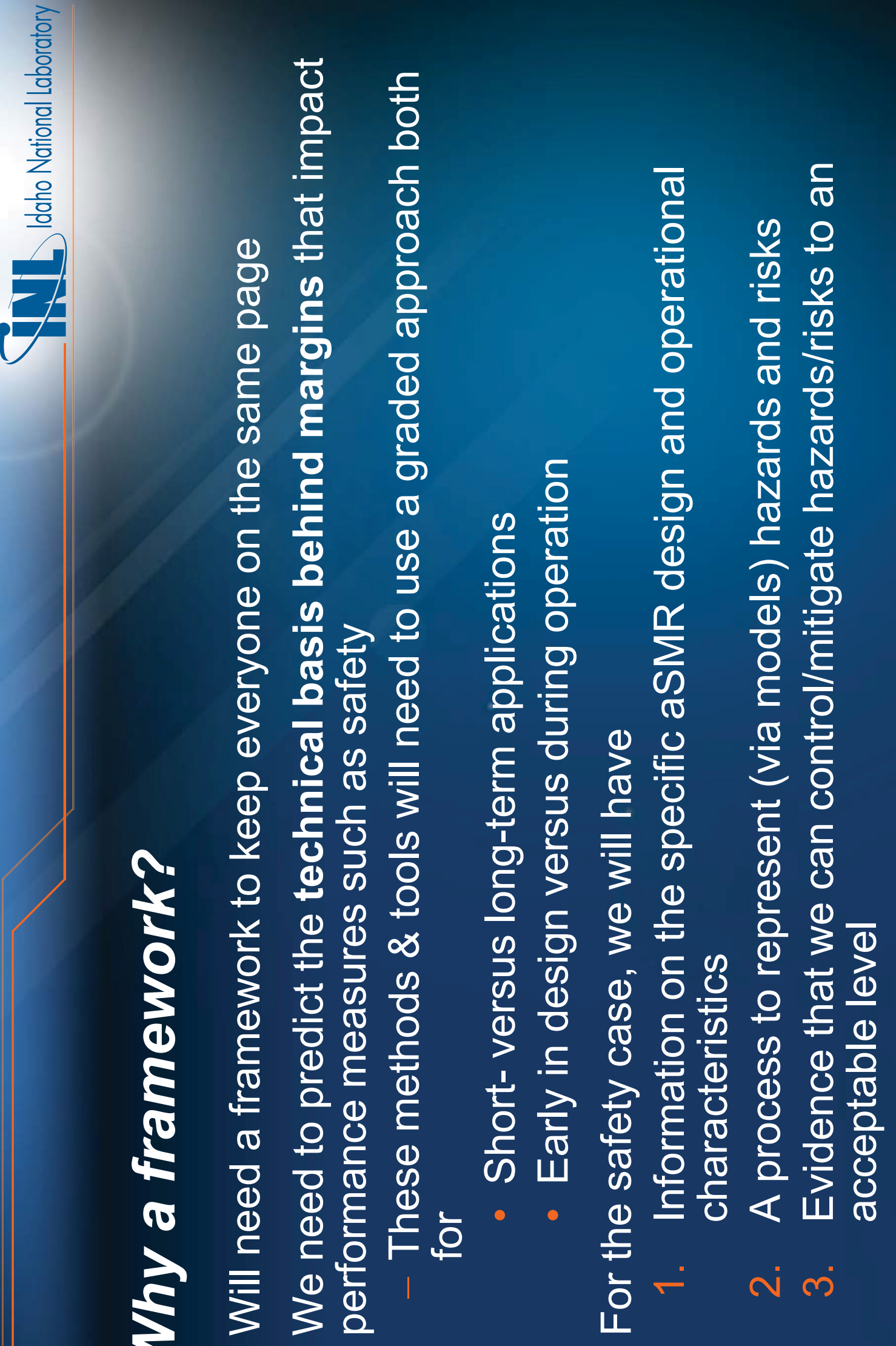

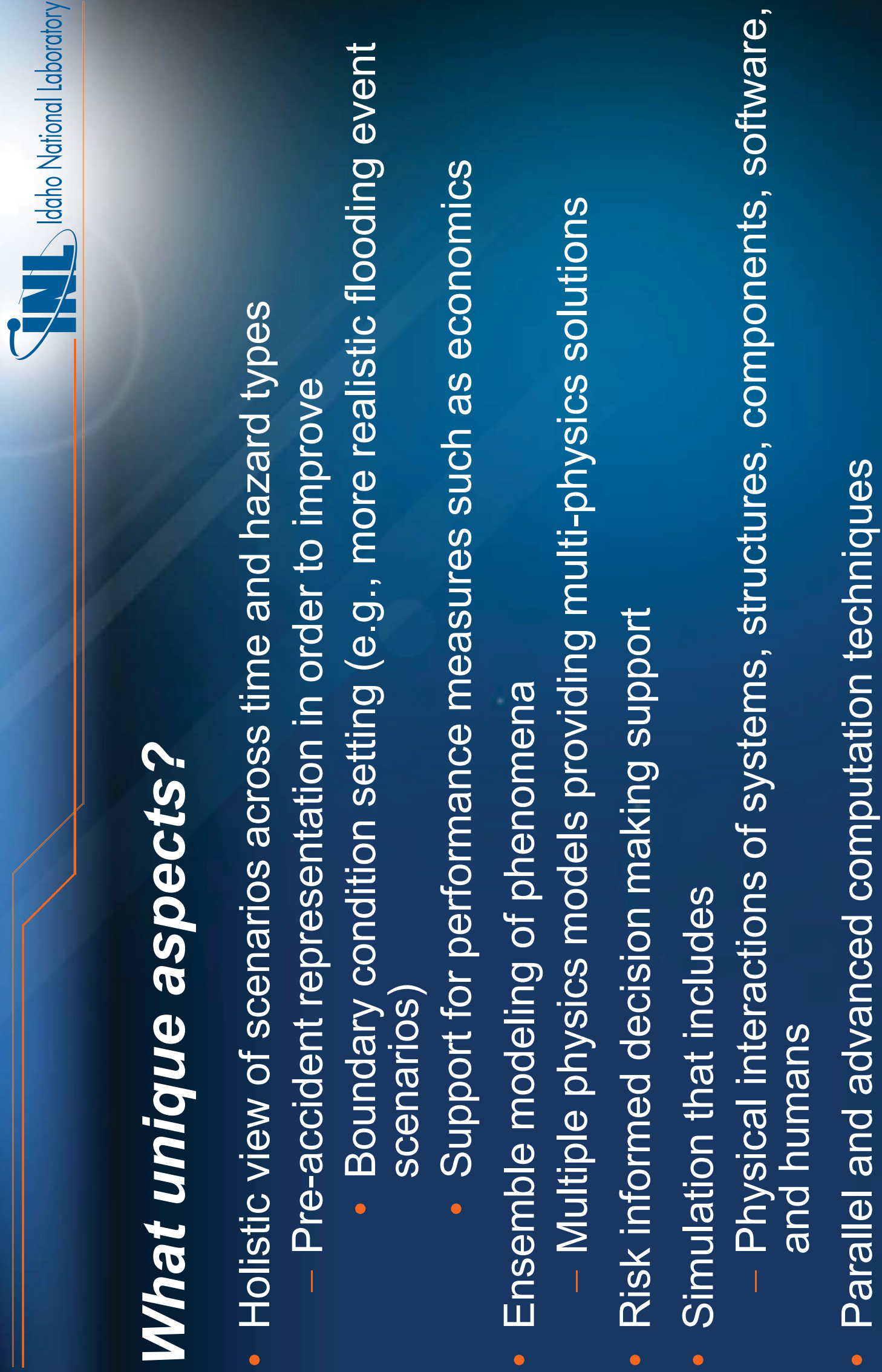


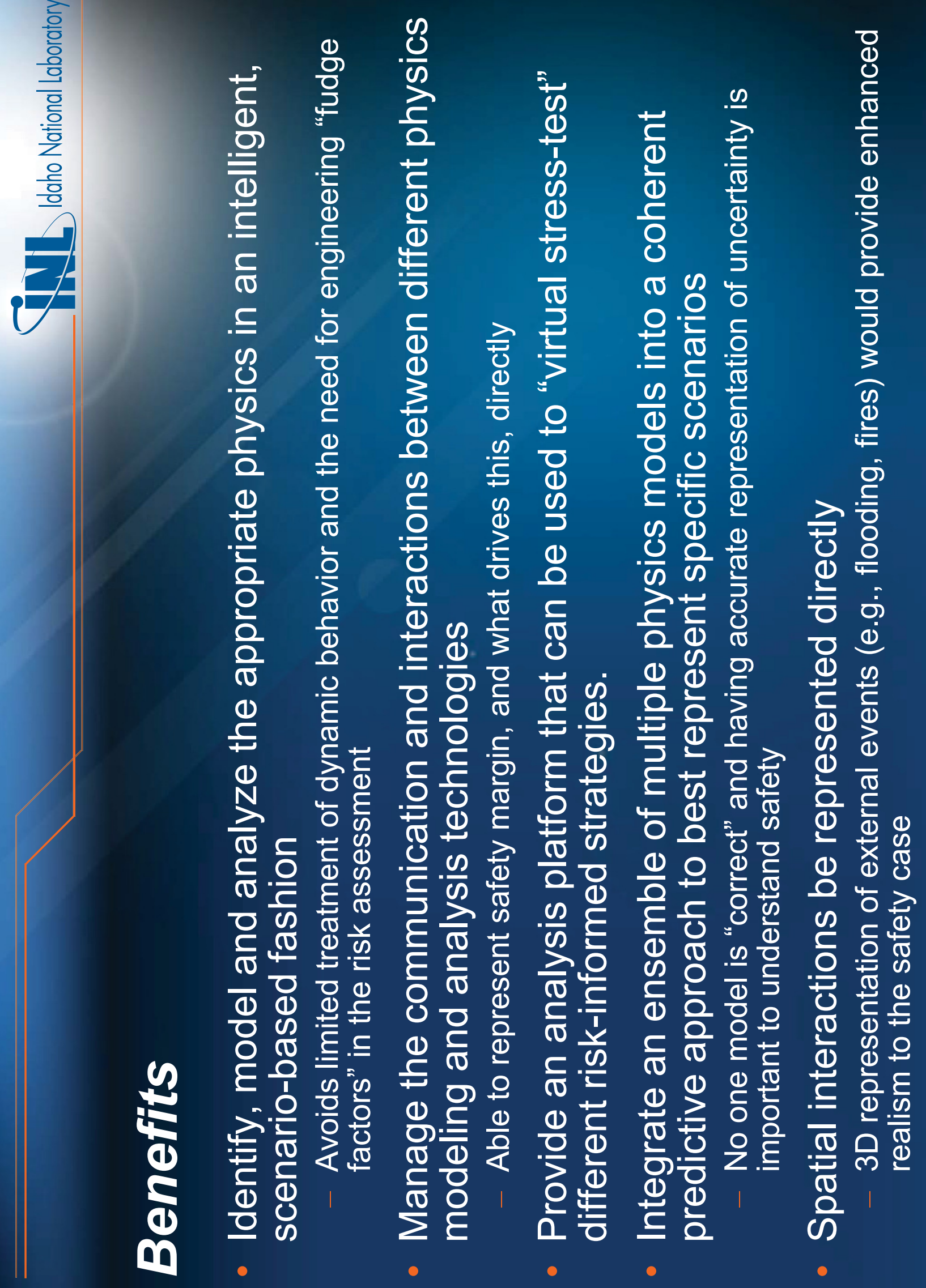



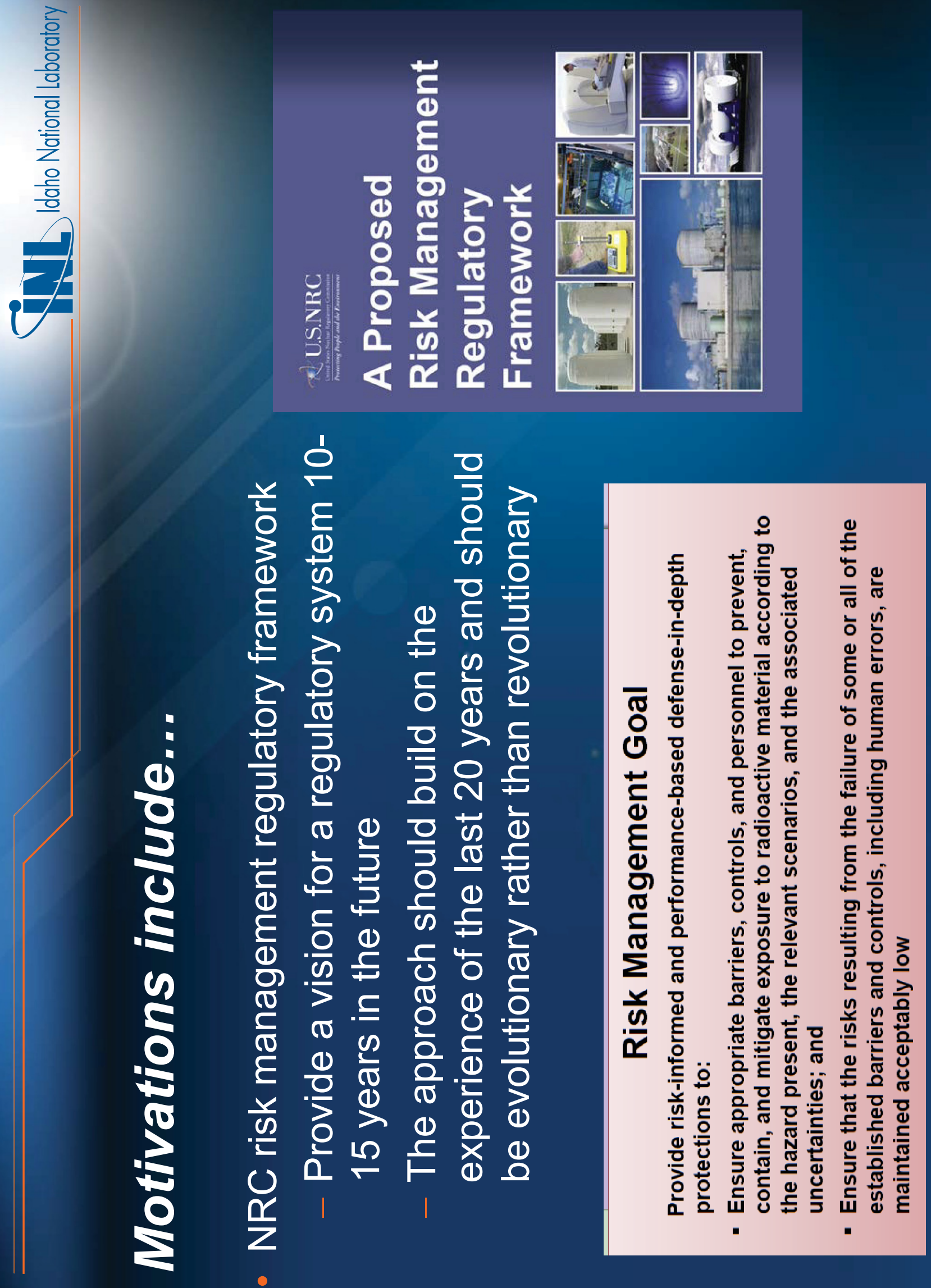


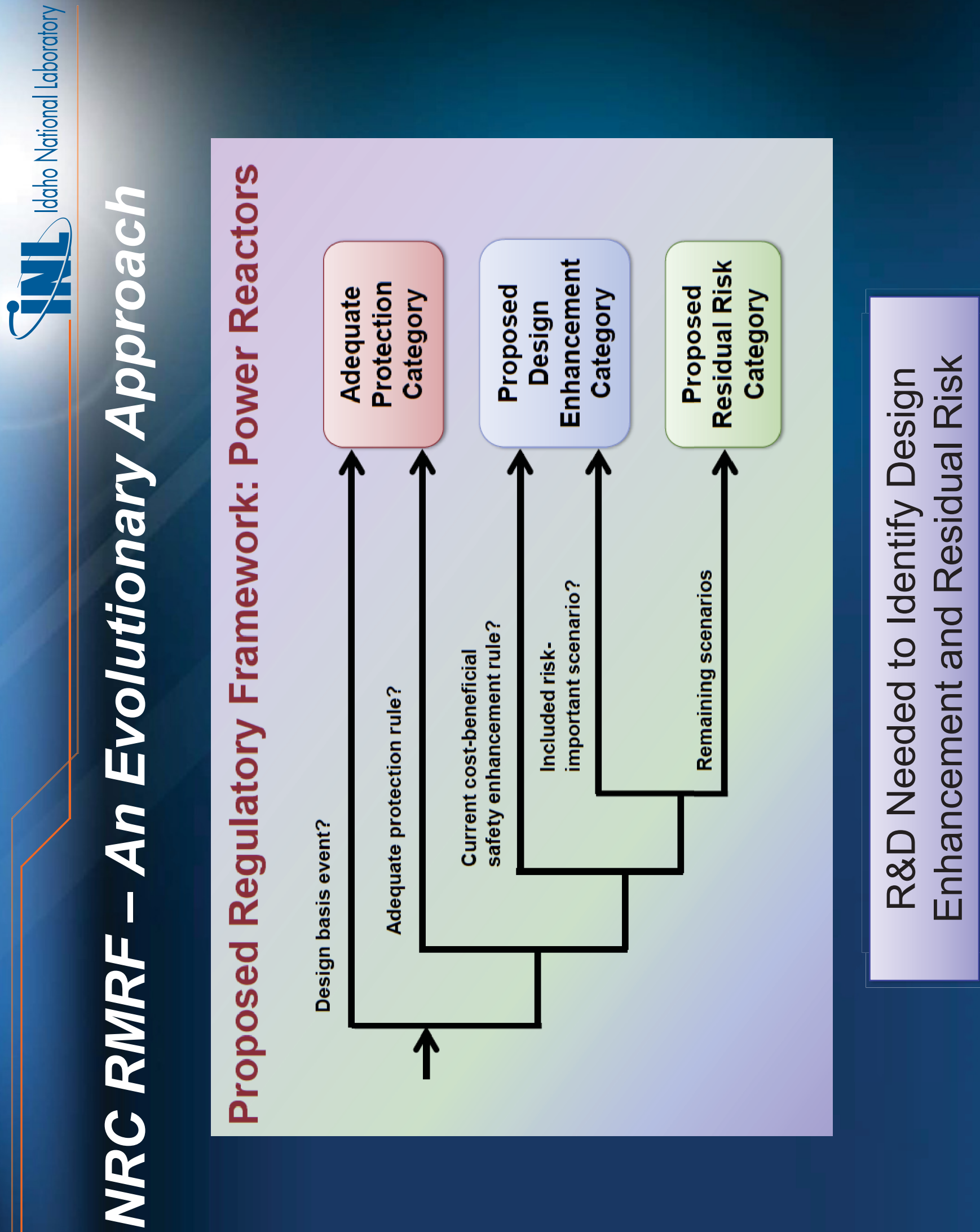




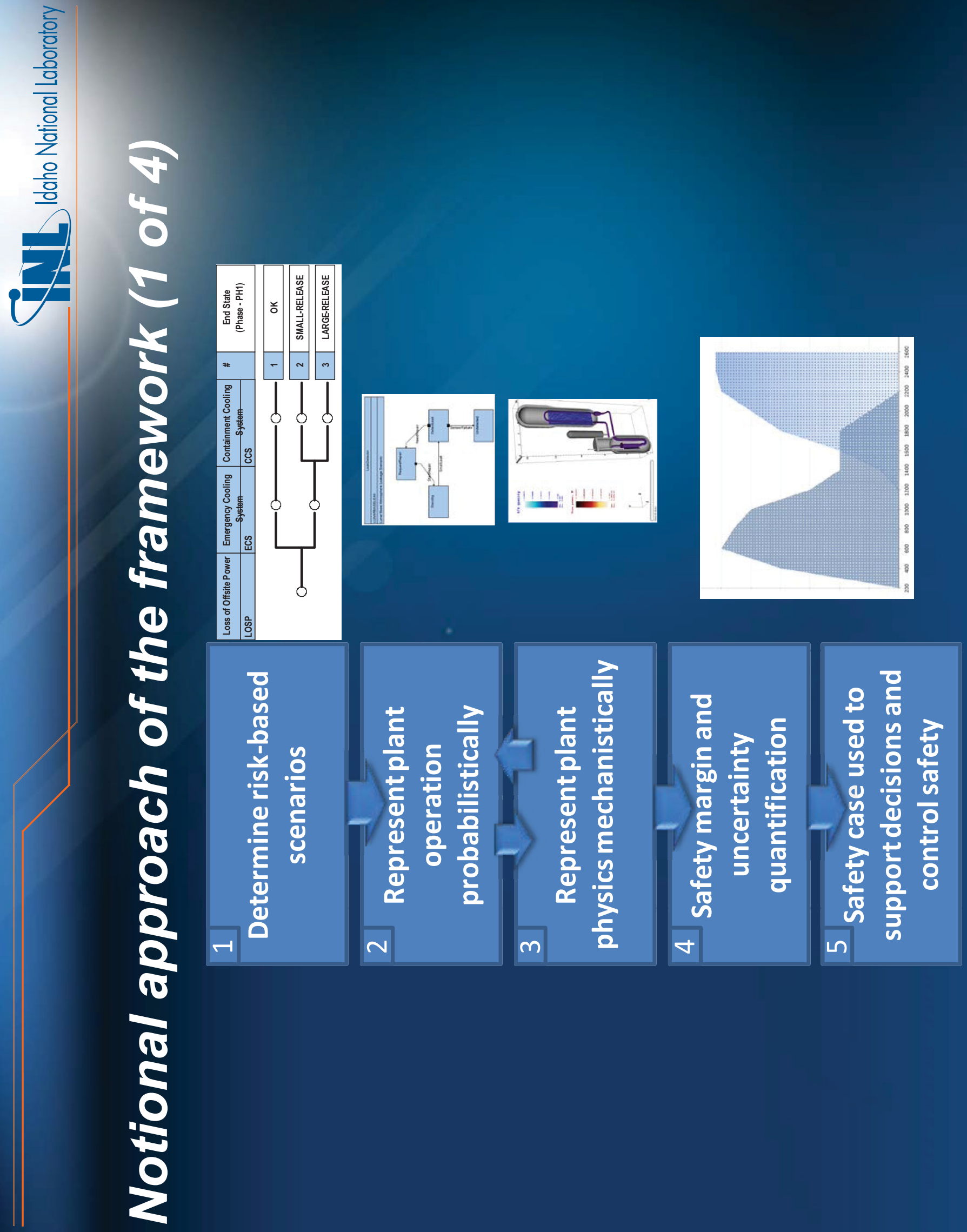




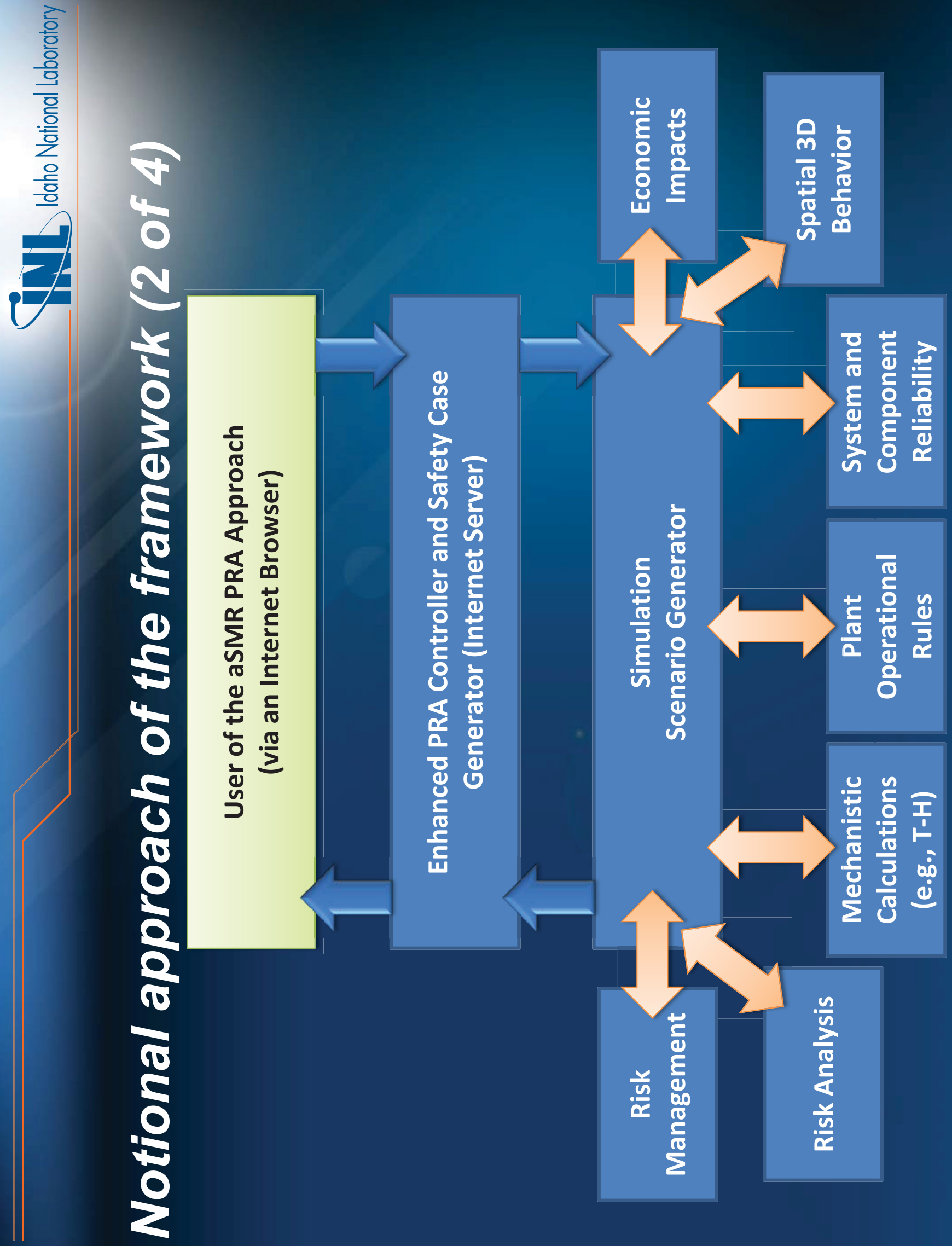



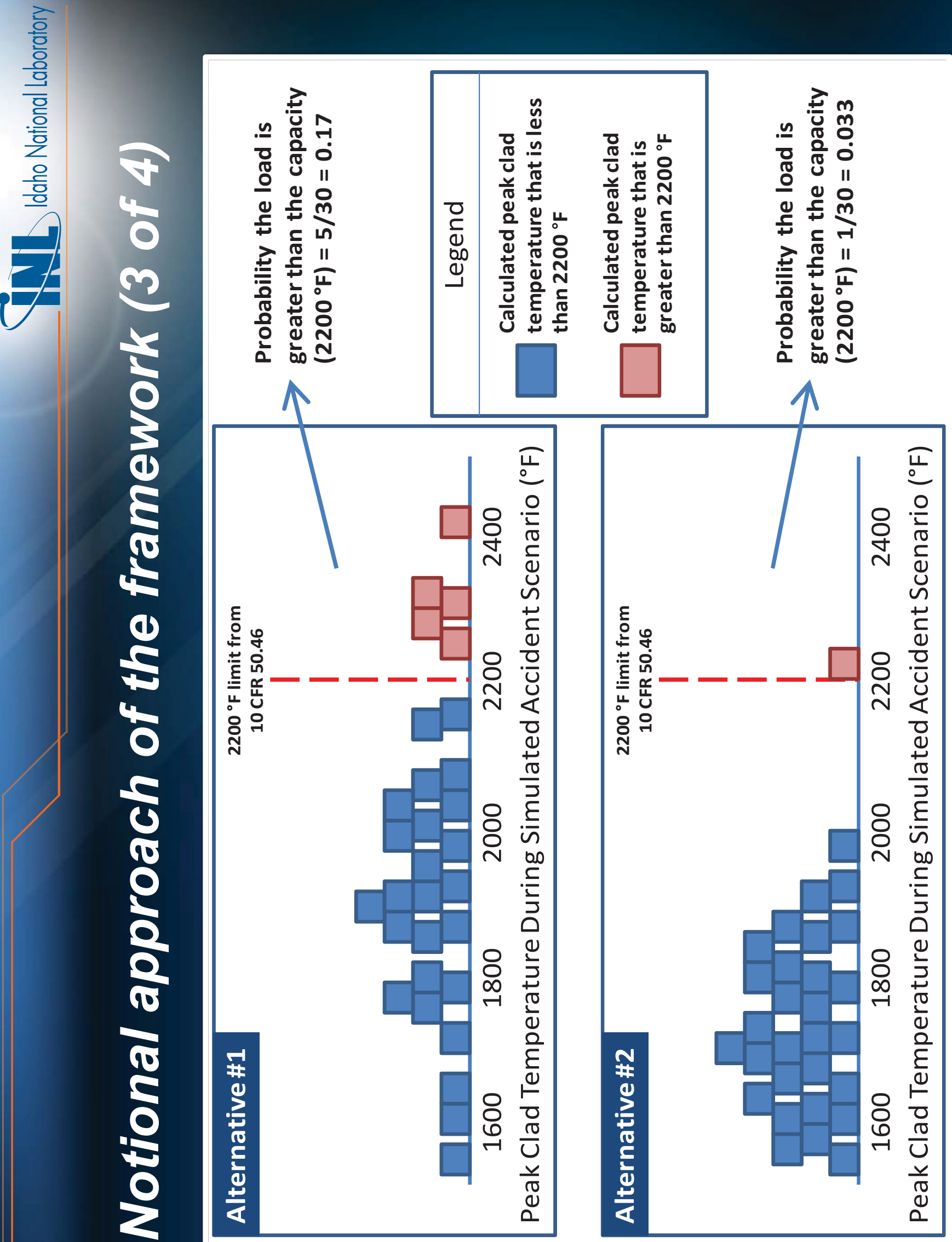


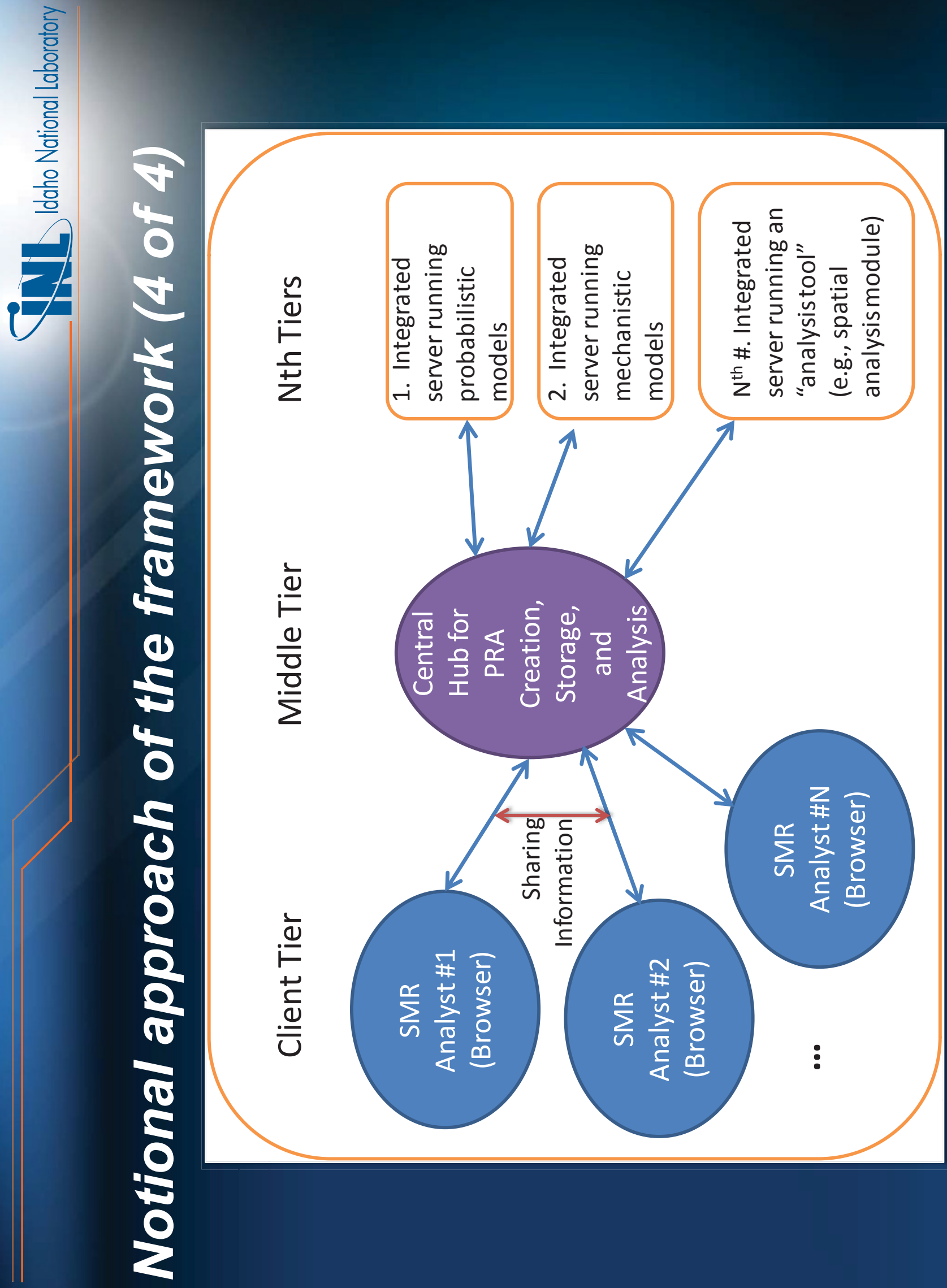




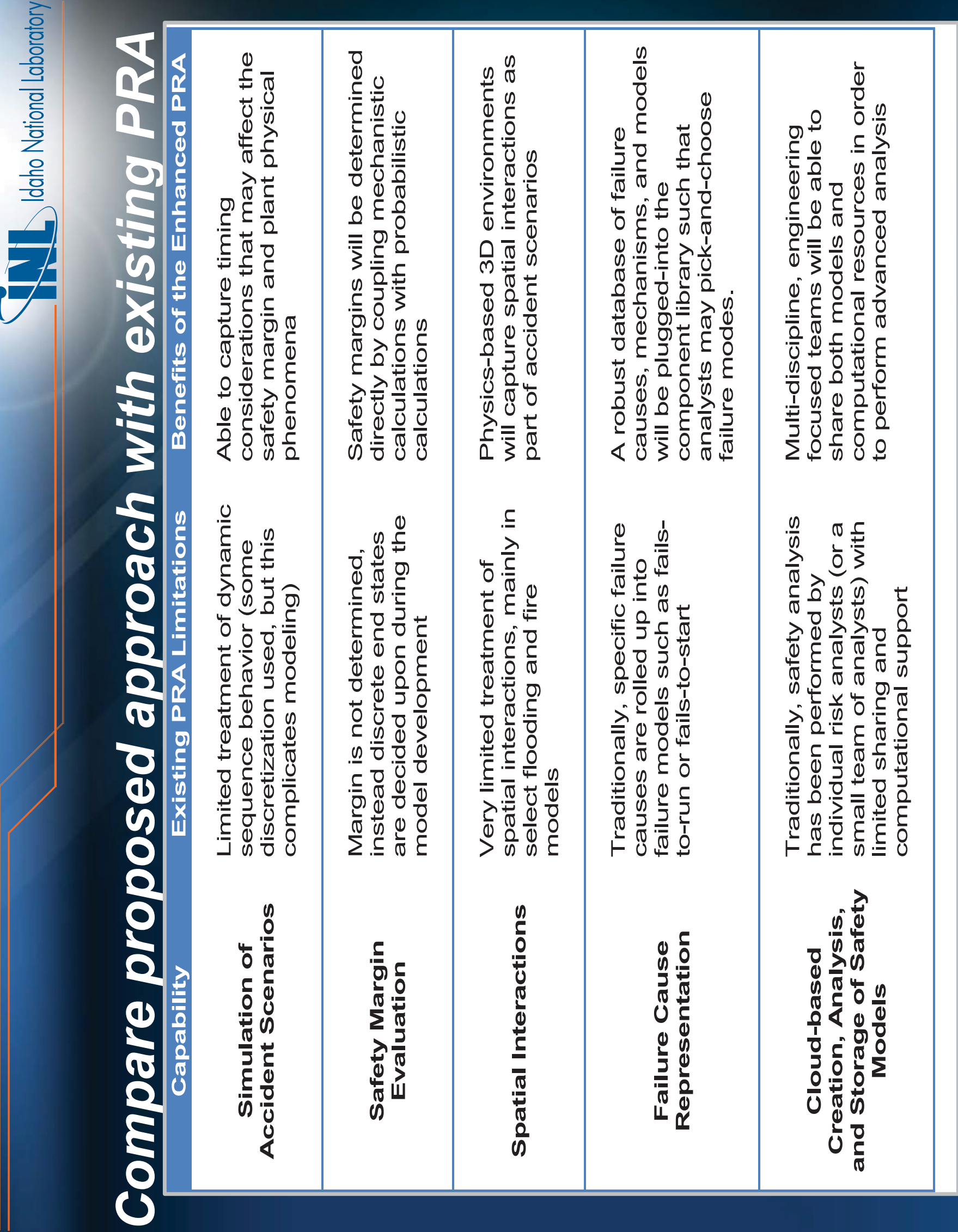




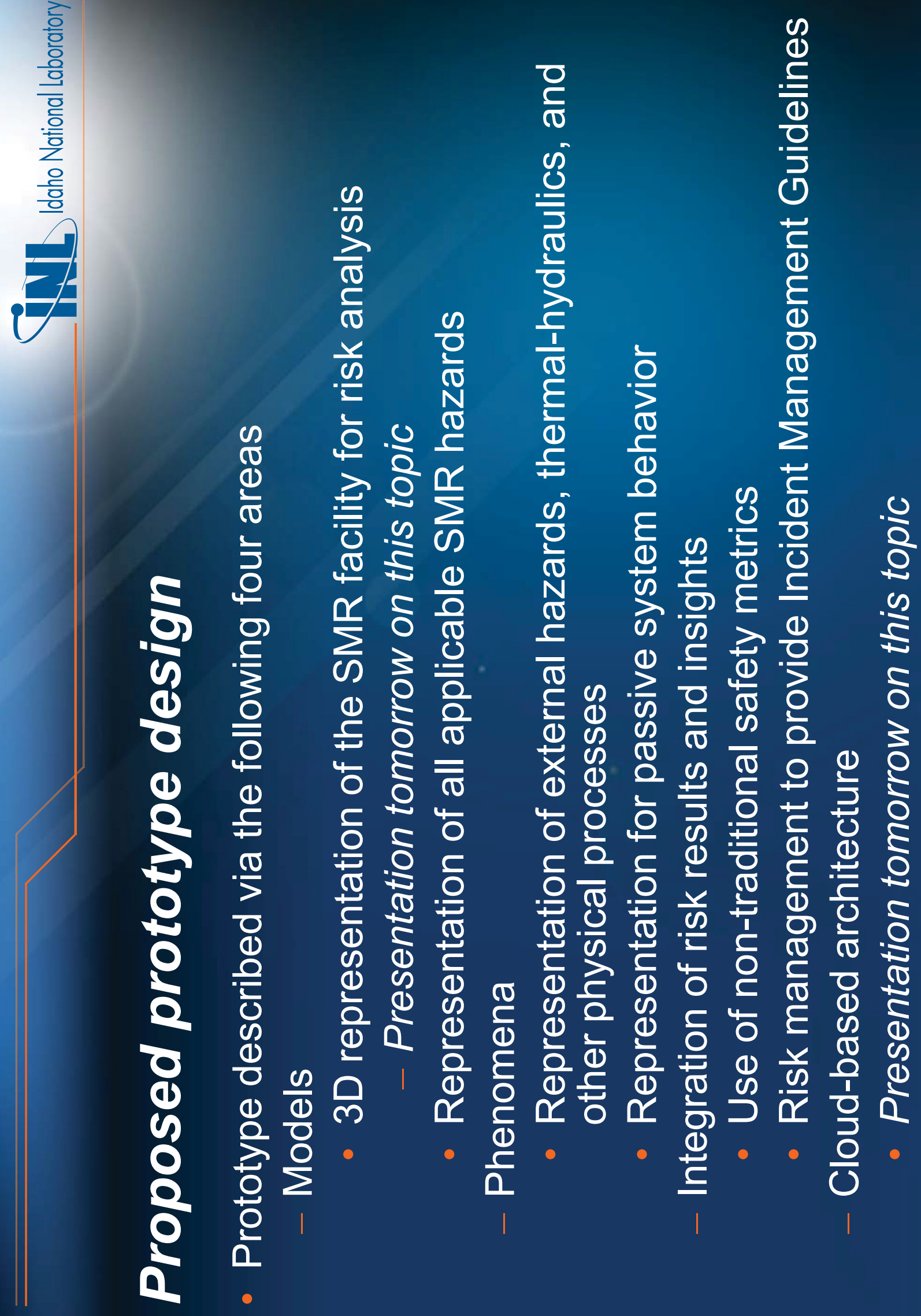



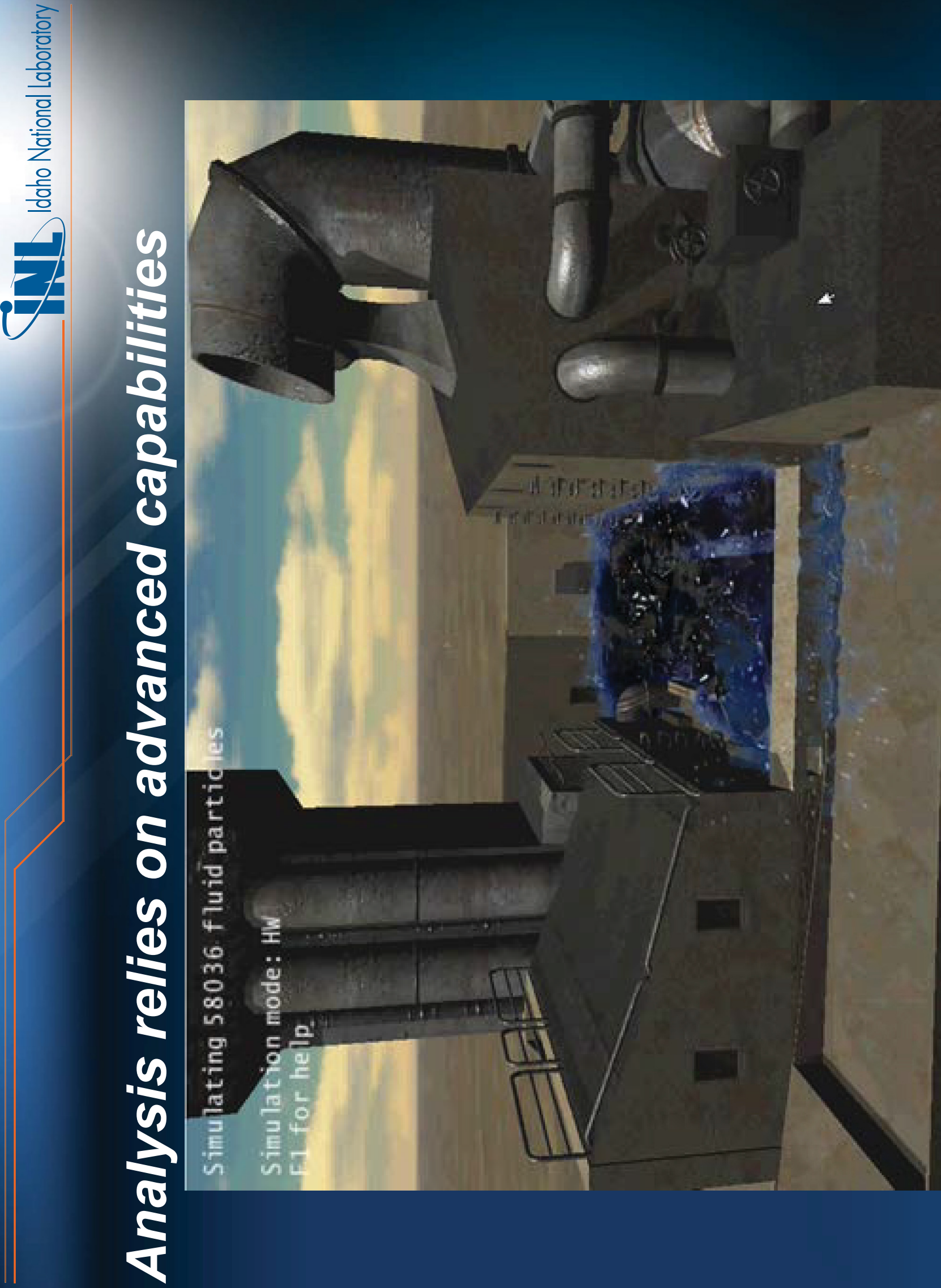


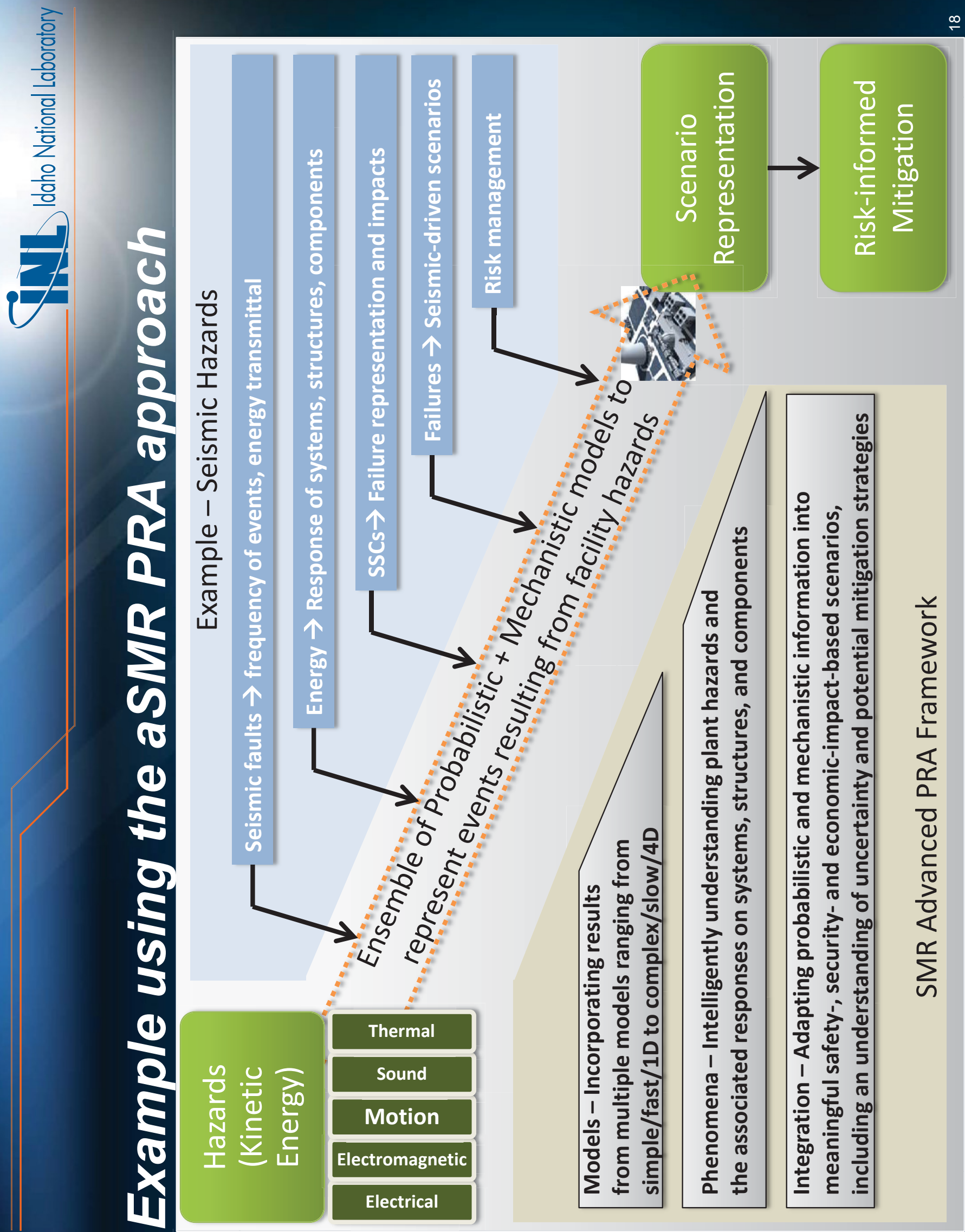




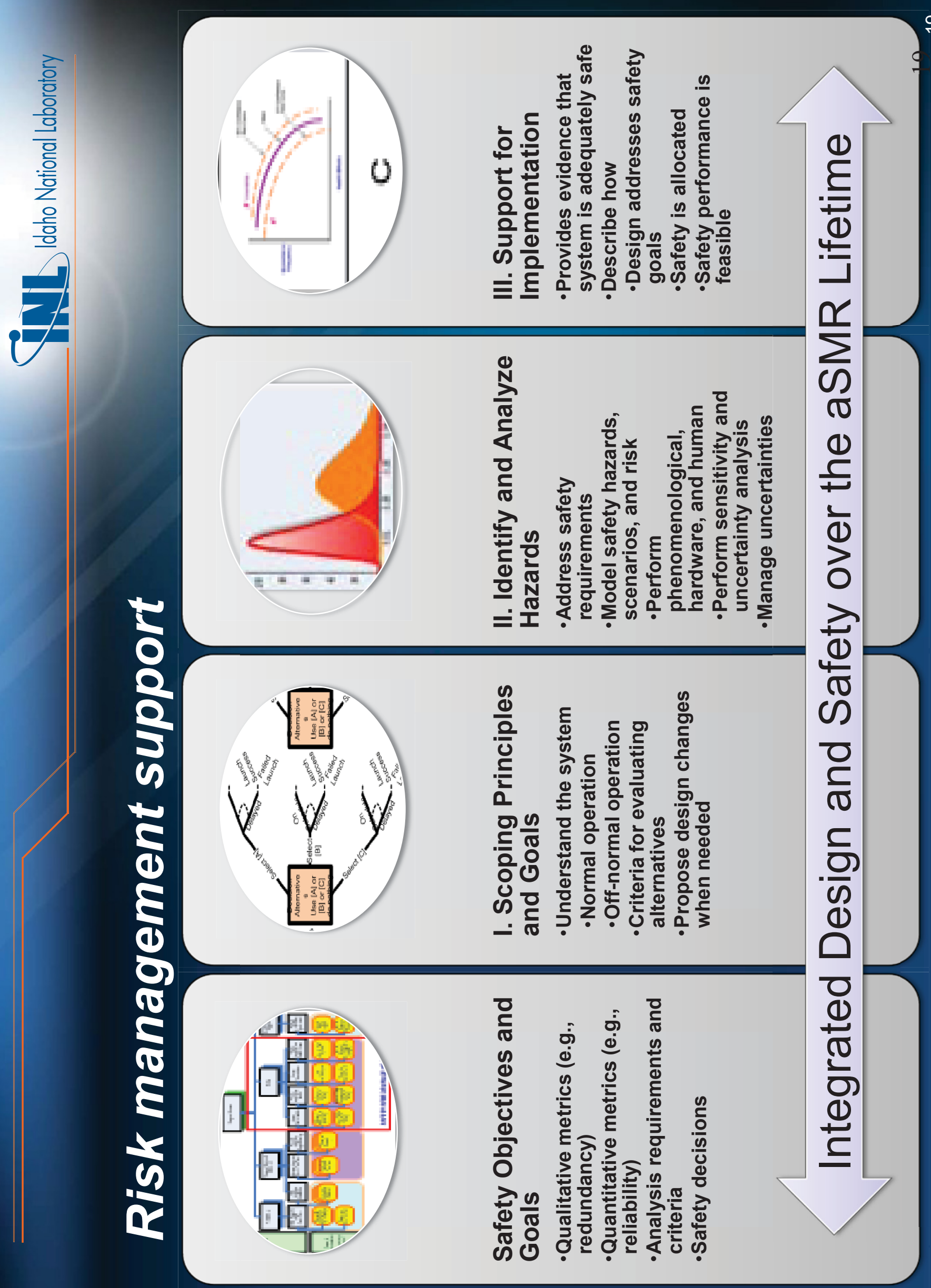




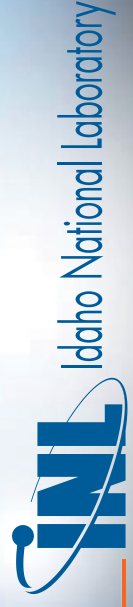

릉

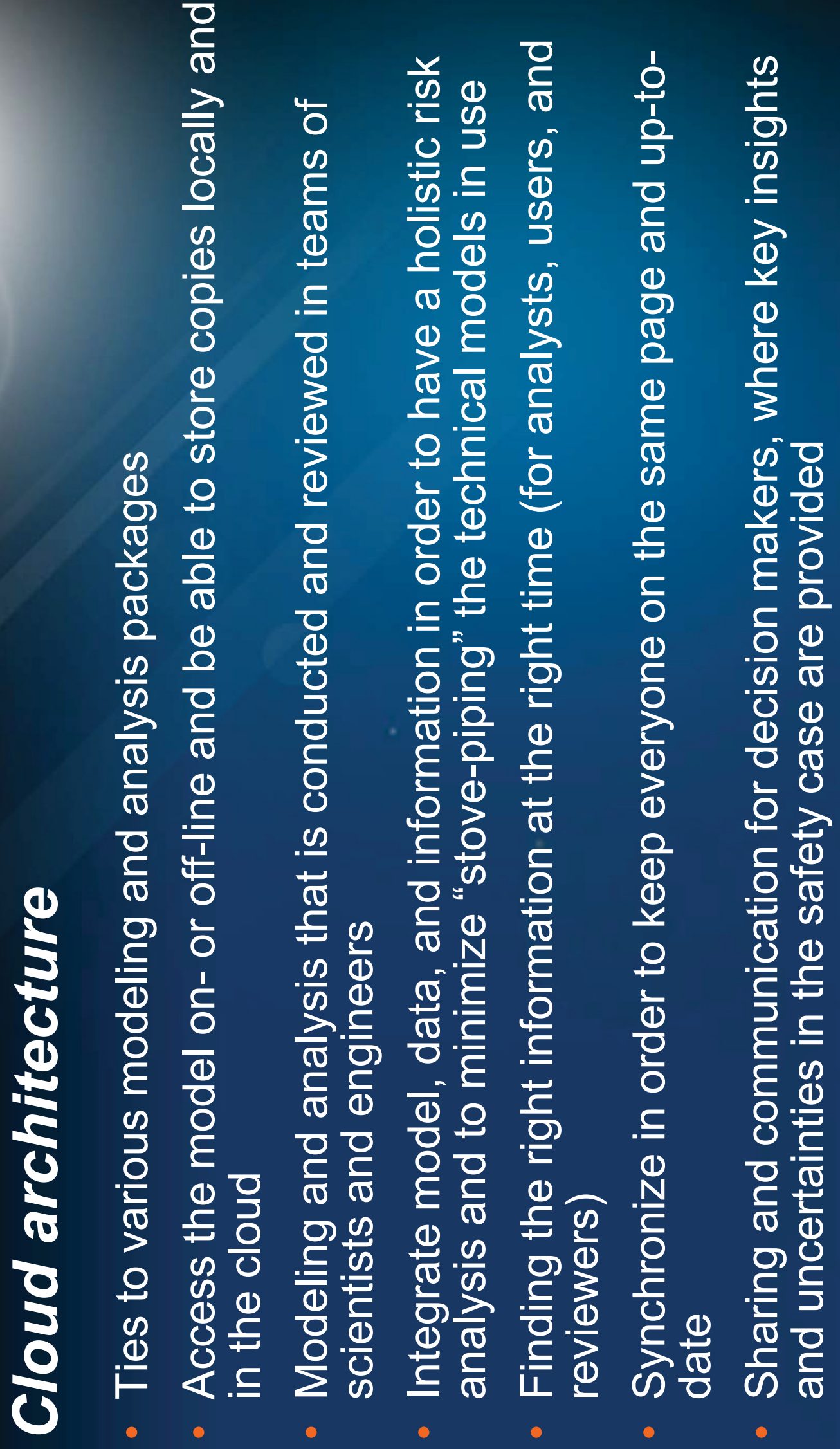


흥

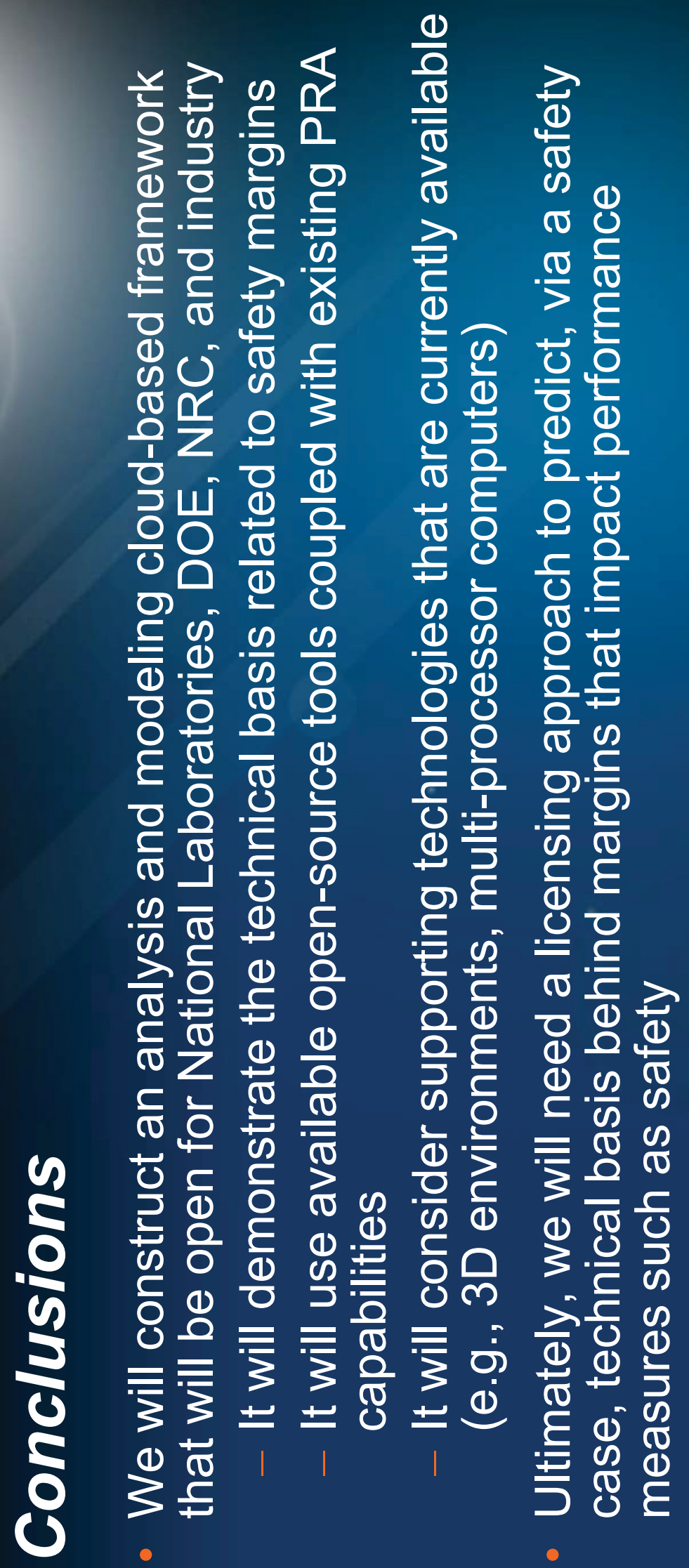


NATIONAL LABORATORY

MANAGED BY UT-BATTELLE

FOR THE DEPARTMENT OF ENERGY

\section{Development of Surrogates for Core Damage Frequency and Large Early Release Frequency for Advanced Small Modular Reactors}

June 2013

Prepared by

G. F. Flanagan

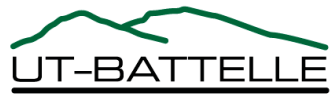

ORNL-27 (4-00) 
This report was prepared as an account of work sponsored by an agency of the United States Government. Neither the United States Government nor any agency thereof, nor any of their employees, makes any warranty, express or implied, or assumes any legal liability or responsibility for the accuracy, completeness, or usefulness of any information, apparatus, product, or process disclosed, or represents that its use would not infringe privately owned rights. Reference herein to any specific commercial product, process, or service by trade name, trademark, manufacturer, or otherwise, does not necessarily constitute or imply its endorsement, recommendation, or favoring by the United States Government or any agency thereof. The views and opinions of authors expressed herein do not necessarily state or reflect those of the United States Government or any agency thereof. 
ORNL/TM-2013/228

Reactor and Nuclear Systems Division

\title{
DEVELOPMENT OF SURROGATES FOR CORE DAMAGE FREQUENCY AND LARGE EARLY RELEASE FREQUENCY FOR ADVANCED SMALL MODULAR REACTORS
}

\author{
G. F. Flanagan
}

Date Published: June 2013

Prepared for the

US Department of Energy, Office of Nuclear Energy

Prepared by

OAK RIDGE NATIONAL LABORATORY

Oak Ridge, Tennessee 37831-6165

managed by

UT-BATTELLE, LLC

for the

US DEPARTMENT OF ENERGY

under contract DE-AC05-00OR22725 



\section{CONTENTS}

Page

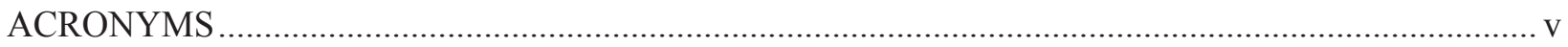

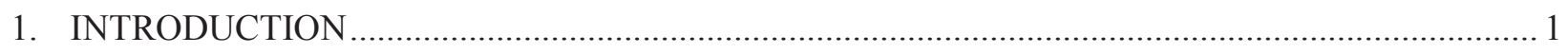

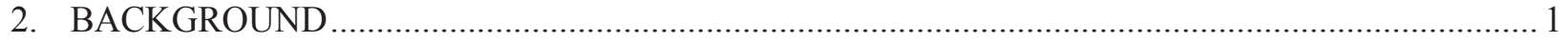

3. THE NEED FOR SURROGATES FOR CDF AND CCFP FOR ADVANCED REACTOR

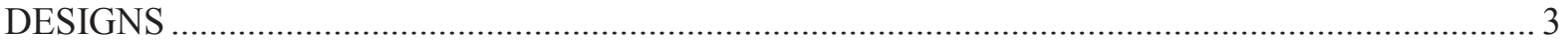

4. POSSIBLE SURROGATES FOR ADVANCED REACTORS_LMR …........................................ 4

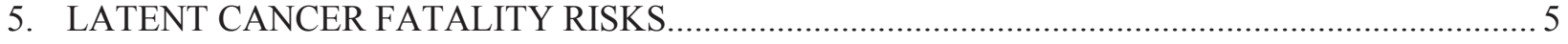

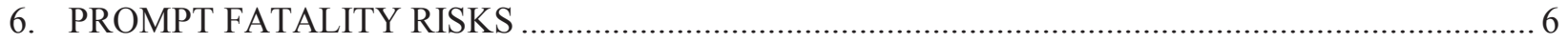

7. RECOMMENDATIONS FOR LMR-TYPE REACTORS …….................................................... 7

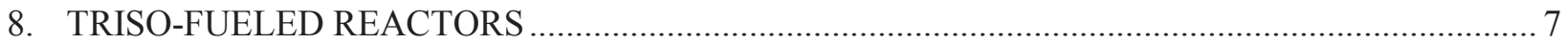

9. RECOMMENDATIONS FOR TRISO-FUELED REACTORS …............................................... 8

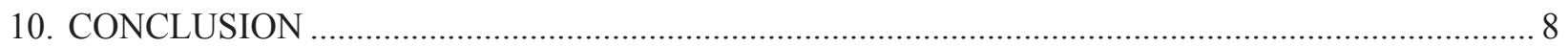

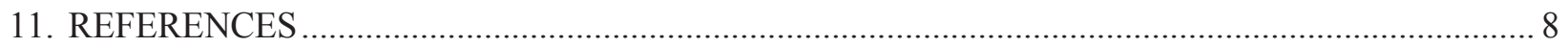





\section{ACRONYMS}

$\begin{array}{ll}\text { ACRS } & \begin{array}{l}\text { Advisory Committee on Reactor Safeguards } \\ \text { advanced small modular reactor }\end{array} \\ \text { CCFP } & \begin{array}{l}\text { conditional containment failure probability } \\ \text { CDF }\end{array} \\ \text { core damage frequency } \\ \text { CLLRPm } & \text { conditional large late probability for accident sequence m } \\ \text { CPLF } & \text { conditional probability of latent fatality } \\ \text { FHR } & \text { fluoride high-temperature reactor } \\ \text { GDC } & \text { general design criteria } \\ \text { HTGR } & \text { high-temperature gas-cooled reactor } \\ \text { ILR } & \text { individual latent risk } \\ \text { LERF } & \text { large early release frequency } \\ \text { LF } & \text { latent fatalities } \\ \text { LLRF } & \text { large late release frequency } \\ \text { LMR } & \text { liquid-metal reactor } \\ \text { LOCA } & \text { loss-of-coolant accident } \\ \text { LRF } & \text { large release frequency } \\ \text { LWR } & \text { light water reactor } \\ \text { MHTGR } & \text { modular high-temperature gas-cooled reactor } \\ \text { NRC } & \text { US Nuclear Regulatory Commission } \\ \text { PRA } & \text { probabilistic risk assessment } \\ \text { PRISM } & \text { Power Reactor Innovative Small Module } \\ \text { QHO } & \text { quantitative health objective } \\ \text { TP } & \text { total population } \\ \text { TRISO } & \text { tri-structural-isotropic }\end{array}$





\section{DEVELOPMENT OF SURROGATES FOR CORE DAMAGE FREQUENCY AND LARGE EARLY RELEASE FREQUENCY FOR ADVANCED SMALL MODULAR REACTORS}

\section{INTRODUCTION}

The current fleet of light water reactors (LWRs) have developed two risk-based surrogates in order to show compliance with the quantitative health objectives (QHOs), which are derived from the US Nuclear Regulatory Commission (NRC) Safety Goal Policy (Ref. 1). The LWR surrogates consist of a preventative component core damage frequency (CDF) and a mitigation component in the form of a containment performance component usually expressed as a conditional containment failure probability (CCFP). In subsequent LWR analyses, these took the form of a CDF and large release frequency (LRF) or large early release frequency (LERF). The purpose of this study is to examine the historical development of the LWR surrogates as contained in SECY-89-102, Regulatory Guide 1.174, and NUREG-1860 and, applying the thought process behind this evolution, to propose surrogates for use in non-LWRs.

\section{BACKGROUND}

In 1986, the NRC issued the Safety Goal Policy Statement. The statement specified two qualitative safety goals and two QHOs. The two qualitative safety goals are as follows.

- "Individual members of the public should be provided a level of protection from consequences of nuclear power plant operations such that the individuals bear no significant additional risk to life and health."

- "Societal risks to life and health from nuclear power plants should be comparable to or less than the risks of generating electricity by viable competing technologies and should not be a significant addition to other societal risks."

The QHOs are as follows.

- "The risk to an average individual in the vicinity of a nuclear power plant of prompt fatalities that might result from reactor accidents should not exceed one-tenth of one percent ( 0.1 percent) of the sum of prompt fatality risks resulting from other accidents to which members of the U.S. population are generally exposed."

- "The risk to the population in the area near a nuclear power plant of cancer fatalities that might result from nuclear power plant operation should not exceed one-tenth of one percent ( 0.1 percent) of the sum of cancer fatality risks resulting from other causes."

The early fatality QHO implies that the risk of early fatalities from a reactor should be less than $5 \times 10^{-7} /$ year. The latent fatality goal implies that the risk of fatal cancer to the population in the area (radius of 10 miles) near a nuclear power plant due to its operation should be limited to $2 \times 10^{-6} /$ year.

In order for the NRC staff to determine whether a nuclear power plant meets the QHOs, the Commission issued the following general performance guideline: "Consistent with the traditional defense-in-depth approach and the accident mitigation philosophy requiring reliable performance of containment systems, the overall mean frequency of a large release of radioactive material to the environment should be less than 1 in 1,000,000 per year of reactor operation." 
Former NRC Commissioner James Asselstine suggested in a separate statement the following containment performance criterion: "the mean frequency of containment failure in the event of a severe accident should be less than 1 in 100 severe core damage accidents" in order to ensure proper balance between accident prevention and accident mitigation.

Former NRC Commissioner Frederick Burnthal suggested a CDF of 1 in 10,000 per year of reactor operation and that for future reactors this frequency goal should be reduced further.

Finally, the NRC requested the staff prepare a specific guideline for implementation of the safety goal policy. In June 1990, SECY-89-102, "Implementation of the Safety Goals," (Ref. 2) was issued. This document stated that the large release guideline, "frequency of a large release of radioactive material to the environment should be less than 1 in 1,000,000 per year of reactor operation," was more conservative by about one order of magnitude than the $\mathrm{QHO}$, and that this guideline should be applied to all designs independent of the size of containment or character of a particular design approach to the release mitigation function. The SECY proposed that the plant performance objective to meet this guideline be focused on accidental release from the plant and eliminate site characteristics, which is in agreement with Advisory Committee on Reactor Safeguards (ACRS) recommendations.

The SECY suggests partitioning of the release guideline to reflect minimum acceptance criteria for prevention using CDF and mitigation using containment or confinement performance, ensuring a multibarrier defense-in-depth balance for a reactor design. Based on the probabilistic risk assessments (PRAs) that had been performed to date, a CDF of 1 in 10,000 per year of reactor operation was proposed as the accident prevention allocation. The remainder would be allocated to a conditional containment failure probability or an appropriate deterministic containment performance criterion as the mitigation allocation. It further recognized that evolutionary designs being proposed may result in a lower CDF ( 1 in 100,000 per year), and therefore a possible 1 in 10 CCFP would be acceptable for such designs. It indicated that a specific subsidiary object might differ from one design class [e.g., LWR and high-temperature gas-cooled reactor (HTGR)] to another. Finally, the SECY stated that the partitioned objectives are not to be imposed as requirements but may be useful as a basis for regulatory guidance.

Regulatory Guide 1.174, “An Approach for Using Probabilistic Risk Assessment in Risk-Informed Decisions on Plant-Specific Changes to the Licensing Basis," (Ref. 3) restates the CDF of 1 in 10,000 as the basis for measuring whether a change in risks associated with a proposed change in licensing basis will be allowed.

Regulatory Guide 1.174 recognizes that the large release general performance guideline stated in the safety goal policy is the overarching requirement in meeting the QHOs and that CDF and LERF are acceptable methods for meeting the $\mathrm{QHO}$, but direct estimates of large releases can also be used:

"The use of CDF and LERF as the basis for PRA acceptance guidelines is an acceptable approach to addressing Principle 4. Use of the Commission's Safety Goal QHOs in lieu of LERF is acceptable in principle, and licensees may propose their use. However, in practice, implementing such an approach would require an extension to a Level 3 PRA, in which case the methods and assumptions used in the Level 3 analysis, and associated uncertainties, would require additional attention."

In Appendix D of NUREG-1860 (Ref. 4), a derivation of the risk surrogates for LWRs was presented that reached the conclusion that a CDF of $10^{-4} /$ year and a LERF of $10^{-5} /$ year are acceptable surrogates to the latent and early QHOs, respectively, for the current generation of LWRs. 


\section{THE NEED FOR SURROGATES FOR CDF AND CCFP FOR ADVANCED REACTOR DESIGNS}

The large release guideline defined in the safety goal policy applies to all reactor types and can be demonstrated using a Level 3 PRA. However, this is not in keeping with the ACRS recommendations to eliminate site characteristics in meeting this guideline, and it would be subject to the concerns regarding uncertainties expressed in Regulatory Guide 1.174. In addition, the safety goal policy is directly related to application of risk/benefit design decisions to reduce risks where possible. A Level 3 PRA is an expensive tool to use to assess the risk/benefit of proposed design changes. Thus, the need exists to develop surrogates for advanced small modular reactors (aSMRs) similar to those used by LWRs.

The current use of CDF and LERF (or CCFP) have served this purpose for LWRs. However, as explained below, because of unique features in certain designs, these may not be applicable for some aSMRs. The currently proposed designs for aSMRs are based on two types of fuel designs. The first uses various types of fuel pellets (oxide or metal) in the form of pins clad with metal similar in design to a LWR fuel pin. These include various types of liquid-metal reactors (LMRs). The second type of reactor uses tristructural-isotropic (TRISO) fuel particles contained in a prismatic graphite matrix or in the form of pebbles. These include the HTGRs and fluoride high-temperature reactors (FHRs). A third type of advanced reactor (homogeneous) uses liquid fuel; these types of reactors differ significantly from heterogeneous designs and pose unique safety and design challenges and are not considered in this report.

The safety goal policy statement is based on the concept of defense-in-depth, which has been a part of the design of nuclear reactors from the beginning. All the aSMRs have a series of physical barriers that make up part of their defense-in-depth design strategy.

In order to have a large release at the site boundary as described in the safety goal policy, it is necessary for the fuel to fail in such a manner as to release significant radioactive fission products into the reactor coolant, which in turn must escape the primary coolant boundary, and then the containment or confinement. This does not assume any emergency response action takes place. Thus, one can assume at least three physical barriers must be breached to have a large early release: (1) fuel coating or clad, (2) primary coolant boundary, and (3) the containment or confinement boundary. All heterogeneous reactor designs, LWR and non-LWR, have the three boundaries listed above. A large release at the site boundary would only occur for beyond-design-basis events since these three boundaries are assumed to be protected for design basis events.

For LWRs, the barrier failure sequence was based on the fact that there was only a small margin associated with cladding failure once the water coolant began to exceed the safety design limits (departure from nucleate boiling or exceeding the critical heat flux). Therefore, it was expected that the first barrier to fail was the fuel cladding, resulting in a release of fission products into the coolant. This was followed by primary system boundary failure due to the stresses associated with the two-phase behavior of the coolant and/or hydrogen release from high-temperature clad interaction with steam. Once the primary system boundary failed, pressure stresses were introduced on the containment boundary that, if high enough, could lead to failure of the containment either rapidly (over stressed) or slowly (increased leak rate). Only then would a large release of radioactivity enter the environment. For loss-of-coolant accidents (LOCAs), a failure of the primary system boundary was the initiating event. If the cladding failed during a LOCA, the radioactive fission products were immediately introduced into the containment.

For advanced reactors such as liquid-metal reactors (LMRs) that have fuel pellets surrounded by cladding acting as a fission product retention barrier, the release of fission products is initiated by failure of the cladding, even though these reactor types have much more margin to failure than LWRs due to the single phase and high boiling point of the coolant, and low-pressure operation. This is followed by failure of the primary system boundary, generally due to high temperatures (creep rupture) or possible energetic releases, followed by failure of the containment or confinement. These latter failures are based on the 
severity of the accident. For some types of LMRs (sodium-cooled reactors), containment failure may result from over-pressurization due to coolant chemical reactions.

For the reactors using TRISO fuel, core damage, as postulated in the case of LWR and LMR systems, is highly unlikely since failure of a very large number of small fuel particles would be needed to yield a significant quantity of fission product release. The fuel particles have been shown to have significant robust behavior even at temperatures exceeding $1600^{\circ} \mathrm{C}$. In addition to the robust fuel, the HTGR designs generally have a confinement instead of leak-tight containment. This is necessary to prevent sudden overpressure of the containment as a result of a primary system depressurization (e.g., a loss of coolant) accident. The confinement is designed to allow a rapid release of the early pressure pulse containing a limited quantity of fission products (as a result of normal operation) followed by a filtered release. The confinement also acts as a barrier to prevent air or moisture ingress into the reactor following a rapid depressurization, which may have a deleterious effect on the reactor internals and or fuel coating.

The FHR uses the same robust particle fuel as HTGRs; however, they operate at near atmospheric pressure. FHRs will likely have a leak-tight, low-pressure containment (similar to a LMR) in order to prevent the release of tritium or beryllium during normal operation or as a result of a primary system boundary failure. Over-pressurization of the containment will not likely be an issue for accidents in FHRs.

Thus, for these TRISO-fueled reactors, CDF and LERF are not applicable surrogates to address the LRF requirements associated with safety goal compliance for particle fuel reactors. This position was also taken in the Next Generation Nuclear Plant white paper on PRA (Ref. 5).

\section{POSSIBLE SURROGATES FOR ADVANCED REACTORS—LMR}

For advanced reactors such as LMRs that have fuel pins with metal cladding separating the fuel from the coolant, the concept of CDF could be interpreted in much the same manner as for LWRs, and therefore, $\mathrm{CDF}$ is an applicable surrogate. The issue then becomes the following: Is a frequency of $10^{-4} /$ year, the value suggested for LWRs, the appropriate value for LMRs? LMRs operate at lower pressures, and the coolants have significantly better heat conductivity and operate far below the boiling point compared to LWRs, resulting in significantly larger margins to cladding failure compared to LWRs. LMR designers have considered using a CDF goal of CDF of $10^{-5} /$ year in order to meet the Commission's expectation (Ref. 6) that advanced reactors should have at least the equivalent level of safety as the current LWRs and will provide enhanced margins of safety. Current LMR designs can achieve a $10^{-5} /$ year CDF based on studies performed on the Power Reactor Innovative Small Module (PRISM) and sodium advanced fast reactor passively safe designs (Ref. 7). Thus, setting a goal of CDF of $10^{-5} /$ year, the preventative component requirement can more than adequately be met, even allowing for uncertainty due to the lack of operational data.

If this value is used as the preventative component in meeting the QHO as suggested in SECY-89-102, then the CCFP could be reduced to $10^{-1}$ year in order to meet the goal of $10^{-6}$ /year large release and yet retain an appropriate ratio of prevention to mitigation. Since LMR containments are generally not the high pressure leak-tight systems found in typical LWRs, reducing the CCFP by an order of magnitude will allow flexibility in the design of LMR containments, yet retain a reasonable ratio of prevention vs mitigation, as suggested in SECY-89-102. "The Commission has no objection to the use of the $10^{-1}$ CCFP objective for the evolutionary design in the manner described above." Thus, the large release performance guideline $\left(10^{-6} /\right.$ year $)$ can be met by the LMR using $10^{-5} \mathrm{CDF}$ and a CCFP of $10^{-1}$.

NUREG-1860 (Ref. 4) suggested that CDF could be a direct surrogate for the latent cancer death QHO when applied with open containment for the existing fleet of LWRs. The following derivation, based on a similar derivation from NUREG-1860, indicates that a CDF of $10^{-5} /$ year for an LMR could be used as a 
surrogate for the latent cancer QHO provided the largest conditional probability of latent fatalities (CPLFs) within a10-mile radius for internal initiators is $<4 \times 10^{-2}$. In order to establish this case, a LMR Level 3 PRA is needed to ensure a CPLF $<4 \times 10^{-2}$ can be achieved. The following derivation as presented in Sect. 5 from NUREG-1860 Appendix D was used to justify this suggestion.

\section{LATENT CANCER FATALITY RISKS}

The risk to the population from cancer "resulting from all other causes" is taken to be the cancer fatality rate in the United States, which is about 1 in 500 or $2 \times 10^{-3} /$ year. The safety goal criteria of one-tenth of one percent of this figure implies that the risk of fatal cancer to the population in the area near a nuclear power plant due to its operation should be limited to $2 \times 10^{-6} /$ reactor year.

$$
\text { i.e.: } 1 / 10 * 1 \% * 2 \times 10^{-3}=2 \times 10^{-6} \text {. }
$$

The "area" is understood to be an annulus of 10-mile radius from the plant site boundary. The cancer risk is also determined on the basis of an average individual latent risk (ILR), that is, by evaluating the number of latent cancers (societal risk) due to all accidents to a distance of 10 miles from the plant site boundary, weighted by the frequency of the accident, dividing by the total population (TP) to 10 miles, and summing over all accidents. This implies

$$
\mathrm{ILR}=\sum_{1}^{M}\left[\left(\mathrm{LF}_{\mathrm{m}} * \mathrm{LLRF}_{\mathrm{m}}\right) / \mathrm{TP}(10)\right], \quad \text { Equation } 1
$$

where $\mathrm{LF}_{\mathrm{m}}=$ number of latent cancer fatalities within 10 miles conditional on the occurrence of the accident sequence " $\mathrm{m}$ " and

$\mathrm{LLRF}_{\mathrm{m}}=$ frequency/year of a release leading to a dose to an offsite individual TP $(10)=$ total population to 10 miles.

The number of latent fatalities $\left(\mathrm{LF}_{\mathrm{m}}\right)$ expected to occur for a certain population TP (10) given an accident is expressed as follows:

$$
\mathrm{LF}_{\mathrm{m}}=\mathrm{CPLF}_{\mathrm{m}} * \mathrm{TP}(10), \quad \text { Equation } 2
$$

where $\mathrm{CPLF}_{\mathrm{m}}=$ conditional probability of an individual becoming a latent fatality for an accident sequence "m".

Therefore, the CPLF is

$$
\mathrm{CPLF}_{\mathrm{m}}=\mathrm{LF}_{\mathrm{m}} / \mathrm{TP}(10) . \quad \text { Equation } 3
$$

Consequently, the ILR is (combining Equations 1 and 3)

$$
\operatorname{ILR}=\sum_{1}^{M} \mathrm{CPLF}_{\mathrm{m}}{ }^{*} \mathrm{LLRF}_{\mathrm{m}} . \quad \text { Equation } 4
$$

It can be shown that if a plant's CDF is $10^{-4} /$ year or less, the latent fatality QHO is generally met. This acceptance can be demonstrated numerically using the results of probabilistic consequence assessments carried out in Level 3 PRAs as follows:

1) Assuming that one accident sequence " $m$ " dominates the latent fatality risk and the LLRF.

2) Assuming the accident sequence dominating the risk is the worst case scenario:

- a large opening in the containment and/or

- an unscrubbed release that occurs after effective evacuation of the surrounding population (i.e., no early fatalities occur). 
3) Assuming that the accident occurs in an open containment, the conditional probability of large late release (CLLRPm) is 1.0; that is,

$$
\begin{aligned}
& \mathrm{LLRF}_{\mathrm{m}}=\mathrm{CDF}_{\mathrm{m}} * \mathrm{CLLRP}_{\mathrm{m}} \quad \text { Equation } 5 \\
& \mathrm{LLRF}_{\mathrm{m}}=\mathrm{CDF}_{\mathrm{m}} * 1.0 \text {. }
\end{aligned}
$$

Therefore,

$$
\mathrm{ILR}_{\mathrm{m}}=\mathrm{CPLF}_{\mathrm{m}} * \mathrm{CDF}_{\mathrm{m}} \text {. } \quad \text { Equation } 6
$$

4) Using results from NUREG-1150 (Table 4.3-1) for the Surry PRA, the largest CPLF (within 10 miles) for internal initiators is $4 \times 10^{-3}$.

The calculated CPLF values are very uncertain and; therefore, the approach adopted was to select a conservative estimate of CPLF. A CPLF value was therefore selected from the high consequence-low frequency part of the uncertainty range. This CPLF value corresponds to a large opening in containment and a very large release. It is therefore consistent with the worst case assumptions for accident scenario "m."

Using the above value of CPLF and assuming a CDF goal of $10^{-4} /$ year, an estimate of the ILR can be made using Equation 6:

$$
\operatorname{ILR}_{\mathrm{m}}=\left(4 \times 10^{-3}\right) *\left(10^{-4}\right)=4 \times 10^{-7} / \text { year . }
$$

The ILR corresponding to a $\mathrm{CDF}=10^{-4} /$ year is less than the latent cancer QHO of $2 \times 10^{-6} /$ year by a factor of about five. Using a CDF goal of $10^{-4} /$ year will generally ensure that the latent cancer QHO is met. Therefore, a CDF of $10^{-4} /$ year is an acceptable surrogate for the latent cancer QHO for LWRs.

Since it is recommended that LMR designers consider using a CDF goal of $10^{-5} /$ year as opposed to using $10^{-4}$ year for LWR, which is used in the derivation above, the latent fatality QHO requirement can more than adequately be met if the LMR Level 3 PRA conditional probability of latent fatalities (within a 10 -mile radius) for internal initiators is $<4 \times 10^{-2}$.

\section{PROMPT FATALITY RISKS}

NUREG-1860 also suggested that the LERF is a surrogate for prompt fatality, which is the more conservative of the QHOs. The definition of LERF used by the staff is "a large early release as a significant unmitigated release from containment before effective evacuation of the close-in population such that there is a potential for prompt health effects" (Ref. 8).

The PSA Applications Guide (Ref. 9) introduced the term LERF and included the following definition for large early release:

- unscrubbed containment failure pathway of sufficient size to release the contents of the containment (i.e., one volume change) within 1 hour, which occurs before or within 4 hours of vessel breach; or

- unscrubbed containment bypass pathway occurring with core damage.

Safety analysis of passively safe LMRs indicates that accident progression is slow compared to LWRs, and the systems operate at near atmospheric pressure. Thus, there is no driver for early containment failure; consequently, the concept of LERF as defined above is not applicable to LMR designs (Ref. 10).

Therefore, the use of LERF as a surrogate for the prompt fatality QHO for an LMR is not applicable. This is consistent with SECY-13-0029, which indicates the LRF will continue to be used for new reactors while LERF will be used for existing plants. 


\section{RECOMMENDATIONS FOR LMR-TYPE REACTORS}

For a LMR, a CDF of $10^{-5} /$ year is achievable with current designs (Refs. 7 and 10) and when combined with a CCFP of $10^{-1}$ more than adequately addresses the guideline in SECY-89-102. This also meets the NRC-stated expectation that advanced nuclear reactors demonstrate a level of safety equal to or better than the current LWRs (see Commissioner Burnthal's comments in Sect. 2 and reference 6). Using the methodology in Appendix D of NUREG-1860, and a CDF of $10^{-5} /$ year, an LMR will meet the Safety Goal QHO for latent fatalities if future Level 3 LMR PRAs show that the conditional probability of latent fatality is $<4.3 \times 0^{-2} /$ year within a 10 -mile radius. A CDF value of $10^{-5} /$ year will therefore meet the latent fatality $\mathrm{QHO}$ with a large margin, which would allow for uncertainties such as would be expected for reactors where little operating experience exists. For LMRs, the concept of an LERF may not apply because of increased margins to coolant boiling, better coolant thermal conductivity, and low-pressure operation. Instead, it is recommended that CCFP (or an appropriate deterministic containment performance requirement) be used for the mitigation portion of defense in depth as suggested in SECY89-102. The CCFP used would be $10^{-1}$, allowing the designer more flexibility in containment design. This is in accordance with SECY-89-102.

\section{TRISO-FUELED REACTORS}

For TRISO-fueled reactors, the concept of CDF does not to apply [non-LWR PRA standard (Refs. 5, 11, and 12)]. Thus, an alternative surrogate is needed if one is to avoid the need for the introduction of site characteristics along with large uncertainties as would occur if using a Level 3 PRA as part of the information needed to comply with the safety goal policy statements.

Based on HTGR and FHR designs, there are three physical barriers to release of fission products: the robust TRISO fuel coating, the primary coolant boundary, and containment or confinement. In order for an accident to progress to a state where there is a potential for significant release of fission products, the primary system would need to be breached, resulting in a loss of cooling capability which, in turn, could lead to some fuel particles reaching fuel temperatures in excess of $1600^{\circ} \mathrm{C}$, or ingress of air or water that may result in fuel damage due to degradation of the fuel coating. Based on accident analysis to date, no release is possible if the primary system boundary remains intact (Ref. 12). Thus, the designs need to prevent such a breach. However, should a breach occur, the reactor systems are designed to remove heat using passive systems and prevent fuel damage. Furthermore, if the primary system boundary is breached, there will likely be small amounts of radioactivity released resulting from normal operations. Thus, even after breach of the primary system, there will not be sufficient release to challenge the performance guideline of $10^{-6} /$ year for large release to the environment. The primary mitigation barrier after failure of the primary system boundary is the fuel particle and the confinement or containment. In analyses to date, significant fuel damage is not expected until the particle temperature reaches $1600^{\circ} \mathrm{C}$ (Ref. 13). Safety analysis of the modular high temperature gas-cooled reactor (MHTGR) indicates that for most accidents, including air or water ingress events following breach of the primary coolant boundary, the fuel temperature remains below $1600^{\circ} \mathrm{C}$. Based on the data developed for the HTGR, the preventive design allocation to meet the performance guideline would be $10^{-4} /$ year for primary system boundary failure. The remaining conditional failure mitigation allocation $10^{-2}$ would be split between preventing releases from the confinement and/or preventing damage to the fuel coating which might result in significant fuel damage. To date, the knowledge gained from TRISO fuel tests and limited operational experience with TRISO fuel indicates that if fabrication quality standards are met, the probability of failure of a large number of TRISO fuel particles resulting in a large radioactive release to the environment is orders of magnitude below $10^{-2}$ given a failure of primary system boundary (Ref. 13). Thus, the performance guideline can be met with large margin by the fuel alone, even if confinement is not credited. The mitigation performance measure would be directly attributed to fuel fabrication quality. 


\section{RECOMMENDATIONS FOR TRISO-FUELED REACTORS}

For TRISO fuel reactors (HTGR and FHR), the concept of using a balance (prevention to mitigation) of defense-in-depth barriers to achieve the safety goal performance guideline as stated in SECY-89-102 results in an allocation of an achievable (based on past HTGR safety analyses - Ref. 12) primary boundary failure frequency of $10^{-4} /$ year as the preventative allocation and relying on either fuel integrity (achieved by a high level of fuel fabrication quality objectives) and/or confinement barrier performance for the remaining $10^{-2}$ mitigation component. The decision as to the allocation attributed to fuel coating integrity or confinement /containment performance would be a design decision allowing considerable flexibility in containment/confinement design performance criteria.

The use of CDF or LERF are not applicable to a TRISO-fueled reactor, and thus, a direct link between the recommended surrogates to the QHOs following the methodology of Appendix D of NUREG-1860 is not applicable to these designs.

In lieu of a surrogate, the designer can use a direct calculation of prompt fatalities and latent cancer fatalities derived from a Level 3 PRA analysis along with appropriate site characteristics to show direct compliance with the QHOs per Regulatory Guide 1.174.

\section{CONCLUSIONS}

The above-recommended surrogates apply to two forms of advanced reactors - those with fuel similar in form to LWRs and those using TRISO fuel. It may be possible to extend this concept of development of a preventative surrogate and a mitigation surrogate in a technology neutral framework that when combined can be used to meet the overall Safety Performance Guideline of $10^{-6} /$ year for all currently conceived aSMRs. However, recently the Department of Energy and NRC have embarked on an effort to develop technology neutral general design criteria (GDC) that will define the boundaries that will be protected and further focus on defense-in-depth approaches for advanced systems. In order to remain consistent with this effort, it seems prudent not to further define technology neutral surrogates until the GDCs are defined. This report as completed, thus far, can provide useful information to the technology neutral GDC task. Once technology neutral GDCs are defined, a consistent set of technology neutral surrogates can be developed.

\section{REFERENCES}

1. "Safety Goals for the Operation of Nuclear Power Plants; Policy Statement," Federal Register, Vol. 51 (51 FR 30028), US Nuclear Regulatory Commission, August 21, 1986.

2. "Implementation of the Safety Goals," SECY-89-102, US Nuclear Regulatory Commission, June 1990.

3. "An Approach for Using Probabilistic Risk Assessment in Risk-Informed Decisions on Plant-Specific Changes to the Licensing Basis," Regulatory Guide 1.174, Revision 1, US Nuclear Regulatory Commission, November 2002.

4. "Feasibility Study for a Risk-Informed and Performance-Based Regulatory Structure for Future Plant Licensing," NUREG-1860, U.S. Nuclear Regulatory Commission, December 2007.

5. "Next Generation Nuclear Plant Probabilistic Risk Assessment White Paper," INL/Ext-11-21270, Idaho National Laboratory, Idaho Falls, ID, September 2011. 
6. "Regulations of Advanced Power Plants; Statement of Policy," Federal Register, 51 FR35461, July 12, 1994.

7. General Electric Advanced Nuclear Technology, PRISM Preliminary Safety Information Document, Appendix A, "PRISM Preliminary Probabilistic Risk Assessment," GEFR-00793, UC-87Ta, December 1987.

8. "History of the Use and Consideration of the Large Release Frequency Metric by the U.S. Nuclear Regulatory Commission," SECY-13-0029, US Nuclear Regulatory Commission, August 15, 1996.

9. “PSA Applications Guide,” EPRI TR-105396, August 1995.

10. M. Denman, J. LaChance, T. Sofu, G. Flanagan, R. Wigeland, and R. Bari, Sodium Fast Reactor Safety and Licensing Research Plan-Volume 1, SAND2012-4260, Sandia National Laboratories, Albuquerque, NM, May 2012.

11. The American Society of Mechanical Engineers, Committee on Nuclear Risk Management, Standard for Probabilistic Risk Assessment for Advanced Non-LWR Nuclear Power Plants, Draft, October 2008.

12. P. M. Williams et al., Draft Pre-application Safety Evaluation Report for the Modular HighTemperature Gas-Cooled Reactor, NUREG-1338, US Nuclear Regulatory Commission, 1989.

13. R. P. Wichner and S. J. Ball, Potential Damage to Gas-Cooled Graphite Reactors Due to Severe Accidents, ORNL/TM-13661, Oak Ridge National Laboratory, Oak Ridge, TN. 


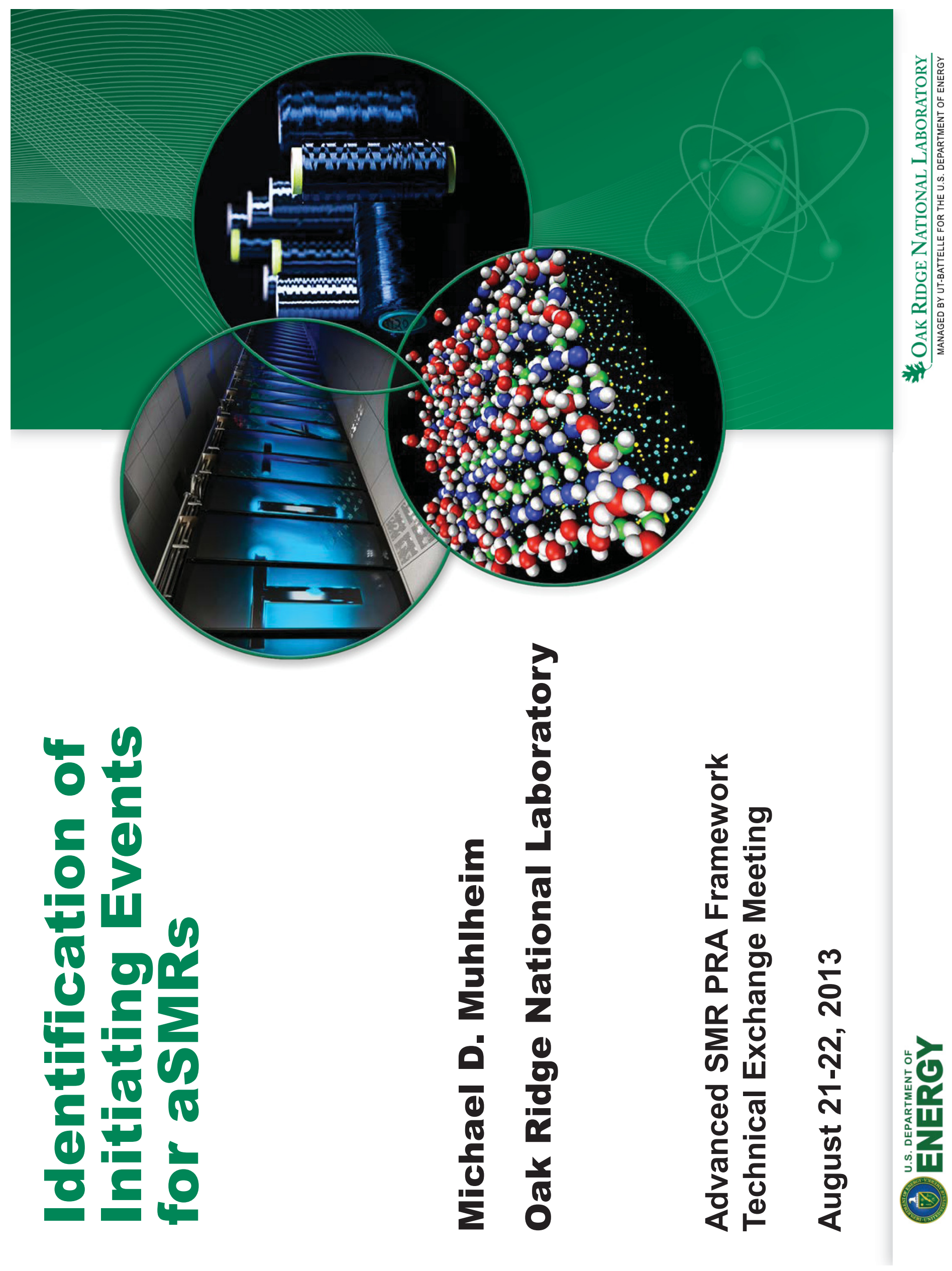



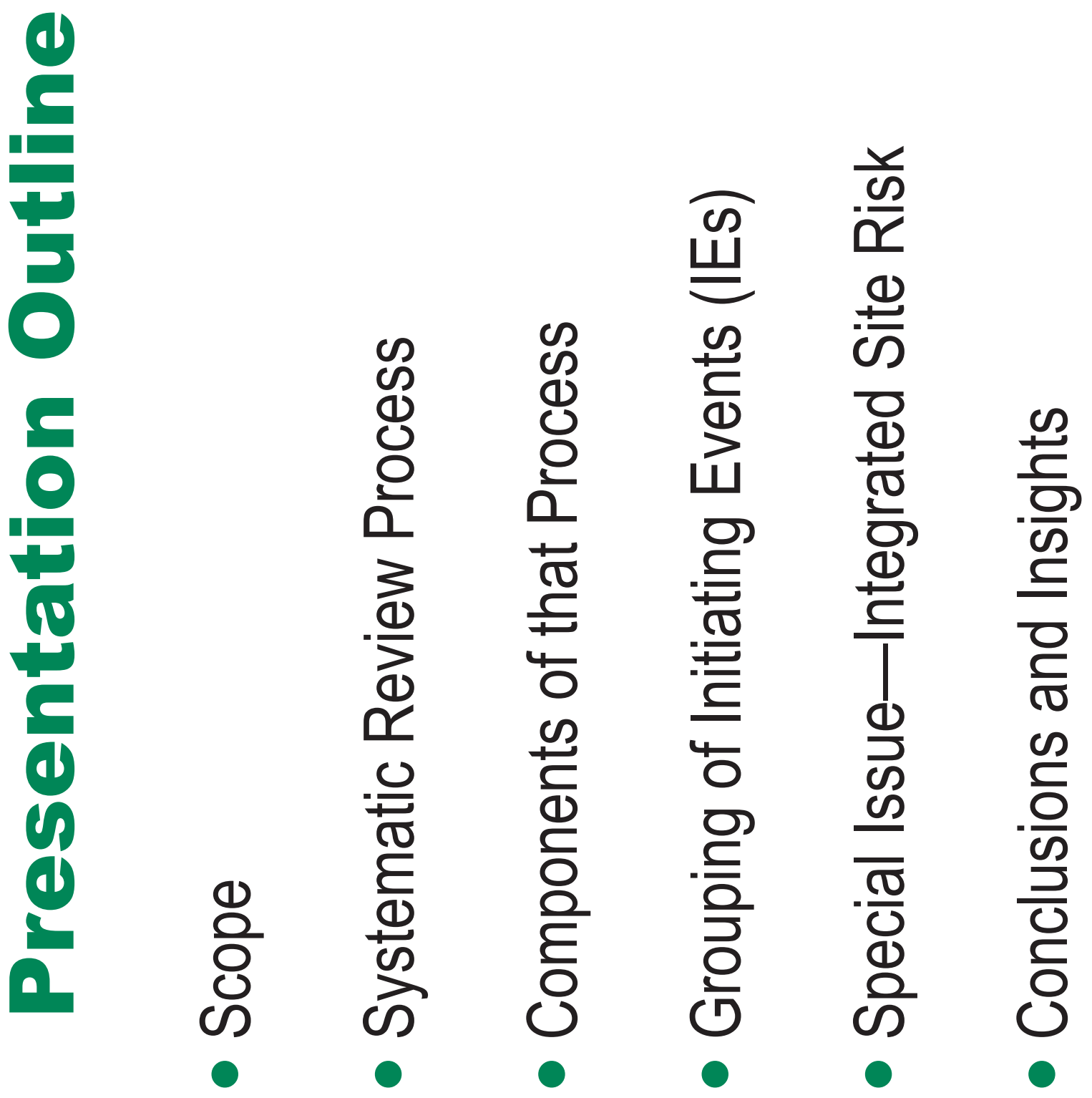


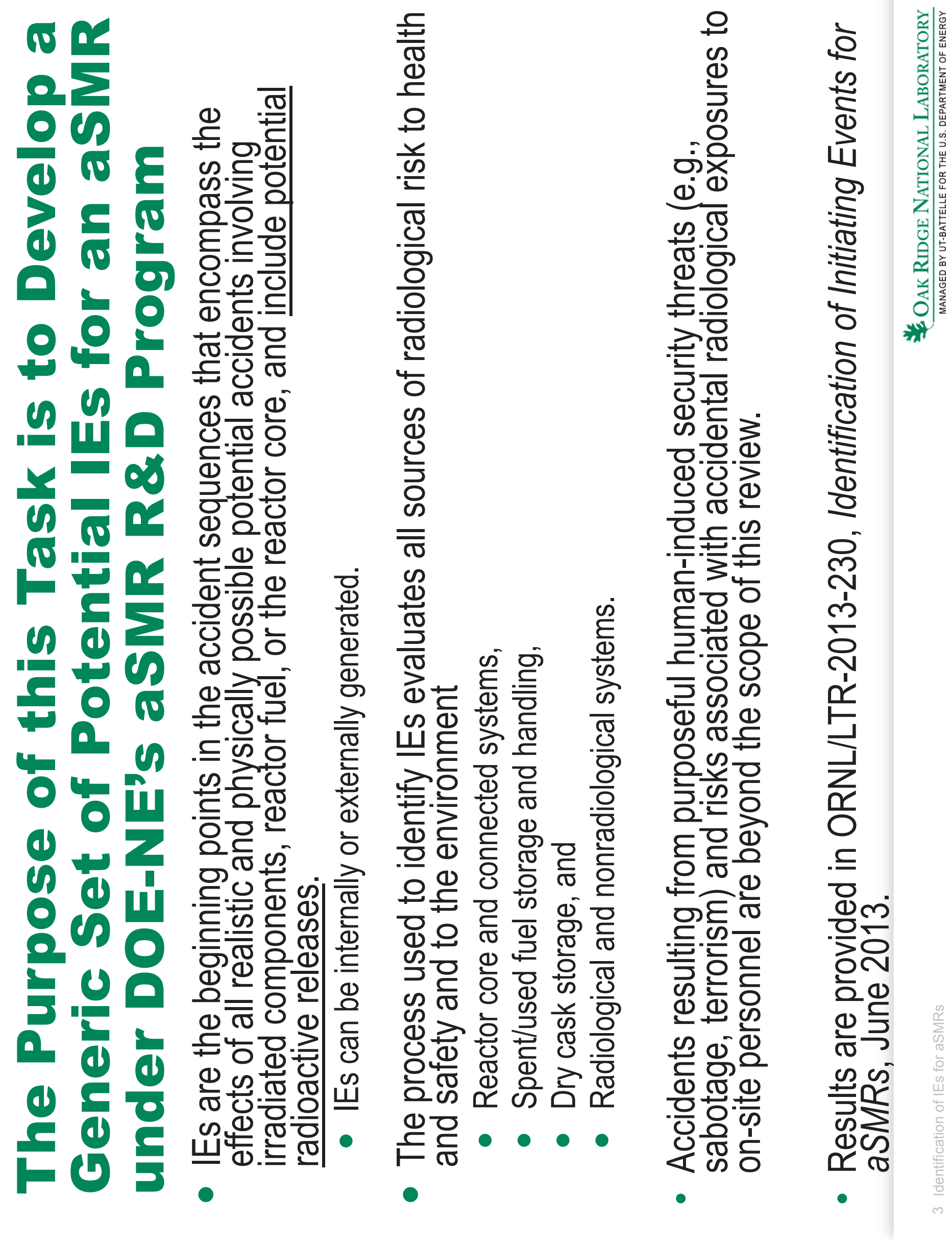




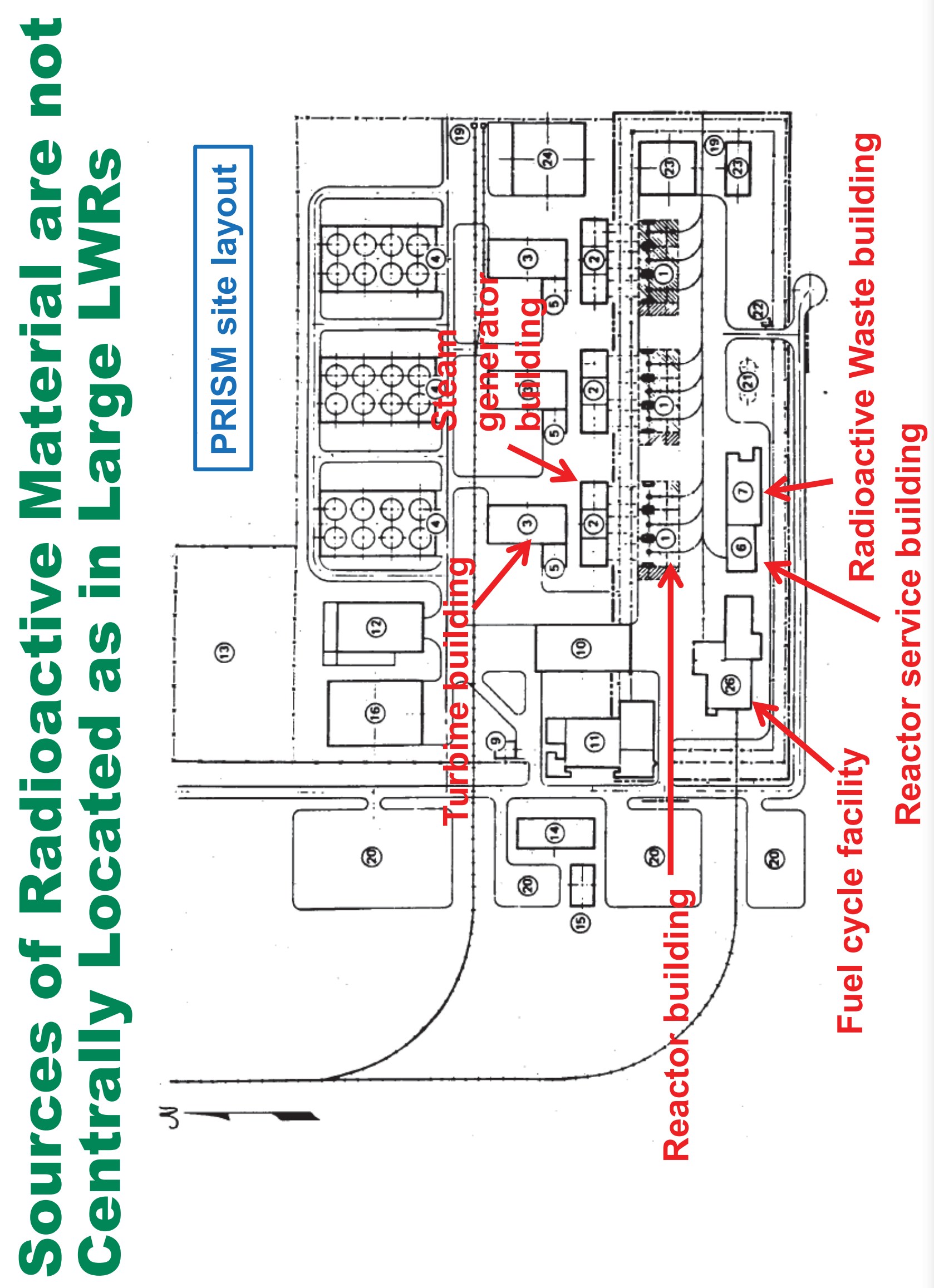




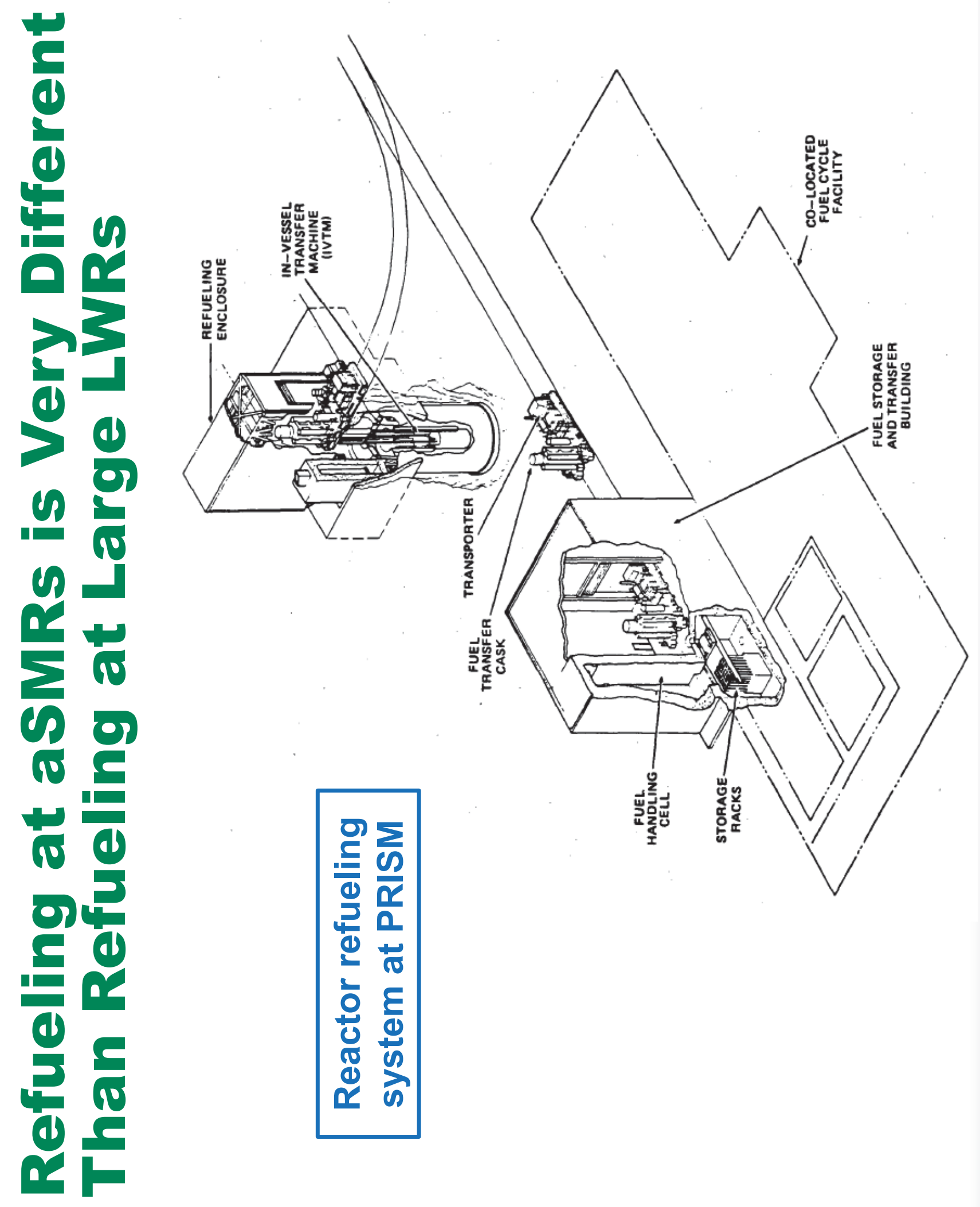

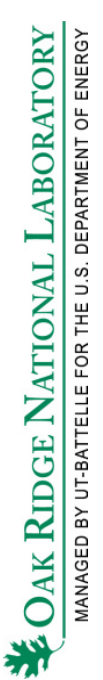




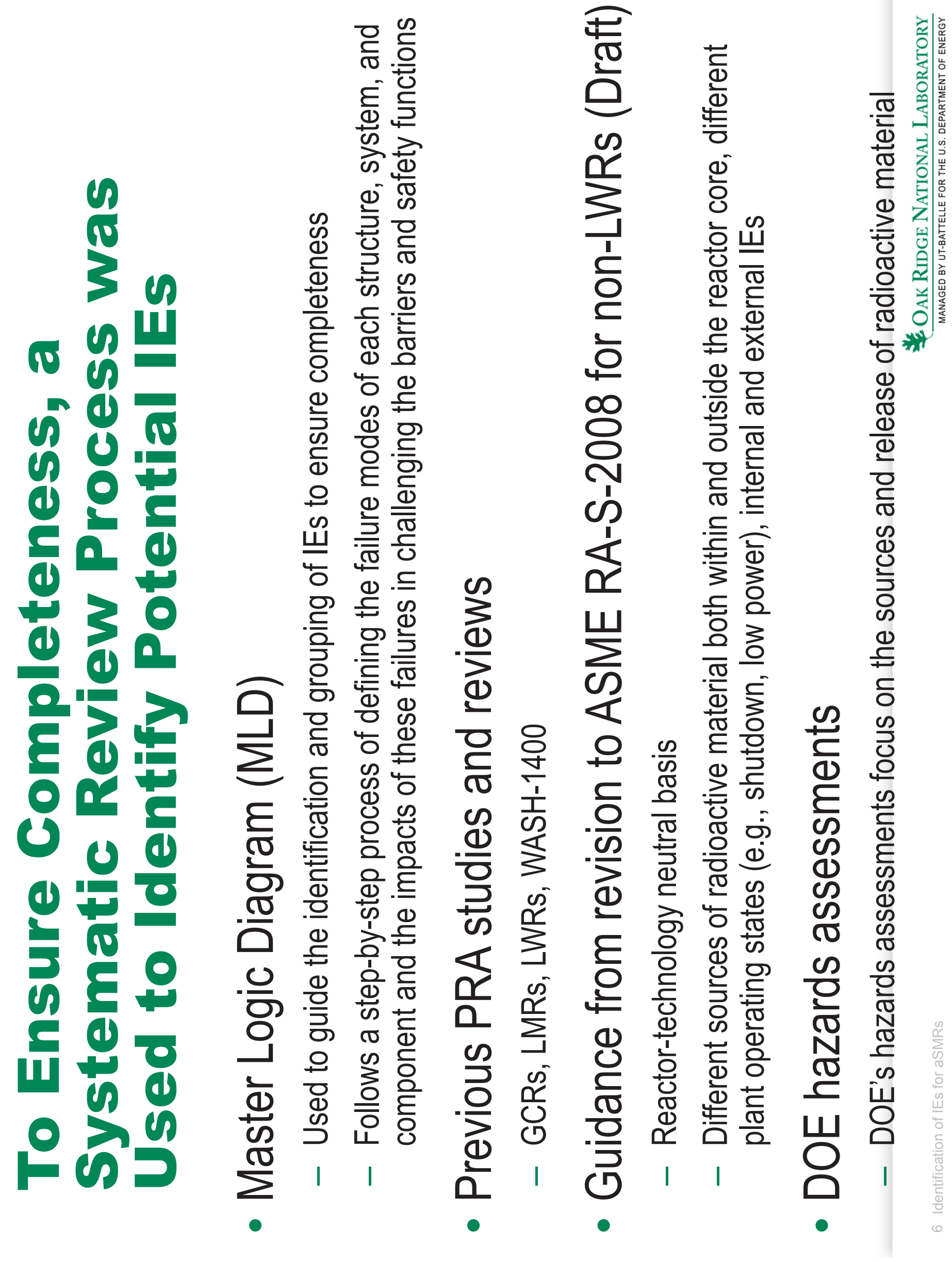




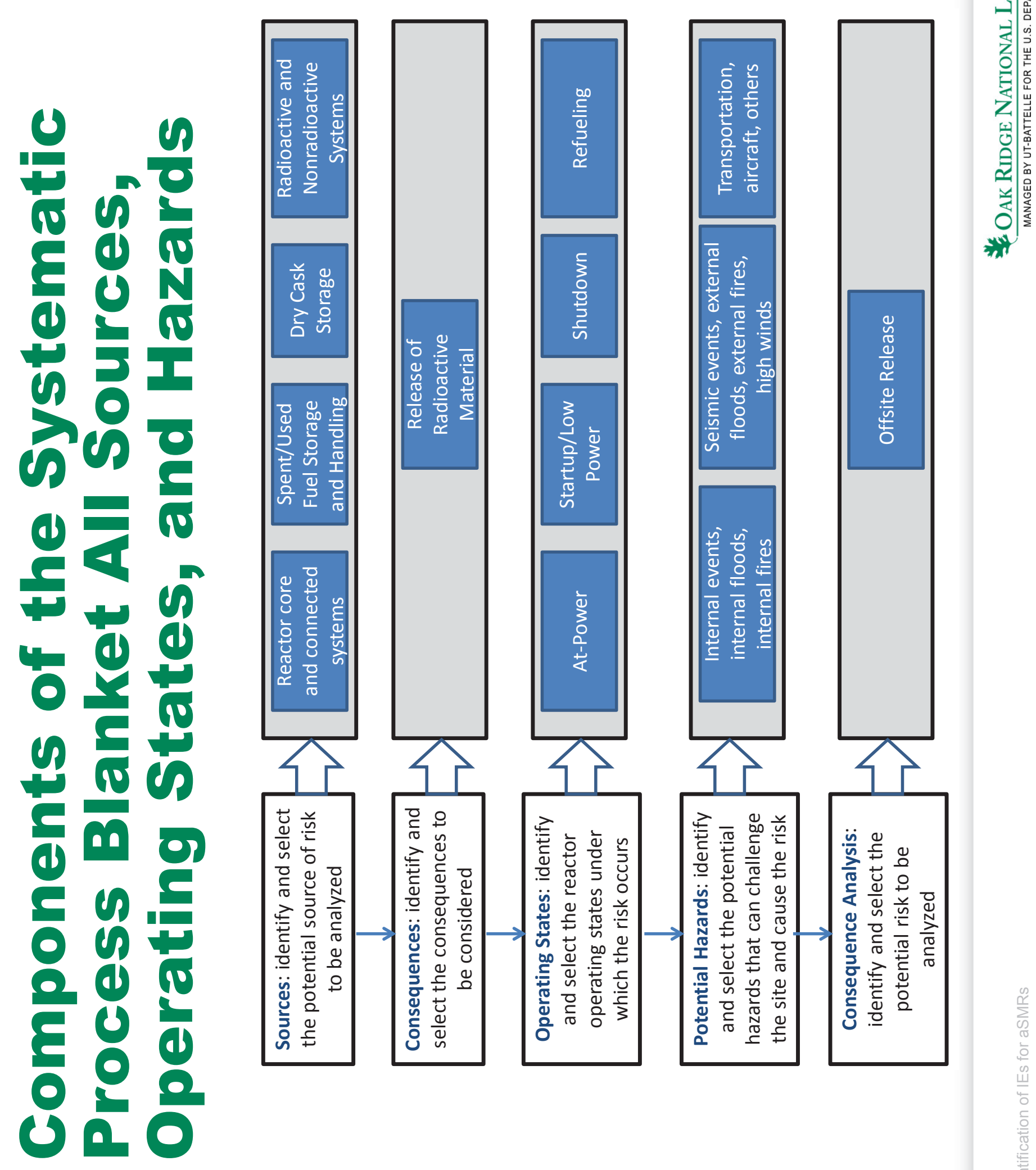




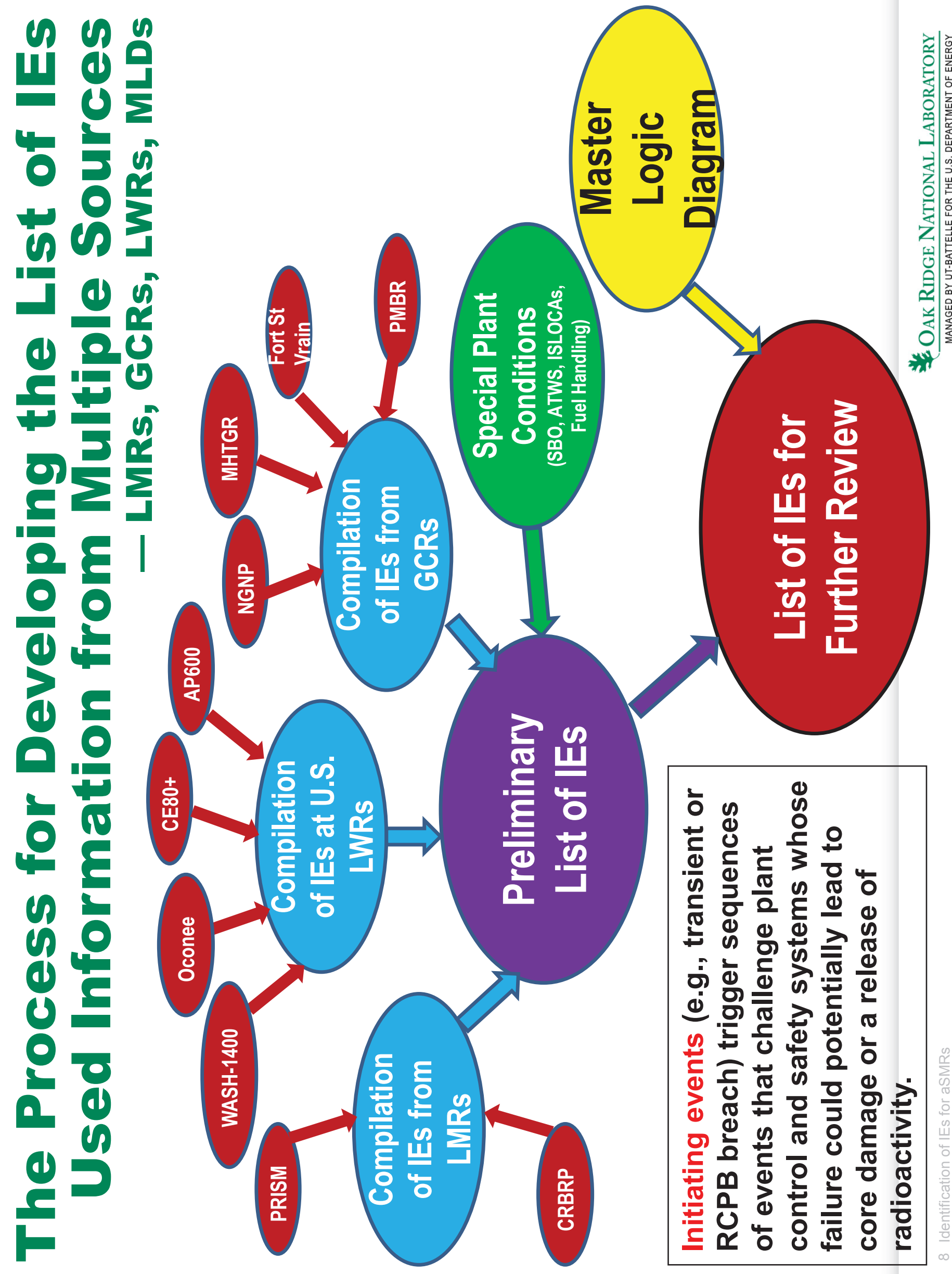




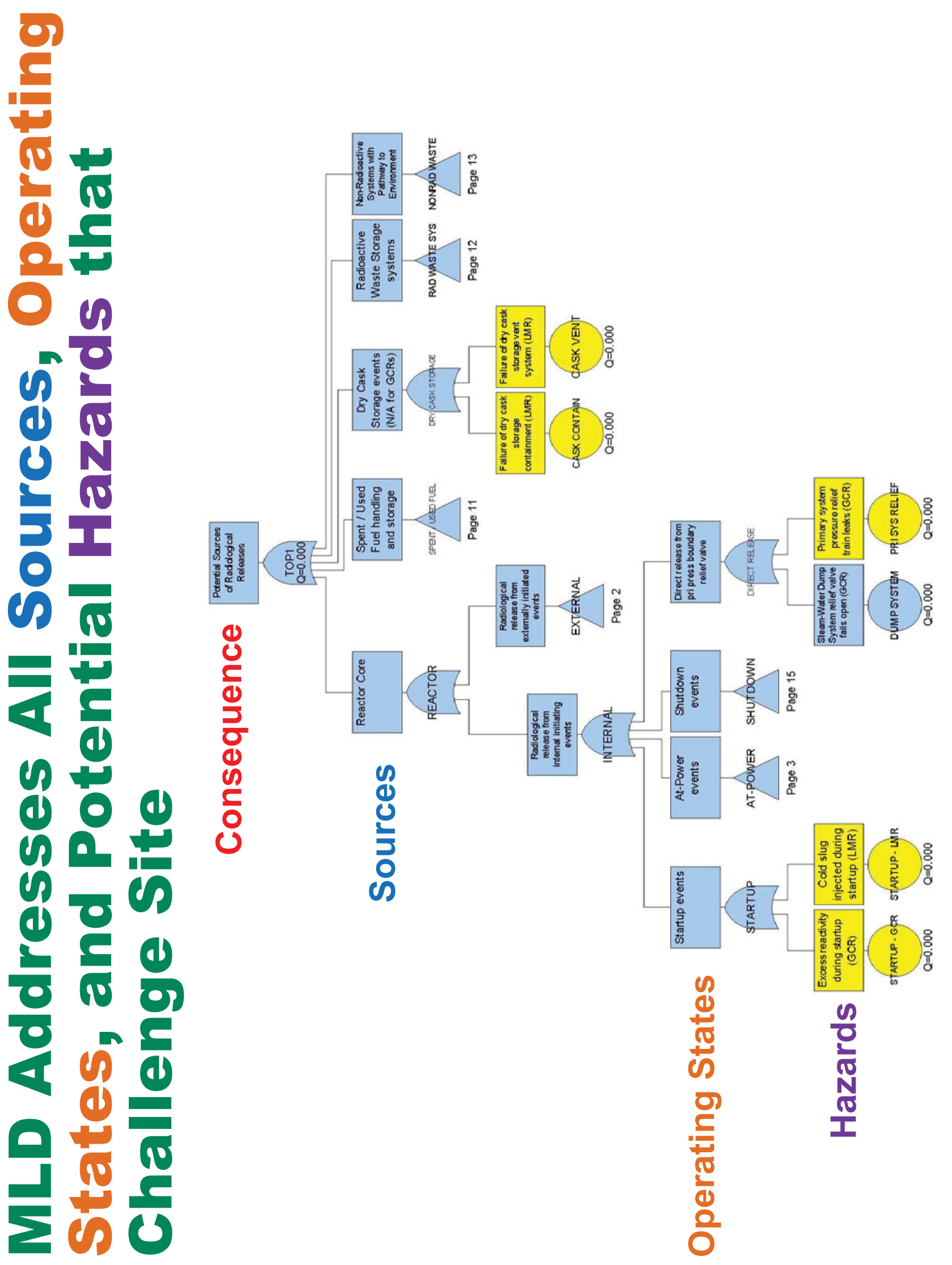




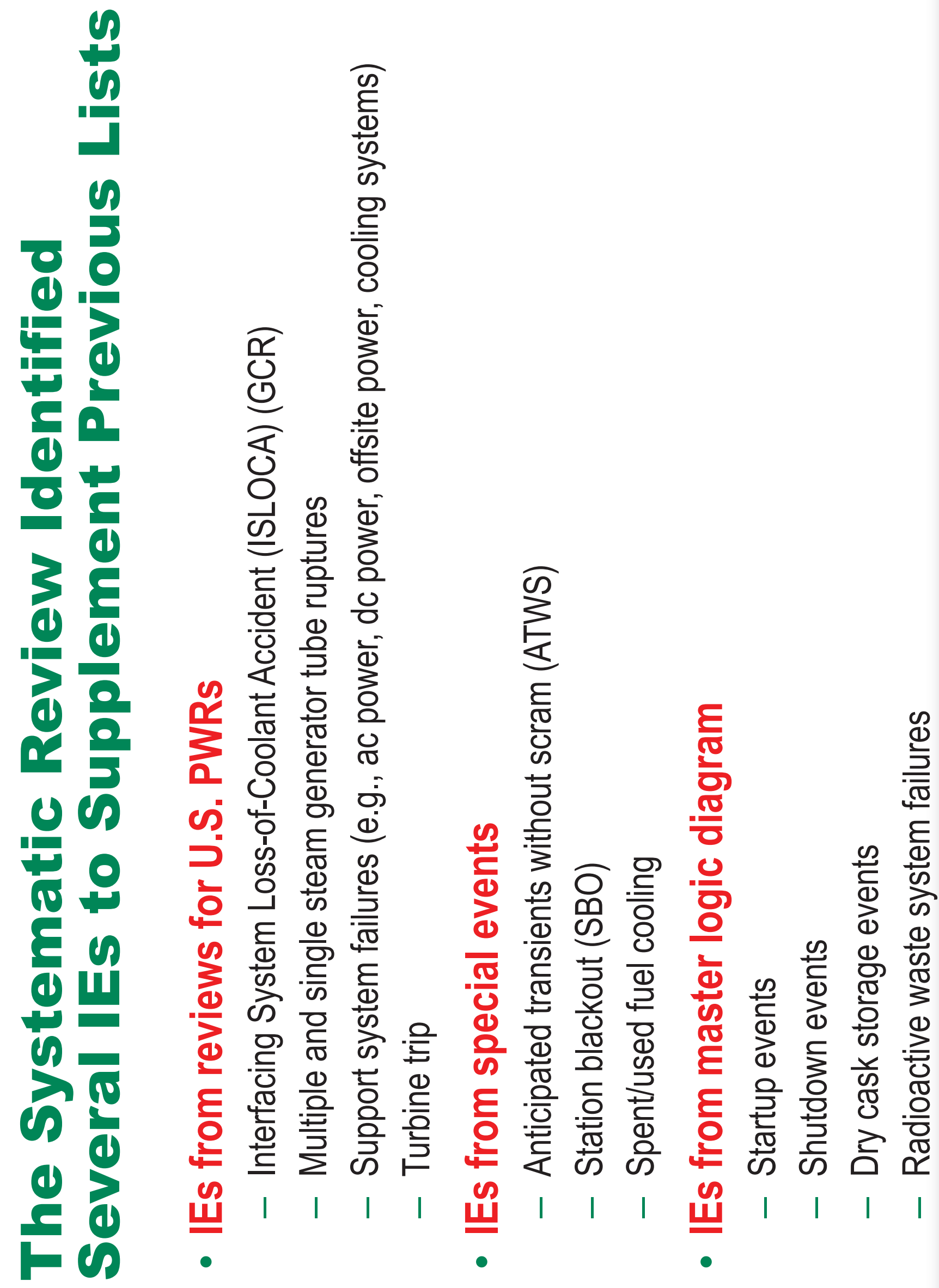




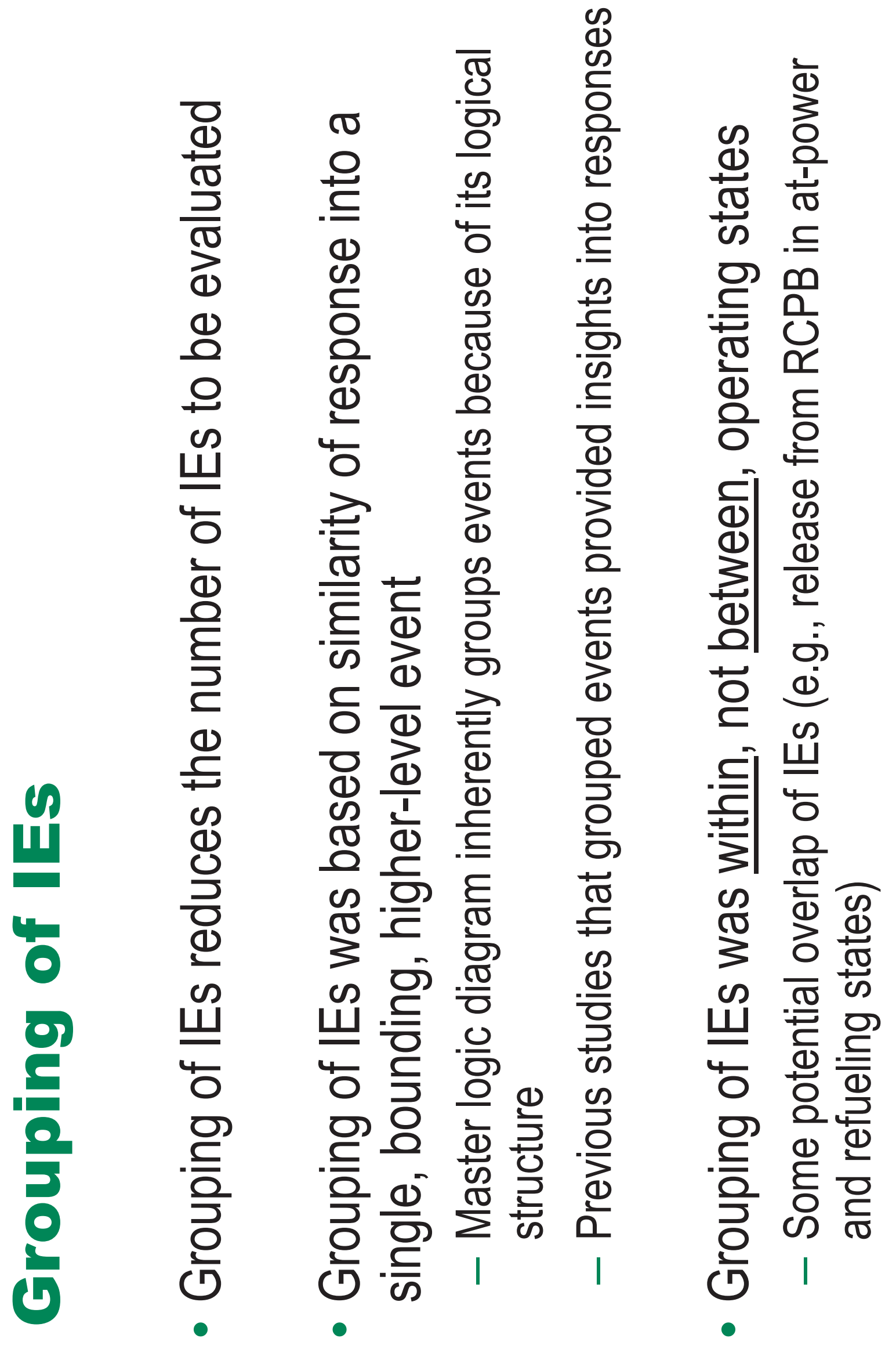




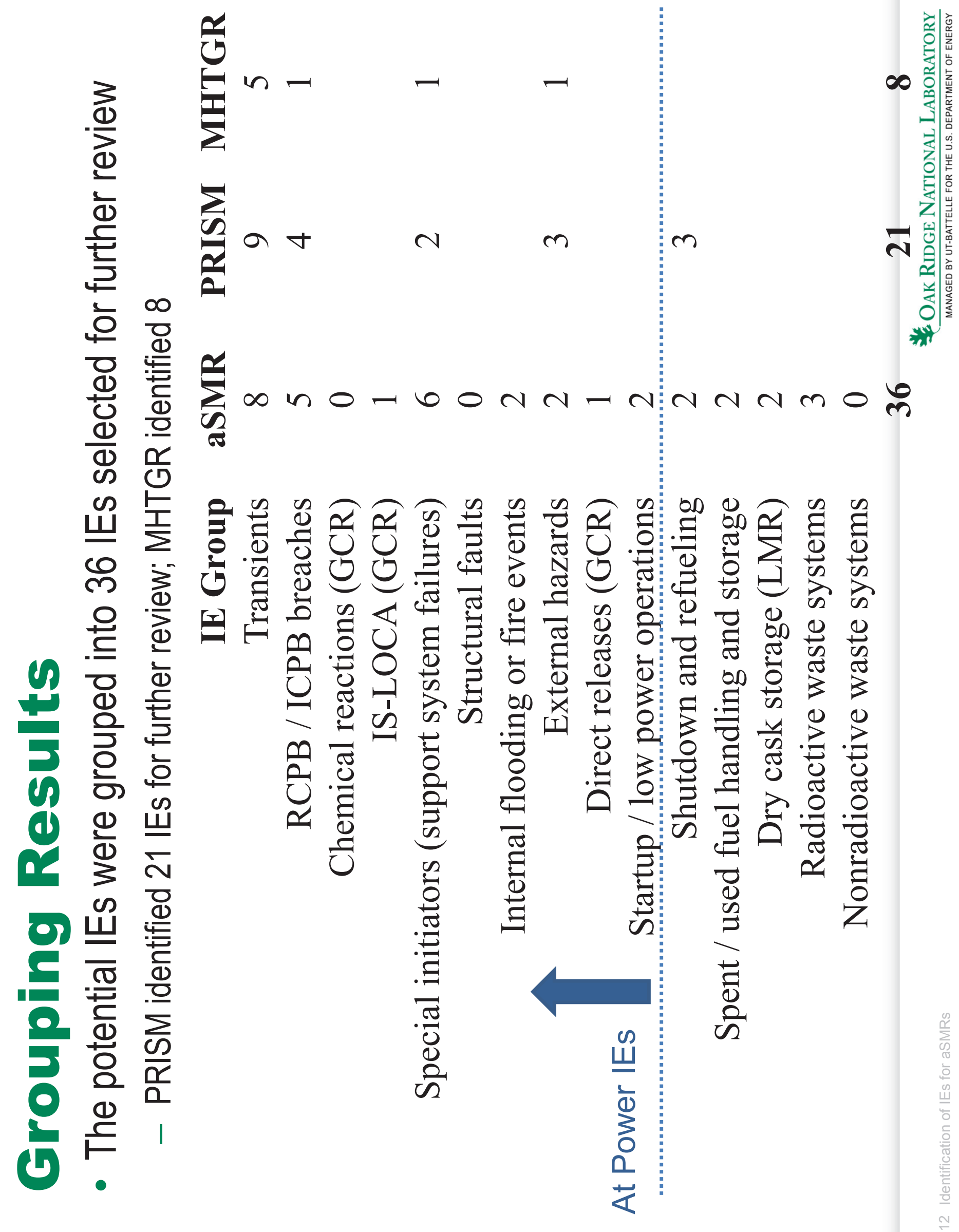




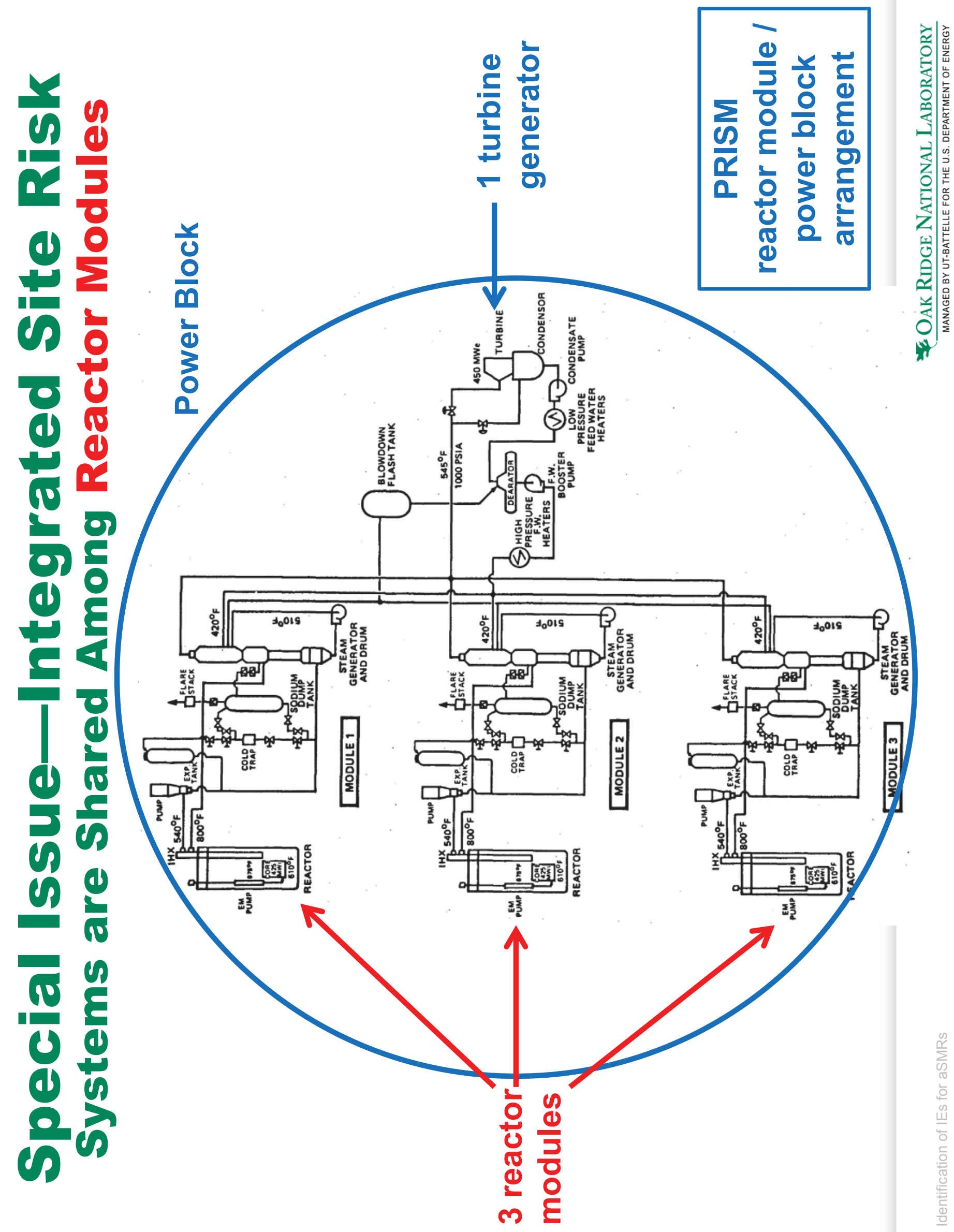




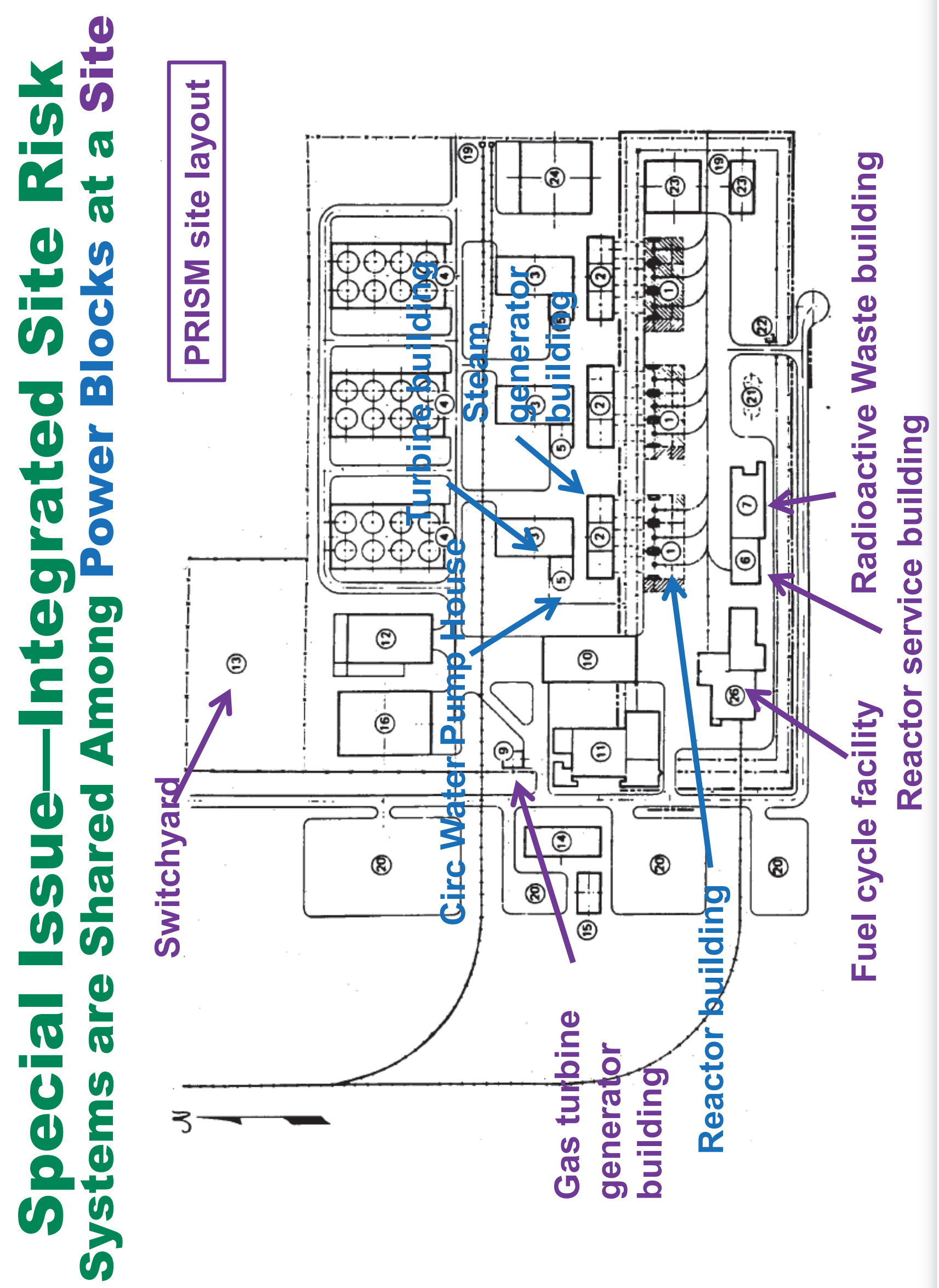




\section{$\sigma$}

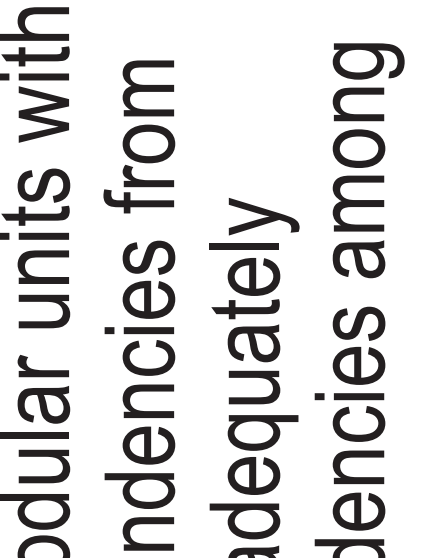

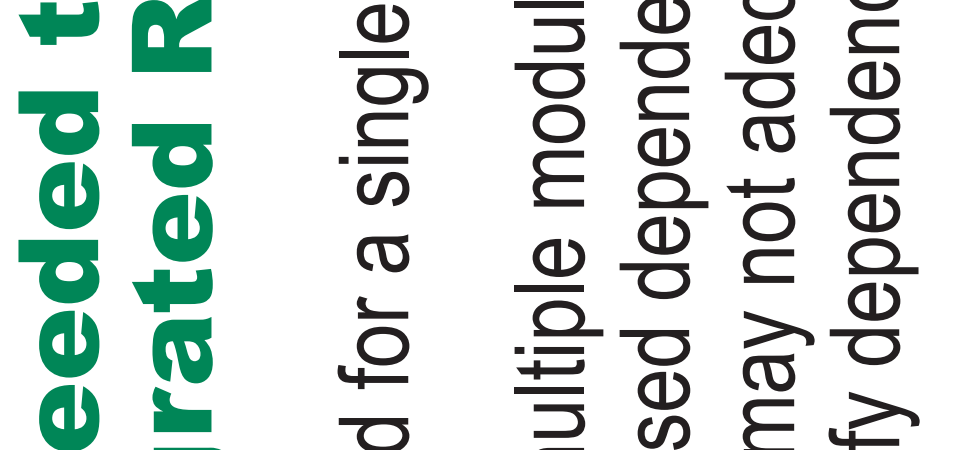

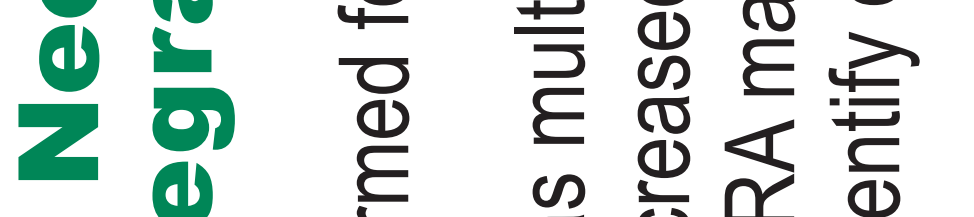

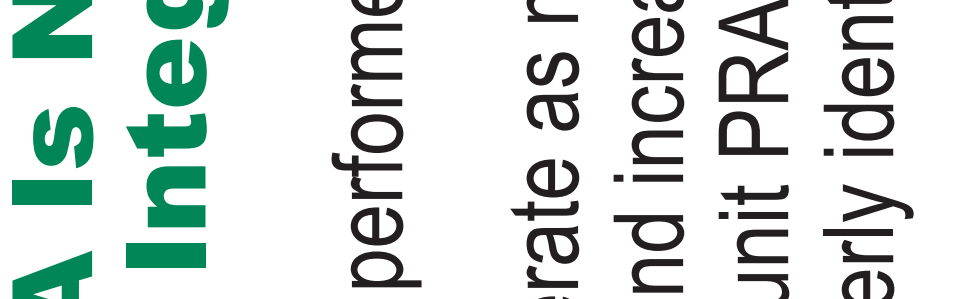

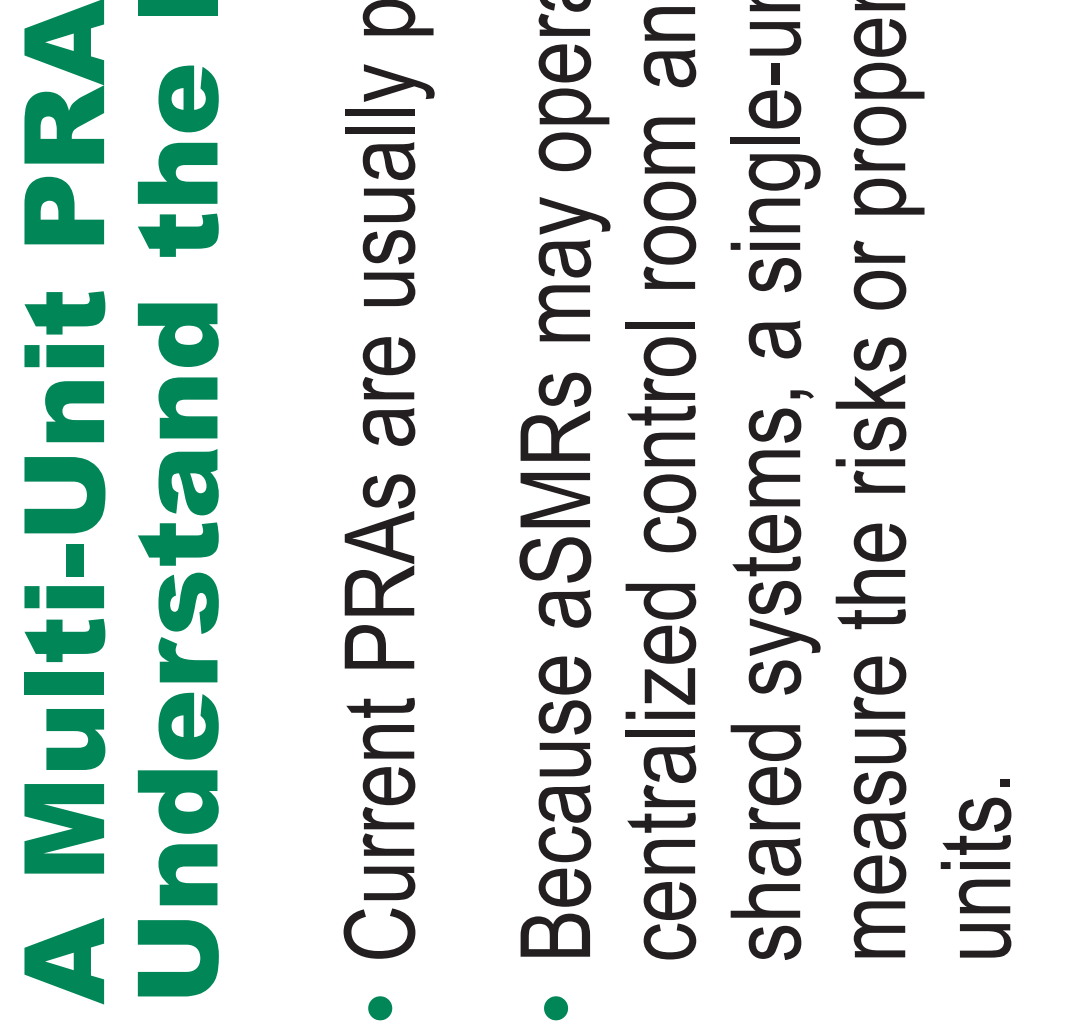

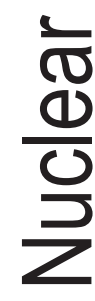

촌

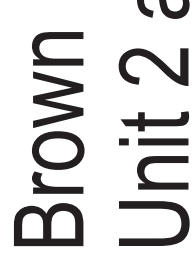

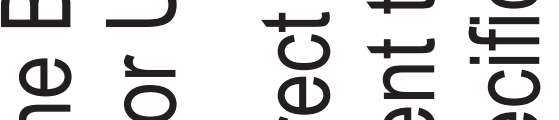

는 잉

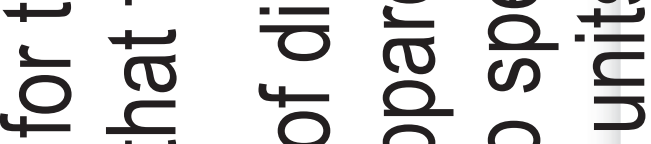

4 당 응응

$\varangle \overline{0}$

중

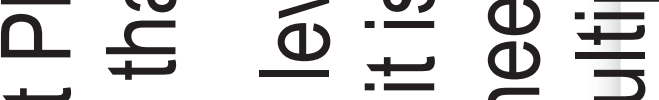

둔

今 क क क

舟

产

허 잉ㅇ

$\varepsilon$ 为

(1)

흔

하

क क 0 잉

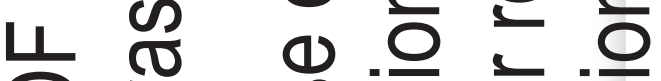

了

$0+\pi \pi$

迹要

둠 


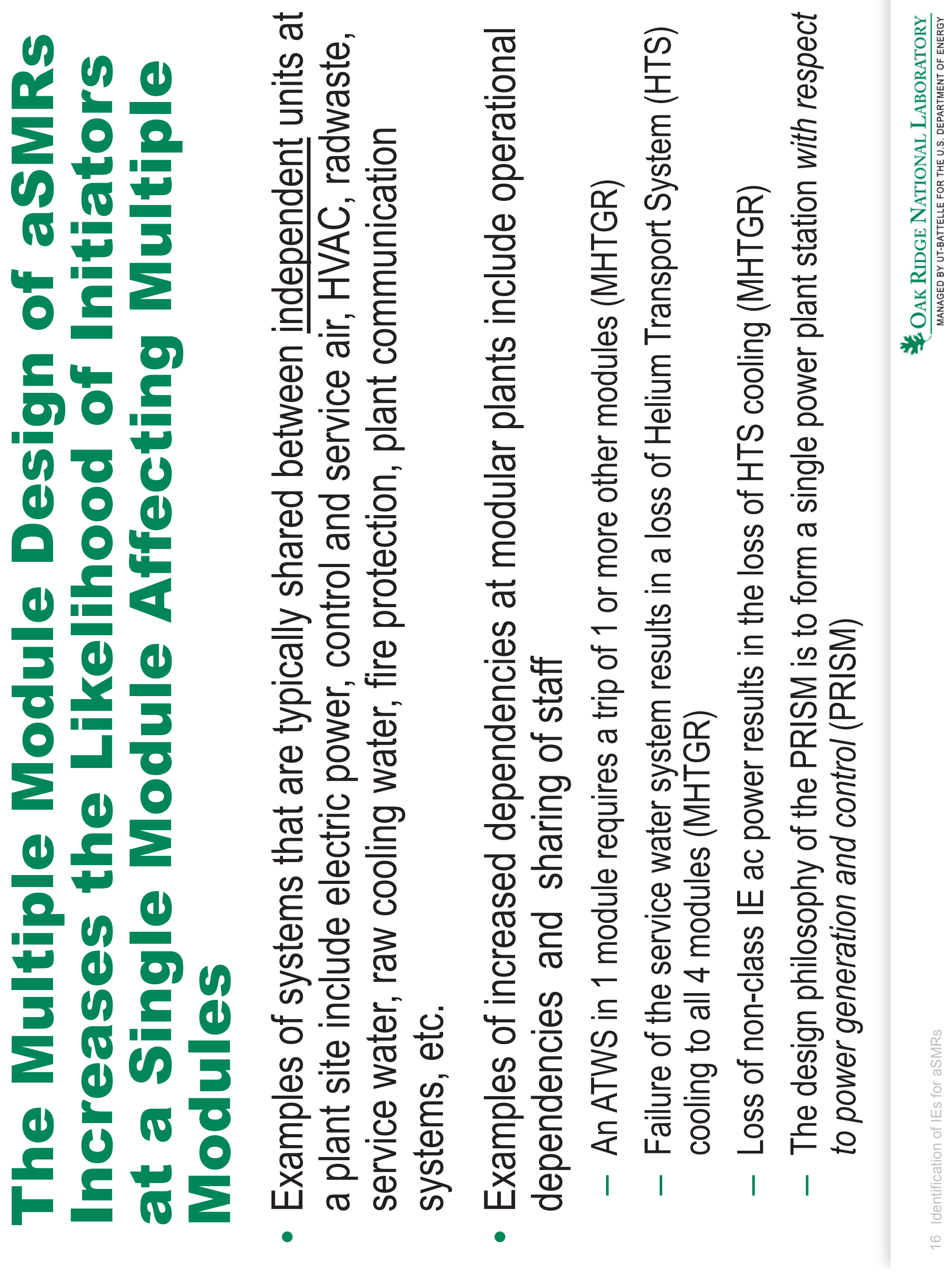




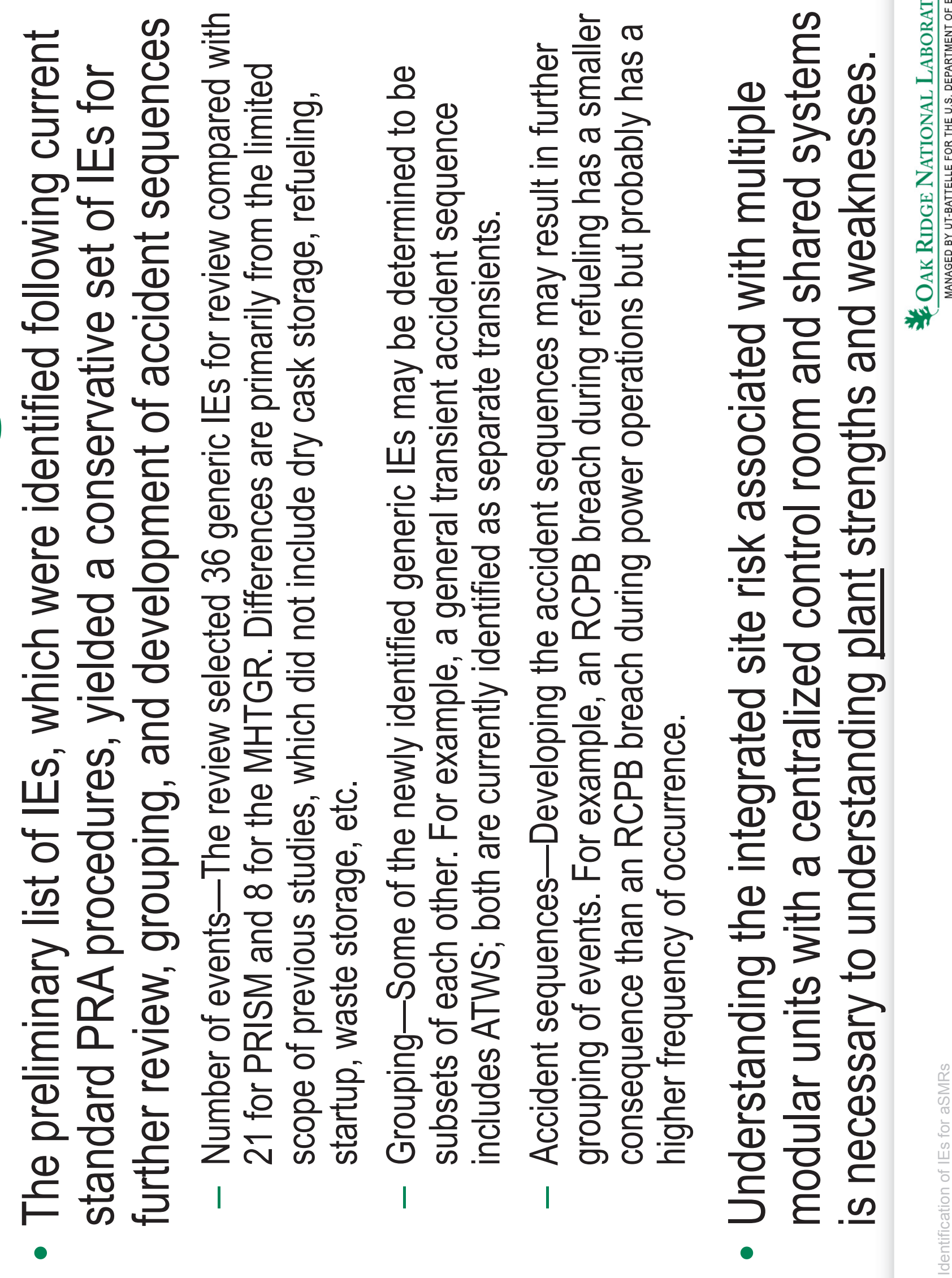



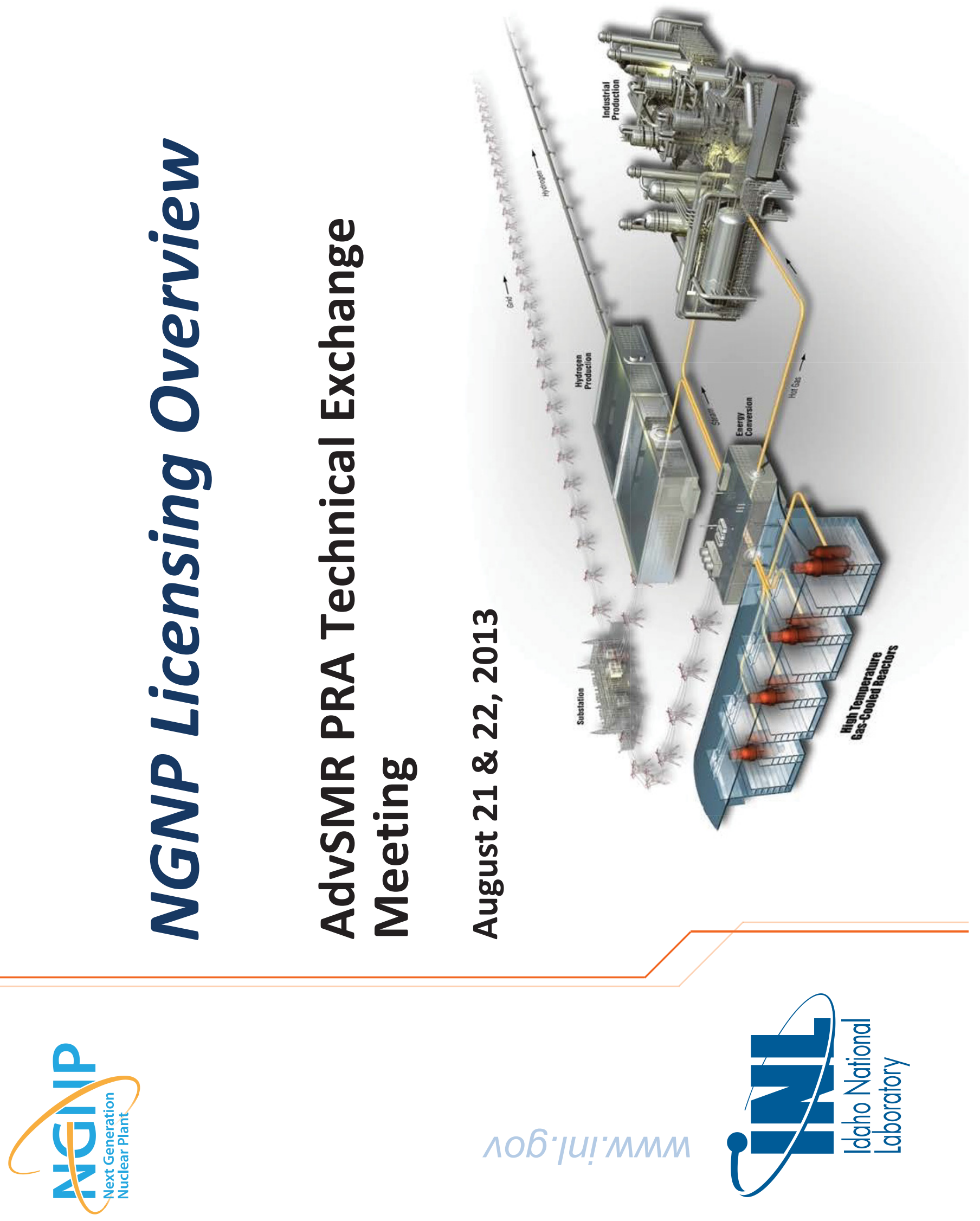

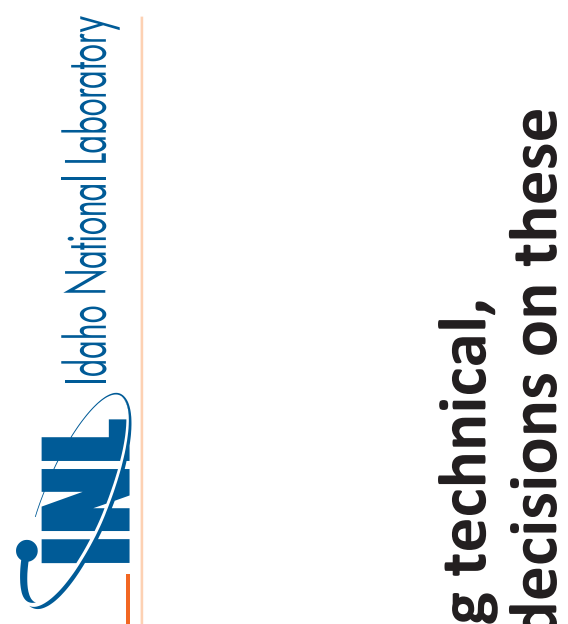

ฮ

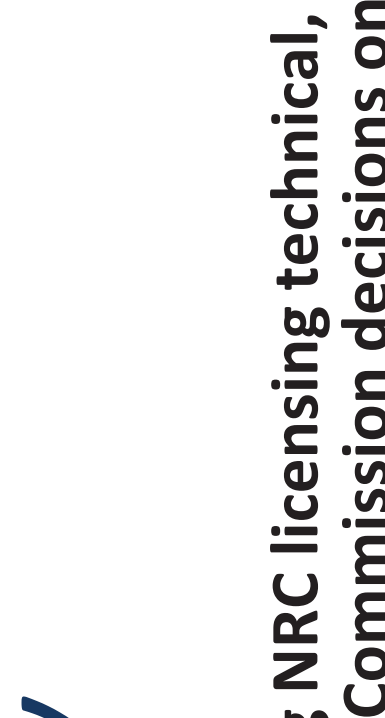

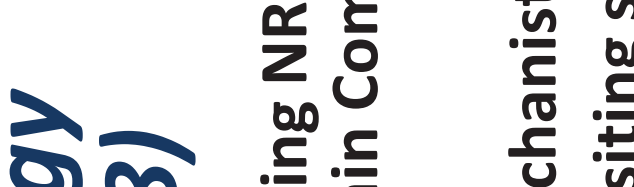

(1) 00 .

$+\infty \frac{0}{0}$ है

$\infty N$

(1) 1 \& है

() थ

- 0 는ำ

(1) 01 는

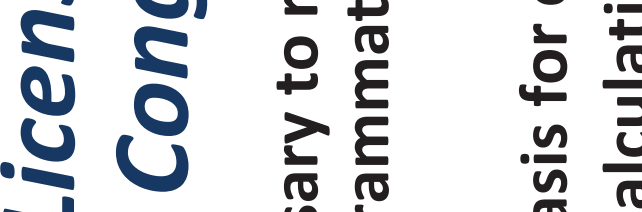

- 0 मे

$1+0$

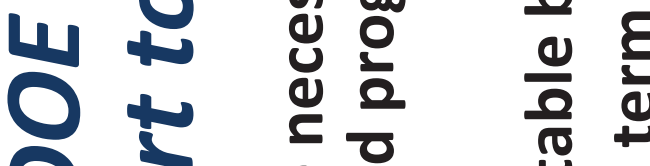

0 व 0 व

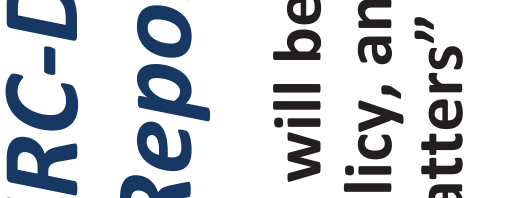

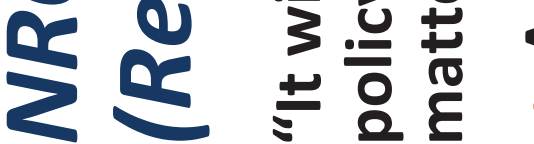

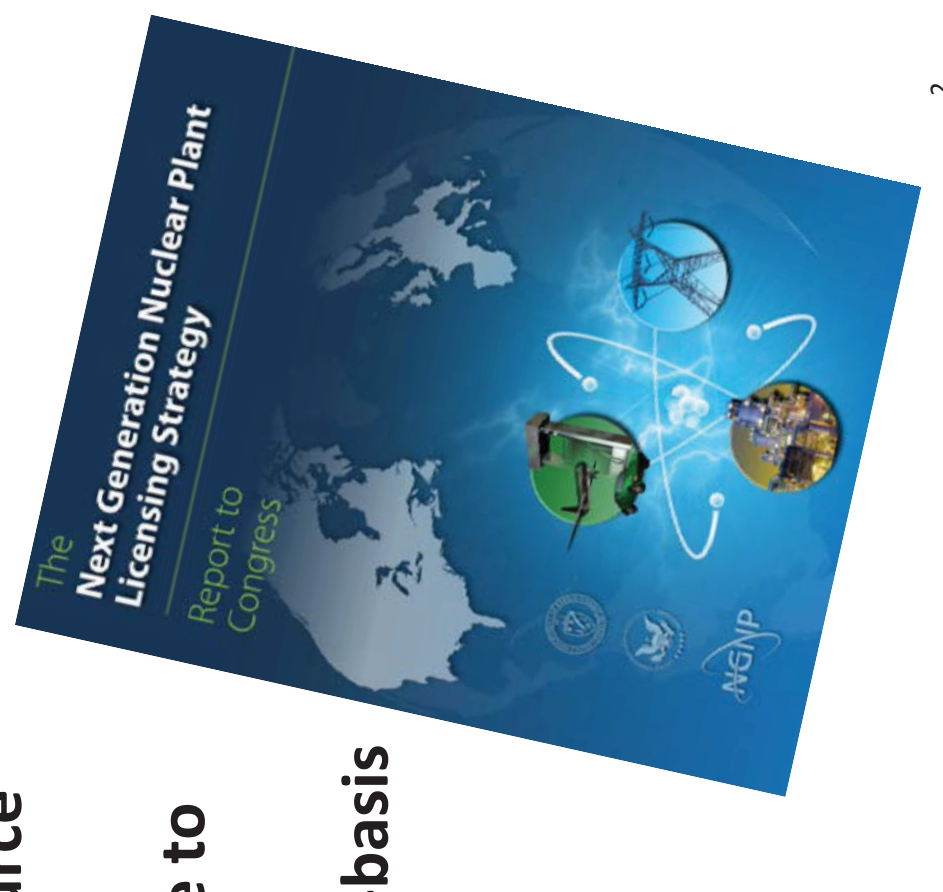

ह

$\div$ 을

d

2 5

بิ

$\sum^{2}$

(1) 음

y bo

(1)

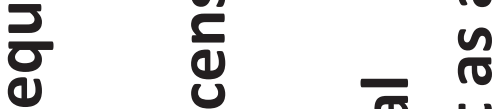

ต 0 으

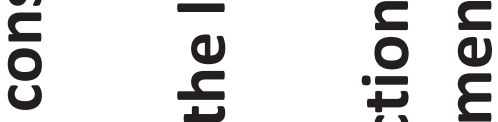

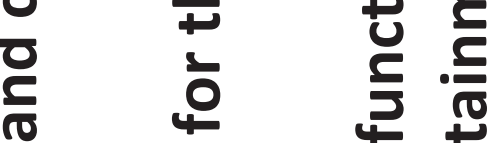

ㄴ

1 든 은 는

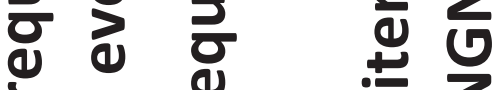

는

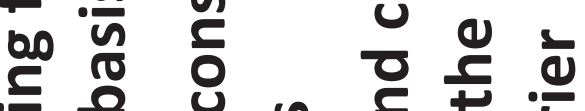

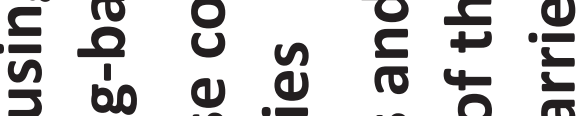

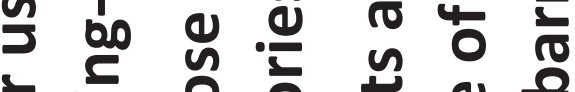

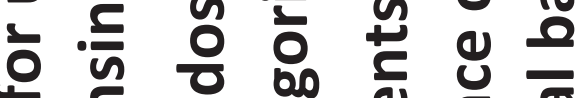

+

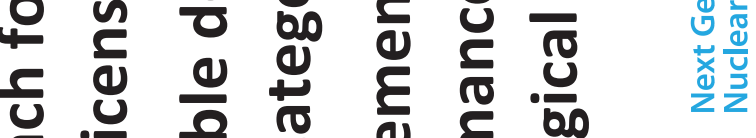

ช 0 으 $\frac{a}{\sigma}$ U ह

인 $E$ 은 난

2

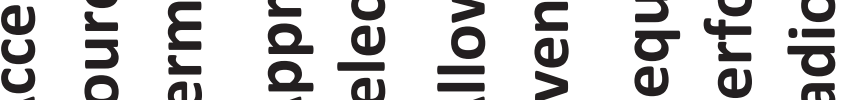

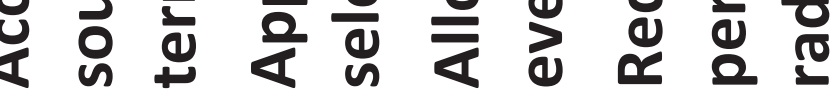




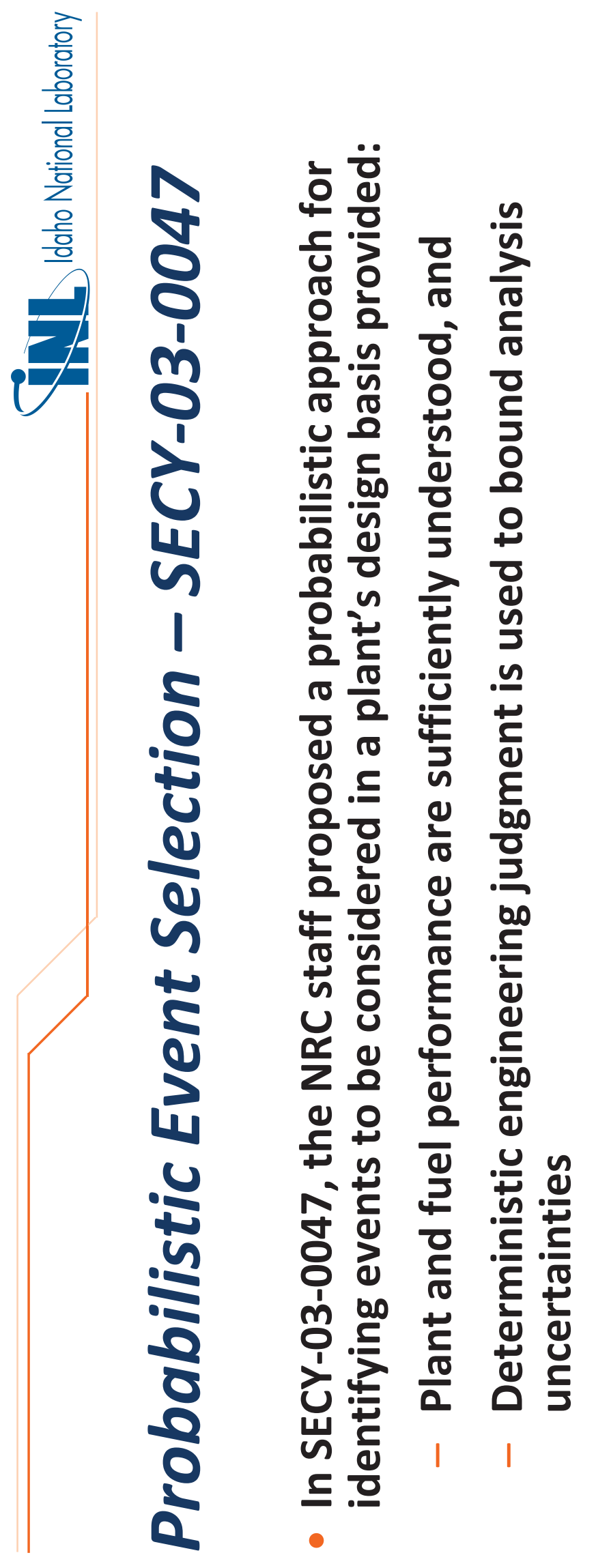

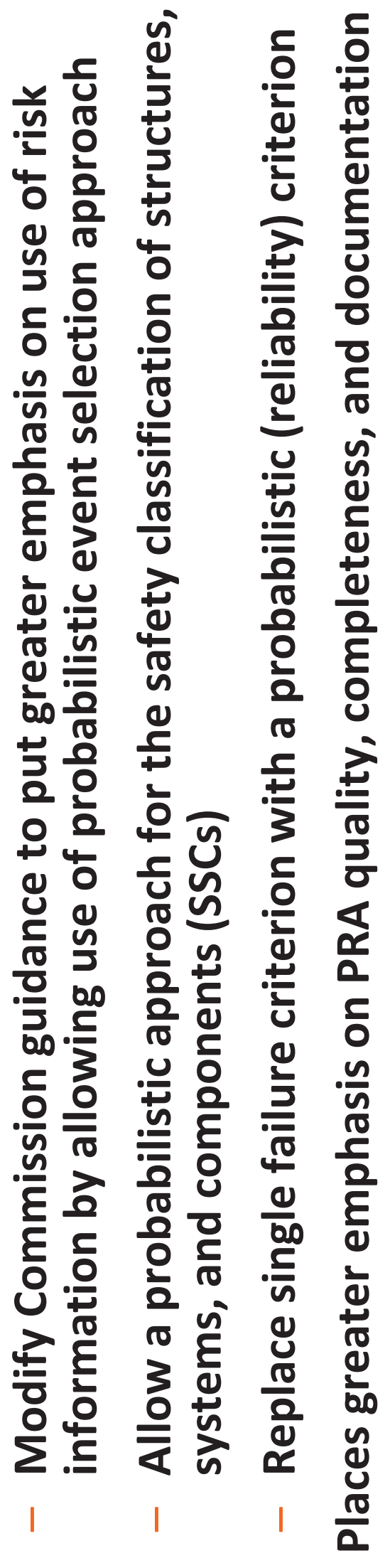

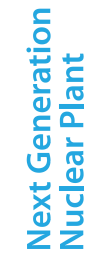




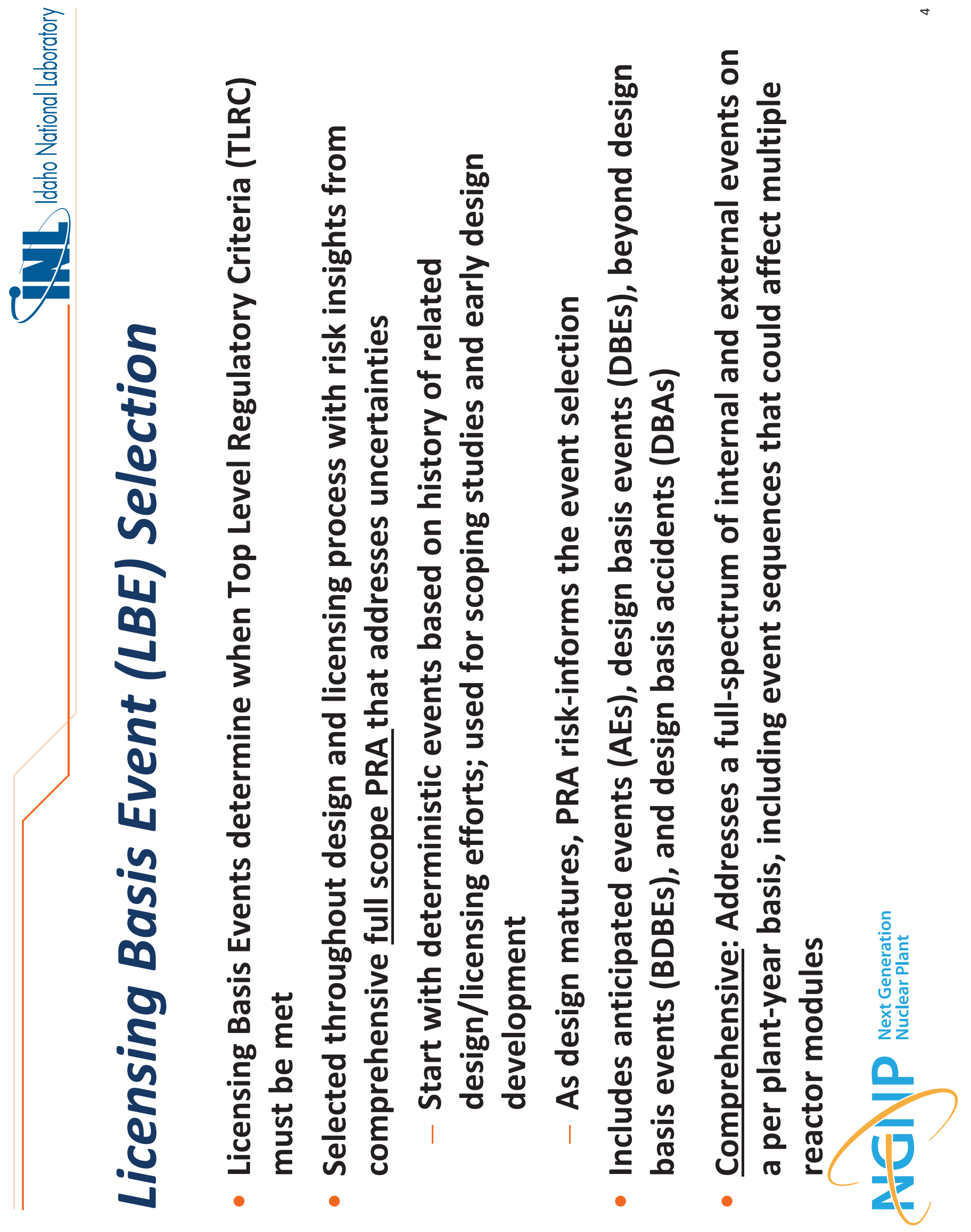



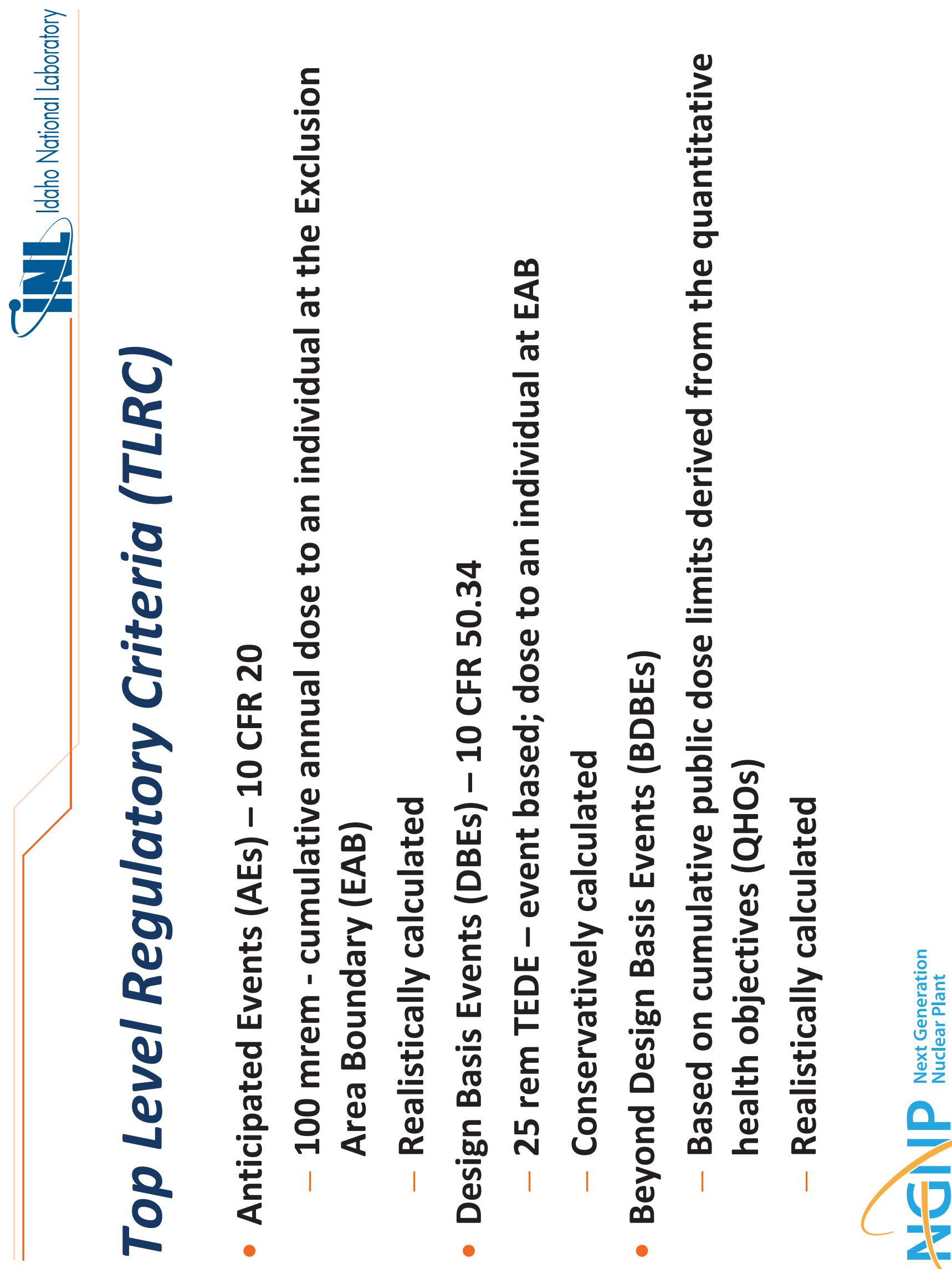

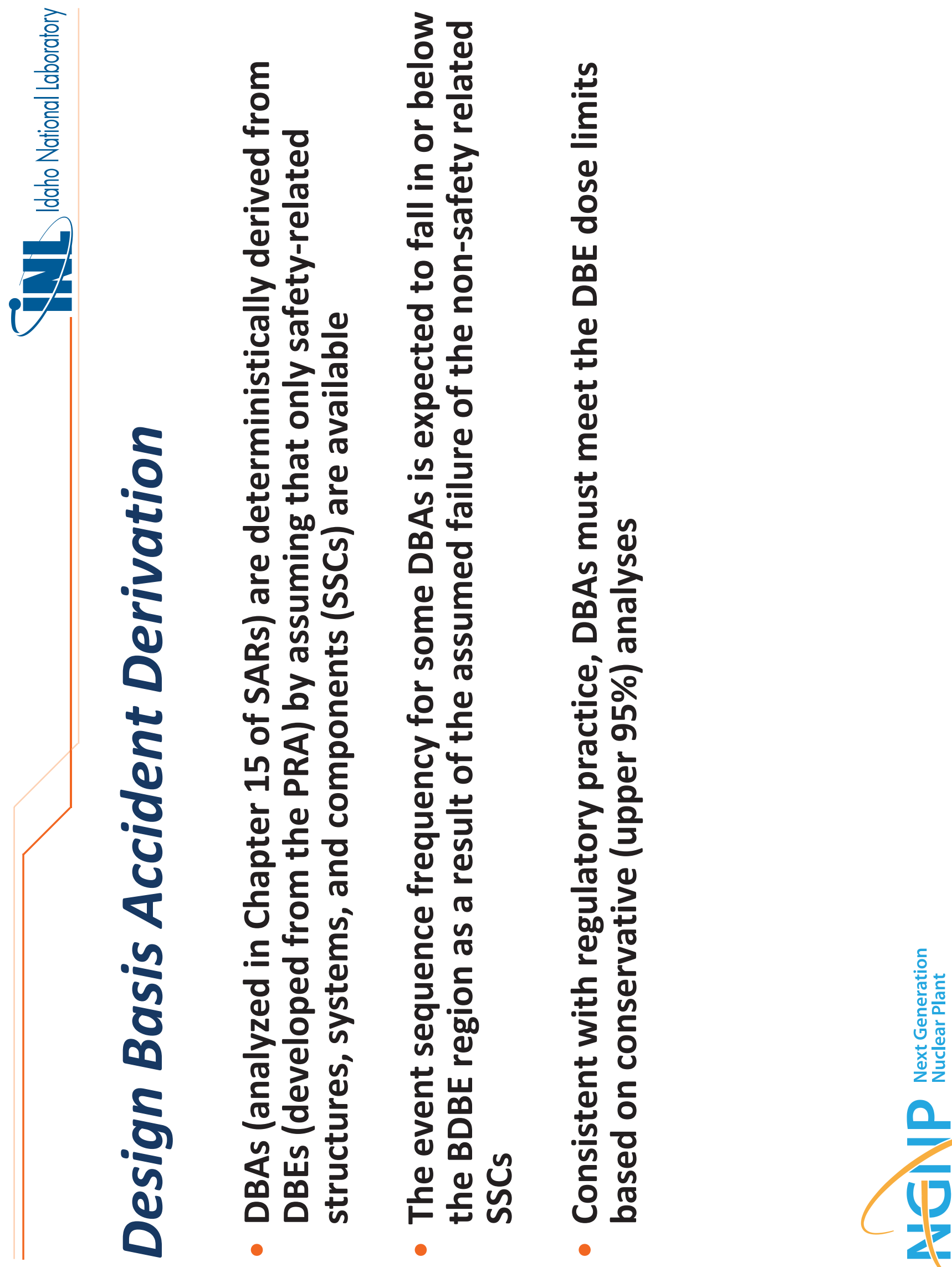


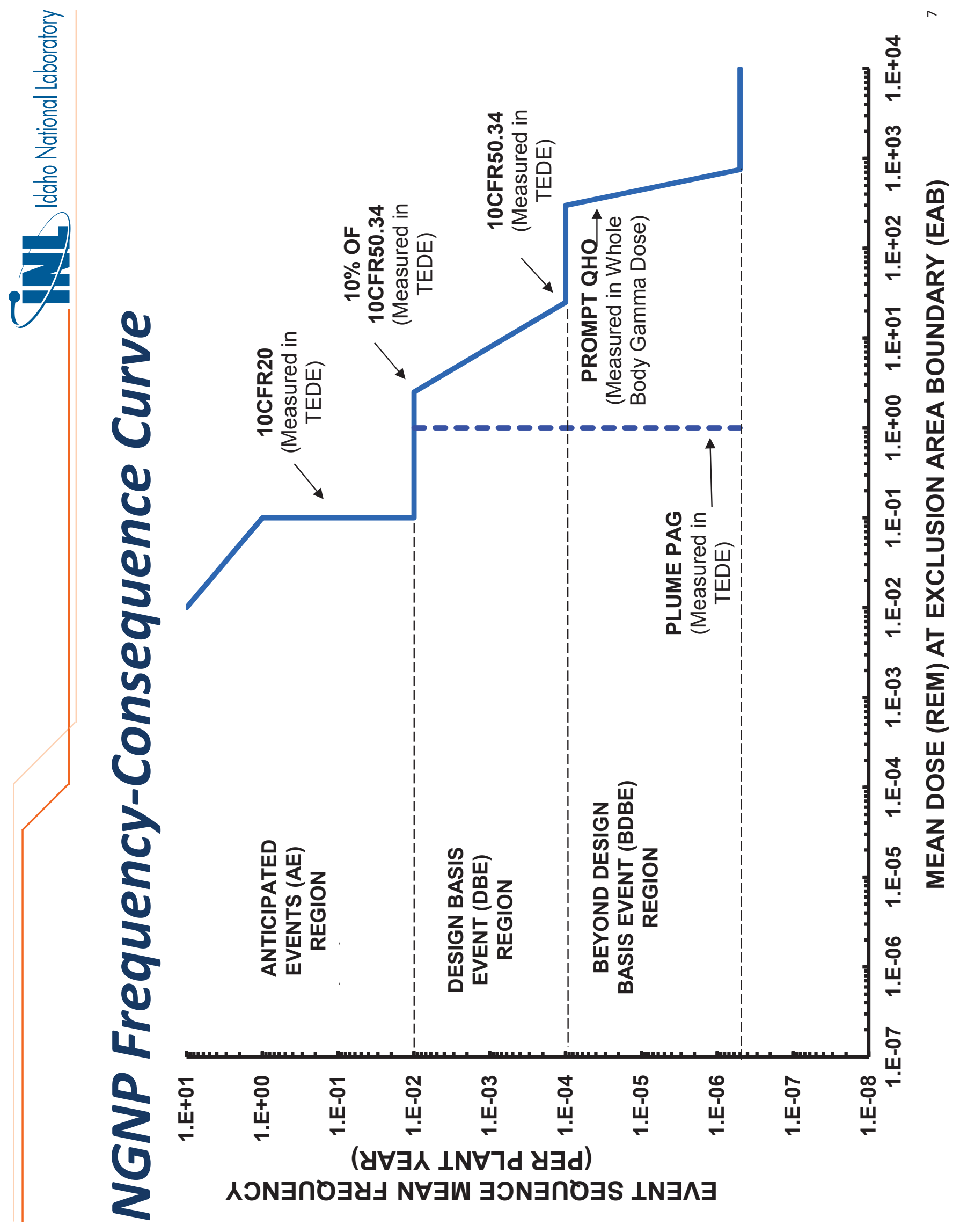




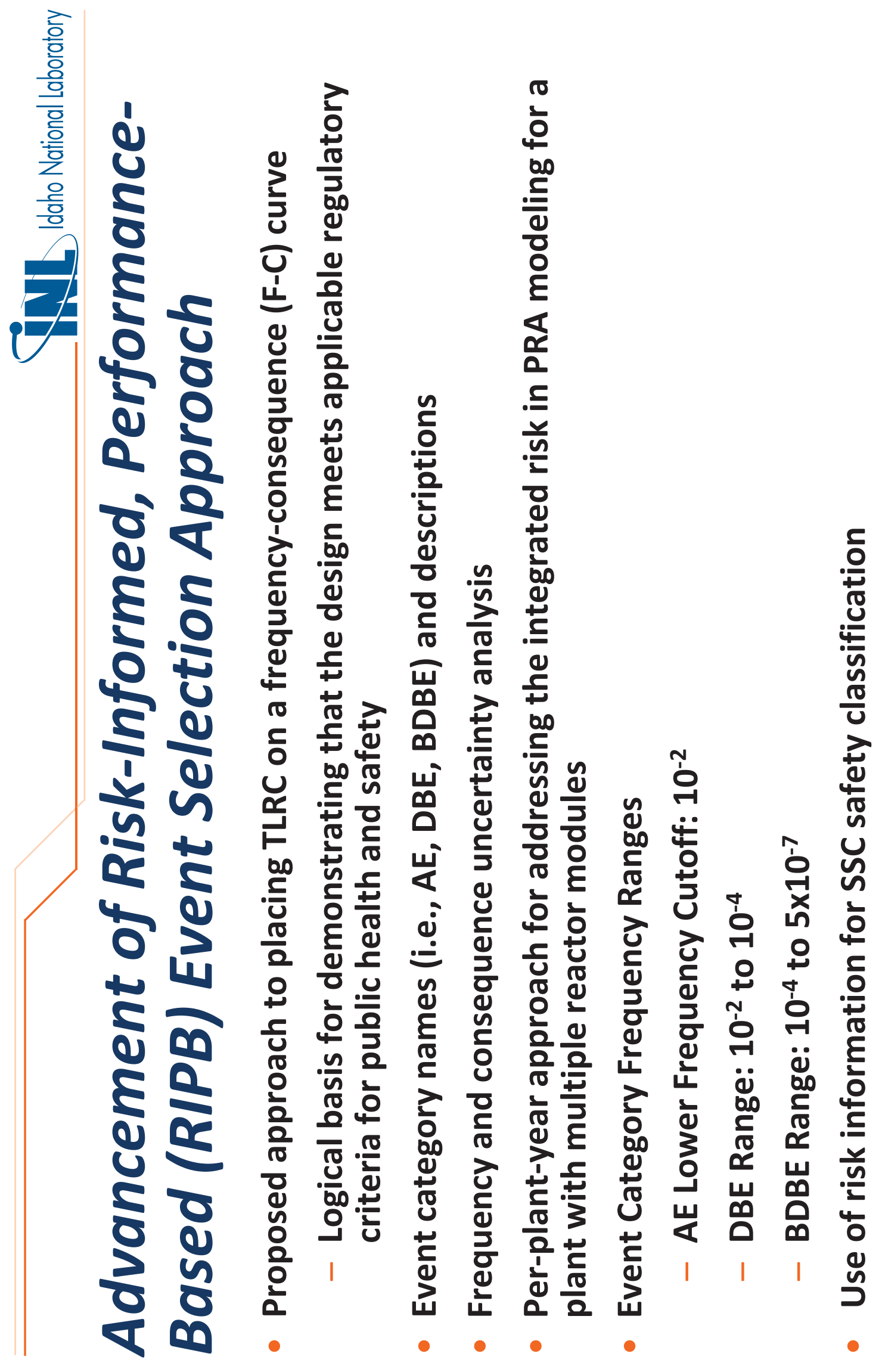




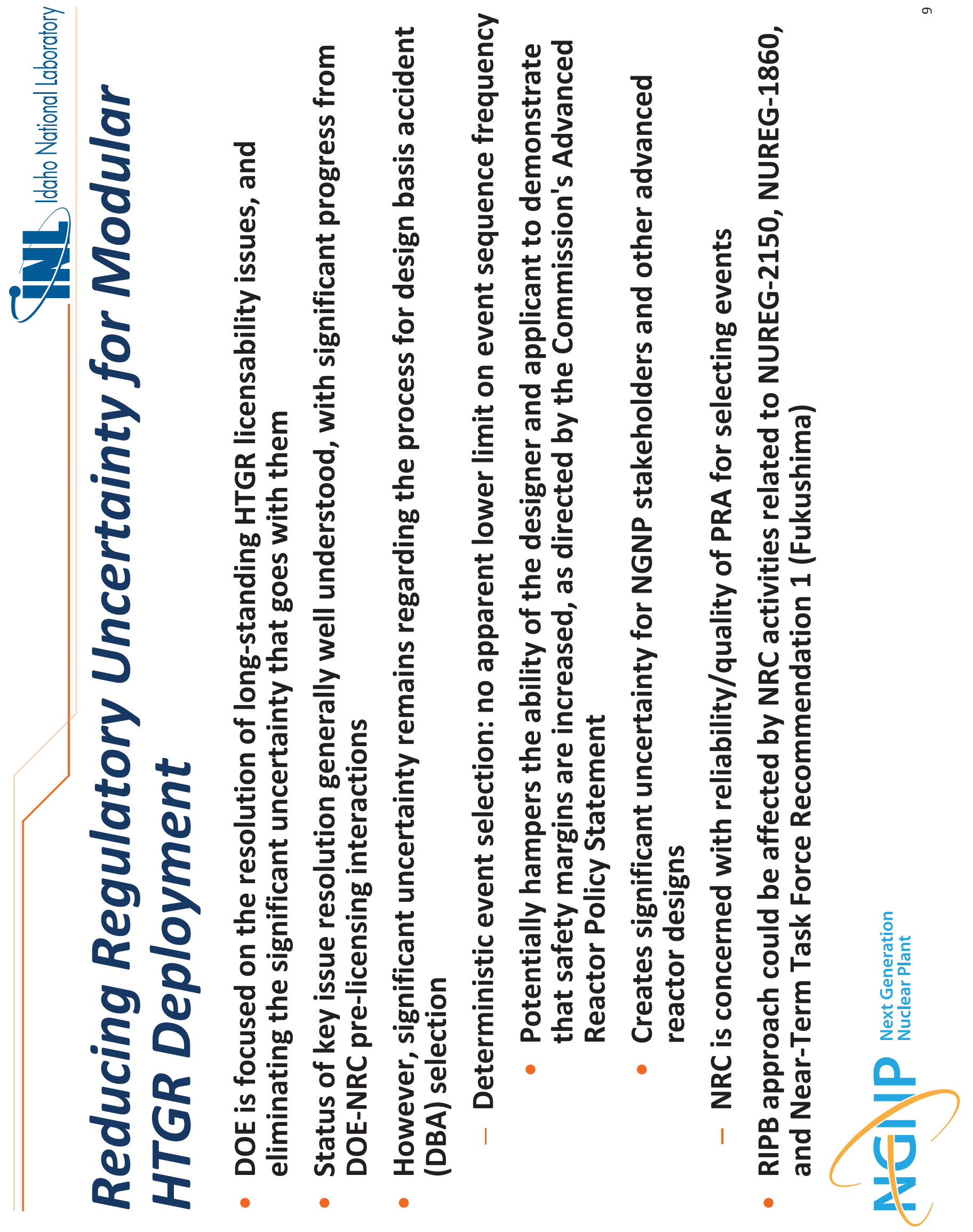




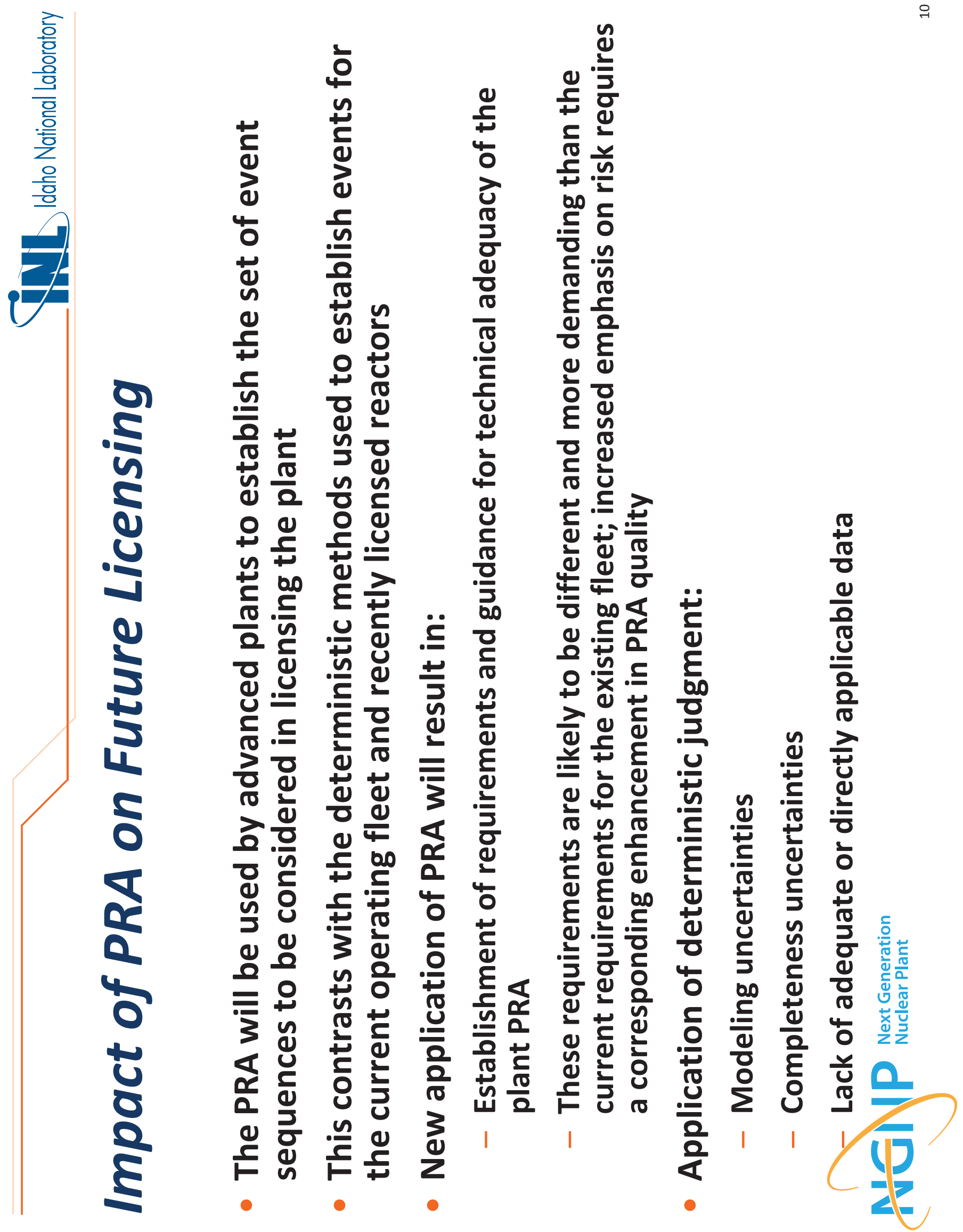




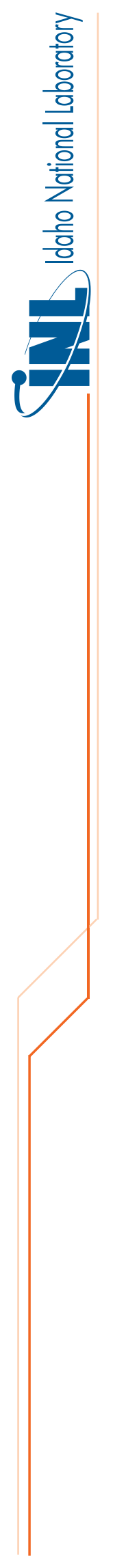

0
$\frac{0}{0}$
$\frac{1}{2}$
$\frac{5}{4}$
$\frac{0}{0}$ 


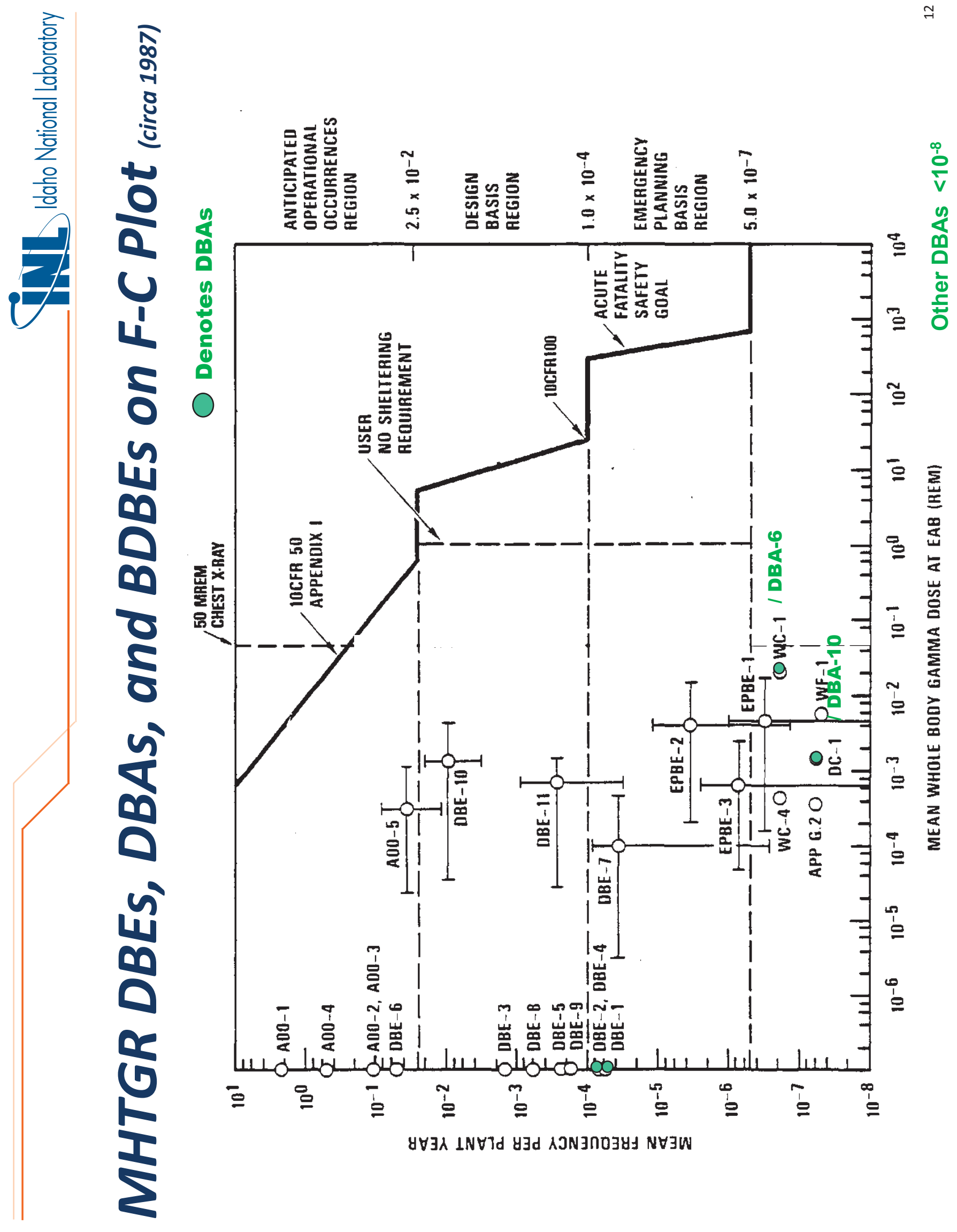




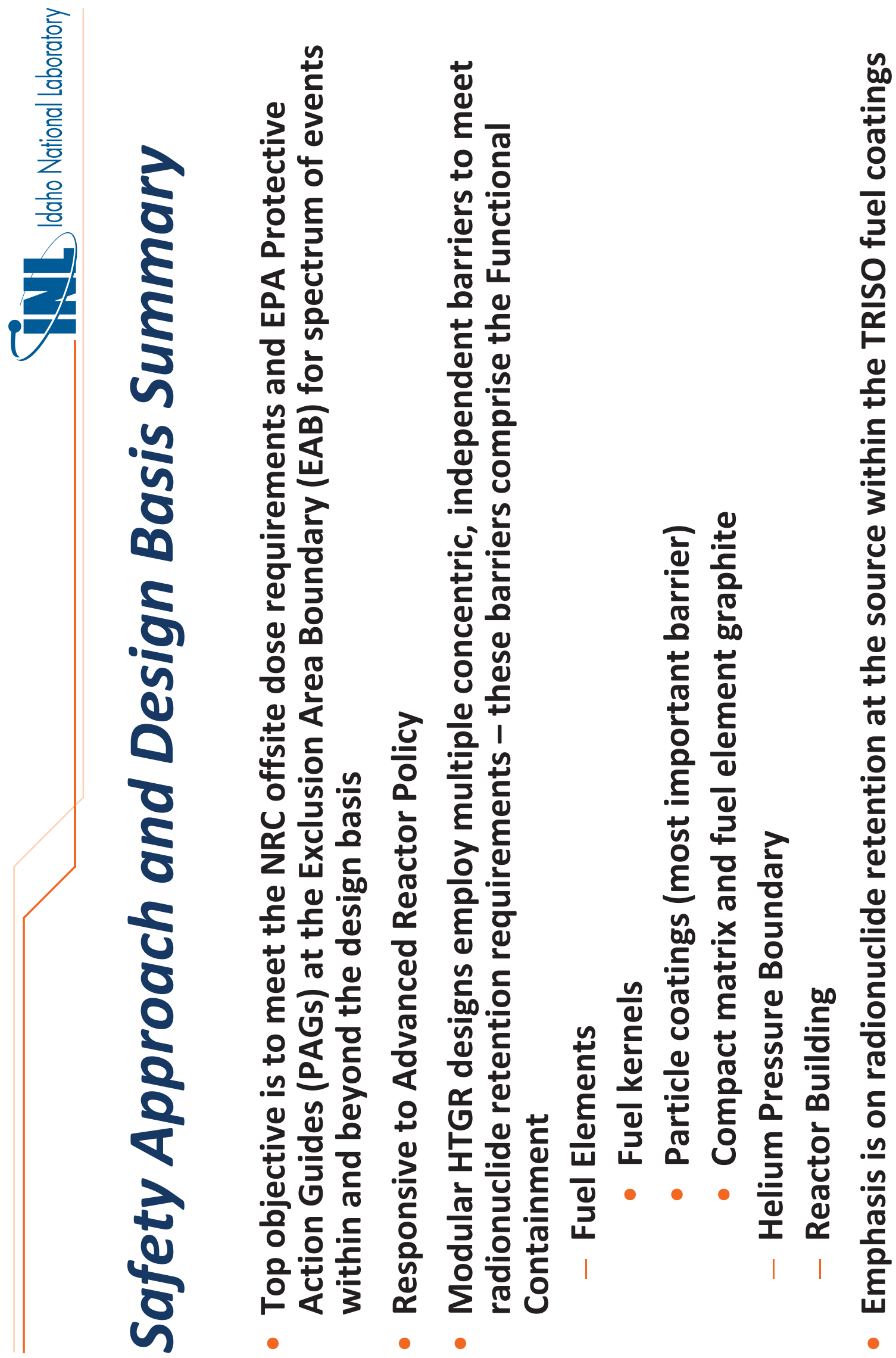




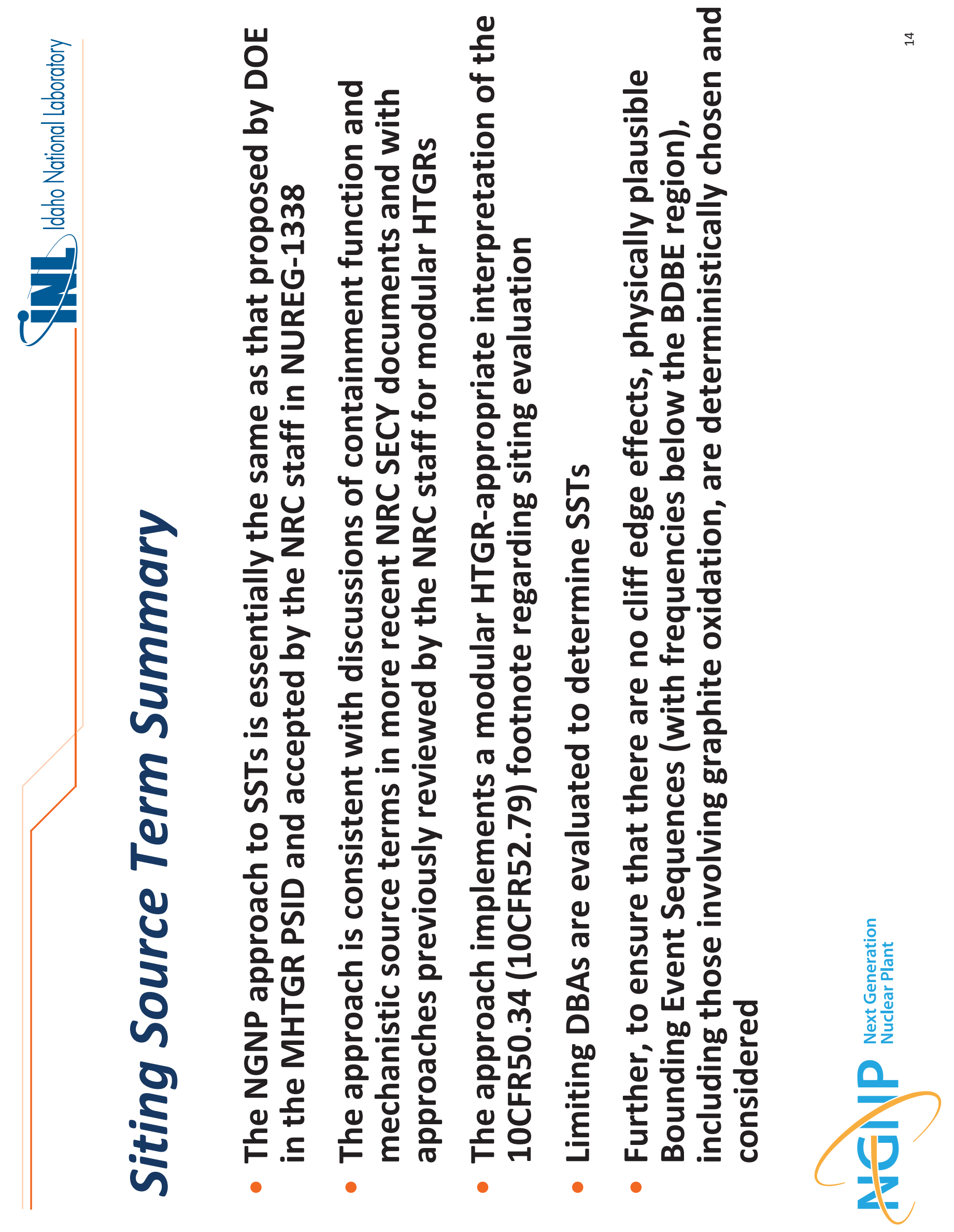




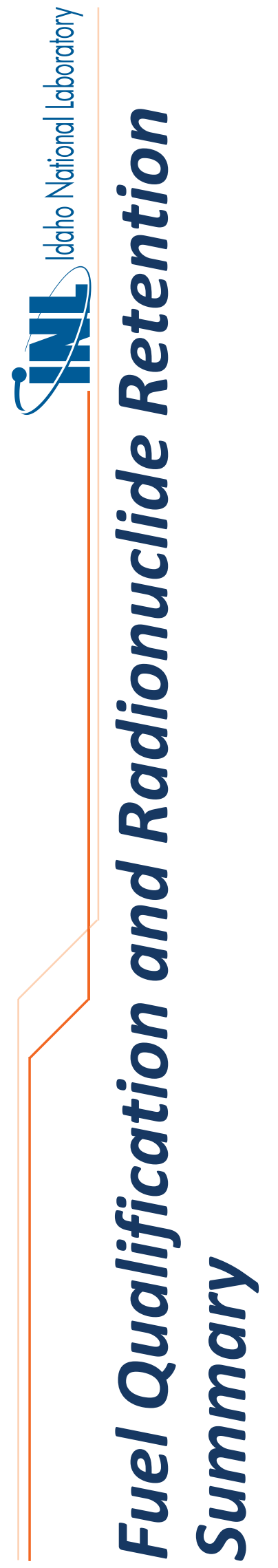

$\frac{2}{\sigma}$

$\frac{c}{\frac{1}{0}}$

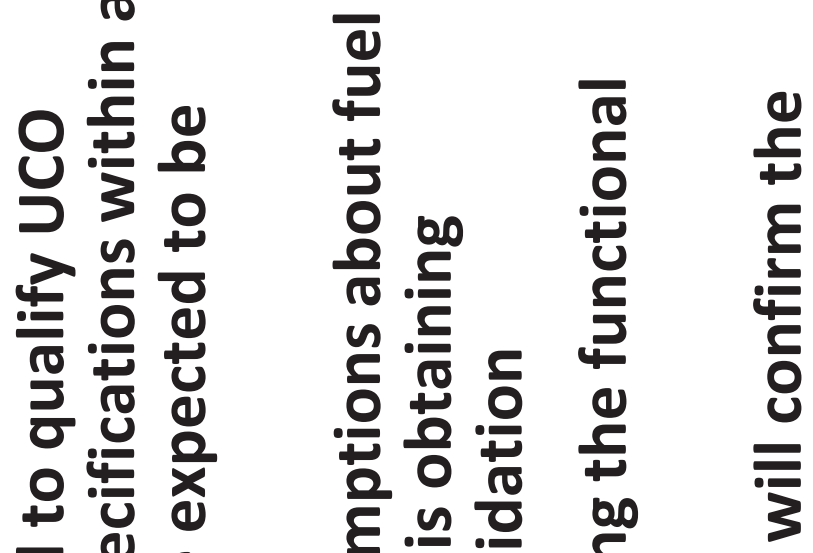

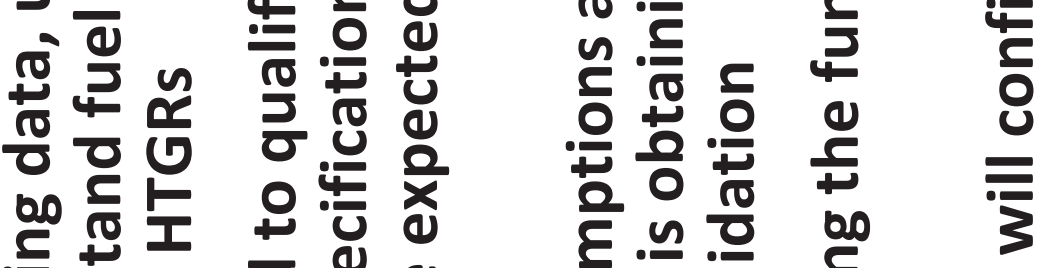

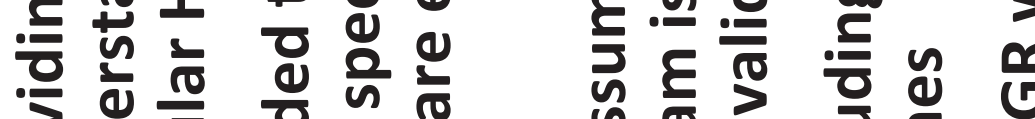

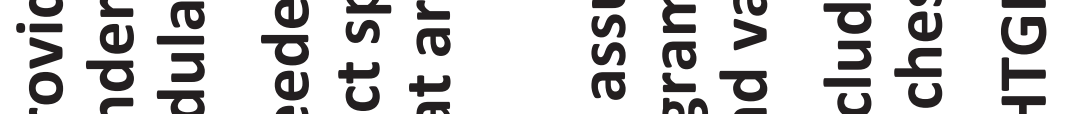

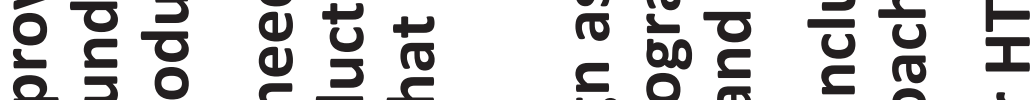

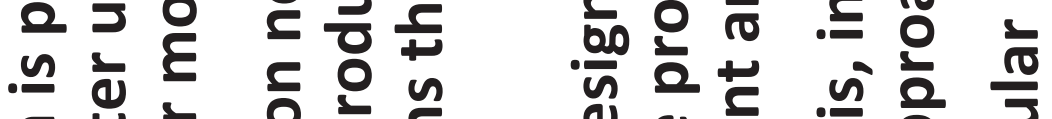

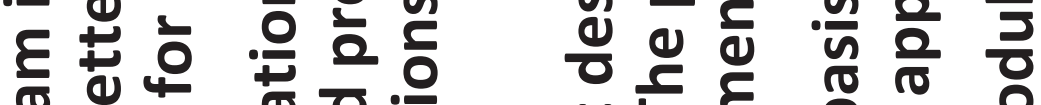

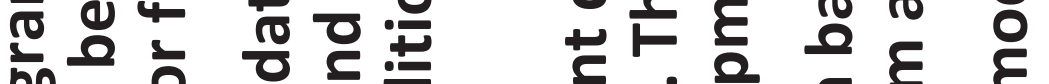

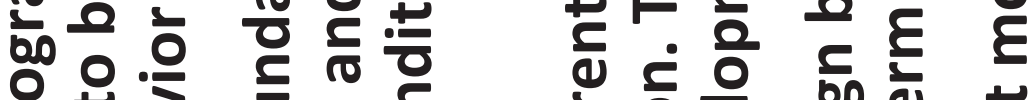

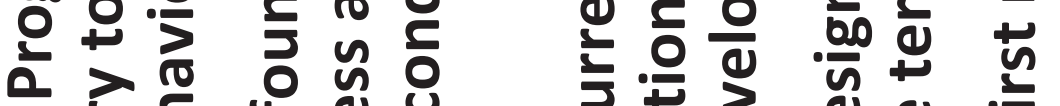

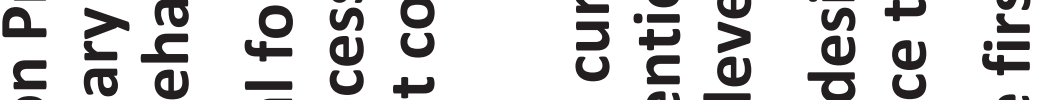

은

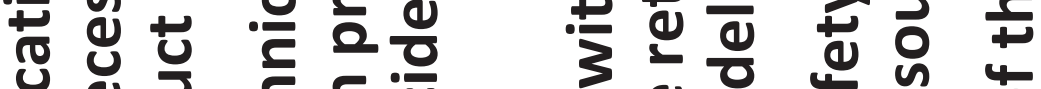

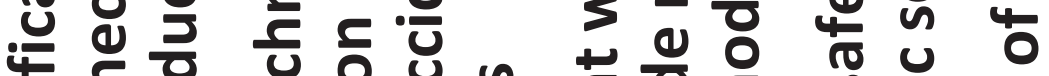

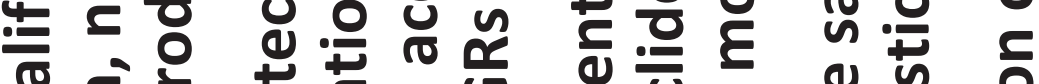

完

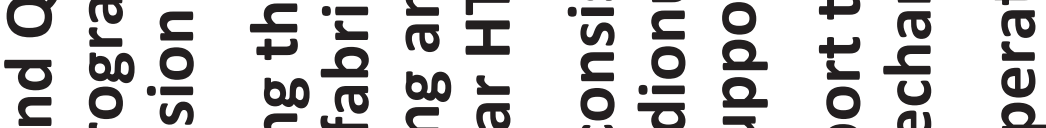

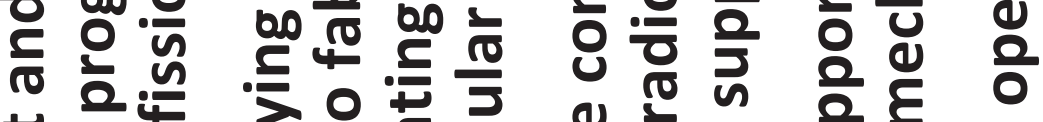

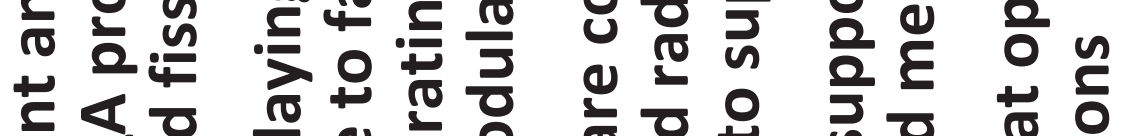

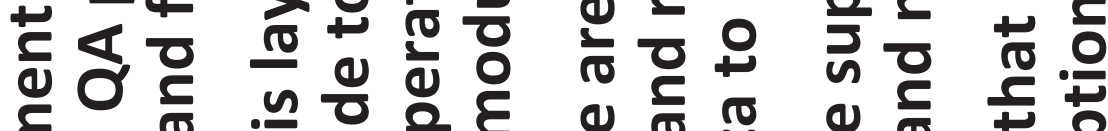

ह

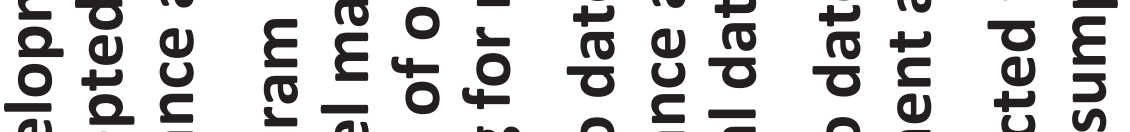

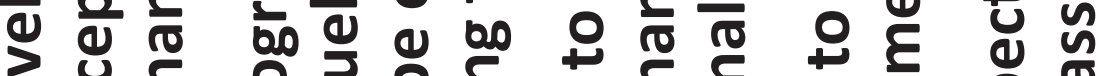



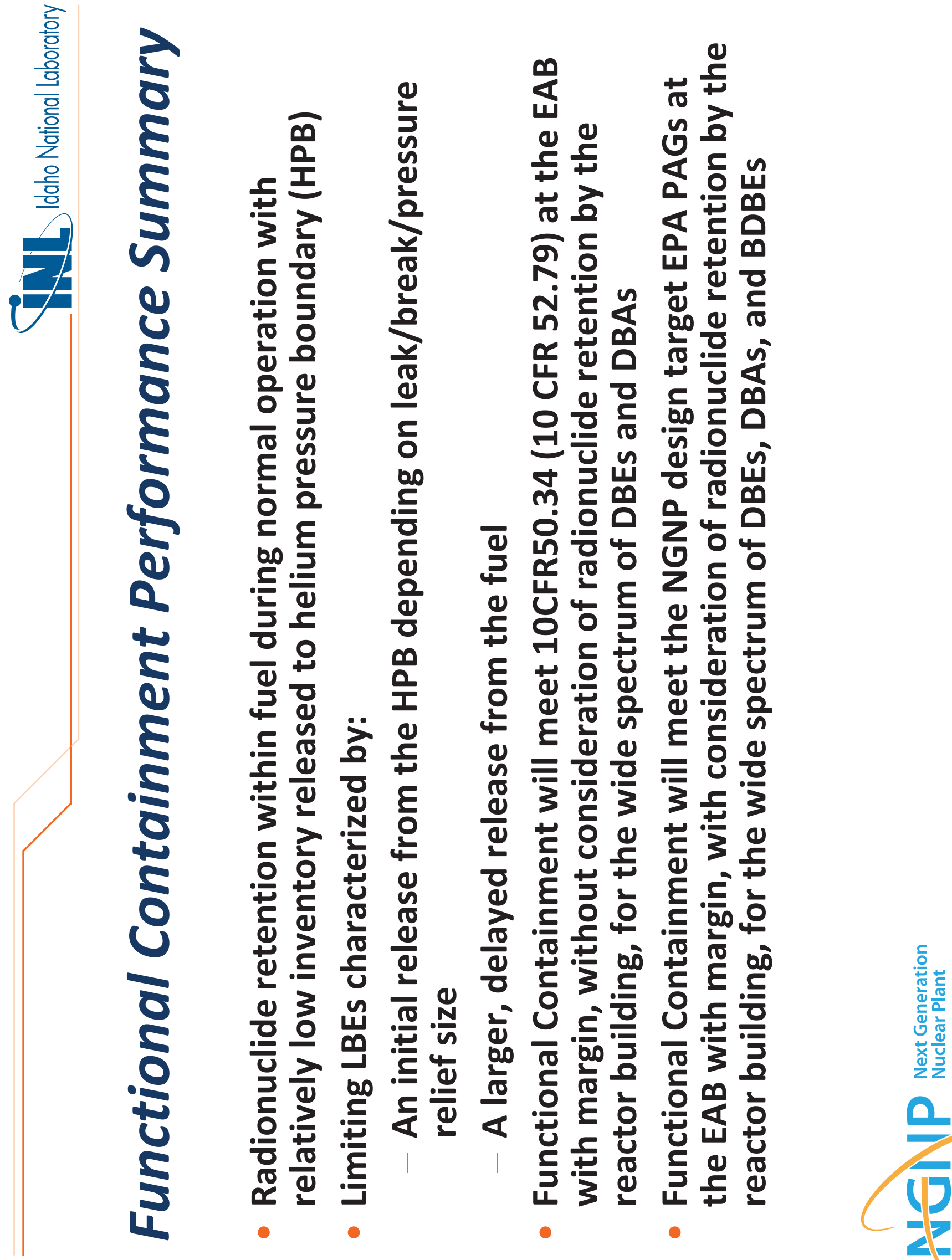

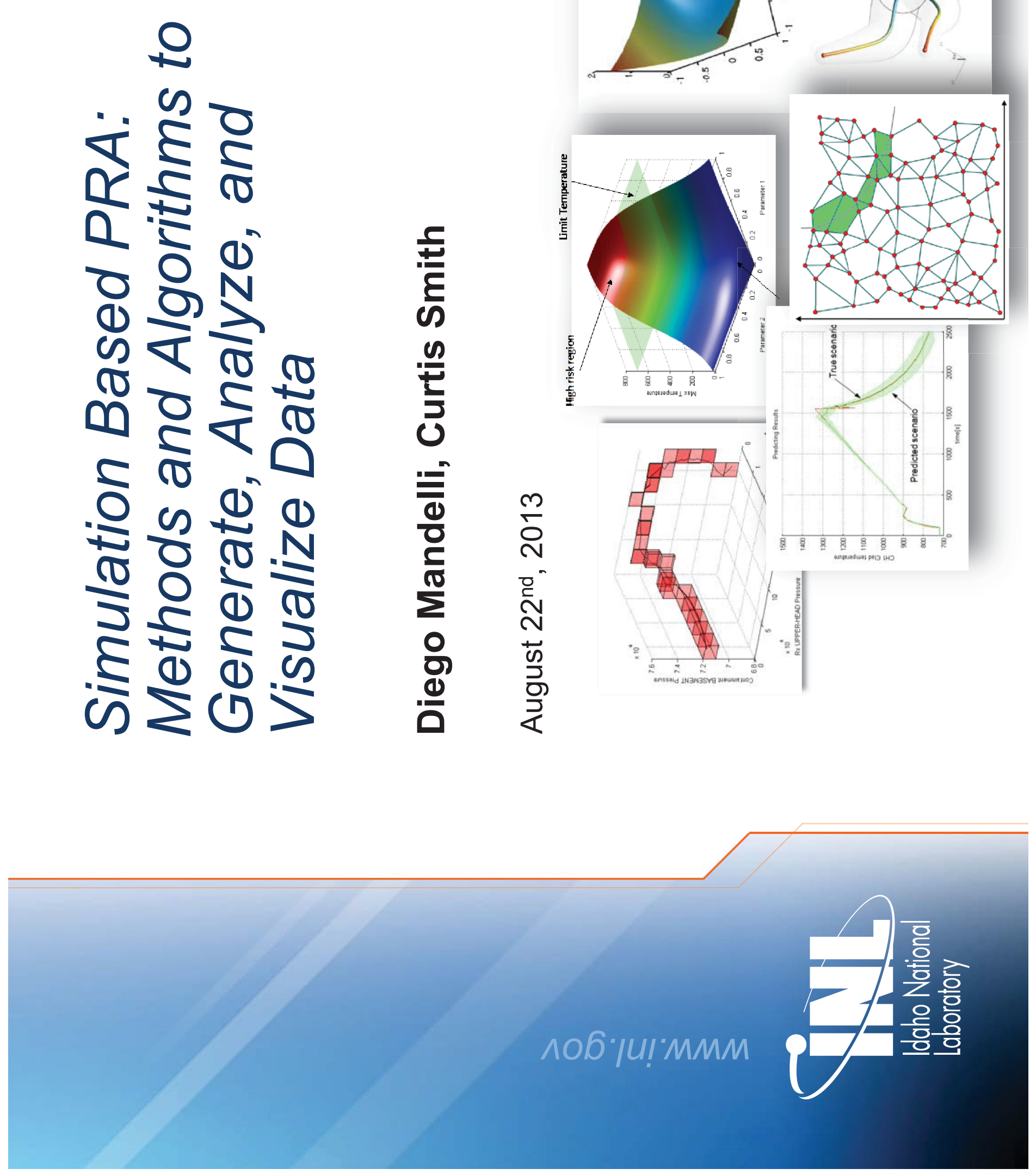

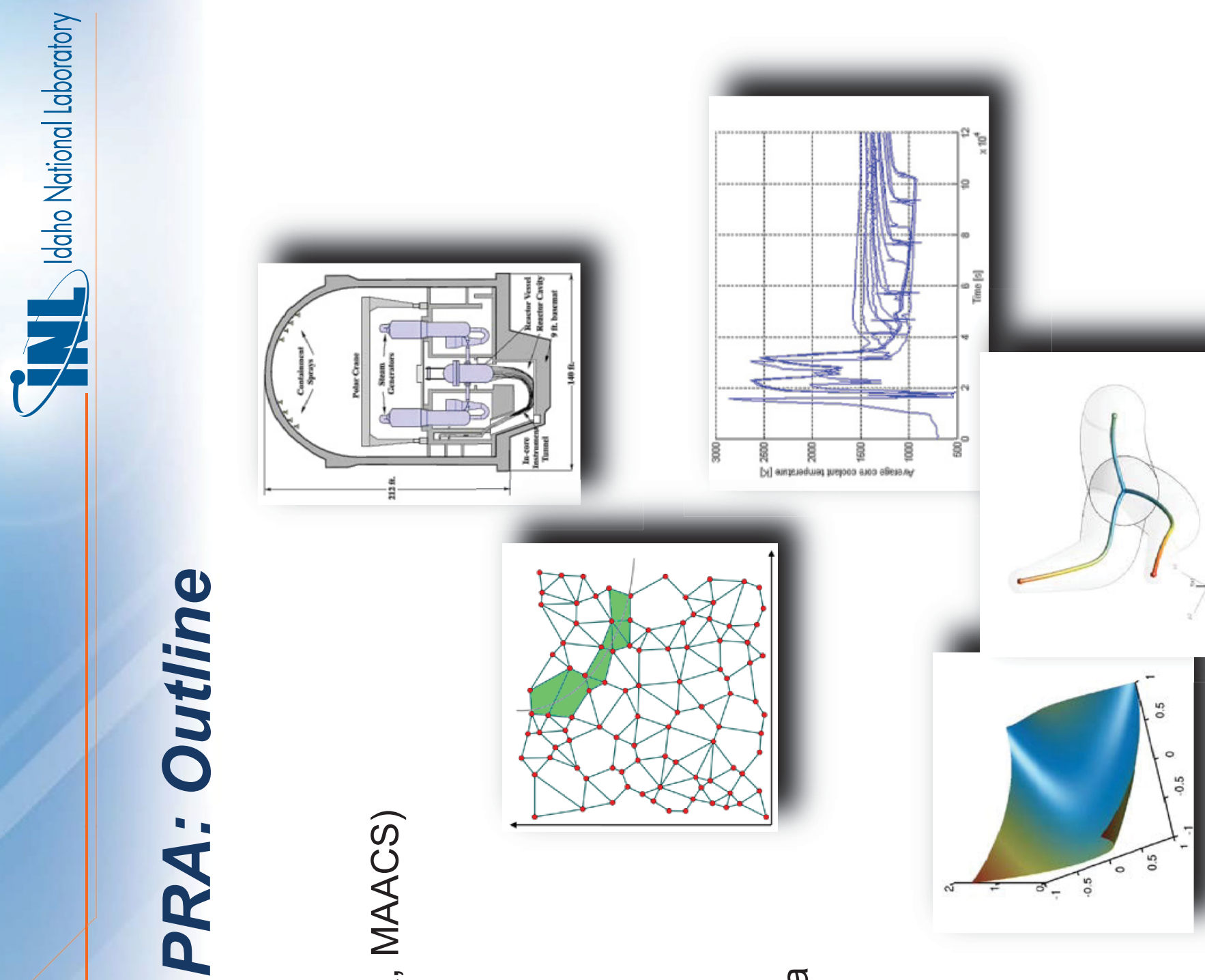

8

के is

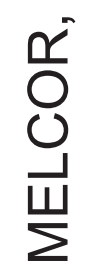



ô $\frac{m}{\bar{t}}$

\& $a$ o

(1) ᄒ⿱

$\frac{\pi}{2} \sum_{0}^{\frac{0}{\pi}} \frac{0}{0}$

ह

क $\stackrel{\Phi}{\risingdotseq}$.

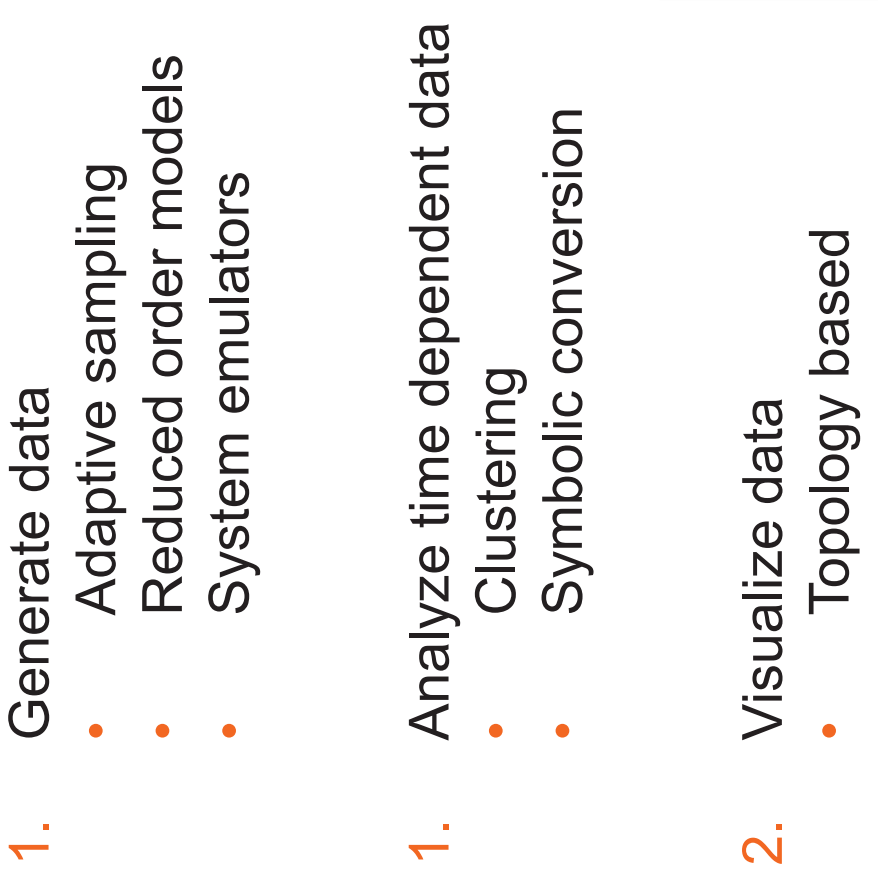



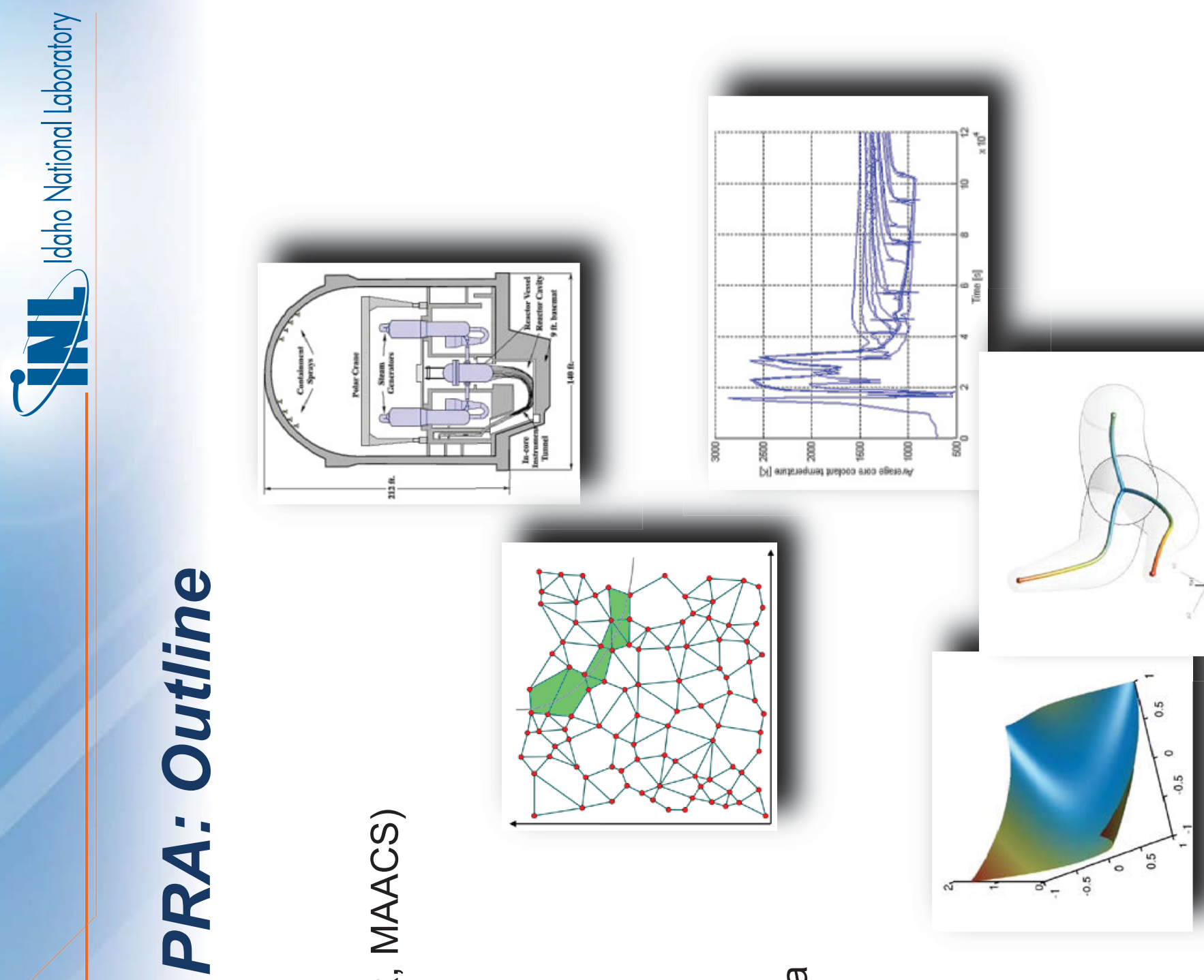

8

宛 㟧

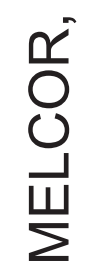



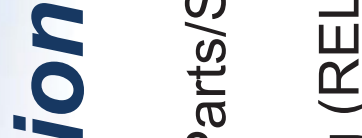

\$ 0 O

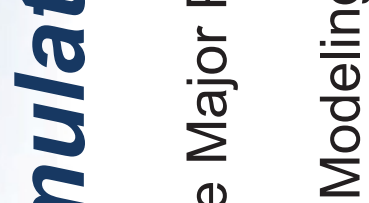

ह

क $\stackrel{\Phi}{\risingdotseq}$.

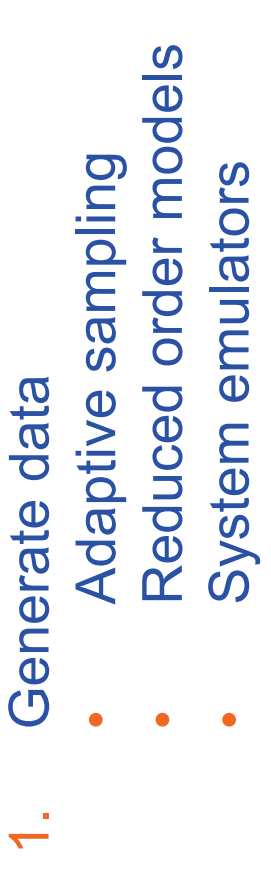

$\stackrel{\mathbb{T}}{\mathbb{0}}$

章

ब)

웡

응

竞

N

$\frac{\lambda}{\pi}$

完。

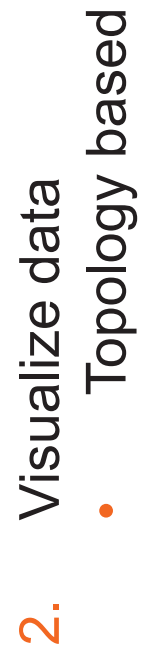




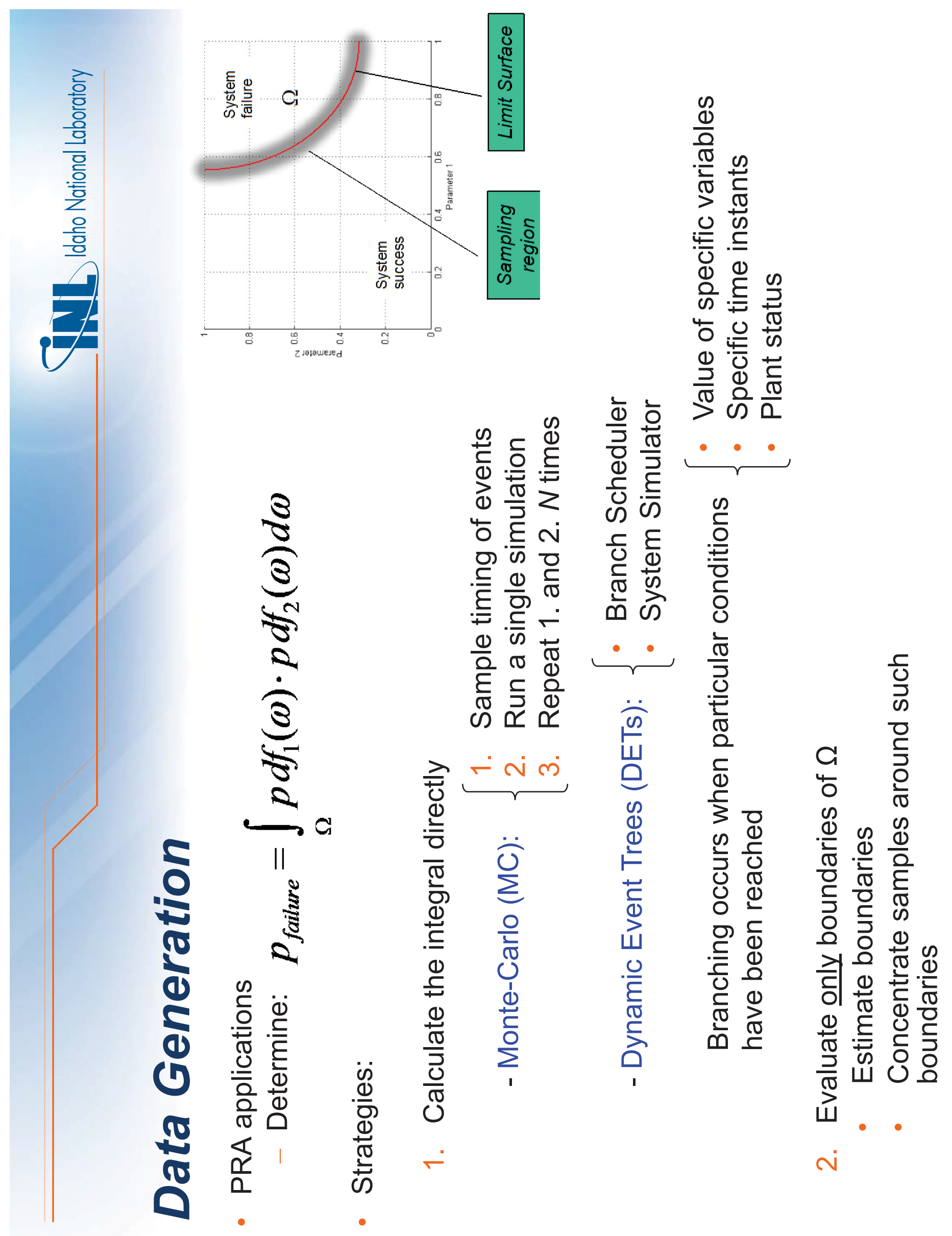



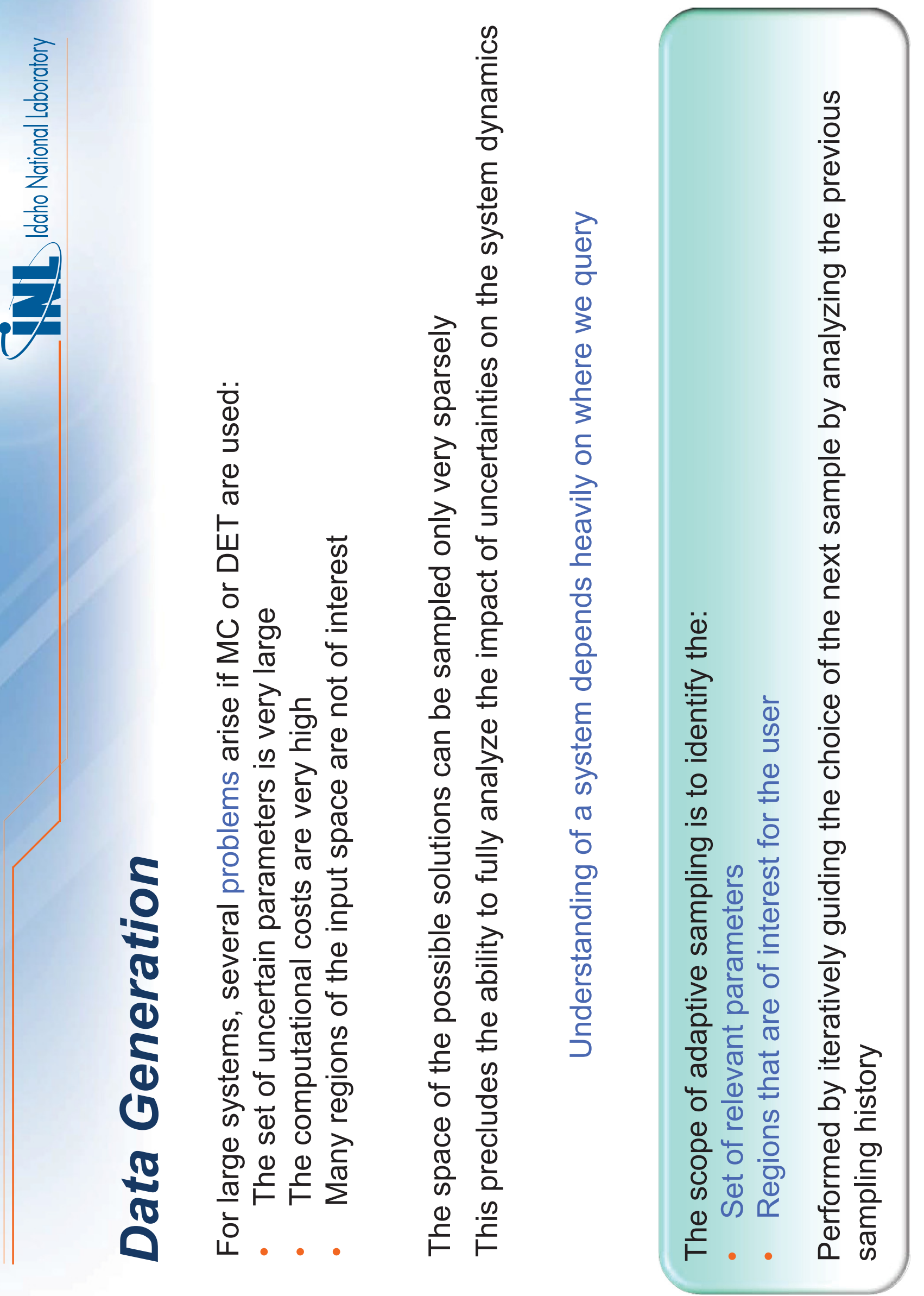

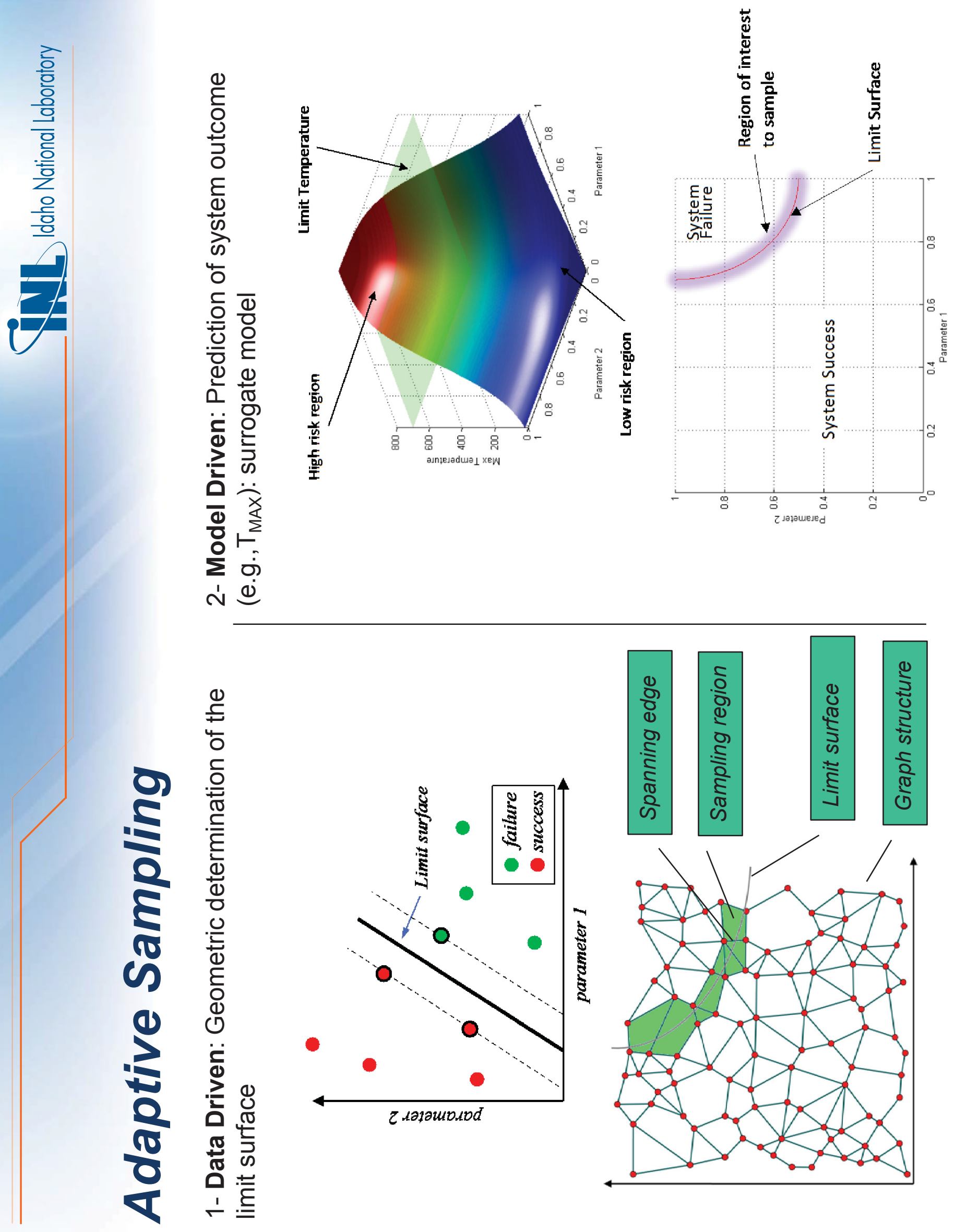

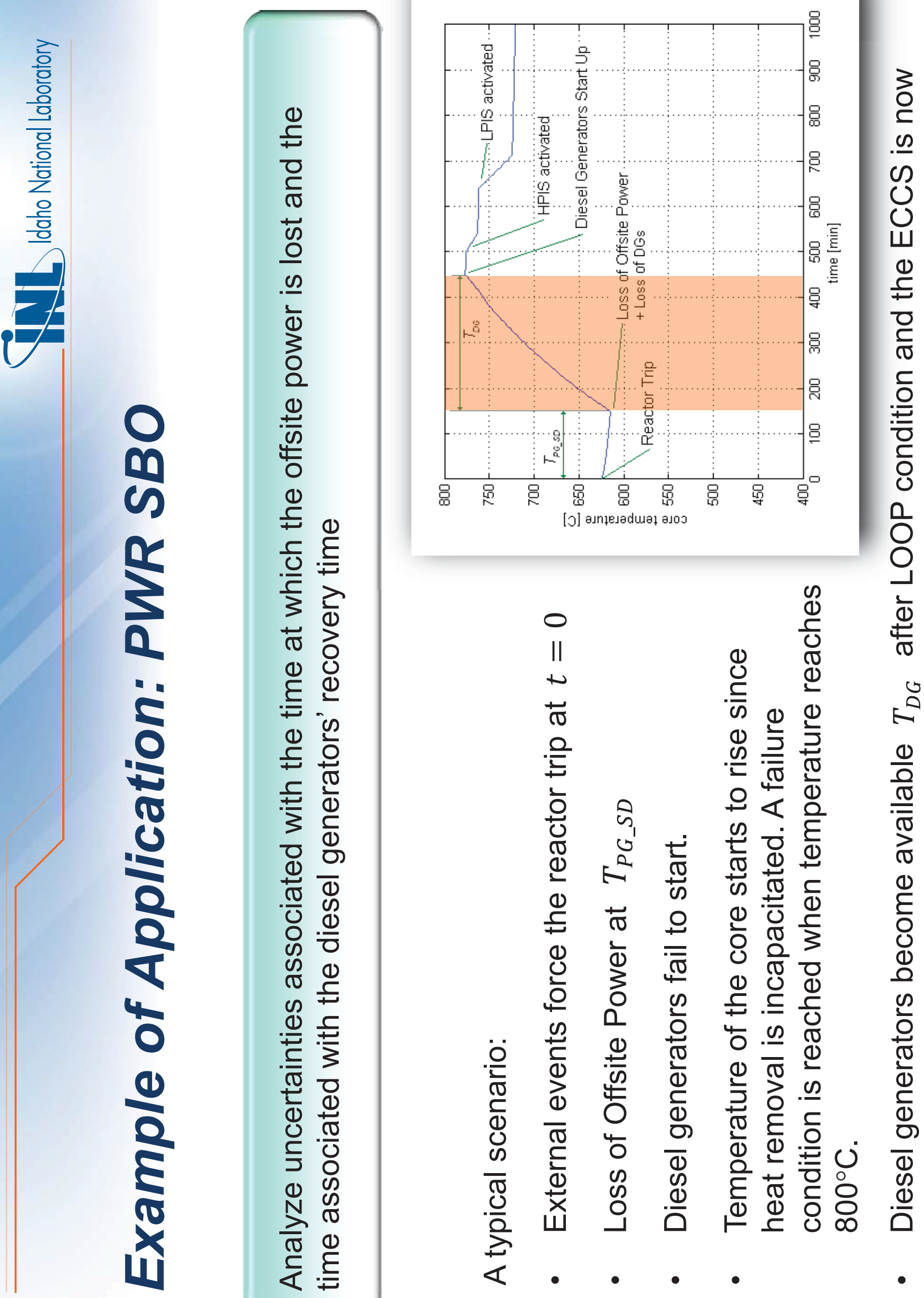

(1)

हญ

$\stackrel{\text { 10 }}{\risingdotseq} \stackrel{0}{\frac{0}{0}}$

声 $\frac{1}{0}$

임

$\stackrel{\Phi}{\Phi}$

ए

유 $\frac{1}{0}$

ণิ ฮ)

क

竞

त

क⿺

U ত

ऽ

(1)

N

它

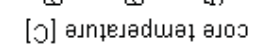




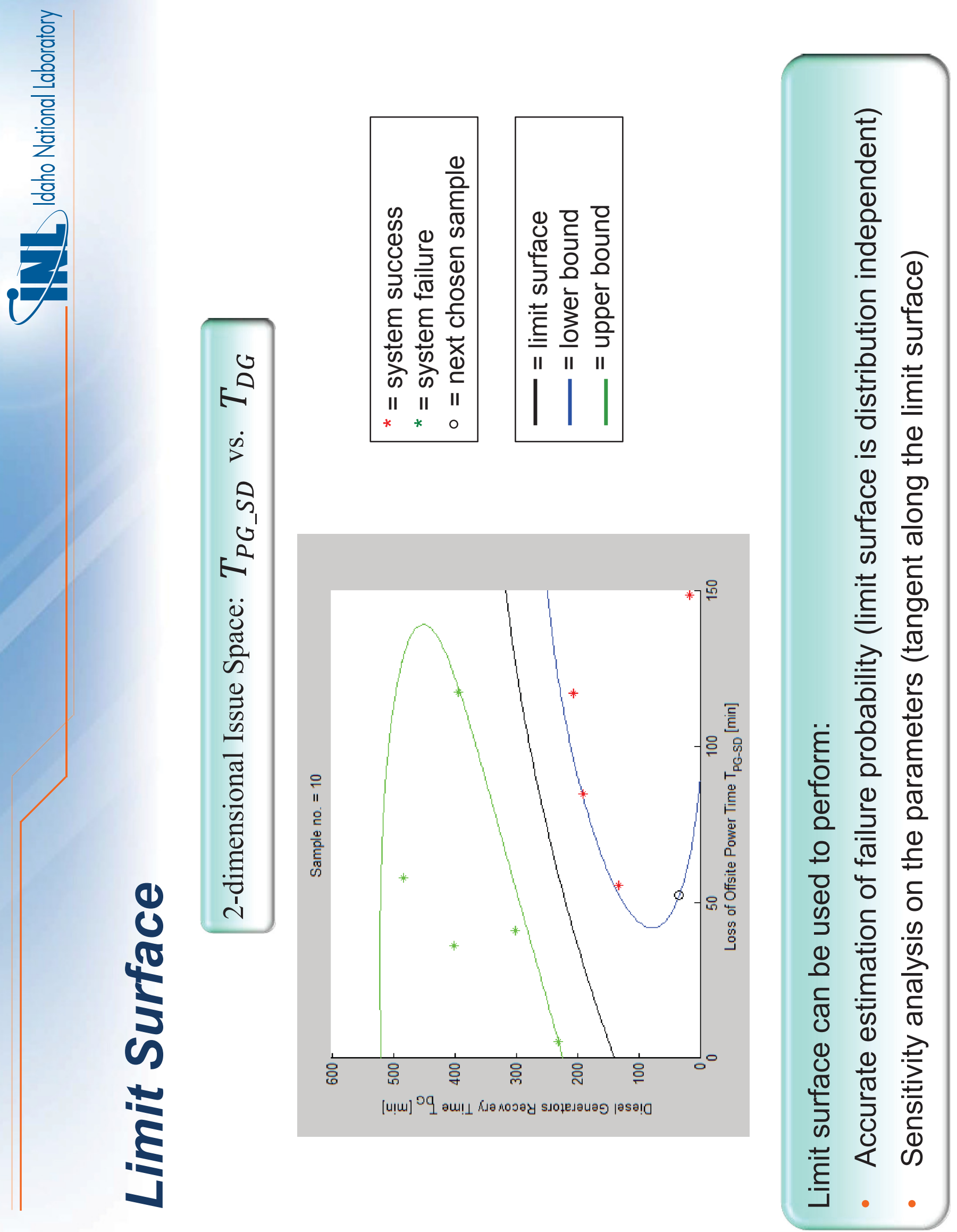




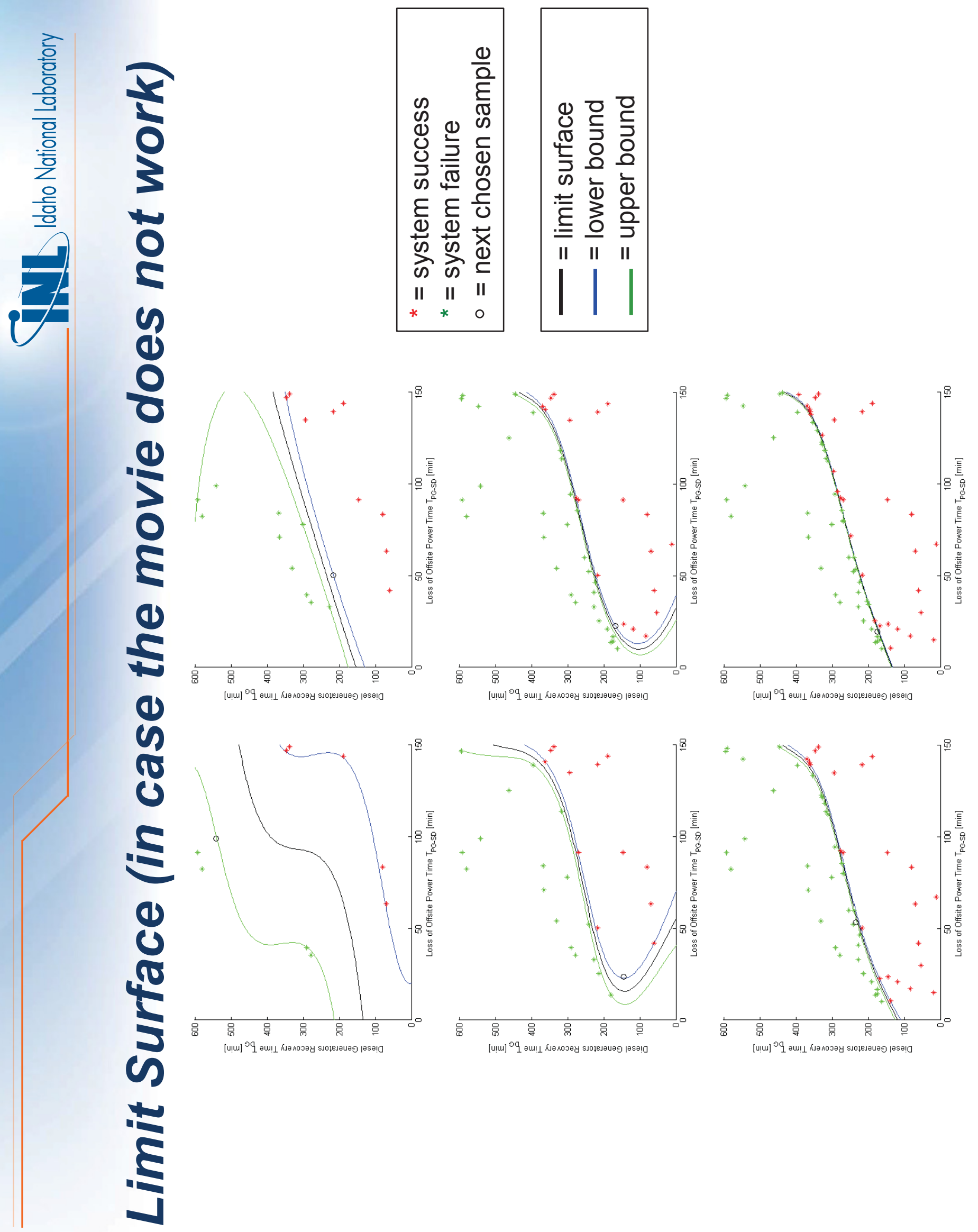



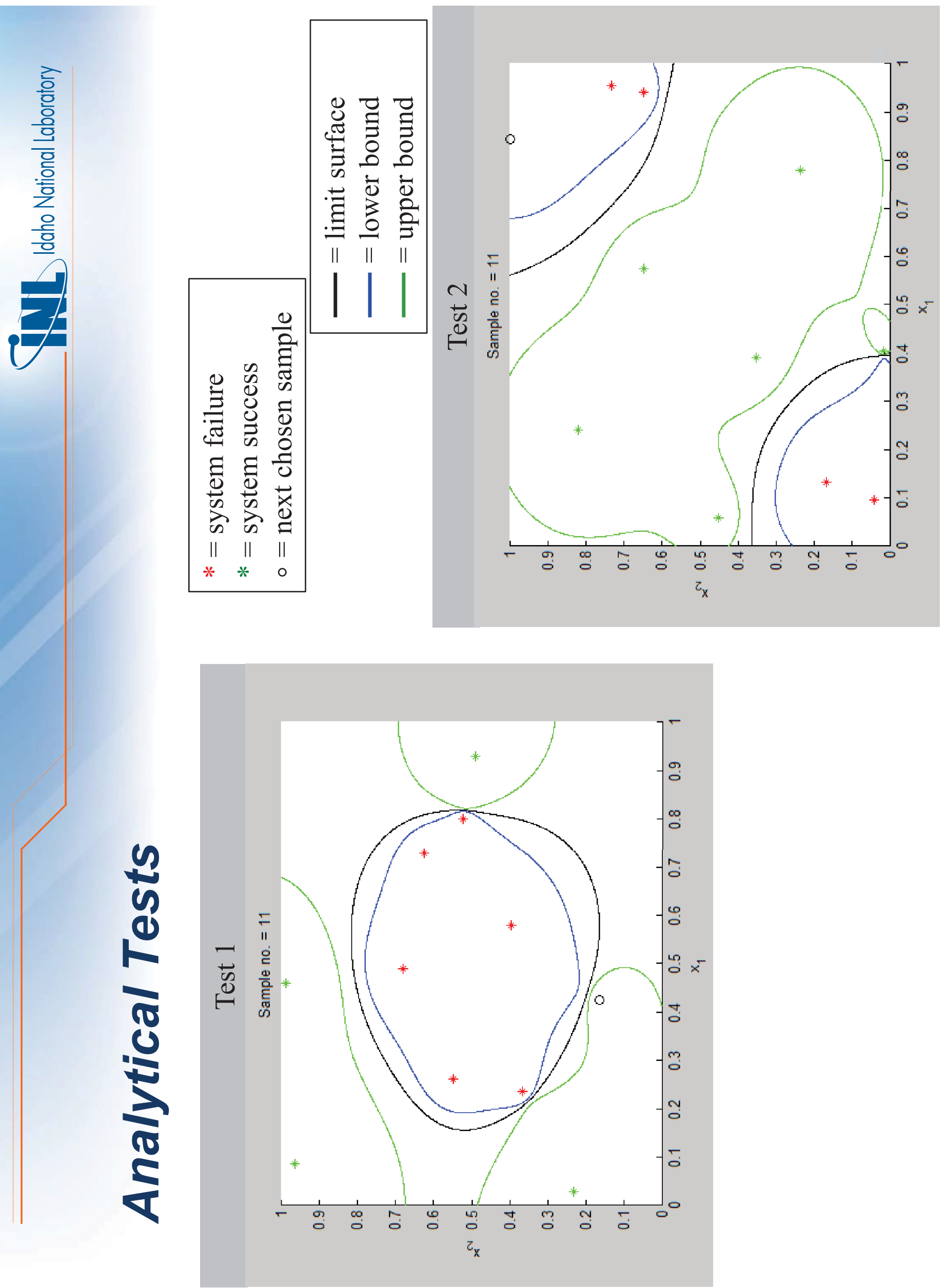
\begin{tabular}{l} 
흫 \\
흘 \\
흘 \\
흘 \\
음 \\
\hline
\end{tabular}

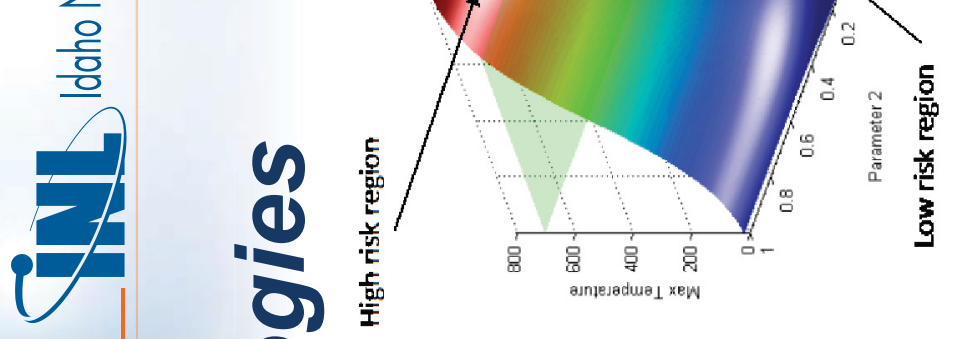

도

능 응

(1) 이

으 ฮ

(1) 으듣

$\stackrel{(1)}{\simeq}$

음

(1) 으를

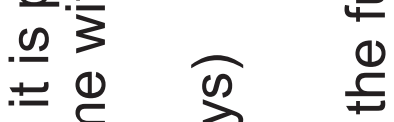

Еँ

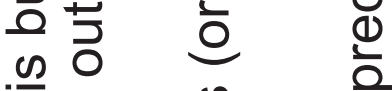

बิ $\frac{1}{0}$ की

ㅇํ욤ำ

ह $\overbrace{\omega}^{\infty}$

(1) ल

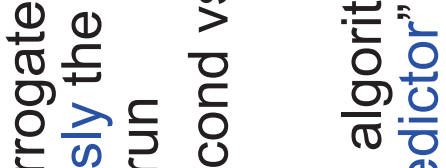

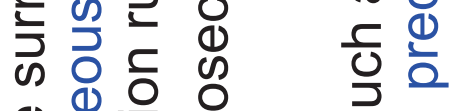

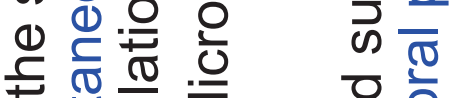

10 돌로

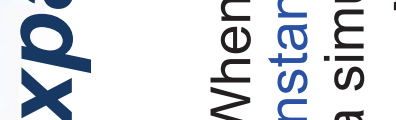

13.

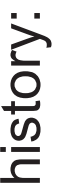

$\stackrel{\Phi}{E}$

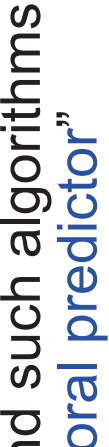

흐을

ํㅣㄹ

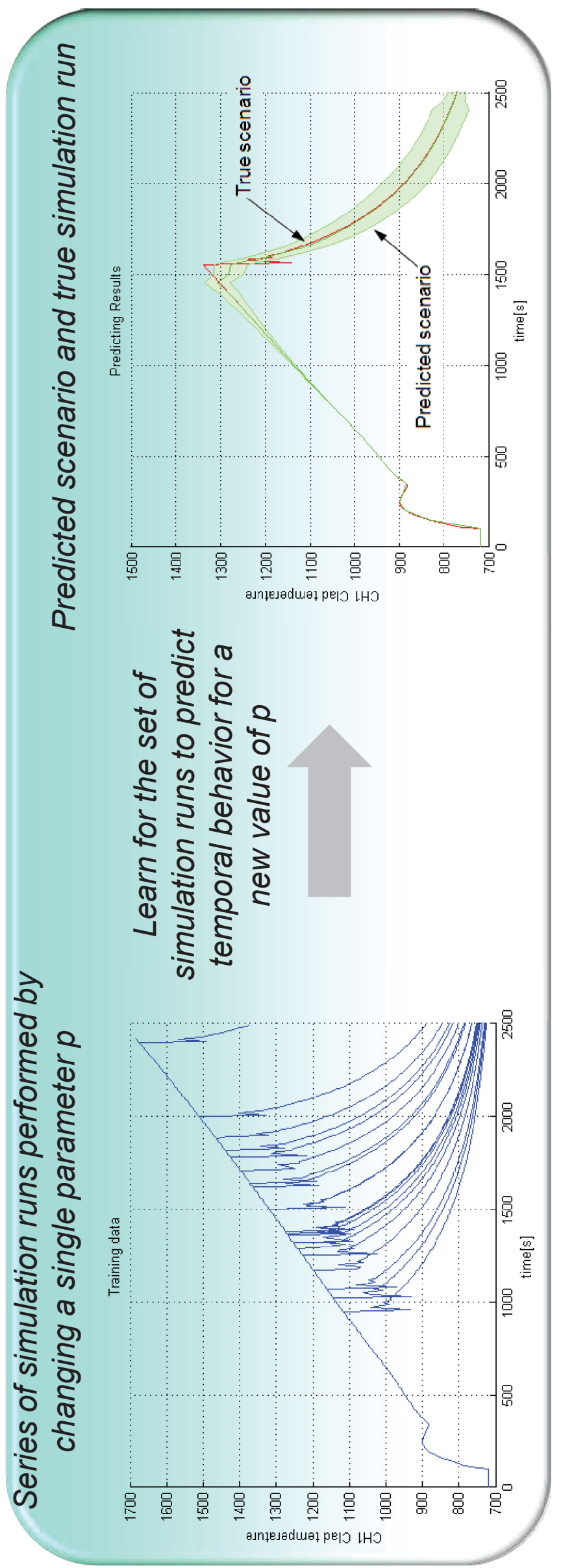



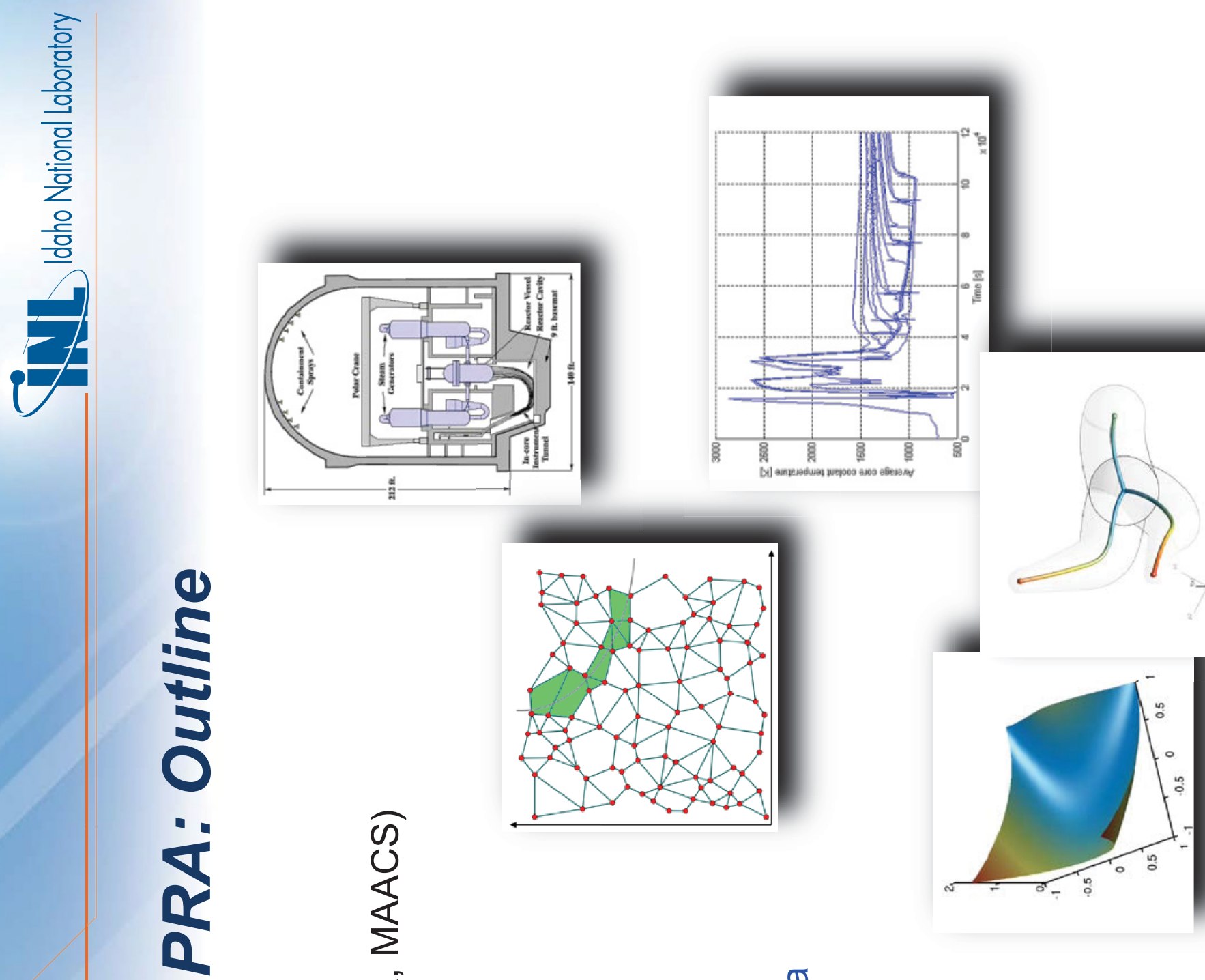

8

宛 㟧

$\infty \frac{0}{0}$
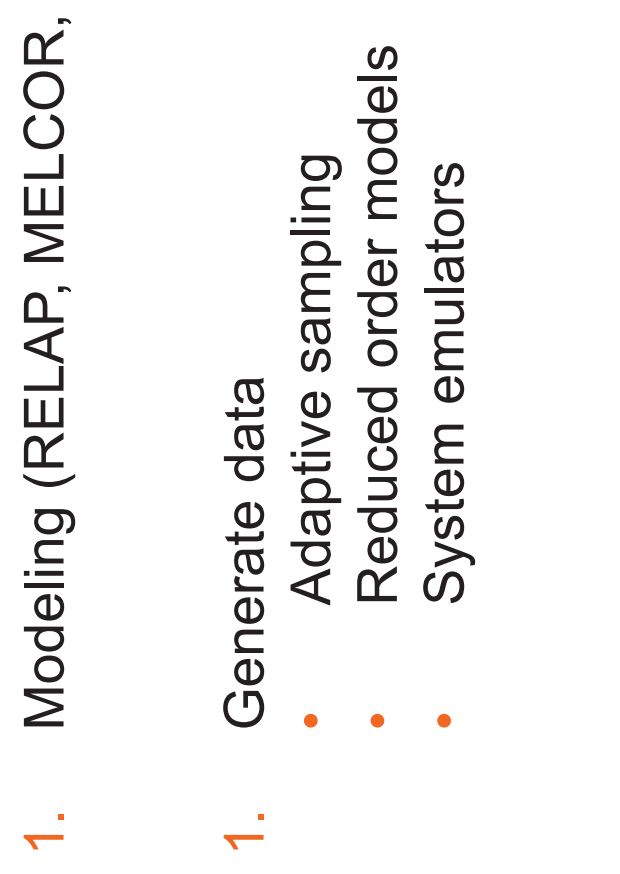

$\frac{\pi}{0}$

늠

이 일

응 잉

(1) 은

है

(1) $\frac{\partial}{\mathrm{D}}$

त

字。

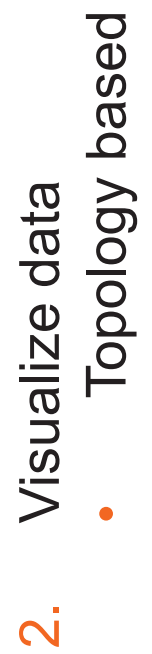




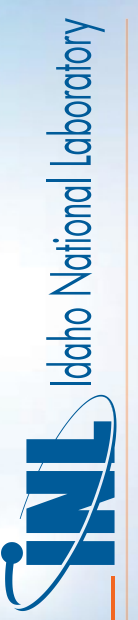

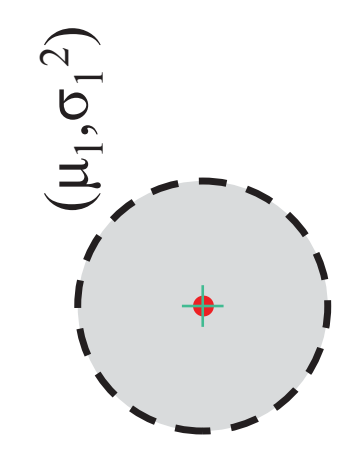

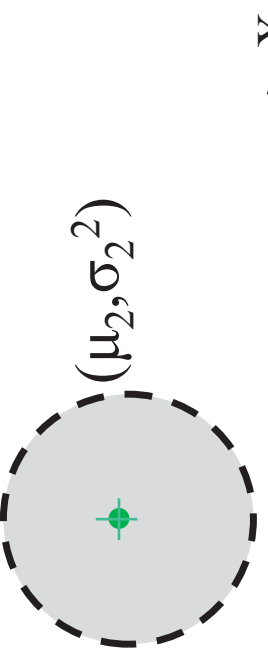

$\frac{\pi}{\pi}$

0

ฮั

8

5

(1)

오

อ

(1)

$\xi$

이

5

()

5

(
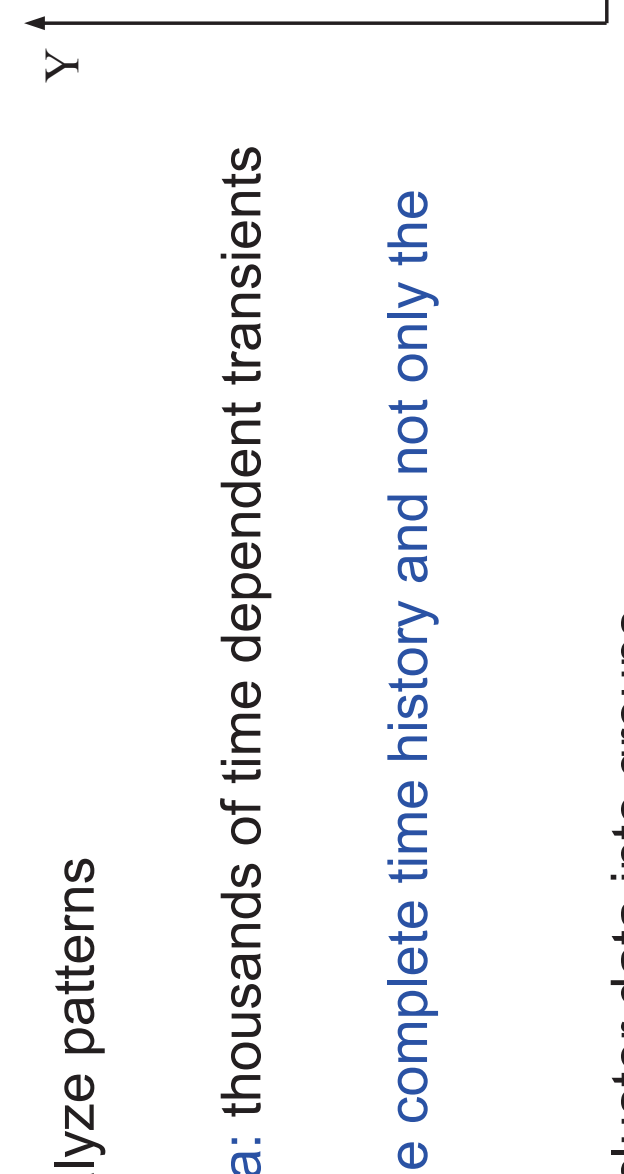

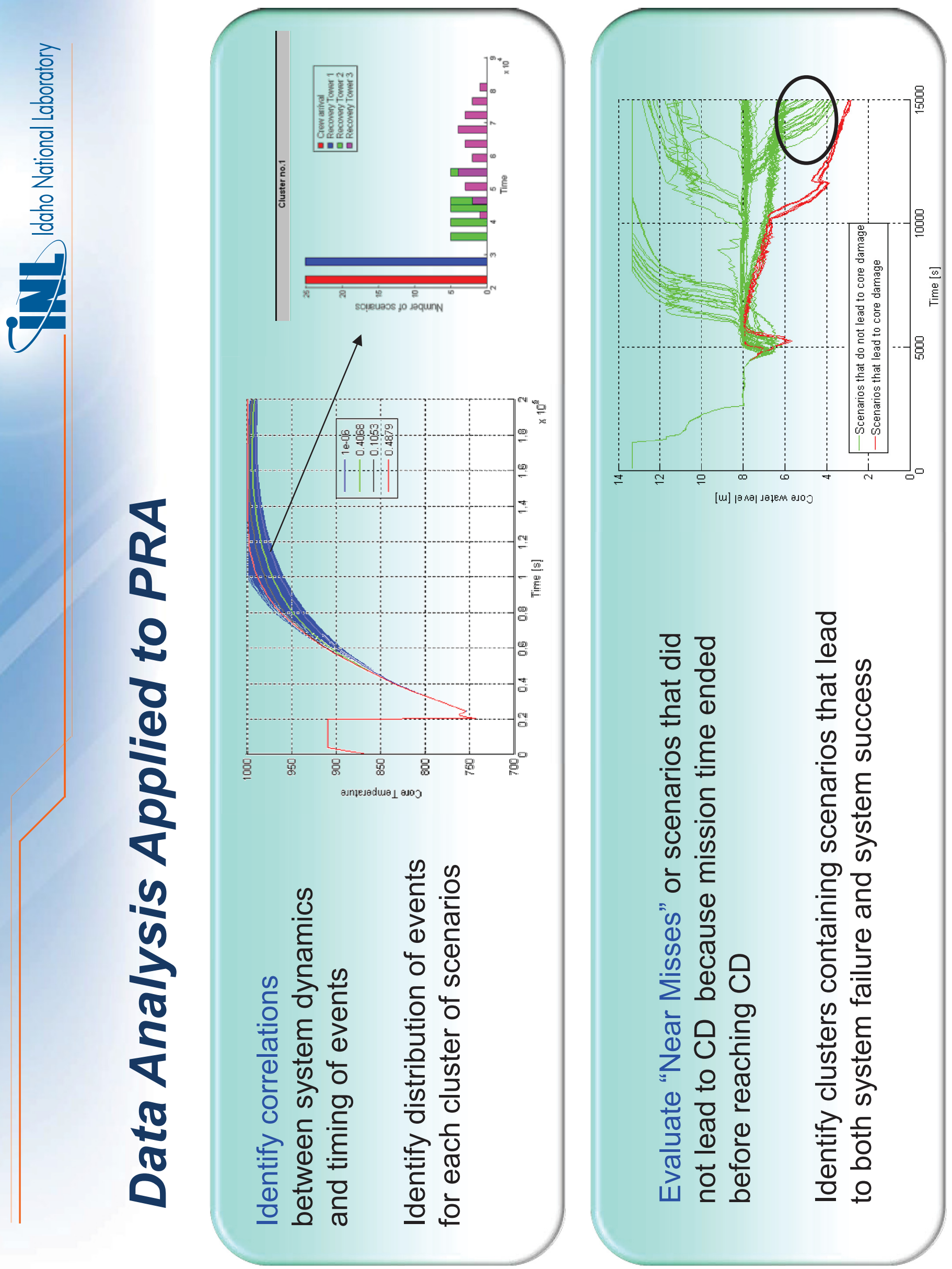

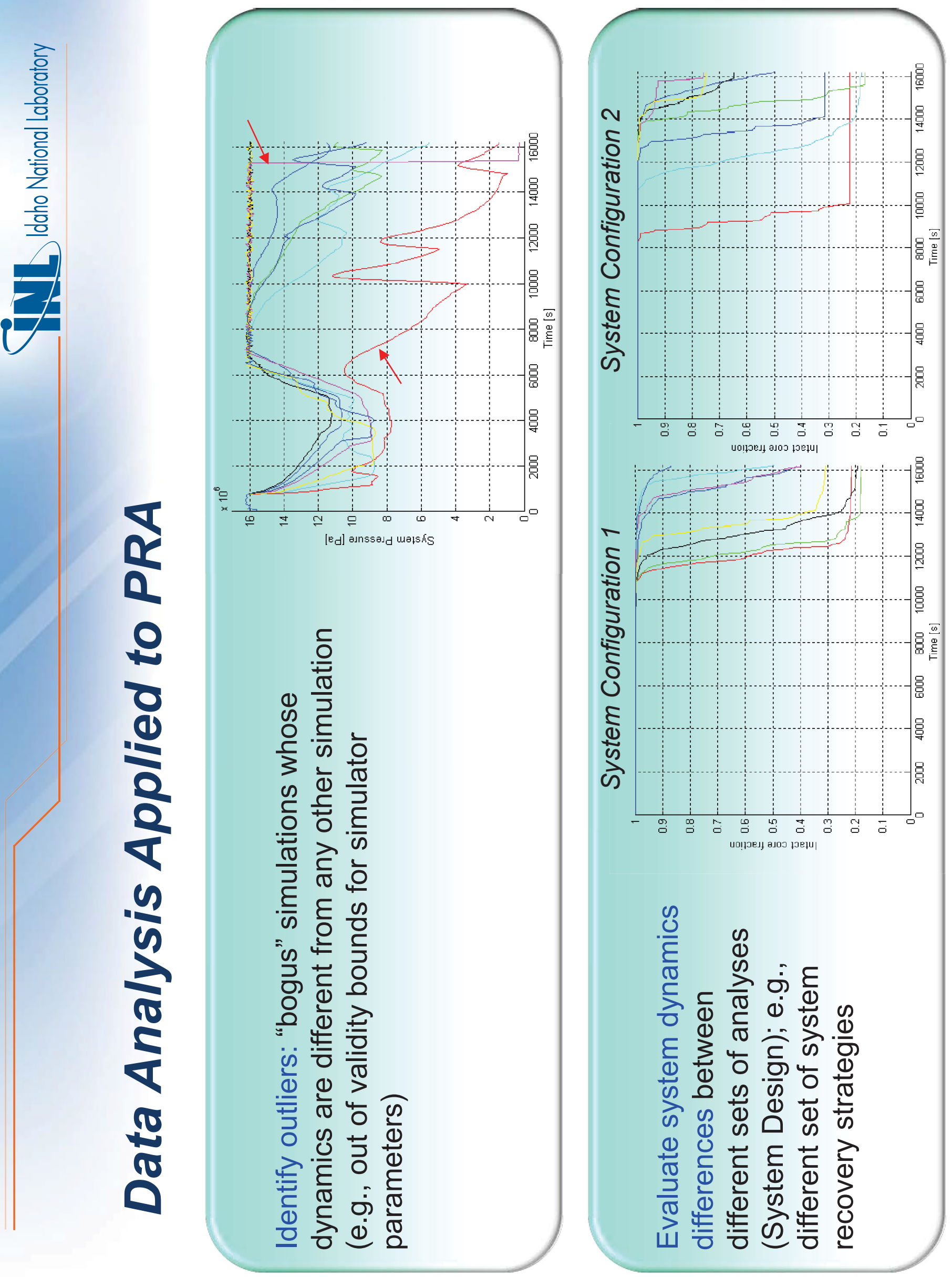

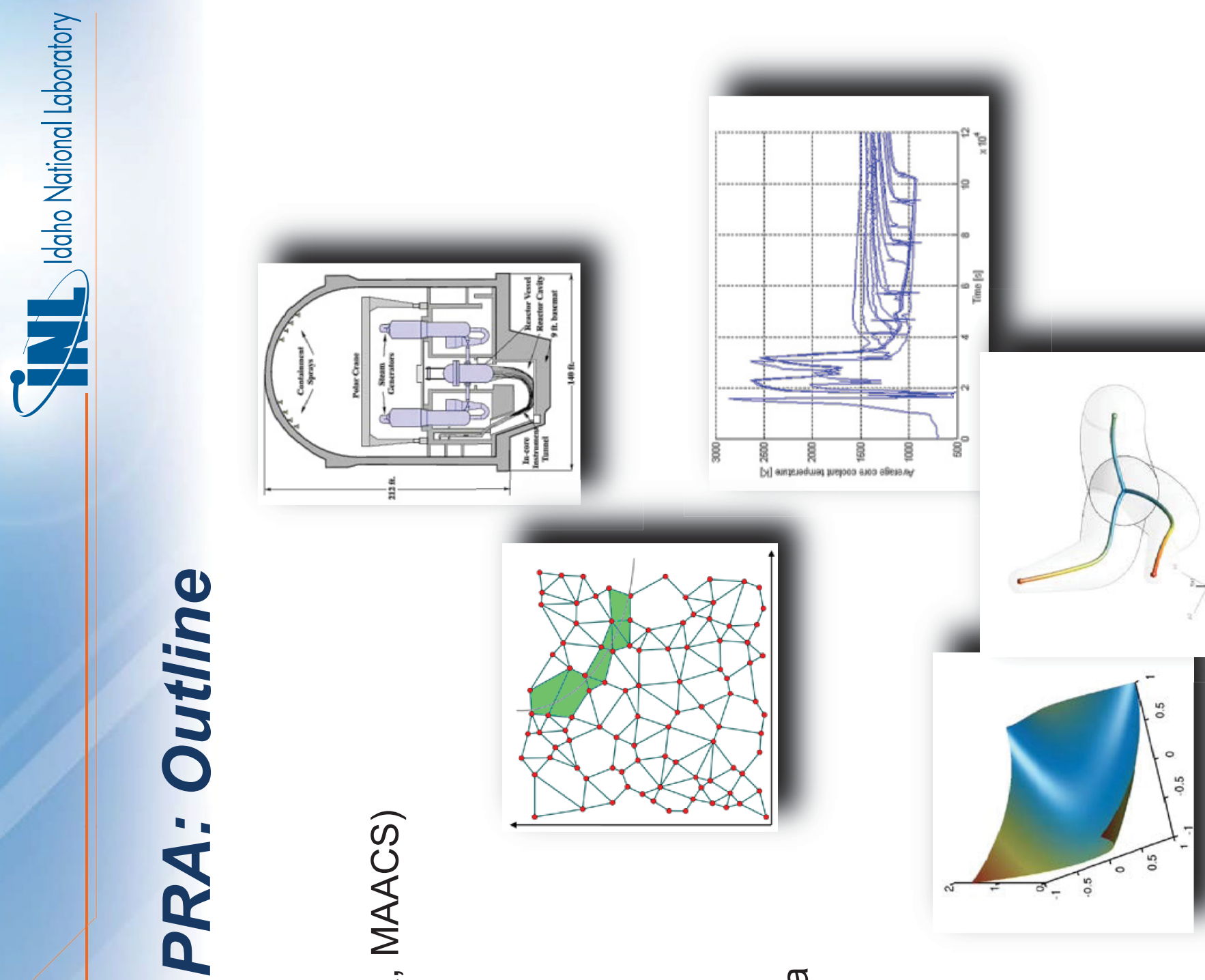

8

के

$\infty \frac{0}{0} \frac{0}{5}$

造

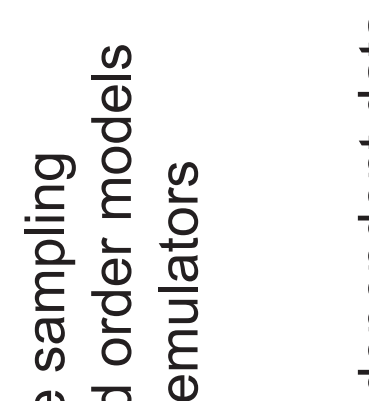

$\frac{\pi}{\pi}$

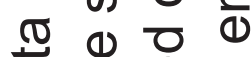

○ 焉 㟧

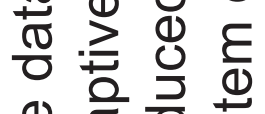

Q $\frac{0}{\pi}$ 궁

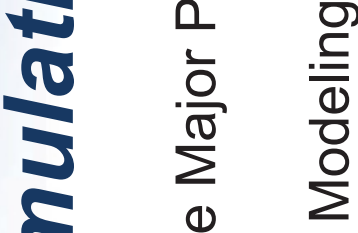

震定品的

$\frac{1}{1}$

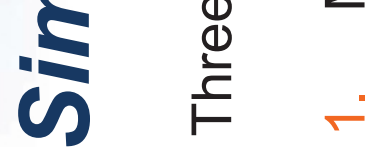

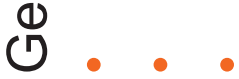

$\frac{0}{0} \frac{0}{0}$

这

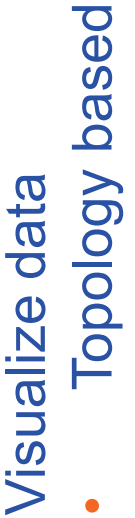

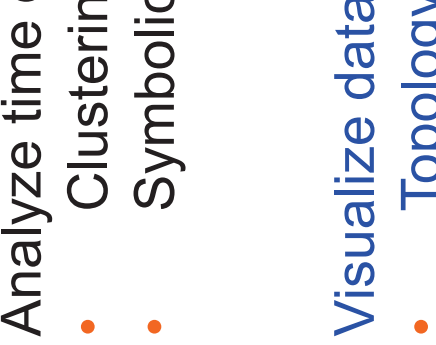




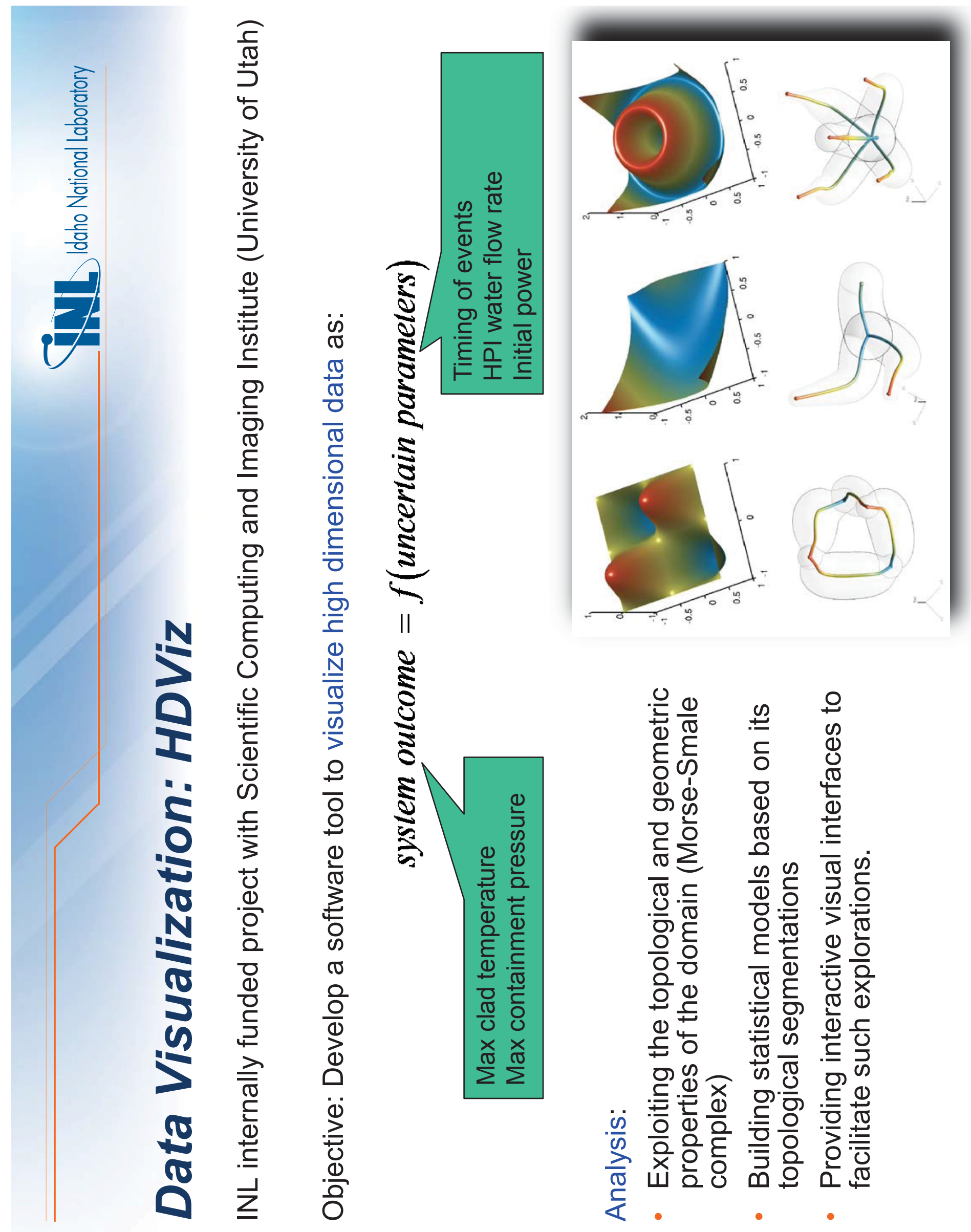



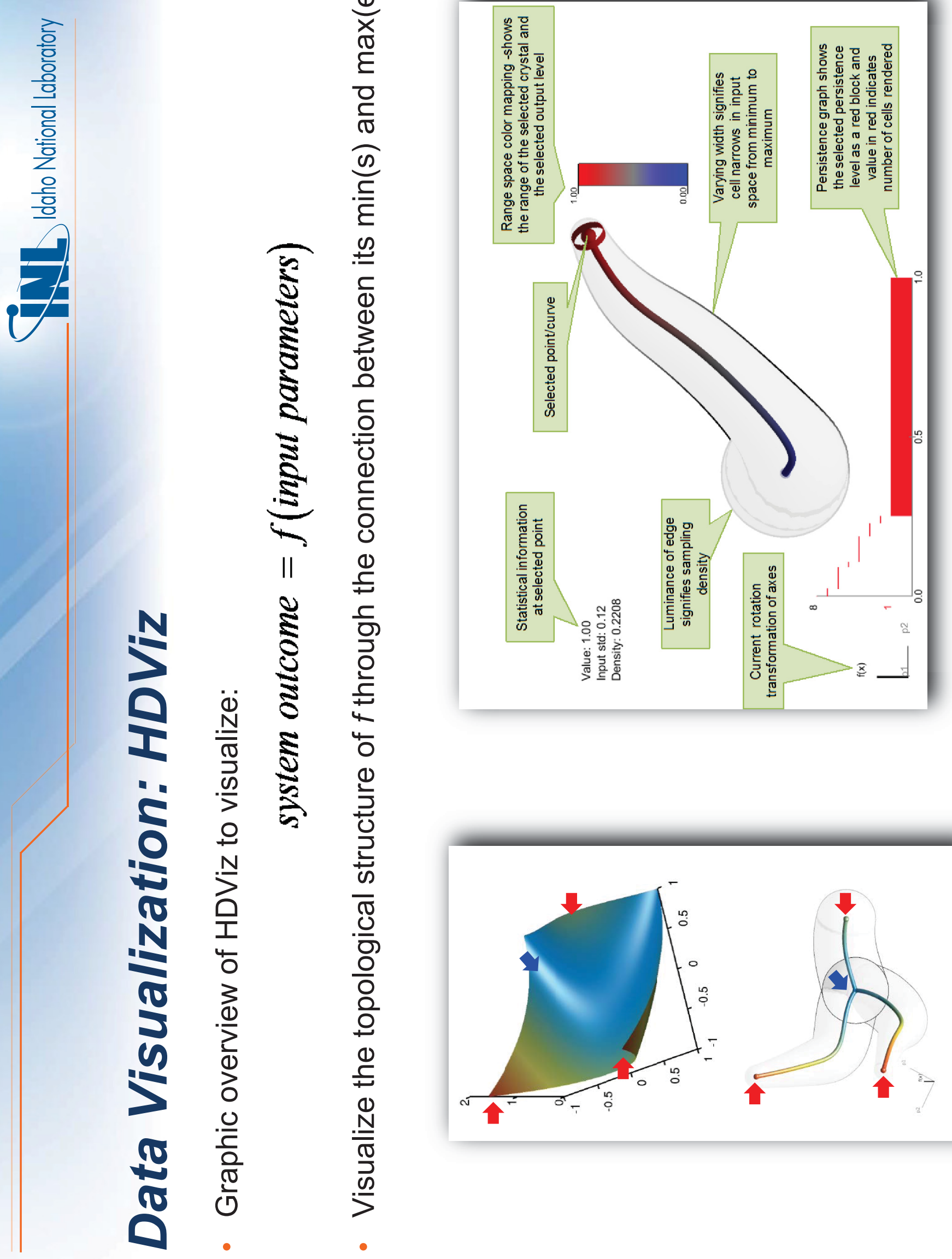

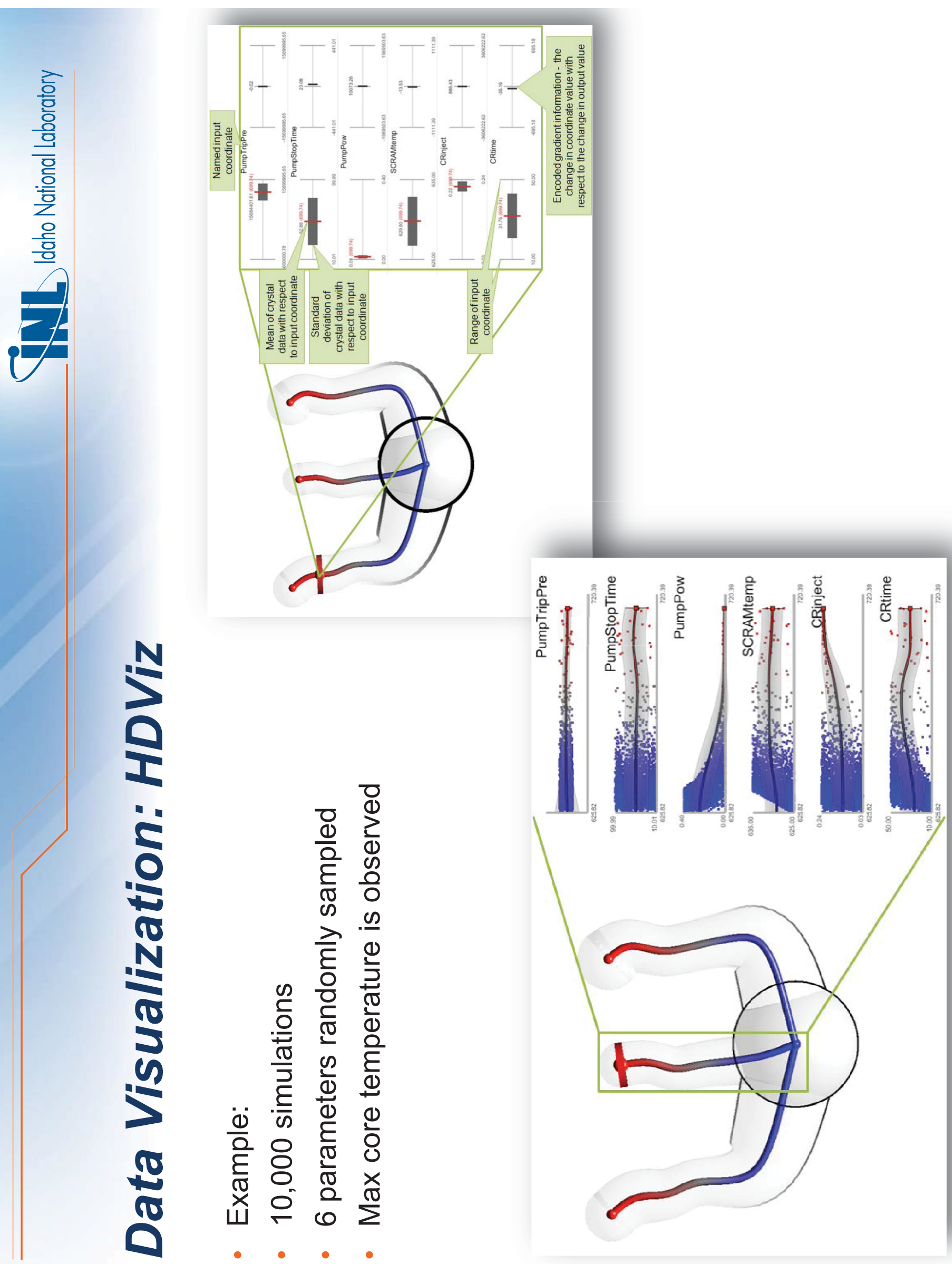

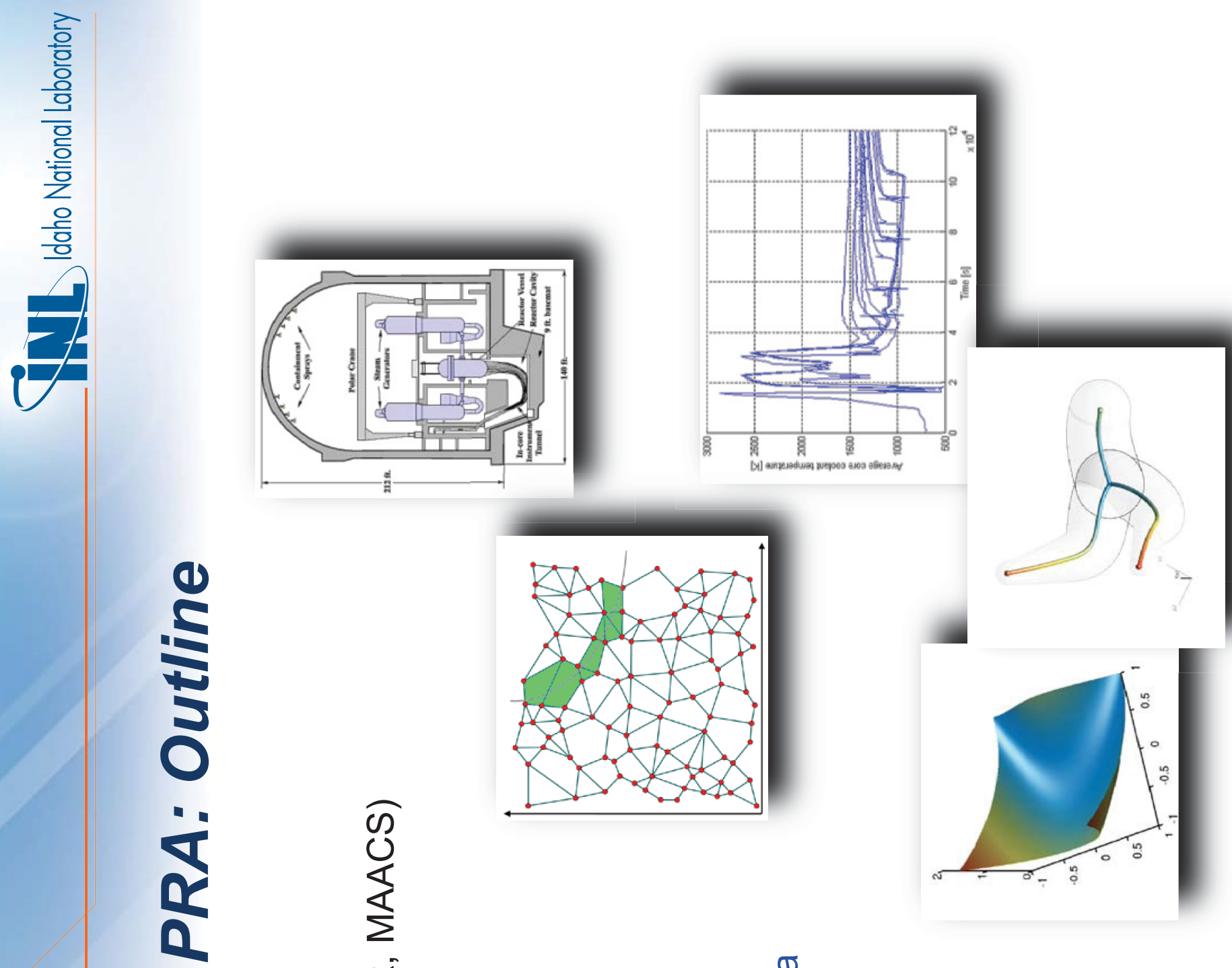

8

号

$\infty \frac{0}{0} \frac{0}{5}$

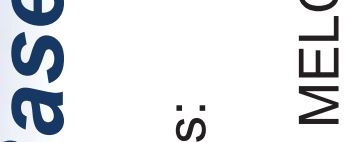

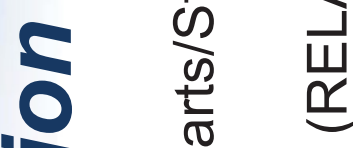

\$ 0

(T)

క $\sum_{0}^{\frac{\pi}{\pi}} \frac{0}{2}$

क $\stackrel{\Phi}{\risingdotseq}$.

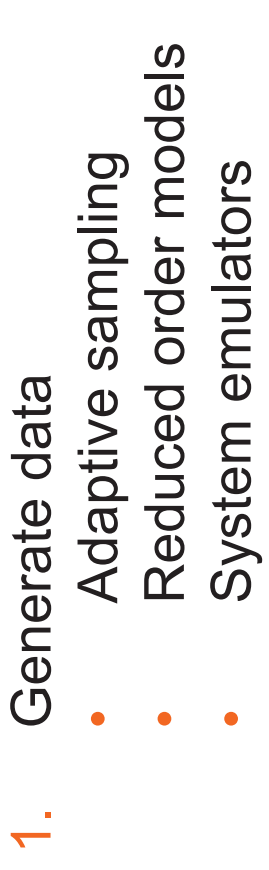

$\frac{\pi}{\frac{\pi}{0}}$

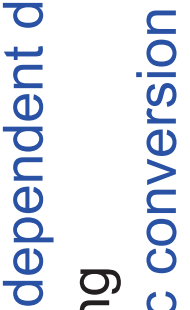

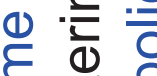

站

(1) गे

$\frac{\lambda}{\pi}$

它。

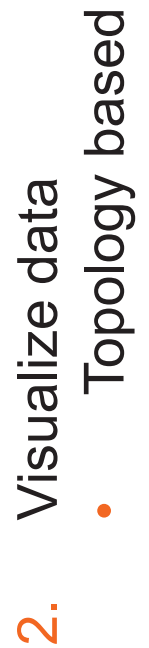



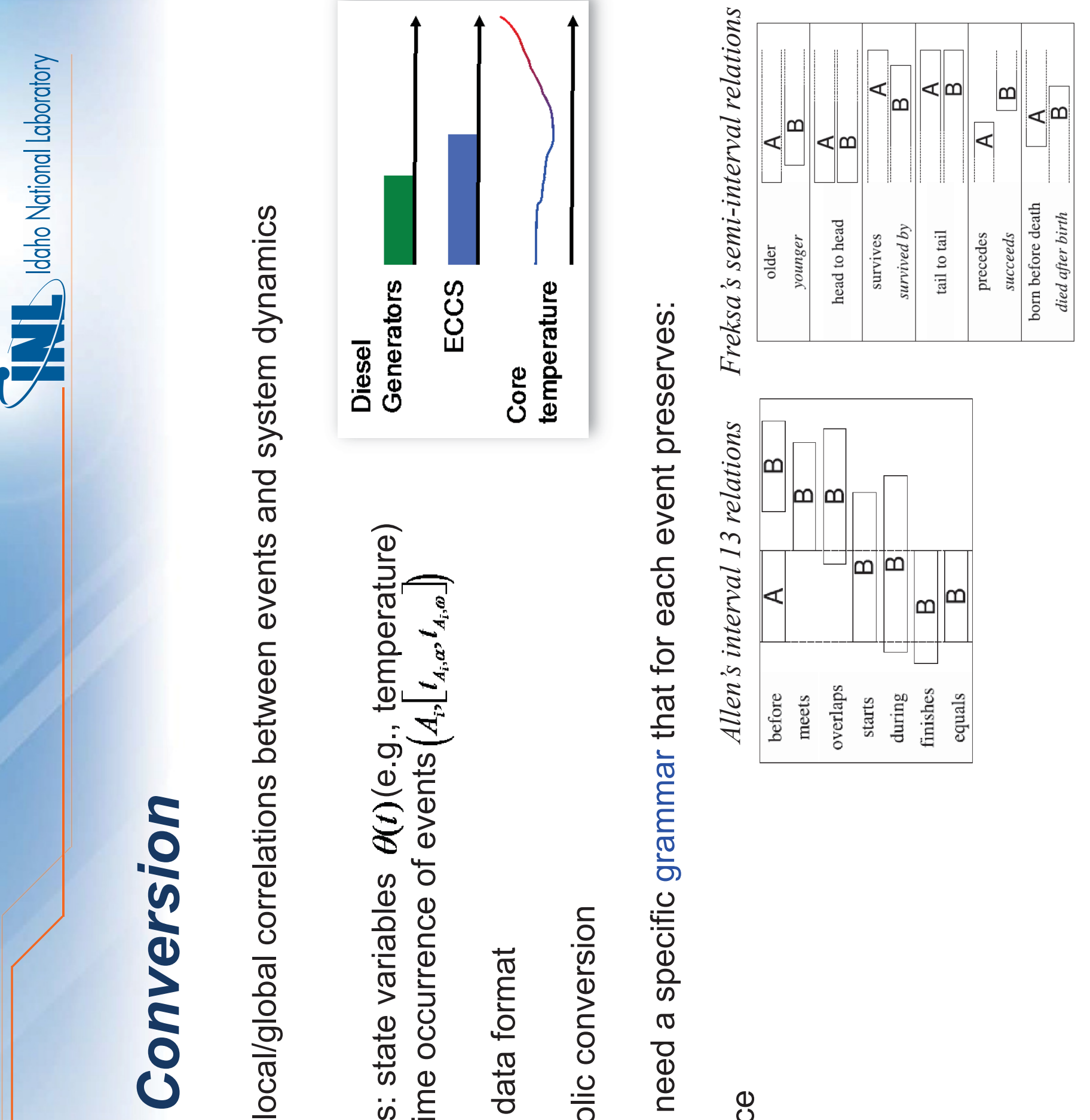

(1)

$\frac{\frac{\varepsilon}{d}}{\omega}$

ஸे

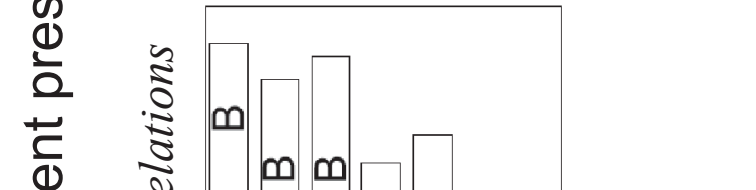

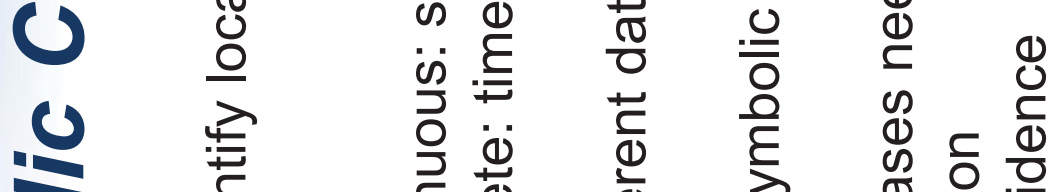

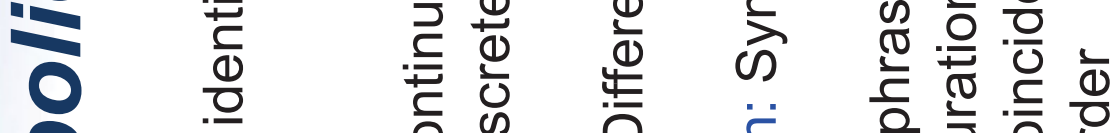

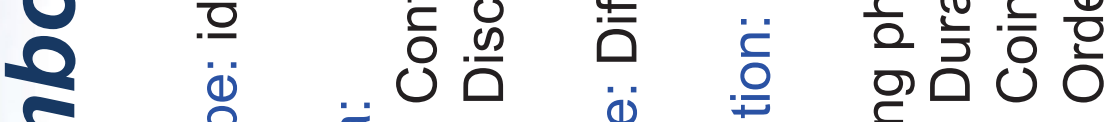

E Oे ชั

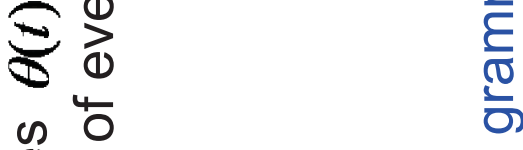

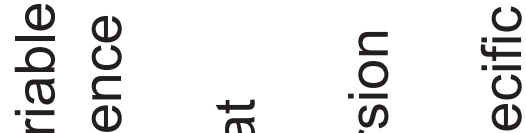

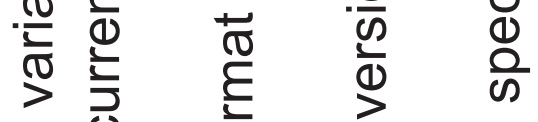

ब)

क ब

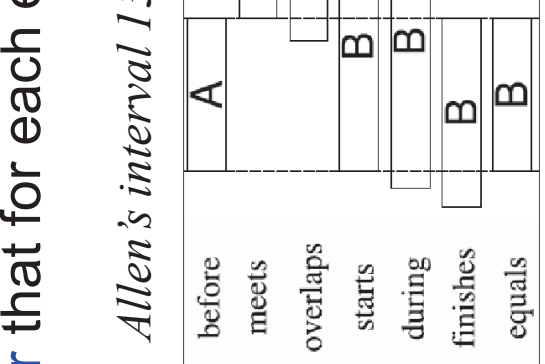

ते

$\frac{2}{2}$ 

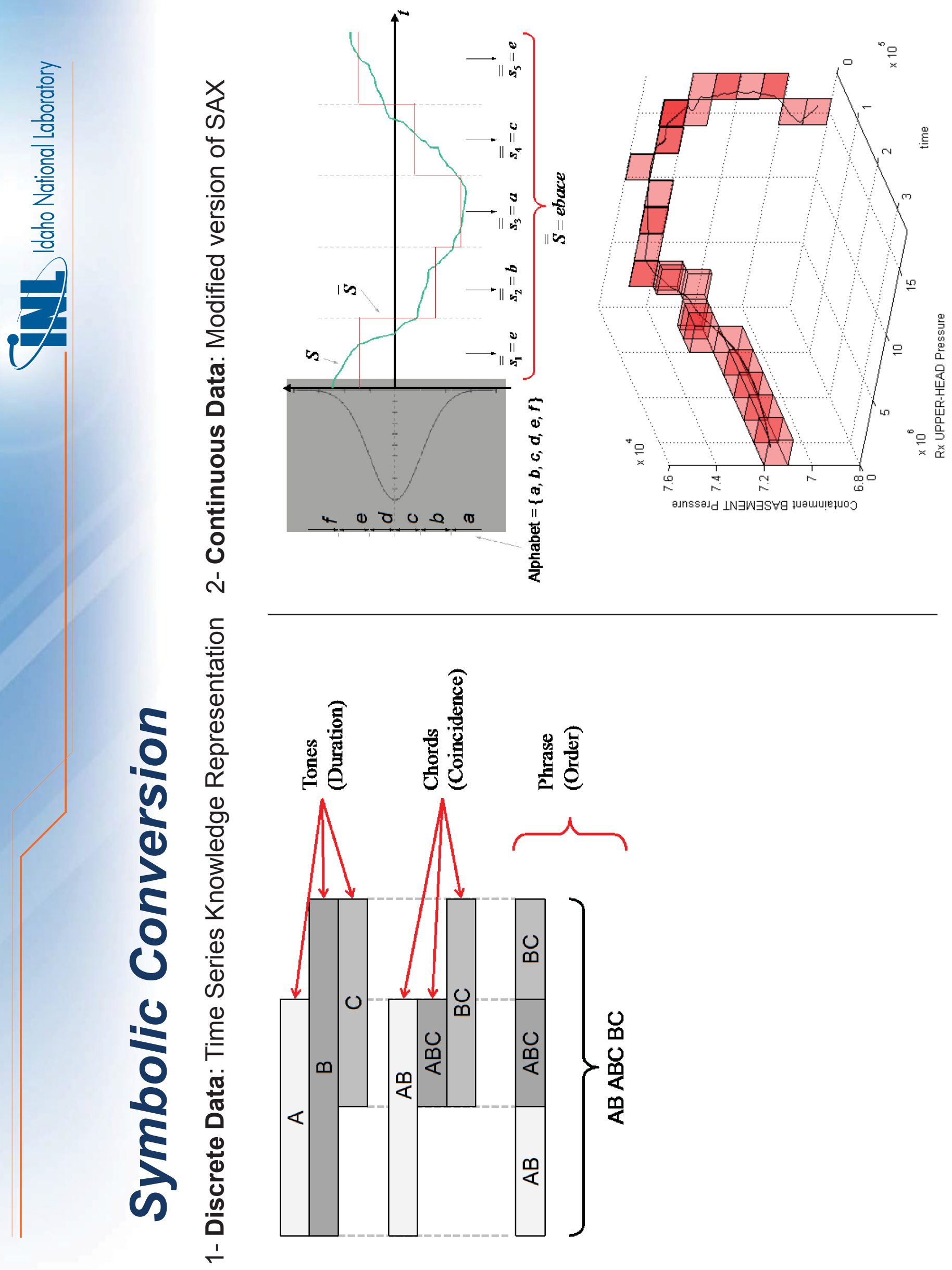


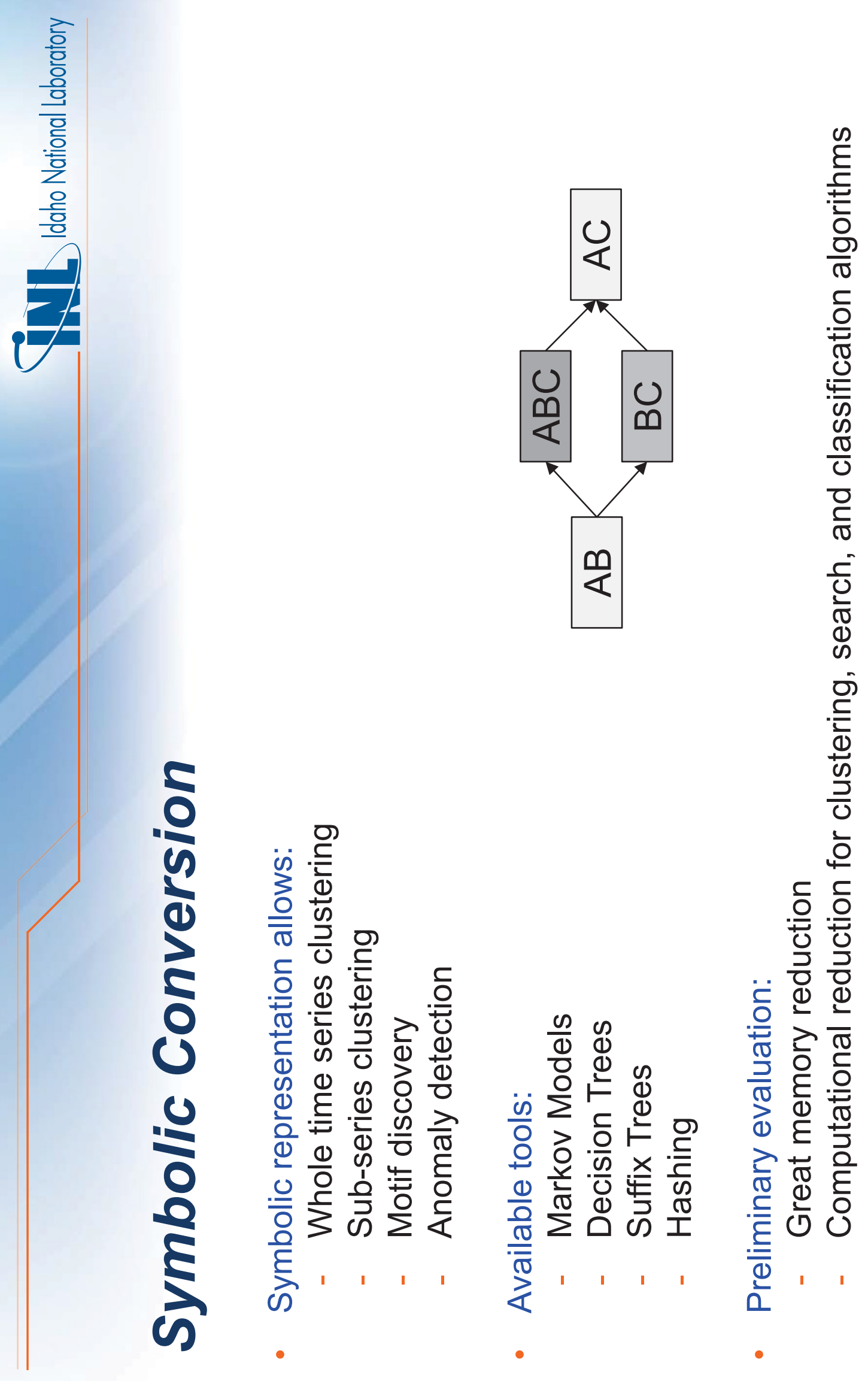



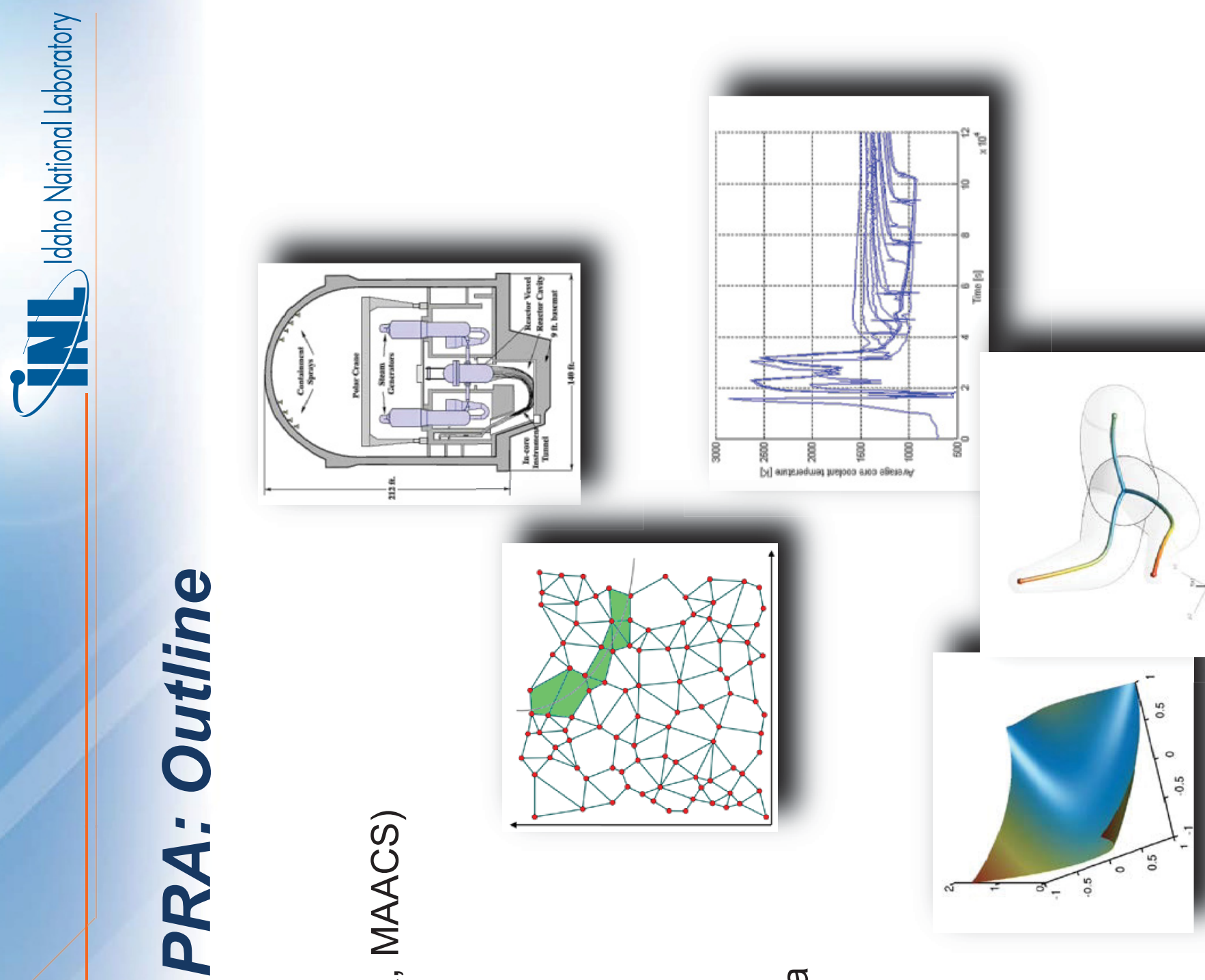

8

के is

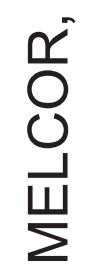



ô $\frac{m}{\bar{t}}$

\& $a$ o

(1) ᄒ⿱

$\frac{\pi}{2} \sum_{0}^{\frac{0}{\pi}} \frac{0}{0}$

ह

क $\stackrel{\Phi}{\risingdotseq}$.

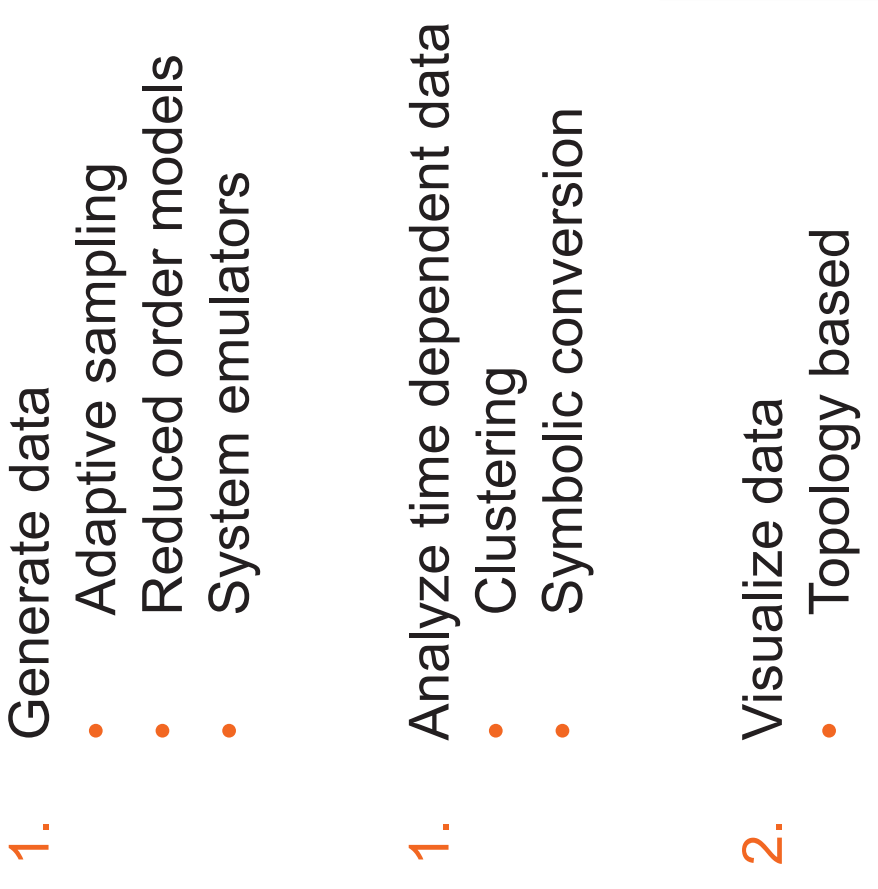




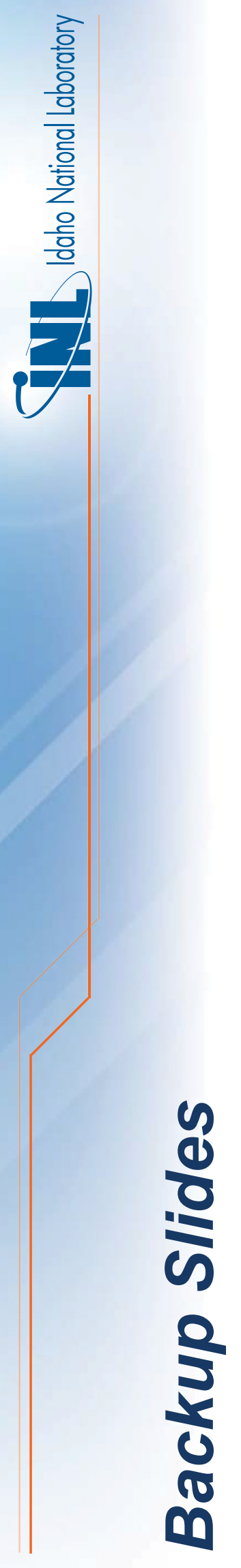




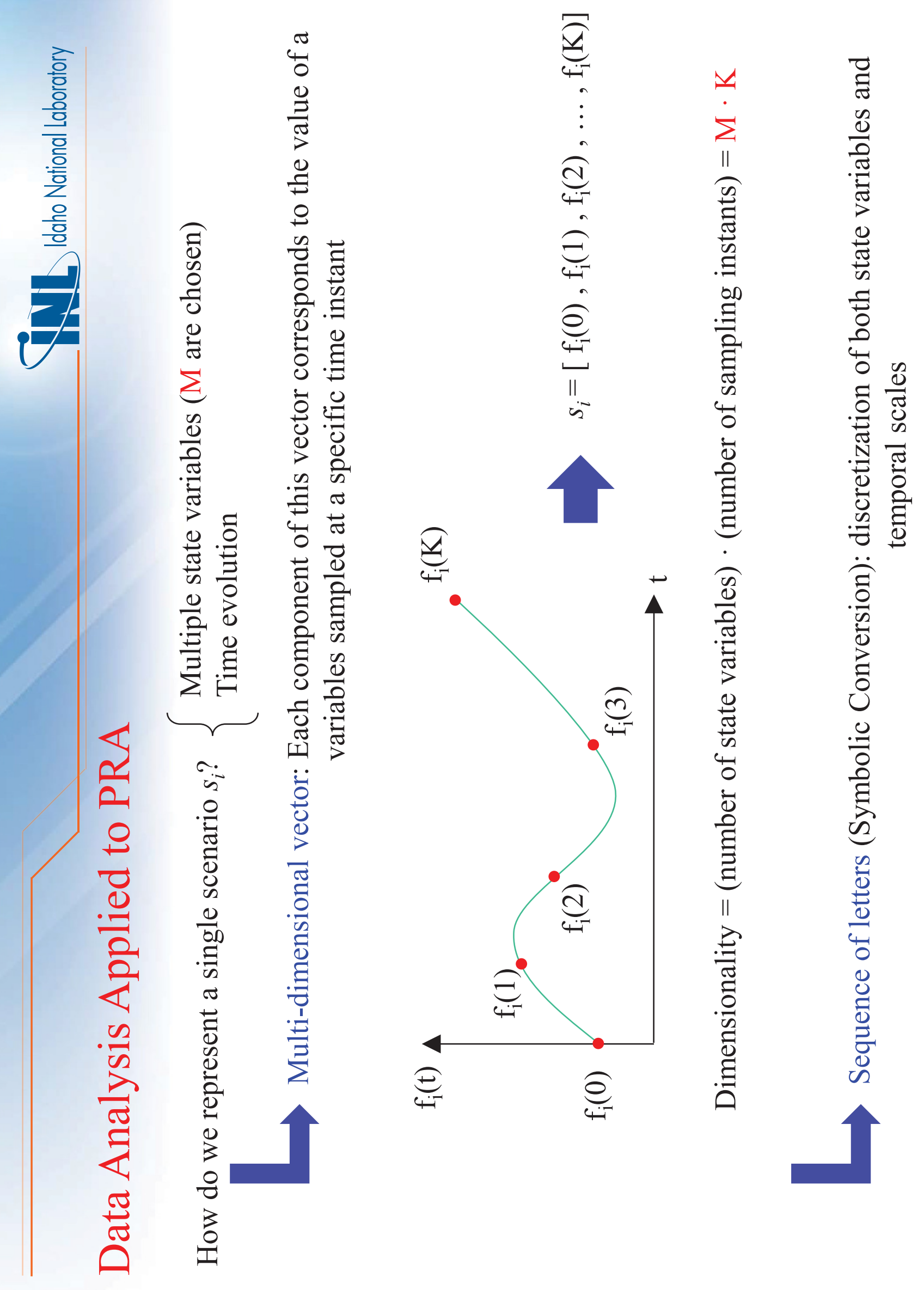




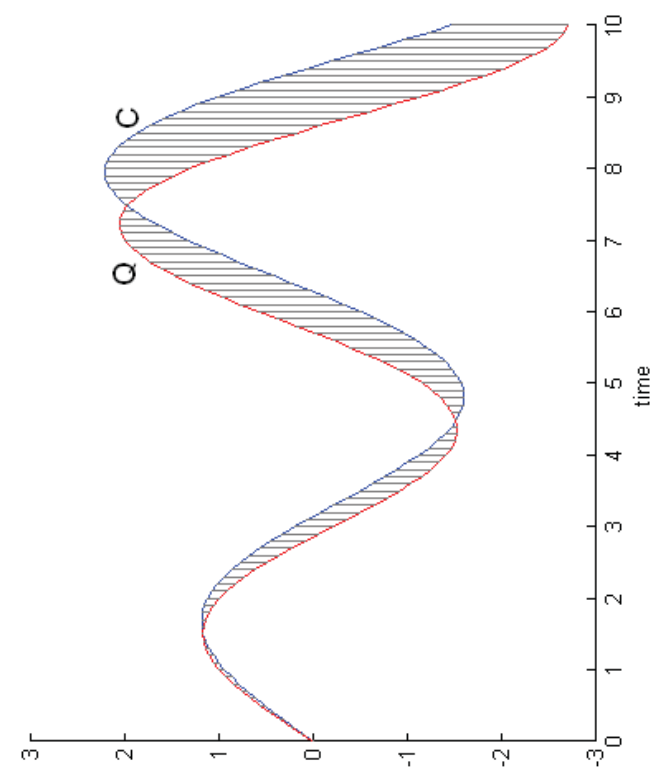

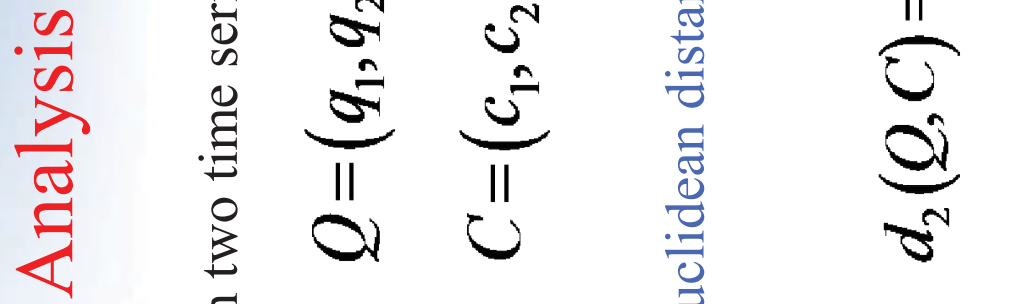

$\stackrel{\nabla}{\approx}$

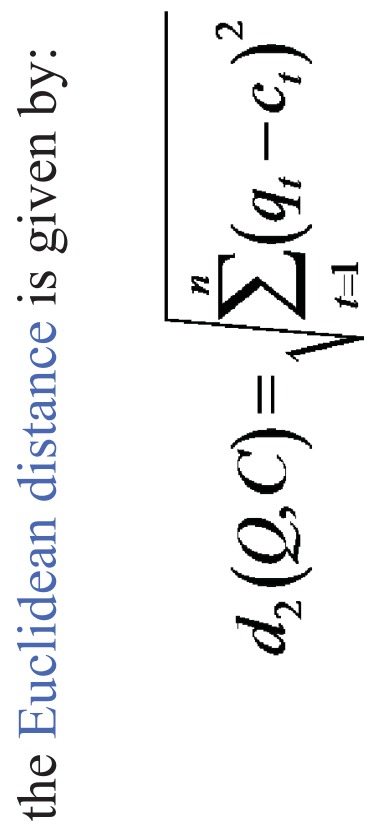




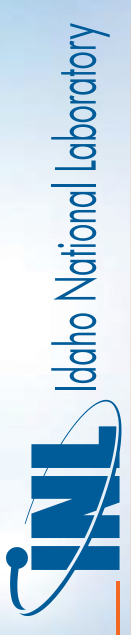

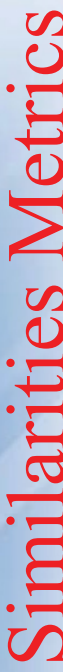

玄

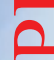

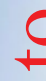

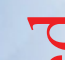

$\frac{0}{2}$

$\cdot \frac{n}{\omega}$

完

苞
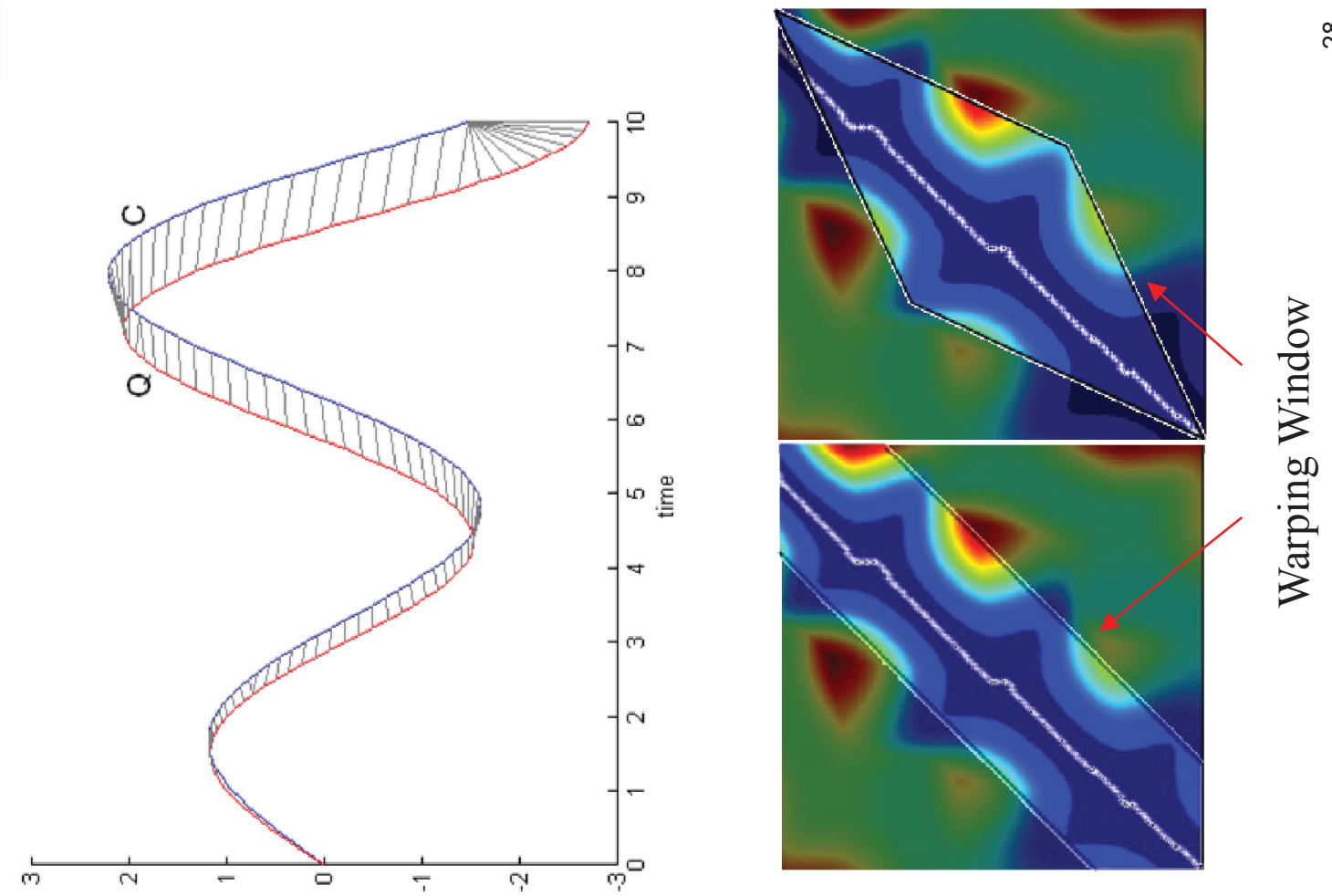

$\infty$

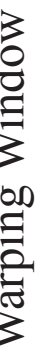

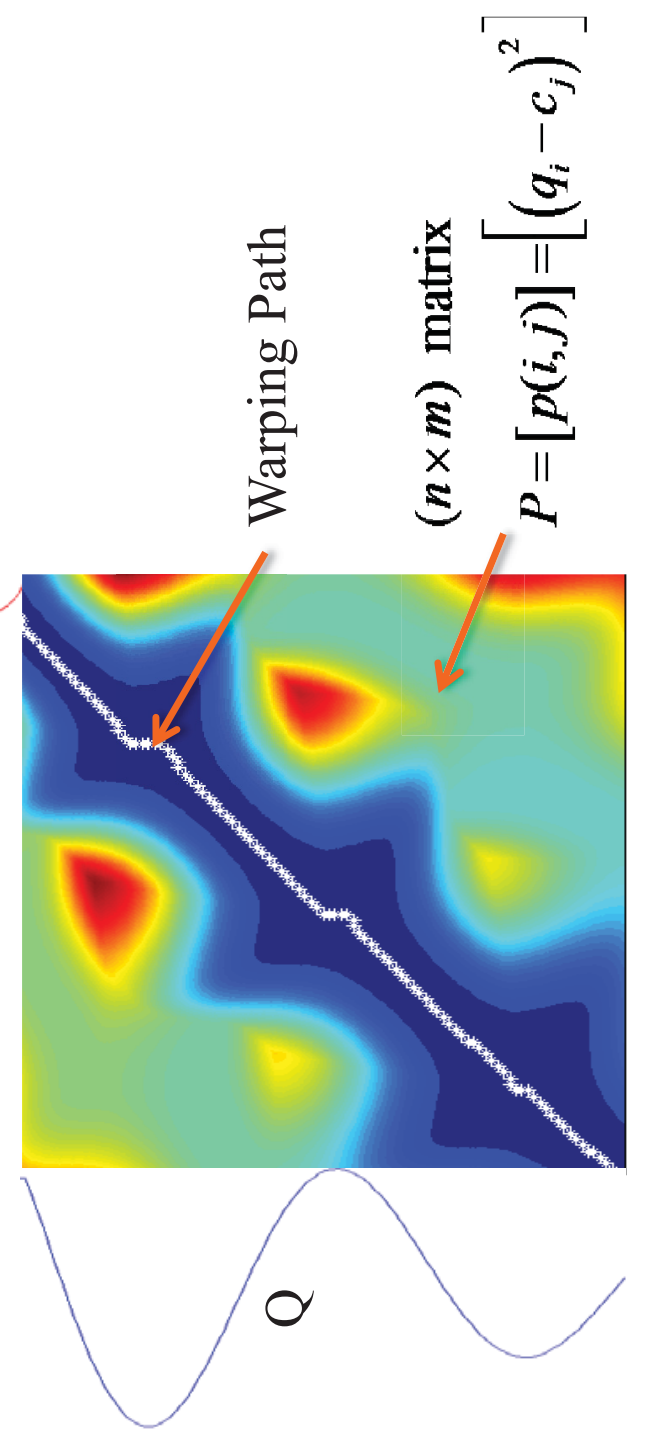




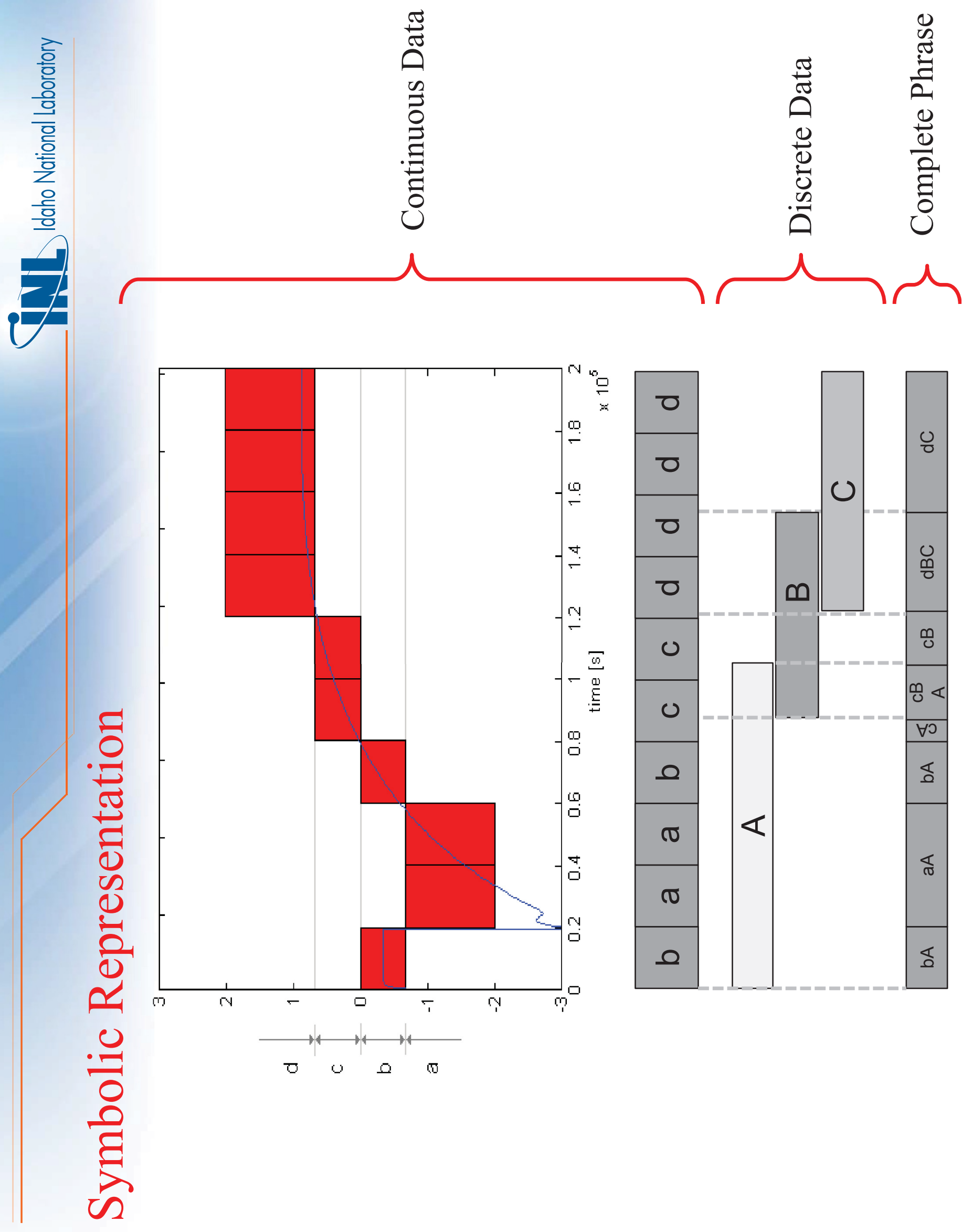




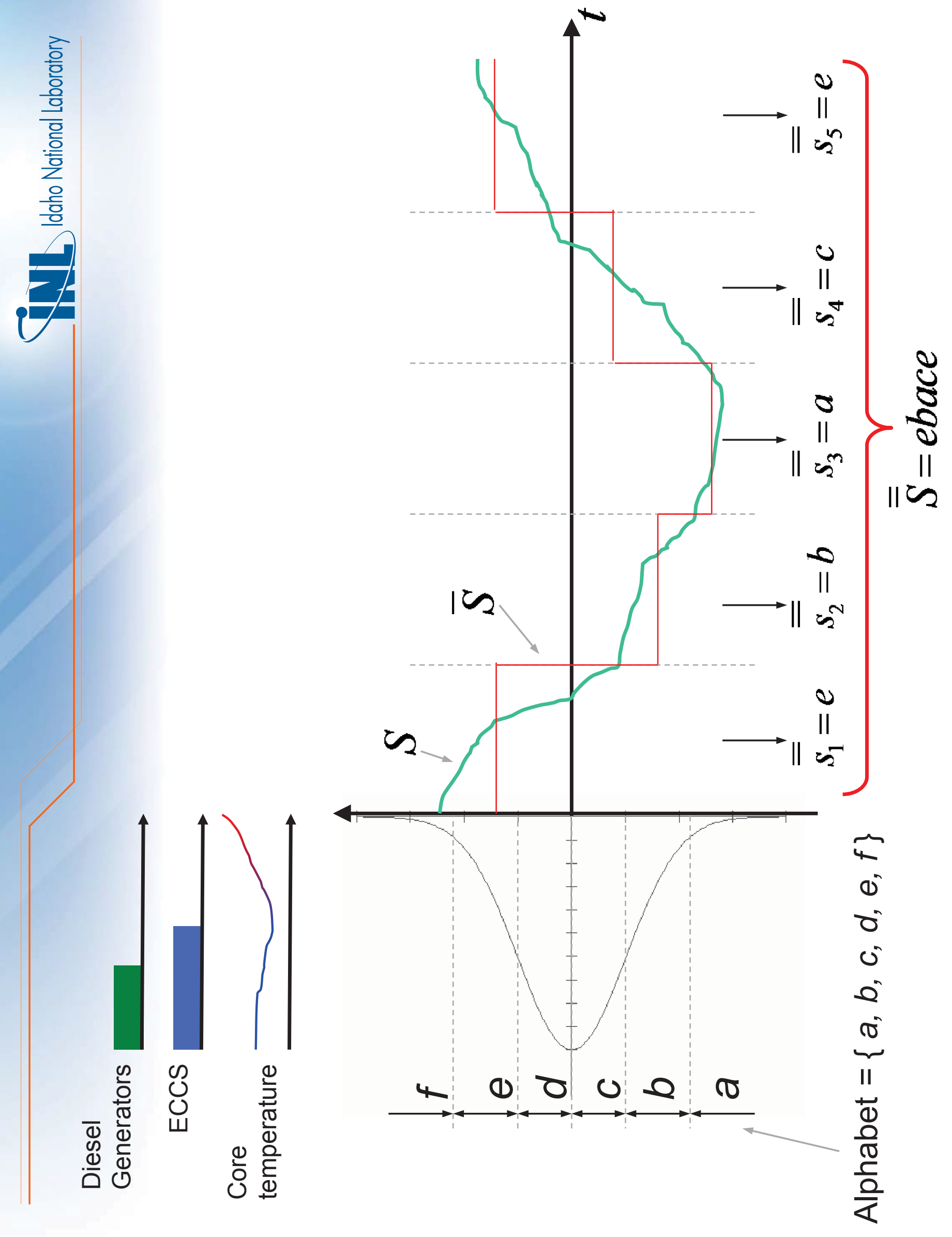



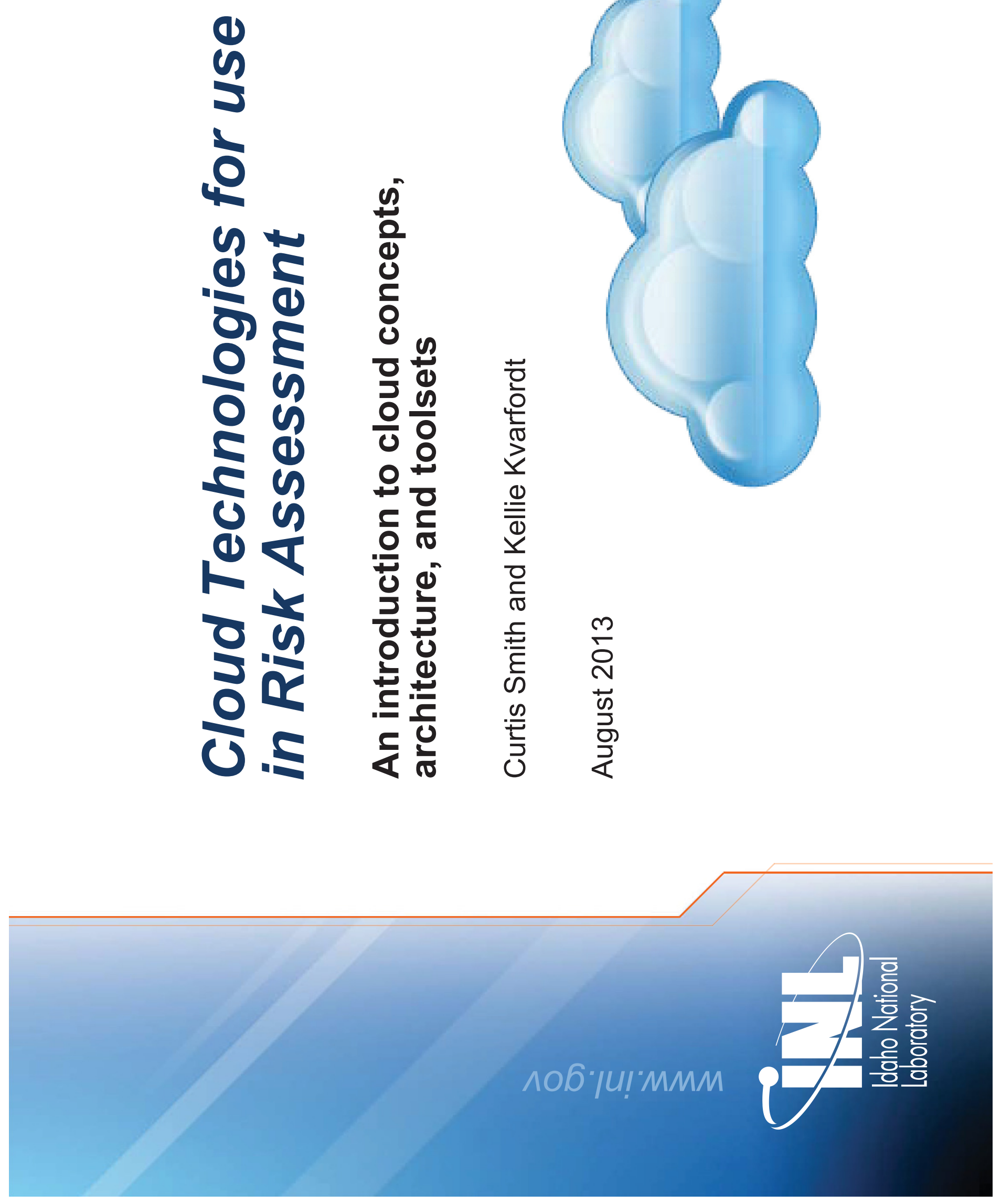


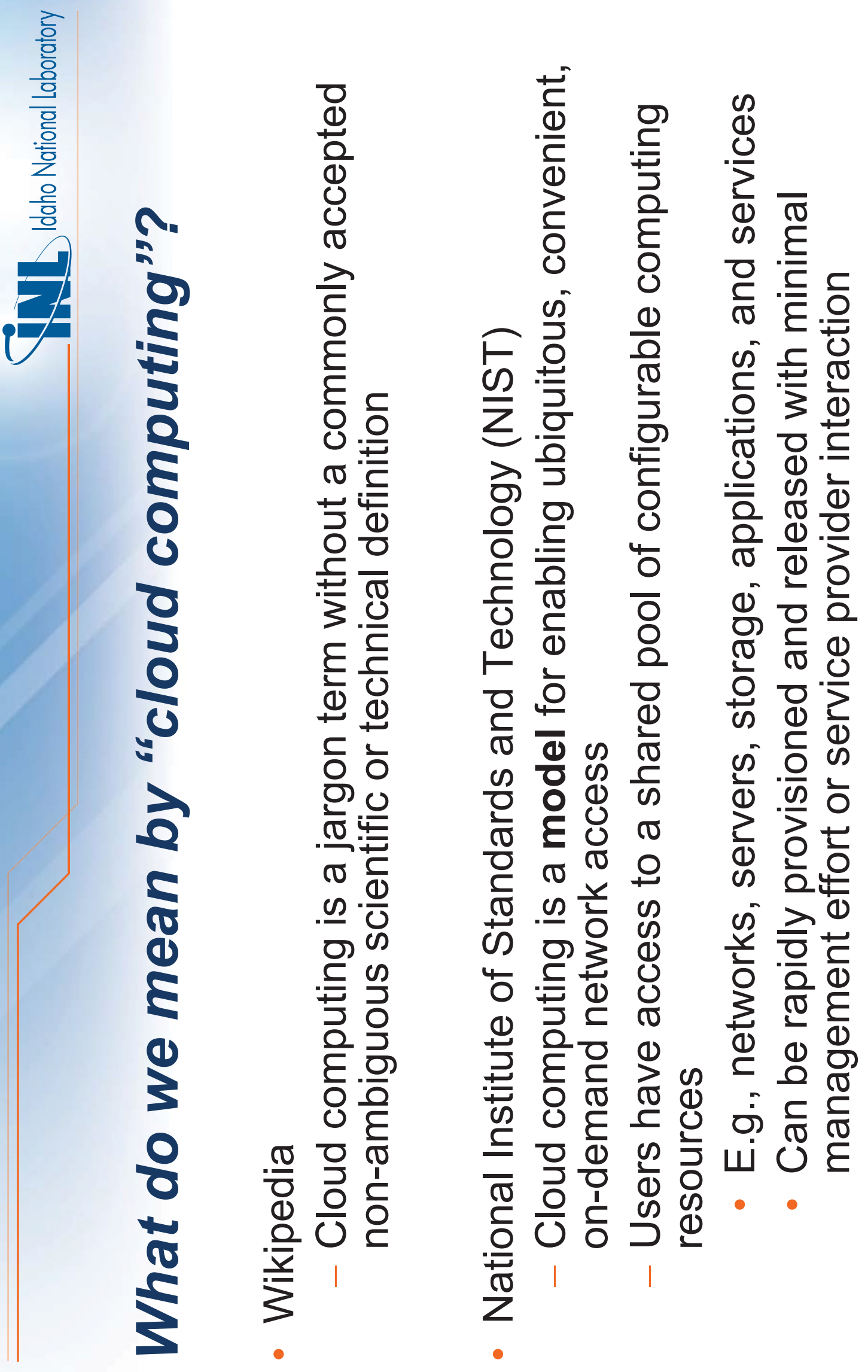




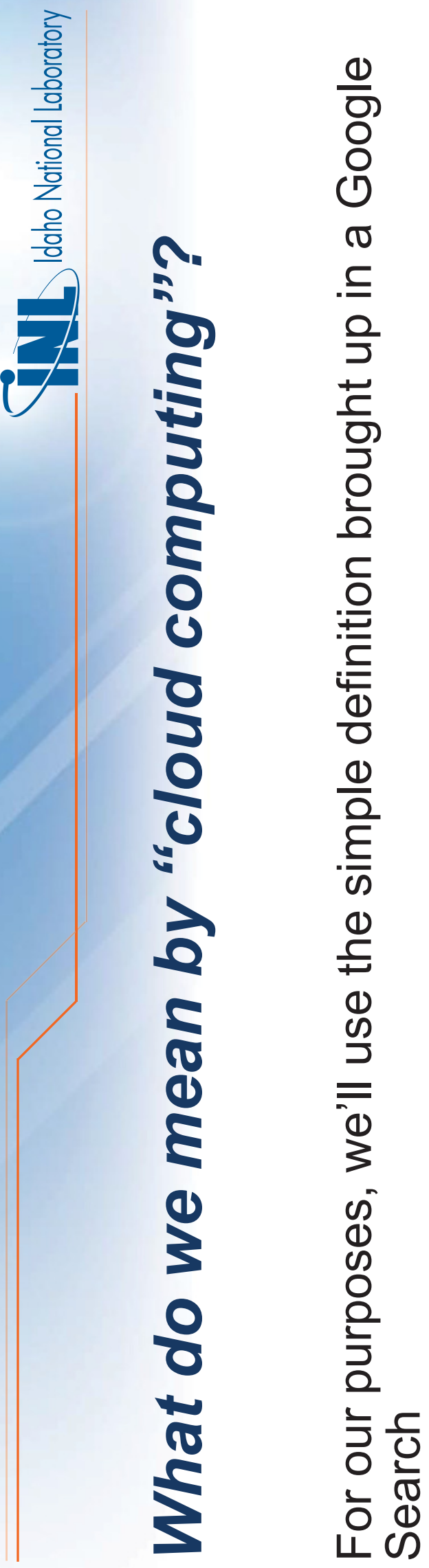

$\frac{\mathrm{d}}{\mathrm{g}}$

을

a

튼

트

롤

듬

미

$\frac{9}{0}$

을

ต

$\sum \pi$

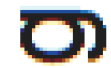

$\frac{5}{5}$

of 으

㟧

을 들

폰

告

는 혼

팜

孪

(T)

क

을

응

$U$

a 므

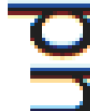

夏

0
0 


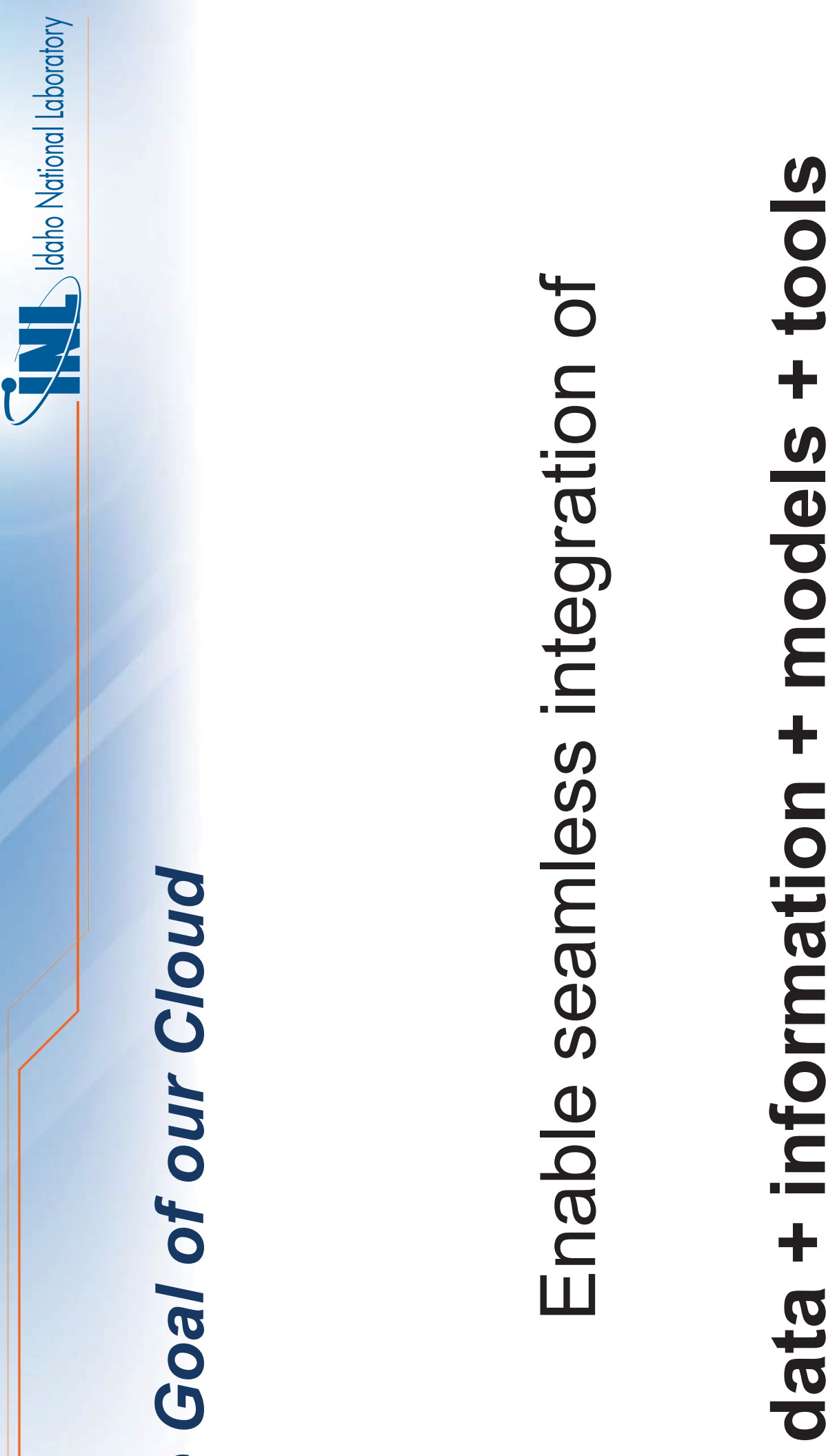

()

$E$ 

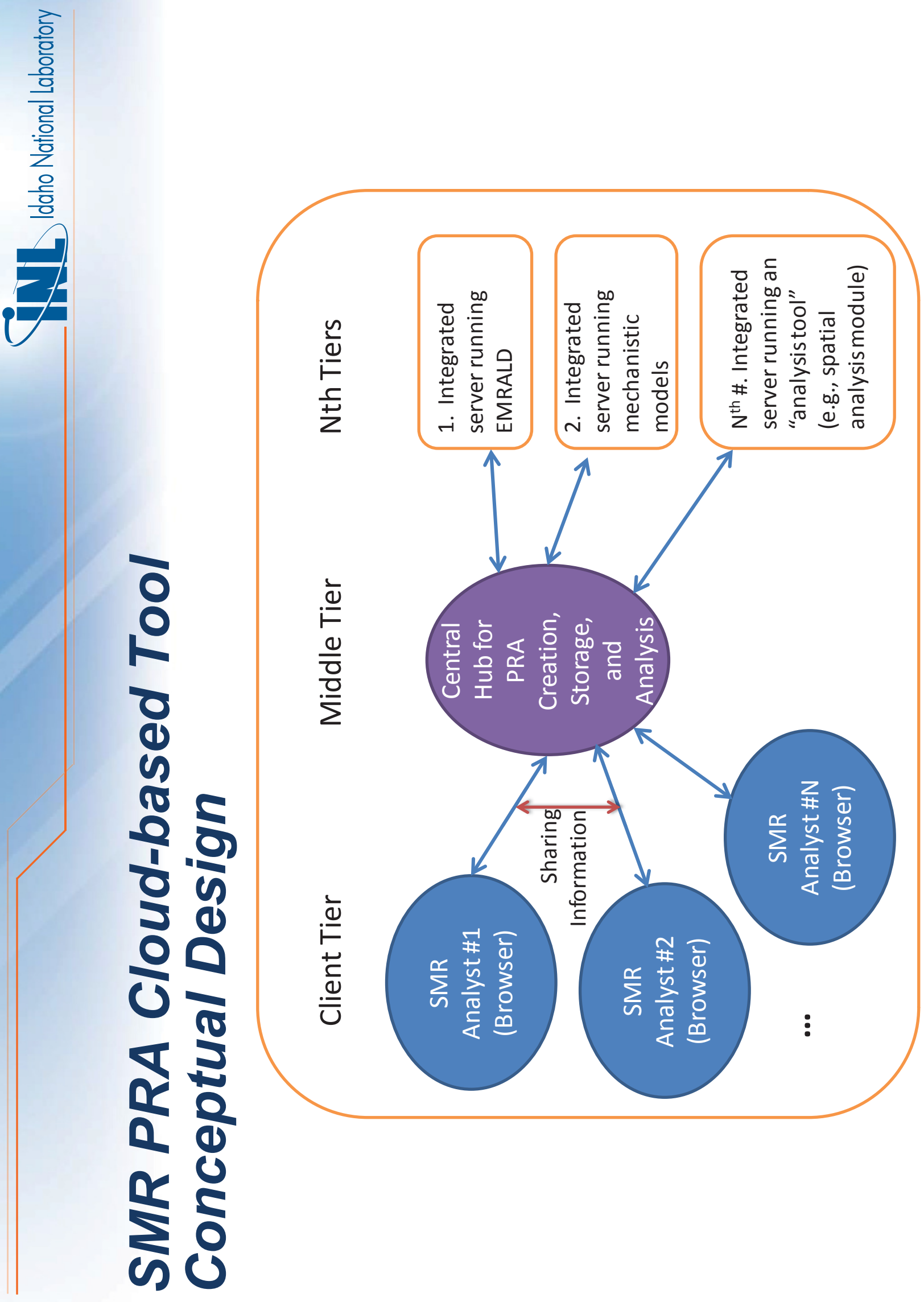

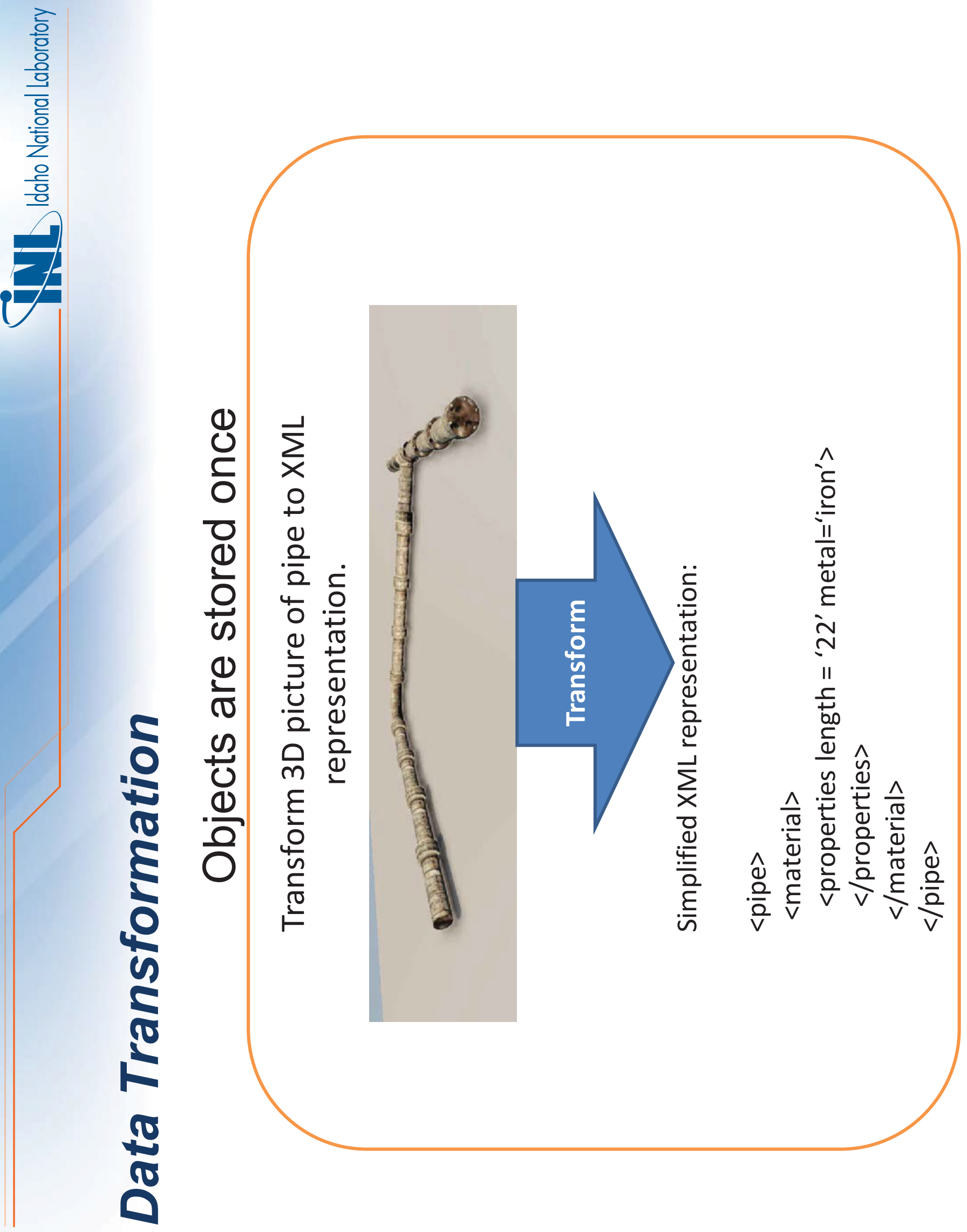

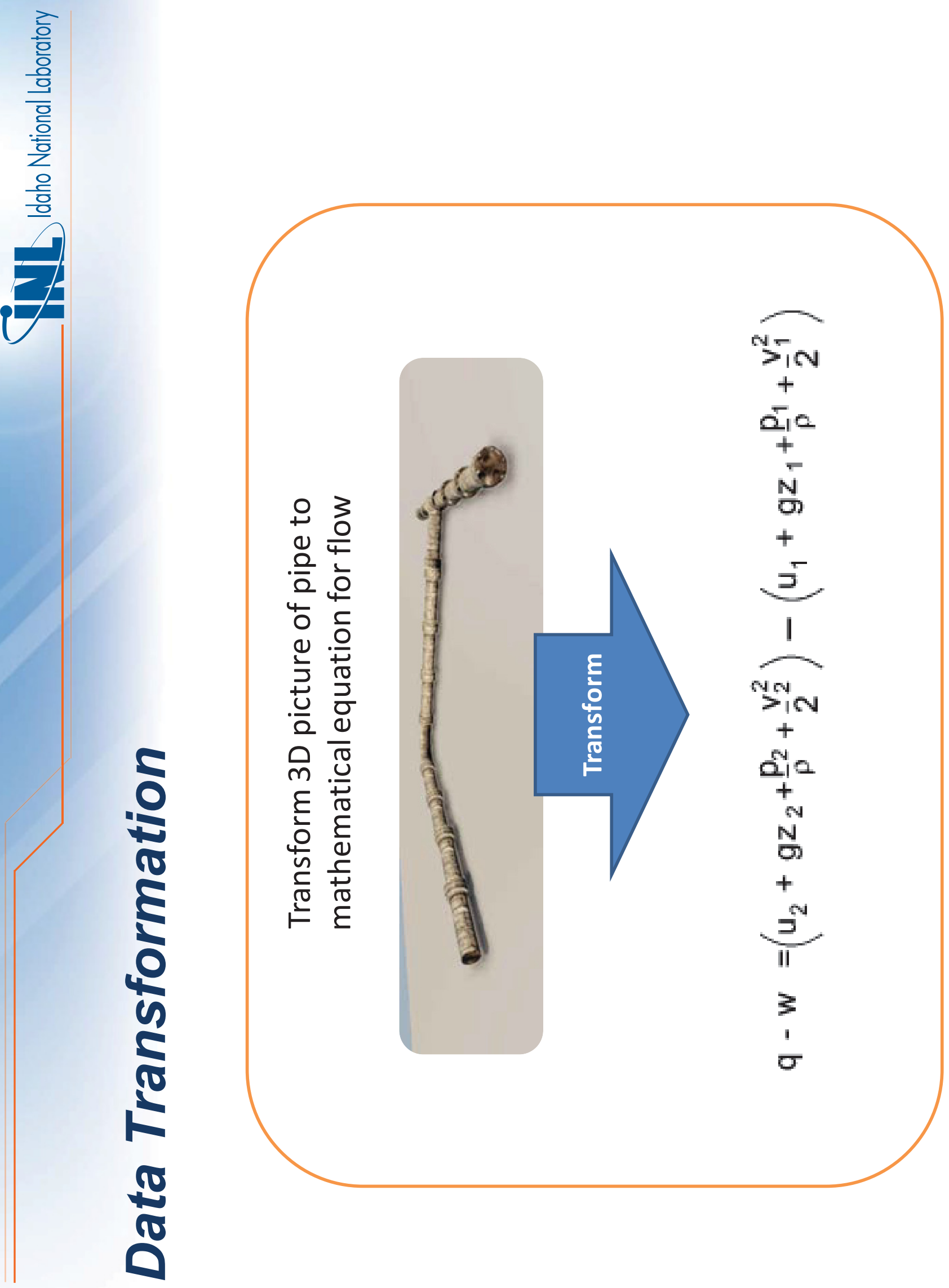

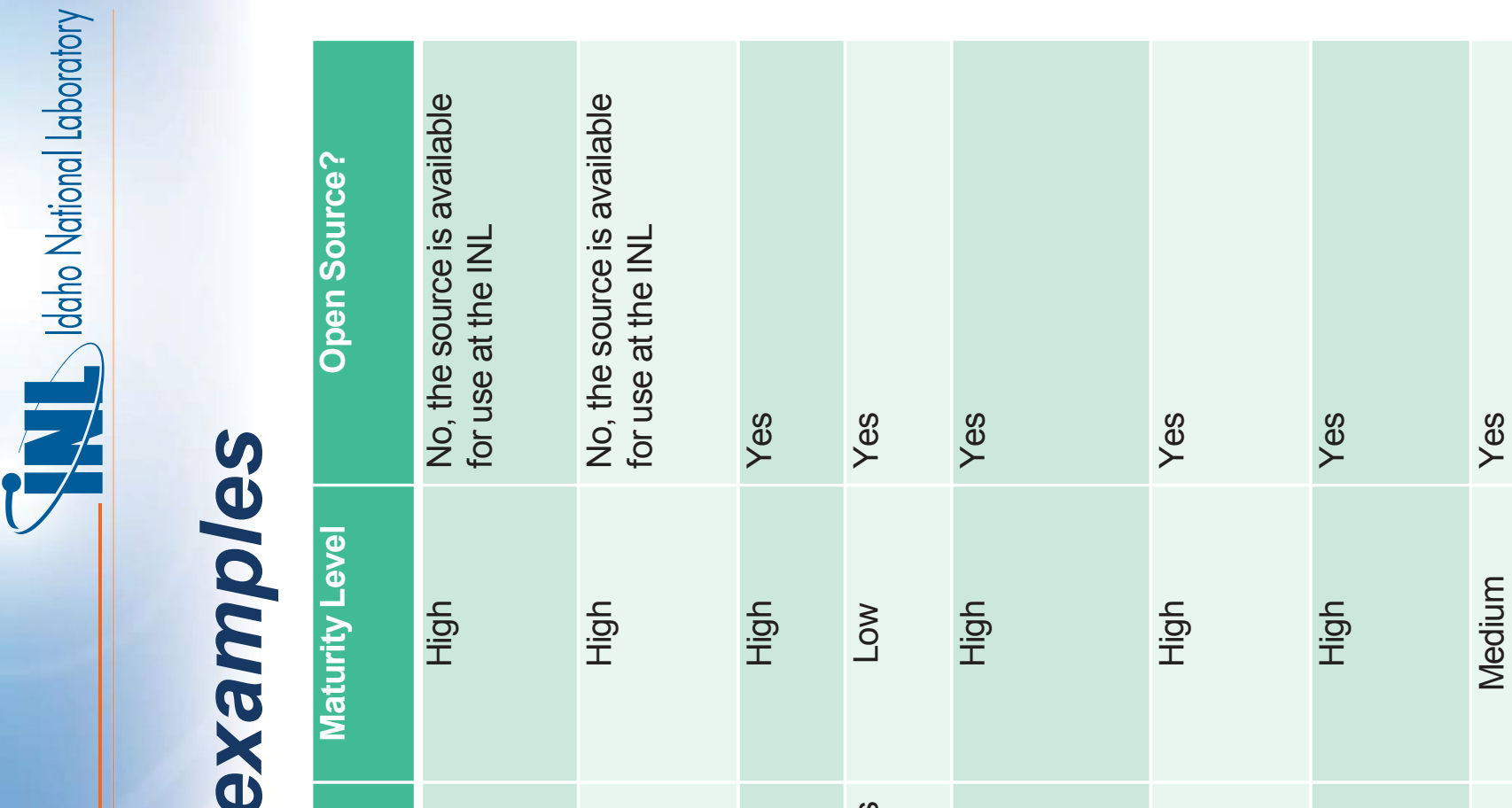

愛

高 言 畐

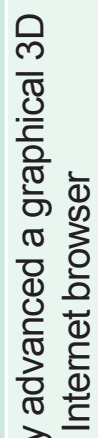
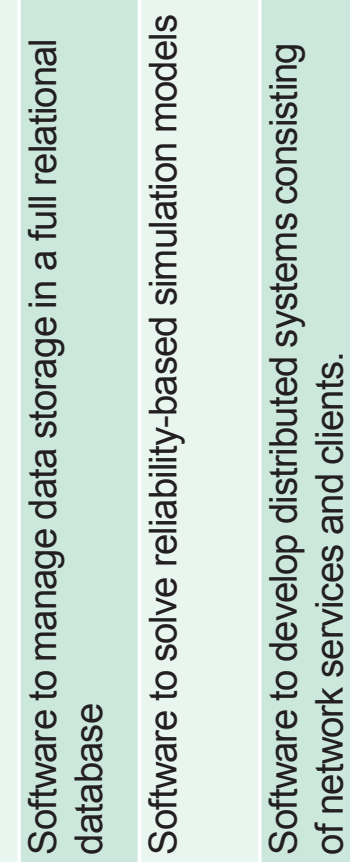

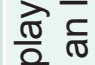

음.

흥 든

के

लि

항

은

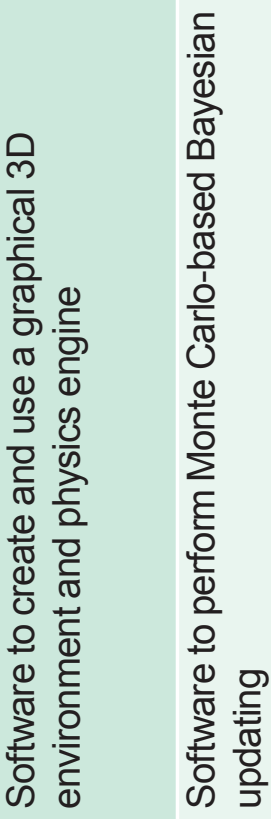

1
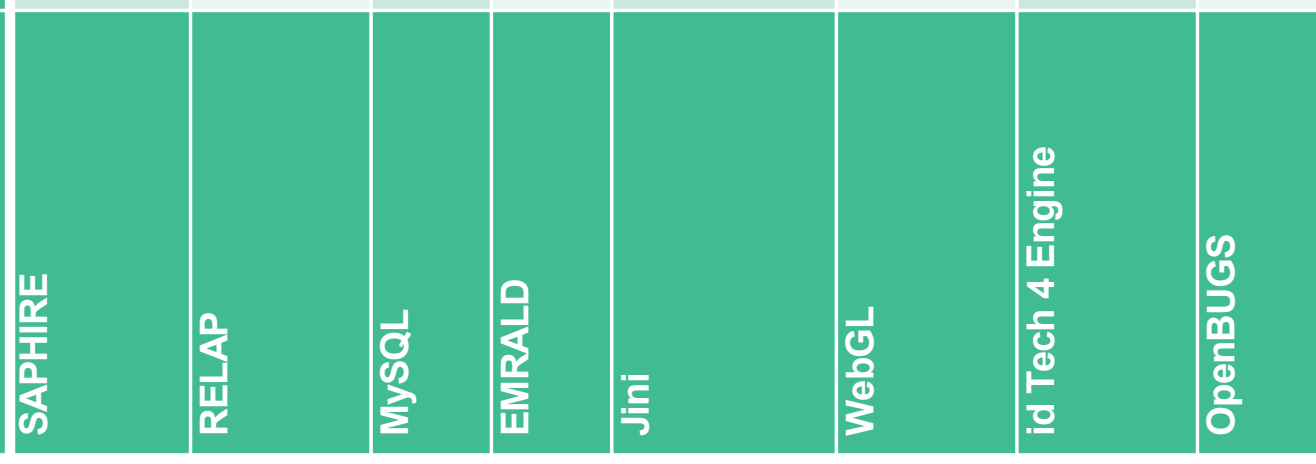

12 


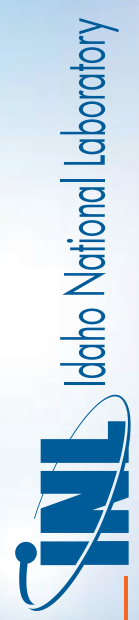

N

(1)

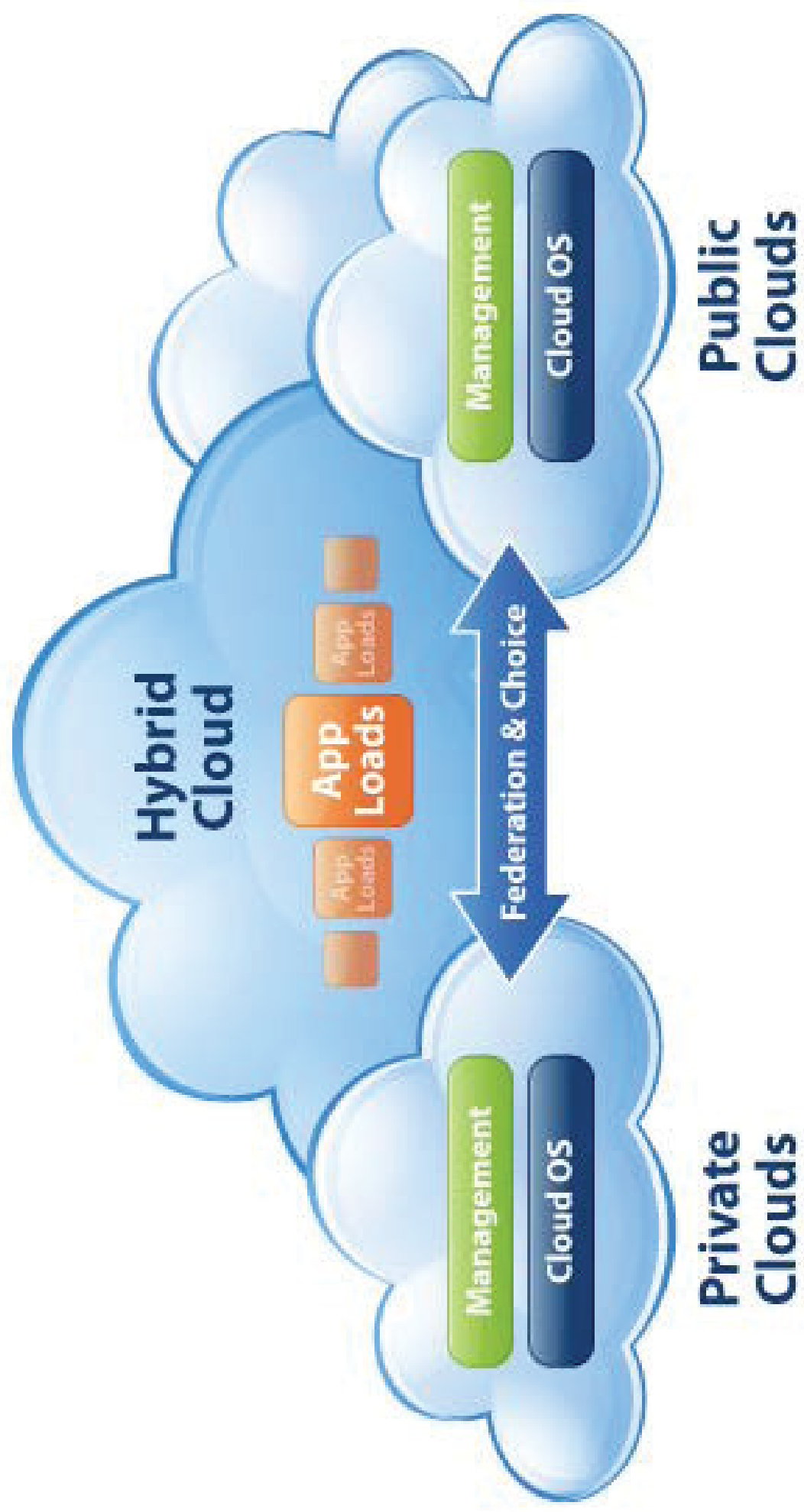



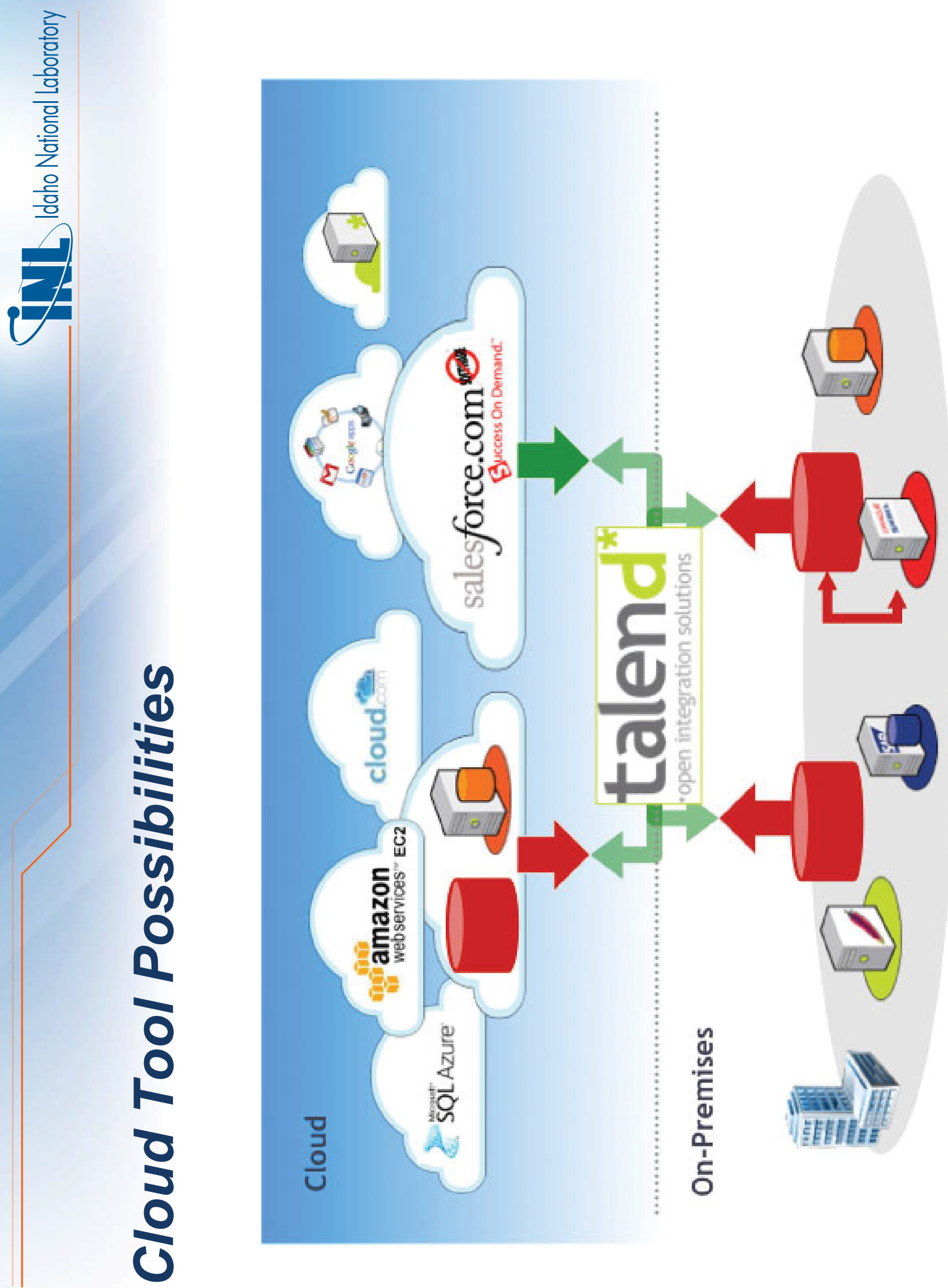

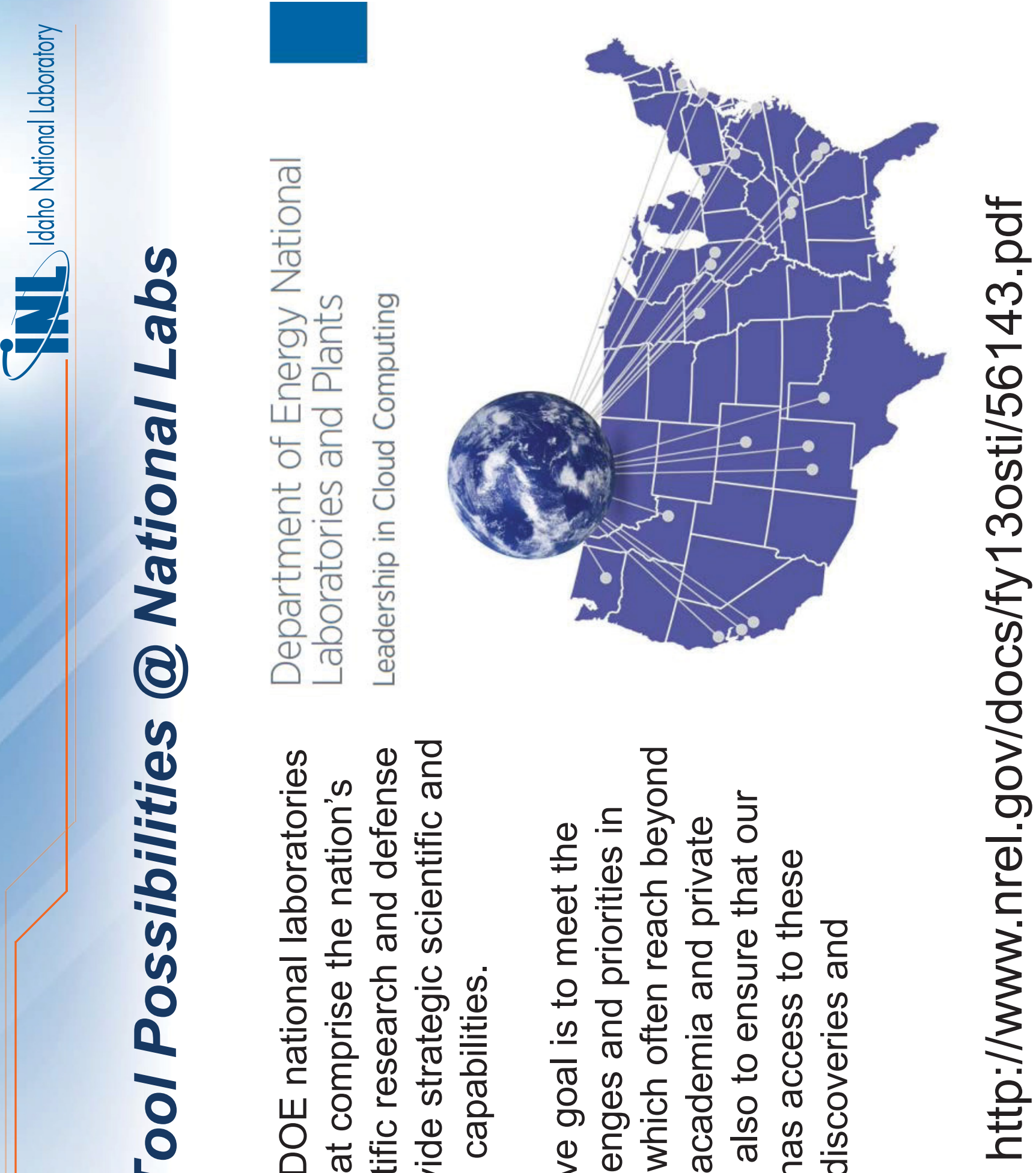

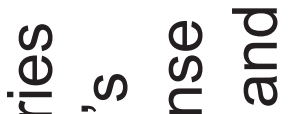

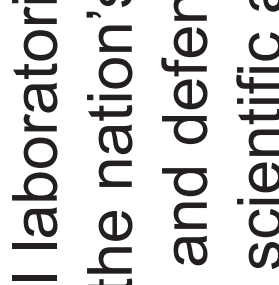

히

으 은 잉

Q

흘 ڤ

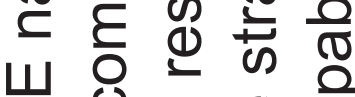

은 은

1

$\frac{9}{0}$

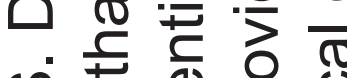

c

㐫

$\supset$ 舟

స $\frac{\overline{0}}{2} \frac{\mathscr{N}}{\mathrm{C}}$ 응

ه 흉

F त远 के

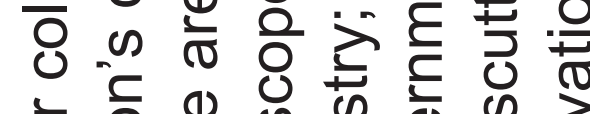

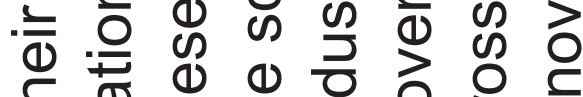

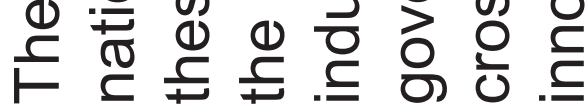



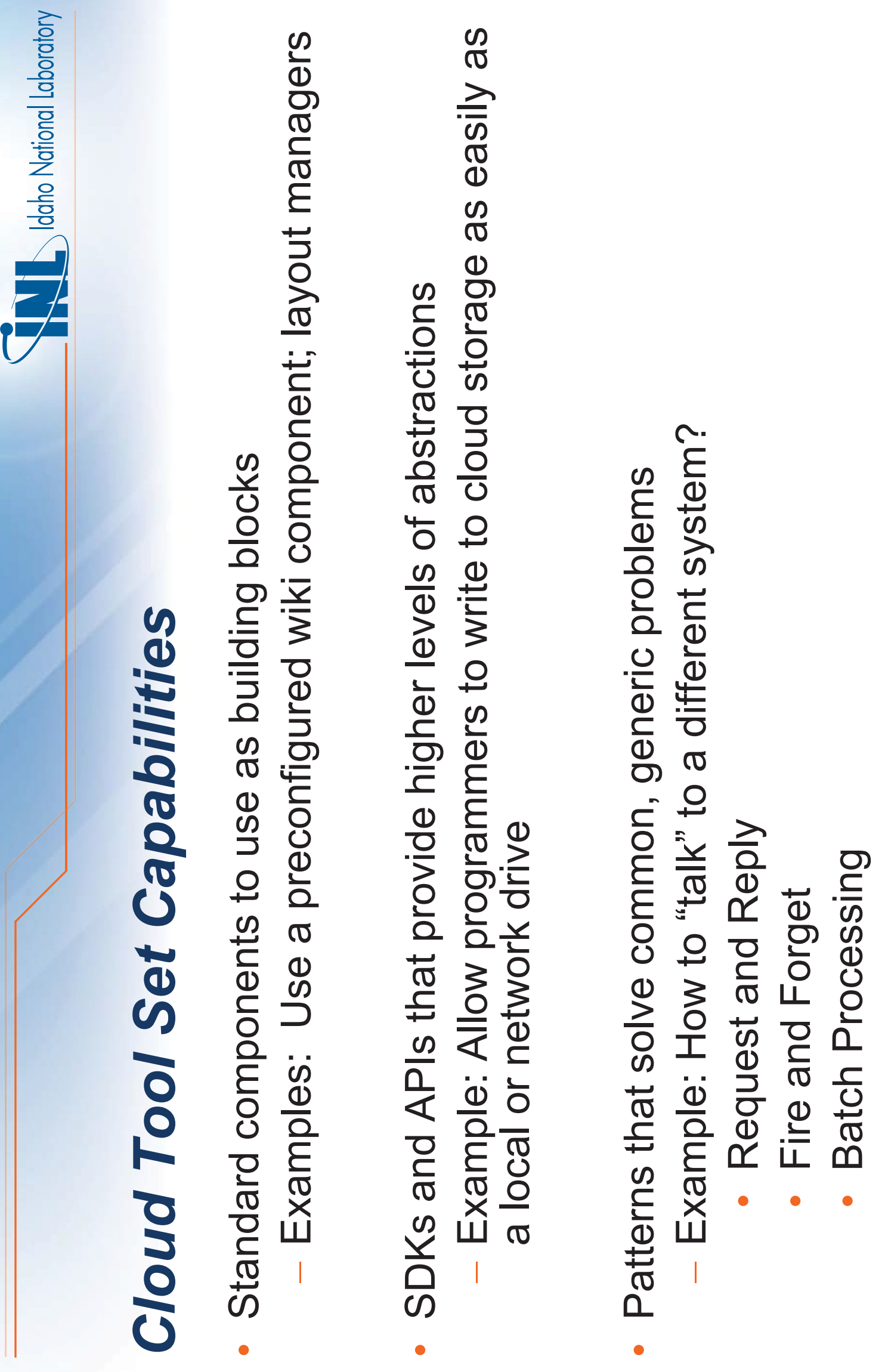


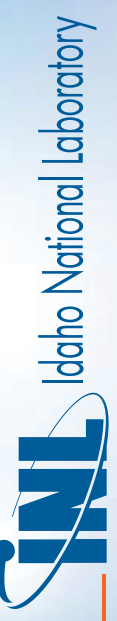

$2 \frac{0}{1}$

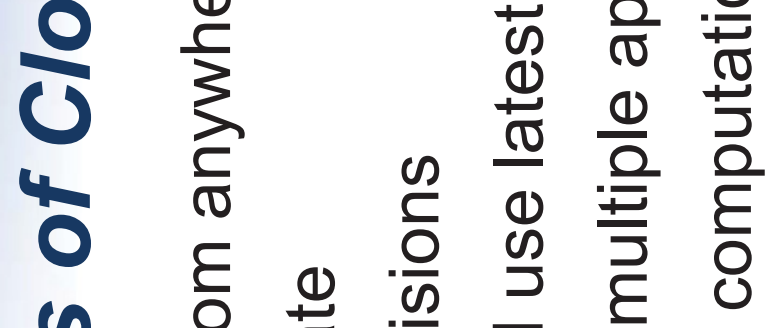

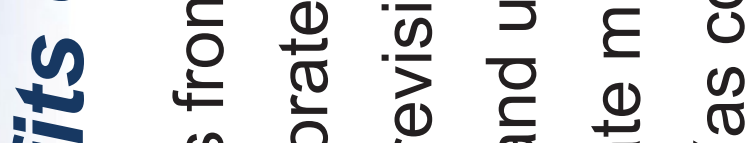

4 क

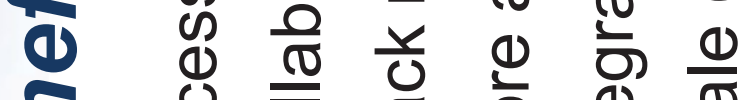

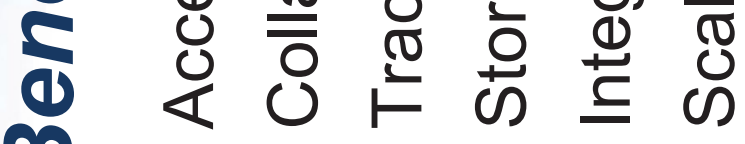

m 

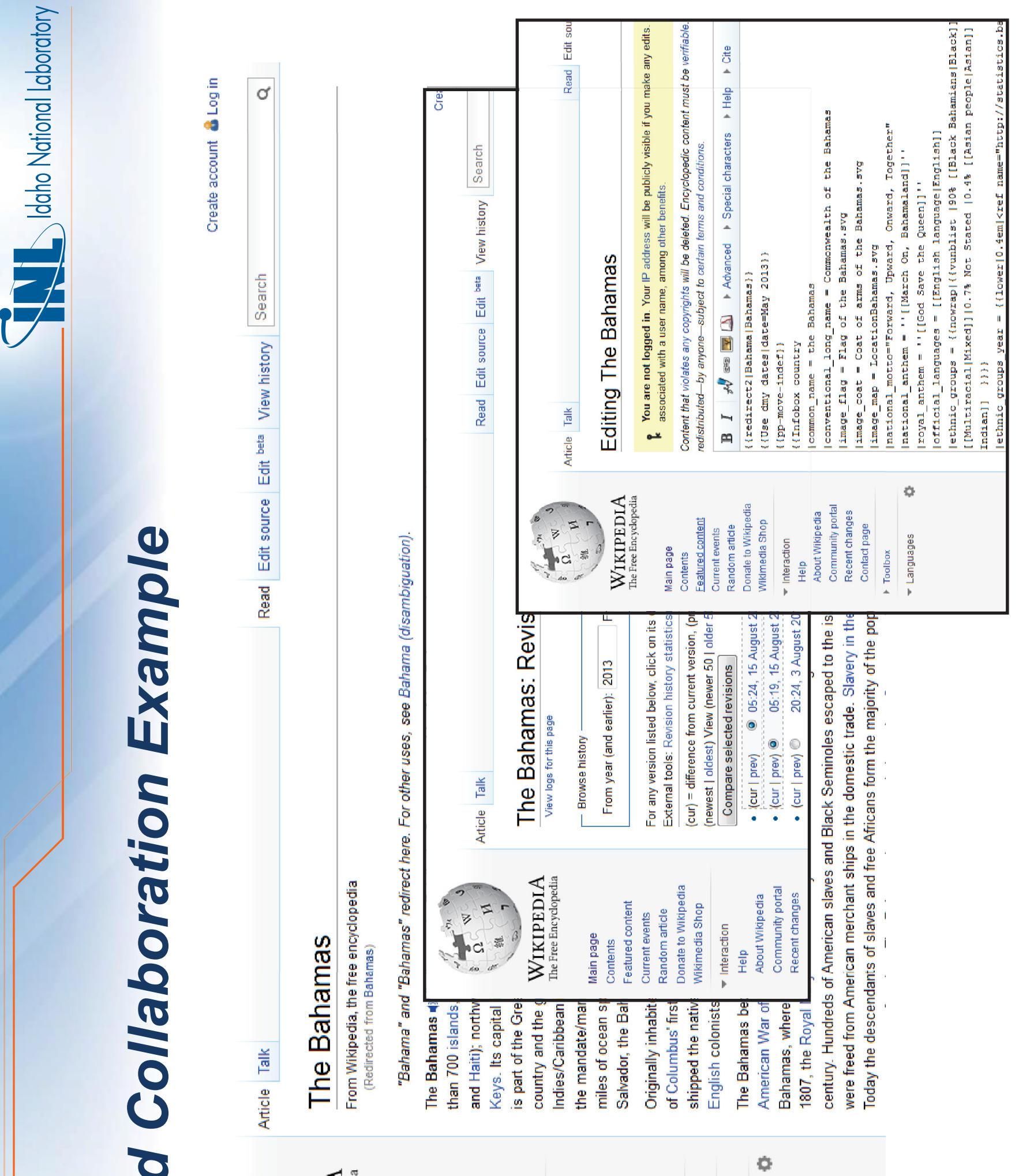

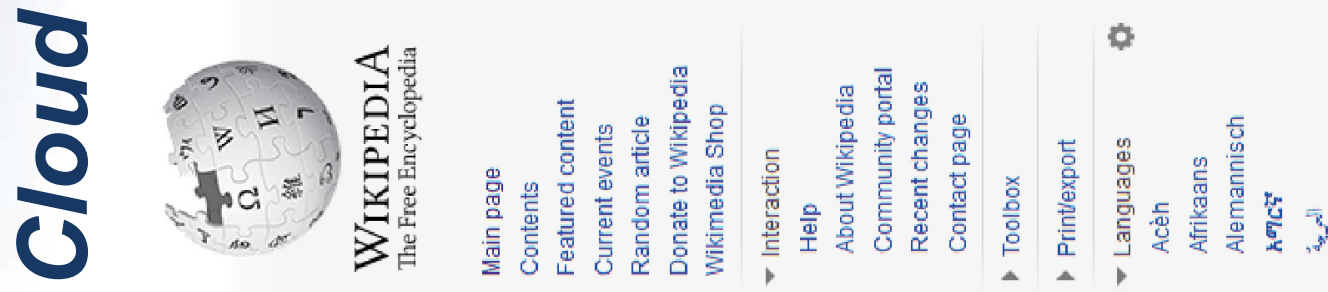



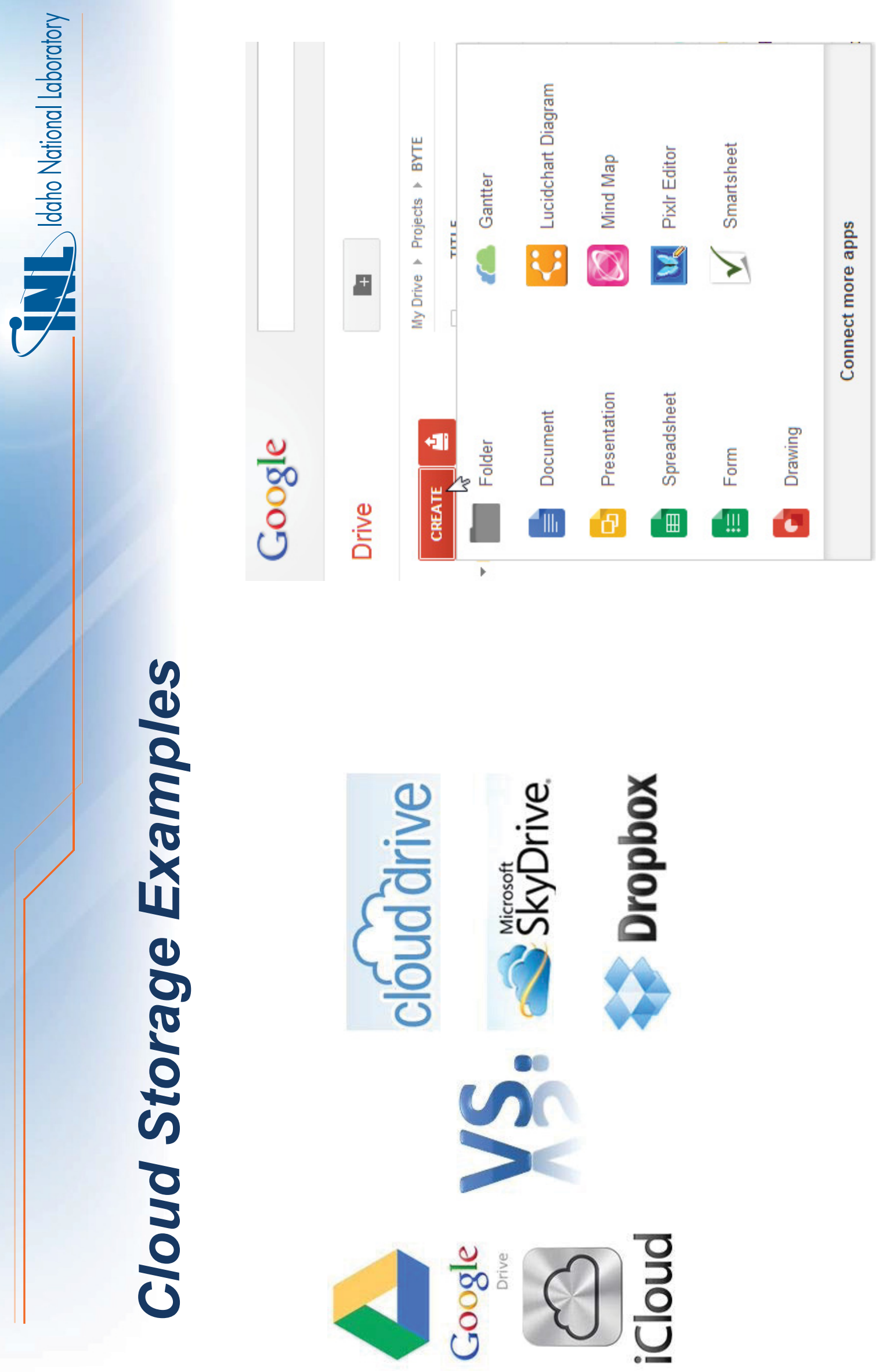

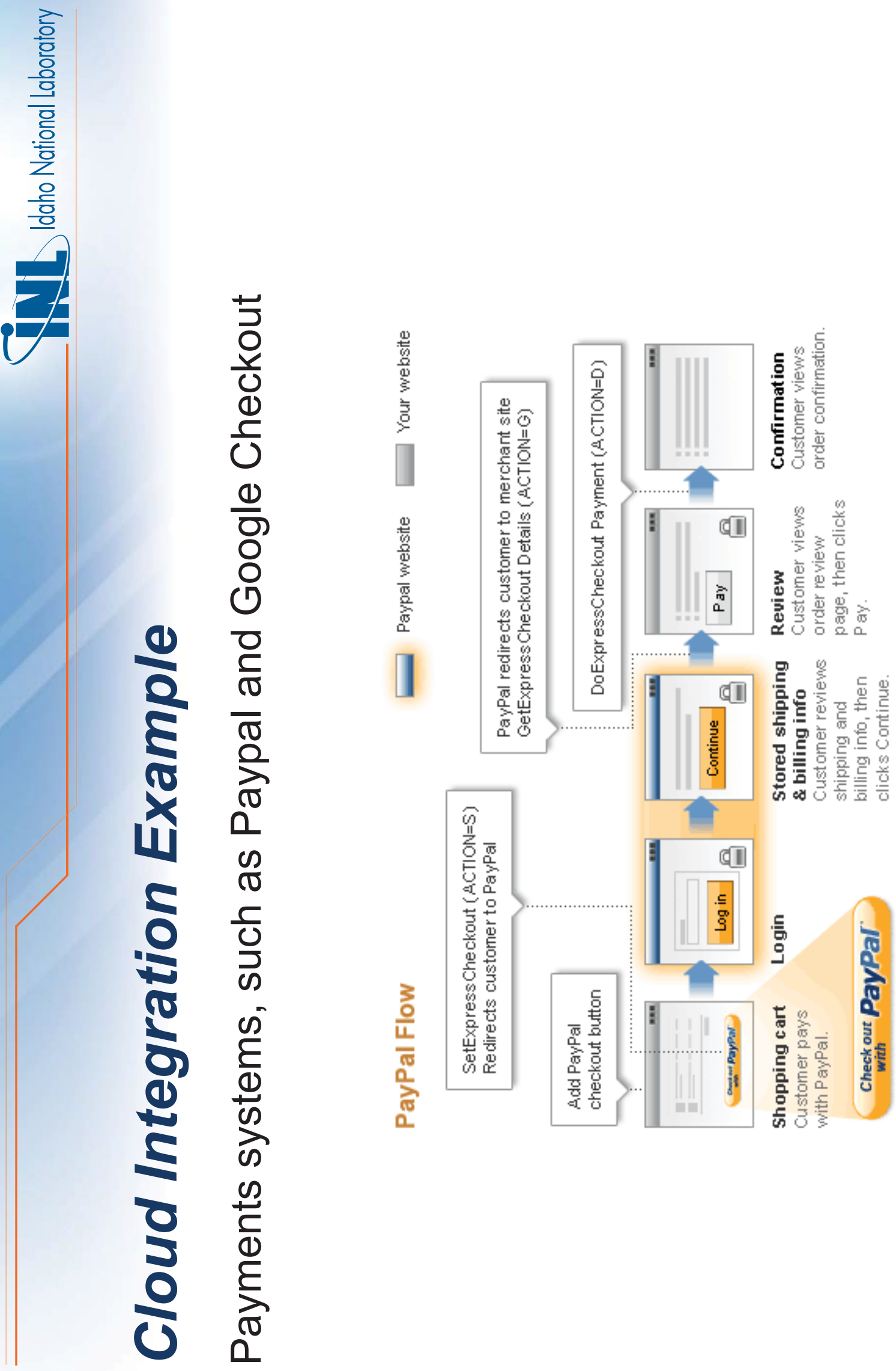

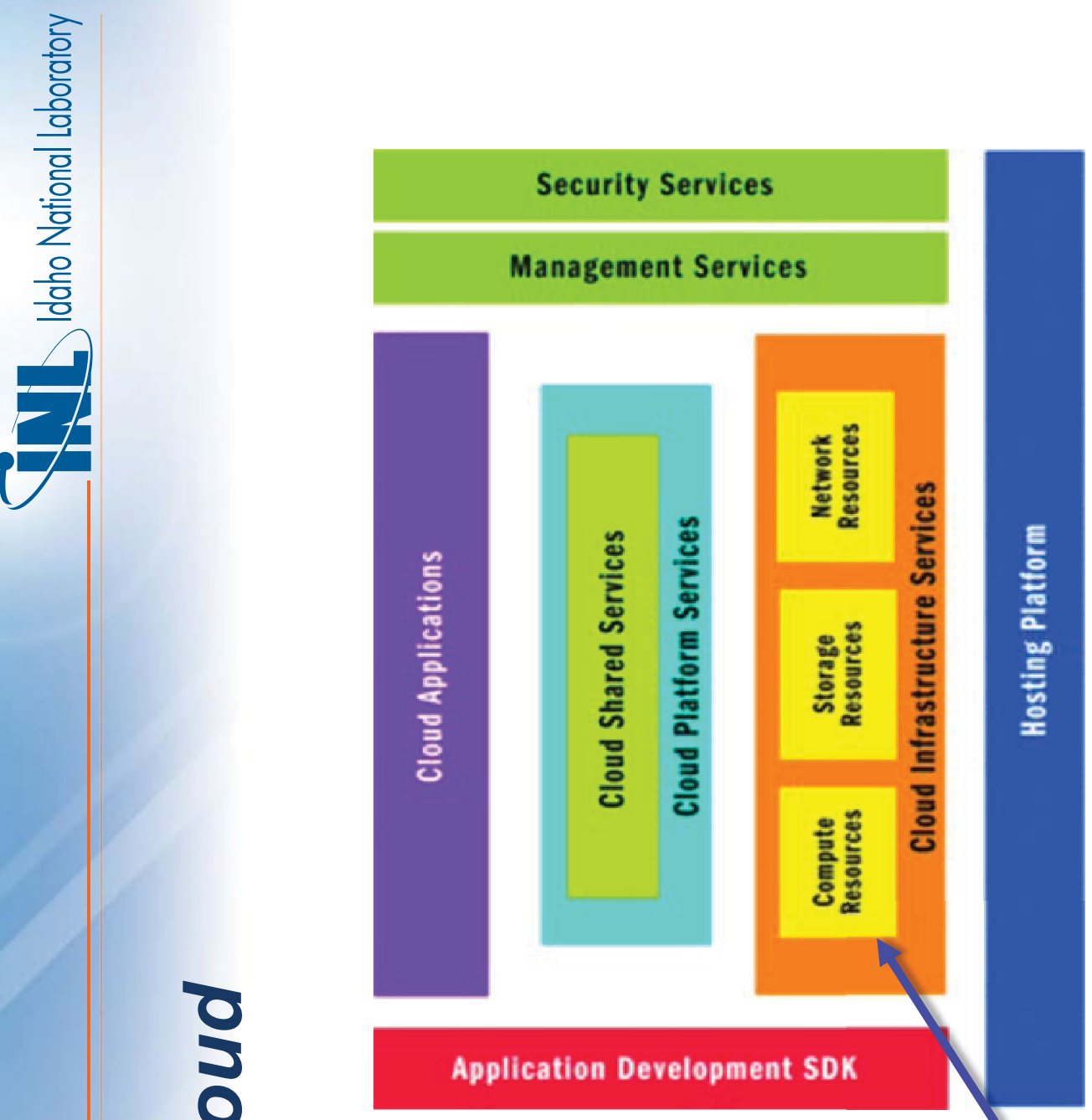

\section{Application Development SDK}

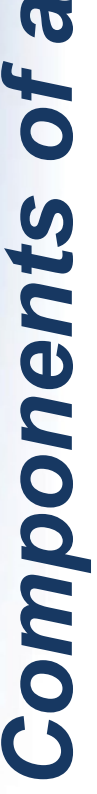



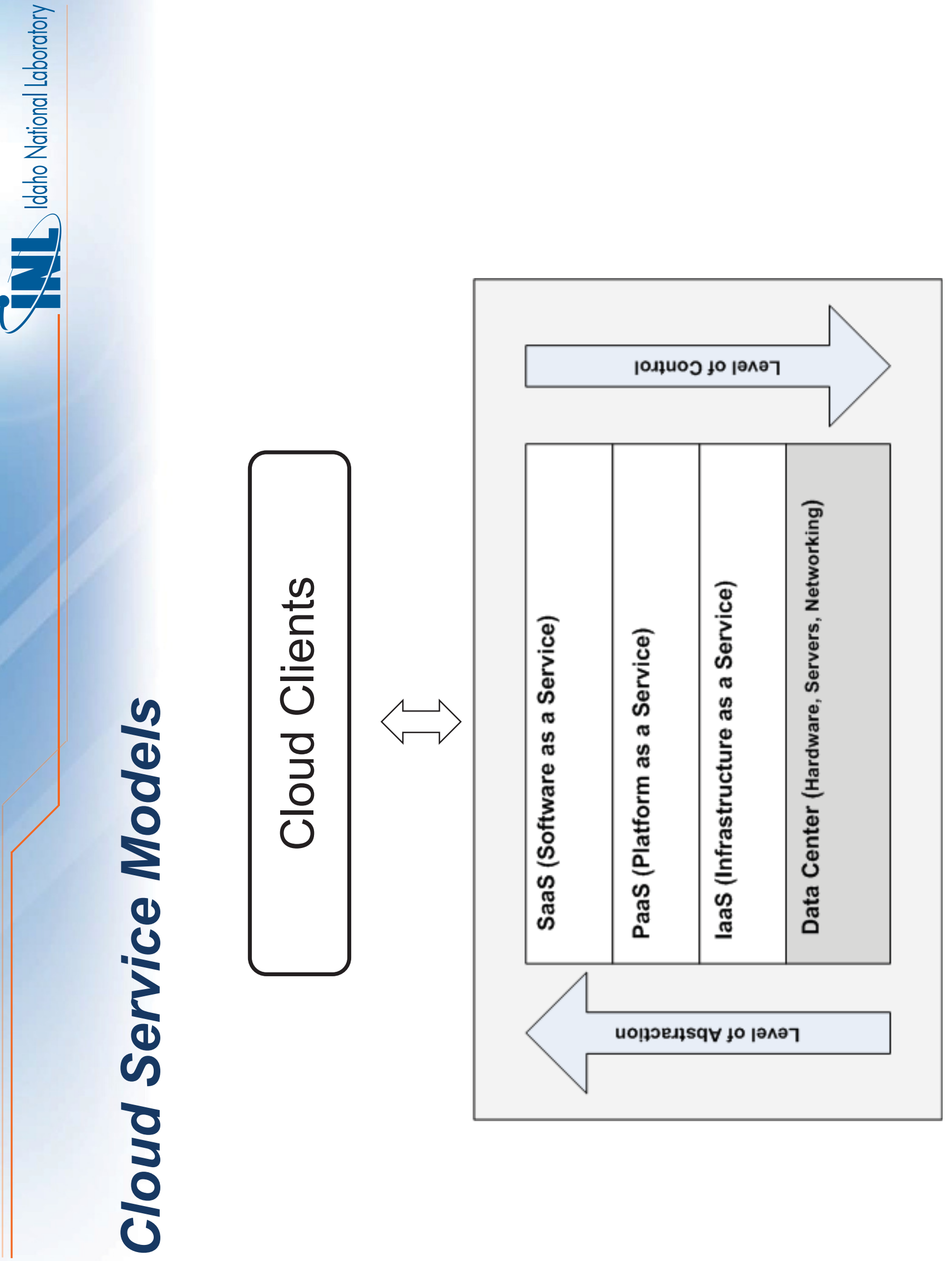


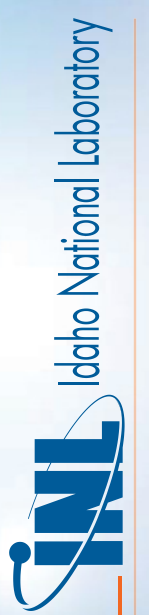

$\frac{\sigma}{0}$

1
0
0
0

단
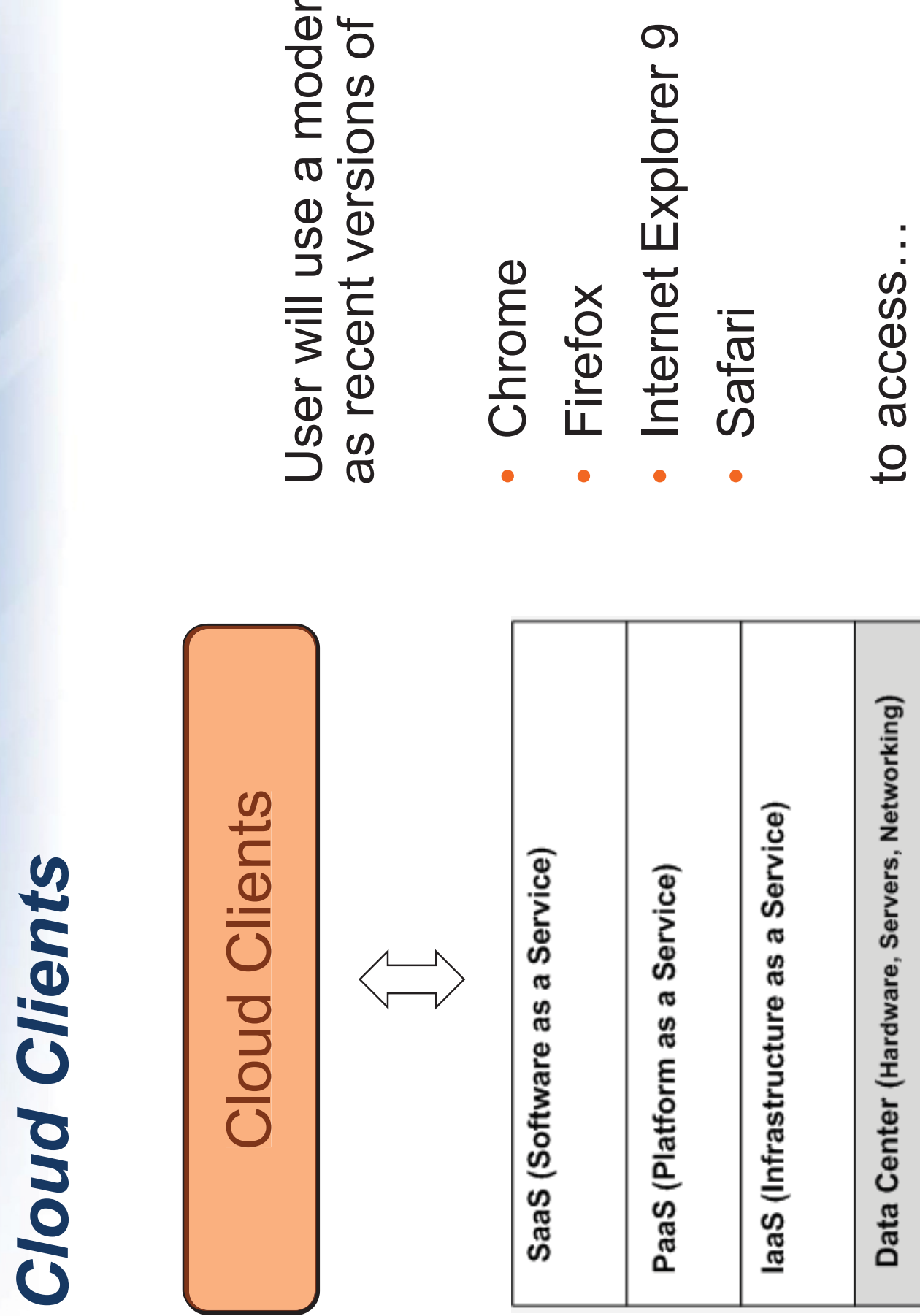

\begin{tabular}{|c|c|c|c|}
\hline 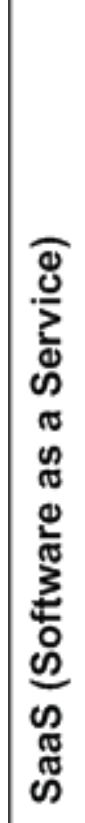 & 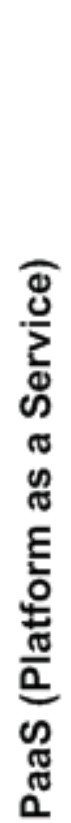 & 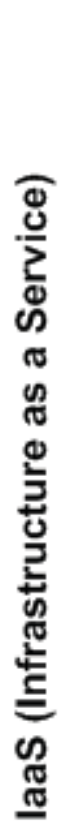 & 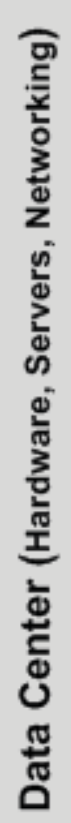 \\
\hline
\end{tabular}



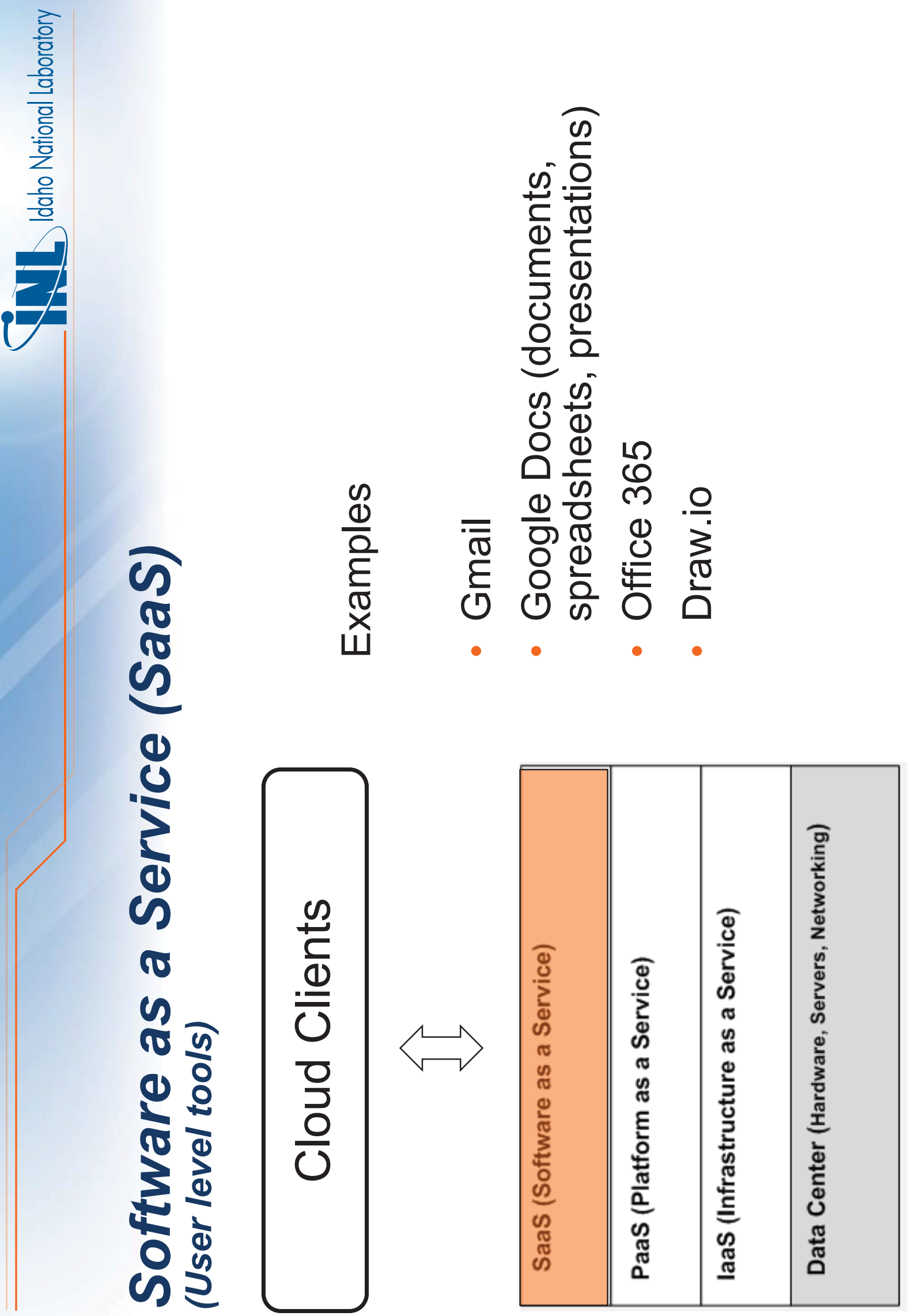

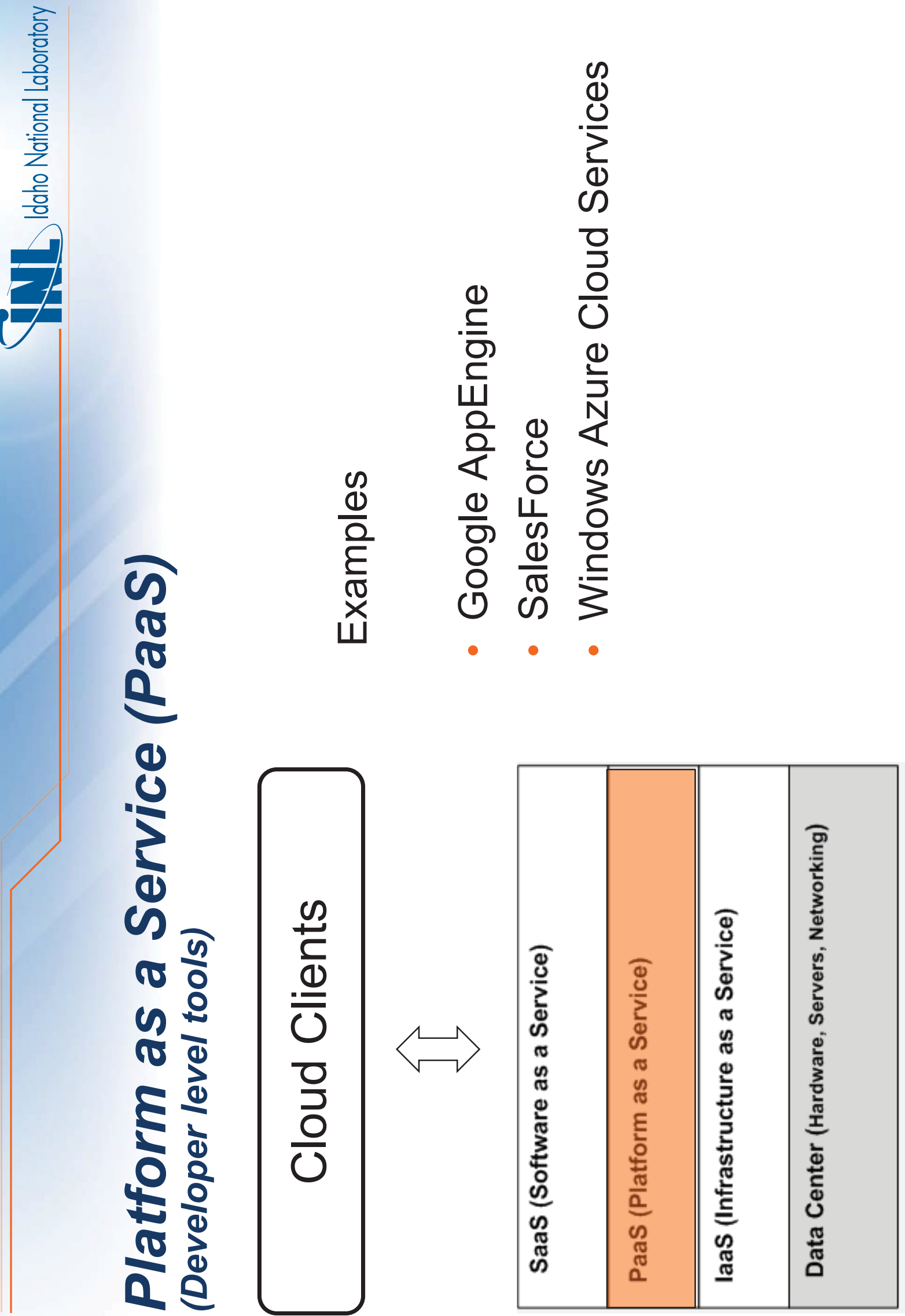

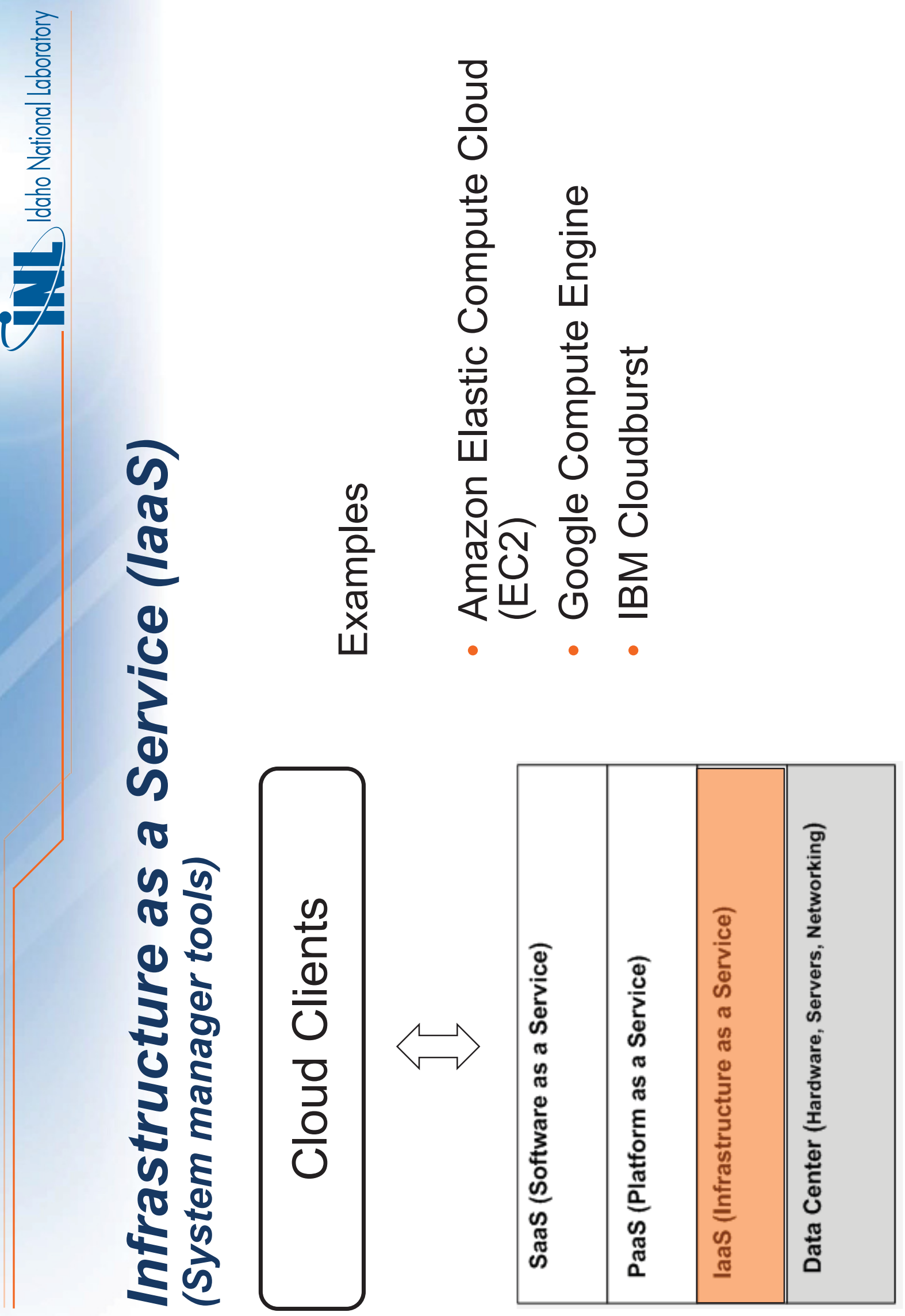

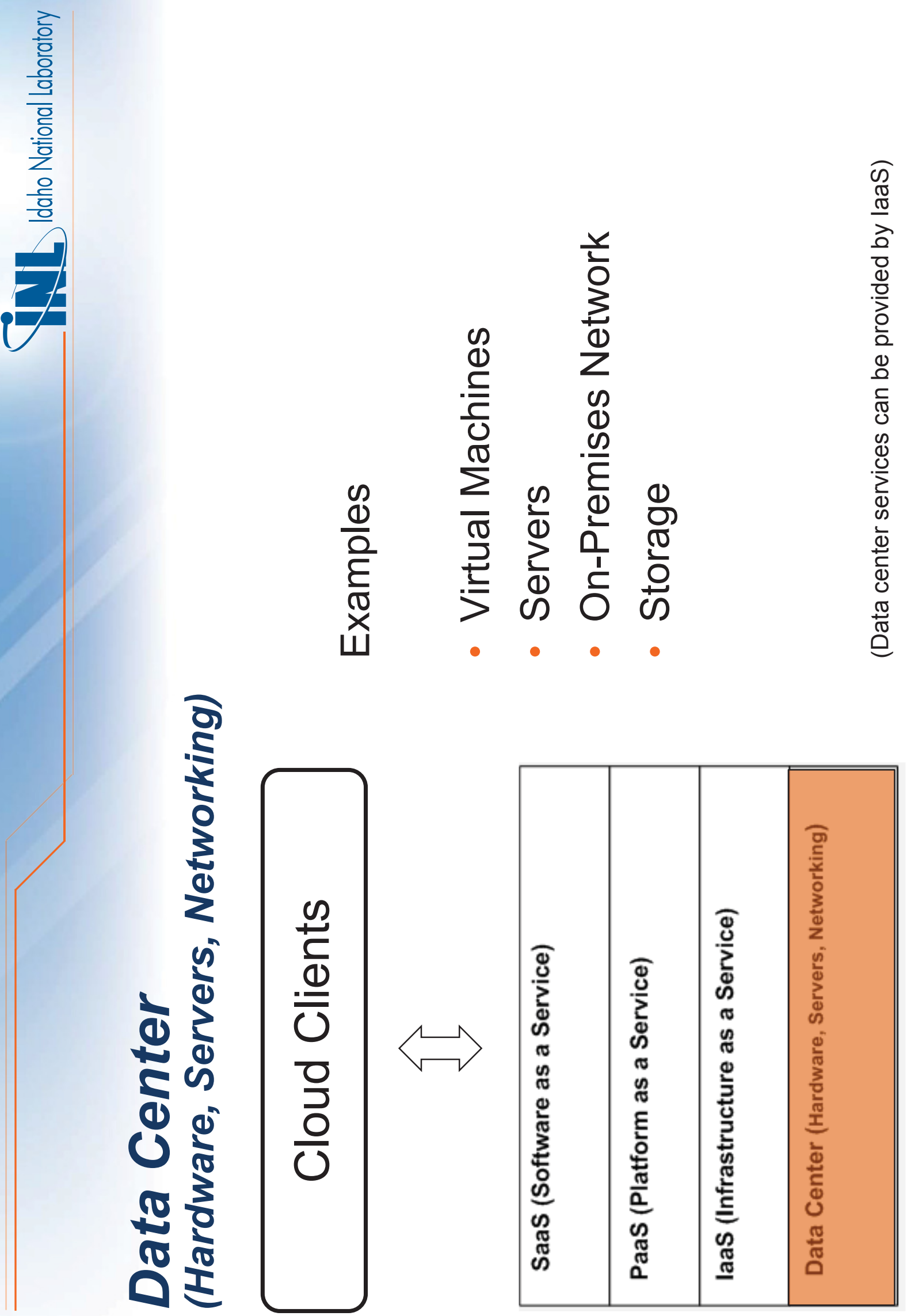


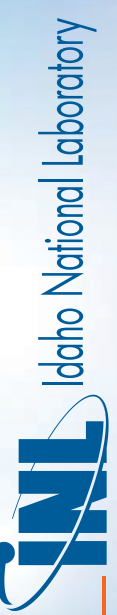

$\frac{\bar{\Xi}}{\bar{\sigma}}$

ह

(1)

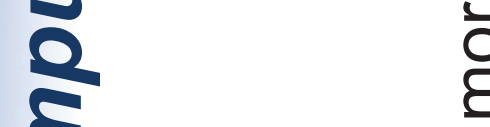

5

ن

$\varepsilon$

$0 \stackrel{0}{\circ}$

웅

0 ह ग

U ज

4 过

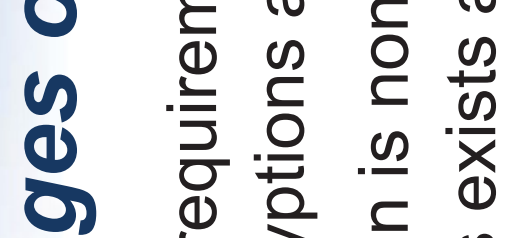

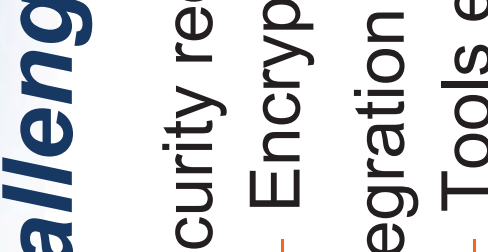

\&

을

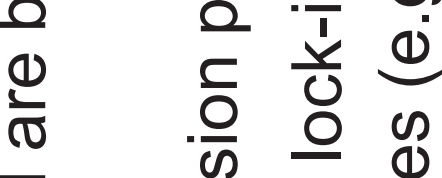

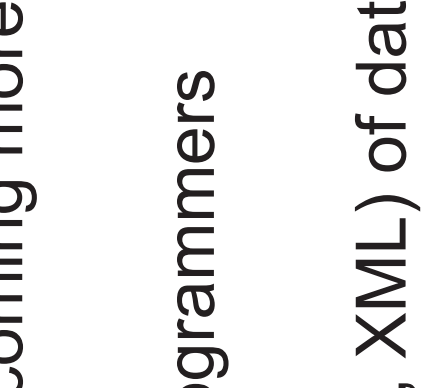

1) 은 둥

O क ज

4)

(1) 는

2 을 응

는 은 는

잏ㅇㅇ 잉

동 요

| 
드 으 응

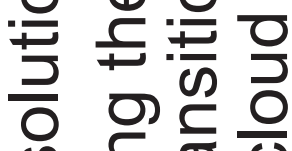

¿ क क

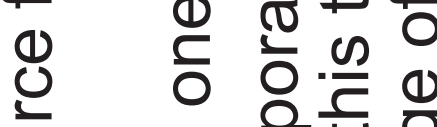

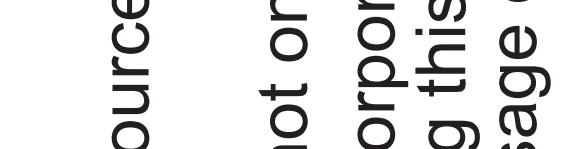

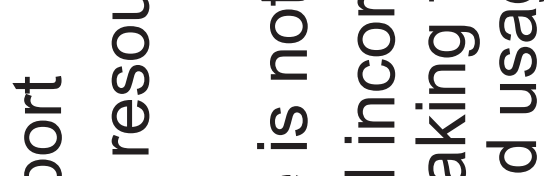

Q

ब1

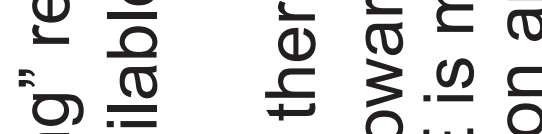

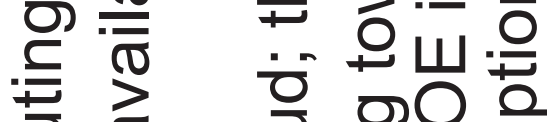

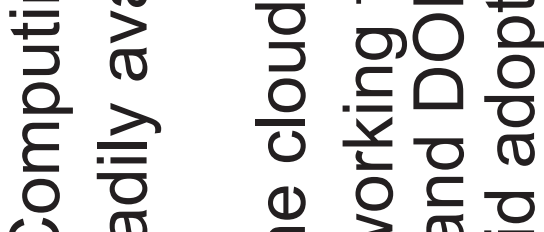

৩

음

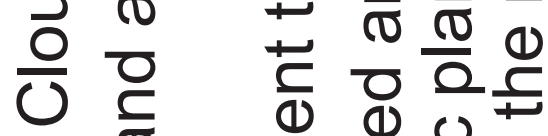

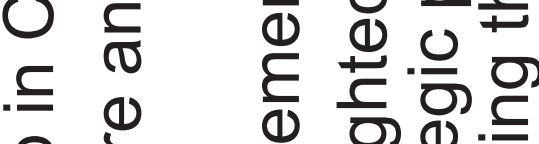

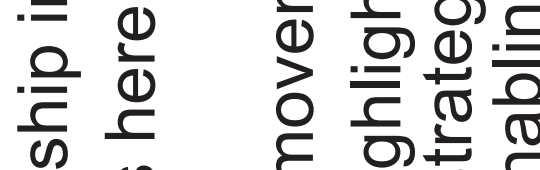

क.

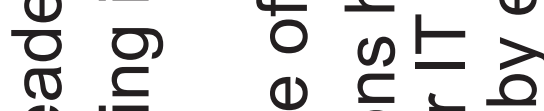

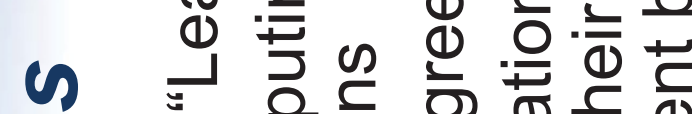

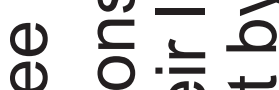

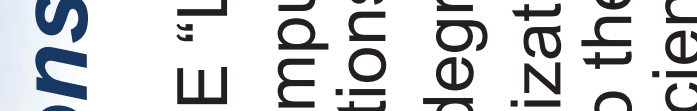

잉

ต

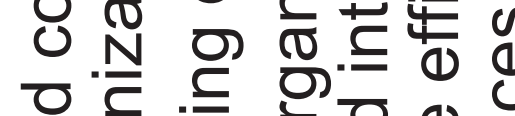

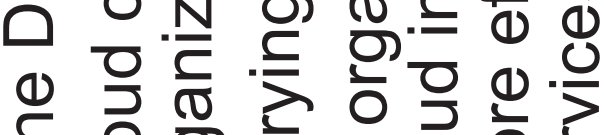

U

농

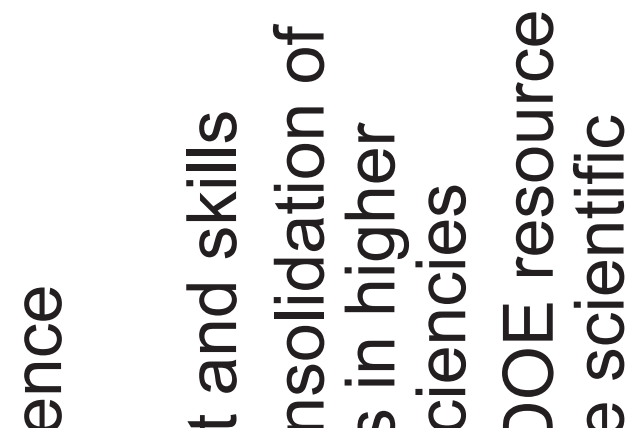

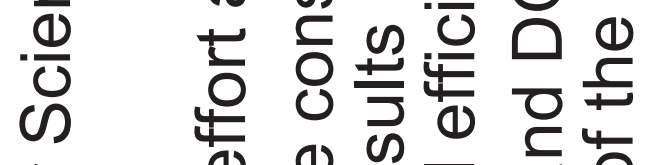

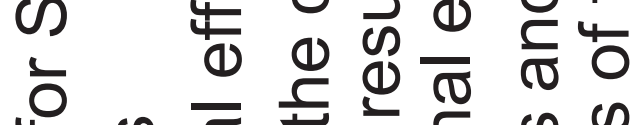

क $\frac{0}{\sigma}$

인

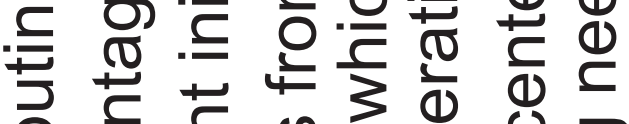

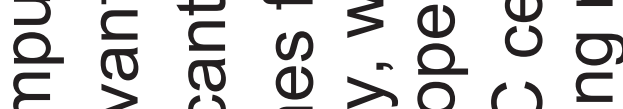

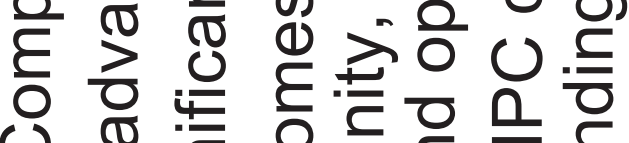

ঠ

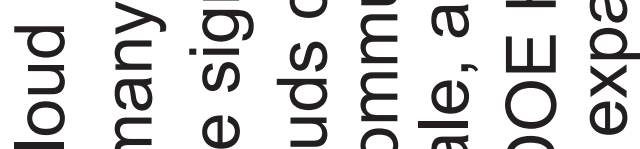

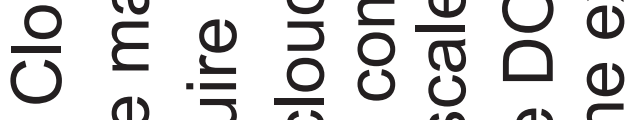

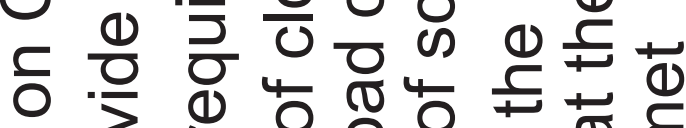

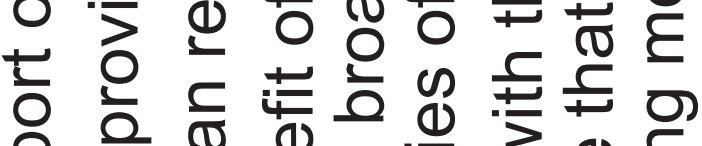

ब

워

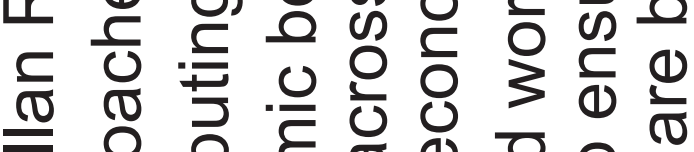

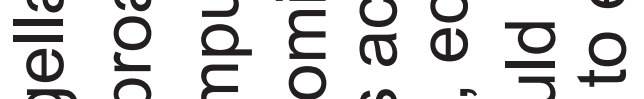

응 응응

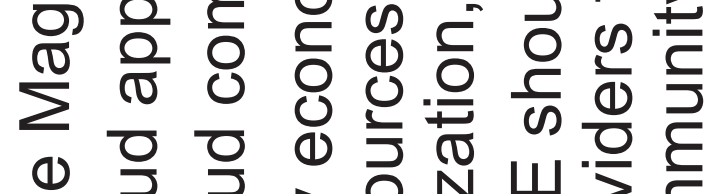

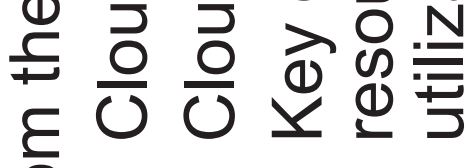

山

; 


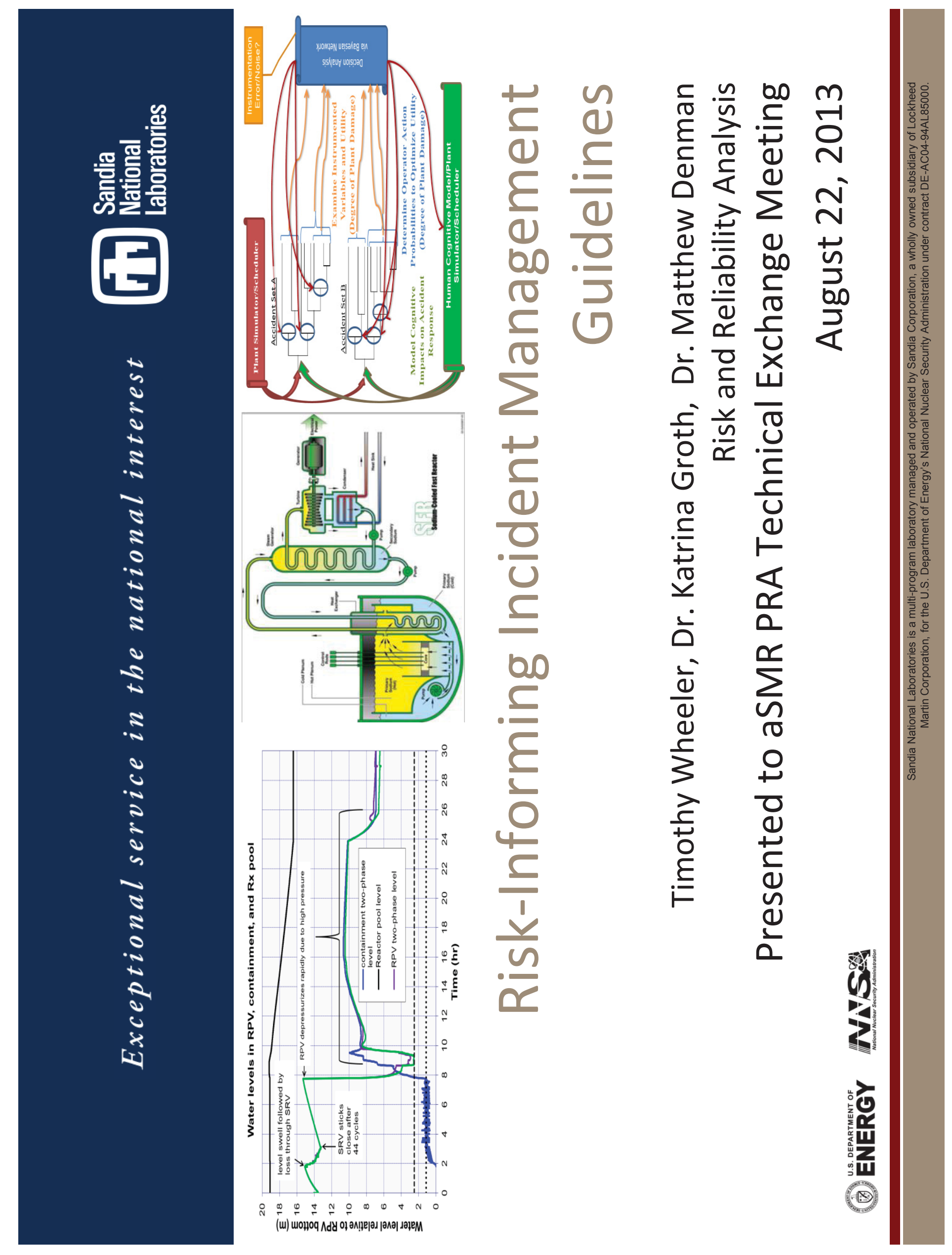



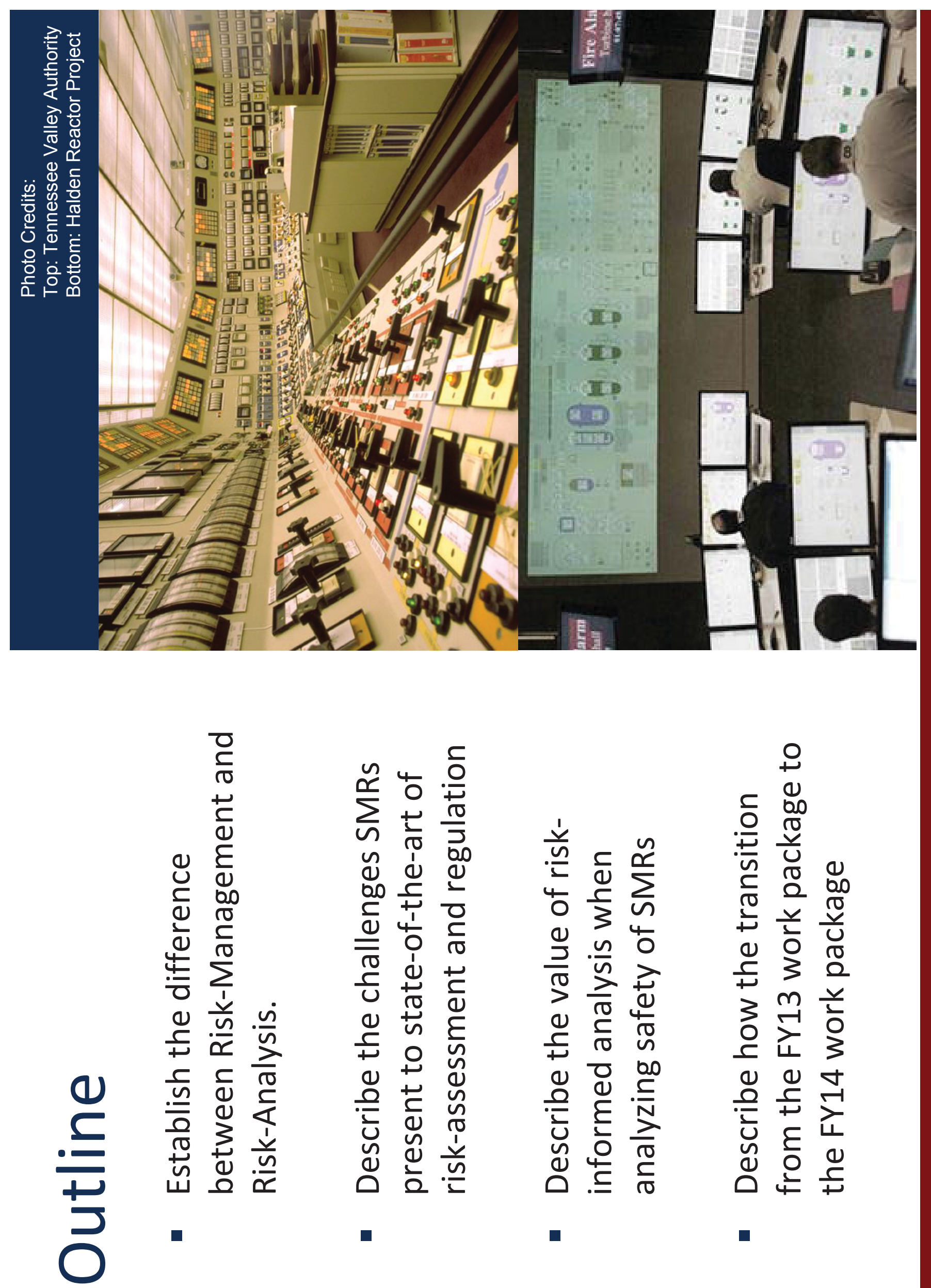


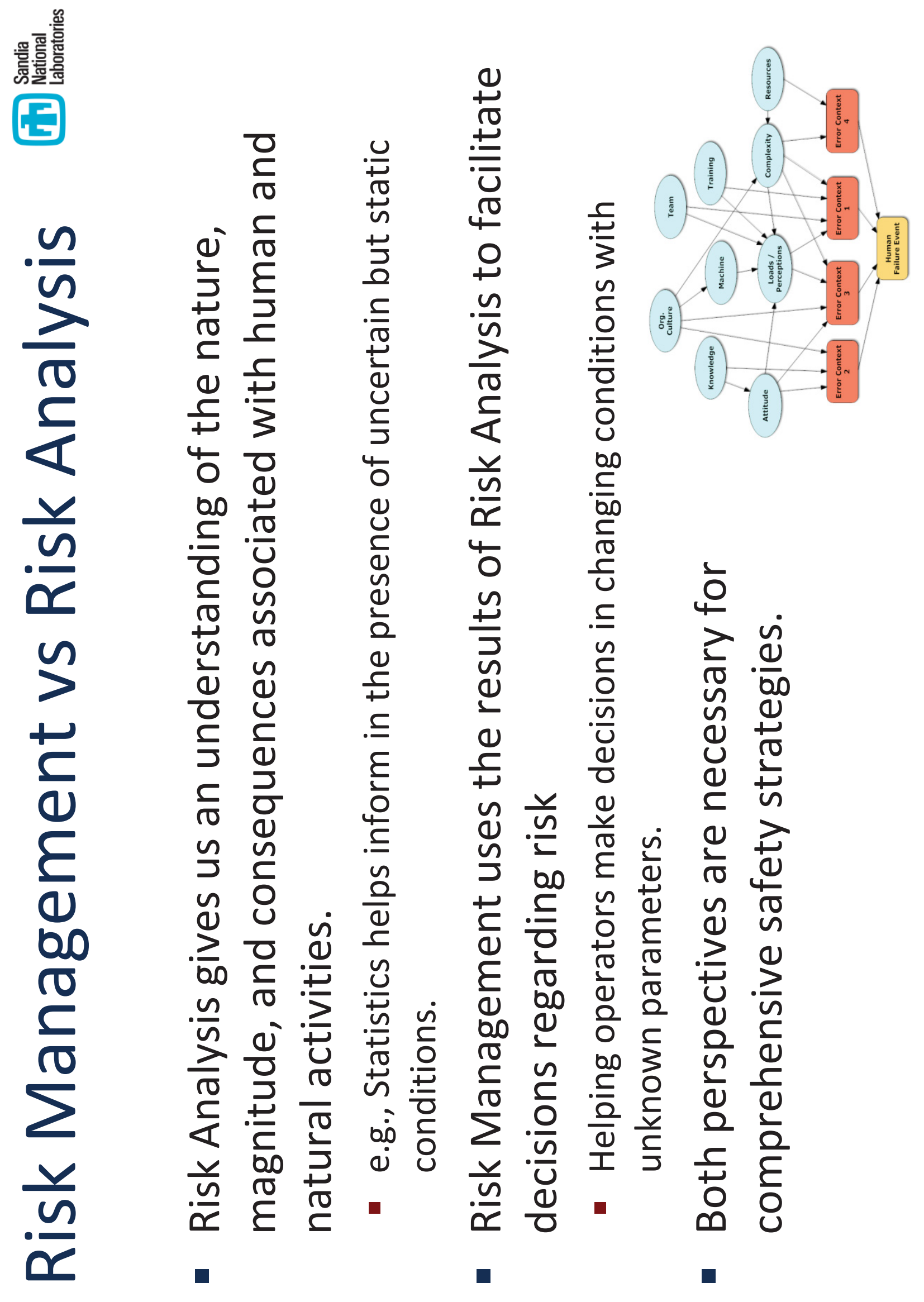


는

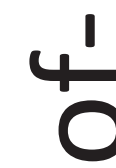

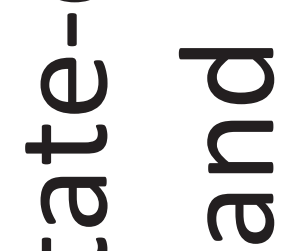

n

을

$\pm \frac{E}{\sim}$

(1) थै ह

(4) ज

는 은

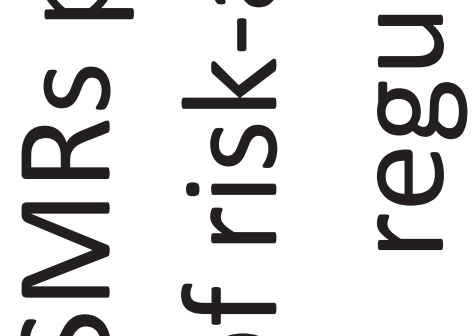

ज 0

(4)

D

$\frac{\bar{\varepsilon}}{\bar{\sigma}} \stackrel{1}{\varepsilon}$

E 


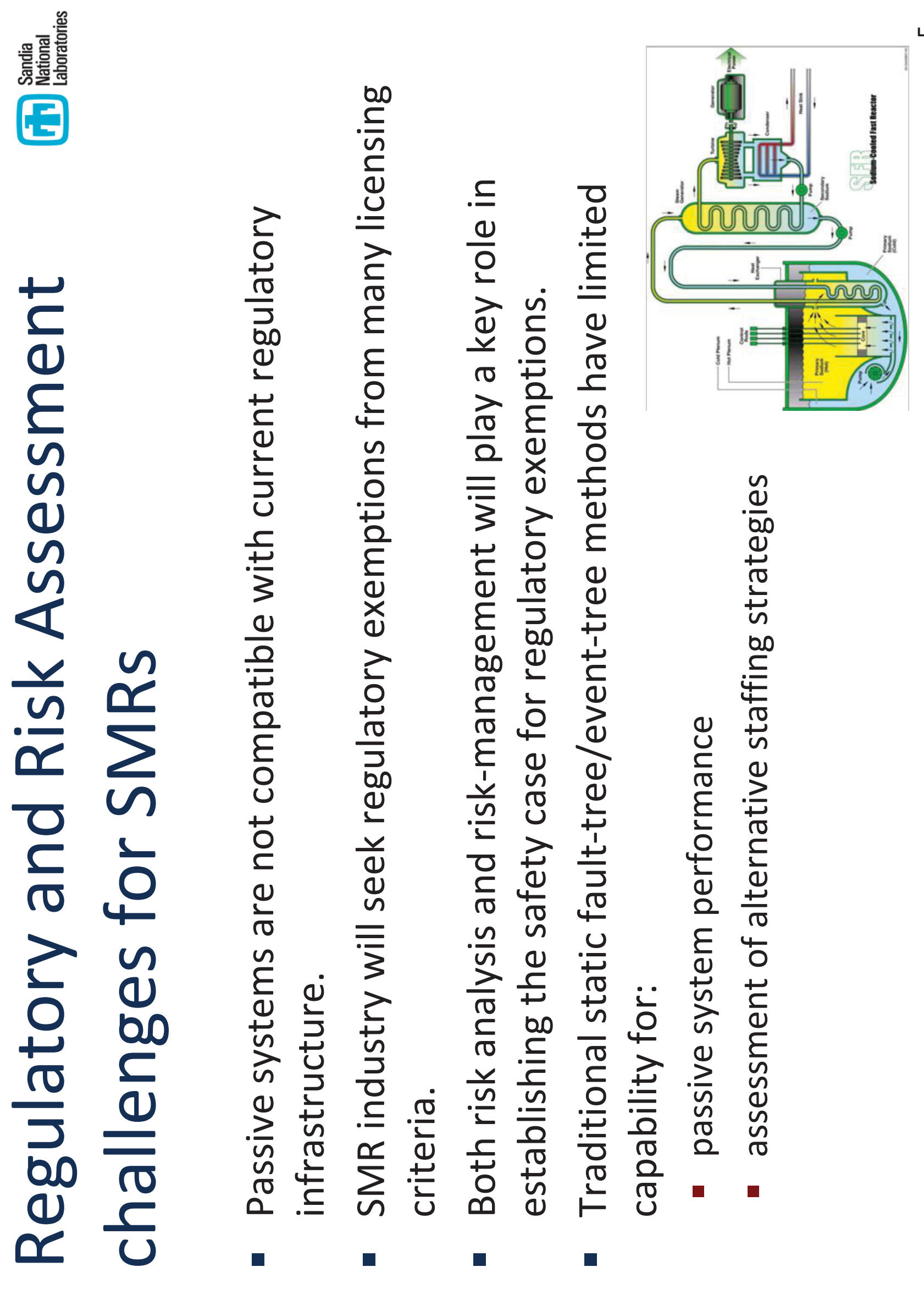



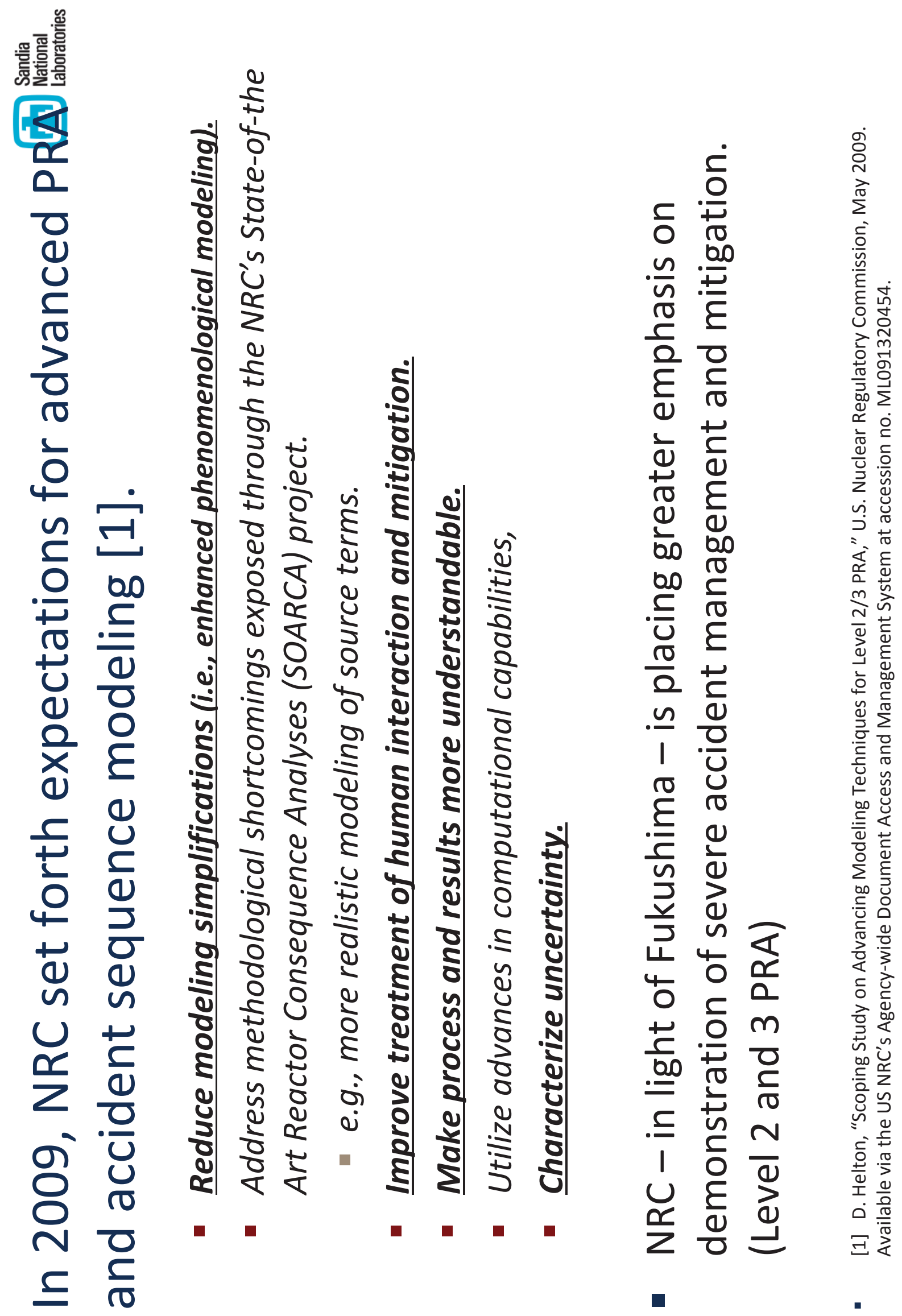


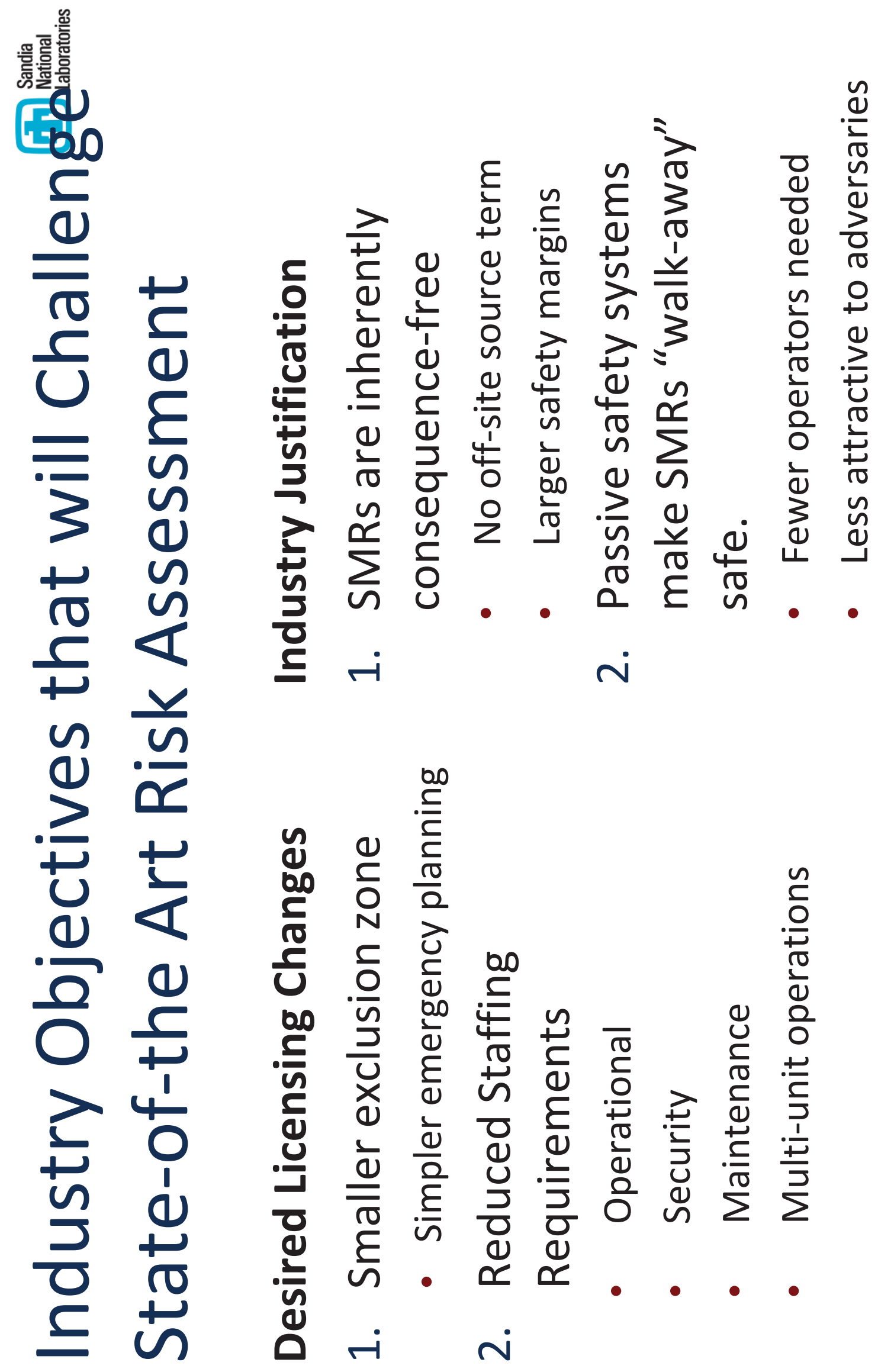




\section{분}

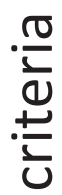

(1)

응

(1)

范 鱼

Uั

요

之

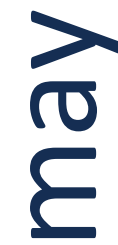

하 츨

is

든

吾 잉

$\sim$

$+$

(1)

כ

$\sigma$

(1)

$\frac{\pi}{5} \frac{}{5}$

정

4

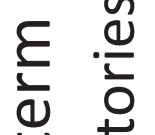

$\stackrel{0}{+}$

过

ठ亏

$\subset \quad$ b

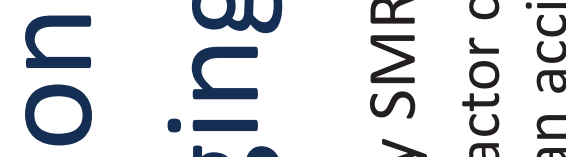

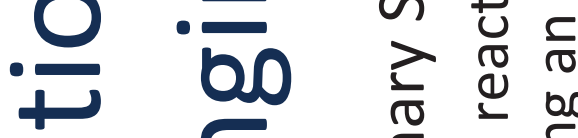

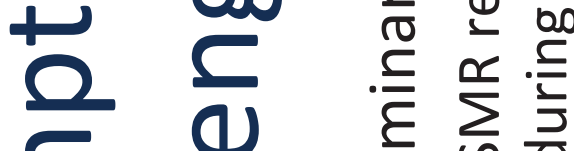

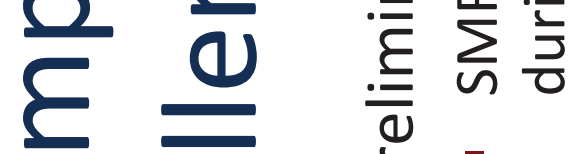

(1) $\bar{\sigma}$

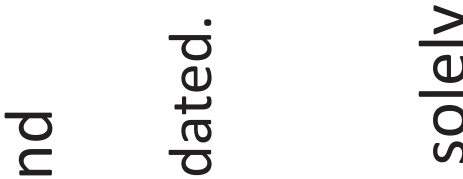

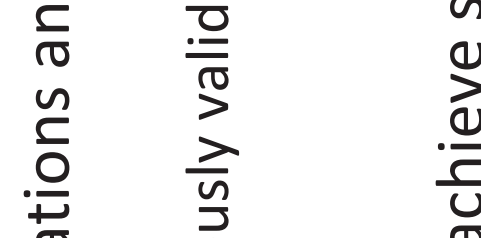

는 잉

(1)

อ 음

뜬

$\varepsilon$ ह

市

O

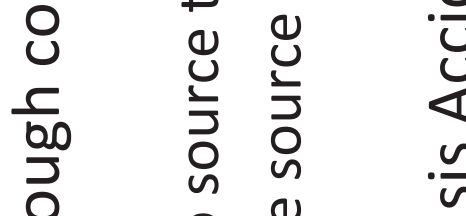

을 을

(1) ठ̀

을 으 봉

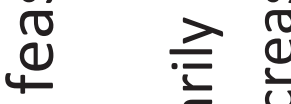

느 는

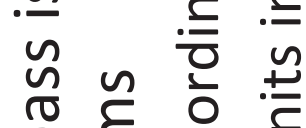

กั้

ลे

두 合

ญ

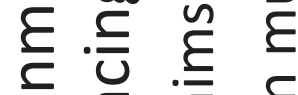

.

兵竎.

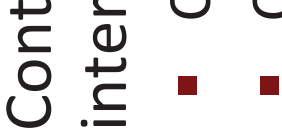

ยิ

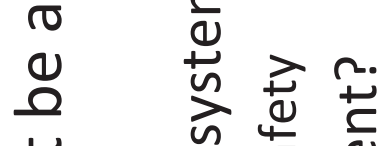

t) ज

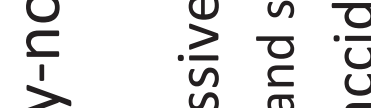

ส

E $\frac{0}{1} \frac{5}{\pi} \frac{5}{\pi}$

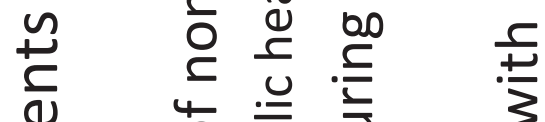

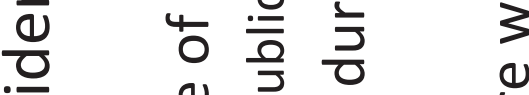

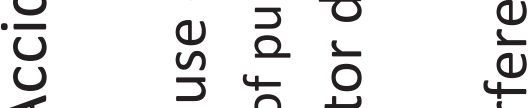

4
0

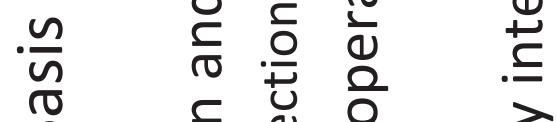

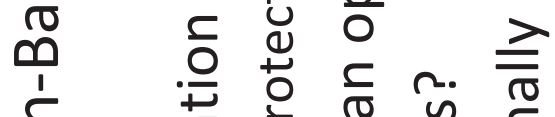
它 竞

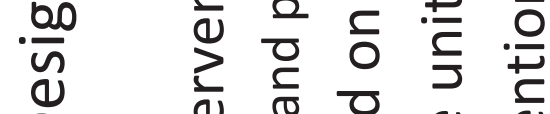
๑ั 음 ․ㅡ 은 으 을

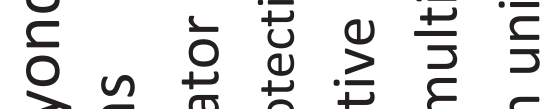
đิ)

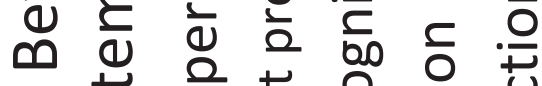

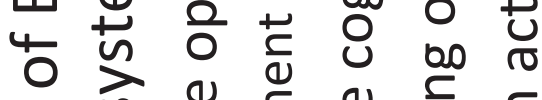
๘

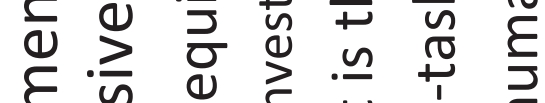
选

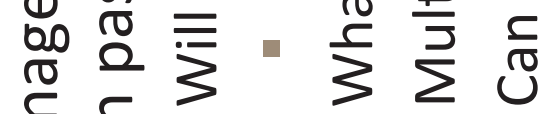

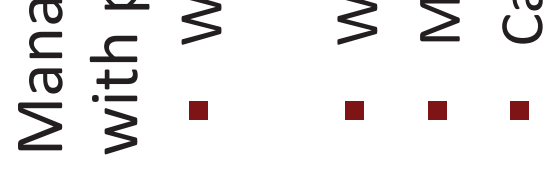




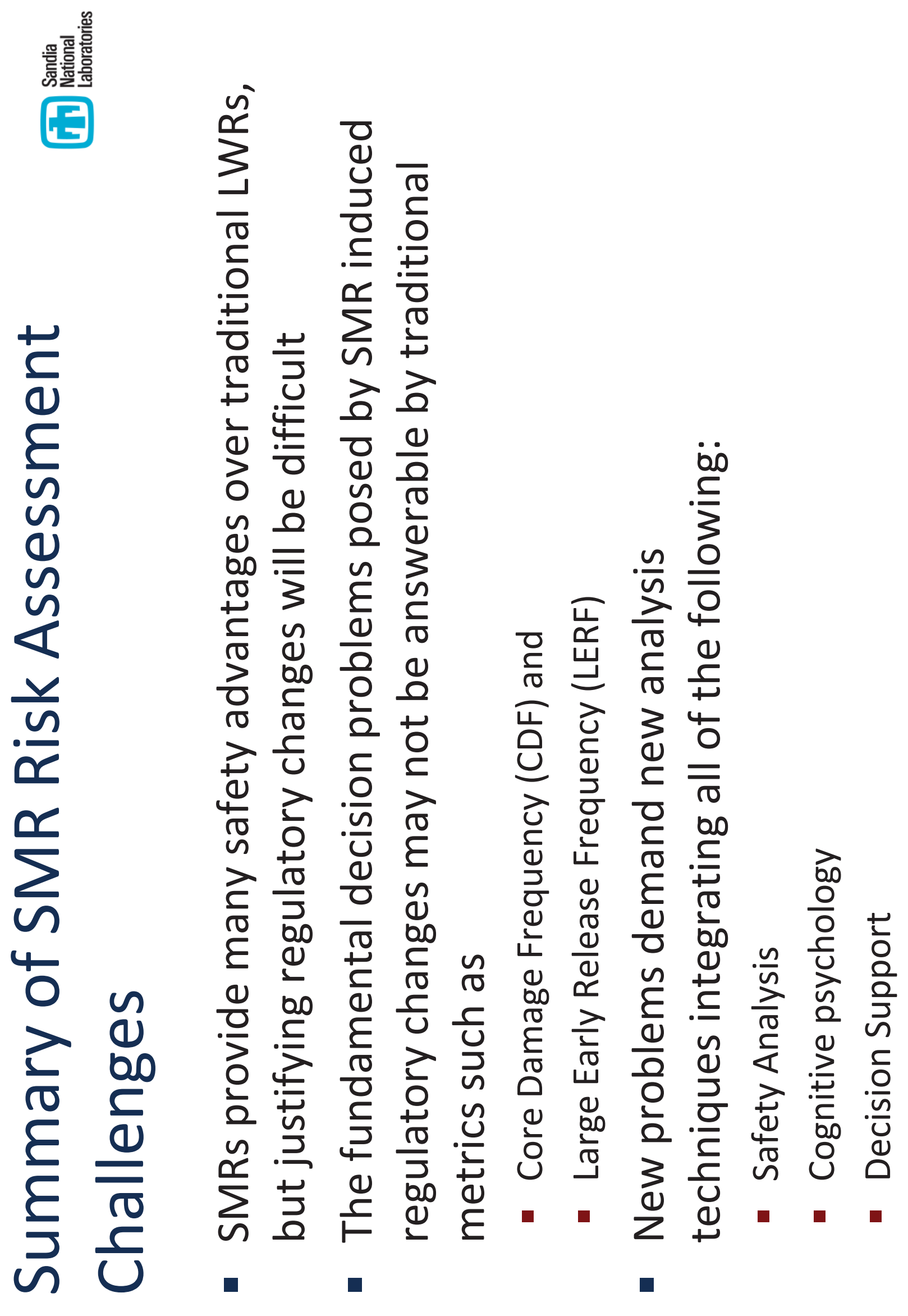




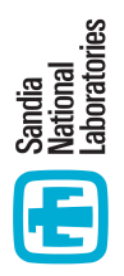

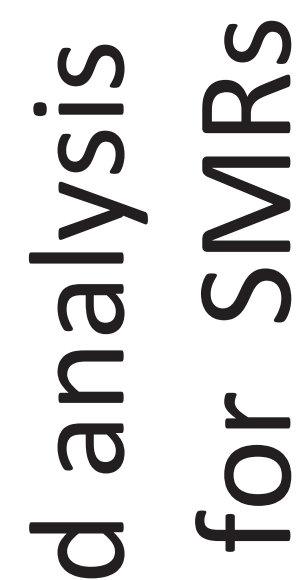

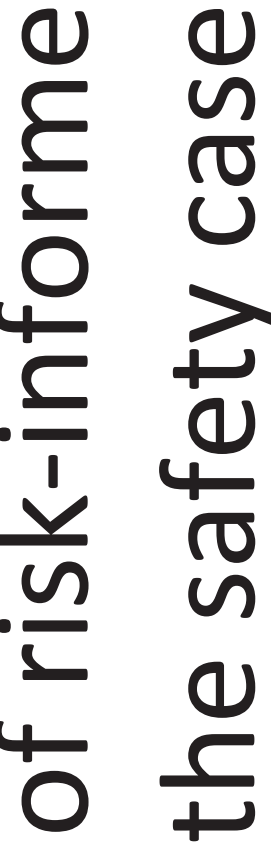

(1)

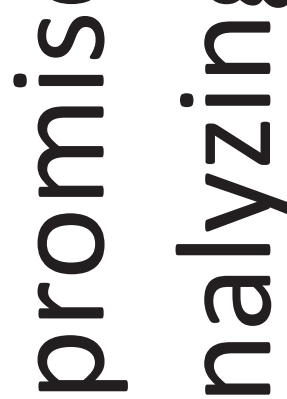

$\stackrel{0}{\rightleftharpoons} \frac{1}{6}$ 


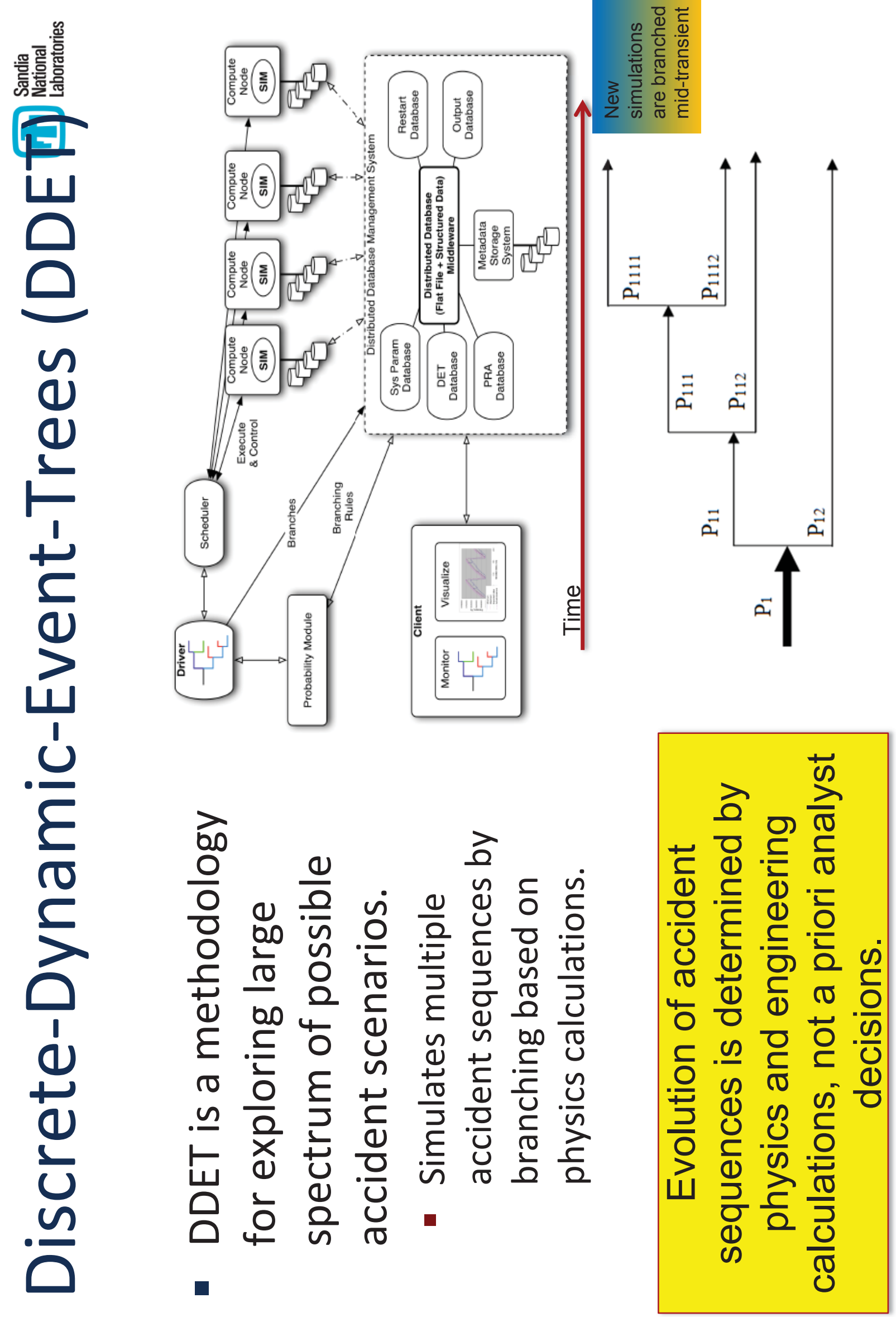




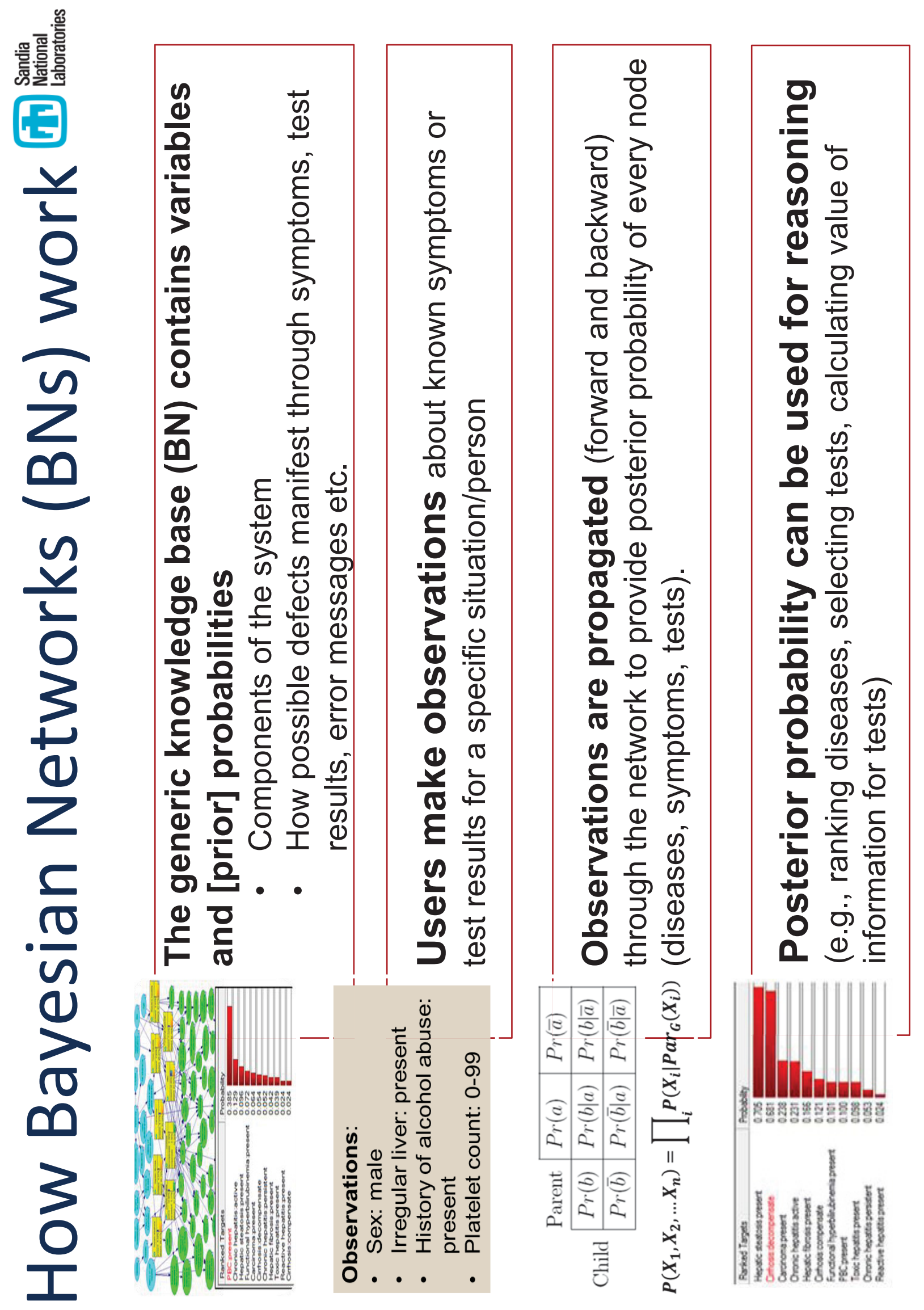




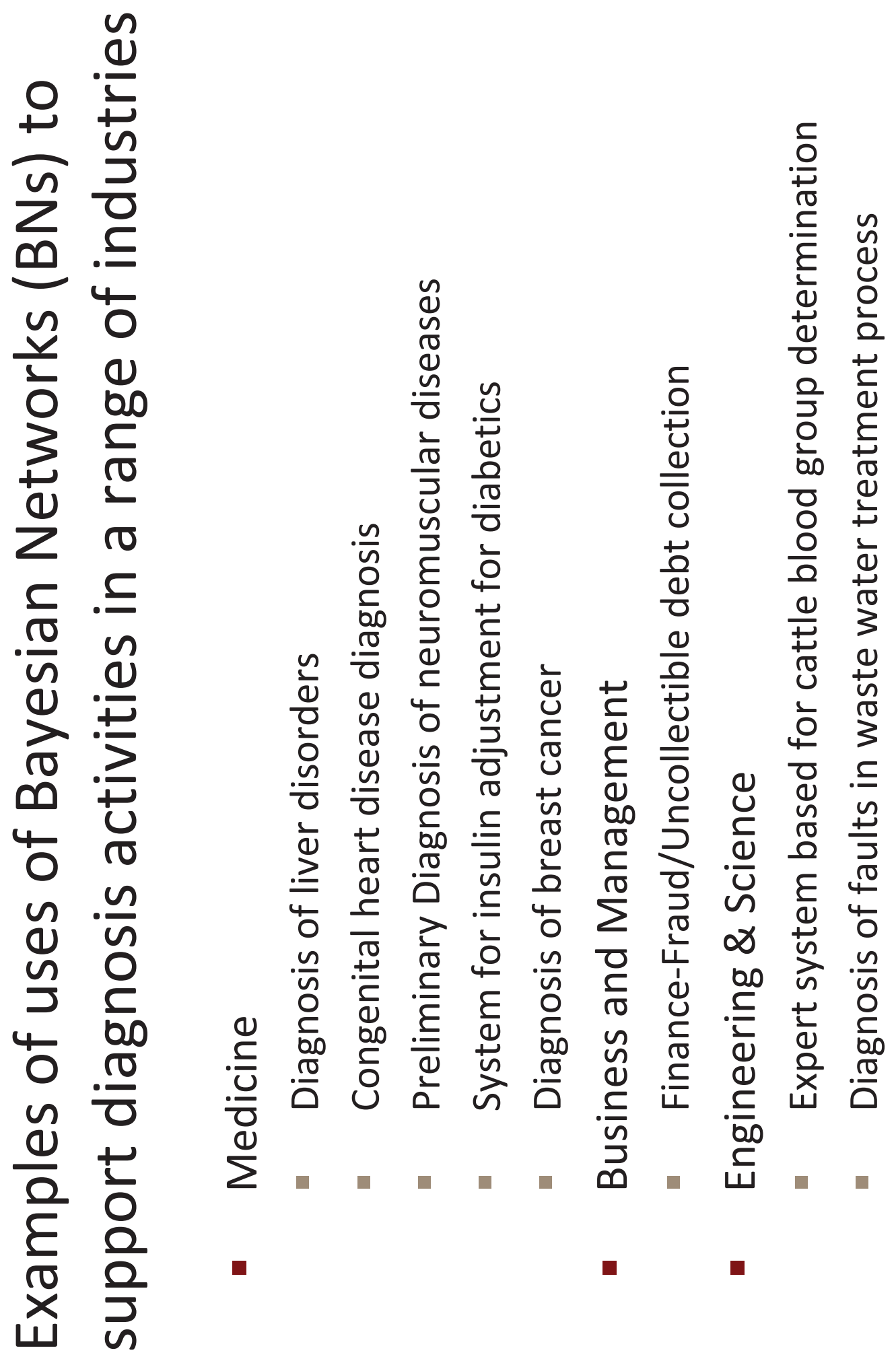




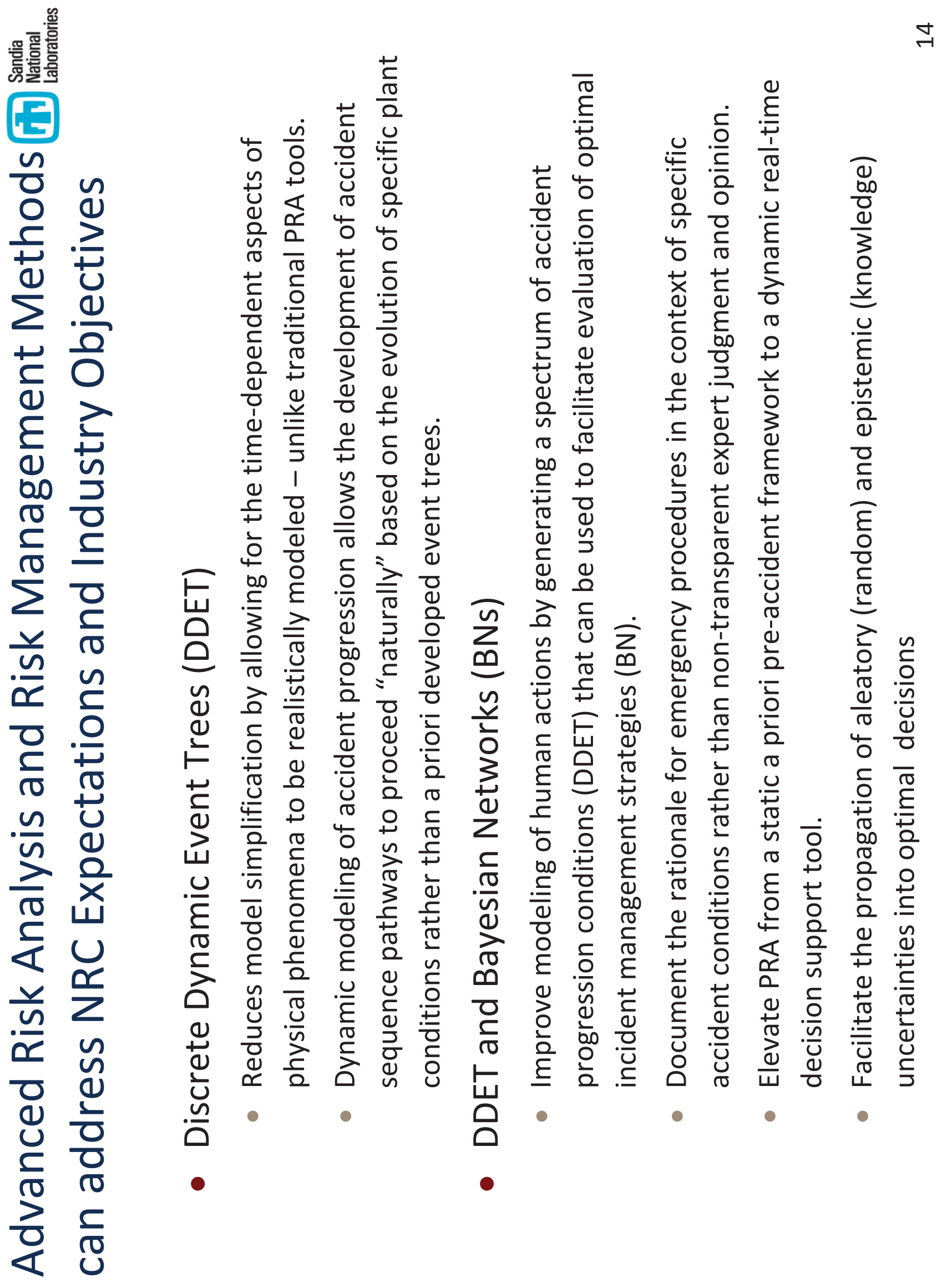




\section{든}

$+$

$+$

$\rightarrow \frac{1}{0}$

$4 \quad-\frac{0}{4}$

$\because 2$

(1) के

$10 \frac{-1}{0}+$

ก 0 E

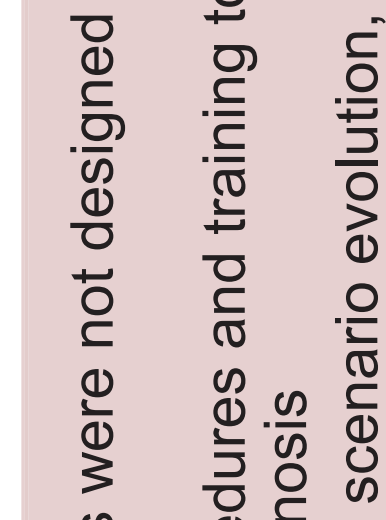

$+\infty=$

(1) ำ

(1) ब

(U) बै है

ए 0 은

(1) 요 드

(1) $\frac{5}{5}$

$\geqslant$ (1)

(1) क ल क

a0 $0=$

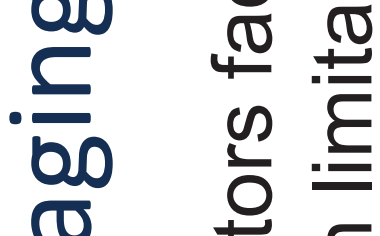

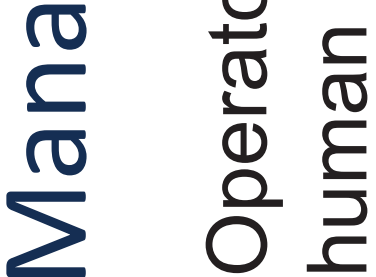

듬

$-\frac{0}{0}$

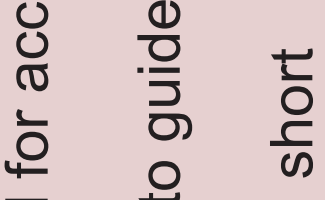

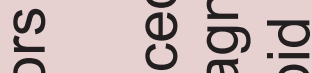

\% 은 음

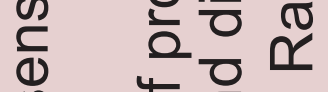

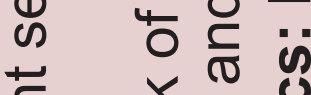

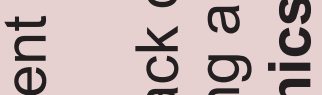

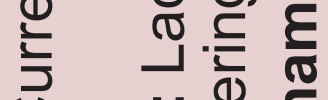

U

듬ํำ

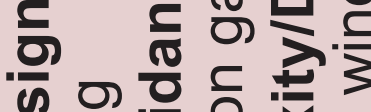

이 을 을 은 흥

ดับ

는 늘 든 응

흥 은 응

ฉ

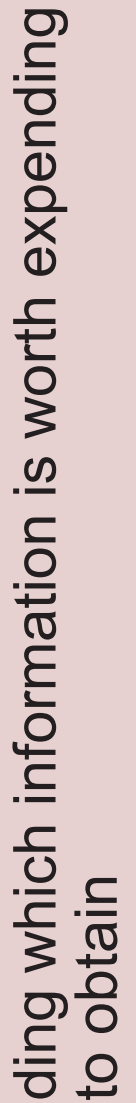

(1) 응 응

\%) 등 엉

이

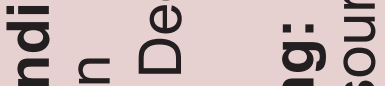

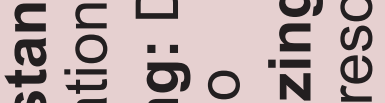

ต

(1) 튼 는 는

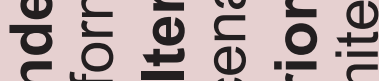

$5 . \underline{5}$ 는 을

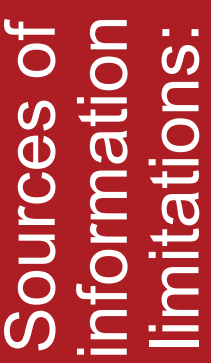



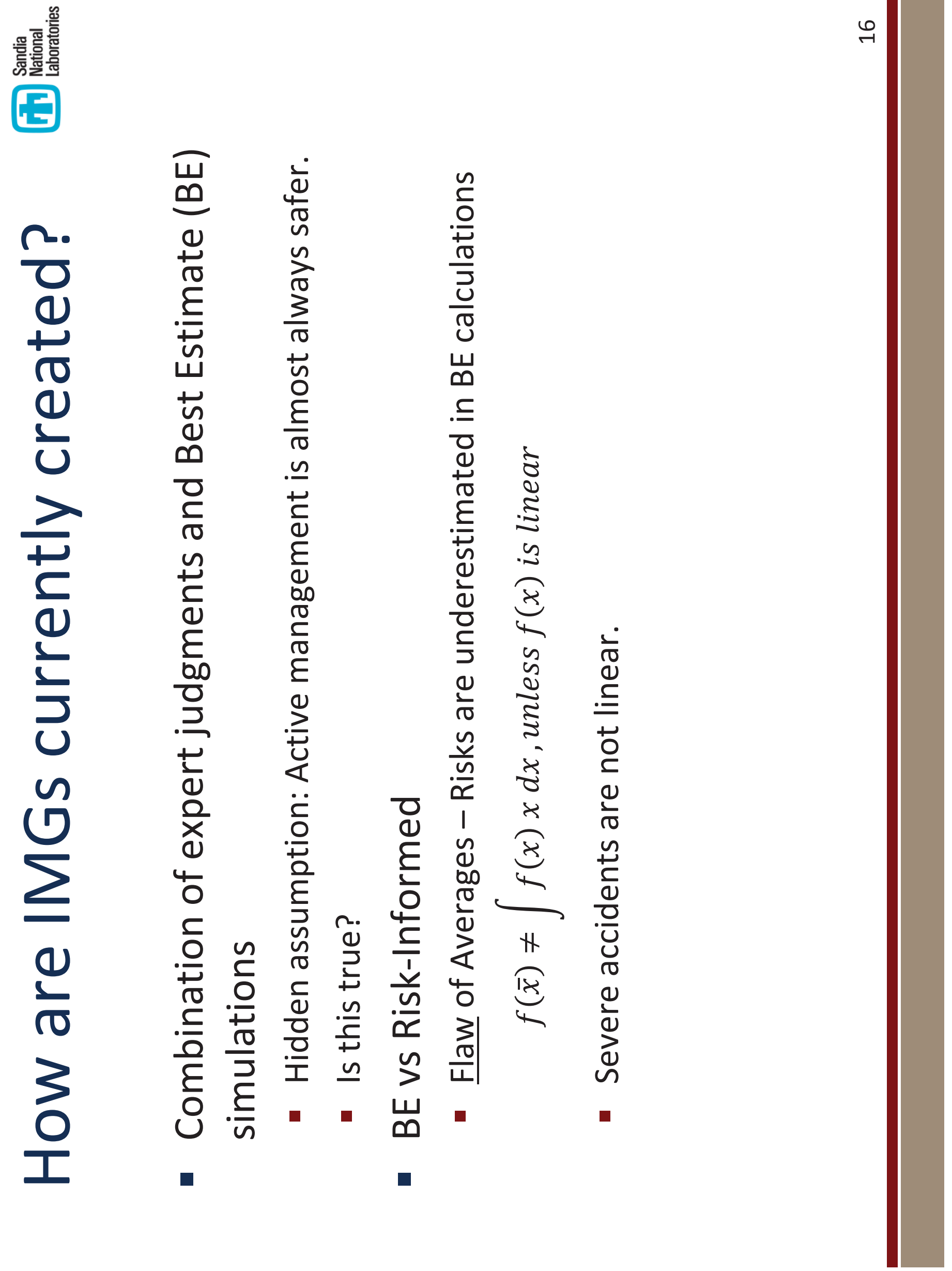


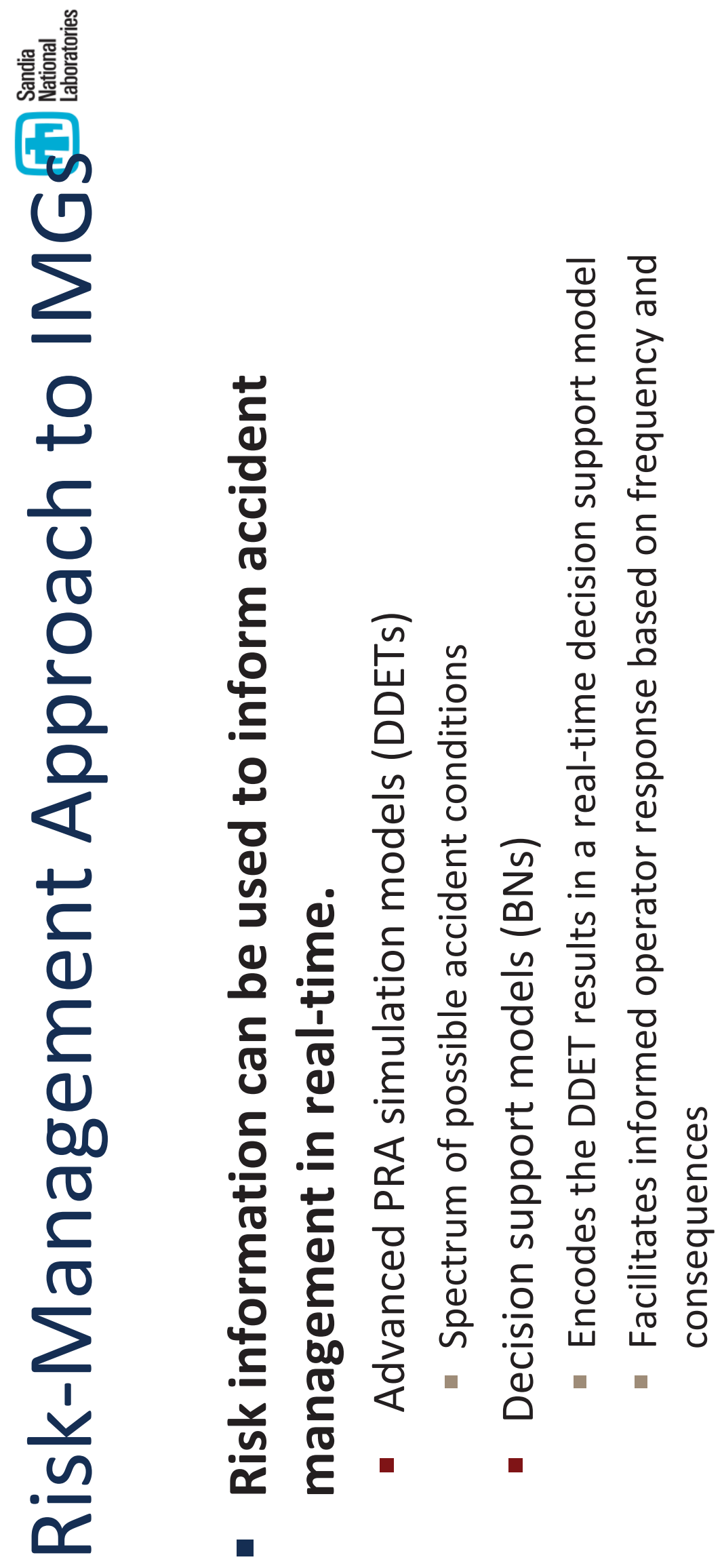



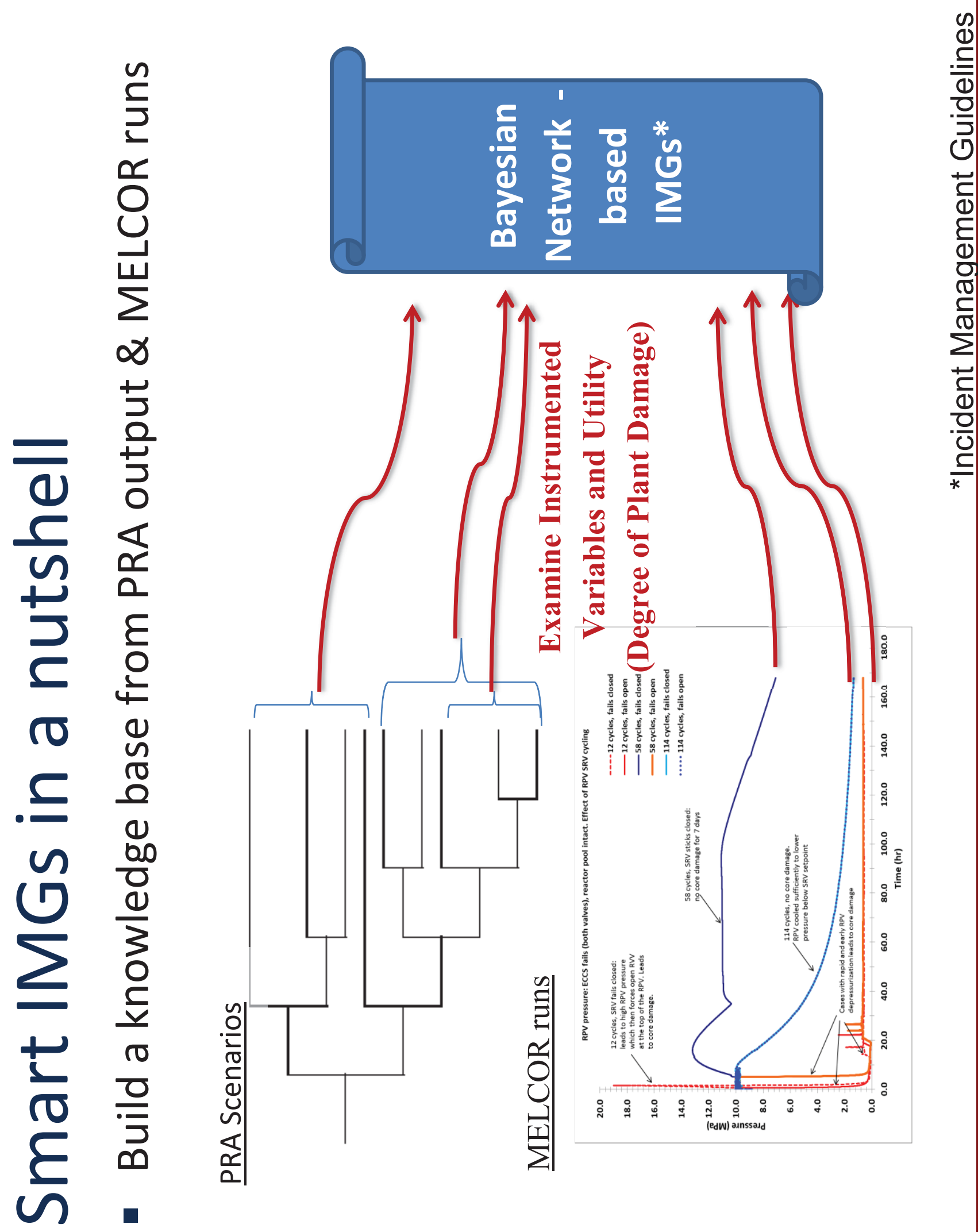


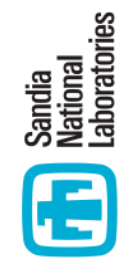

$\stackrel{n}{\Sigma}$

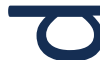

(1)

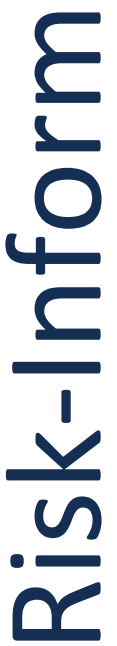

4

$\frac{0}{2}$

To

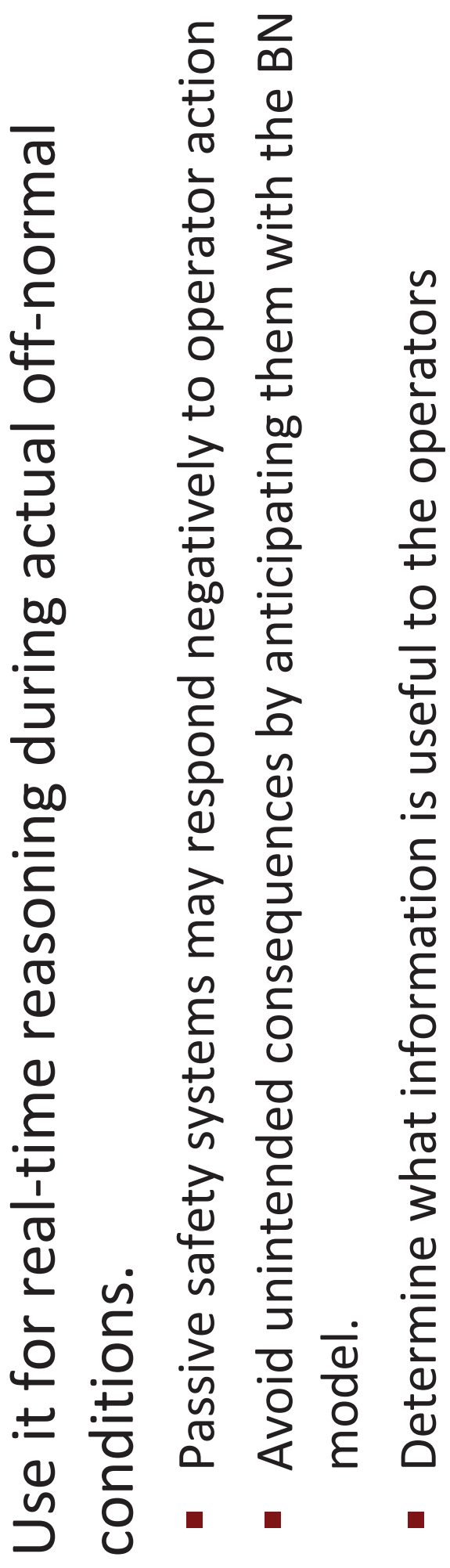

$\frac{u}{4}$

욤

文

을

4

4

$\frac{0}{\frac{1}{4}}$

농 음

$+$

으르

(1) 으

늠

ง

인 年

(ס)

(1)

됴 ᄃ

o $\frac{\text { b }}{\text { n }}$

ㅇ v

ส

ம 는

드 ᄂ 엉

त

छ ن

冷 


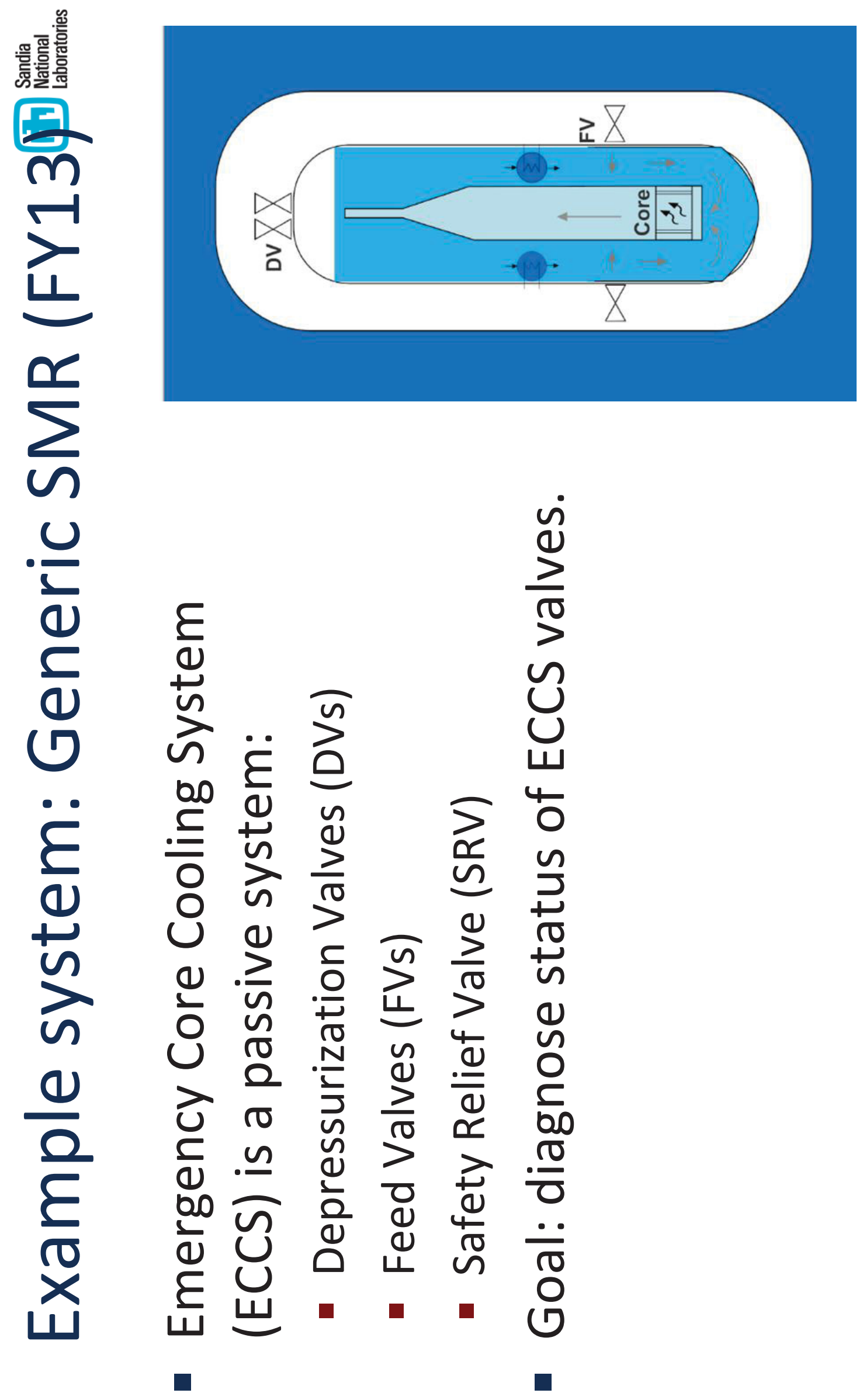



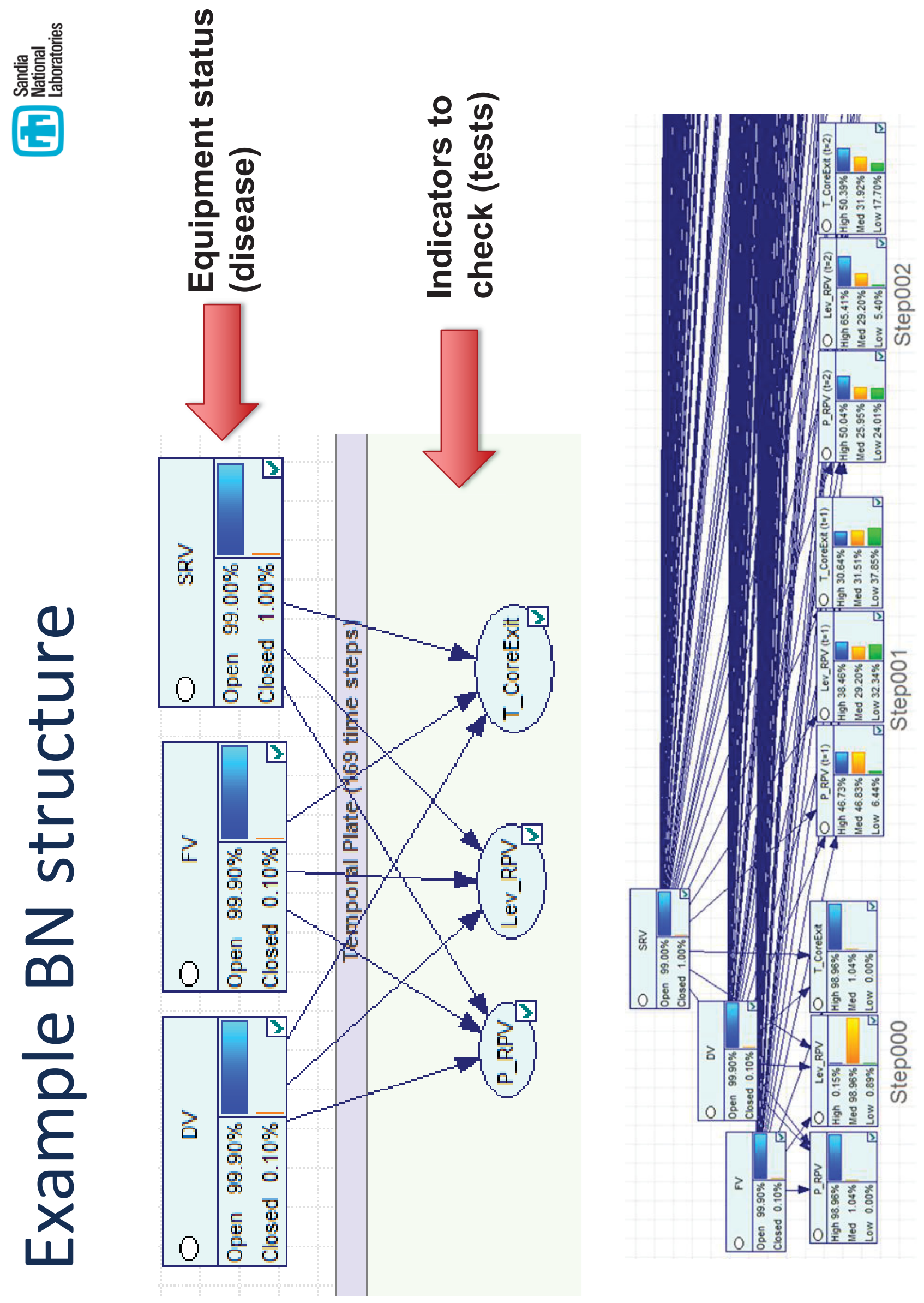

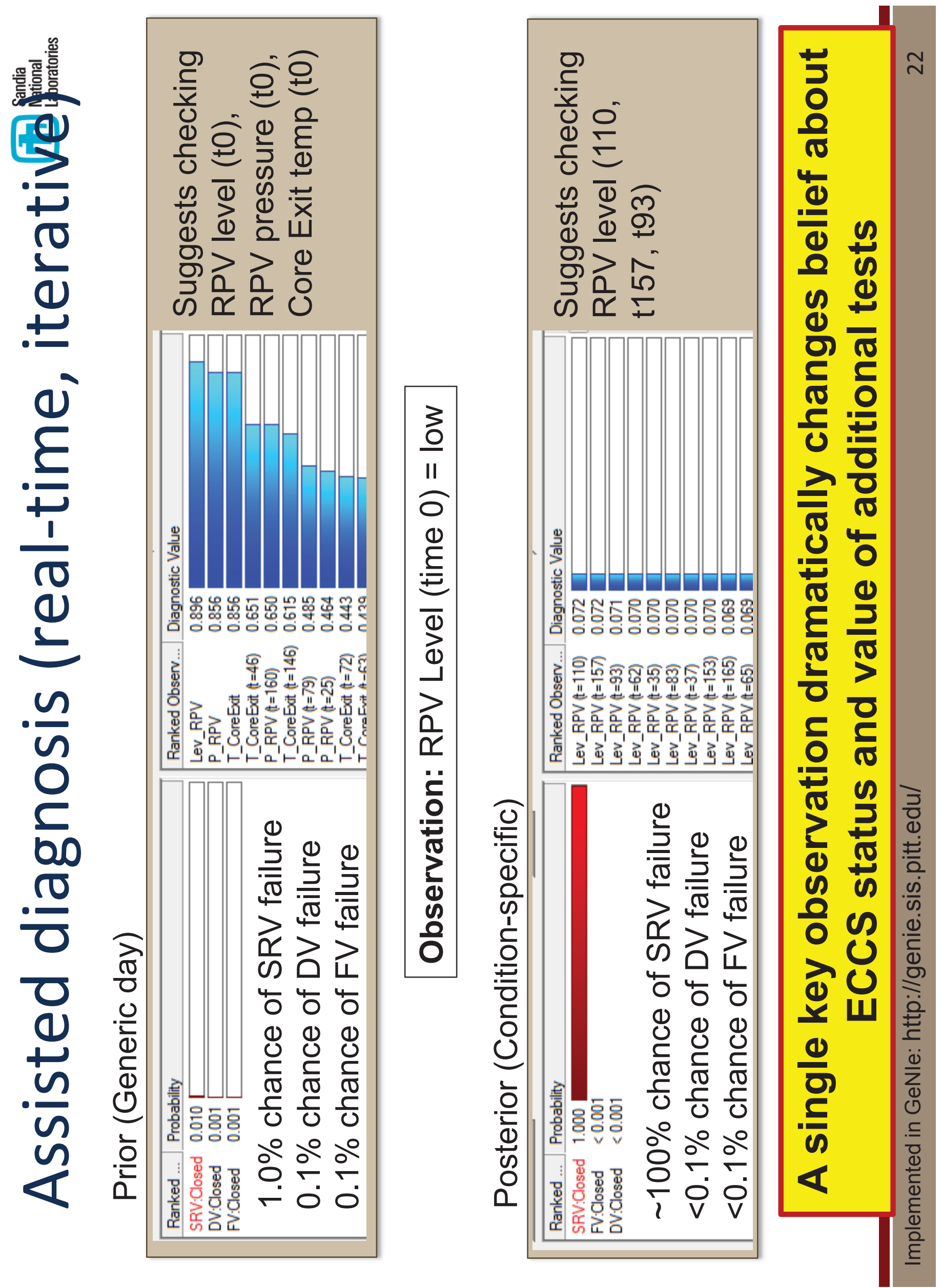


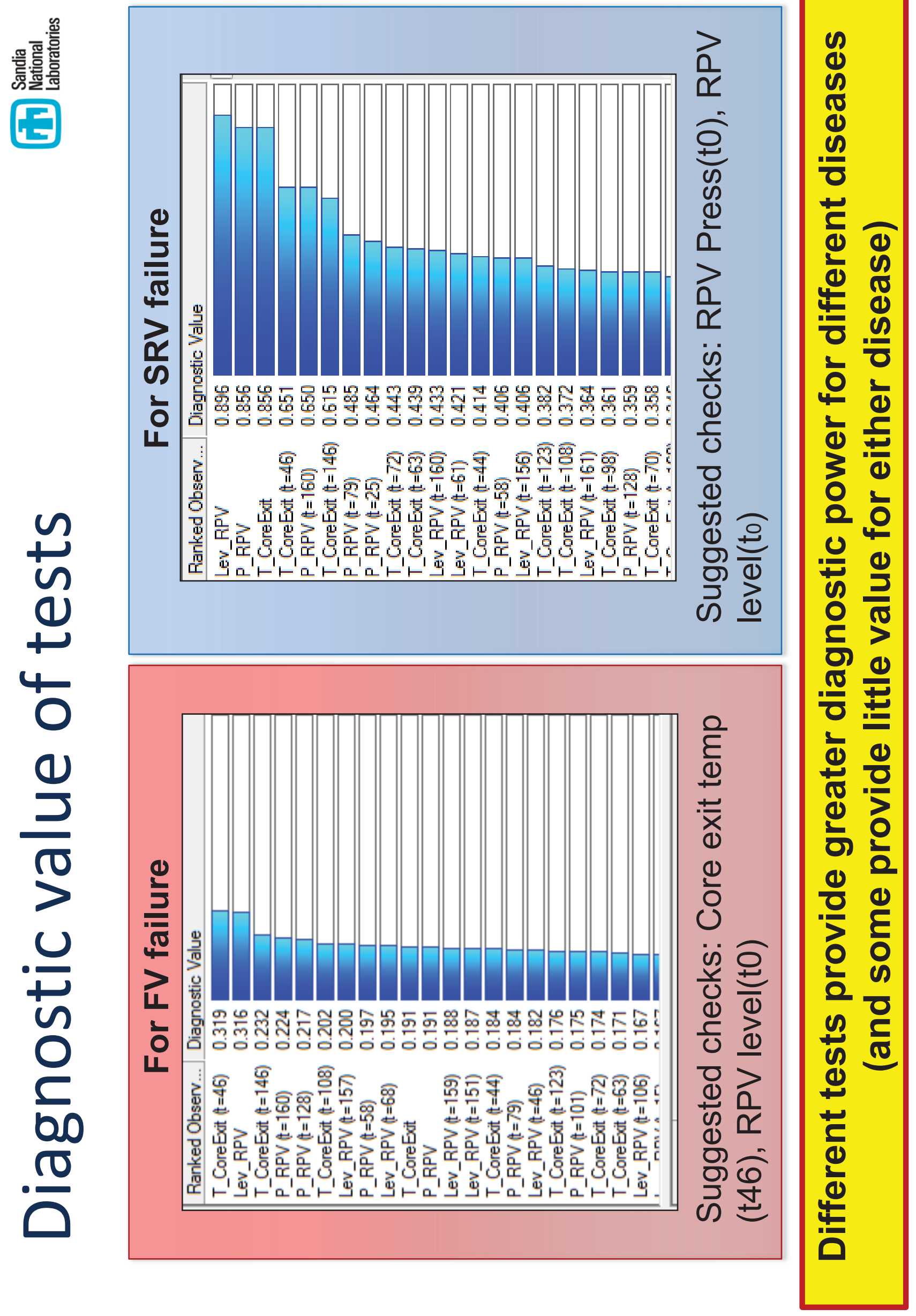




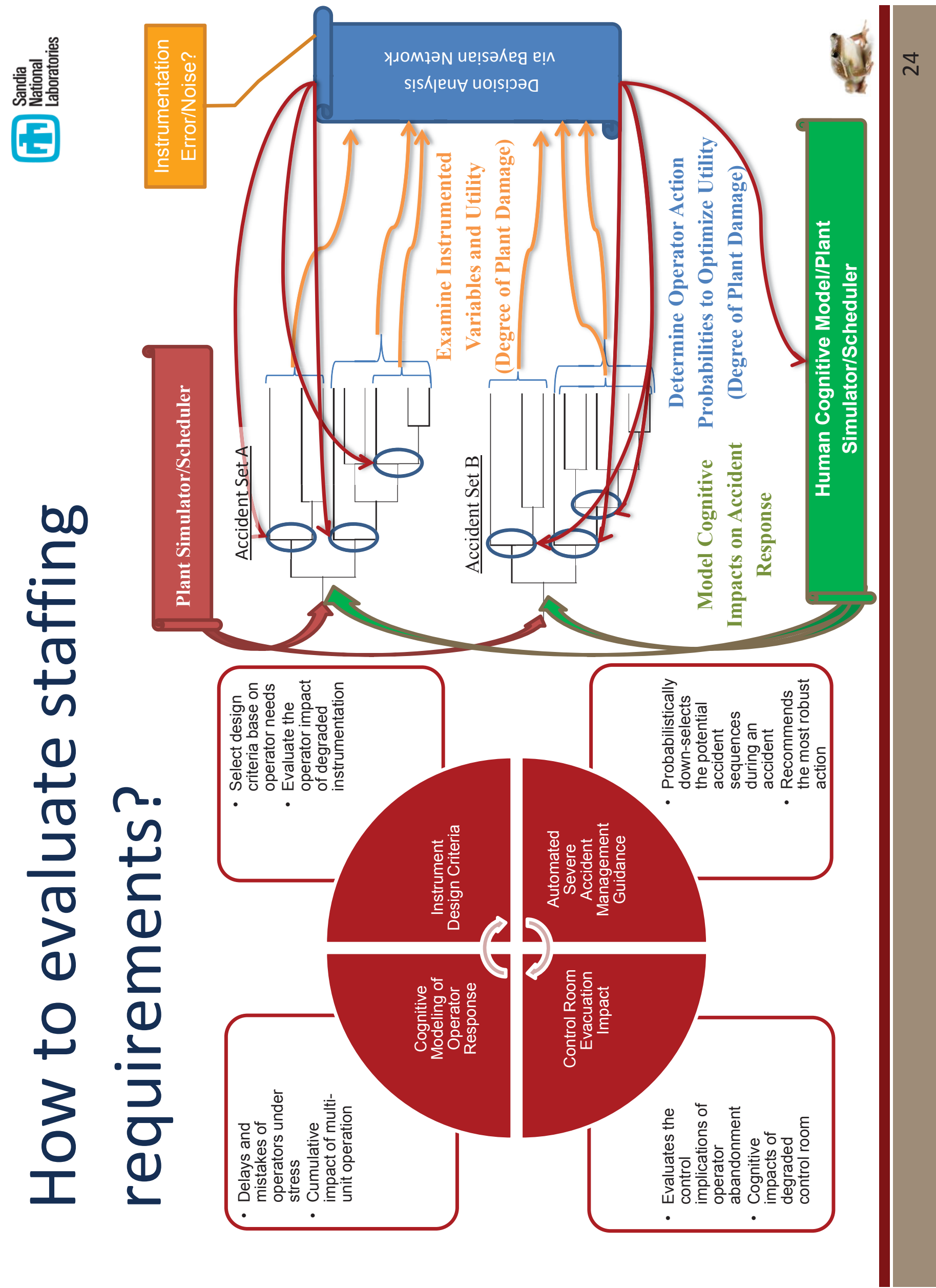



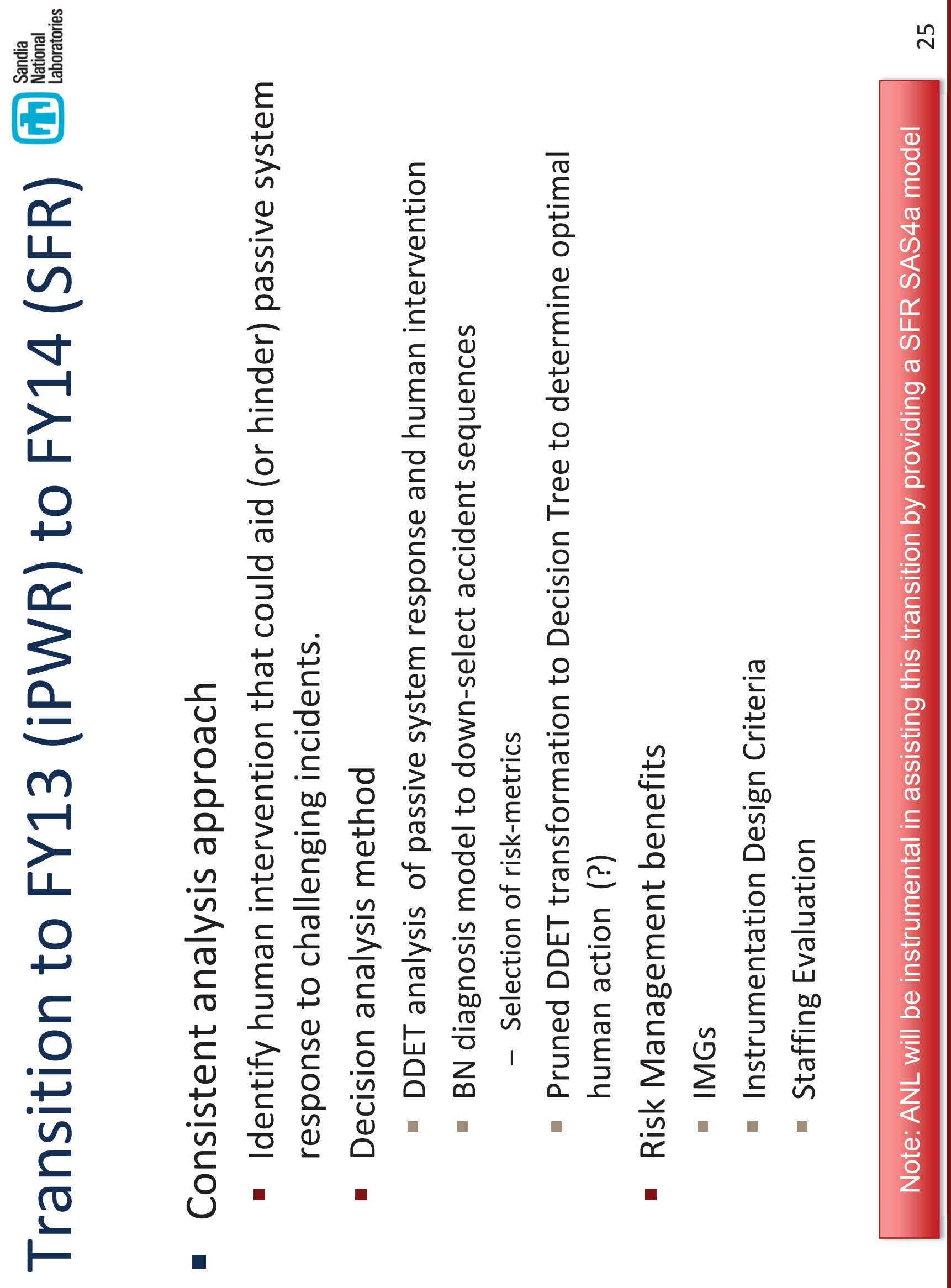


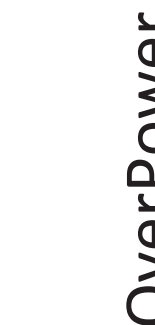

$\sum_{0}^{1}$<smiles>[CH]1C=C[CH-]C1</smiles>

$\frac{\frac{\varepsilon}{d}}{\frac{\pi}{n}}$

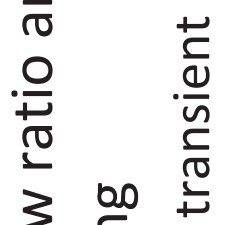

บ는

동

$\approx+$

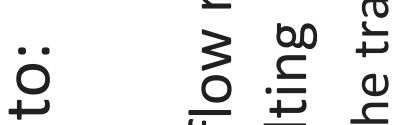

능 들

Q $\frac{1}{n}$ U

$\therefore \quad \frac{c}{0} \quad \frac{0}{0}$ ऐ)

ร >

$\sum \stackrel{0}{1} \quad \frac{0}{0}$

(1)

ॄำ

을 을 덩

$\gtrsim \stackrel{\text { ह }}{£}$

ก. है 厄ั

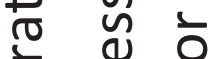

บิ 닝

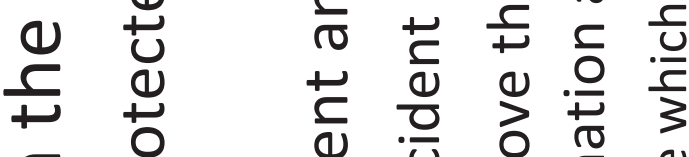

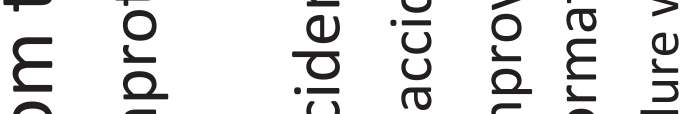

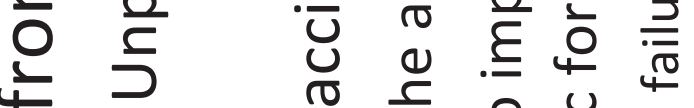

닝

(1) 0

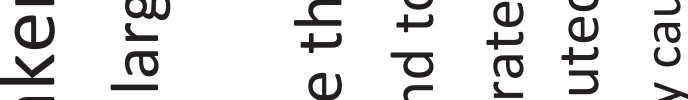

ரु

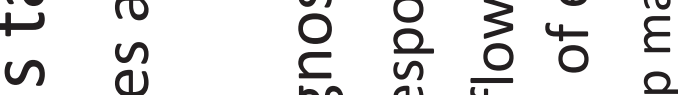

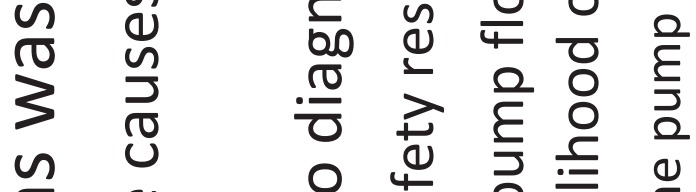

0

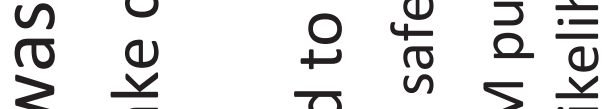

$3 \frac{v}{\frac{\pi}{T}}$

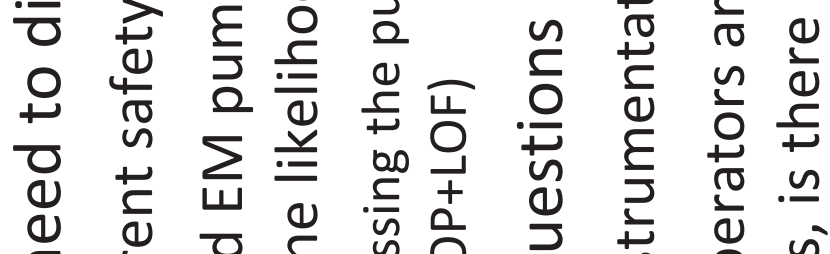

1

$\pm \frac{\nabla}{\sigma}$

Oำ 은

$\stackrel{0}{ \pm}+\stackrel{4}{4}$

을 능

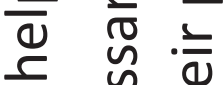

음

은

$3+\frac{1}{3}$

10

(I)

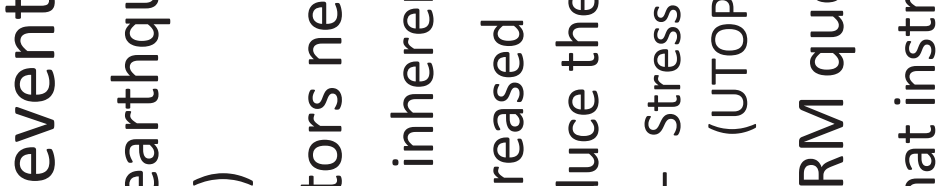

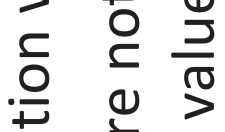

तु $\frac{1}{0}$

$\frac{1}{1}$ थ

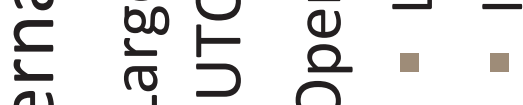

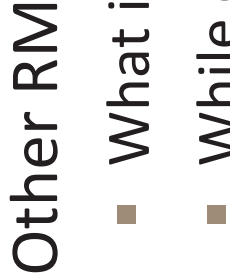

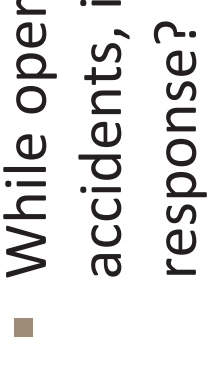




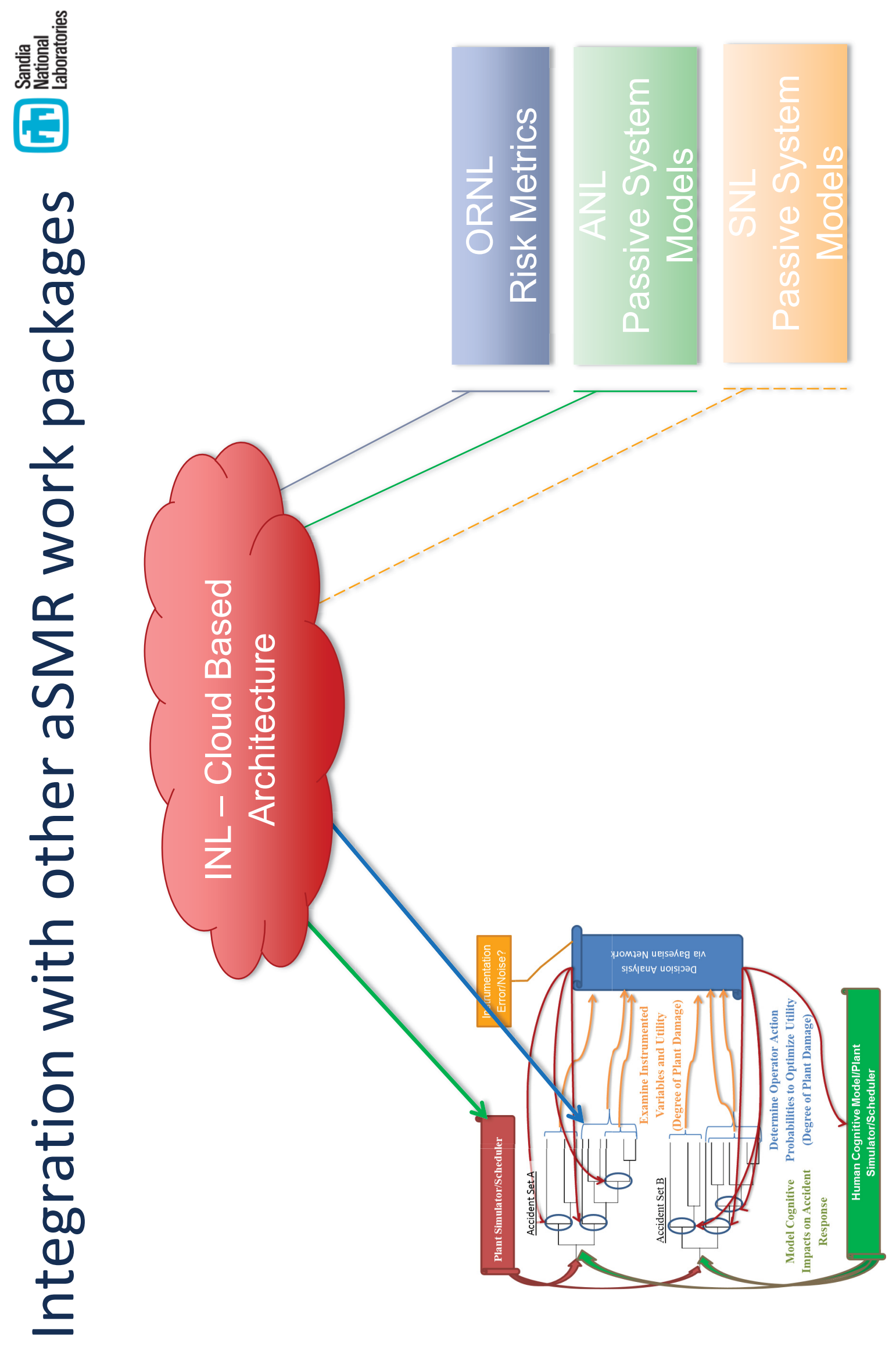




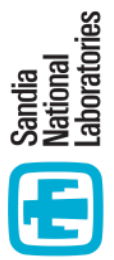
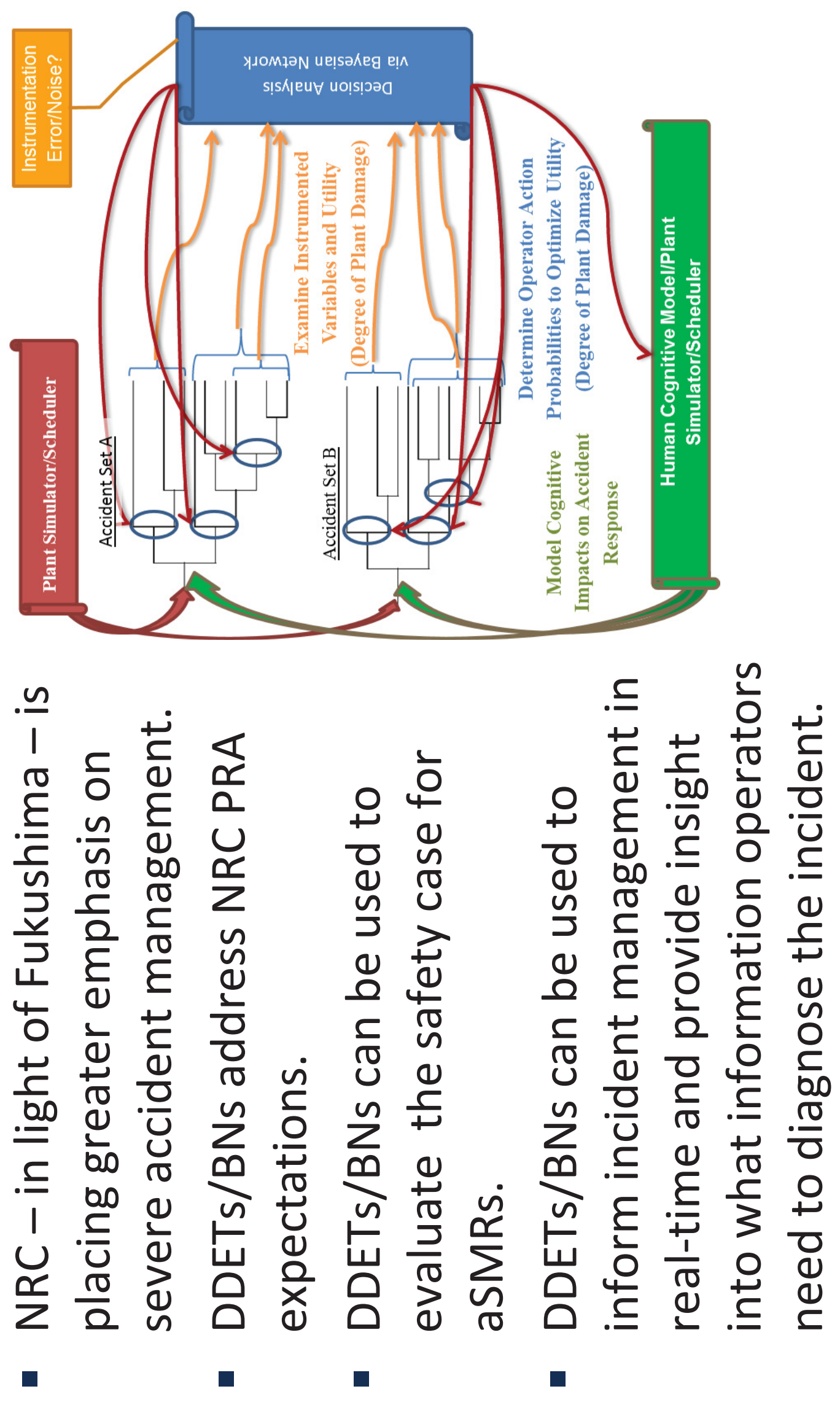

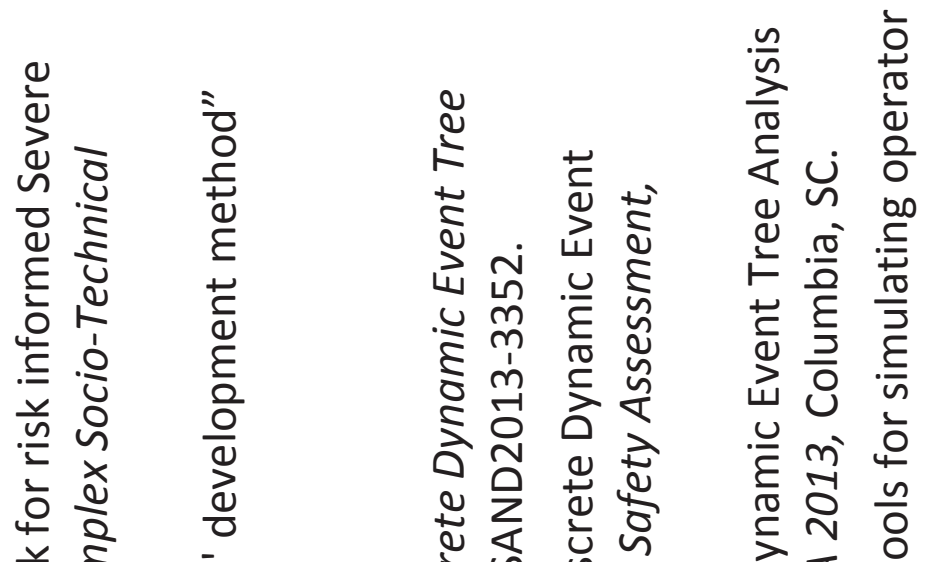

ำ

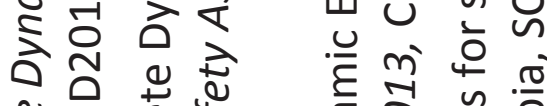

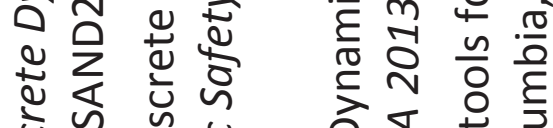

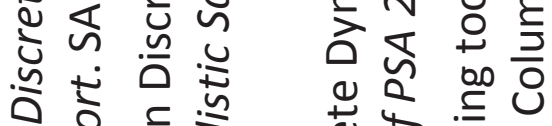

¿े పे

है ญ

닐 을

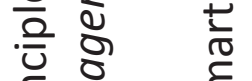

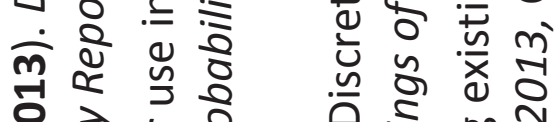

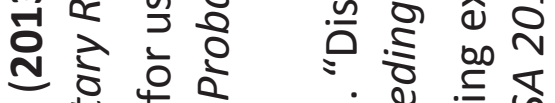

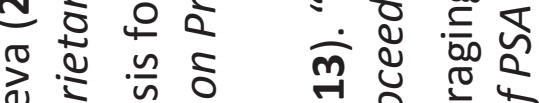

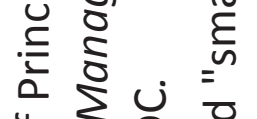

.

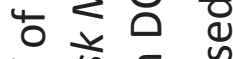

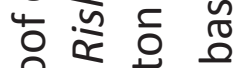

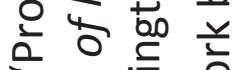

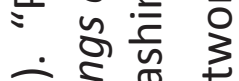

m.

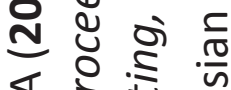

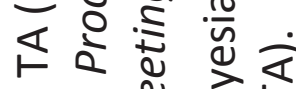

İ $=$ ह ते

ปับ

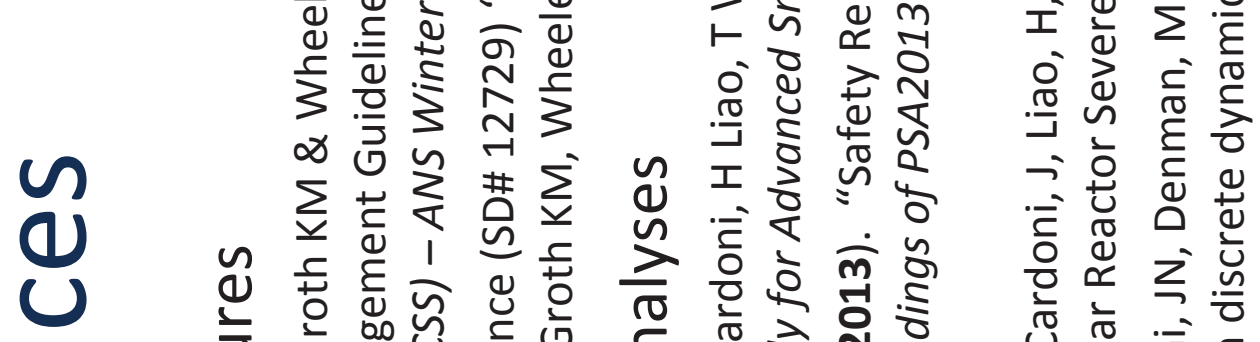

岳主

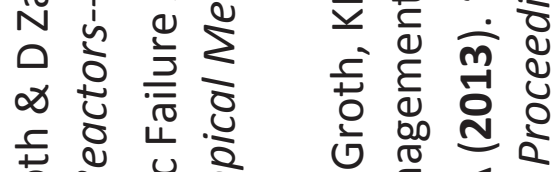

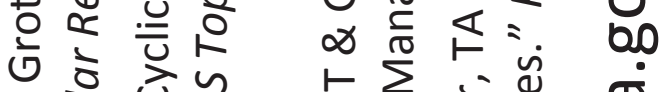

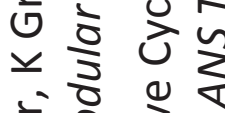

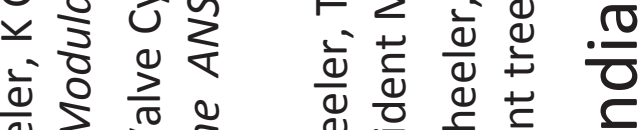

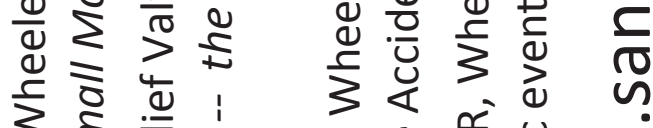

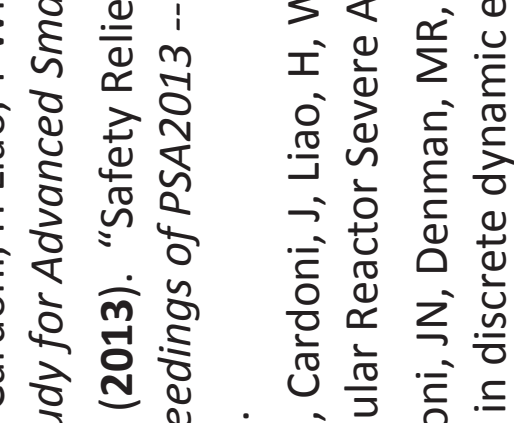

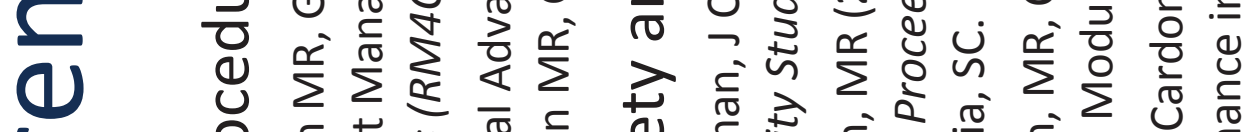

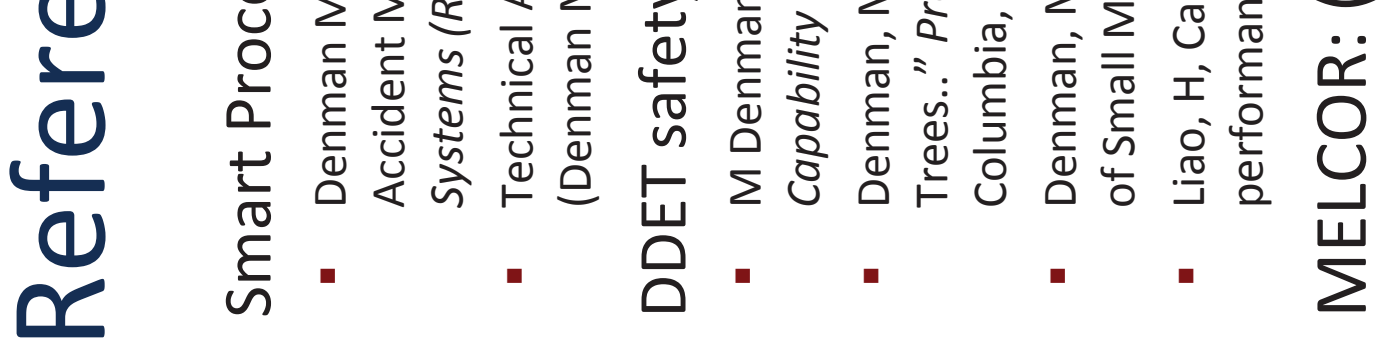

葛 


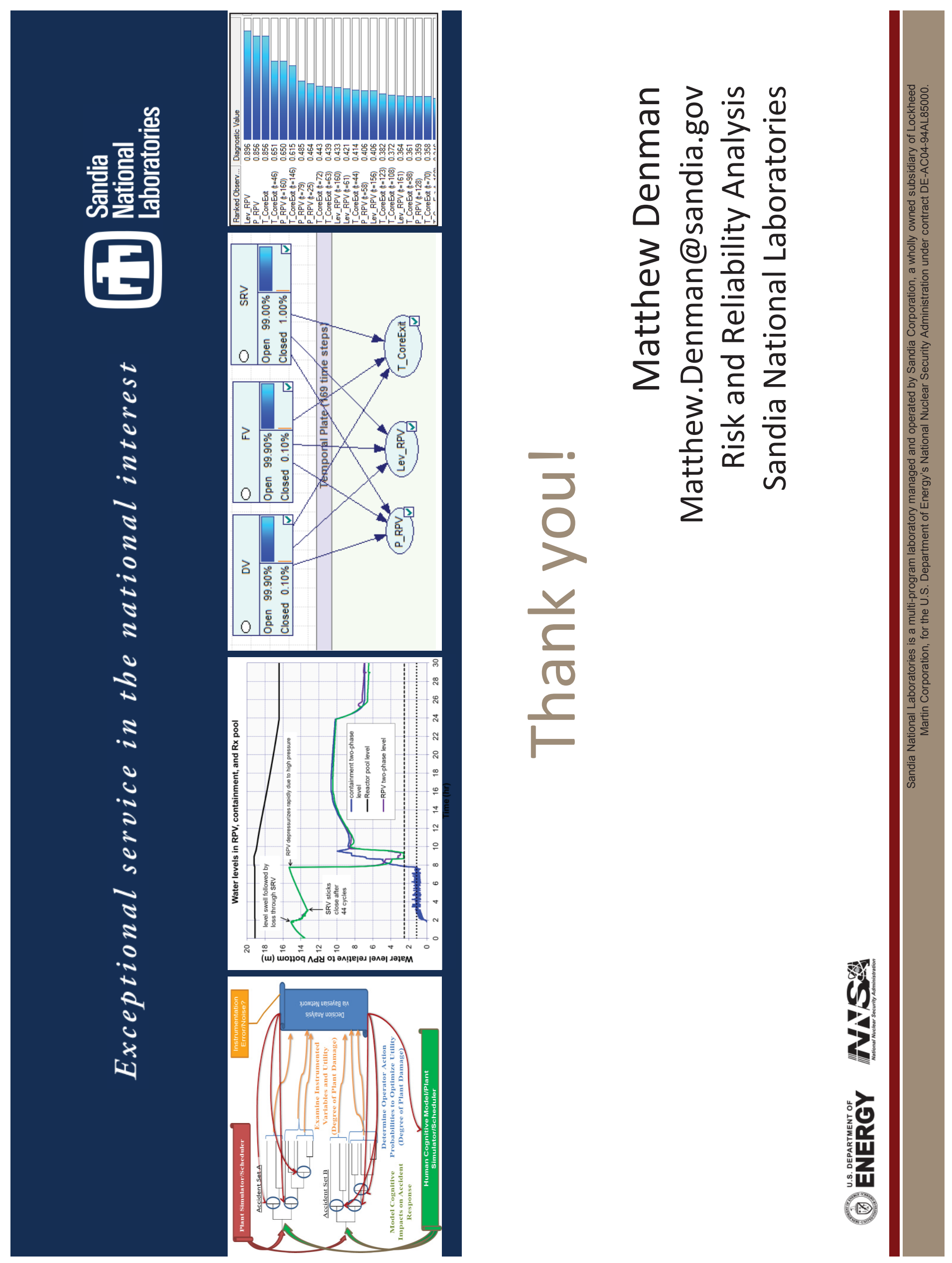


든

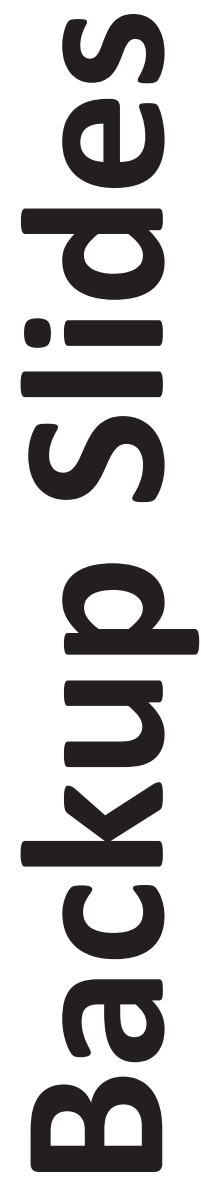



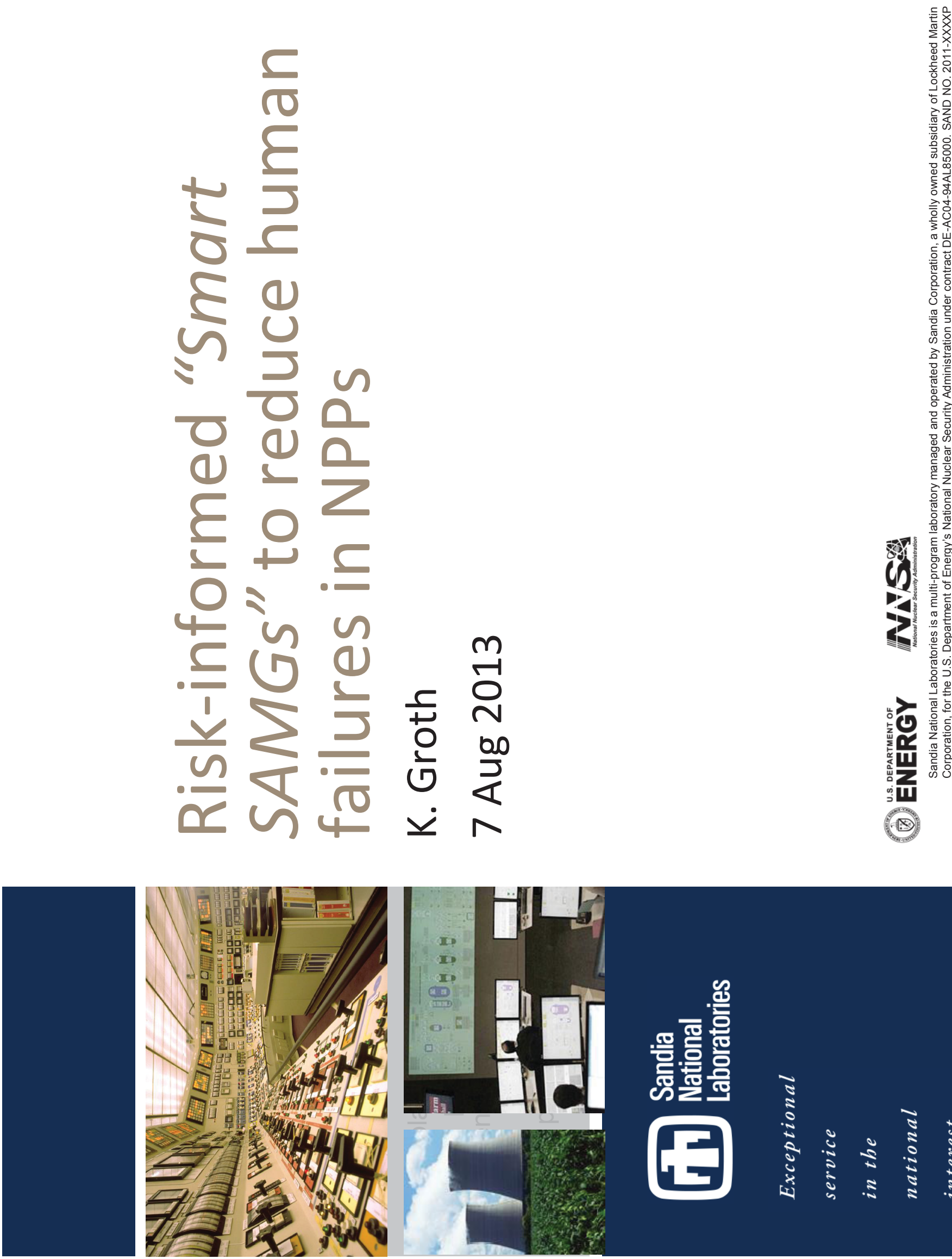

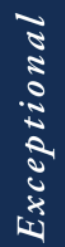

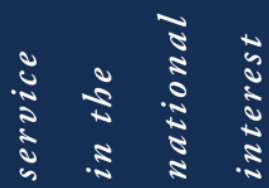



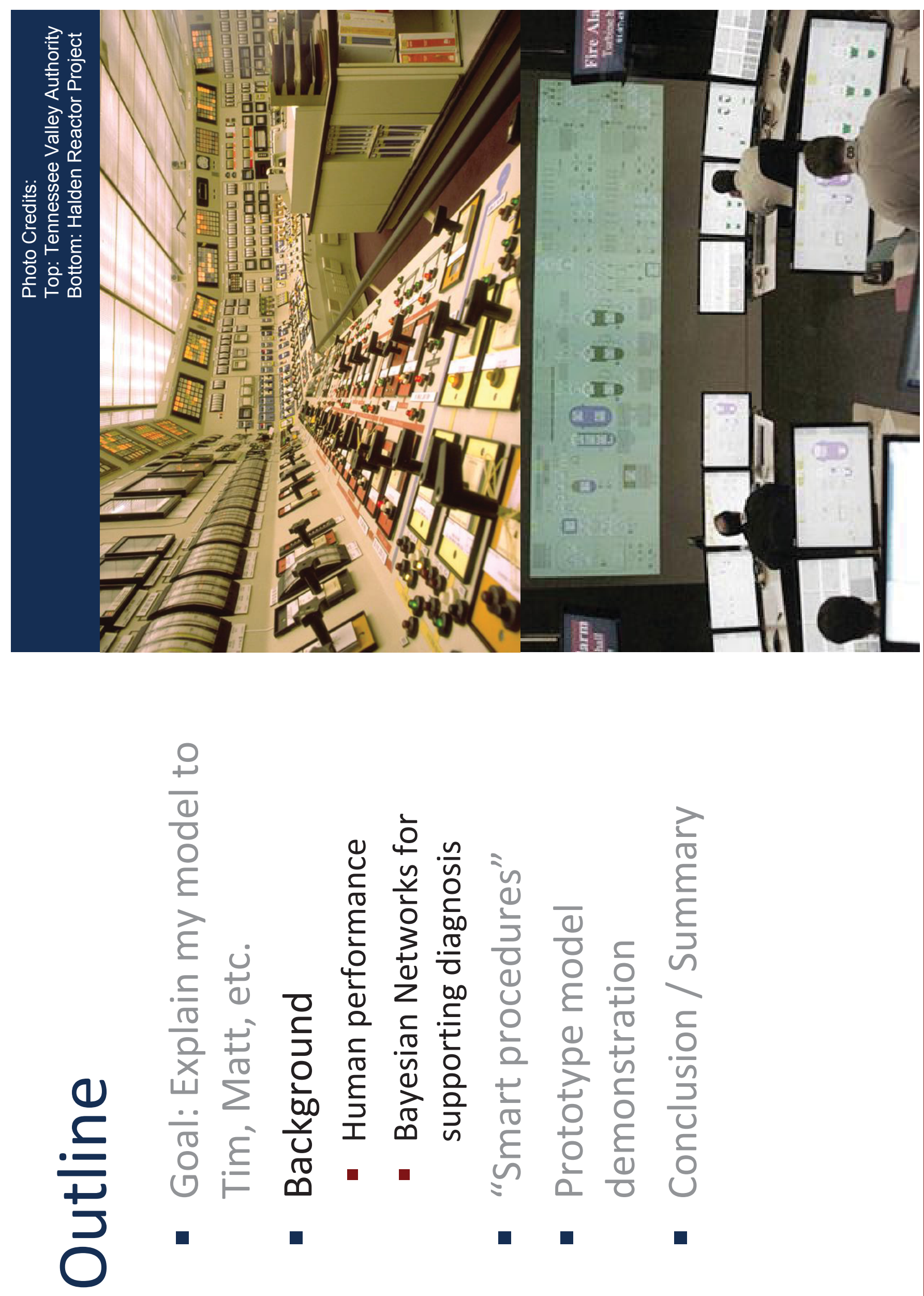


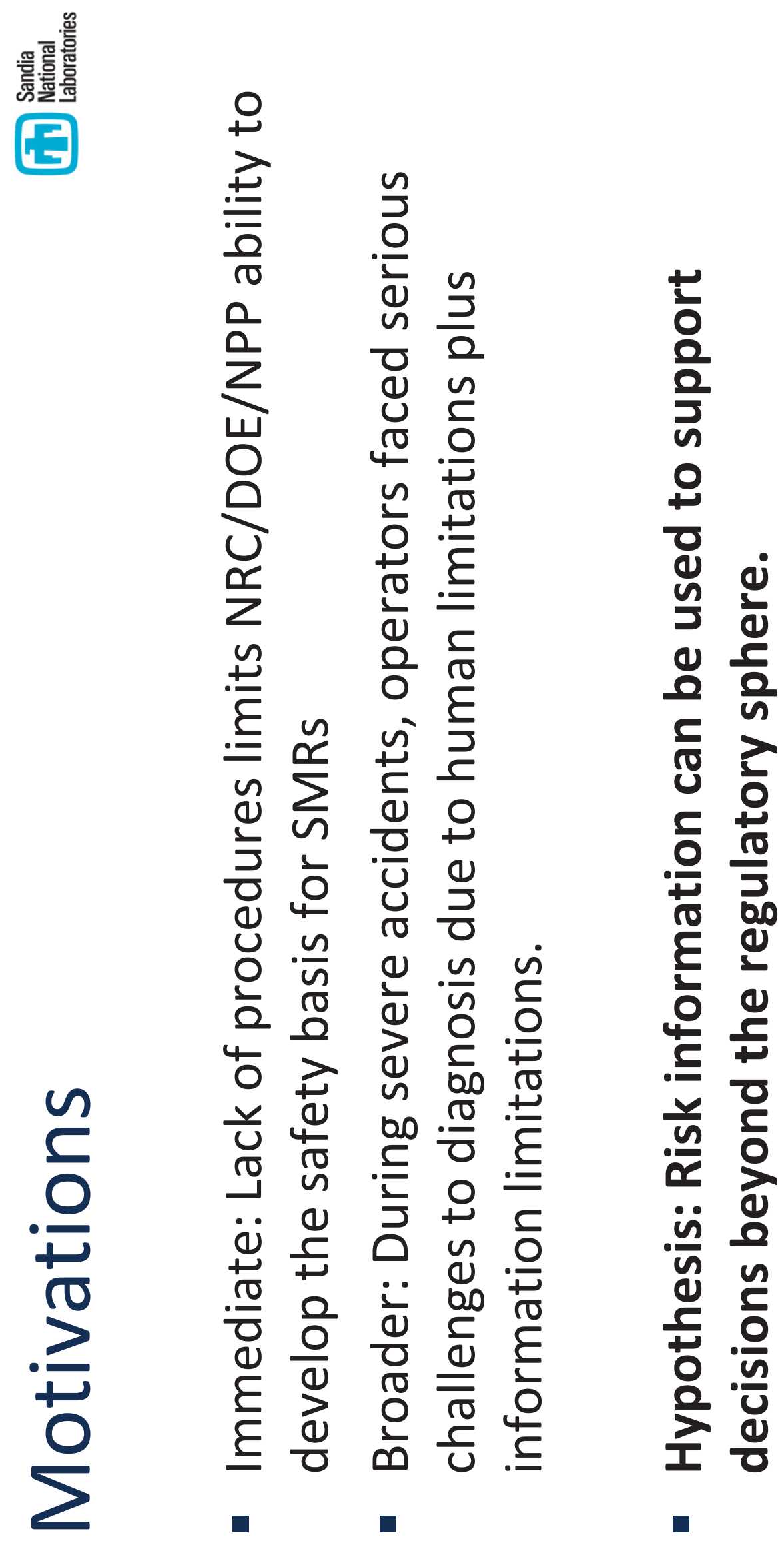




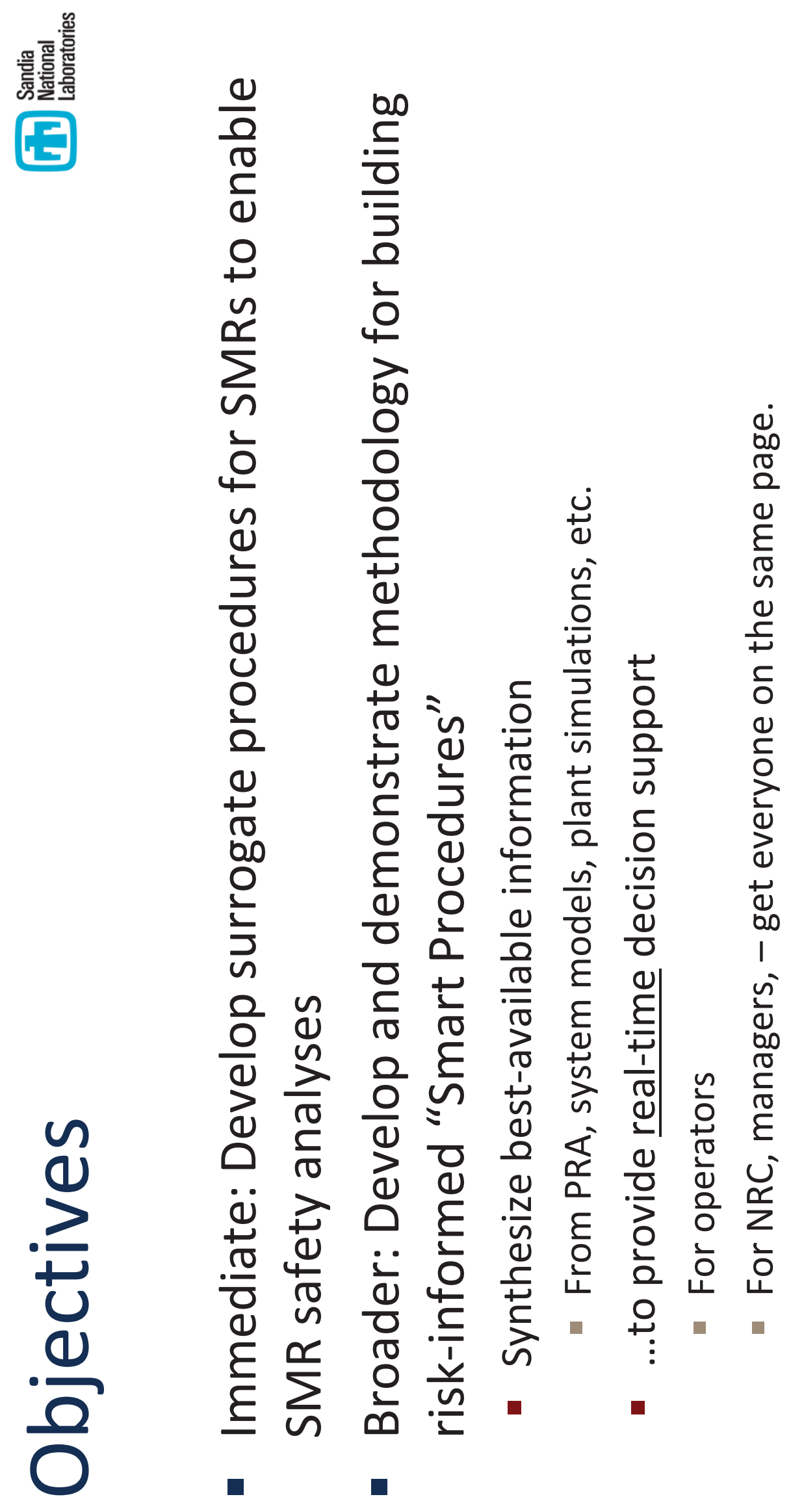




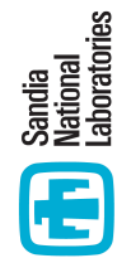

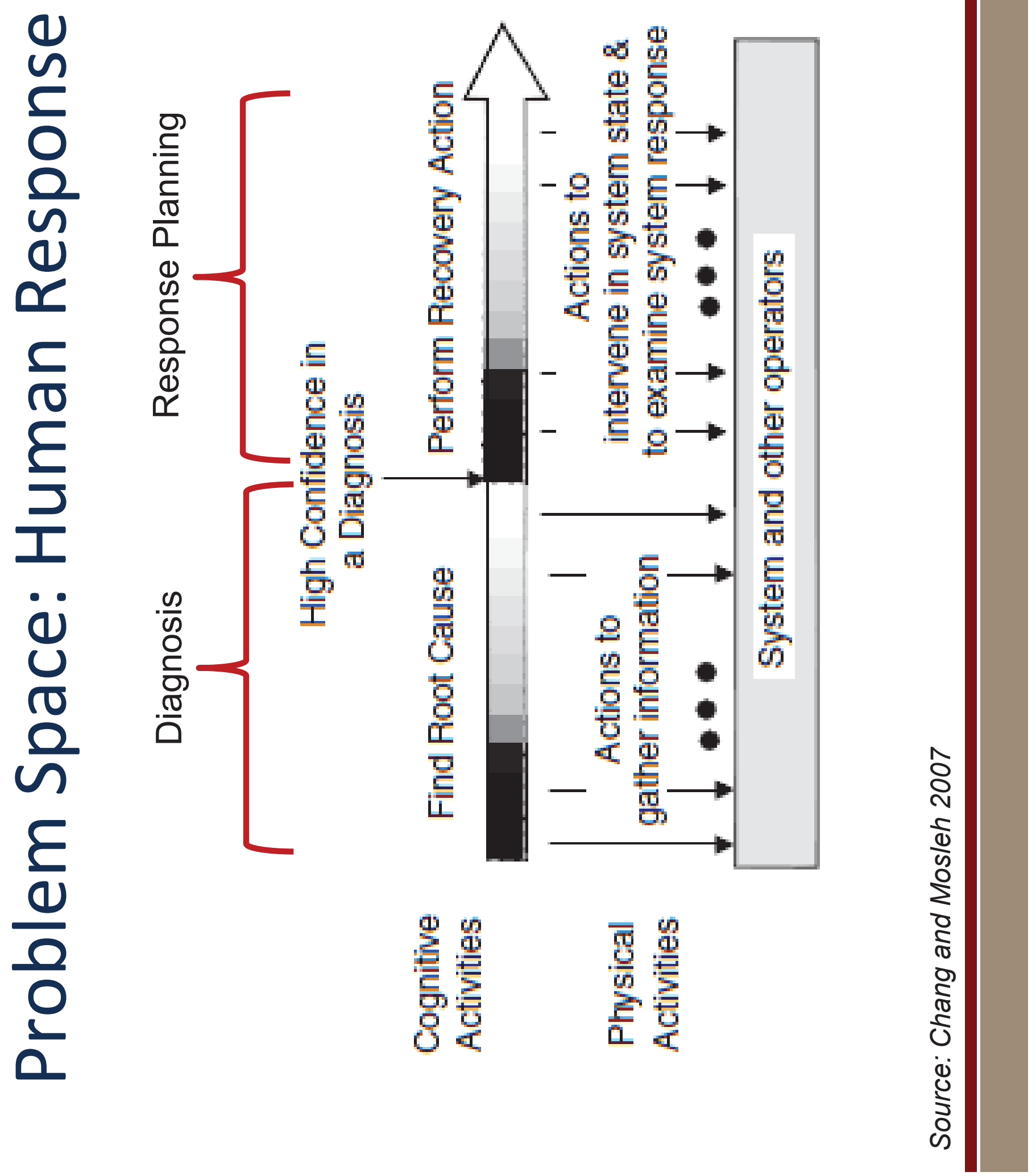




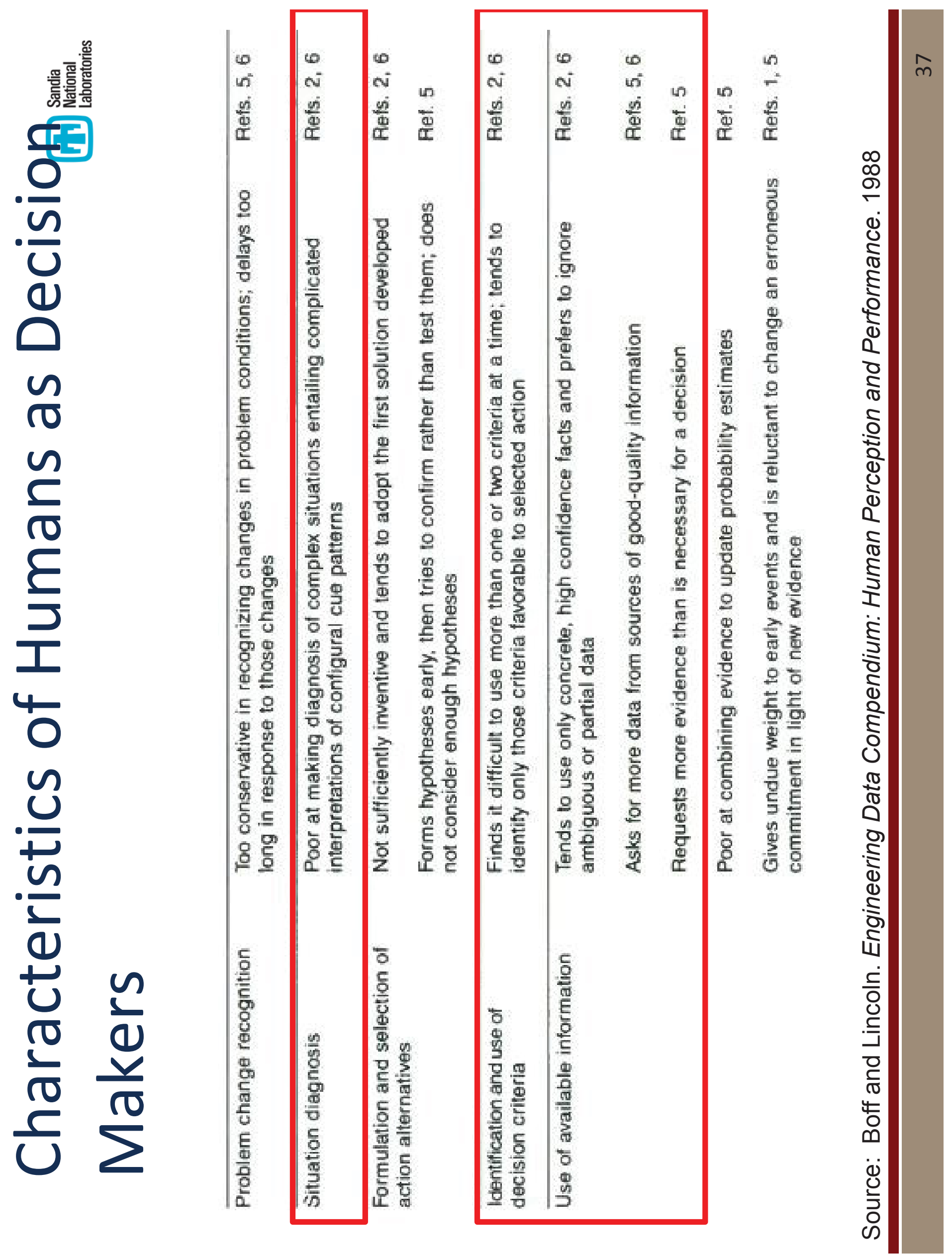




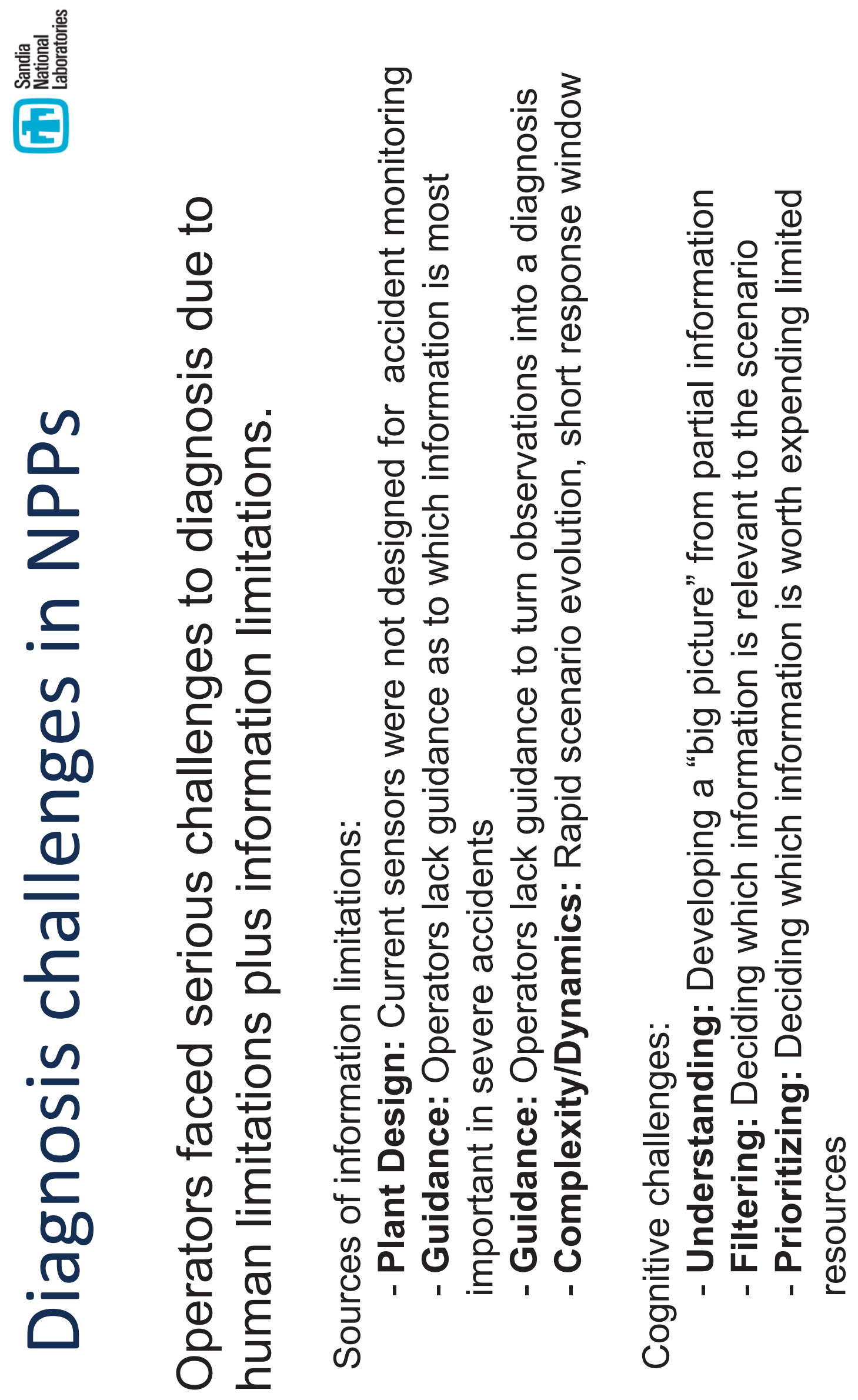




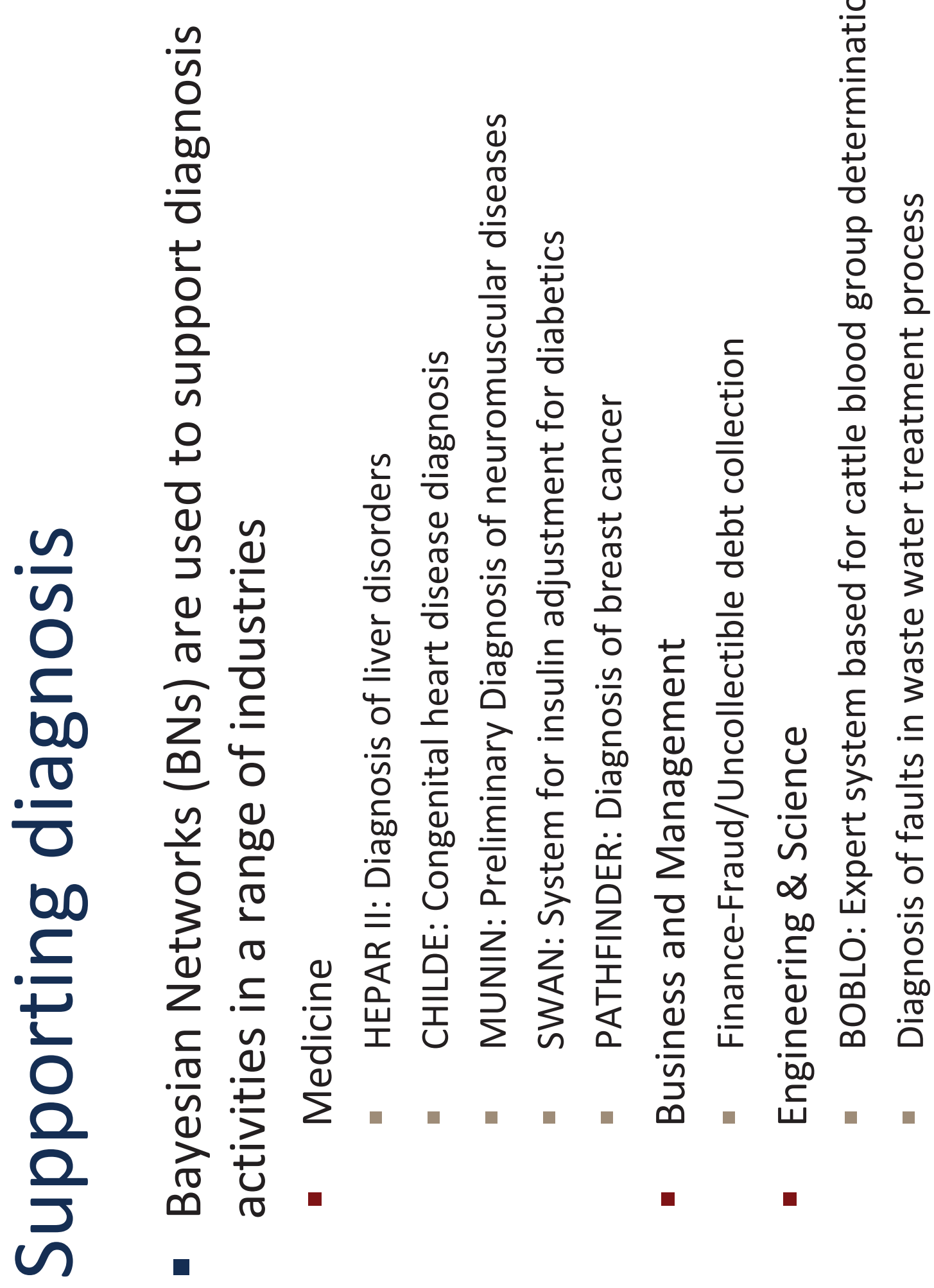




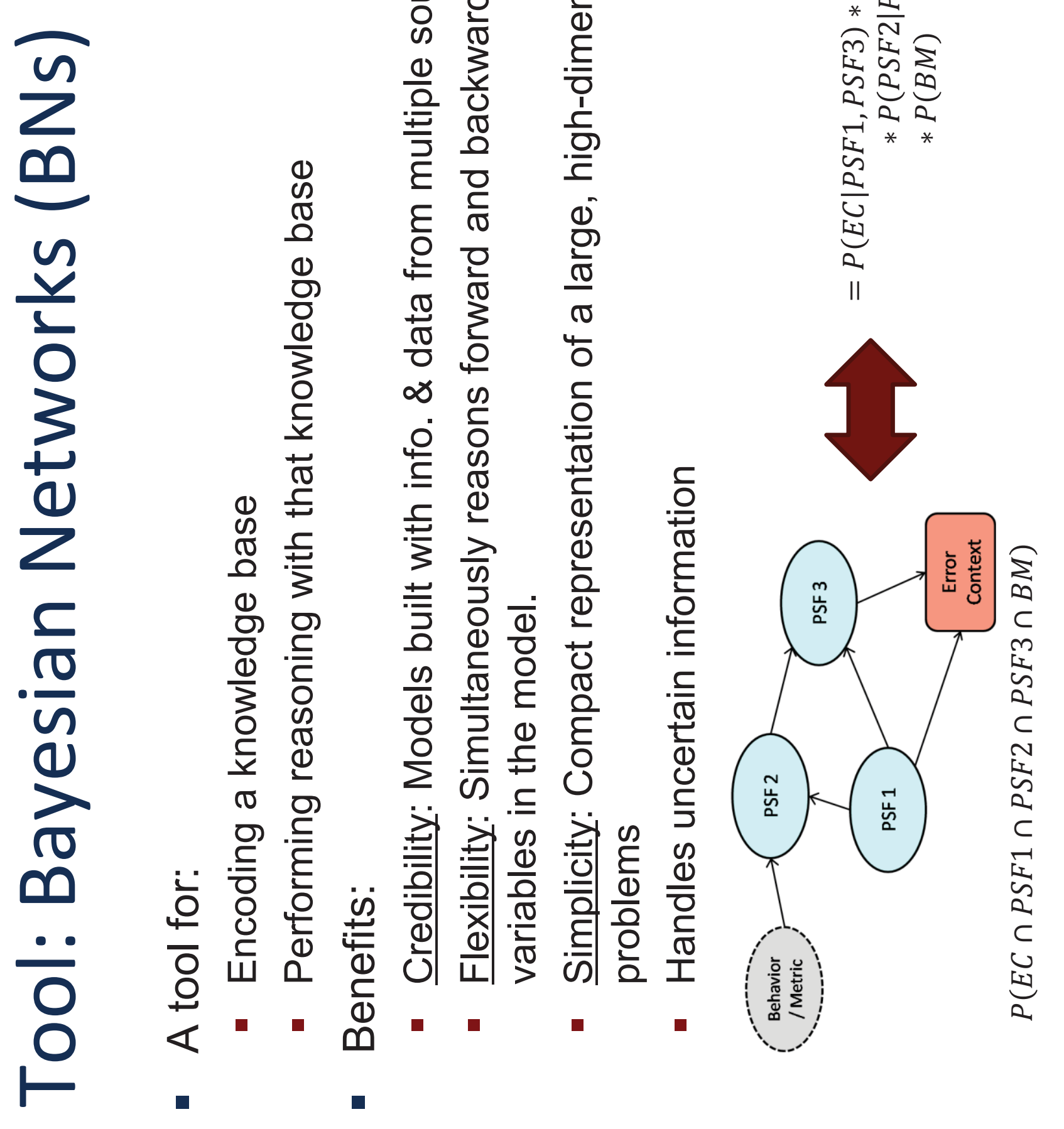



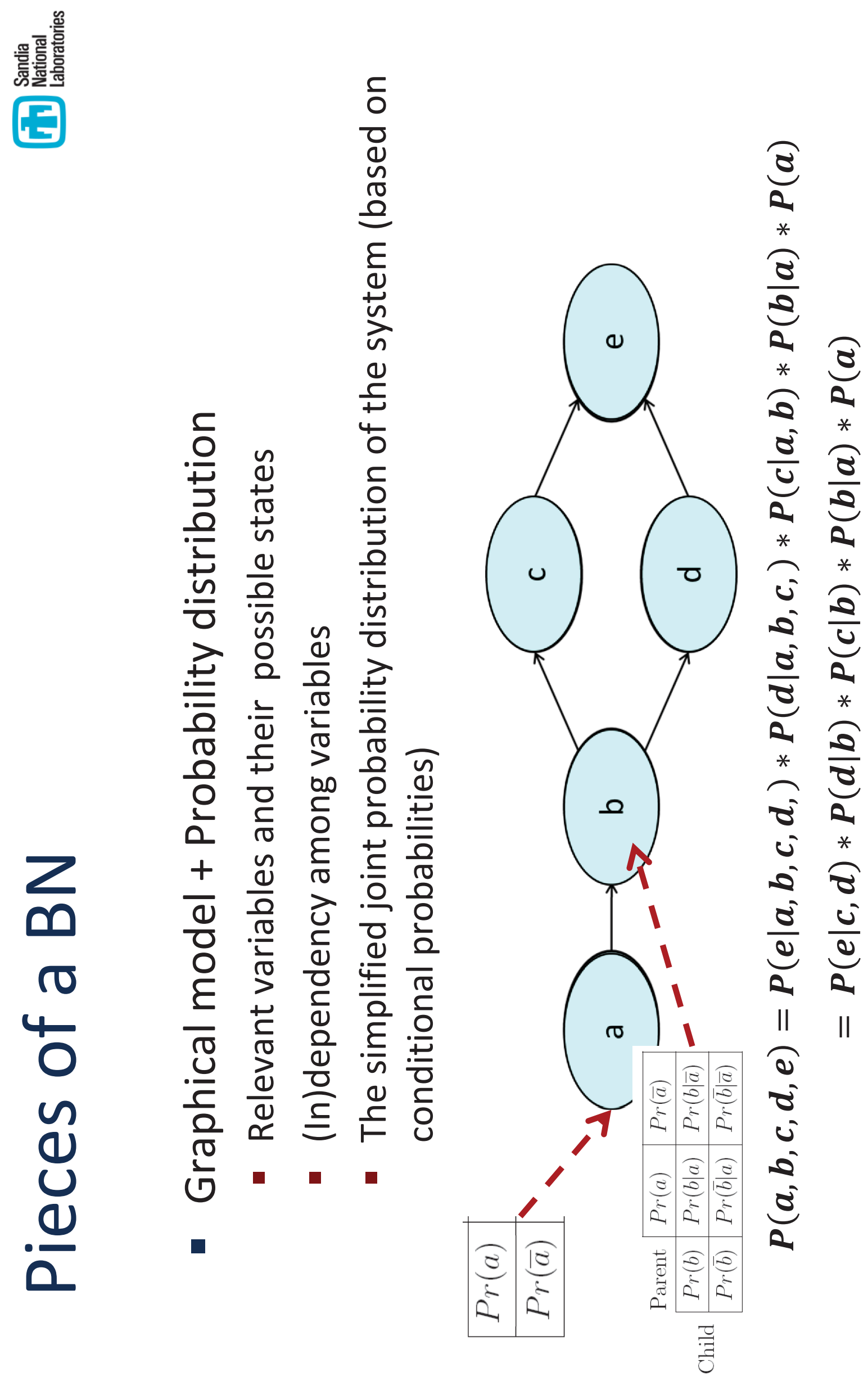


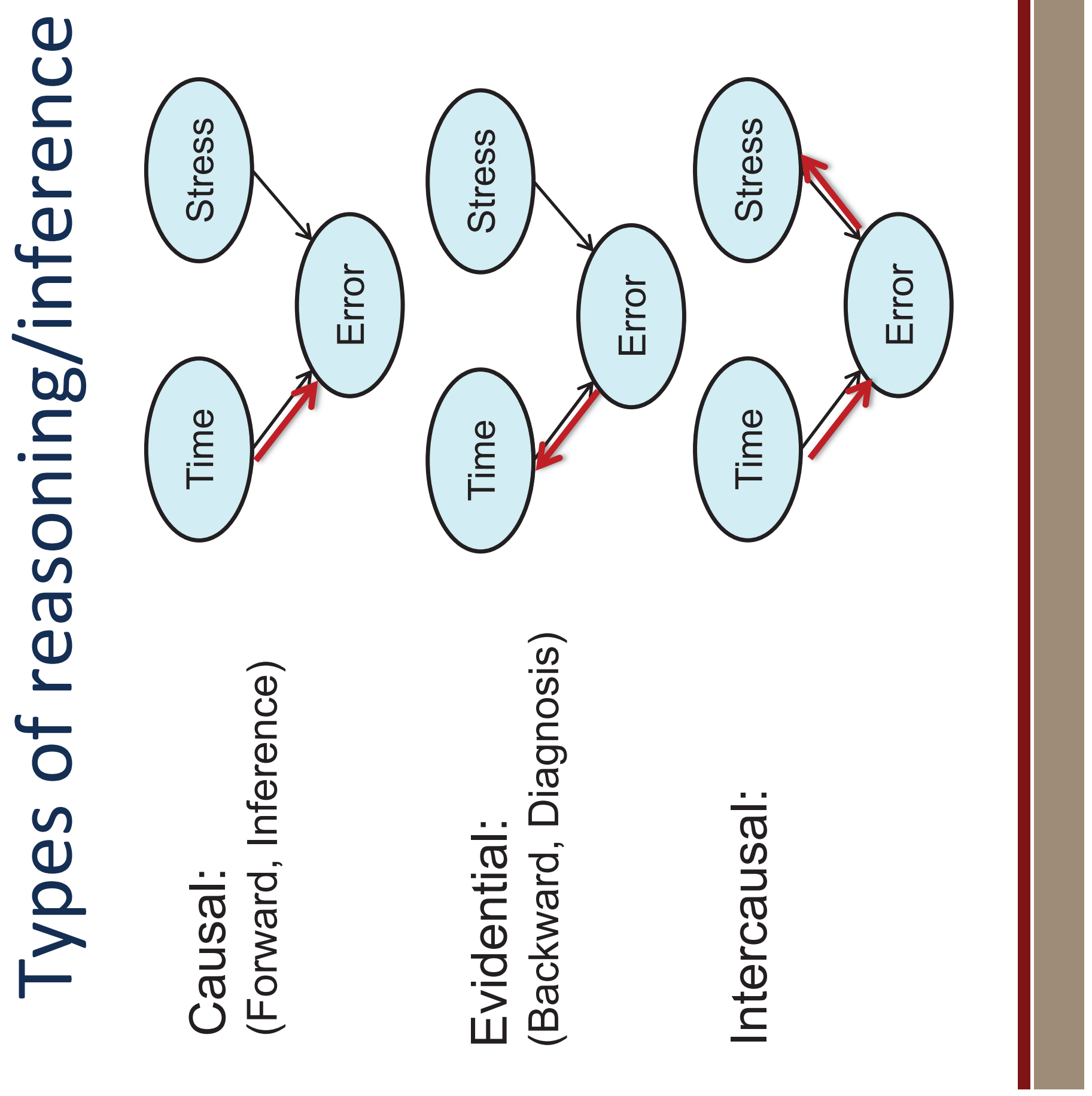




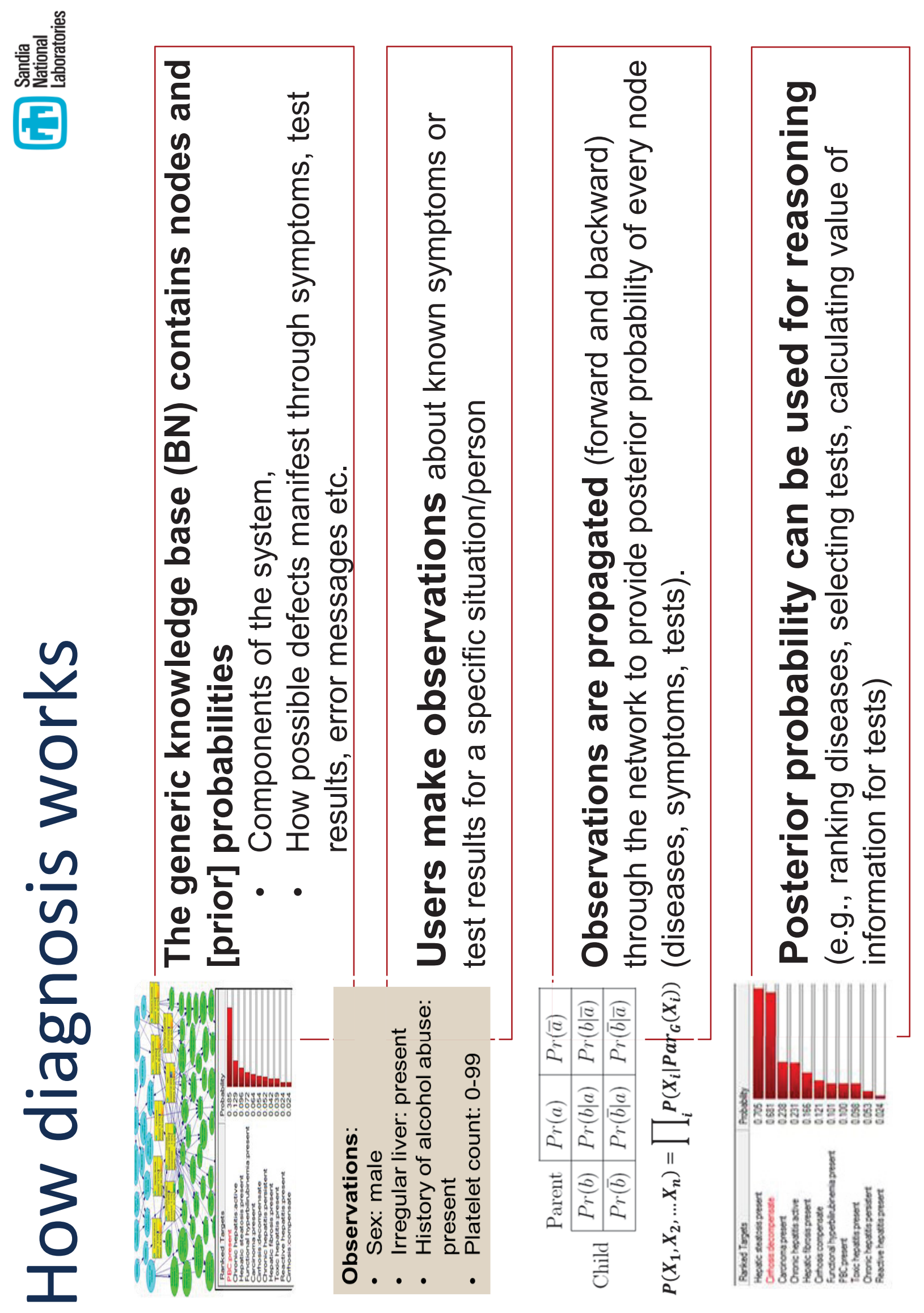




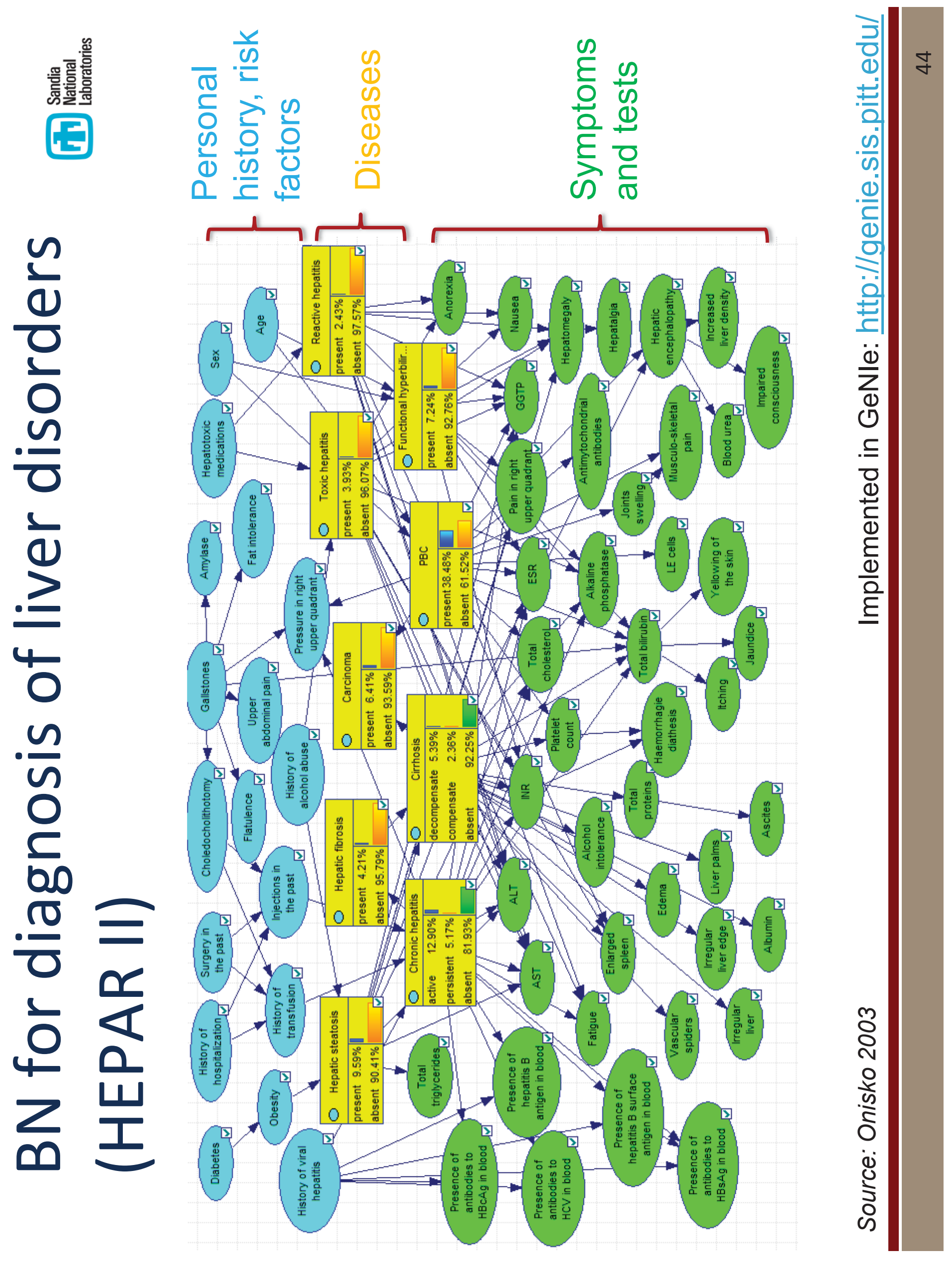




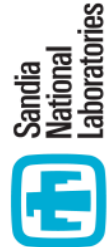
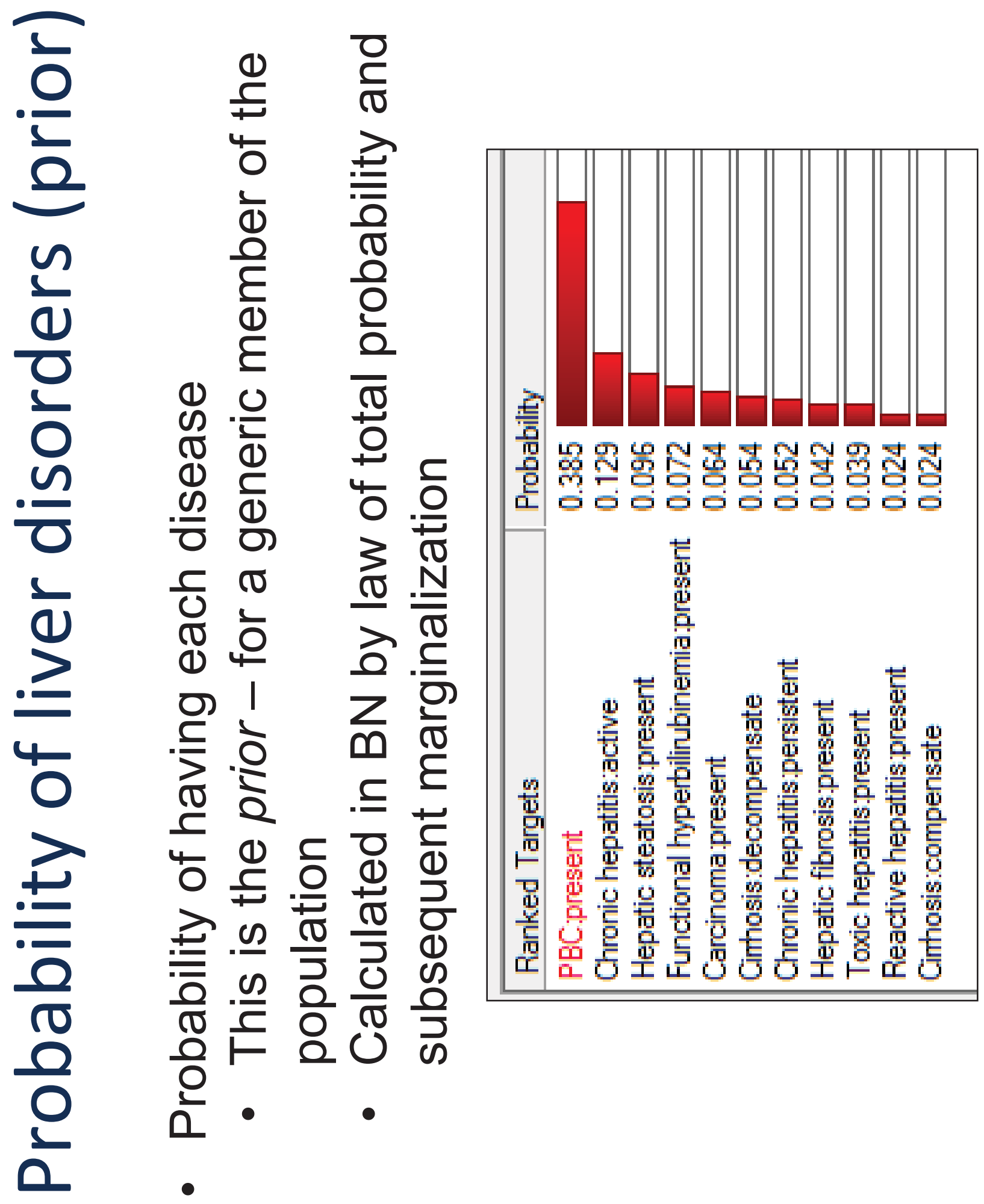

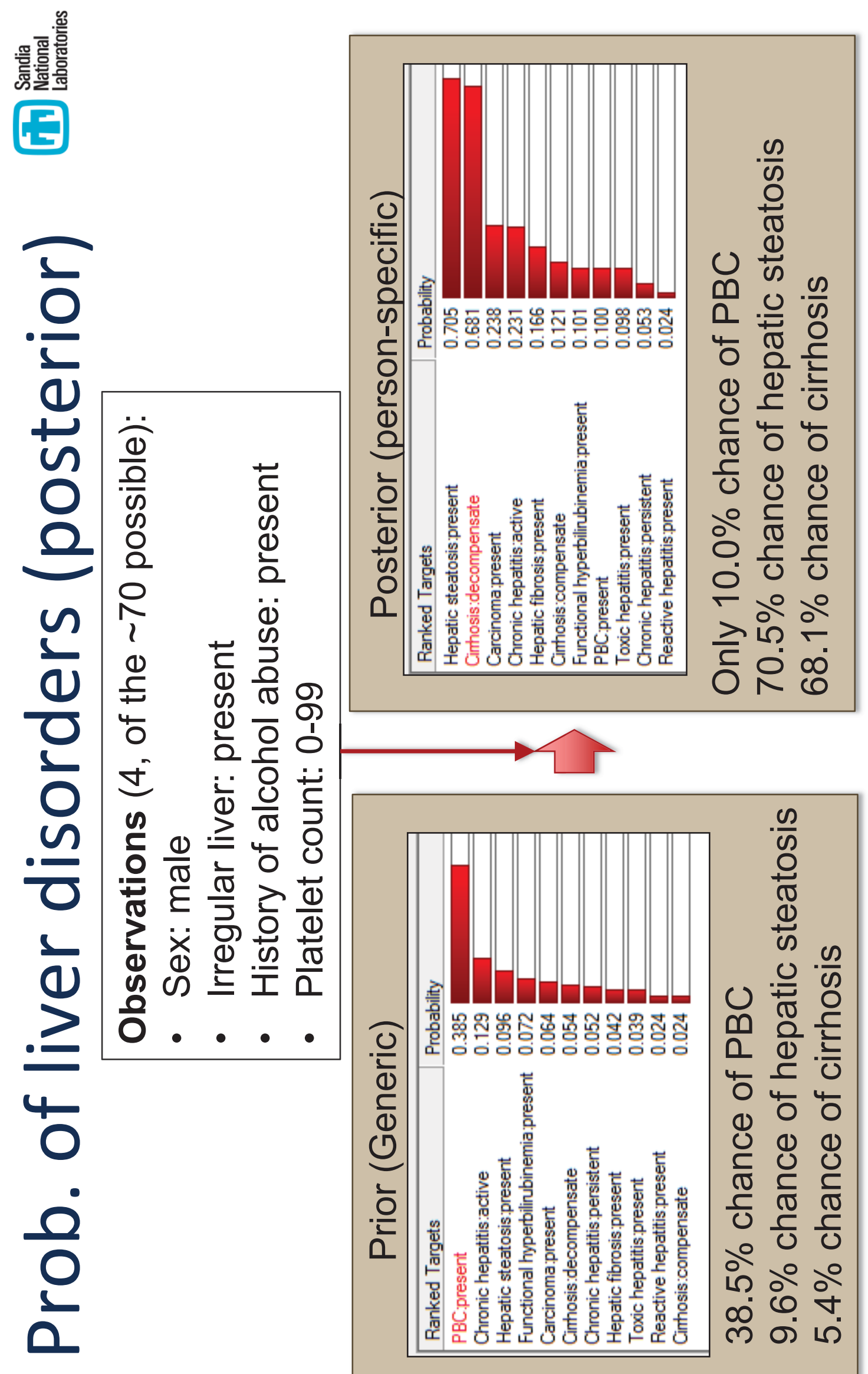

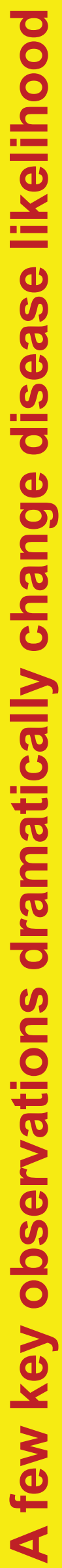



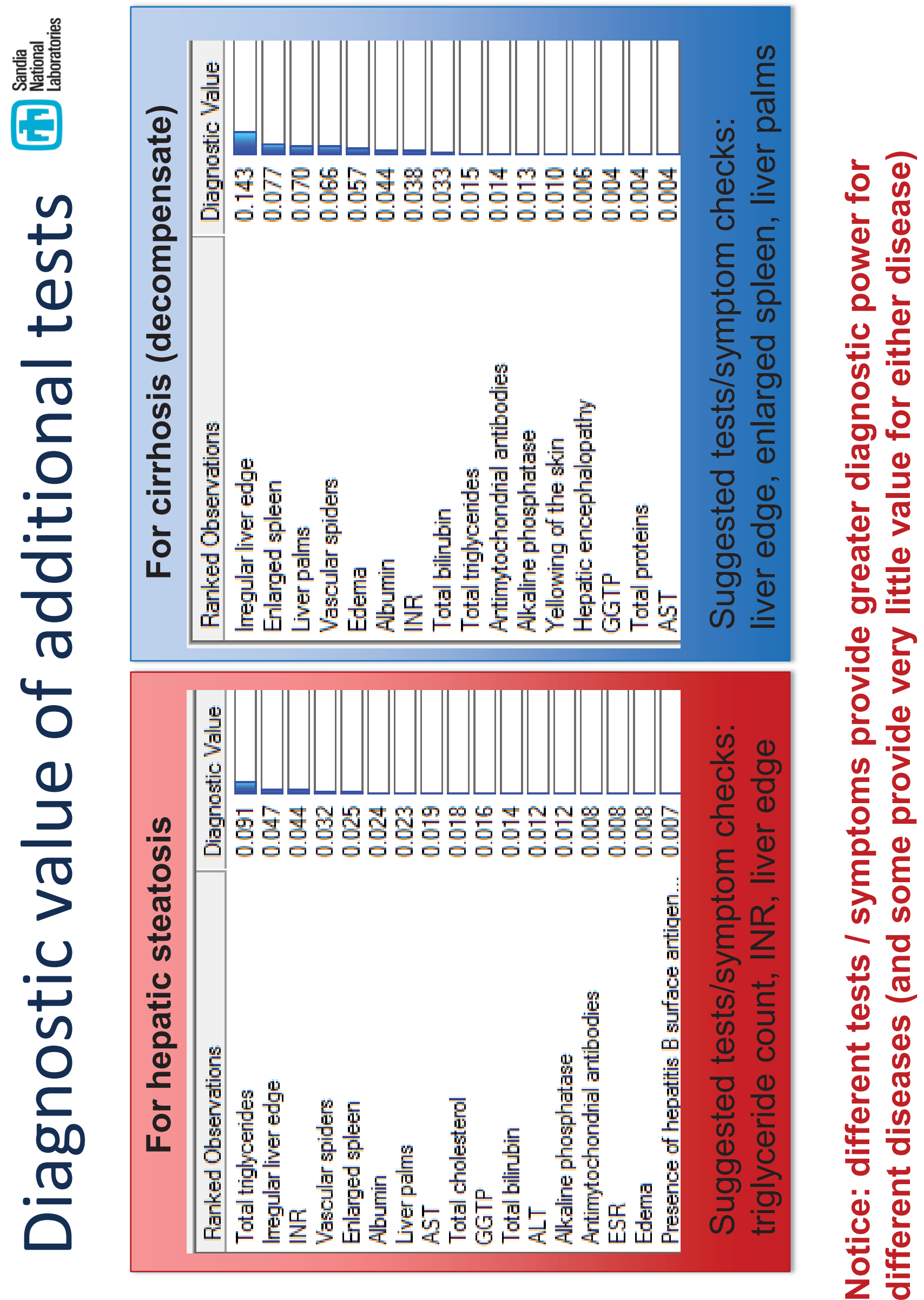


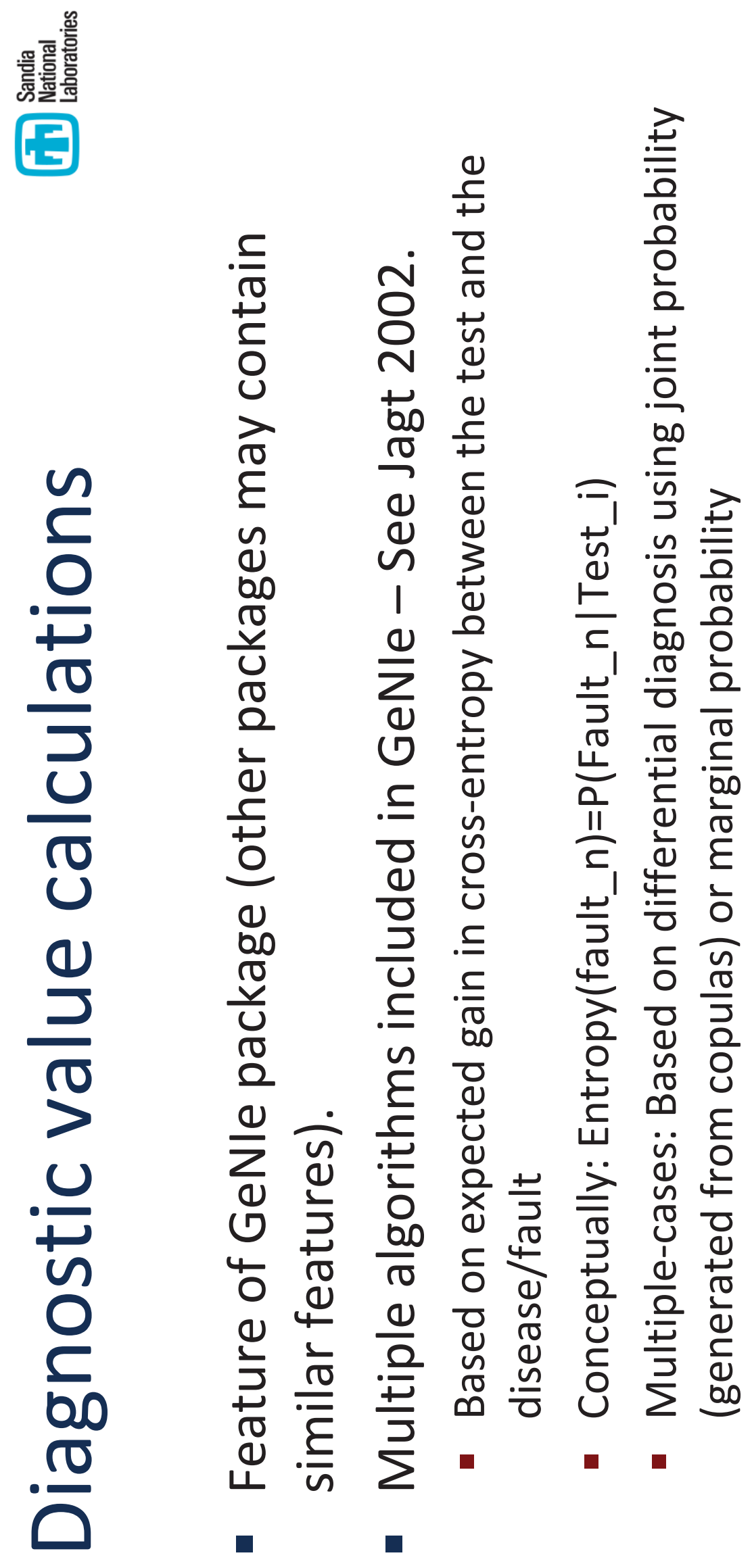



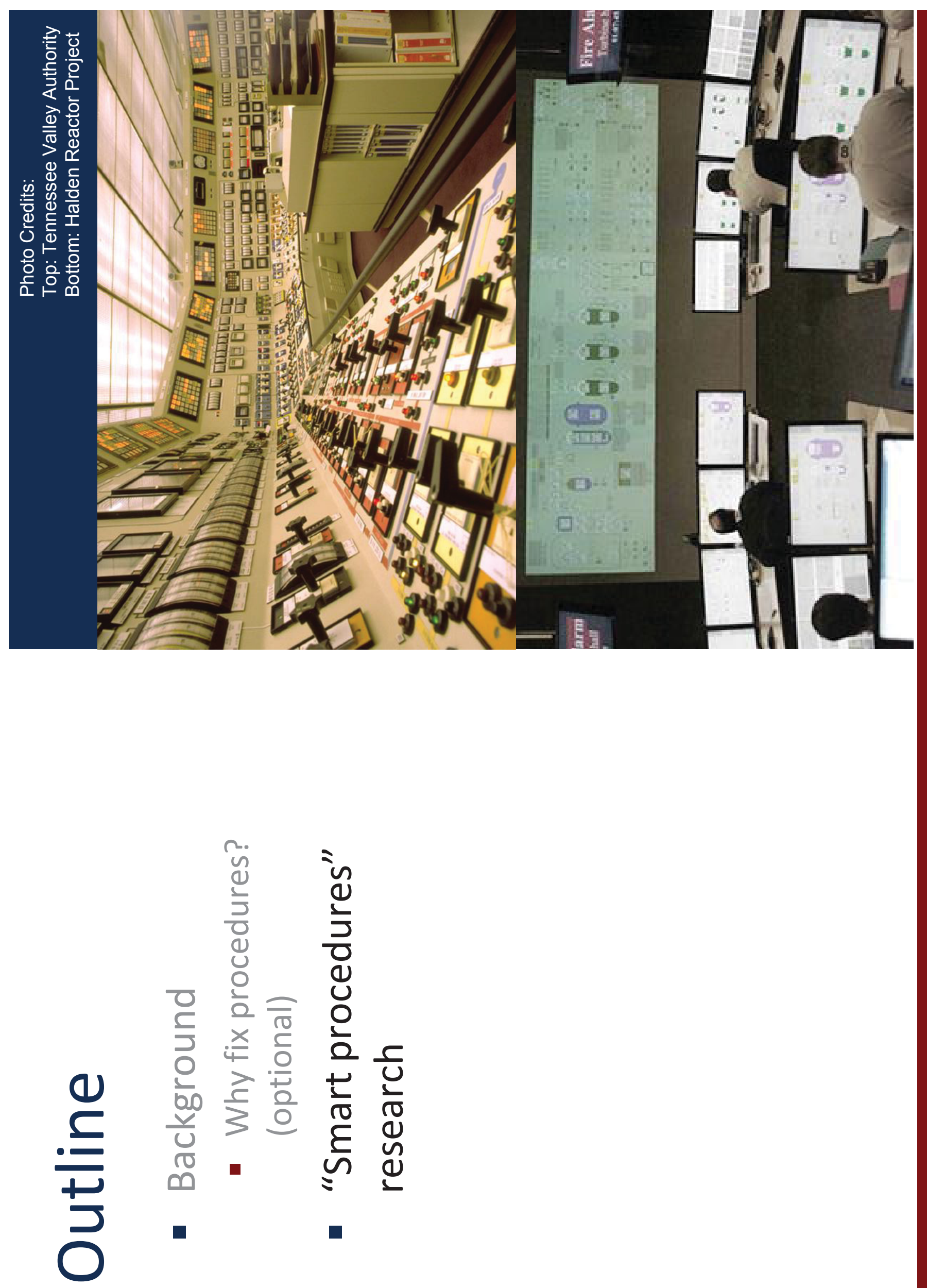


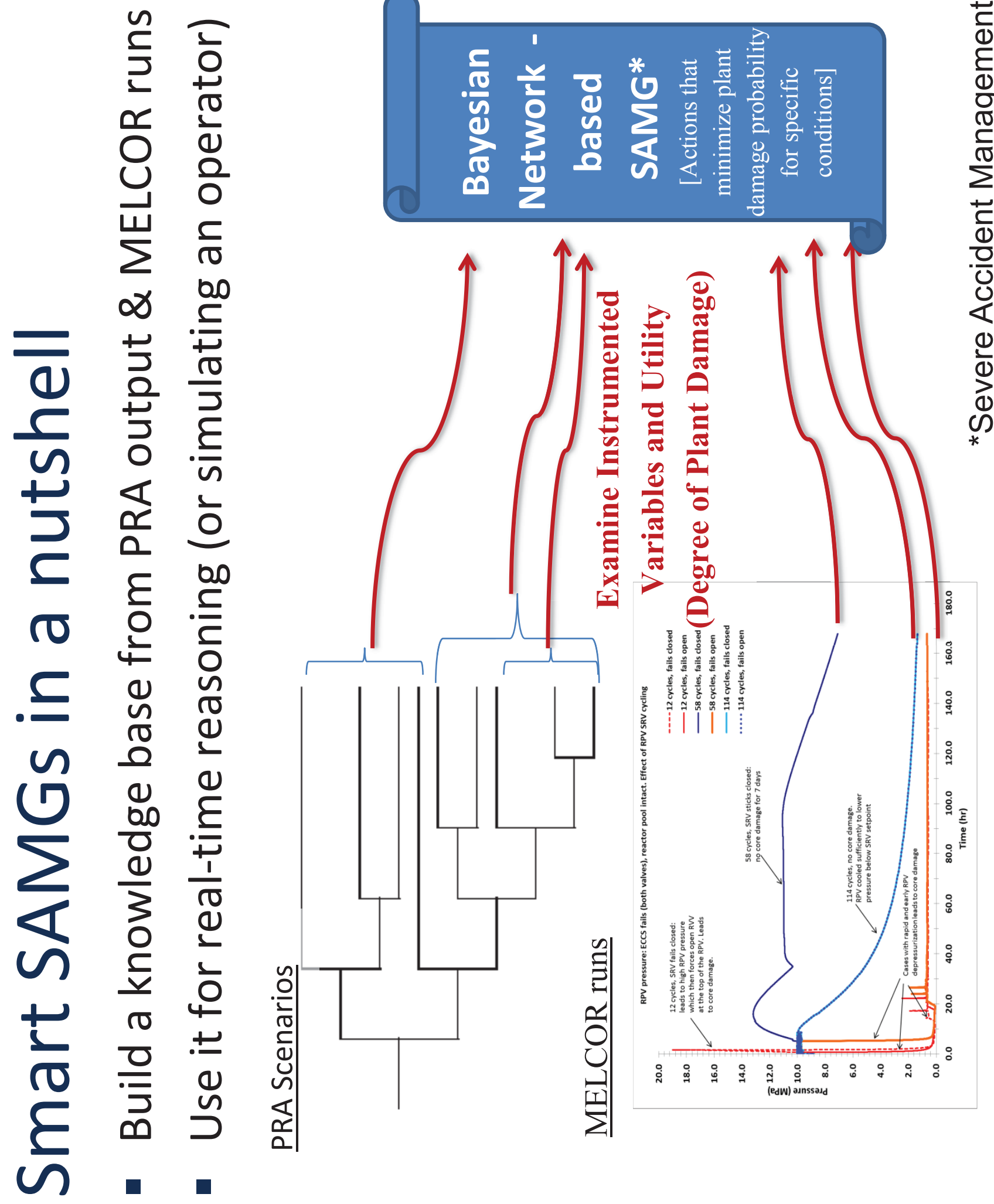




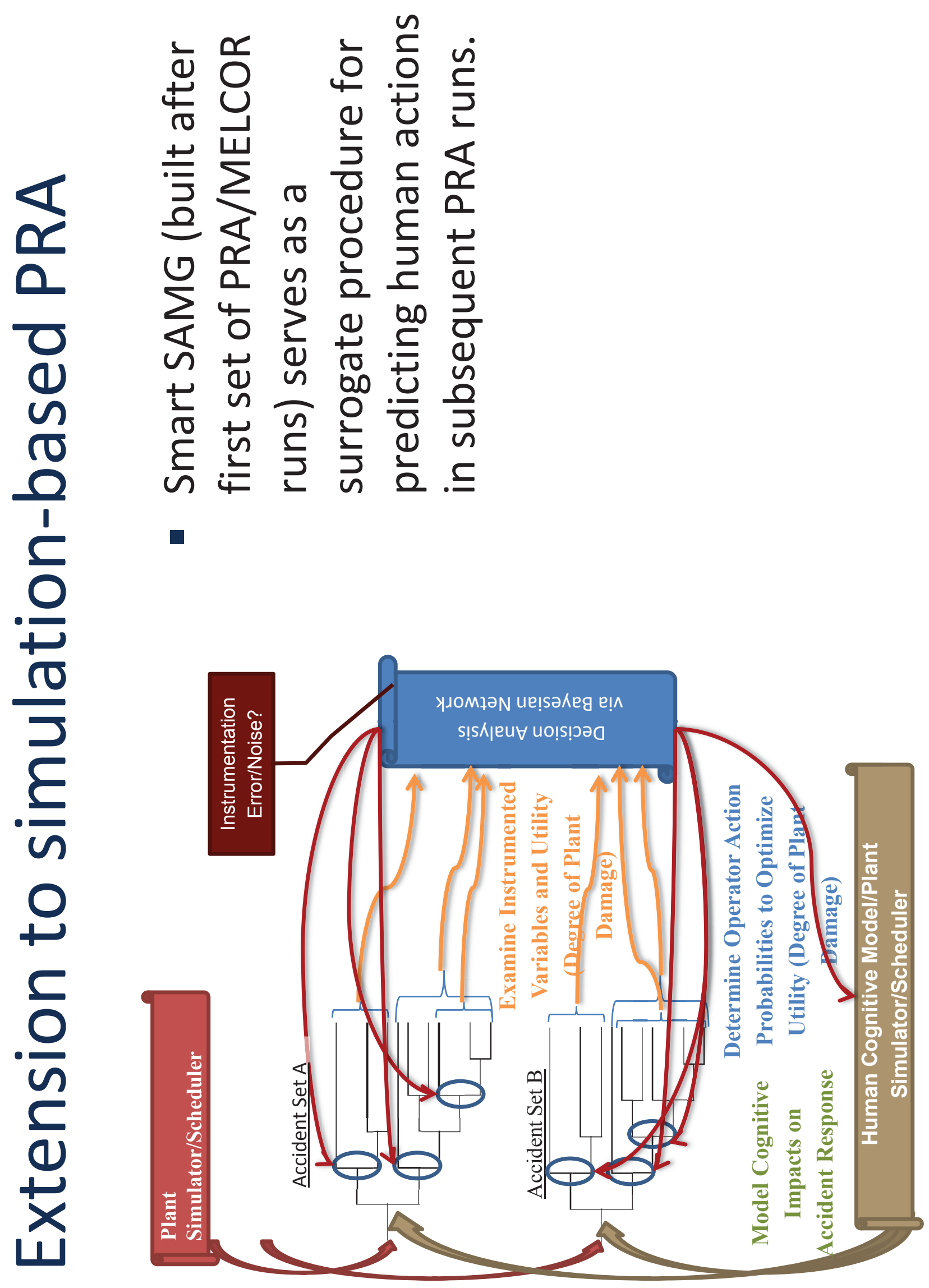



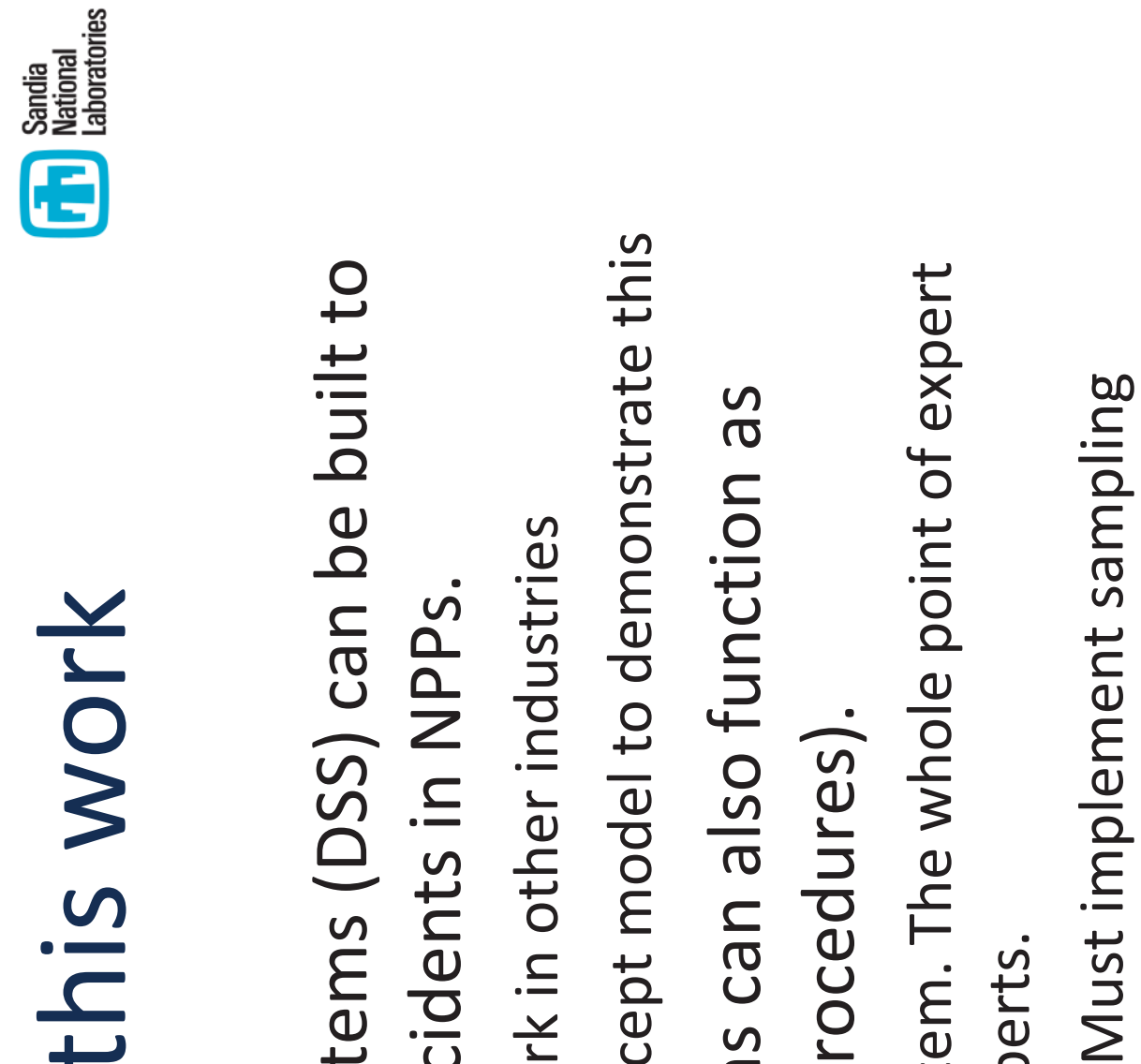

+ U 느 u

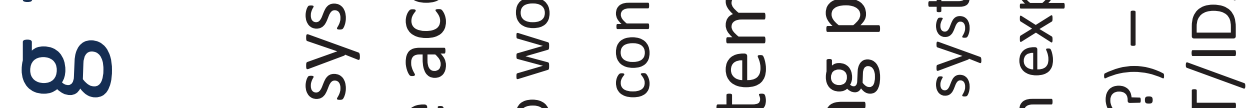

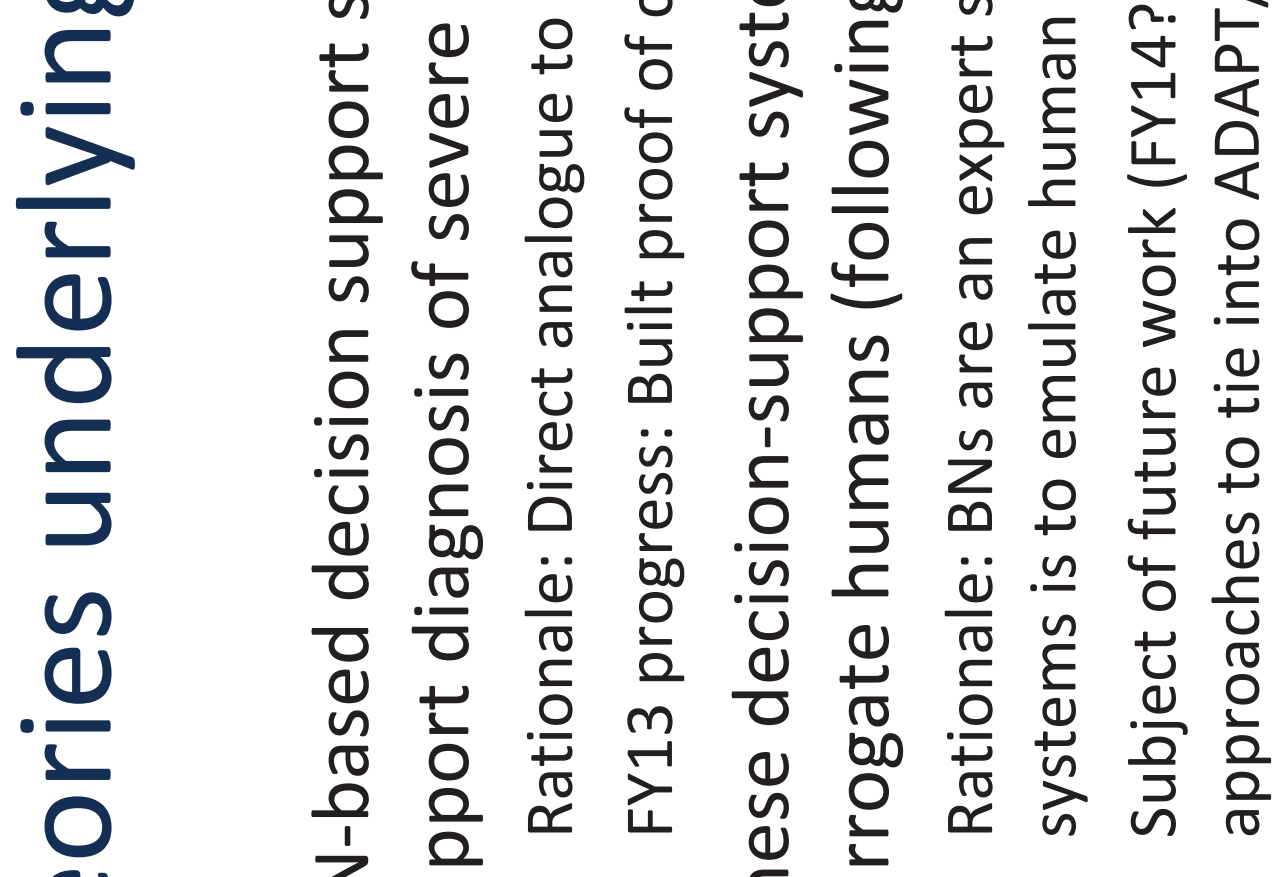

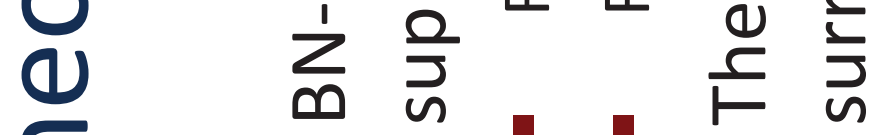

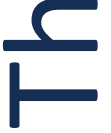

$\dot{1}$

i 


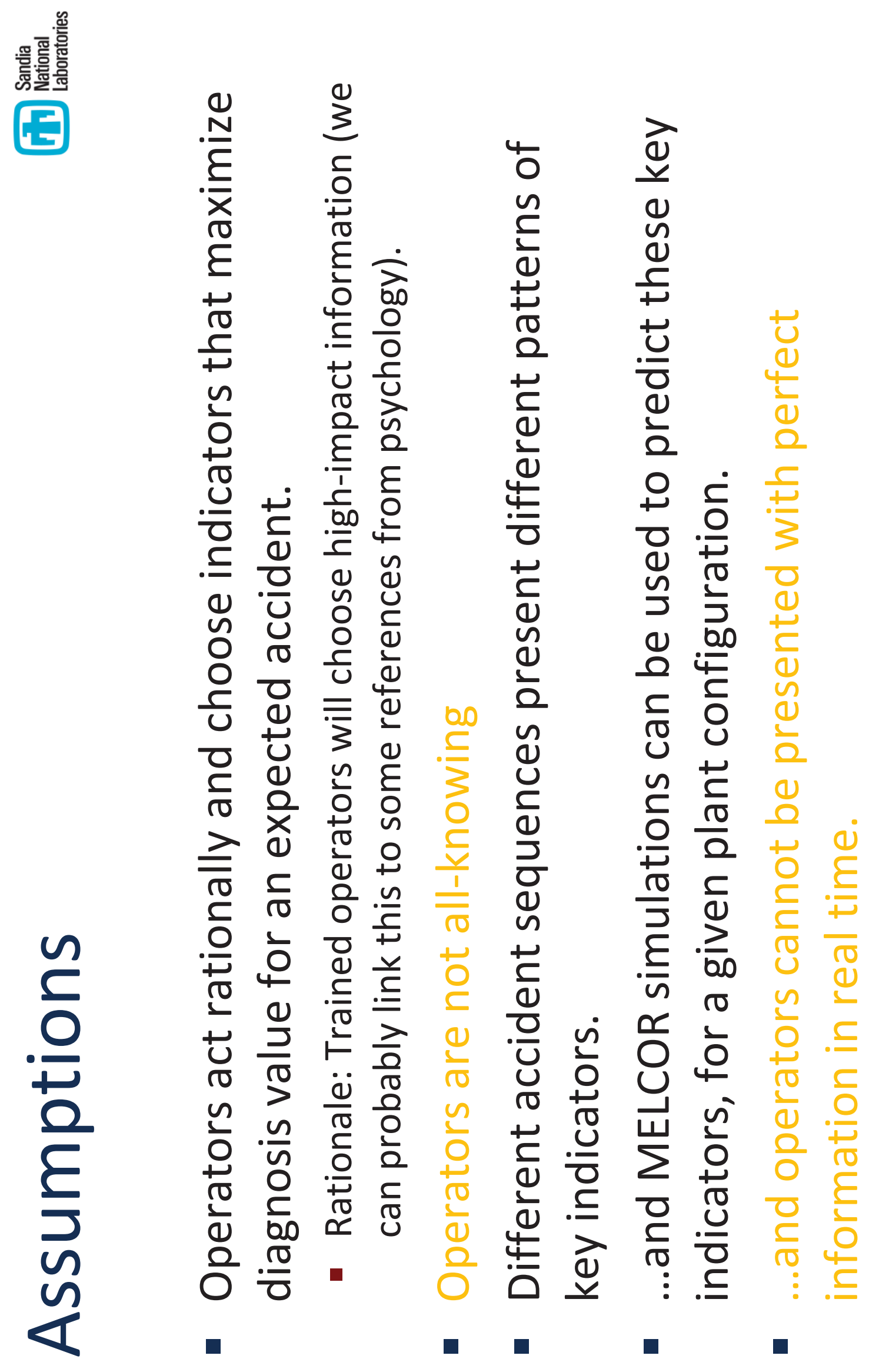



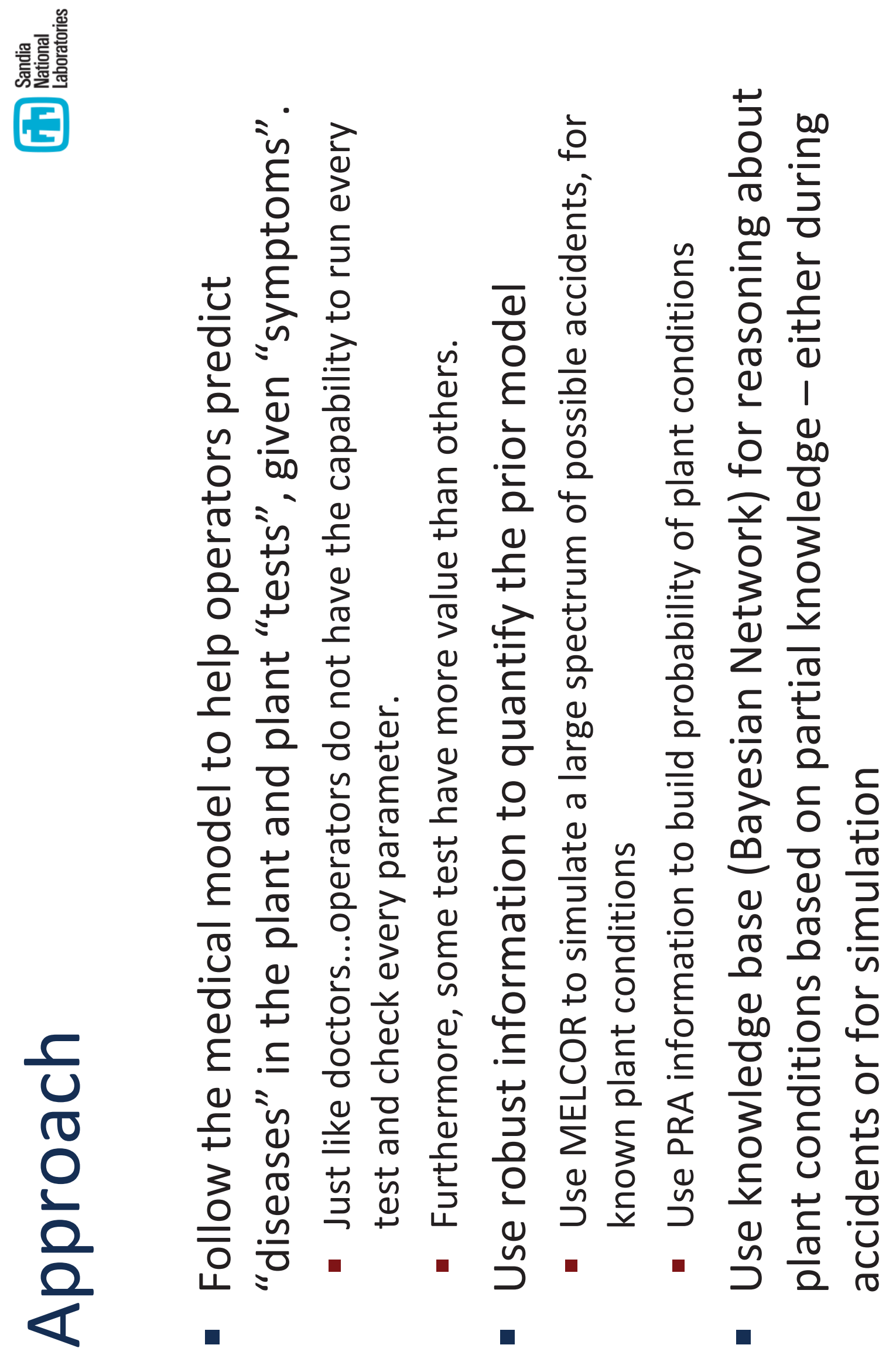

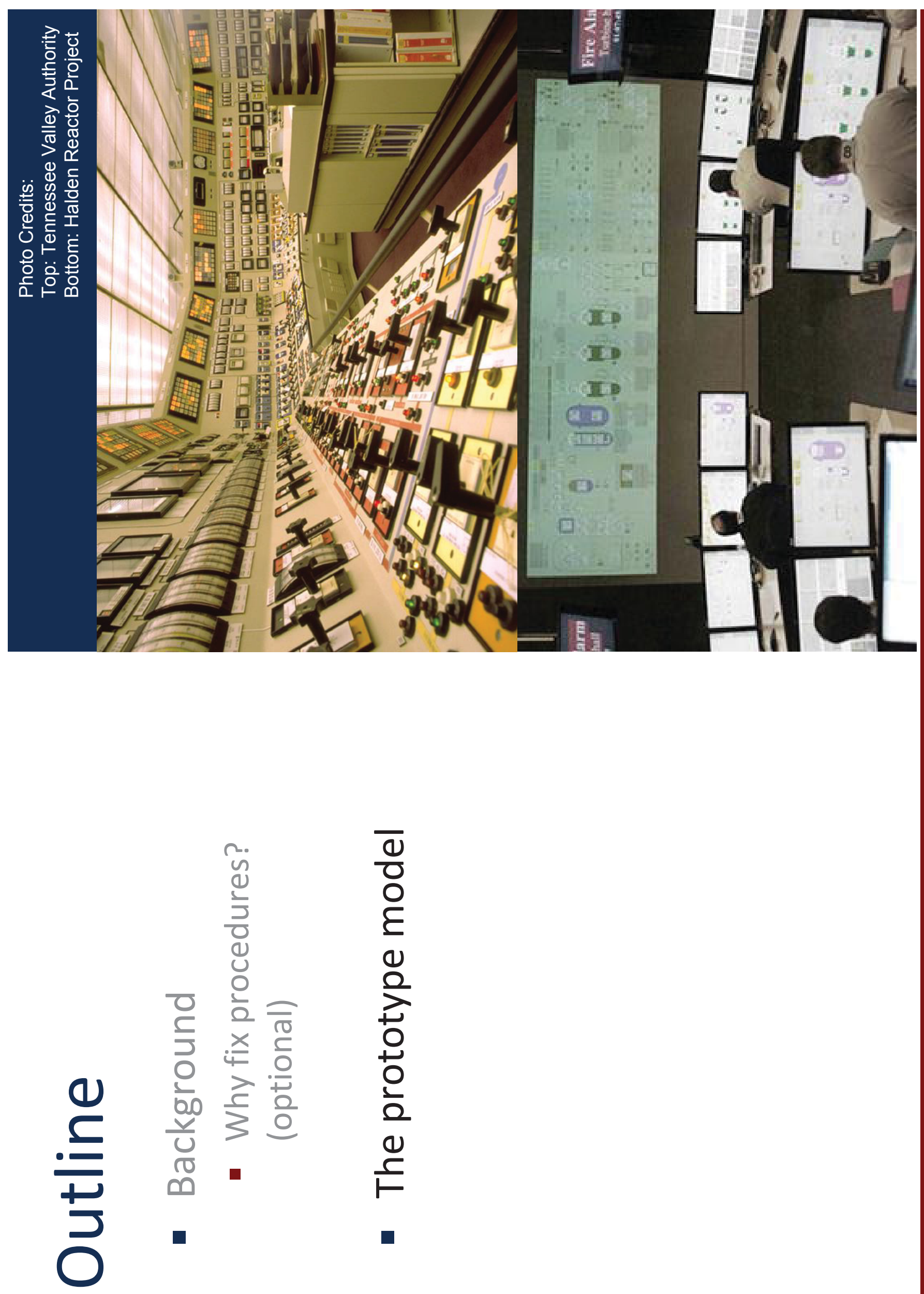


\section{总}

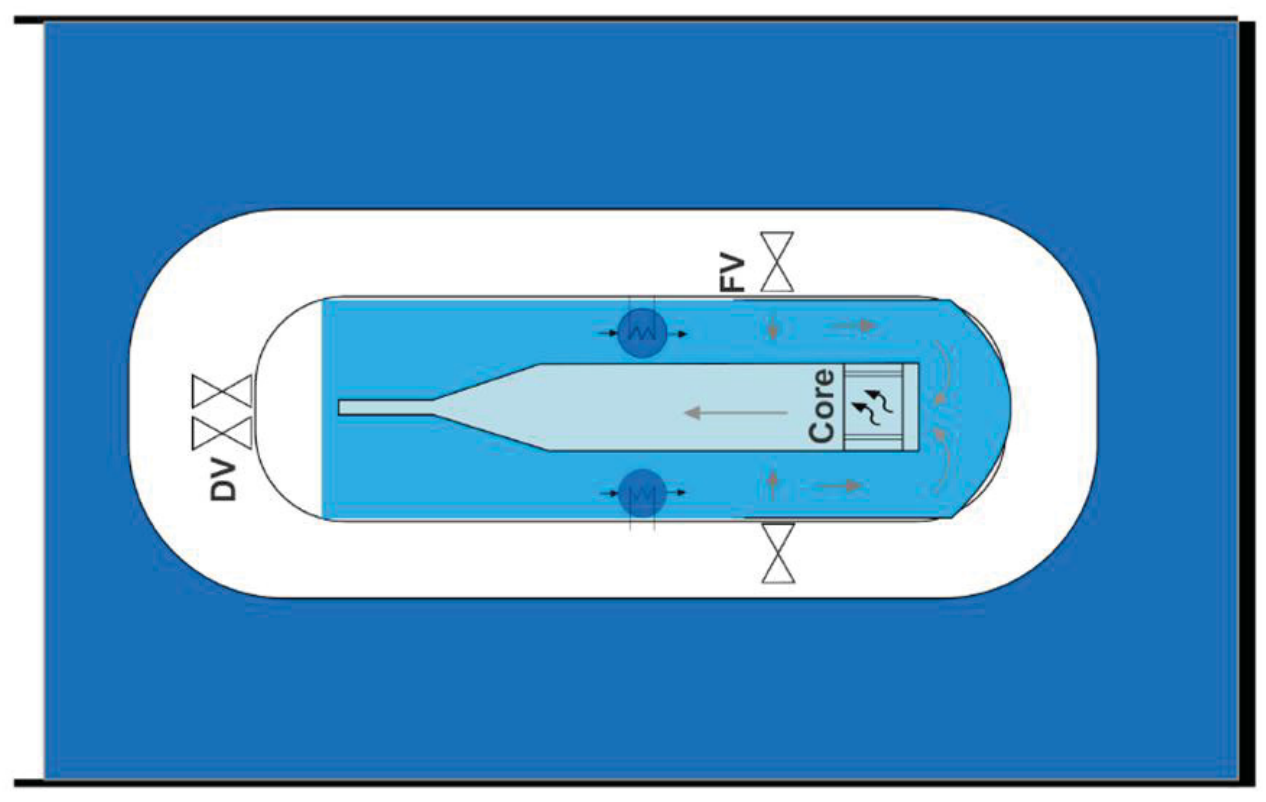

$\varepsilon \quad \stackrel{0}{\frac{1}{0}}$

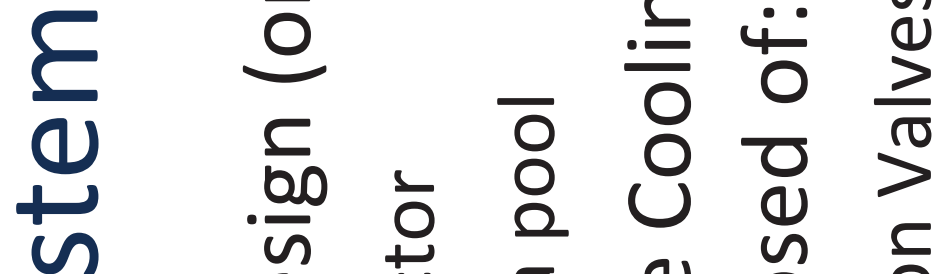

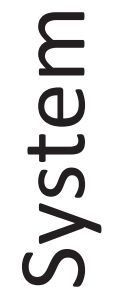

ฮ U

n

(1)

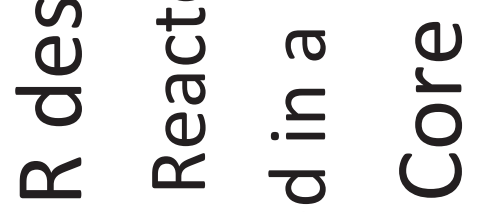

요

$\varepsilon$

$\bar{\sigma}$

ע

$3^{5} \stackrel{0}{0}$

م

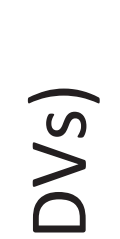

$\frac{7}{4}$

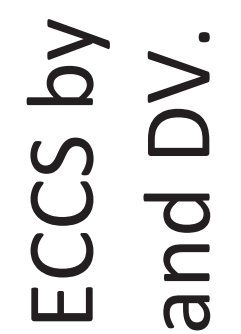

읃

$\frac{\varepsilon}{4}$

(1) 0 을 


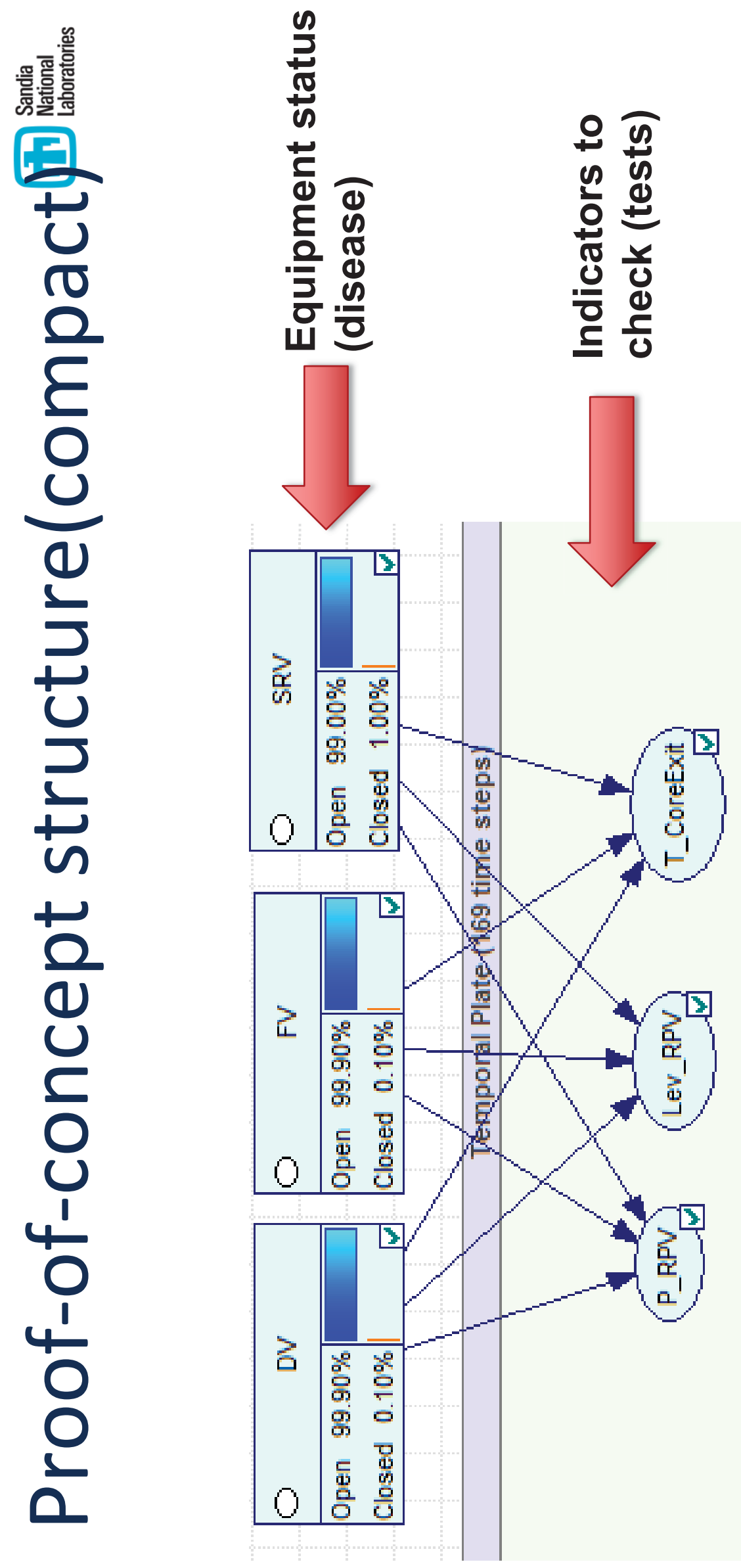




\section{田}
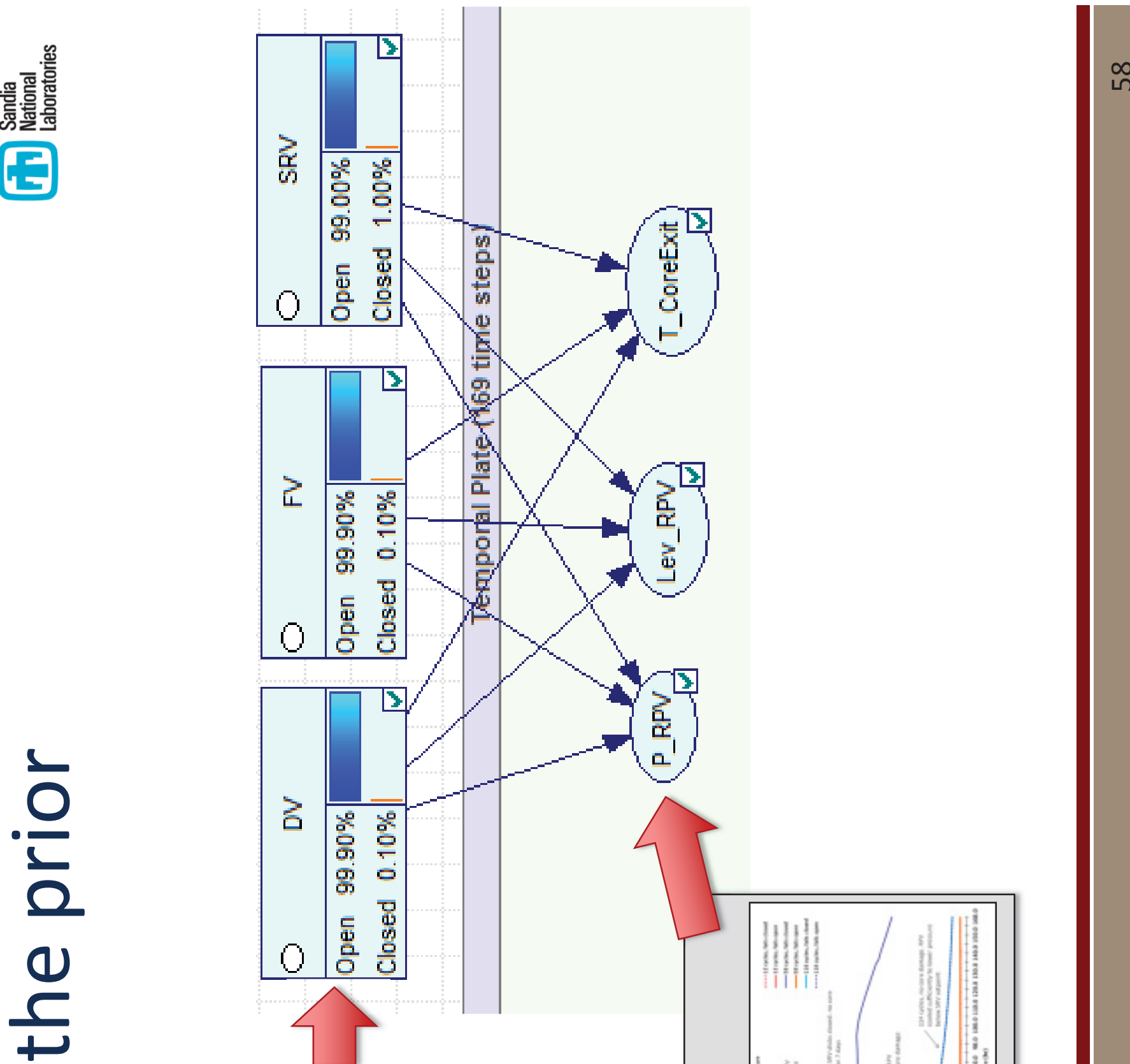

0 产 응

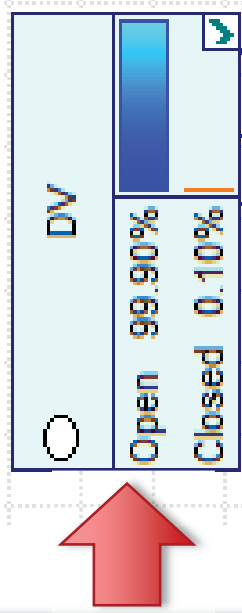

مه
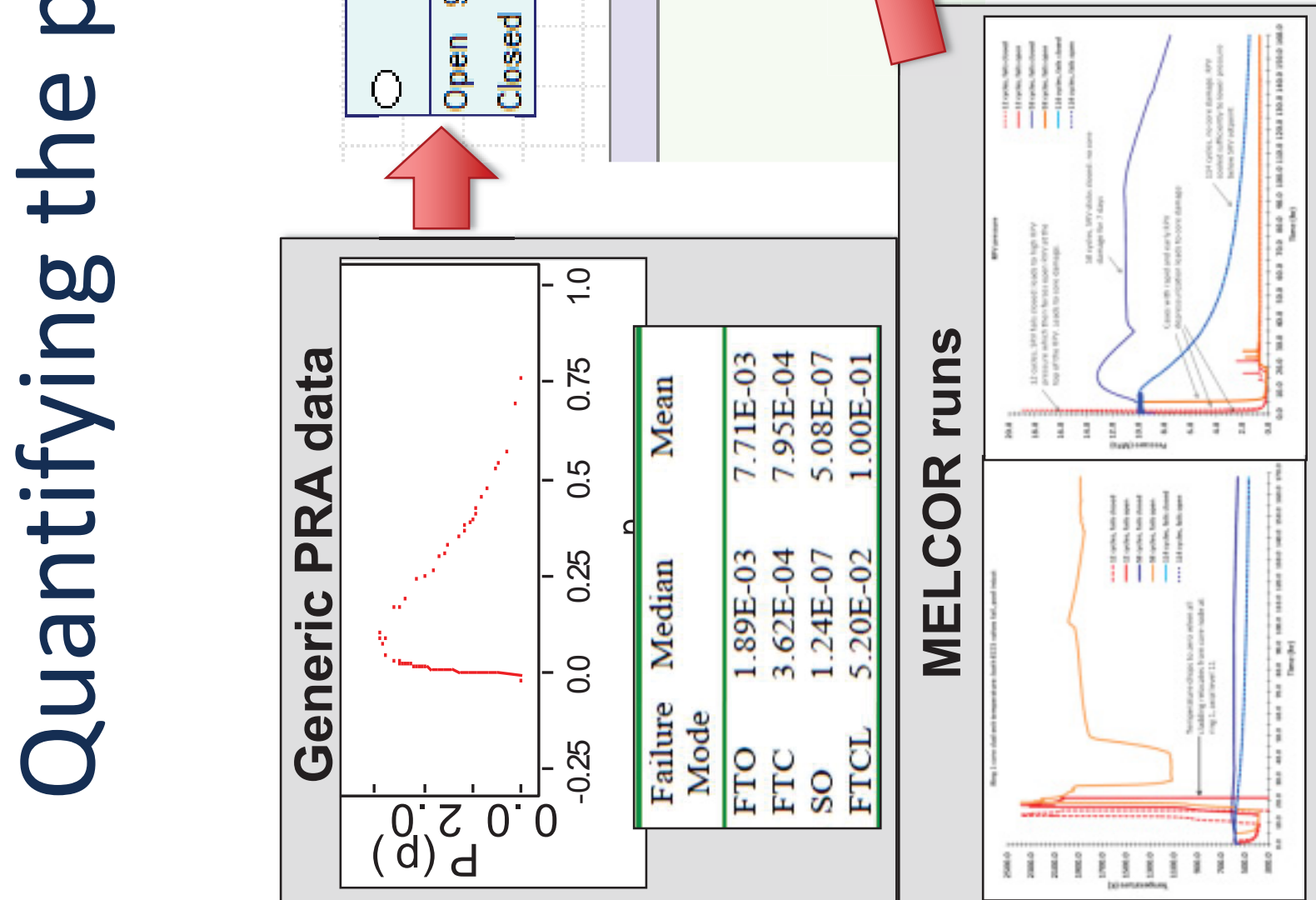


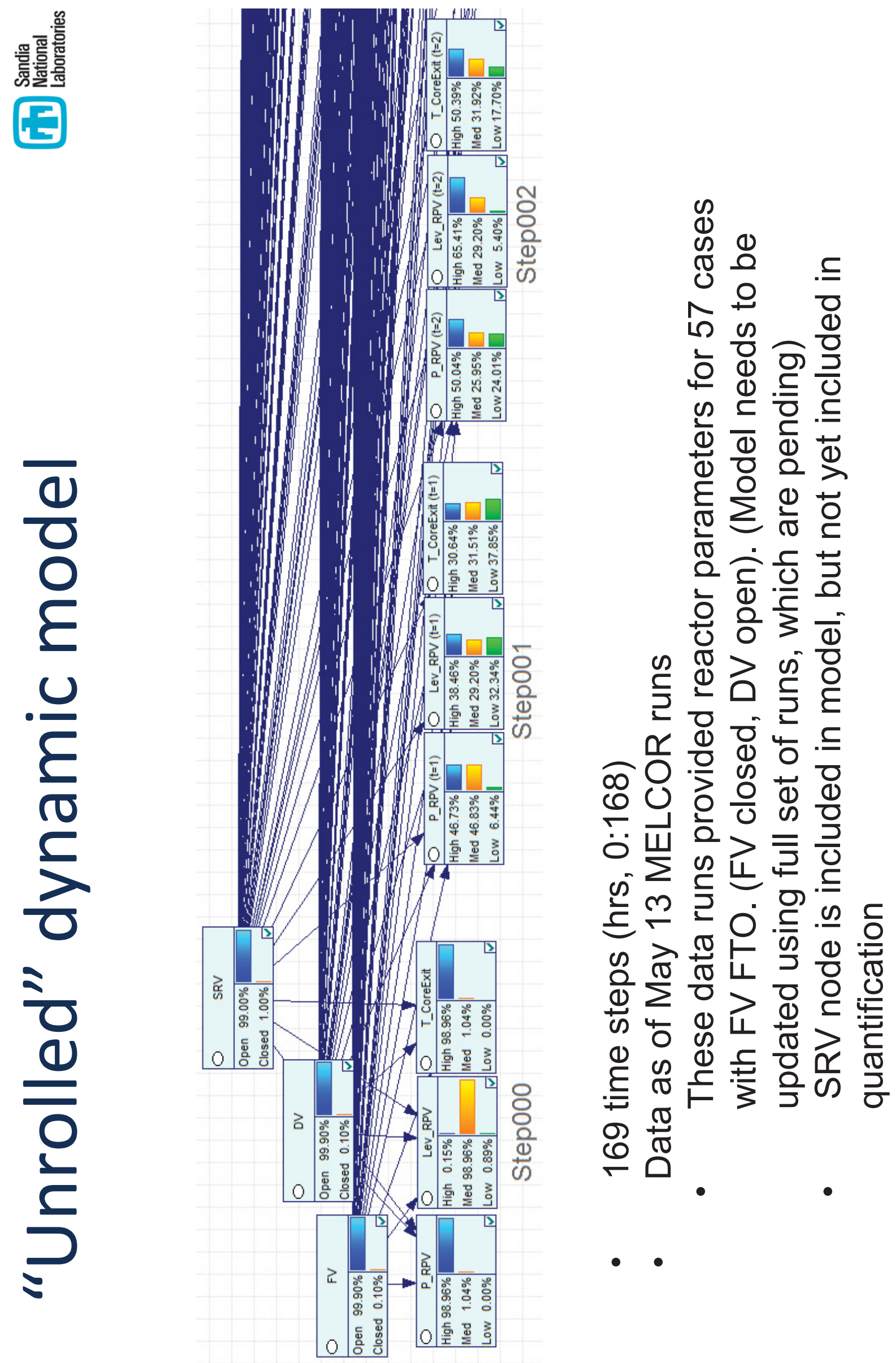




\section{毘}
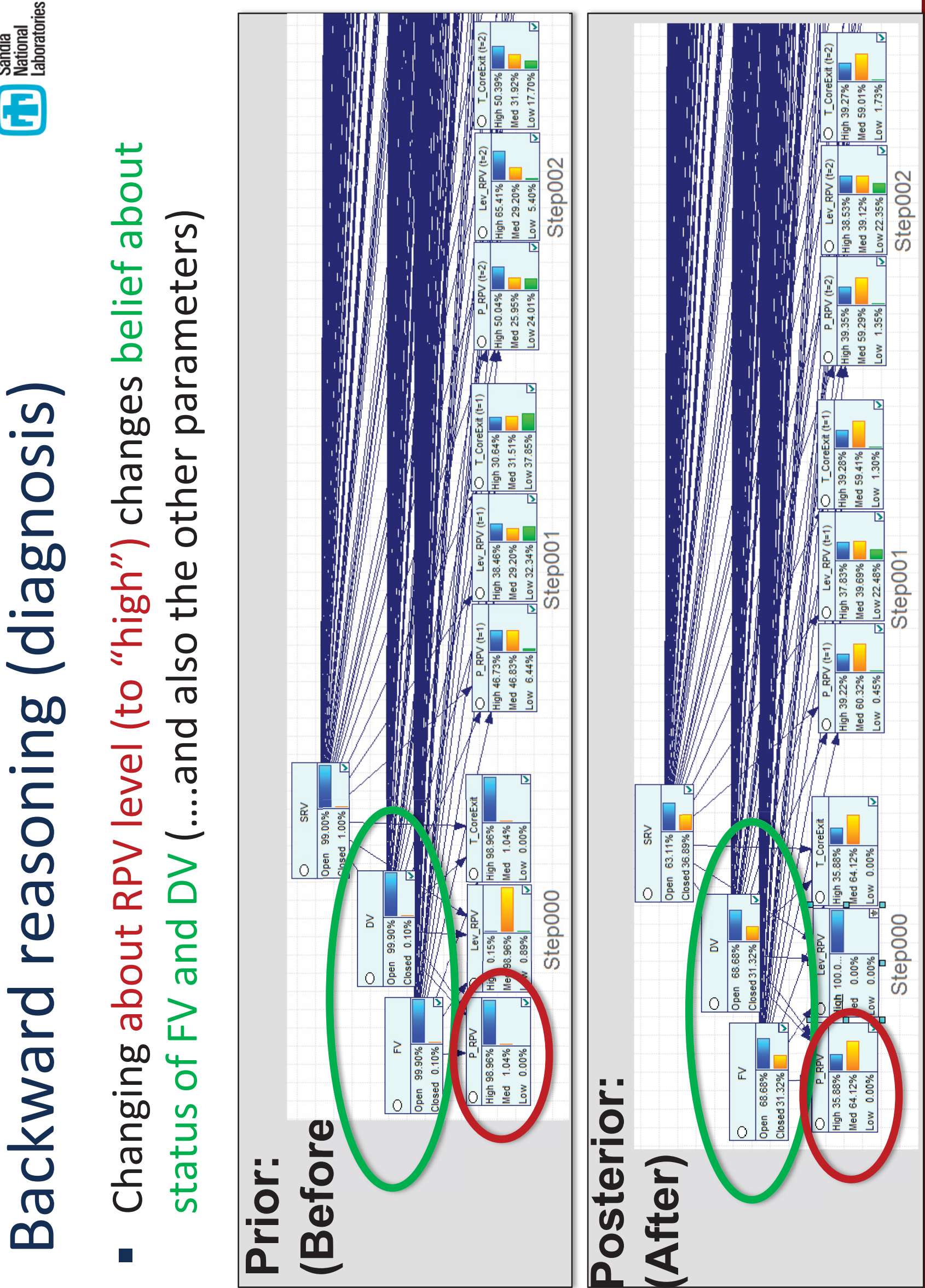

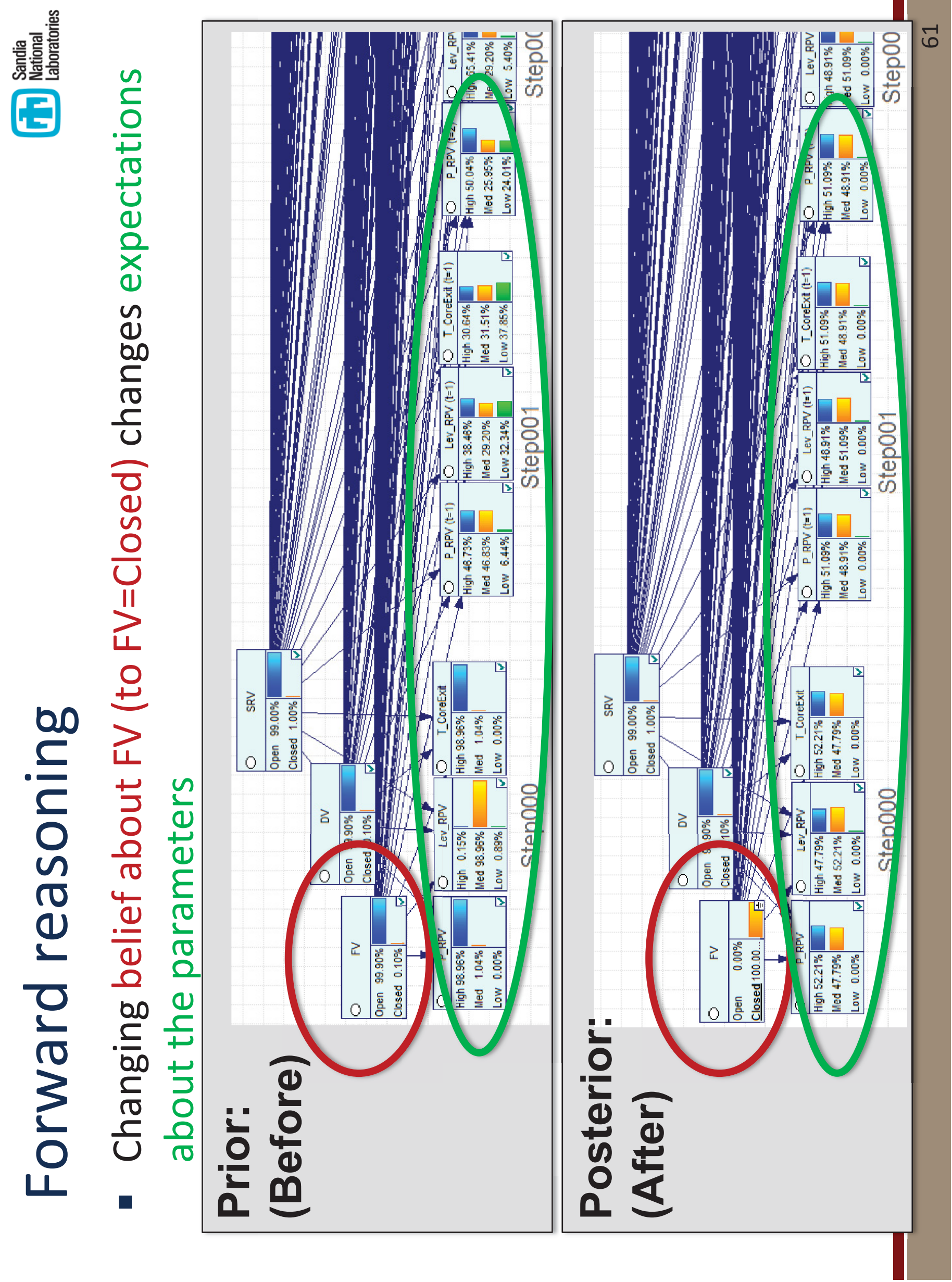


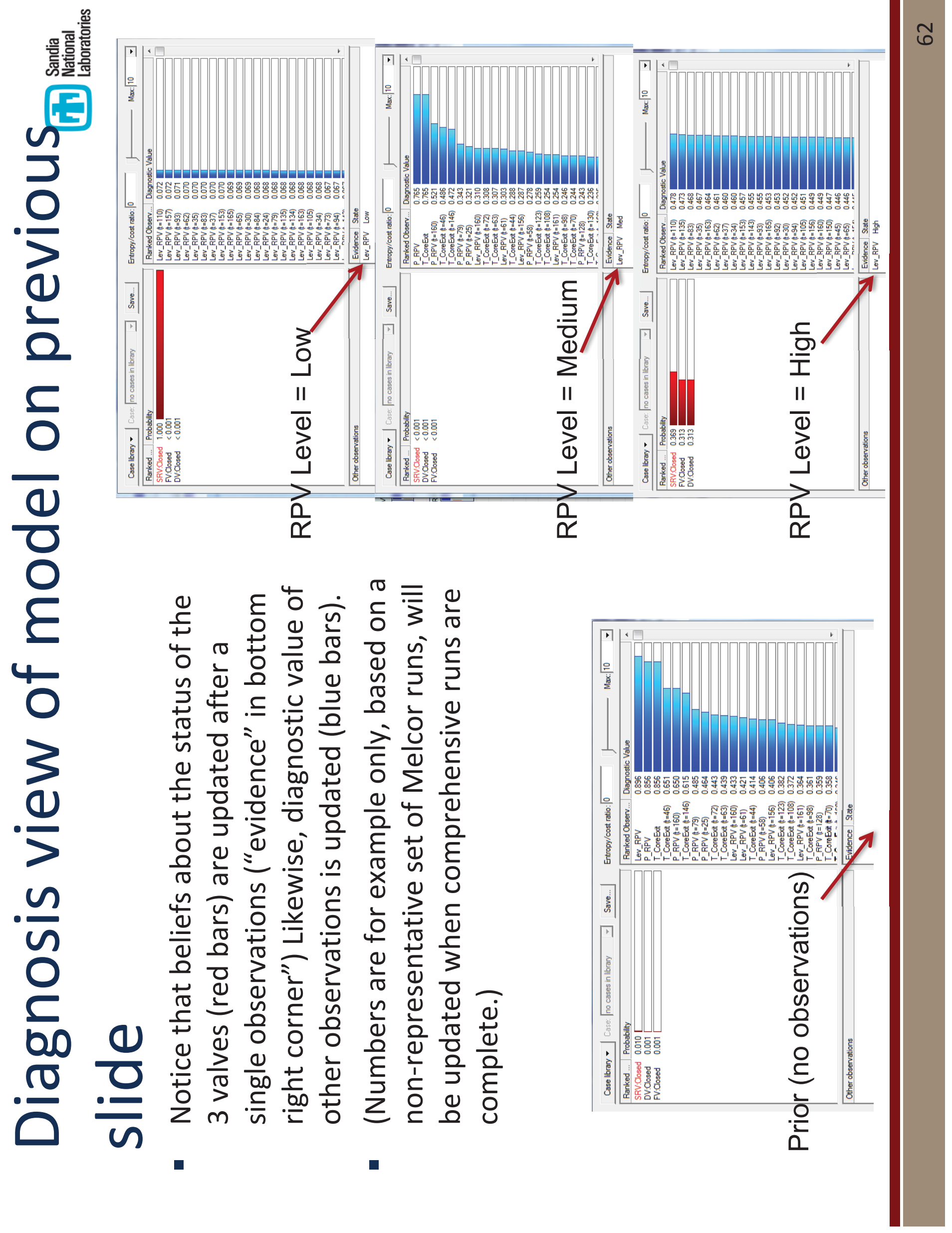




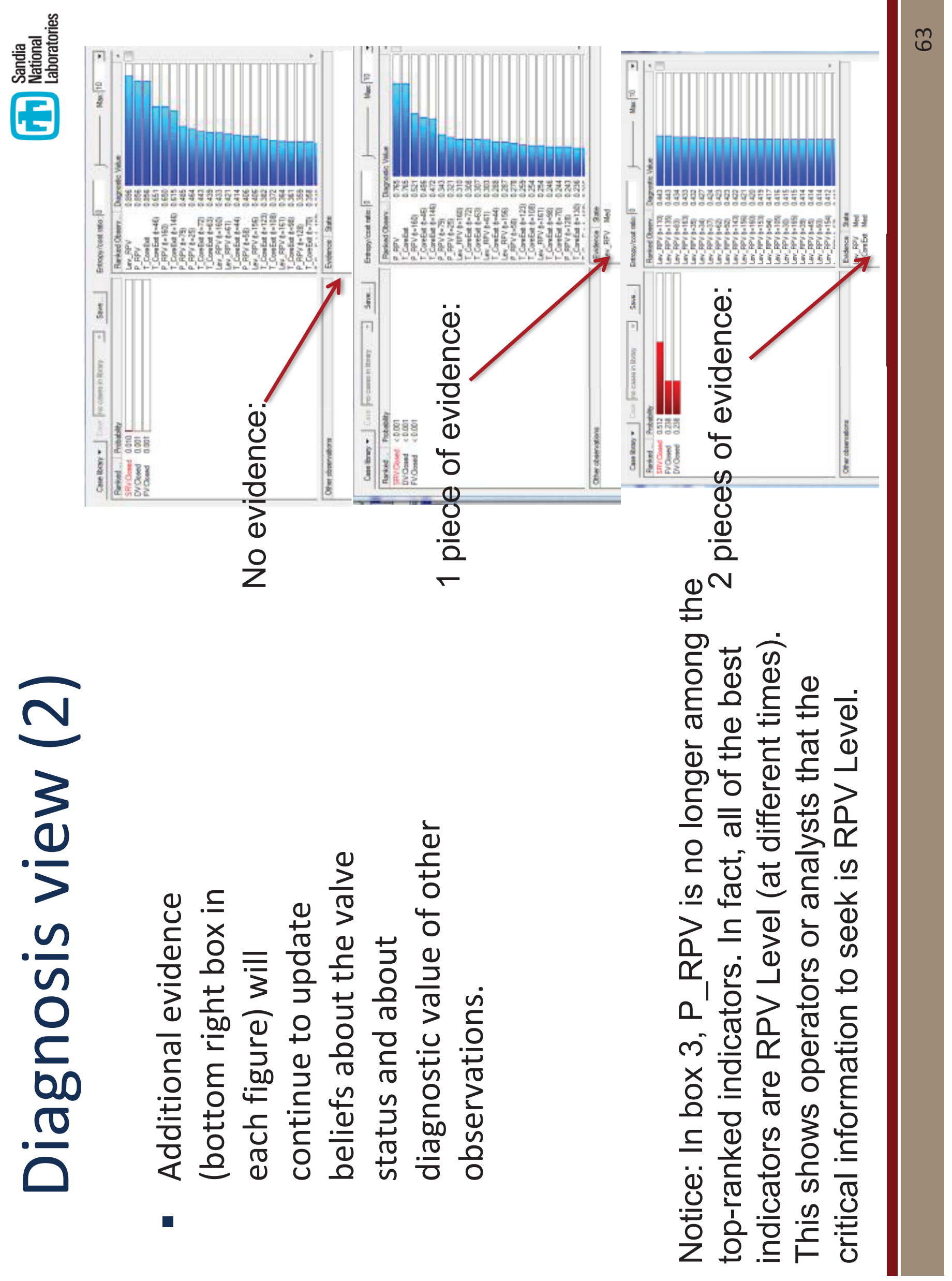




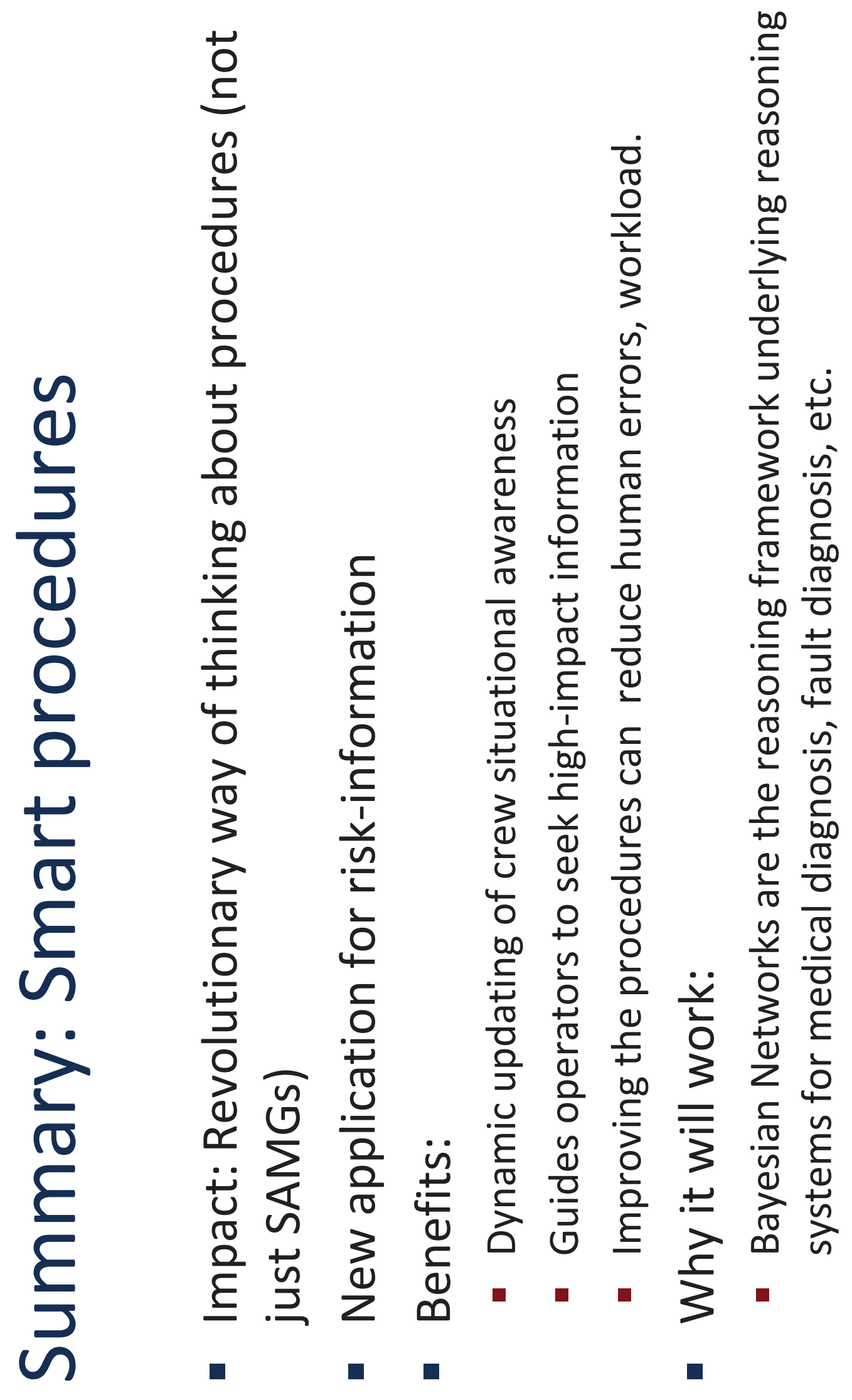


迈

$\frac{5}{4}$

ำ

음 즘

0 엉

โ

용

을 둥

₹े u

نं

:

ปे ปे

$\Sigma \frac{0}{\infty}$

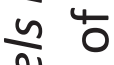

$\frac{1}{2} \stackrel{1}{5}$

$\sum \frac{+}{n}$

드

원 는

$\therefore \stackrel{4}{\pi}$

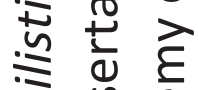

응 जิ

రి

n Q

(1) ⿺辶一

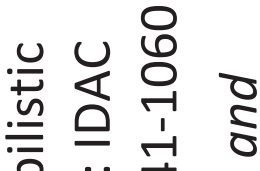

용

드 ने ญे

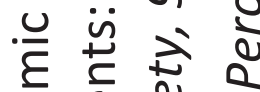

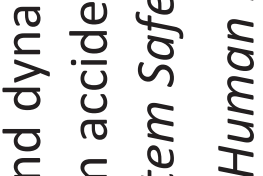

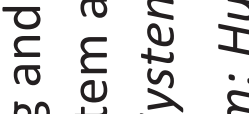

品

ปับ

ह ํㅡㄹ ह

¿ ठิ

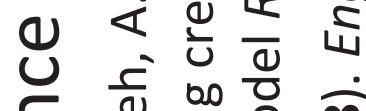

마

है :

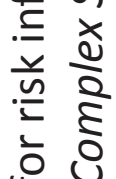

ㅎำ

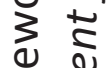

$\frac{\varepsilon}{\pi} \frac{8}{0}$

누

농

플

竞

पू

पั

ㅎํㅎ

m

品

实产

षं घं

$\vdash . \subseteq$ b

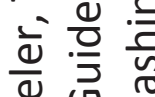

\& ${ }^{\infty}$

至

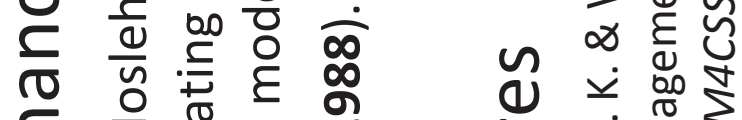

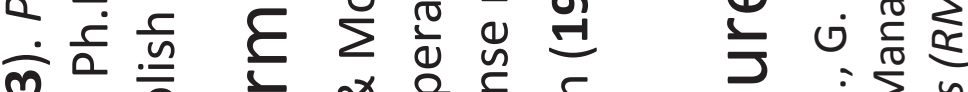

(1)

定

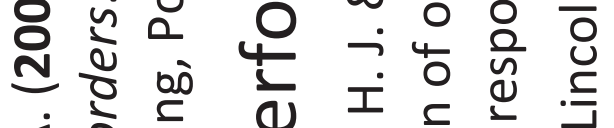

< ذे.

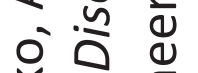

जे ऐे

(1)

(1) ง $0: \exists$

$\infty$ 

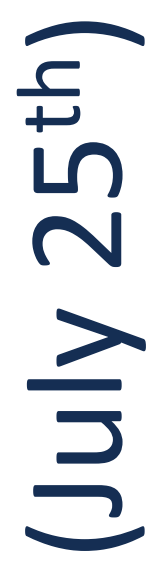

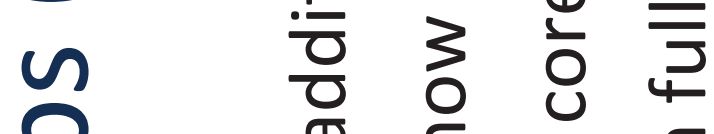

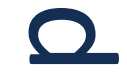

(1)

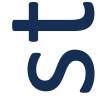

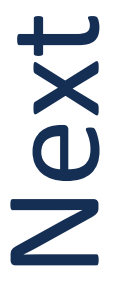

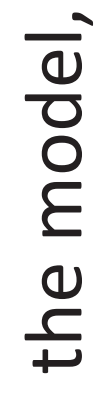

ज ज ए

$\stackrel{0}{ \pm}$

茂 $\frac{\pi}{2}$

$\frac{n}{0} \stackrel{0}{\frac{0}{2}} \stackrel{n}{\frac{1}{5}}$

ब

市

ᄃ

잉

స है

둥 त

-

ᄃ 0 工

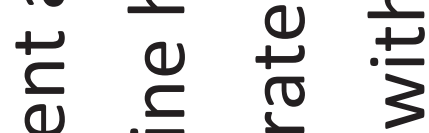

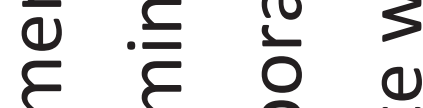

ब

웡

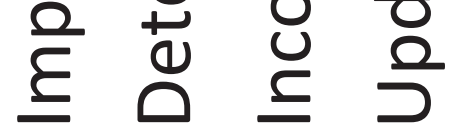

ํㅜㄴ

龺

Q

$\xi$

응

రั

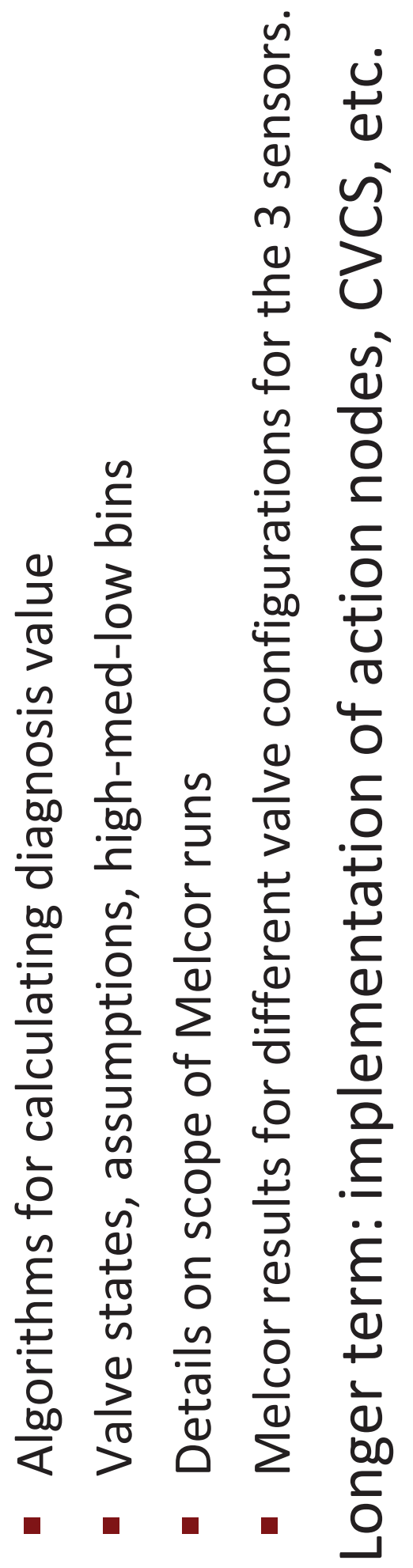

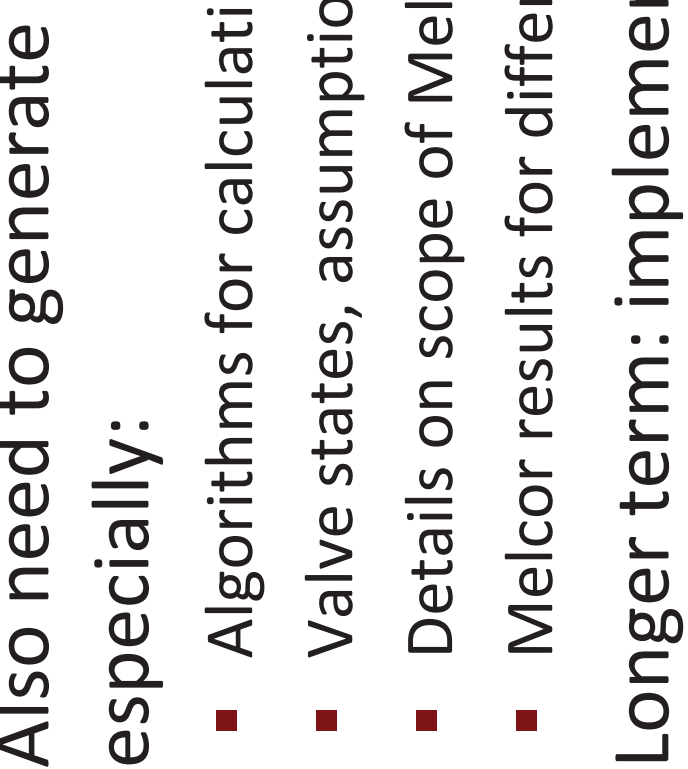




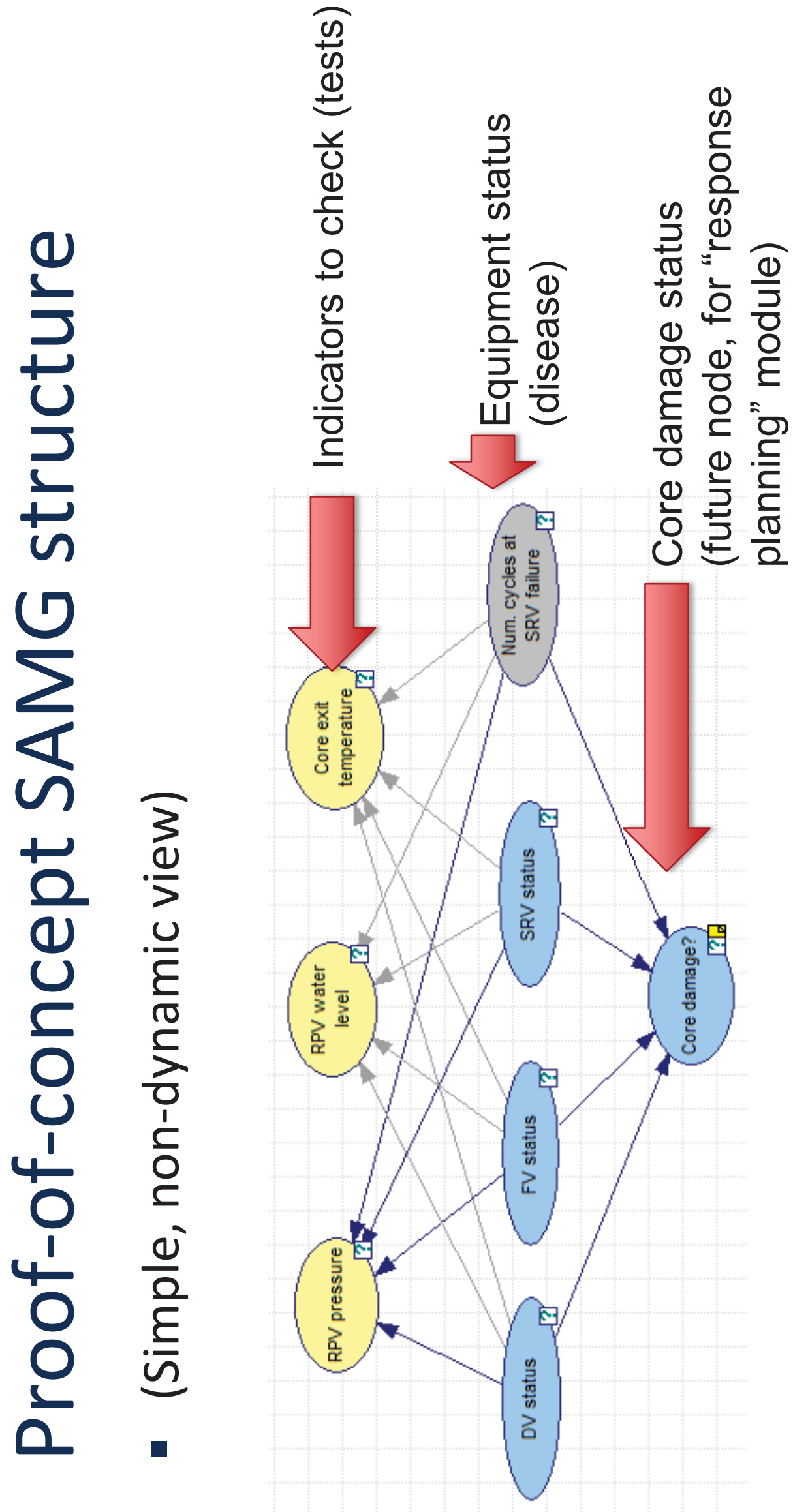




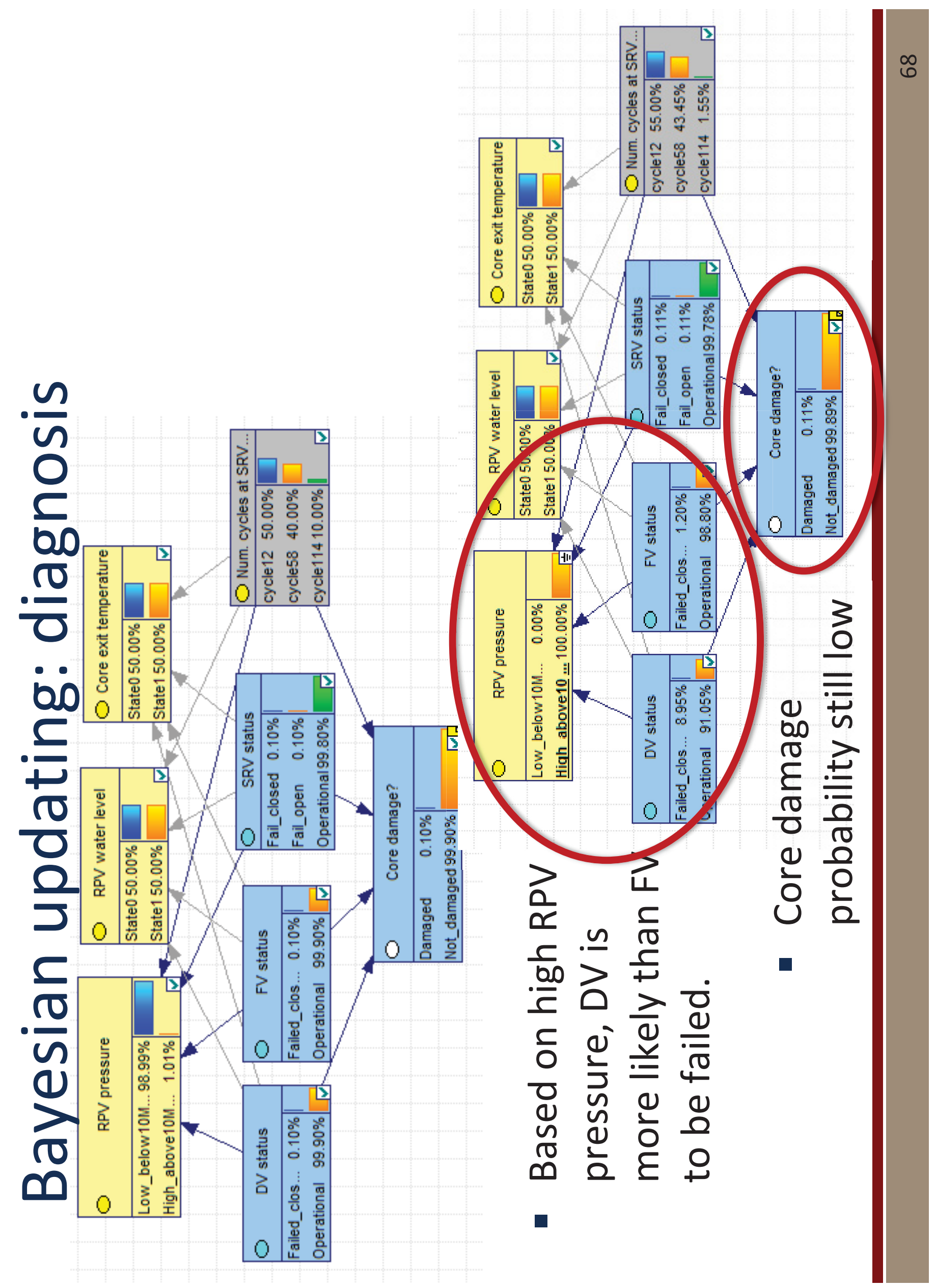




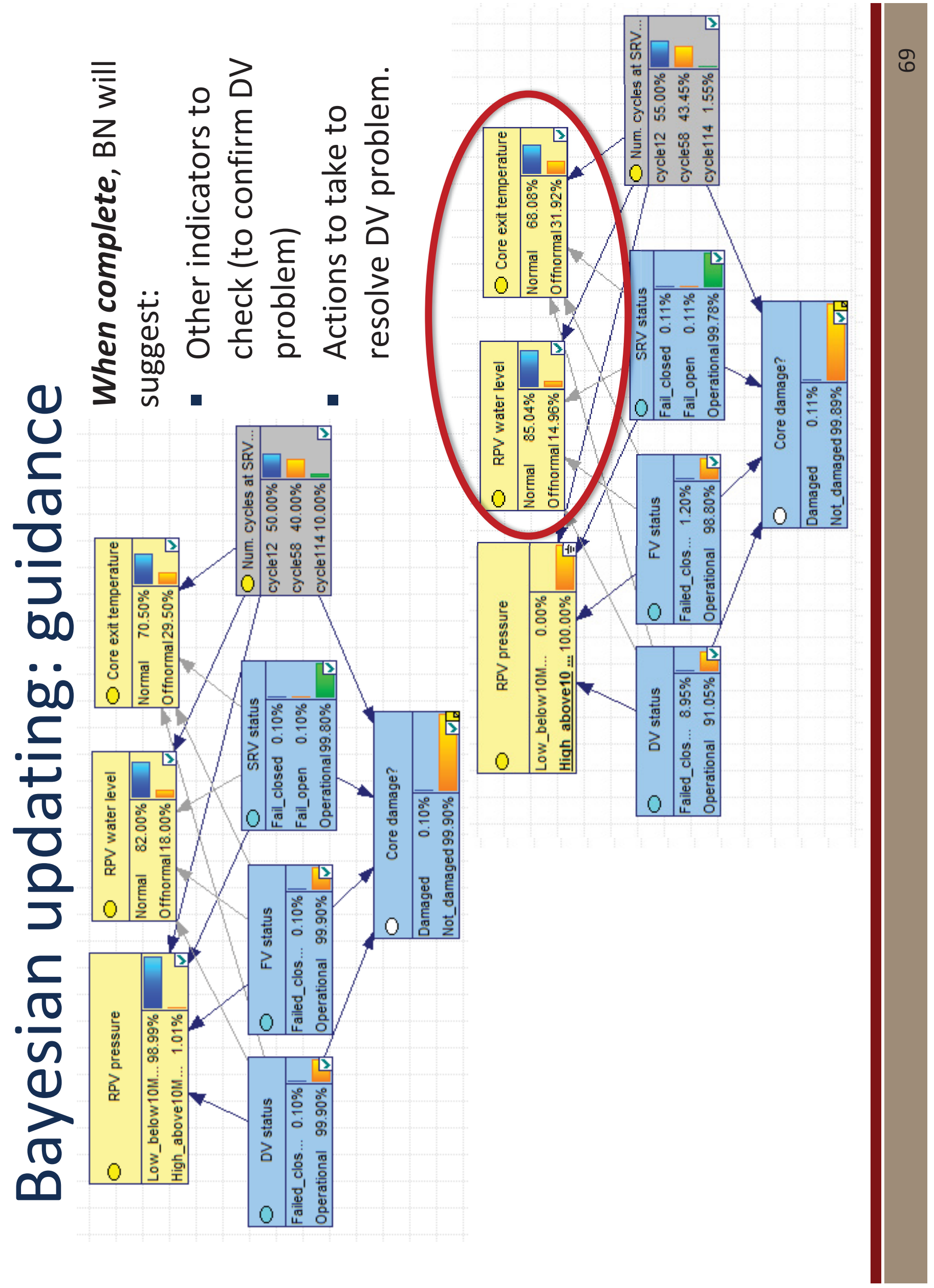




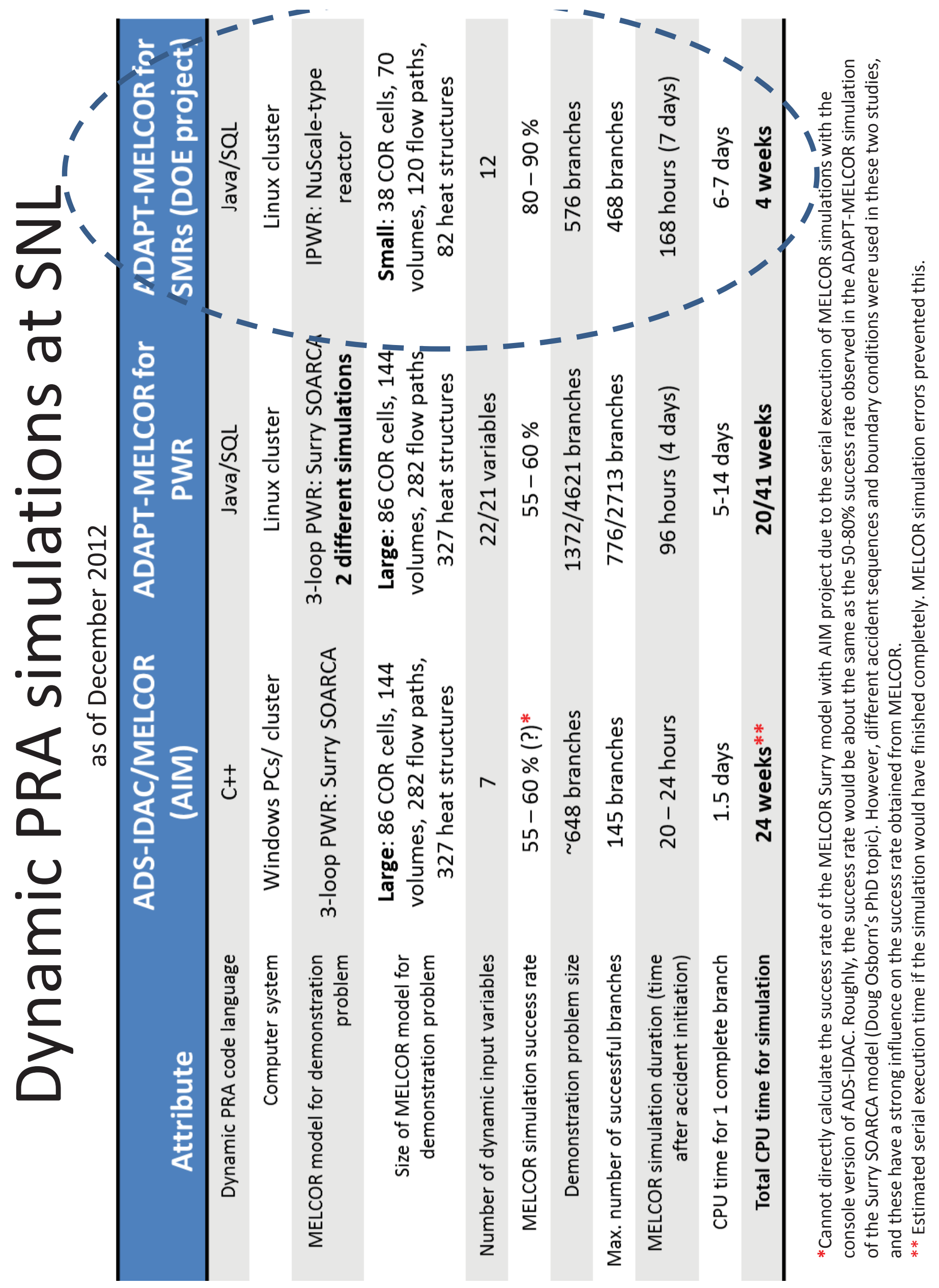



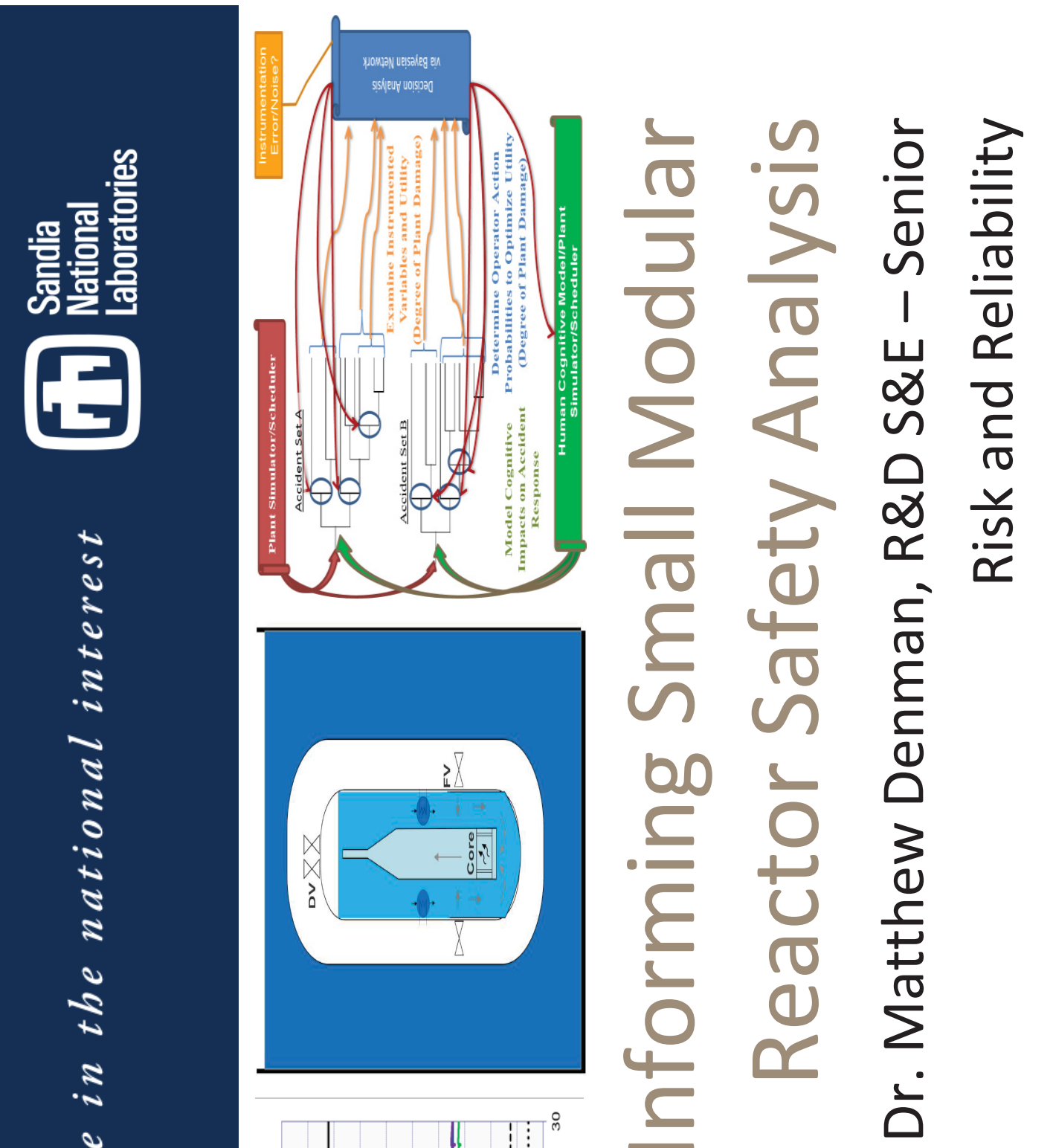

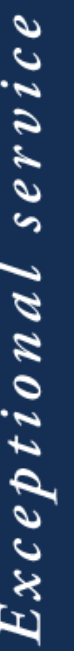
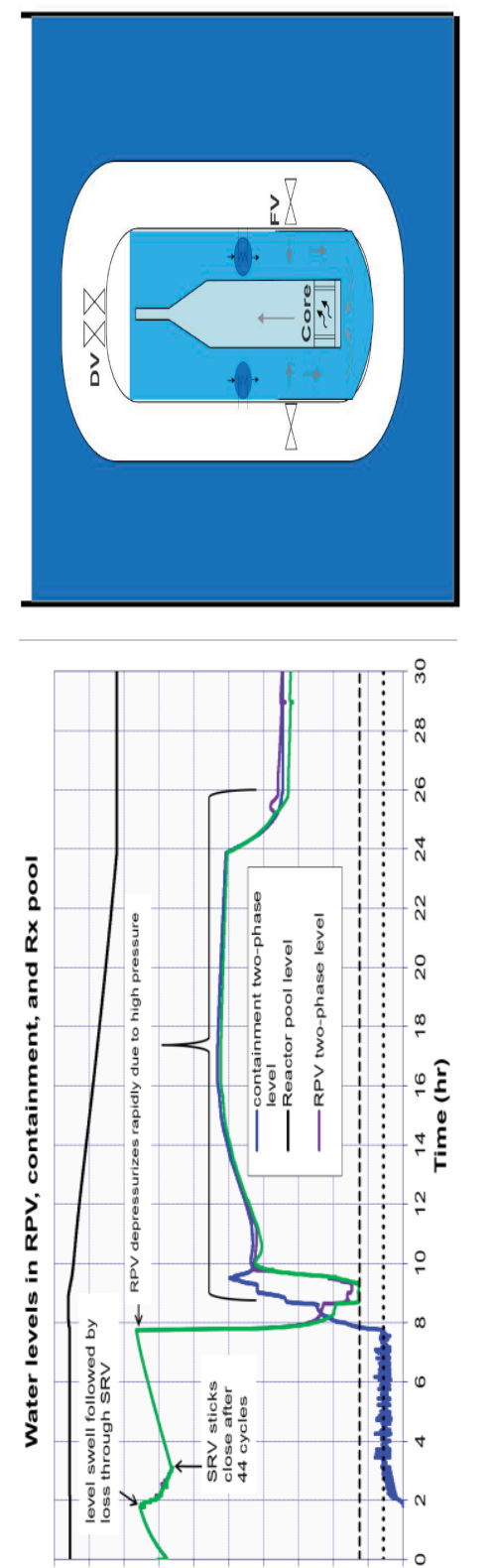

妾

ก
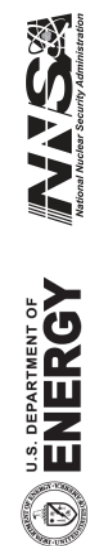
10

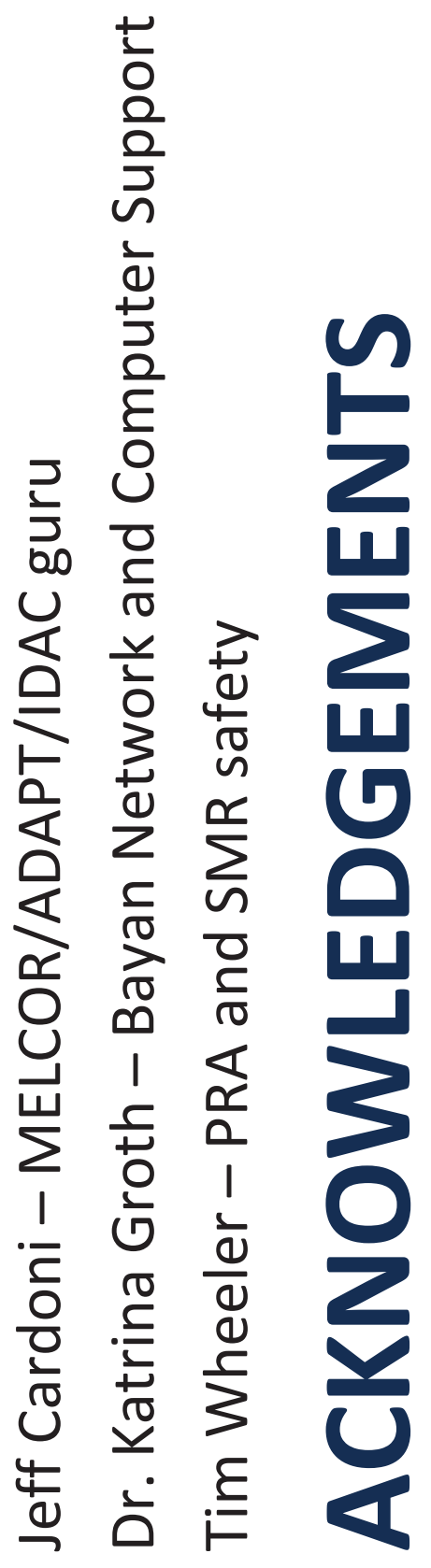









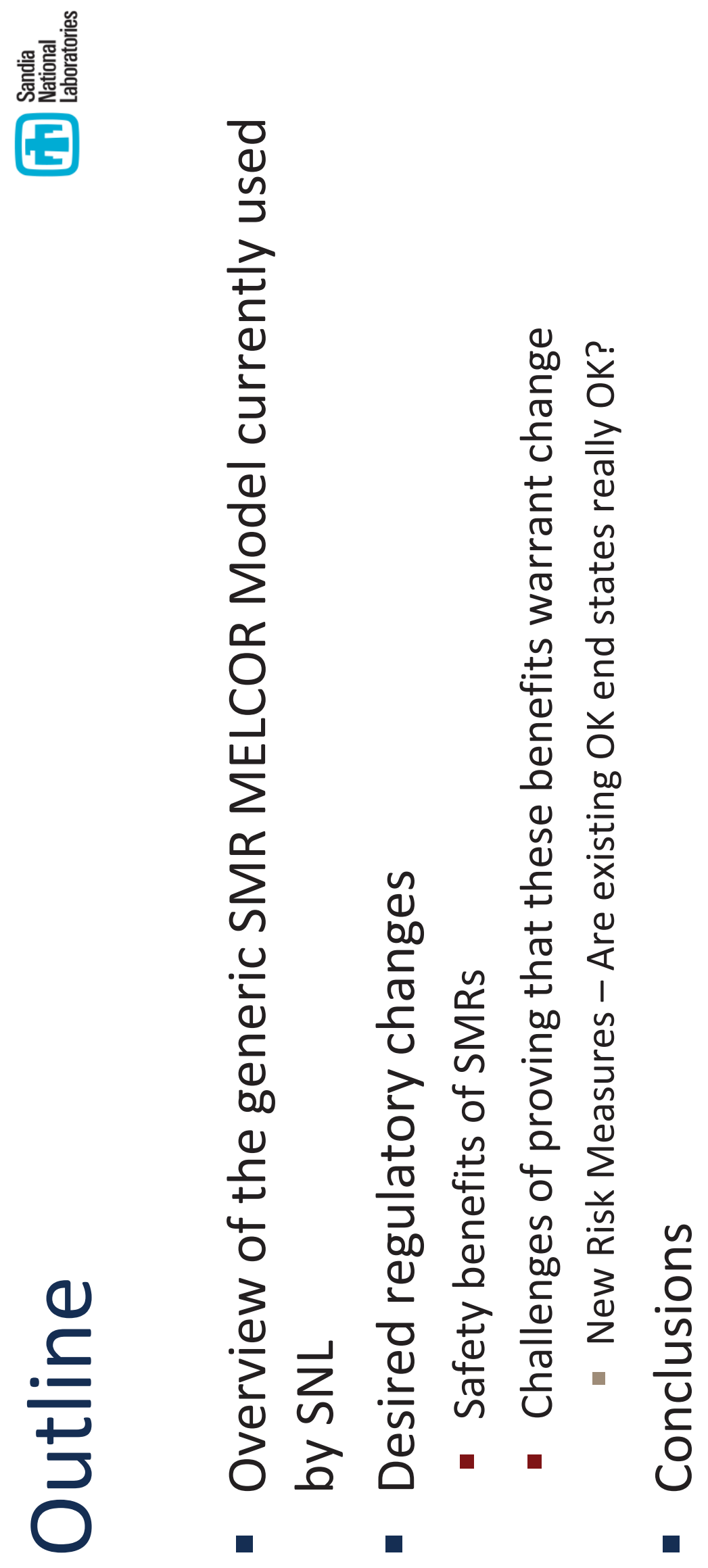



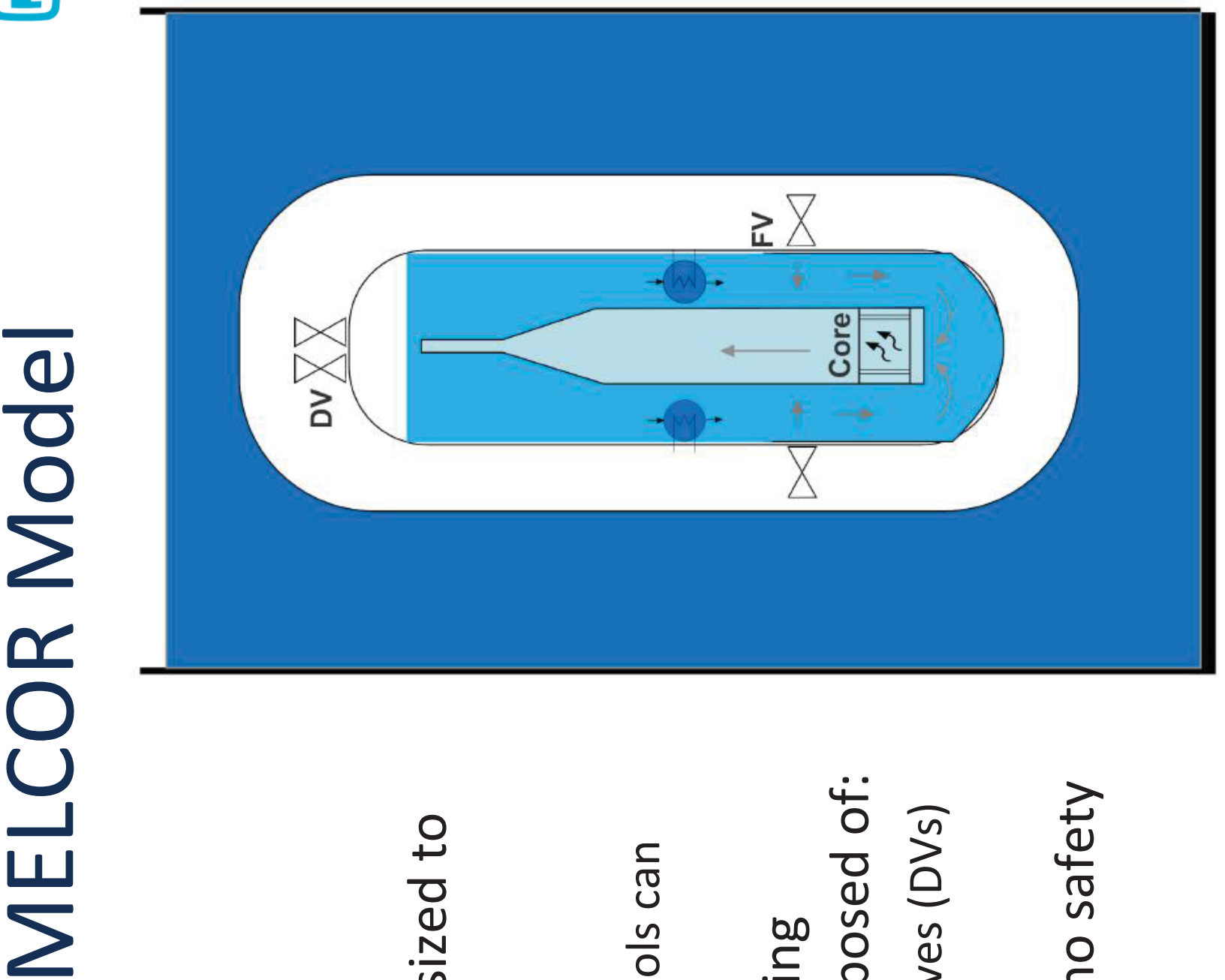

$\sum_{n}^{\infty}$

$\frac{0}{2}$

ᄃ

(1)

(5)

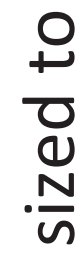

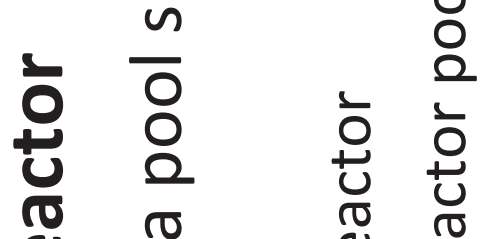

ปั

4

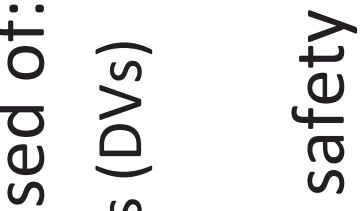

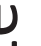

.

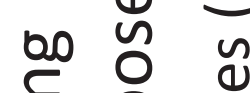

읃

응 릉

苃

(1)

$\propto$ రิ

क व

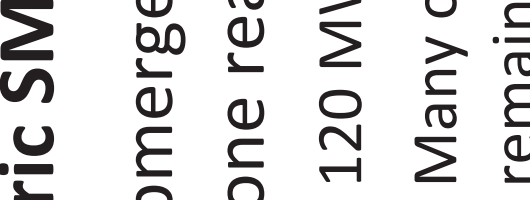

논

(1)

c

0 .

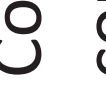




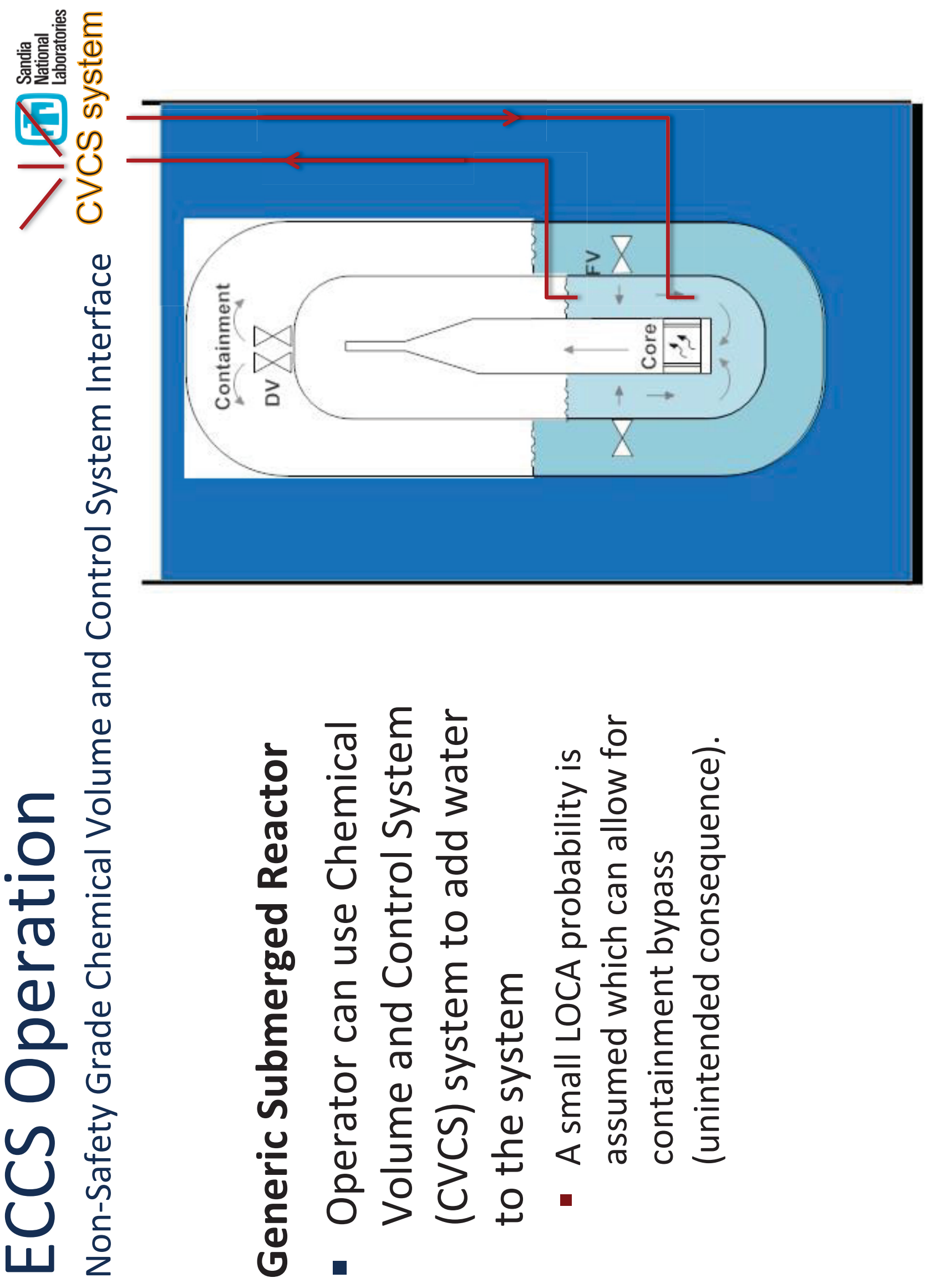




\section{운}

(1)

b
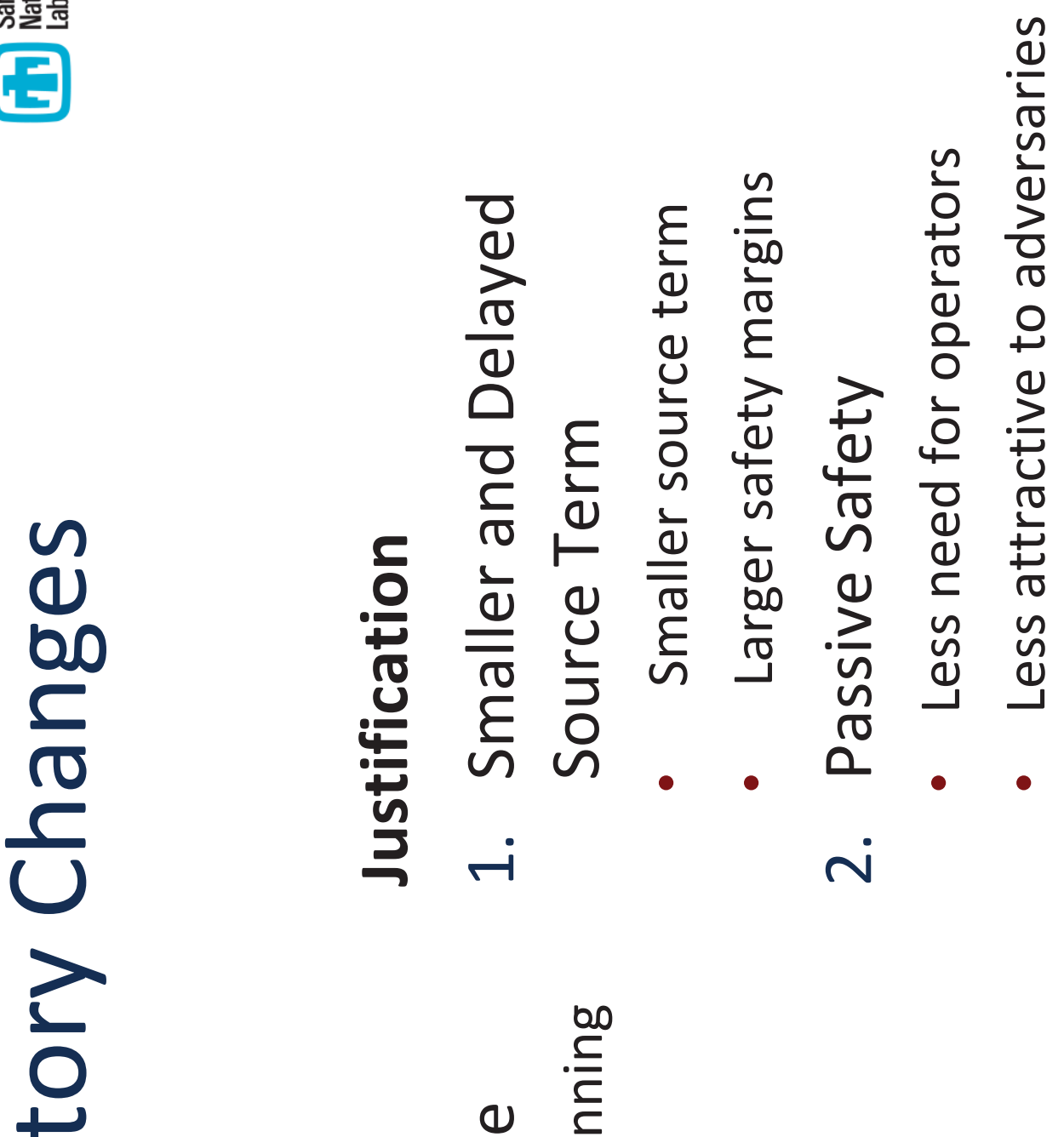

T

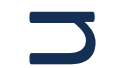

b

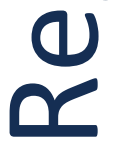

0
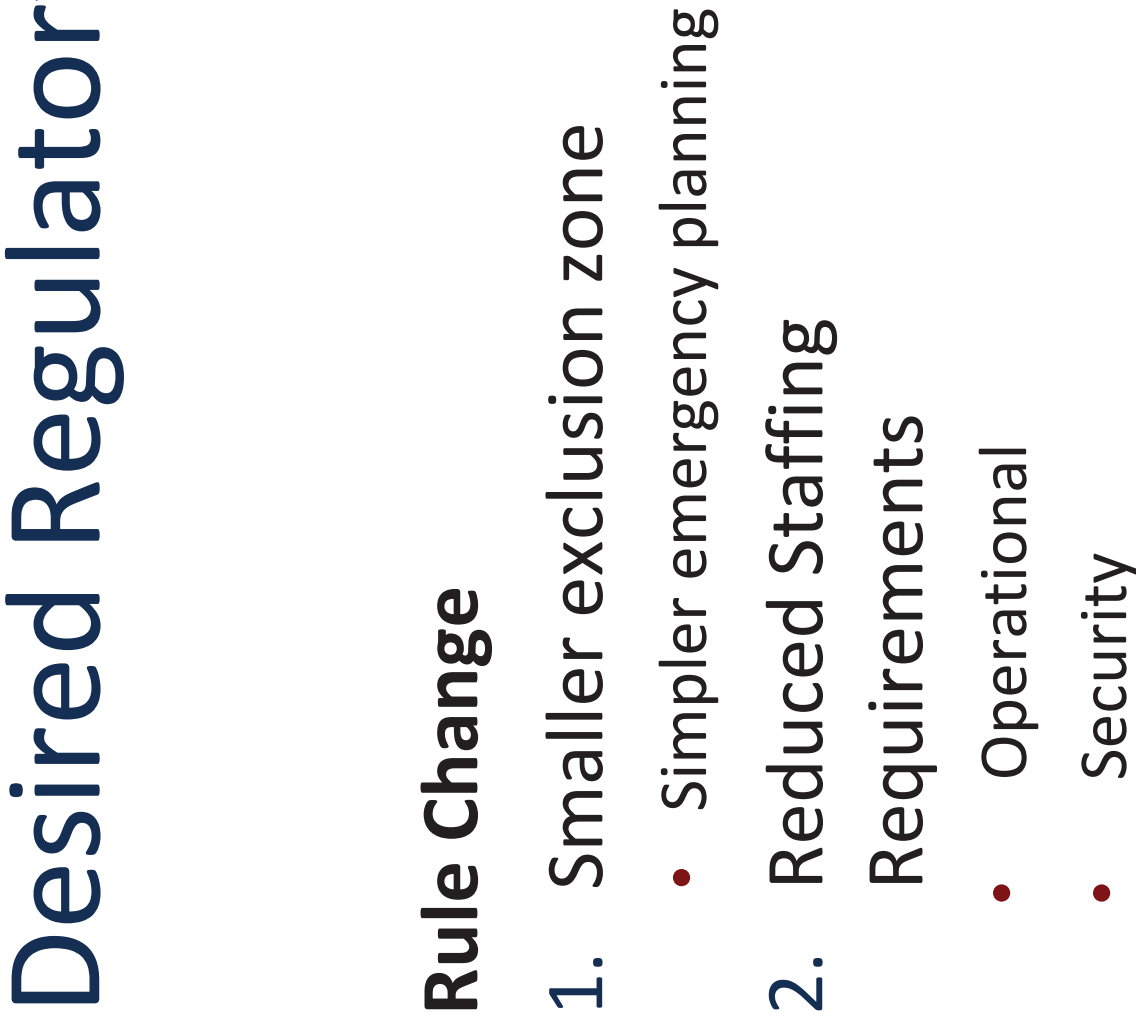

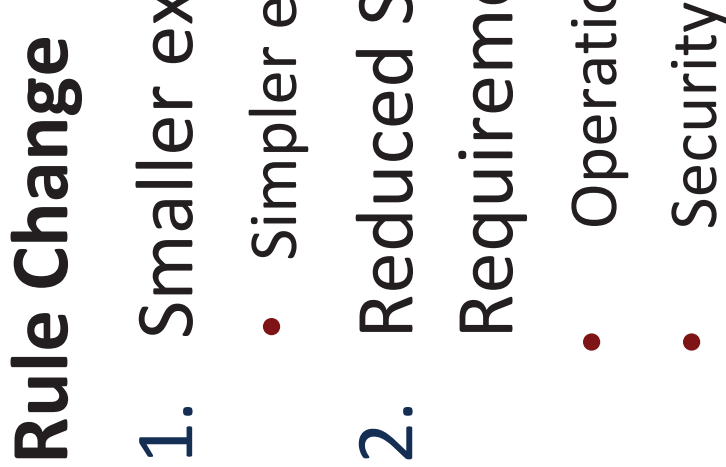




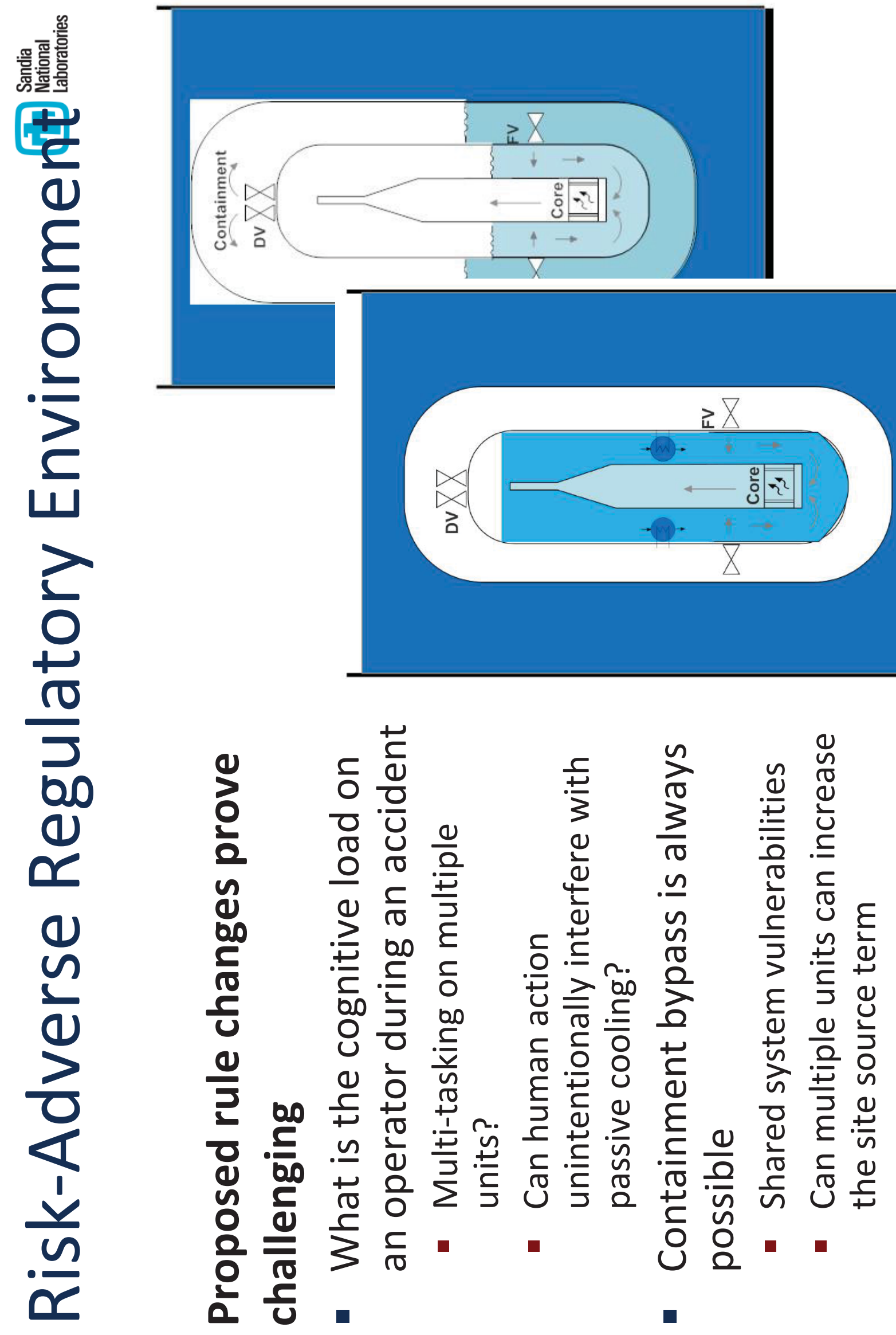




\section{因}
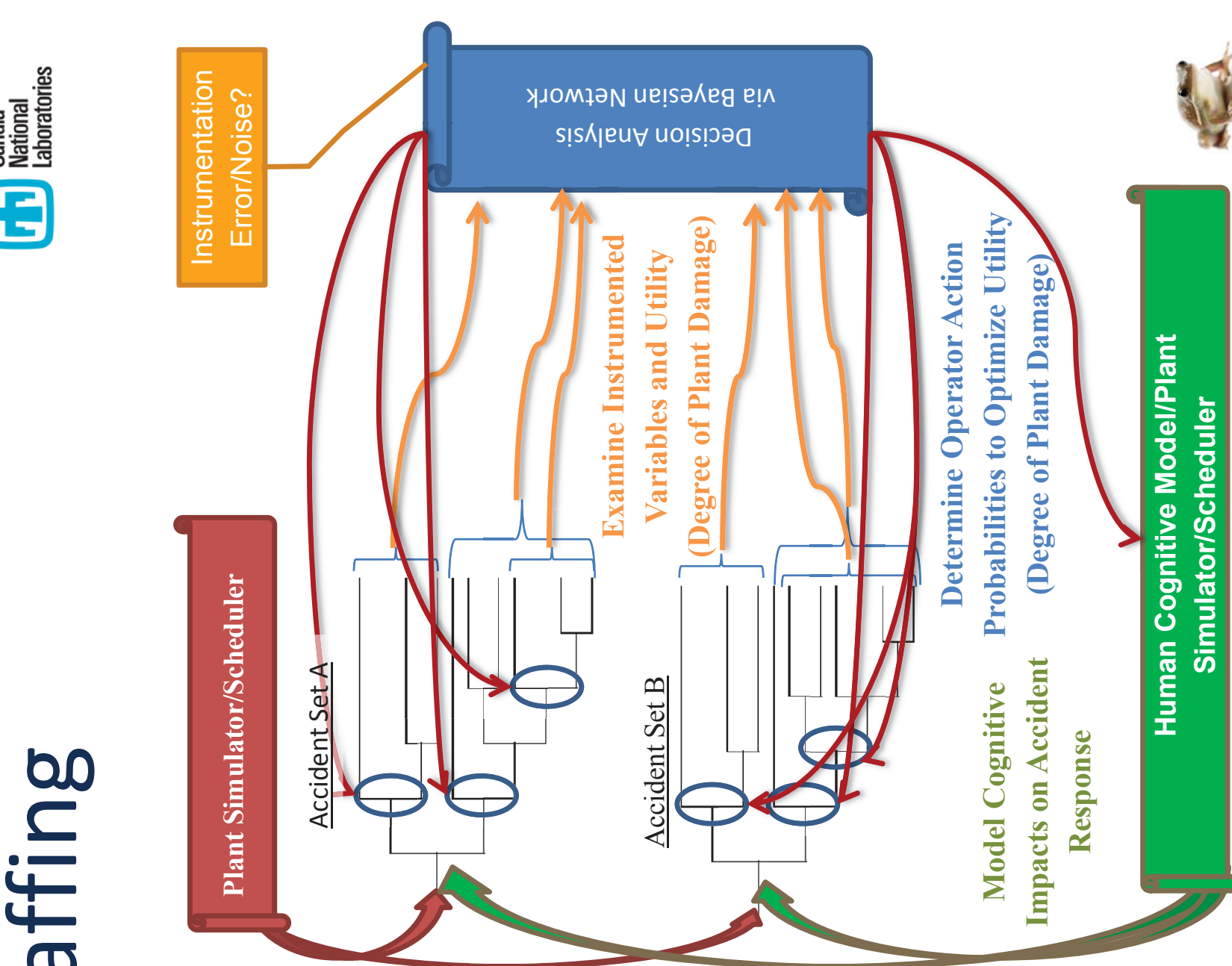

ט

(1)

\%

$\sum_{0}^{\frac{1}{\sigma}} \stackrel{v}{\varepsilon}$

- (1)

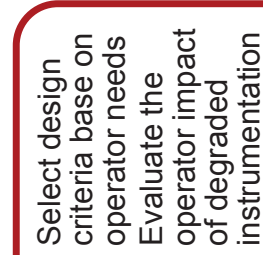

+ 늘

3

으 잉

I 는

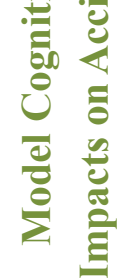
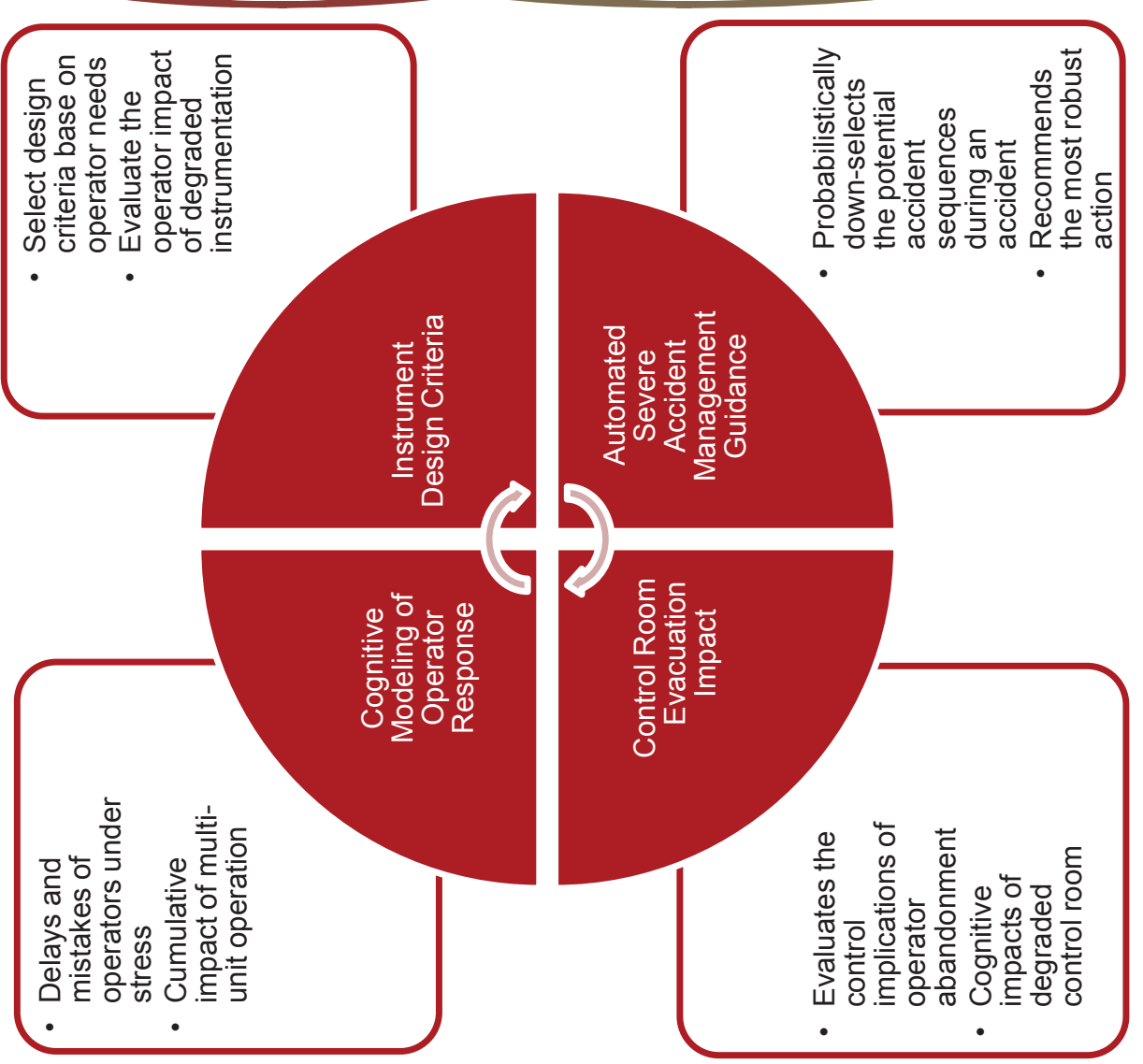


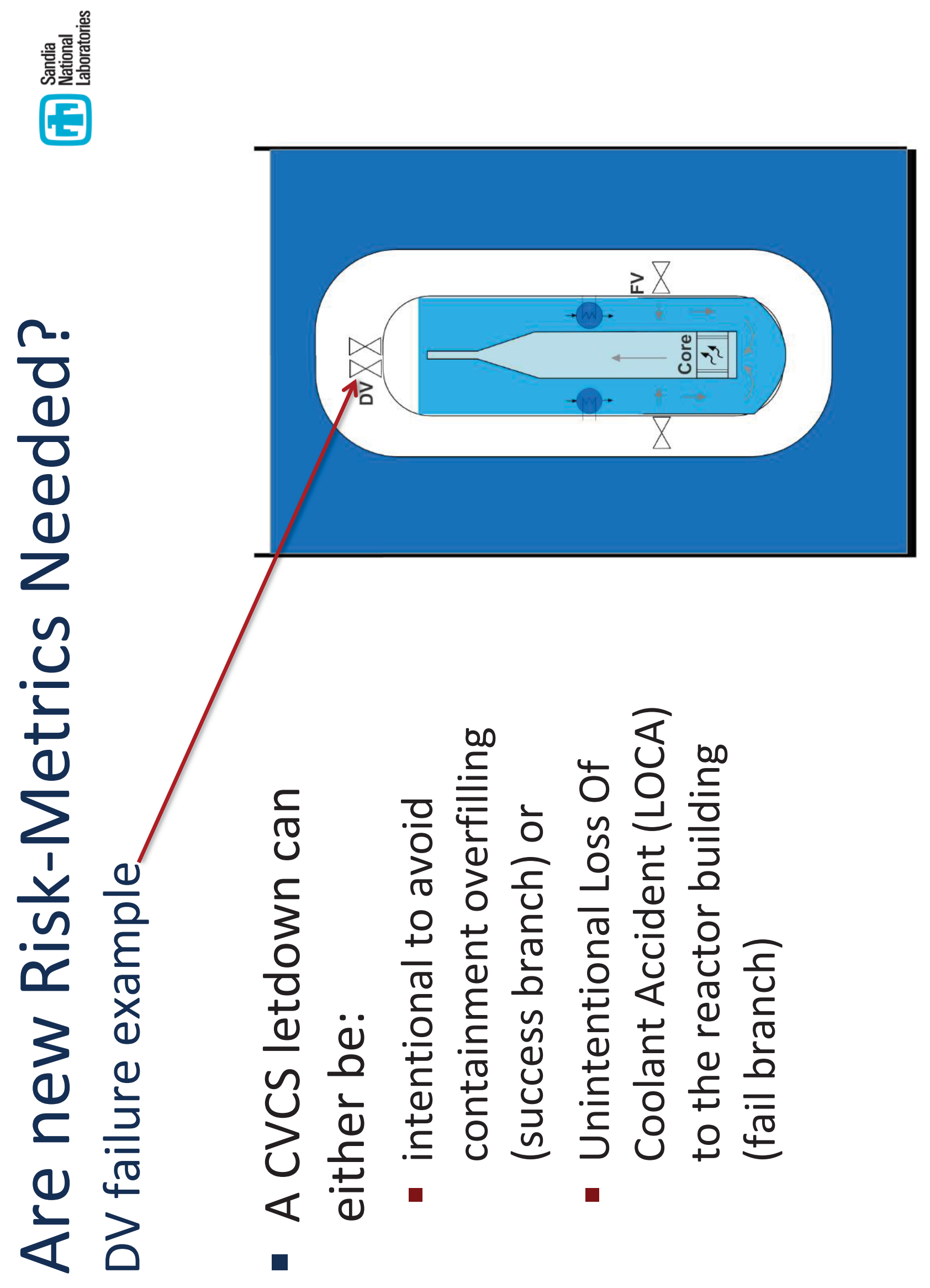




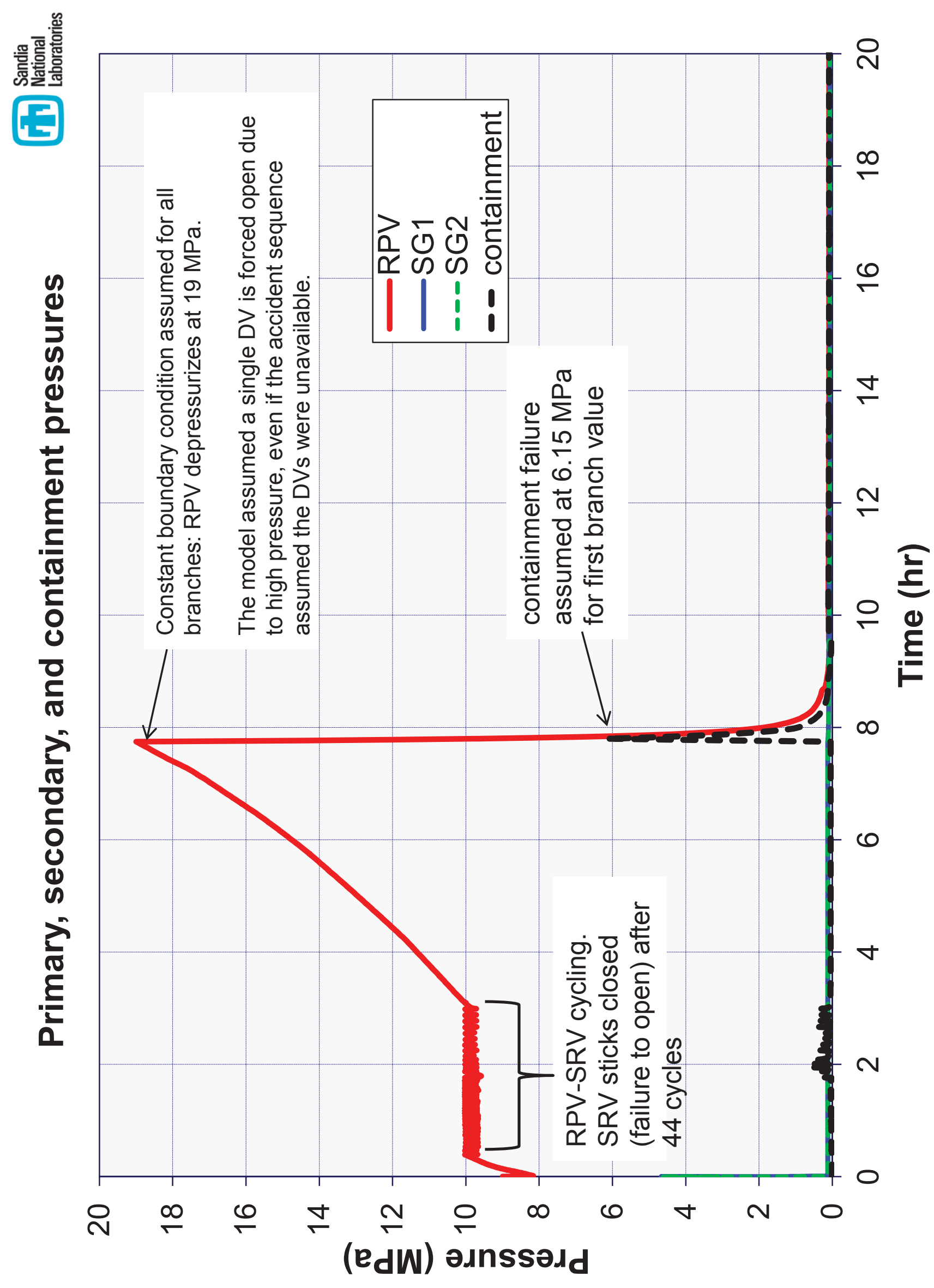




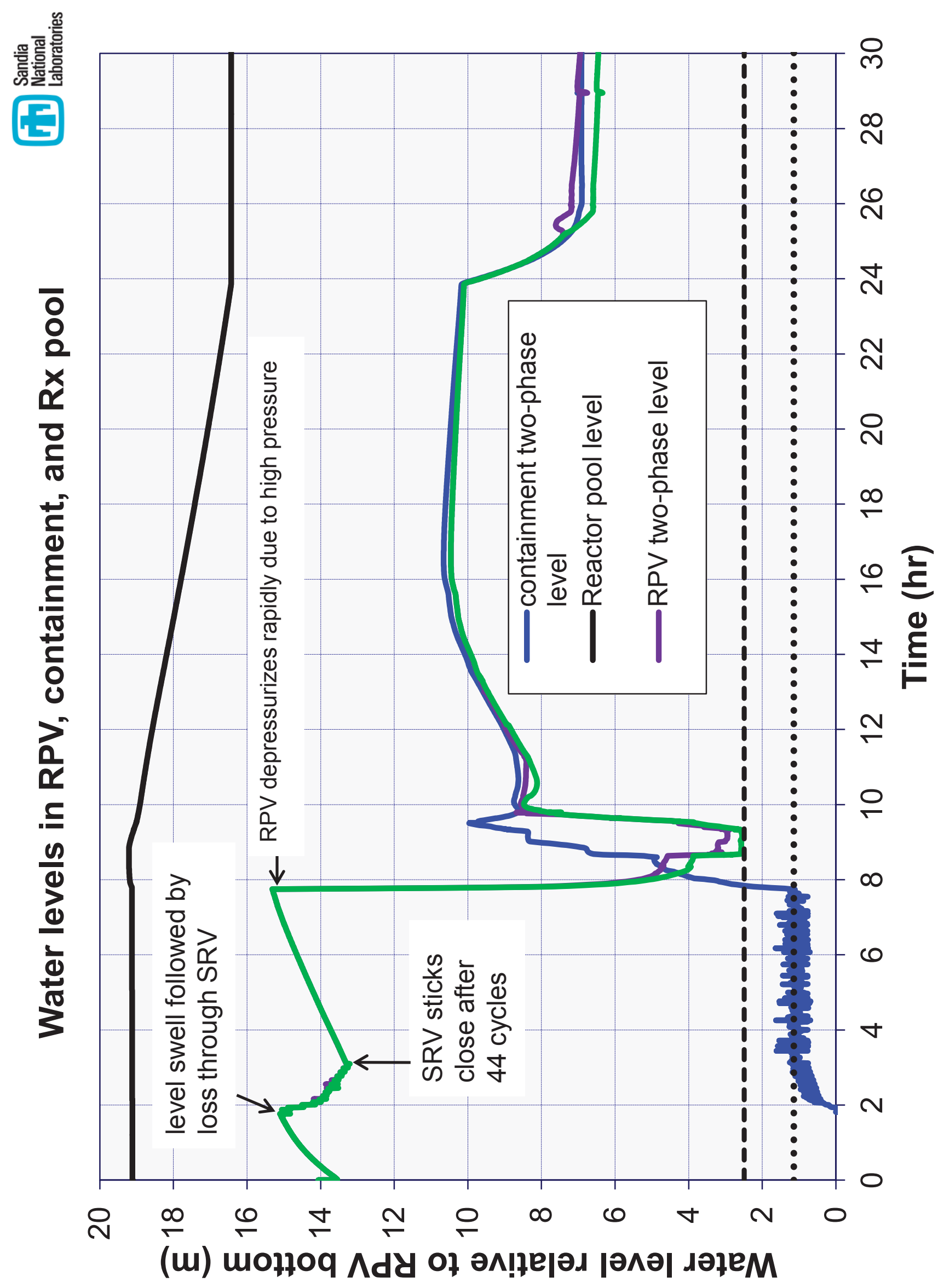




\section{분}

กำ

$\frac{0}{4}$

元

(1)

훈

$\frac{\pi}{5}$

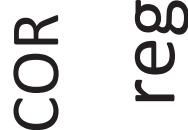

is

$\ddot{0}$

으

年

$\exists$

$\sum_{2} \frac{0}{7}$

를

$\varepsilon$

ro

$x$

(1)

n

כ

0

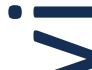

(1)

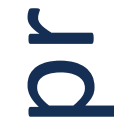

$\stackrel{\theta}{\frac{1}{+}}$

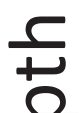

(1)

ลิ

उ

ث

-

(d)

言芯

.

(1)

气

()

$3 \frac{5}{0}$

(ब)

ฯ

๕)

름

4 记

둥

주

离

号

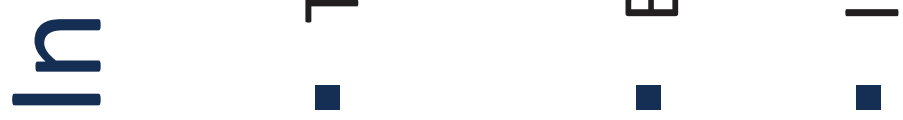




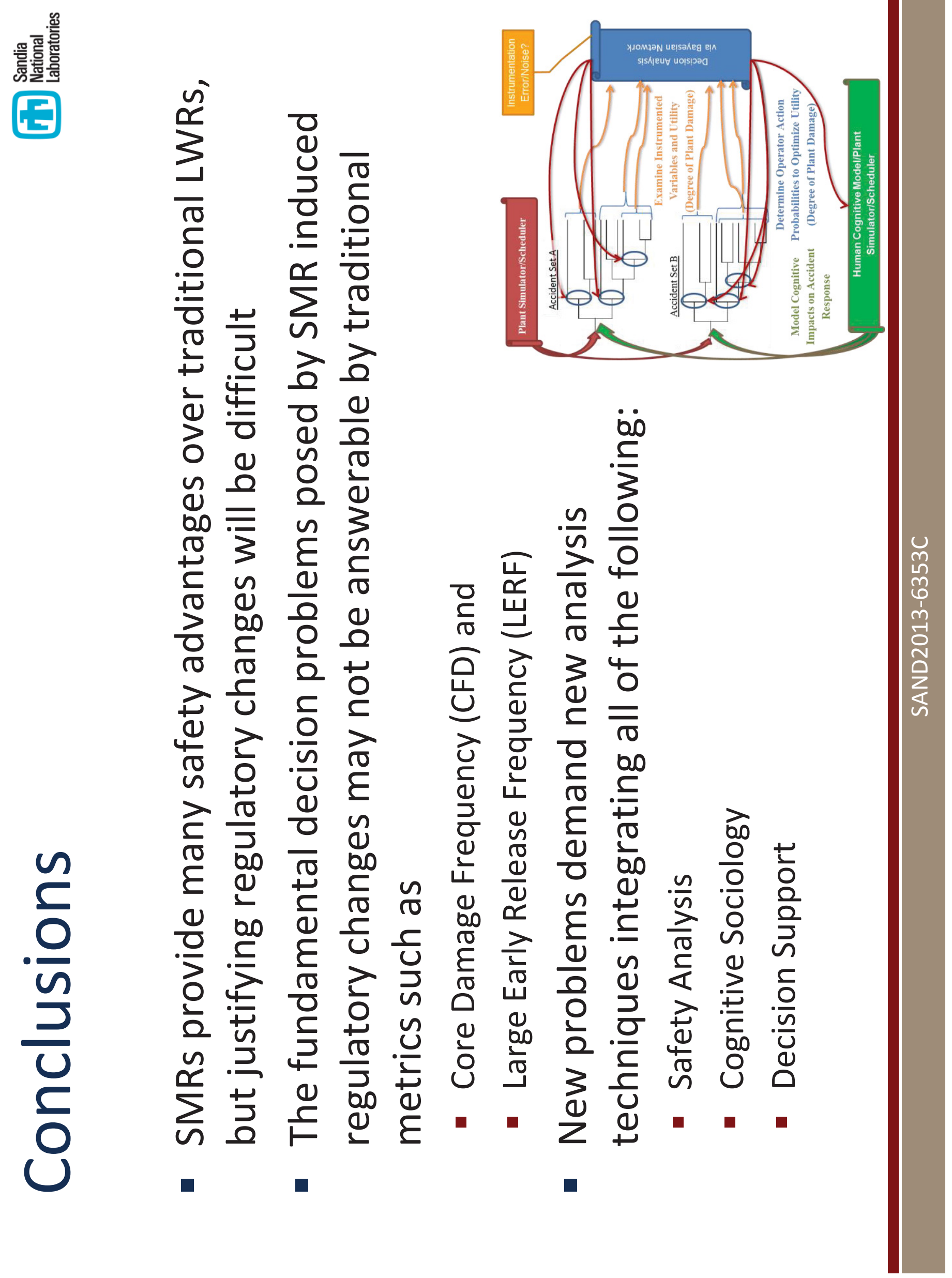




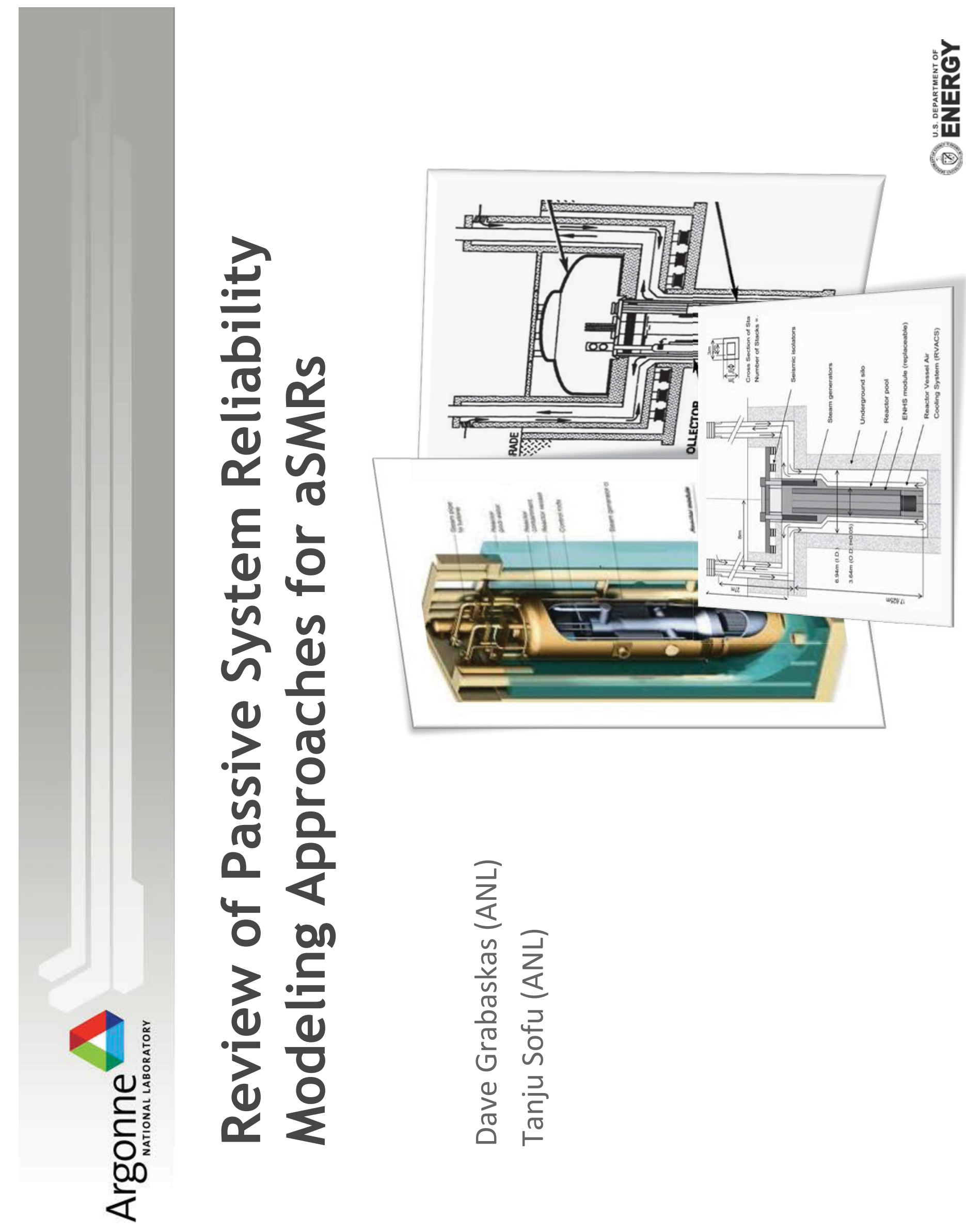




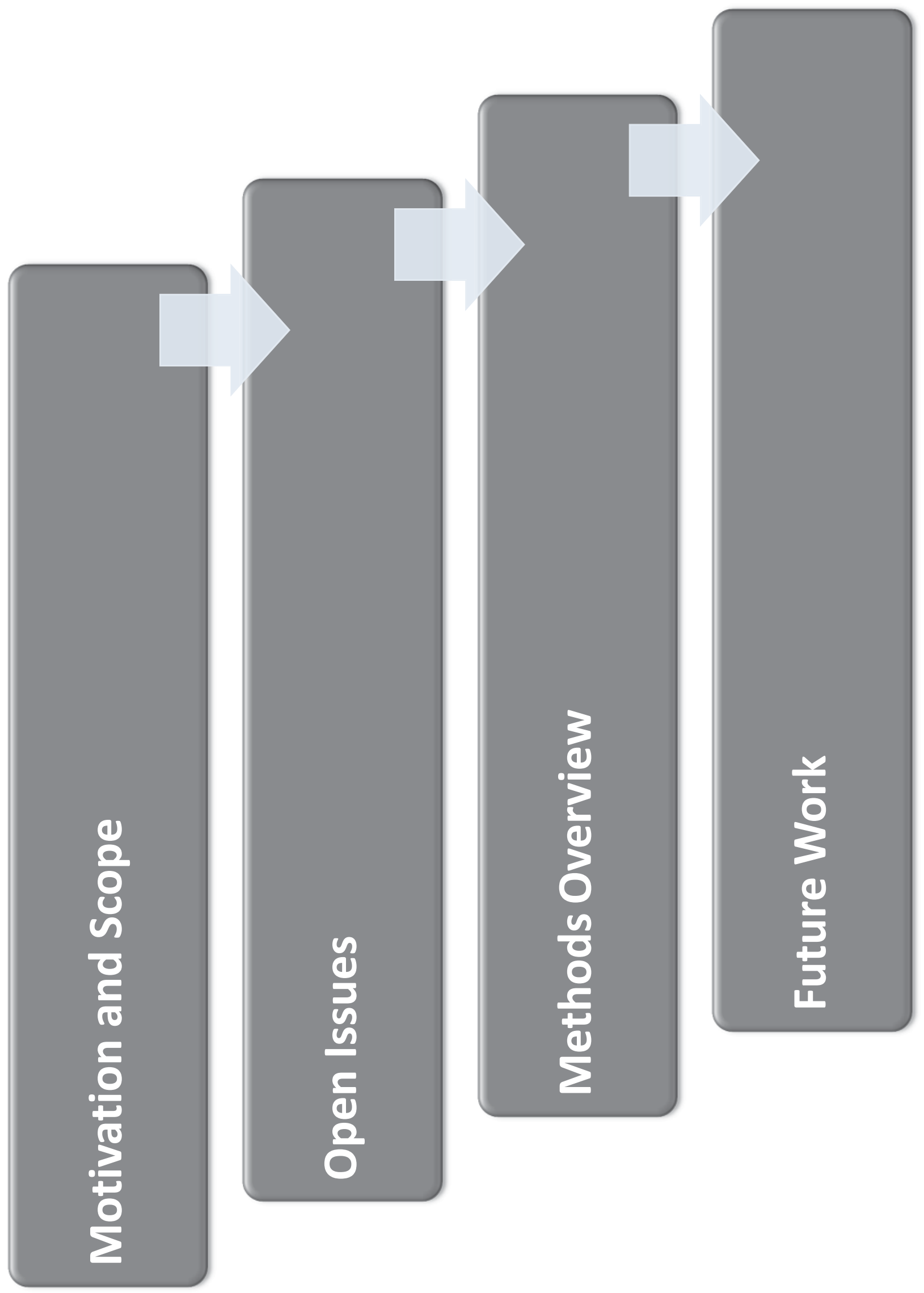




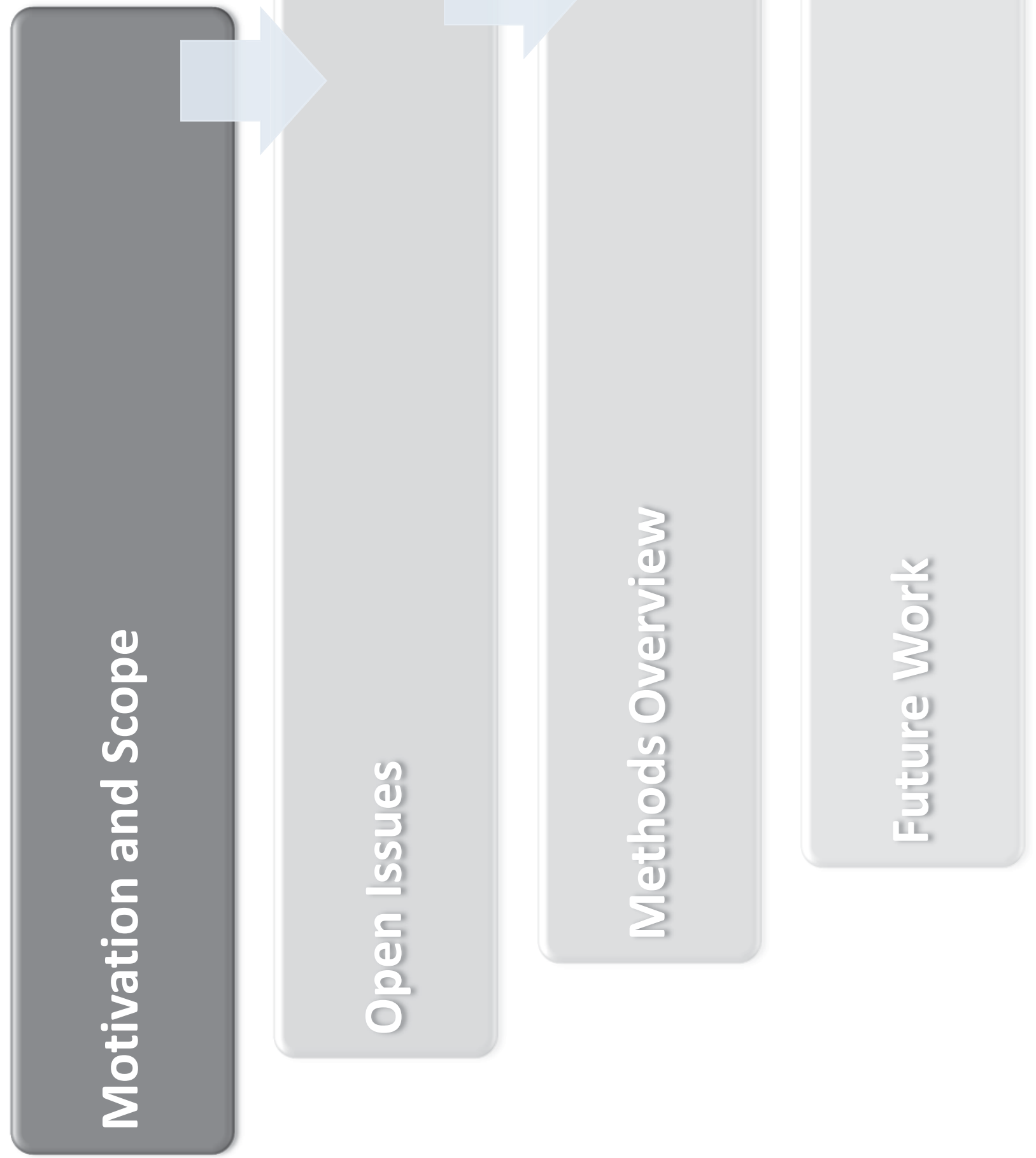




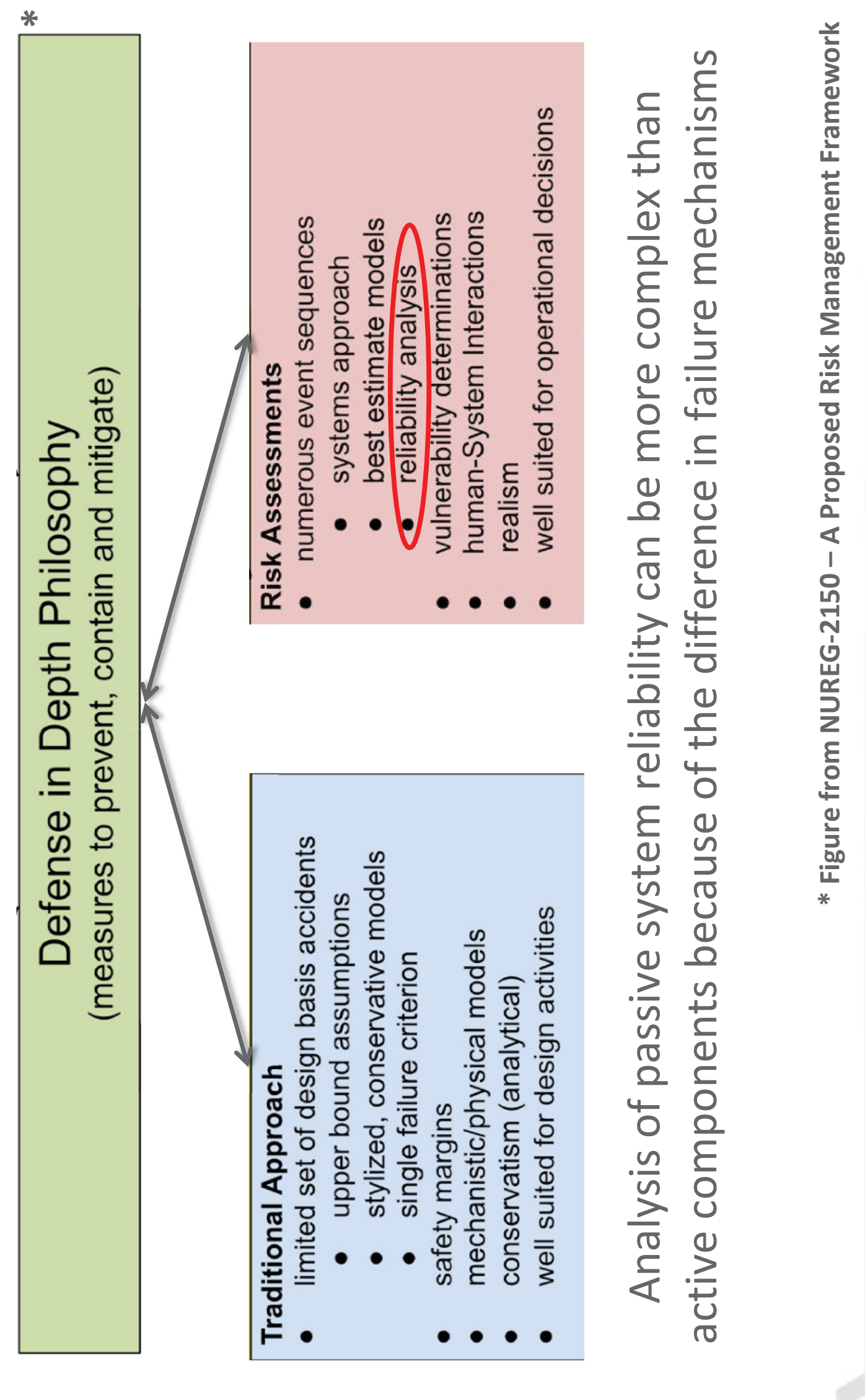




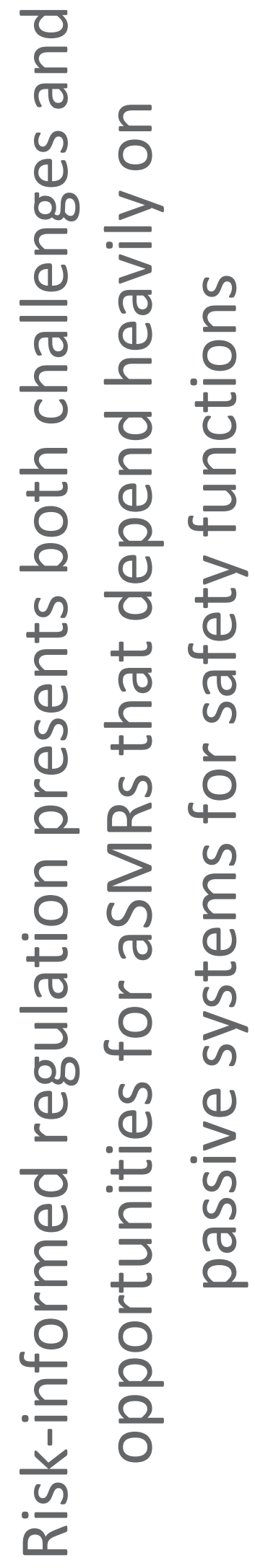




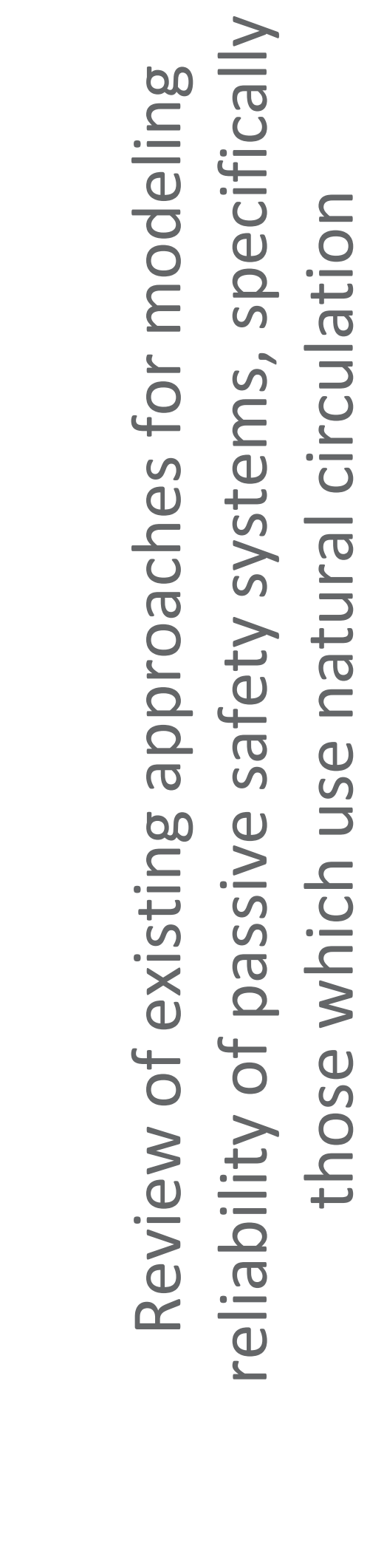




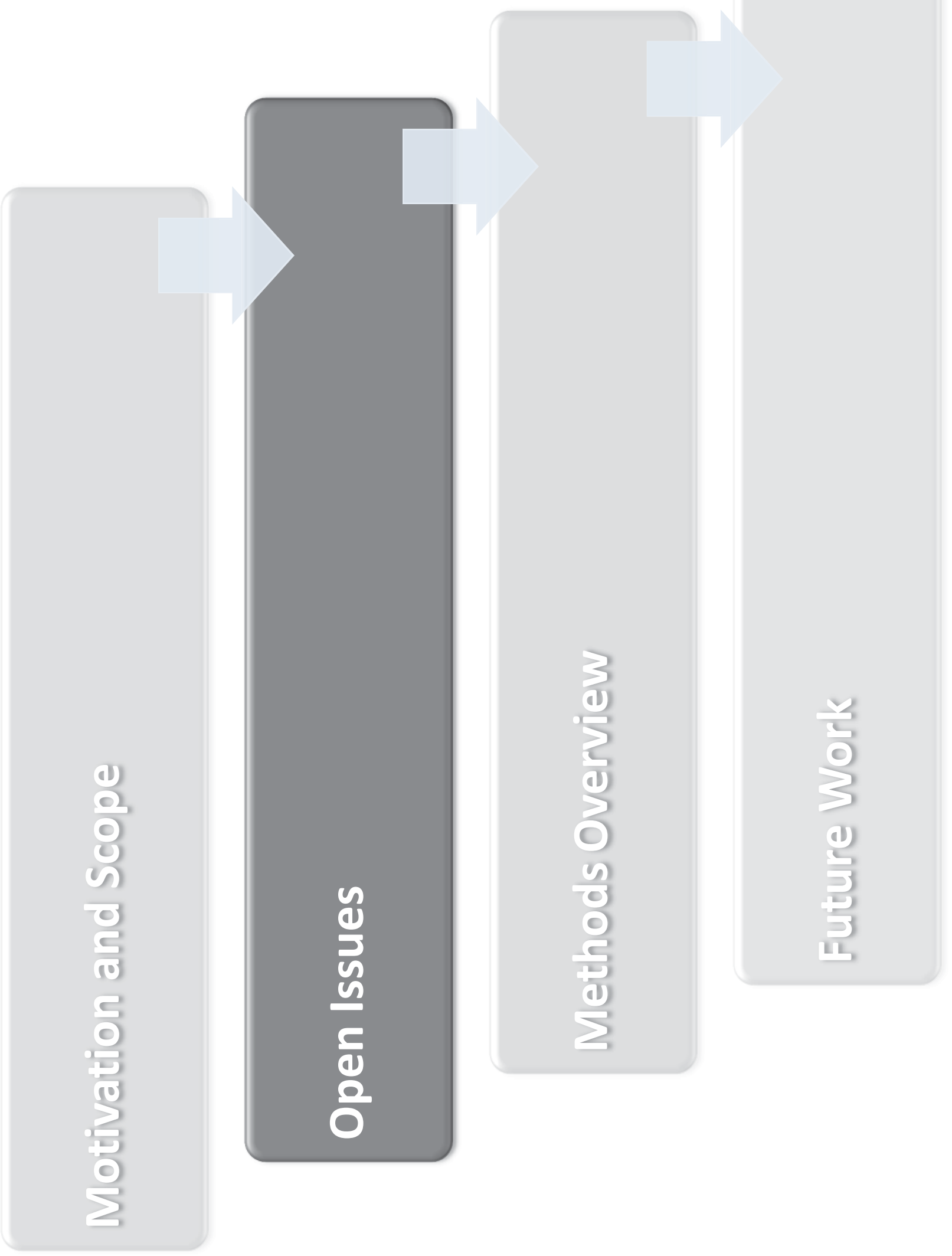


$\frac{\frac{1}{3}}{\frac{\sqrt{0}}{\frac{\pi}{0}}}$

$+$

ขै

잉

हั

$\frac{\sqrt{0}}{\mathrm{C}}$

$\frac{\pi}{2} \cdot \frac{\pi}{2}$

空 $\frac{\pi}{n}$

ט)

ำ

근

$\overline{0} \stackrel{0}{\circ}$

들

勇 1
)

$\frac{\pi}{\tilde{c}}$

$\frac{\grave{2}}{\frac{1}{0}}$

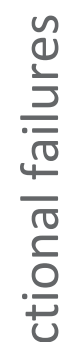

起

4

$\frac{?}{\overline{\frac{a}{0}}}$

ㅇํㅇ

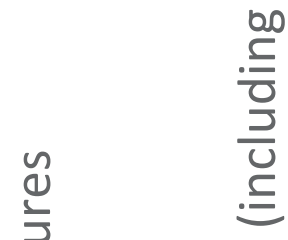

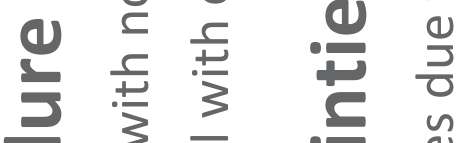

तั

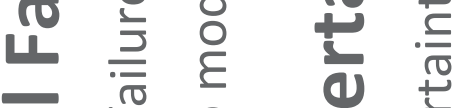

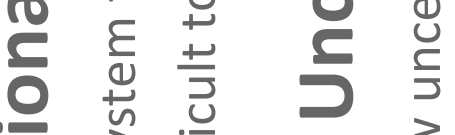

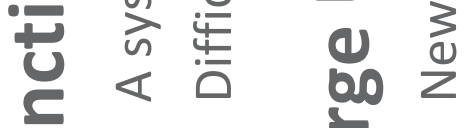

空

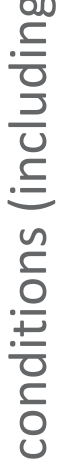

$\frac{7}{2}$

$\frac{\pi}{0}$

음

$\frac{\pi}{\frac{\pi}{0}}$

$\overline{0}$

.”

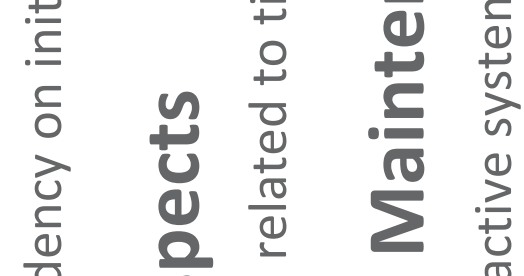

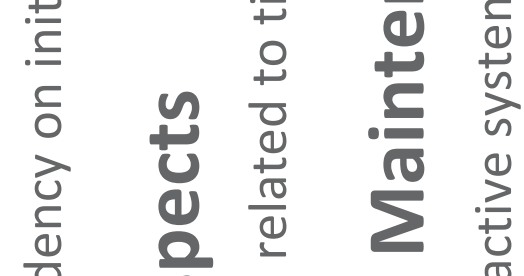

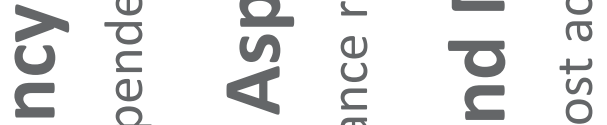

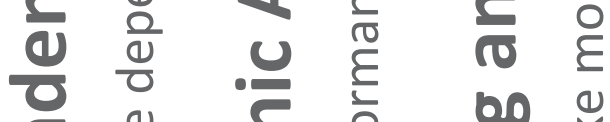

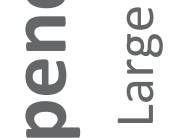

(1)

।

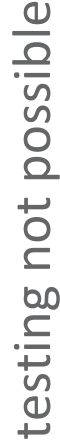

U

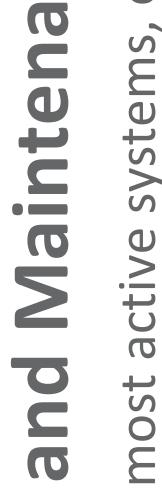

ம

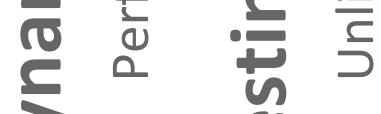

(1) 


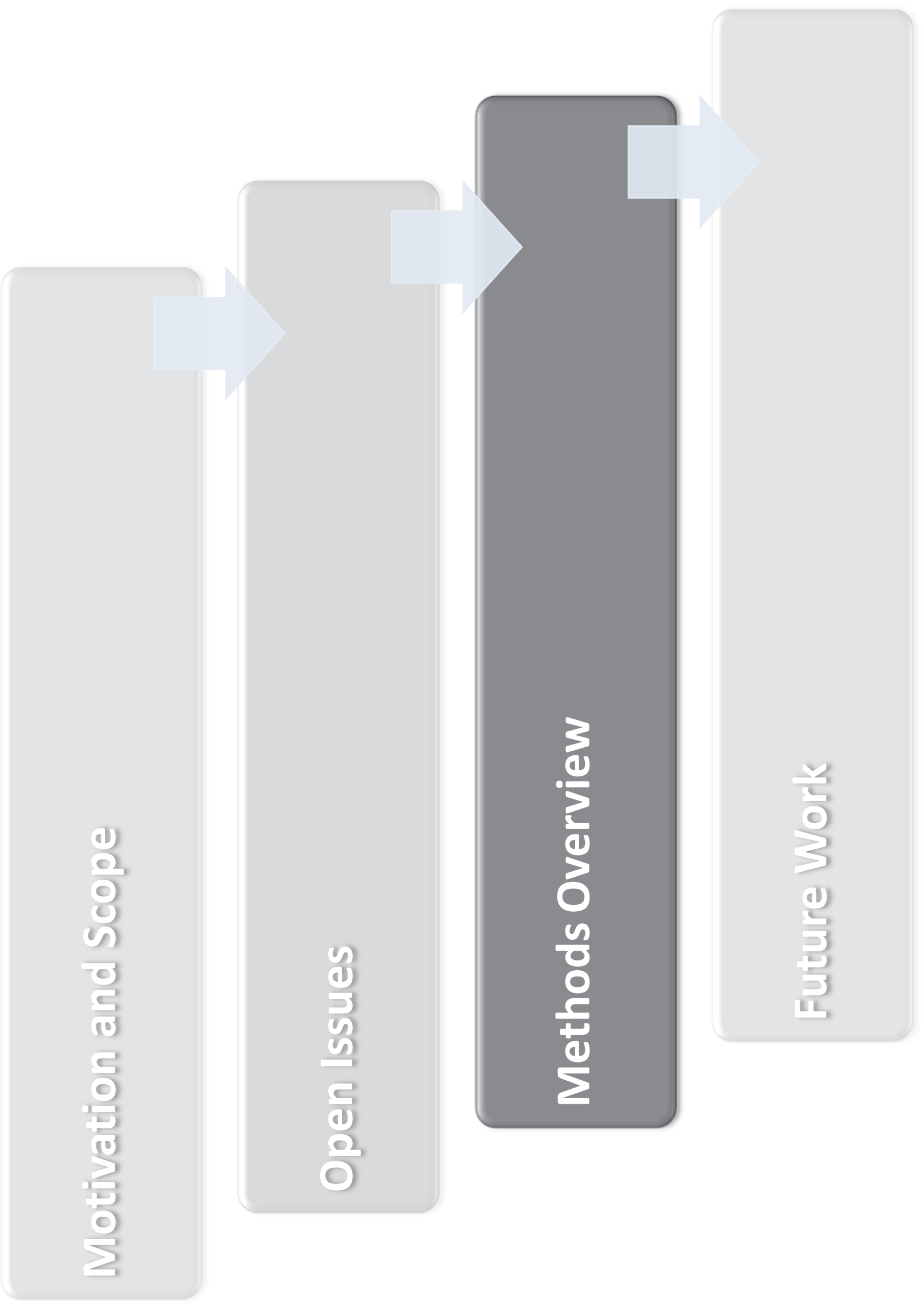




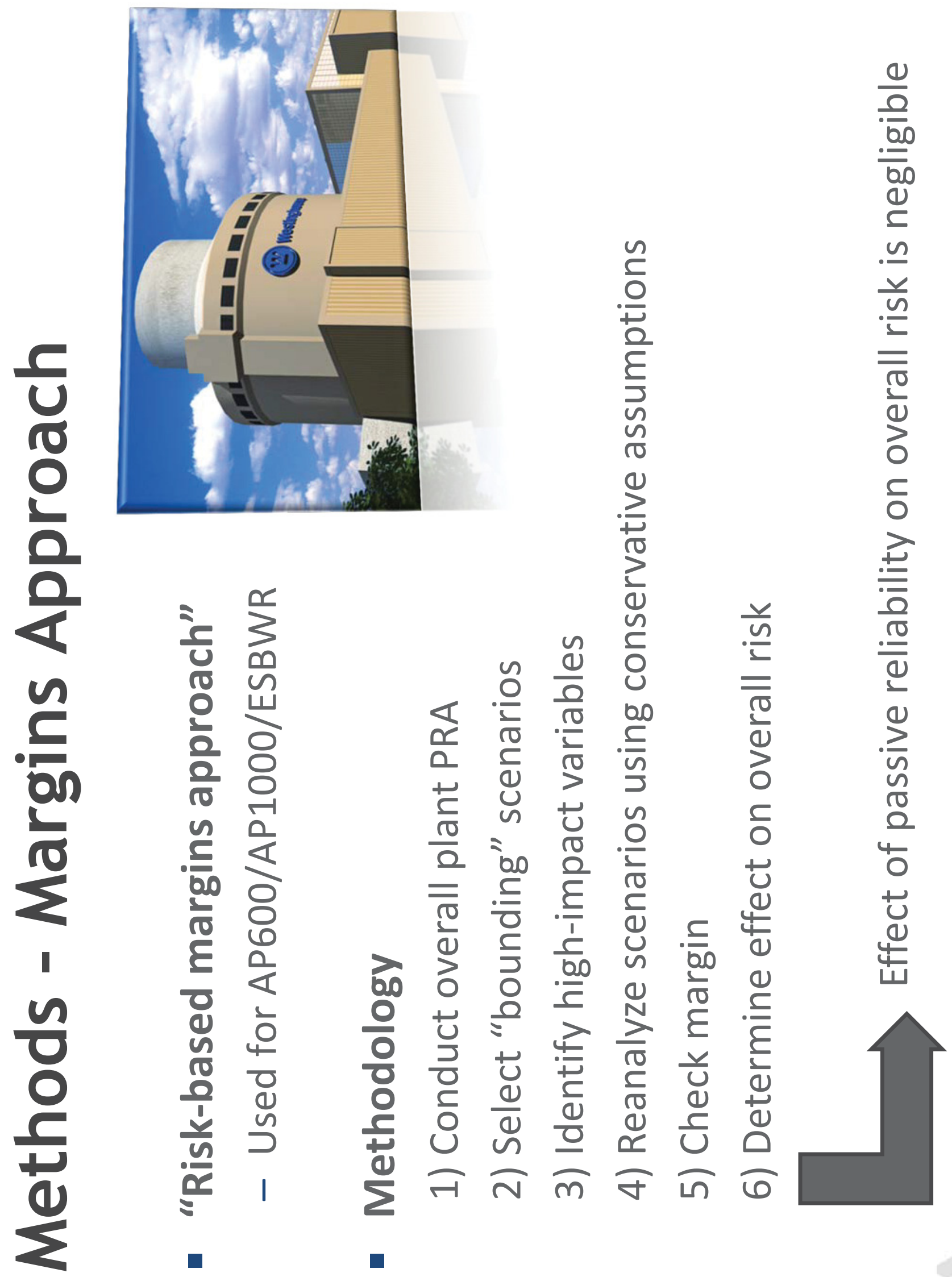



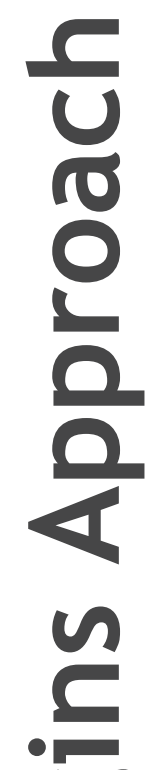

कs

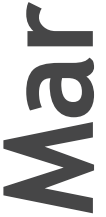

I

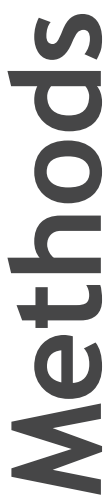

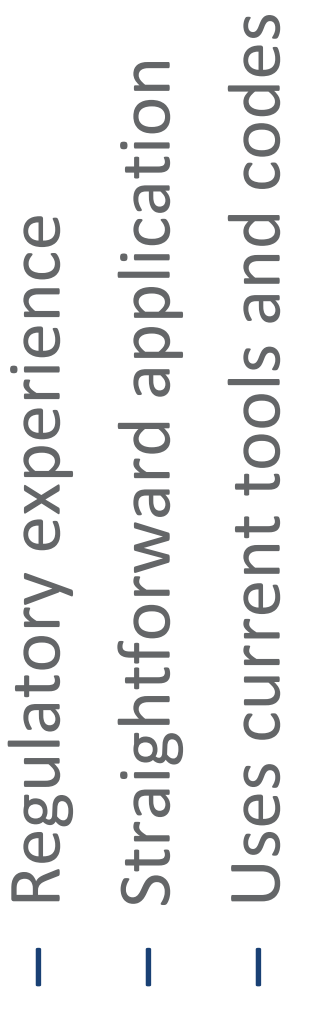

$\sim$

$\frac{\frac{1}{\sigma}}{\frac{\sigma}{\sigma}}$

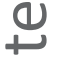

늠

. $\frac{1}{E}$

हغ 乞

닝 으

(1) 을 논

ठ ह

ते जे त्

ก थे ते

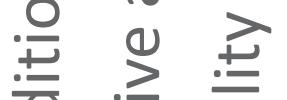

更

뉼 은

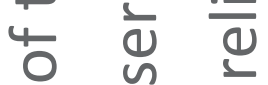

(1) 등

원ำ

$\geq 00$

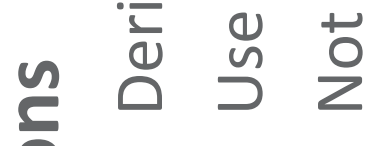

○ 1 I 1 
$U$

10

12

$\bullet$

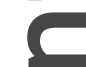

10

2

】

0

$\leftarrow \quad \frac{\pi}{0}$

$\underset{1}{ }$ 트

Ш $\frac{1}{8}$

$\frac{1}{2} \stackrel{ \pm}{\frac{\pi}{2}}$

है ए

ज

(1) E

$\sum_{n} \stackrel{0}{n}$

ज

a

는

- 0

- 1 눈

10

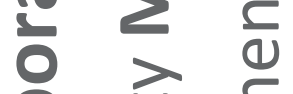

을 ‡

- बू ज

(1) 므

e $\frac{1}{1}$ v

(1)

3 ज \&

0

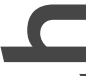

10

(1)

$\sum \frac{1}{\alpha}$

$0 \propto$

I 1 


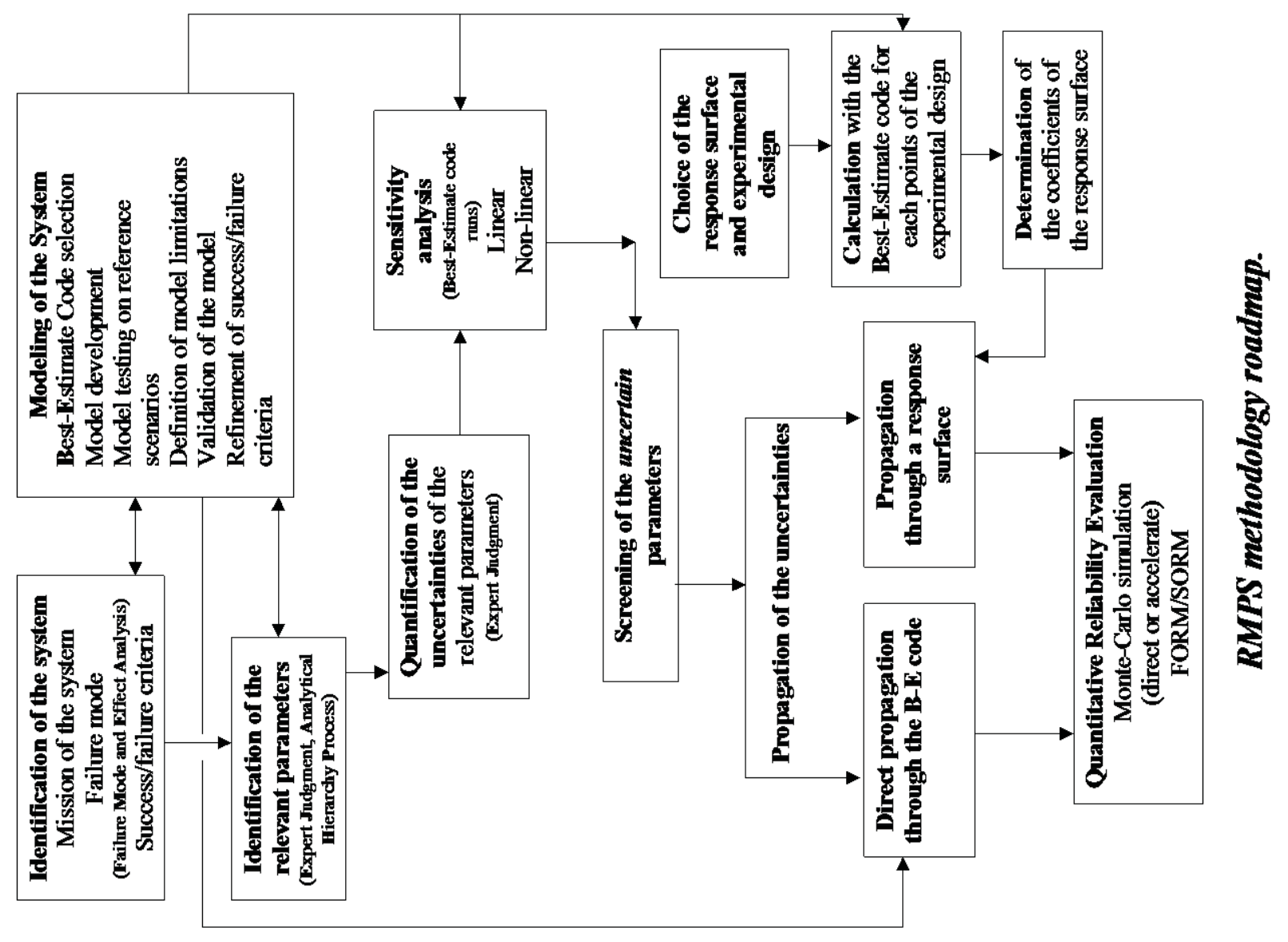



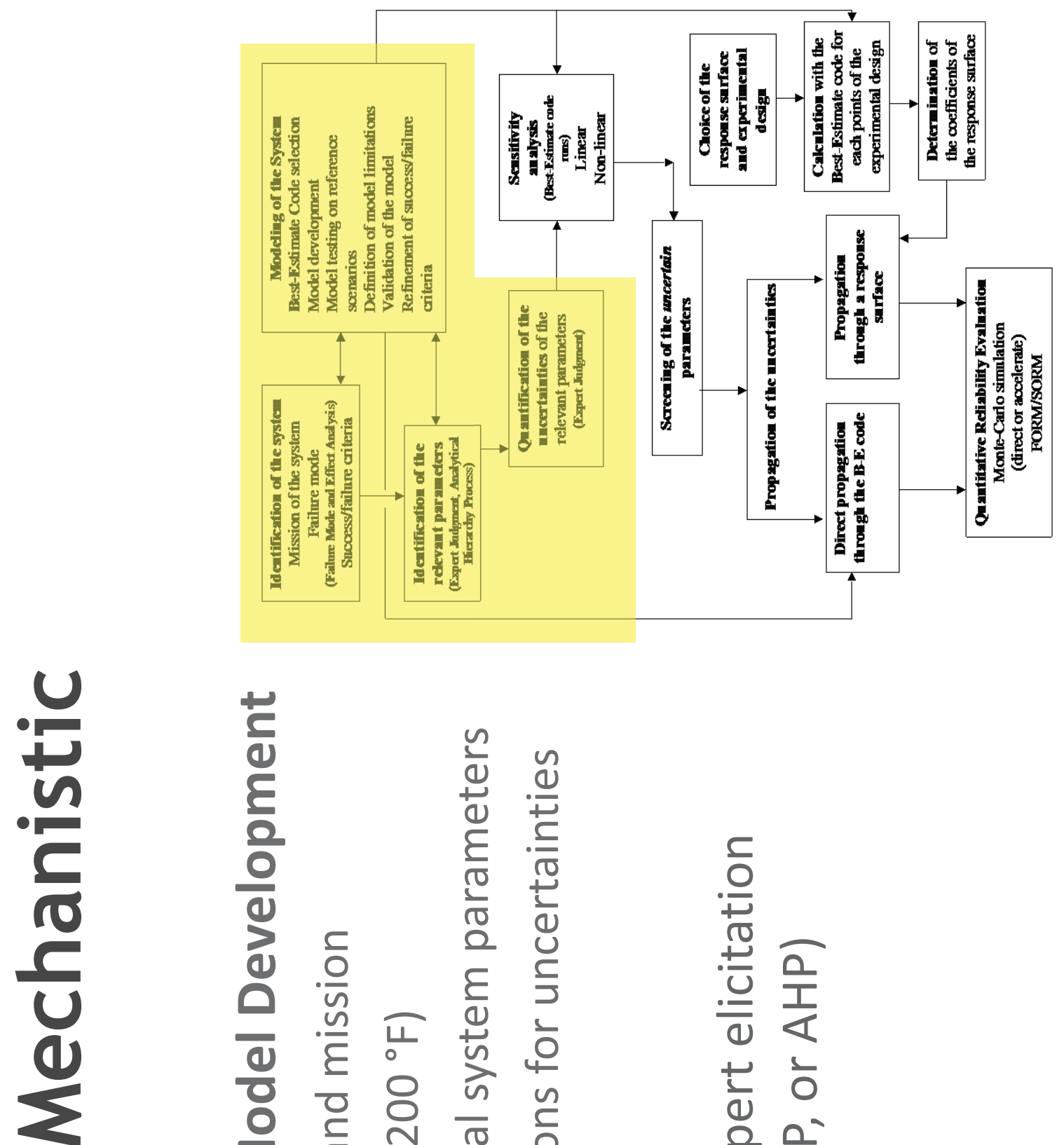

I

0
0
2
1
2
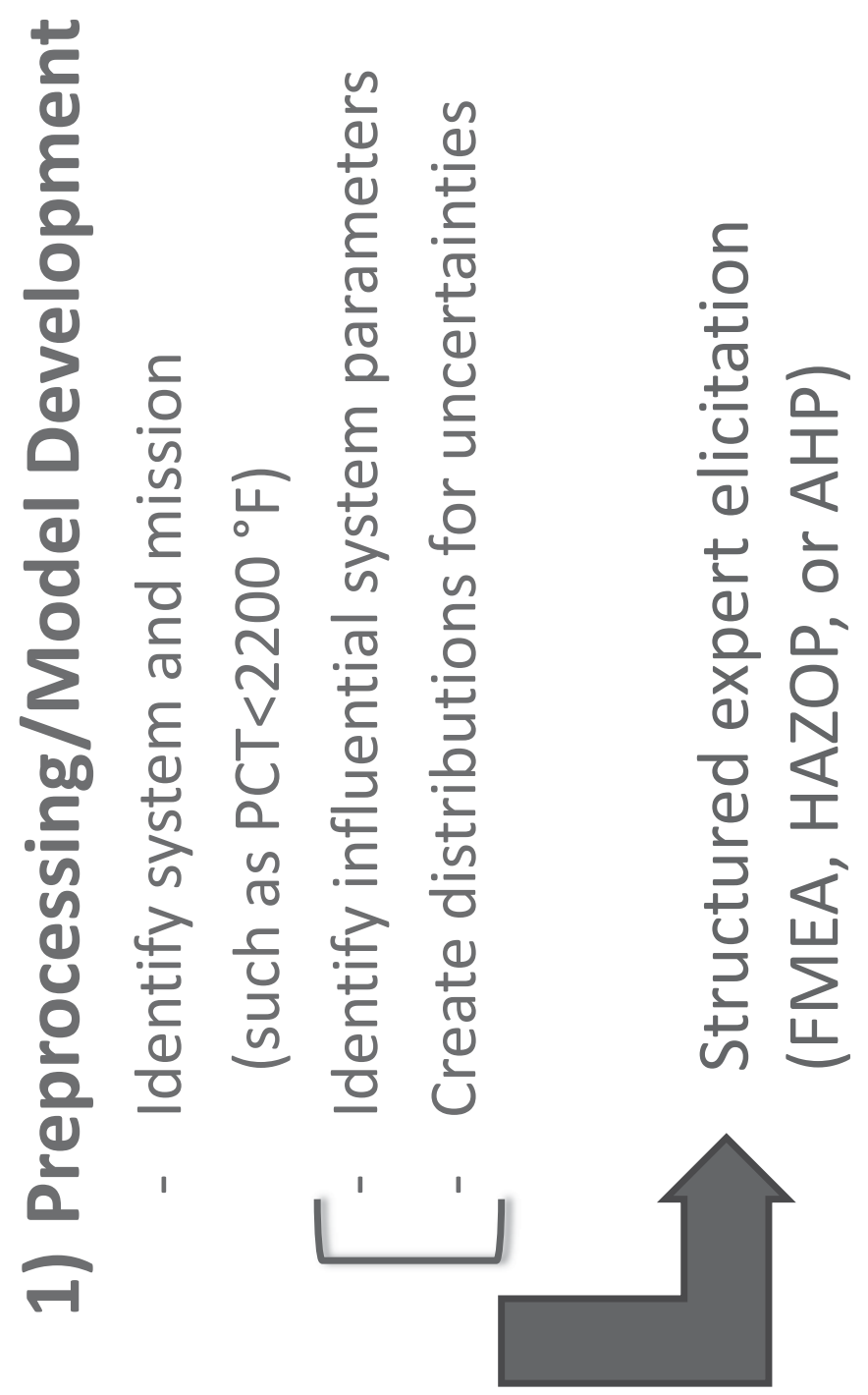

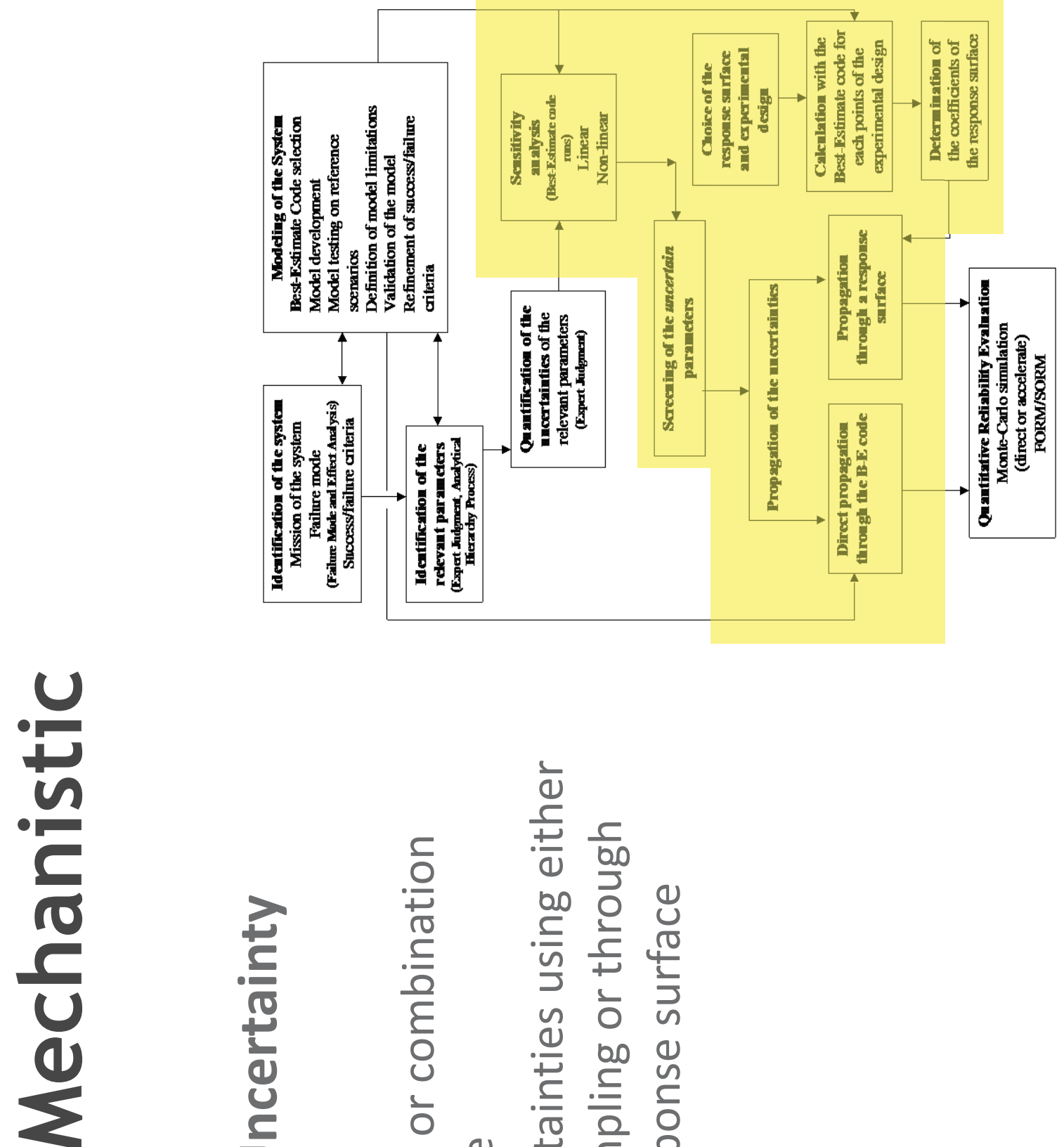

I

0
0
2
2
2

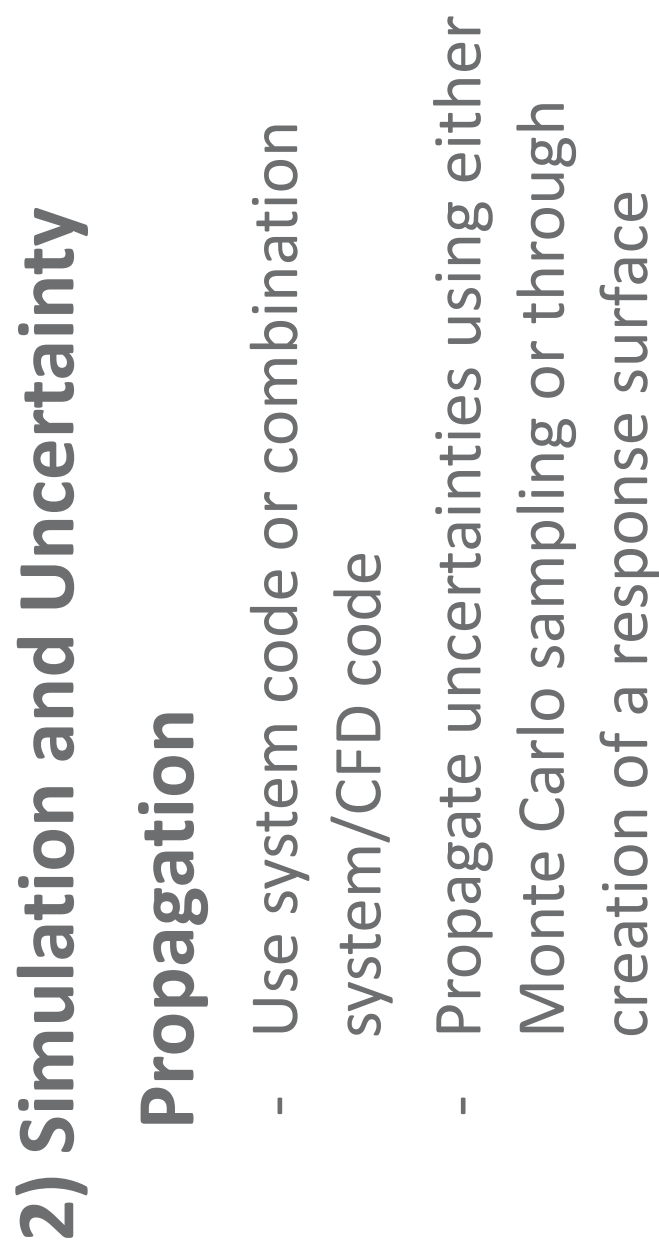



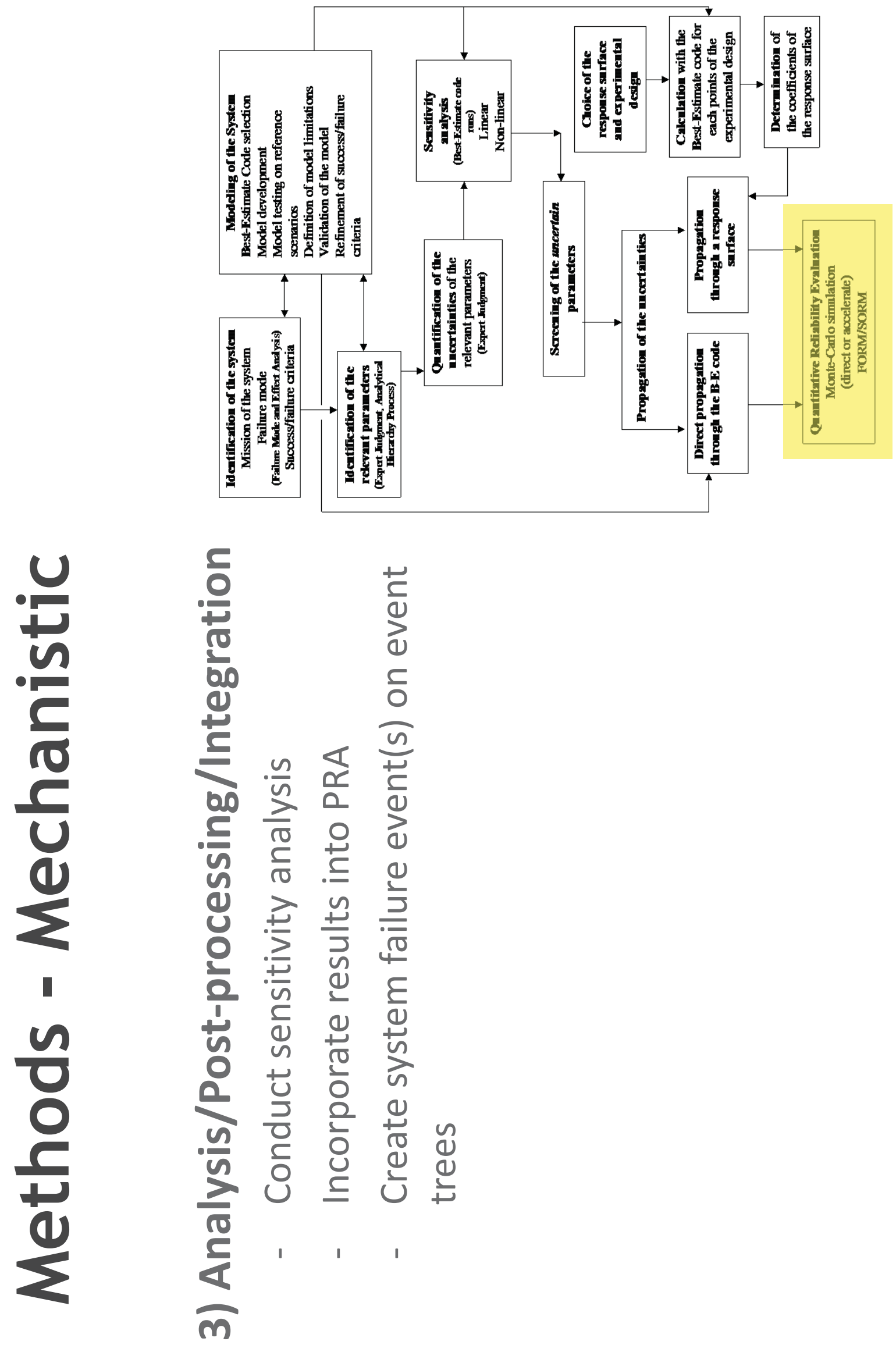


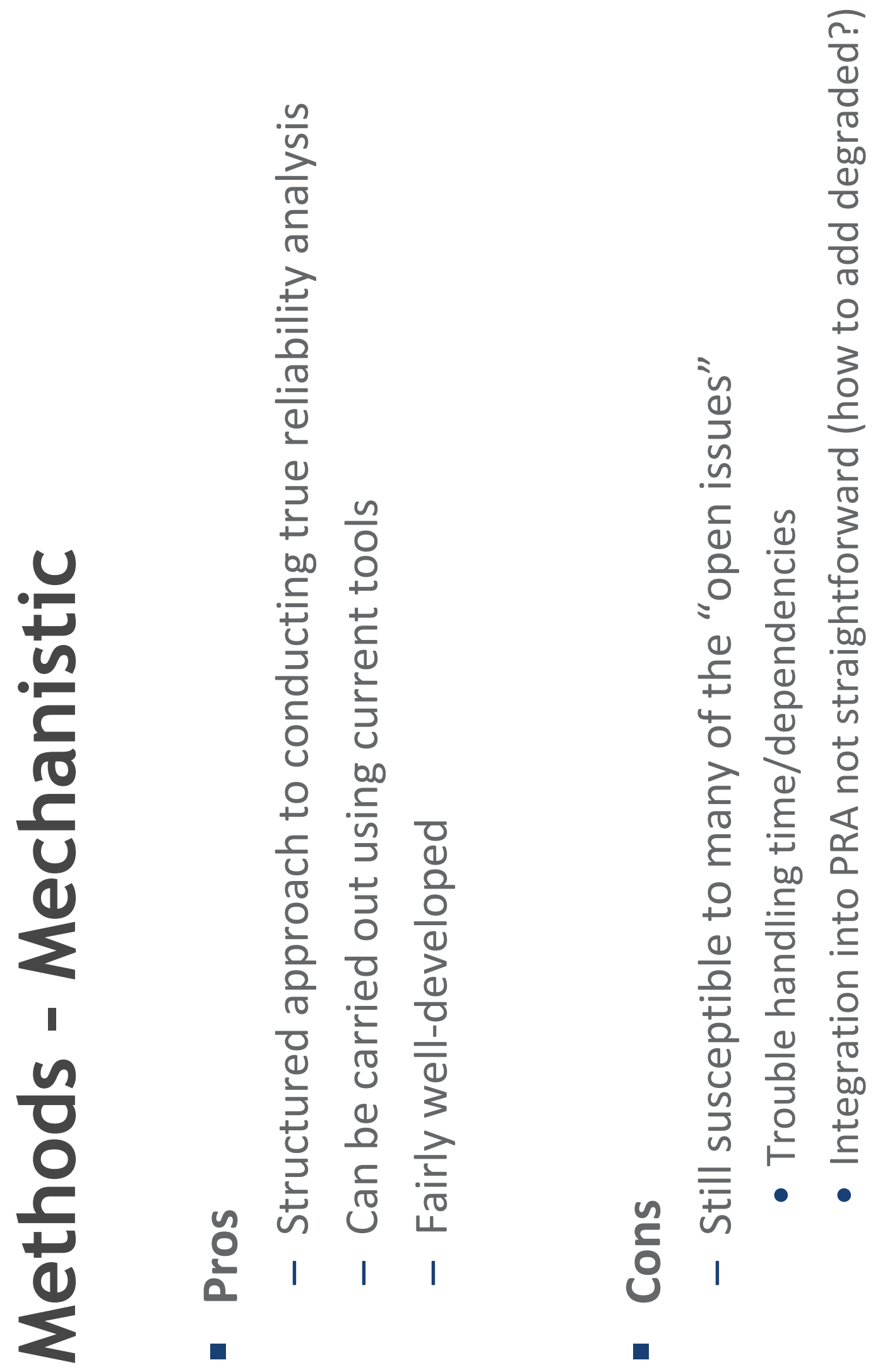



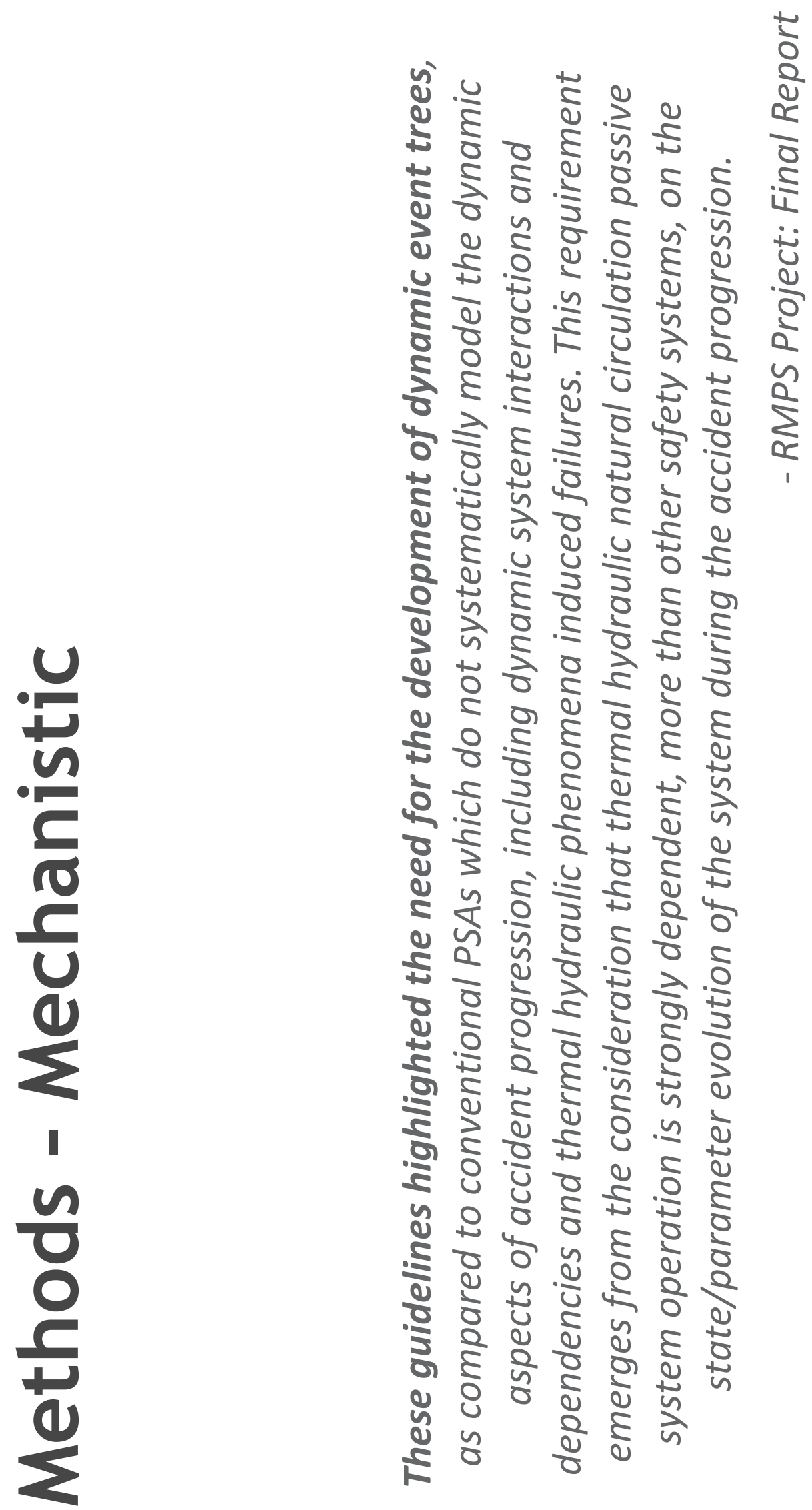


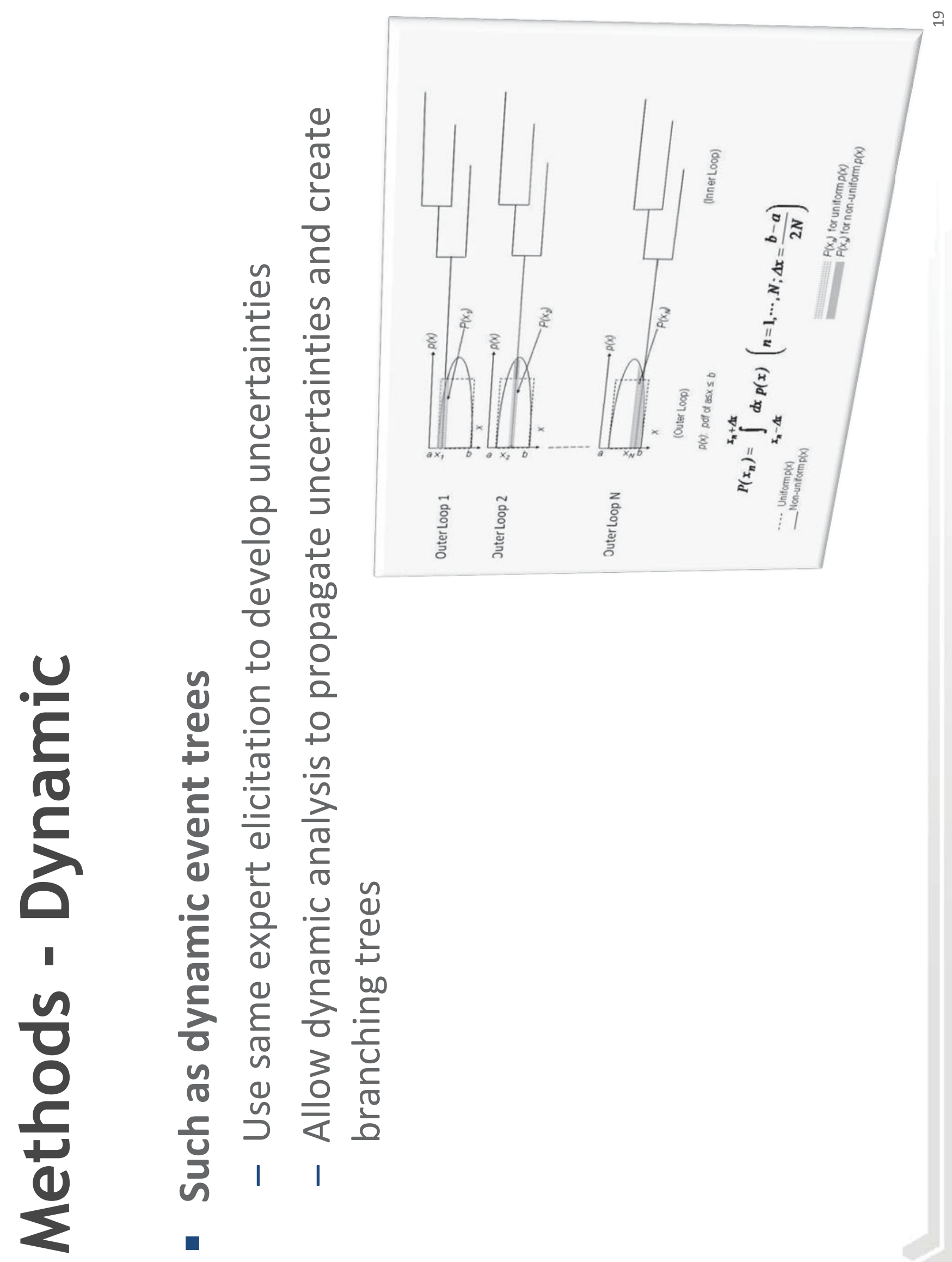



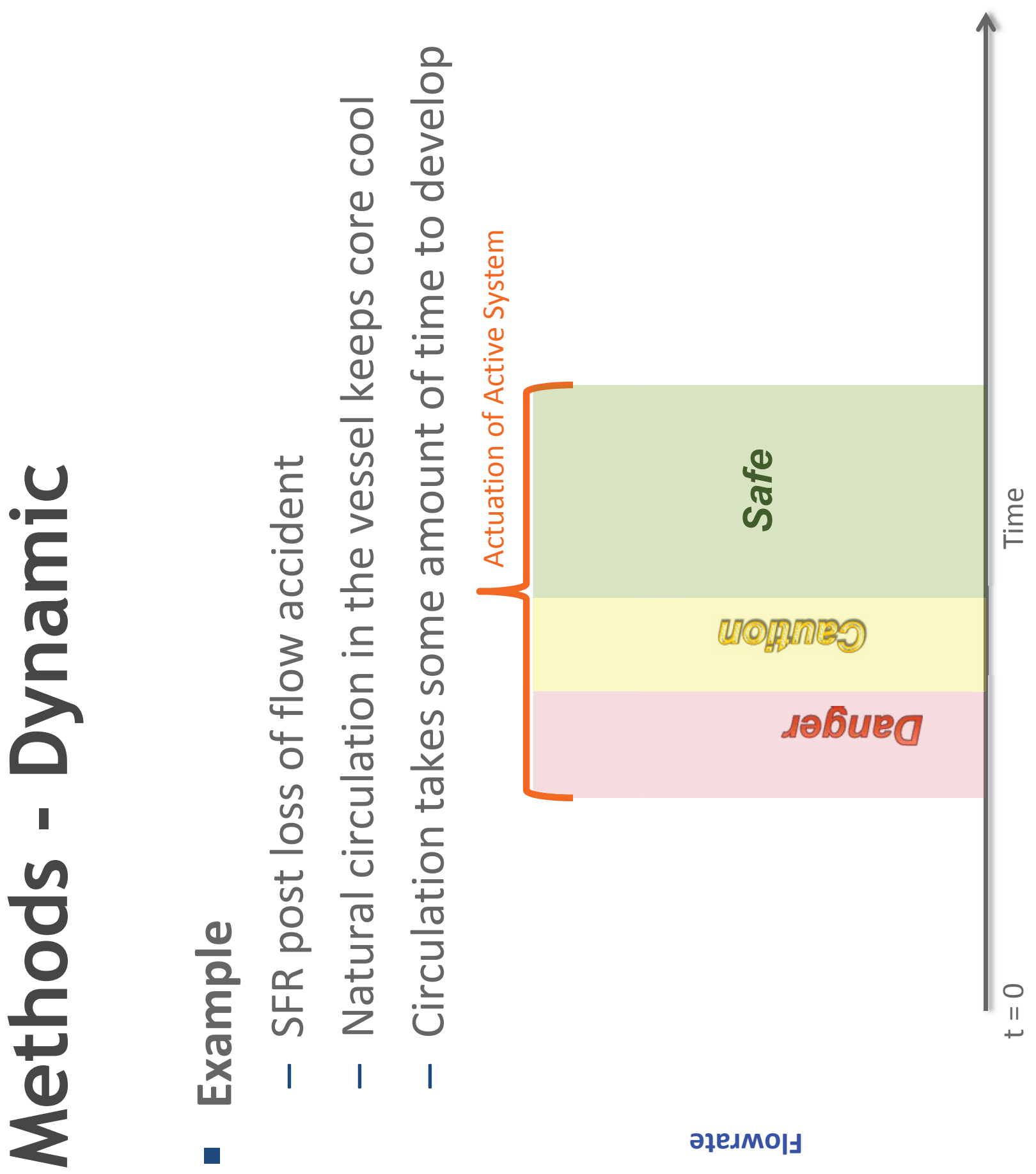


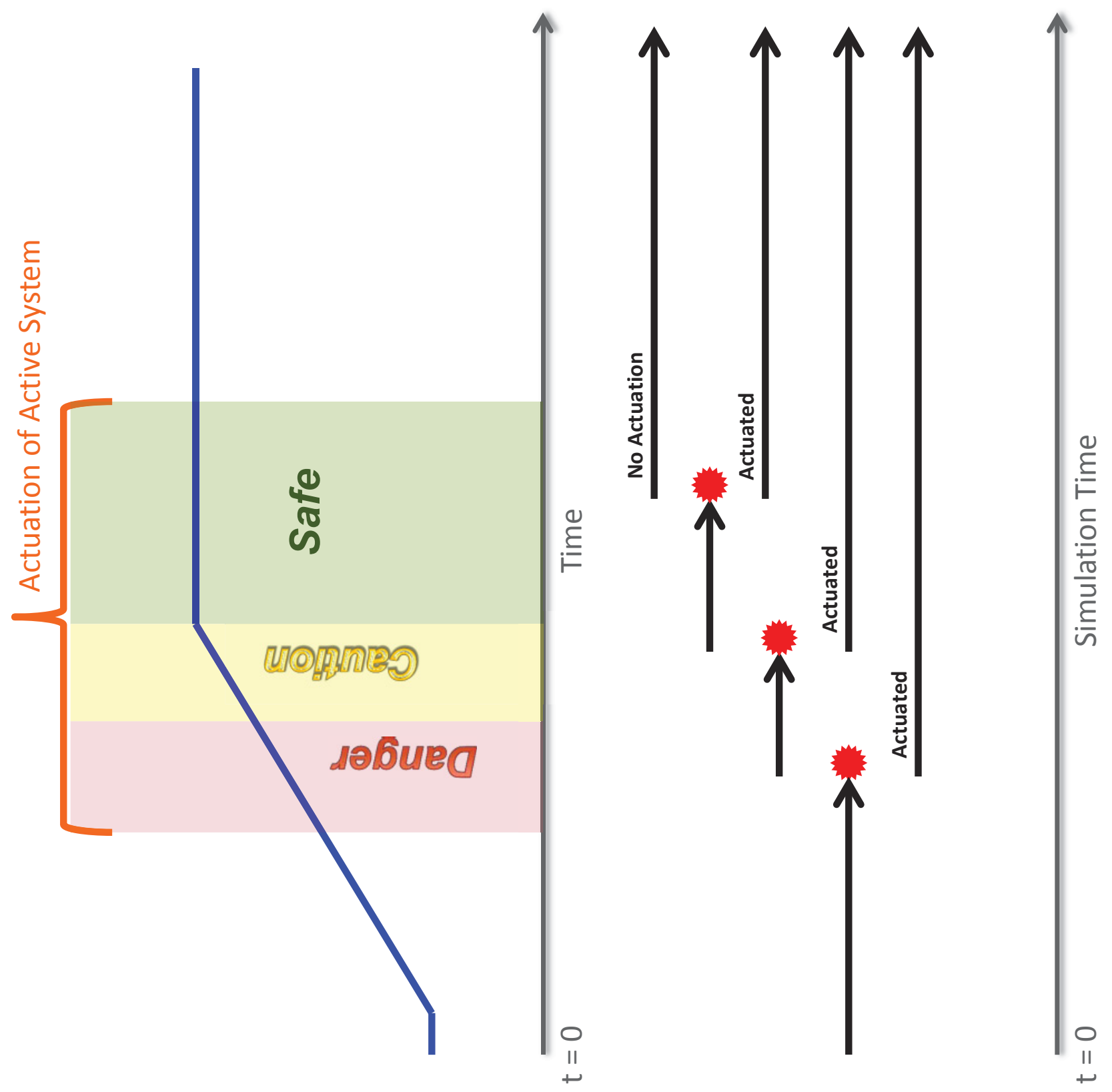

әұеגмㅣㅣ 


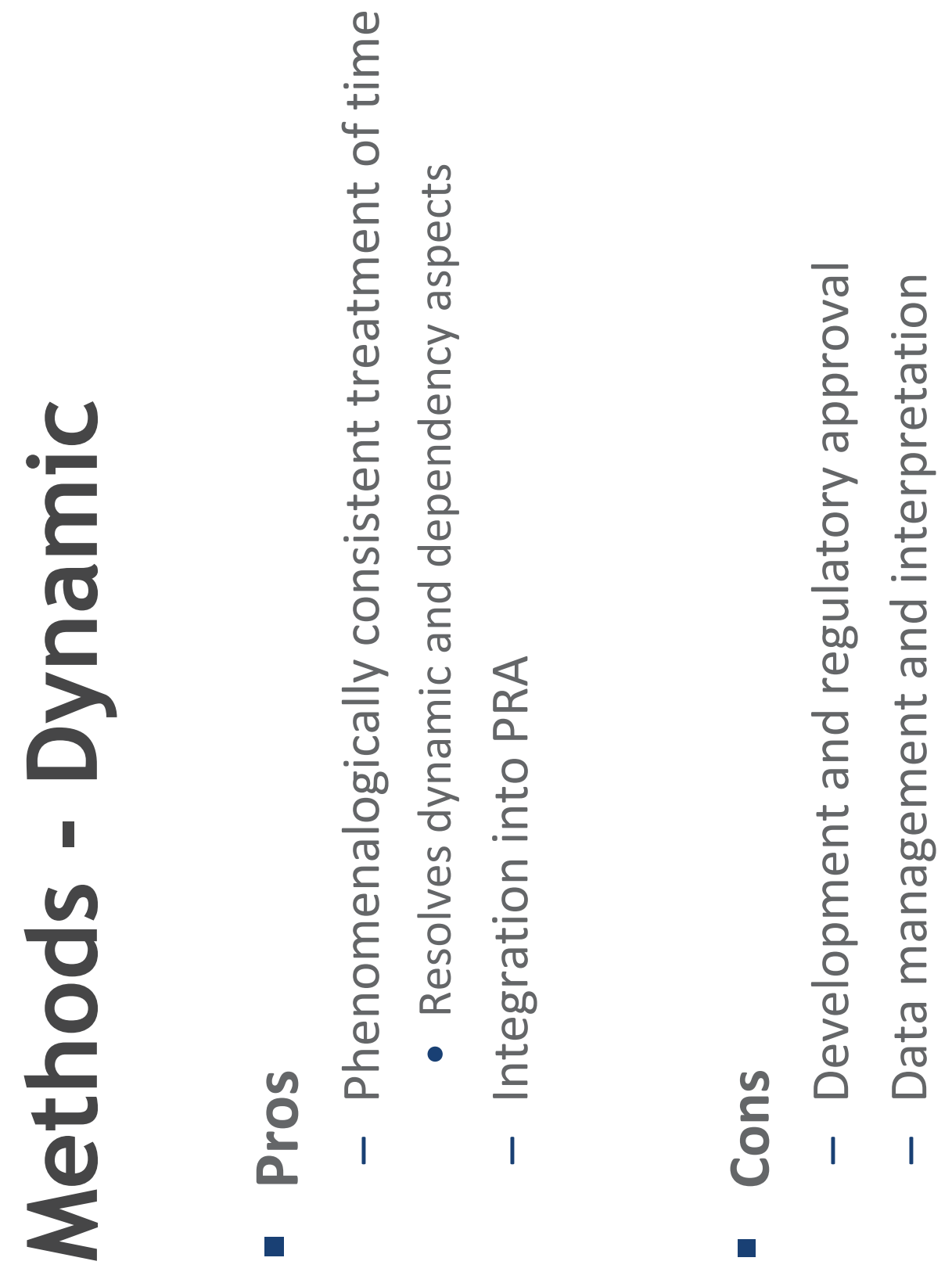




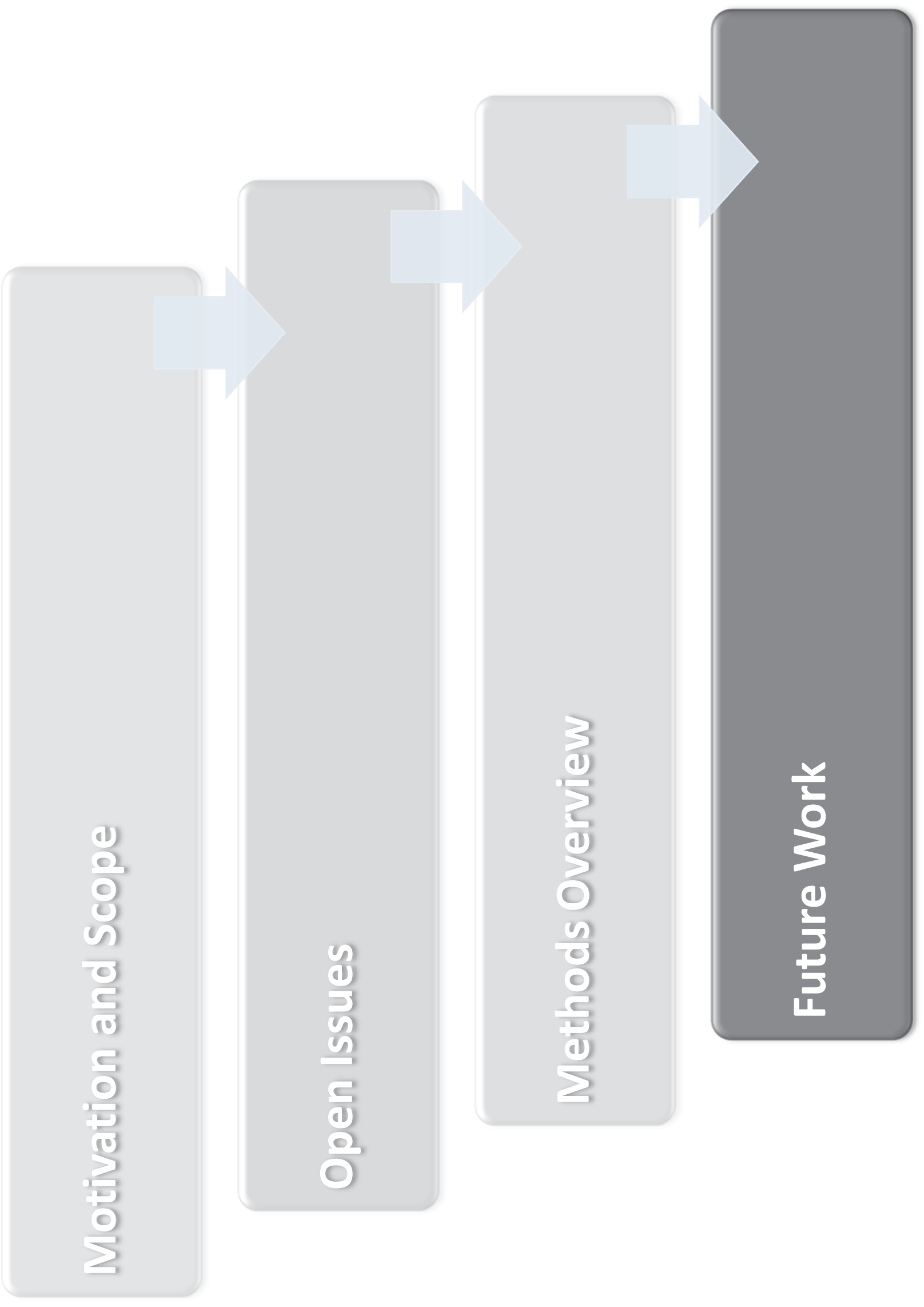




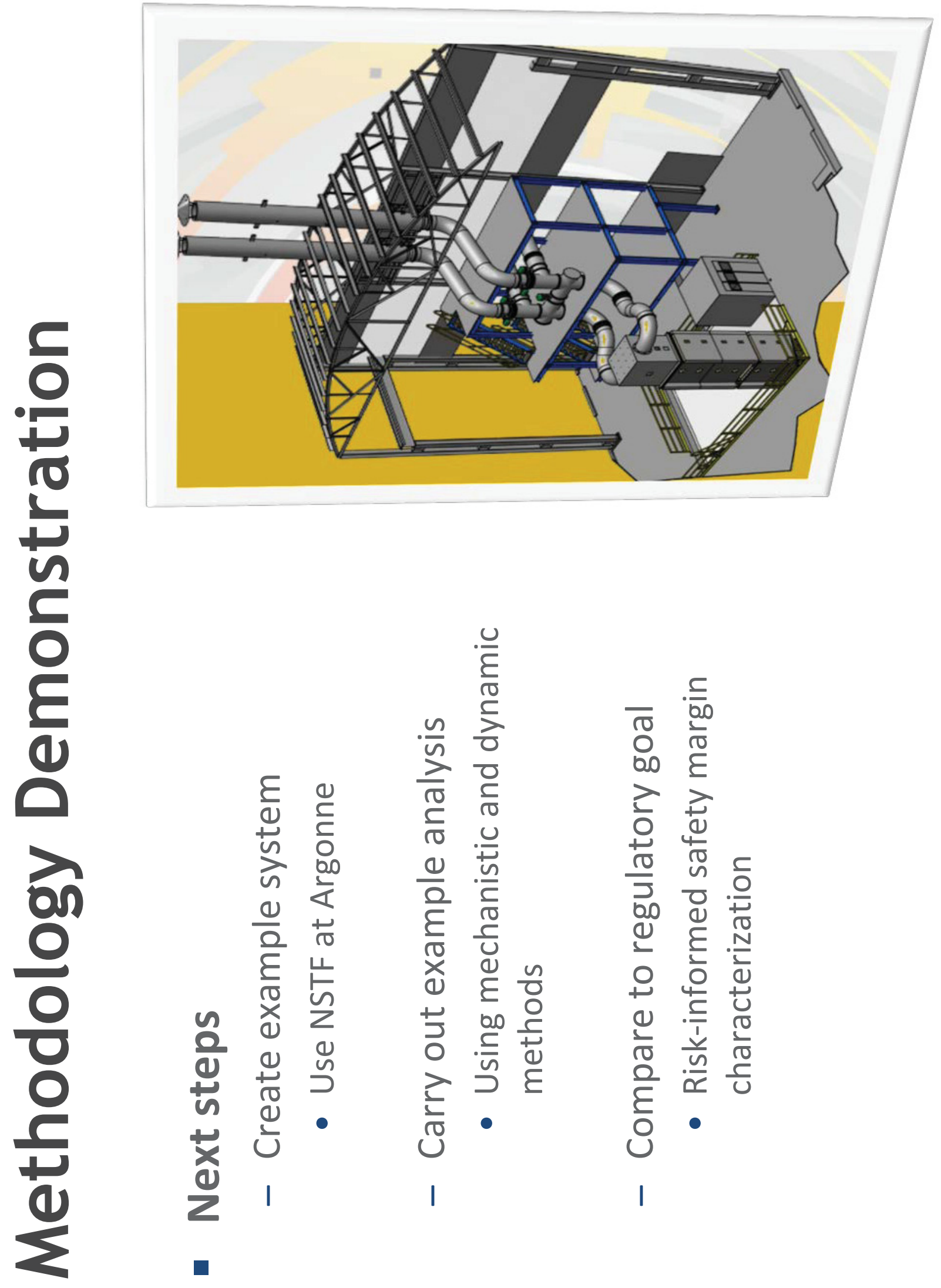




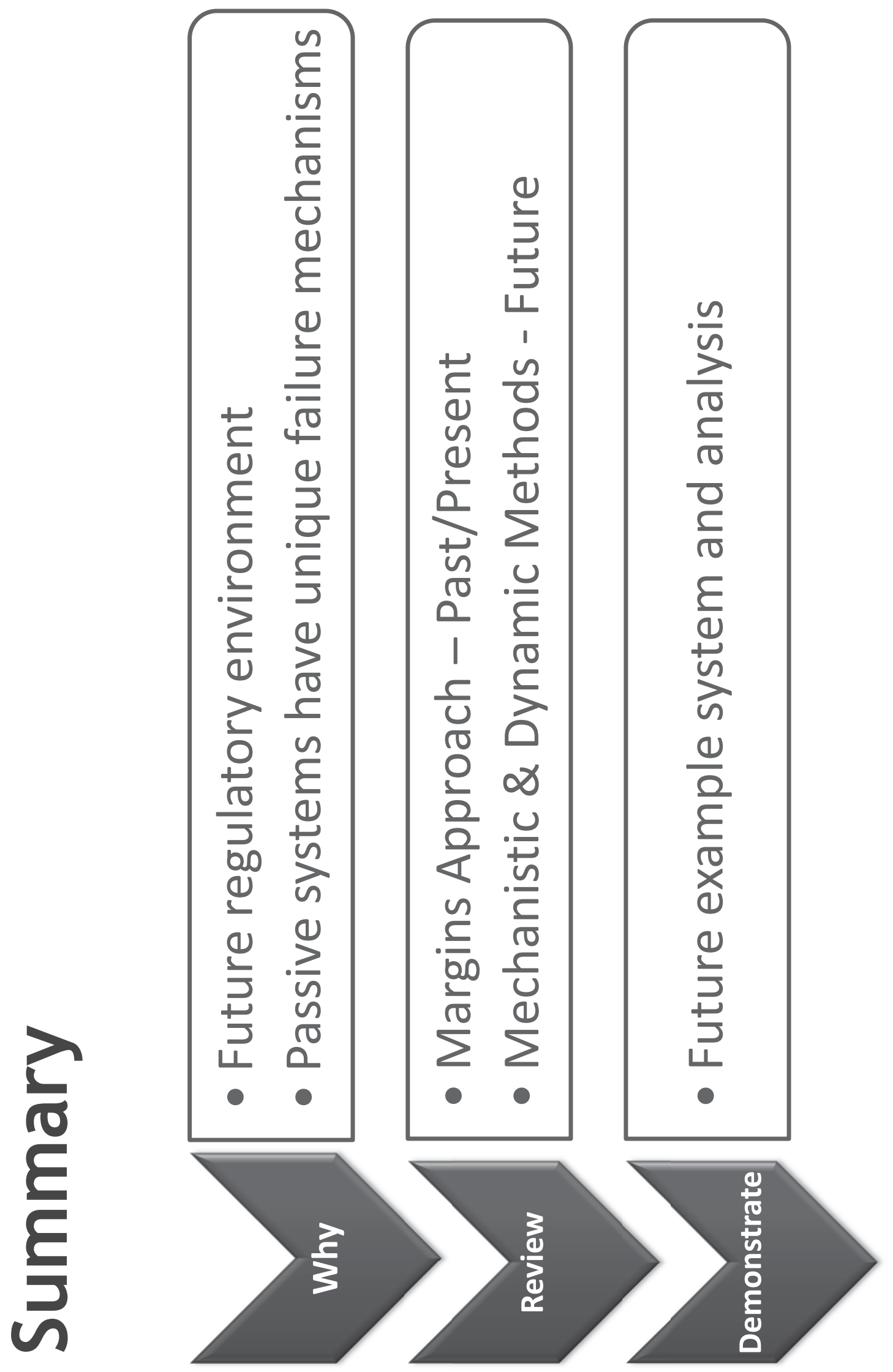



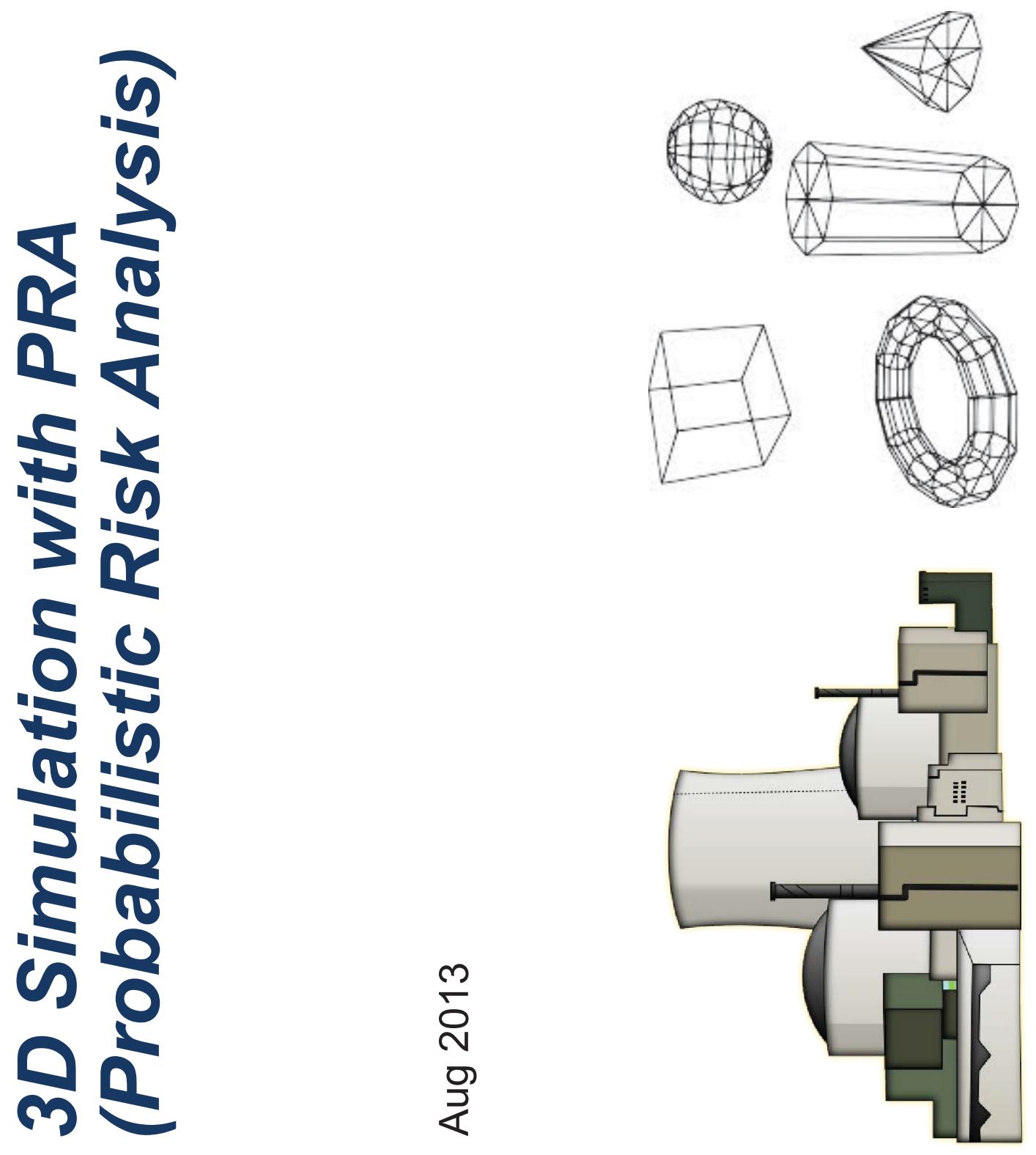

^об'Іи!'мМм

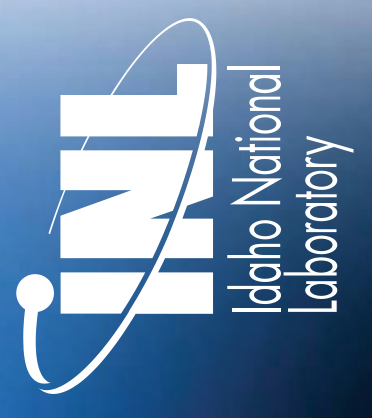




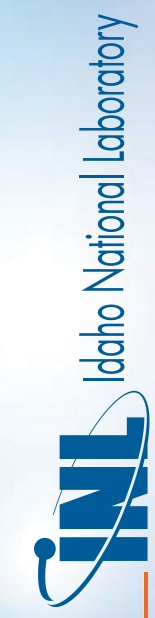

,




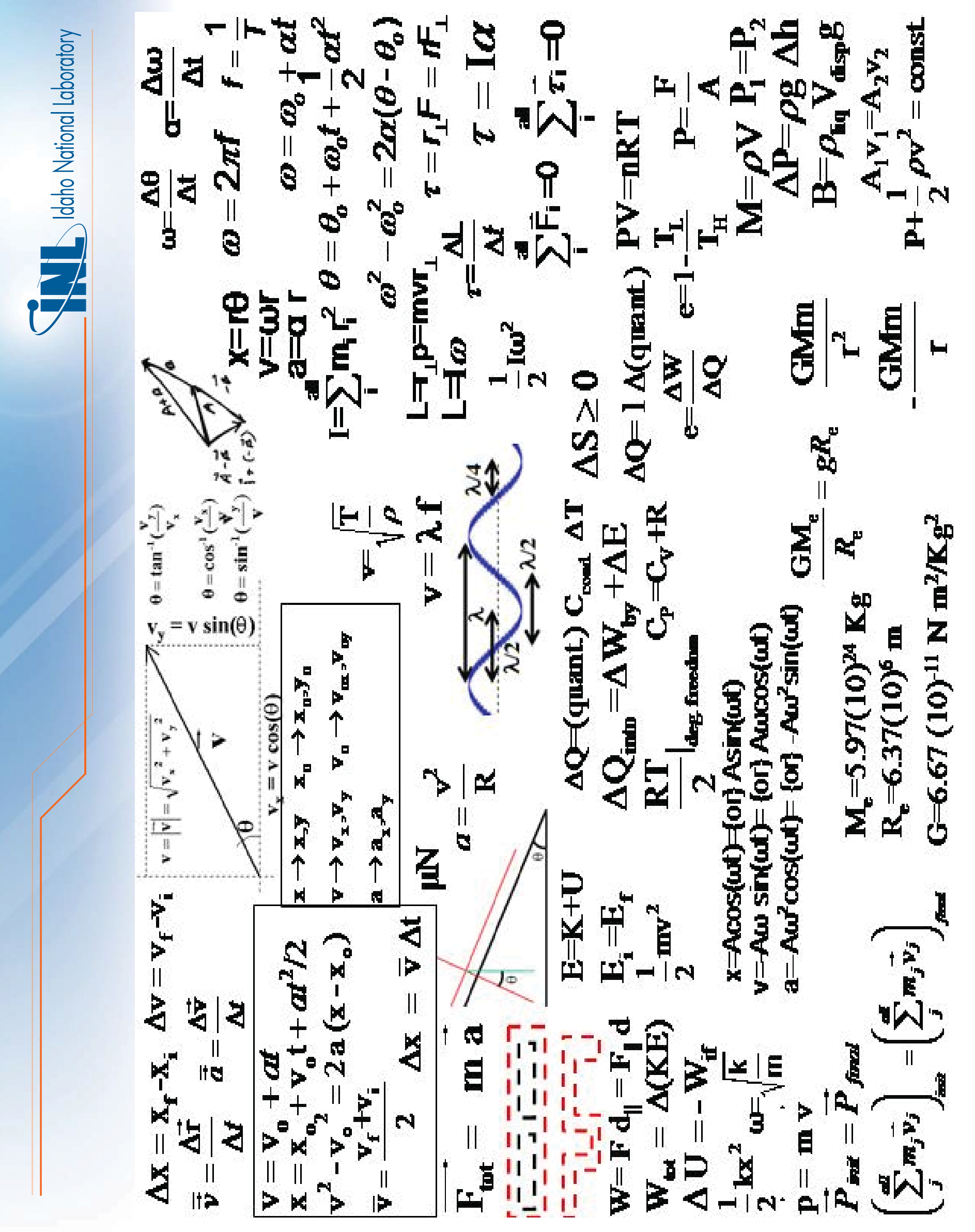




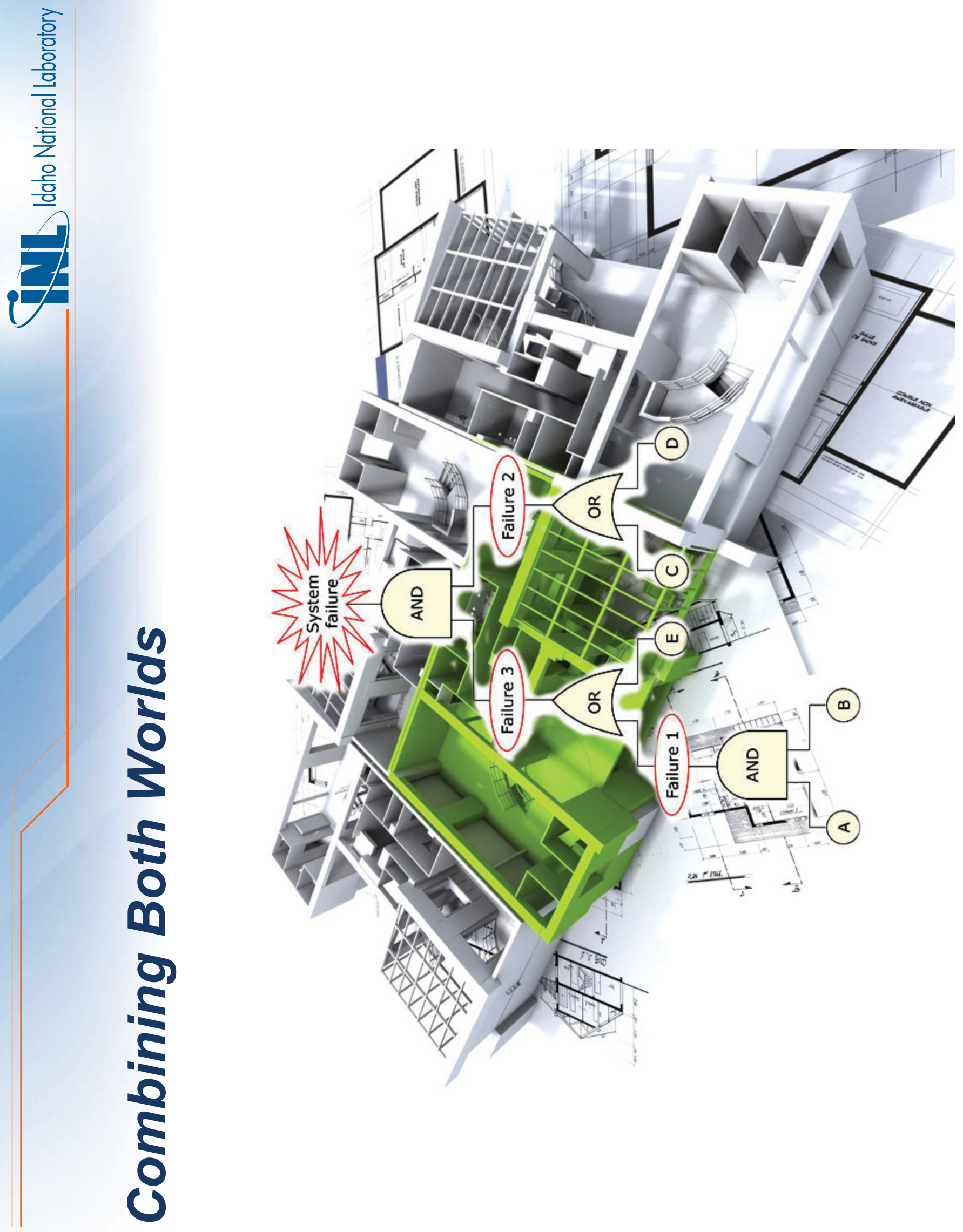




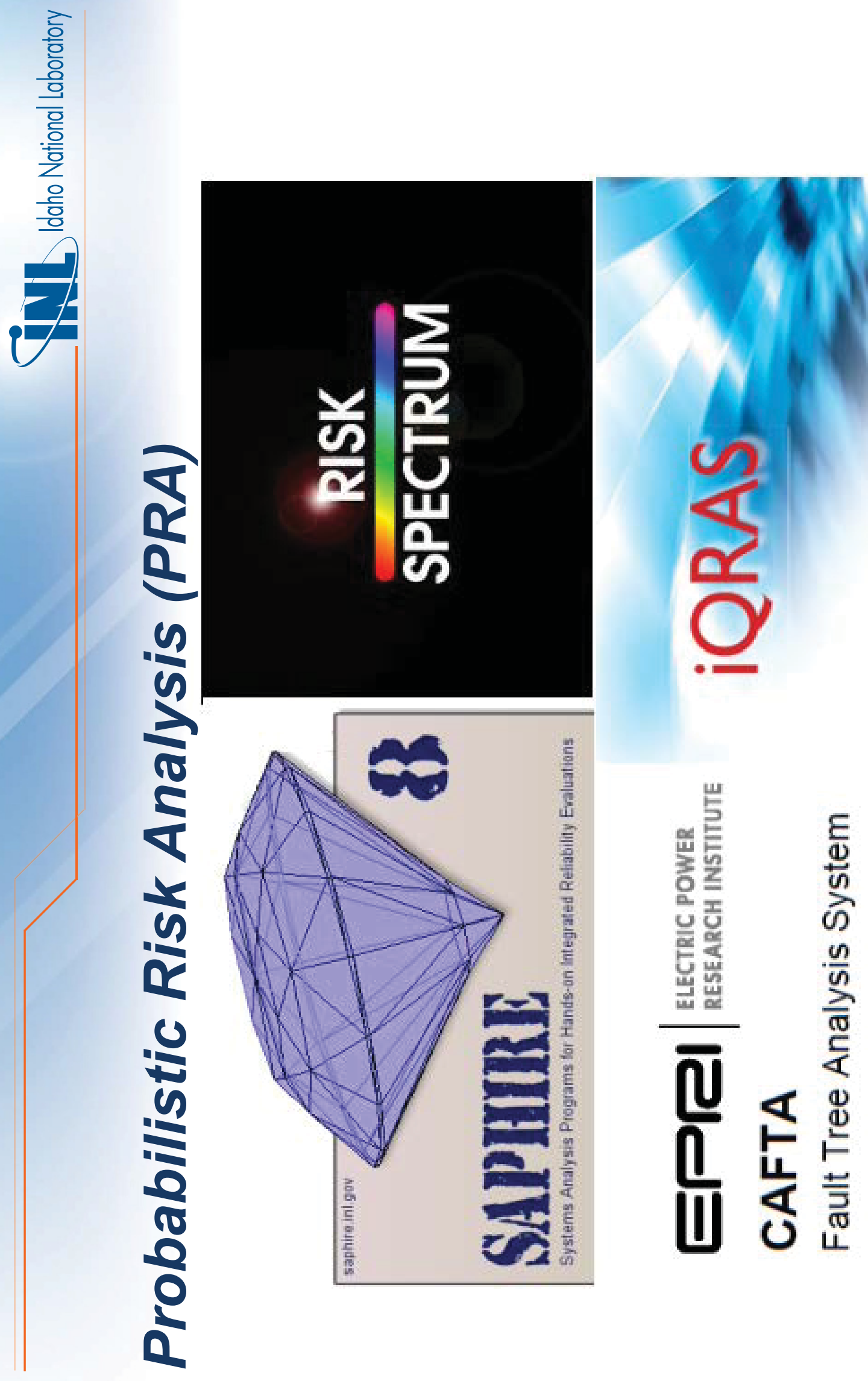



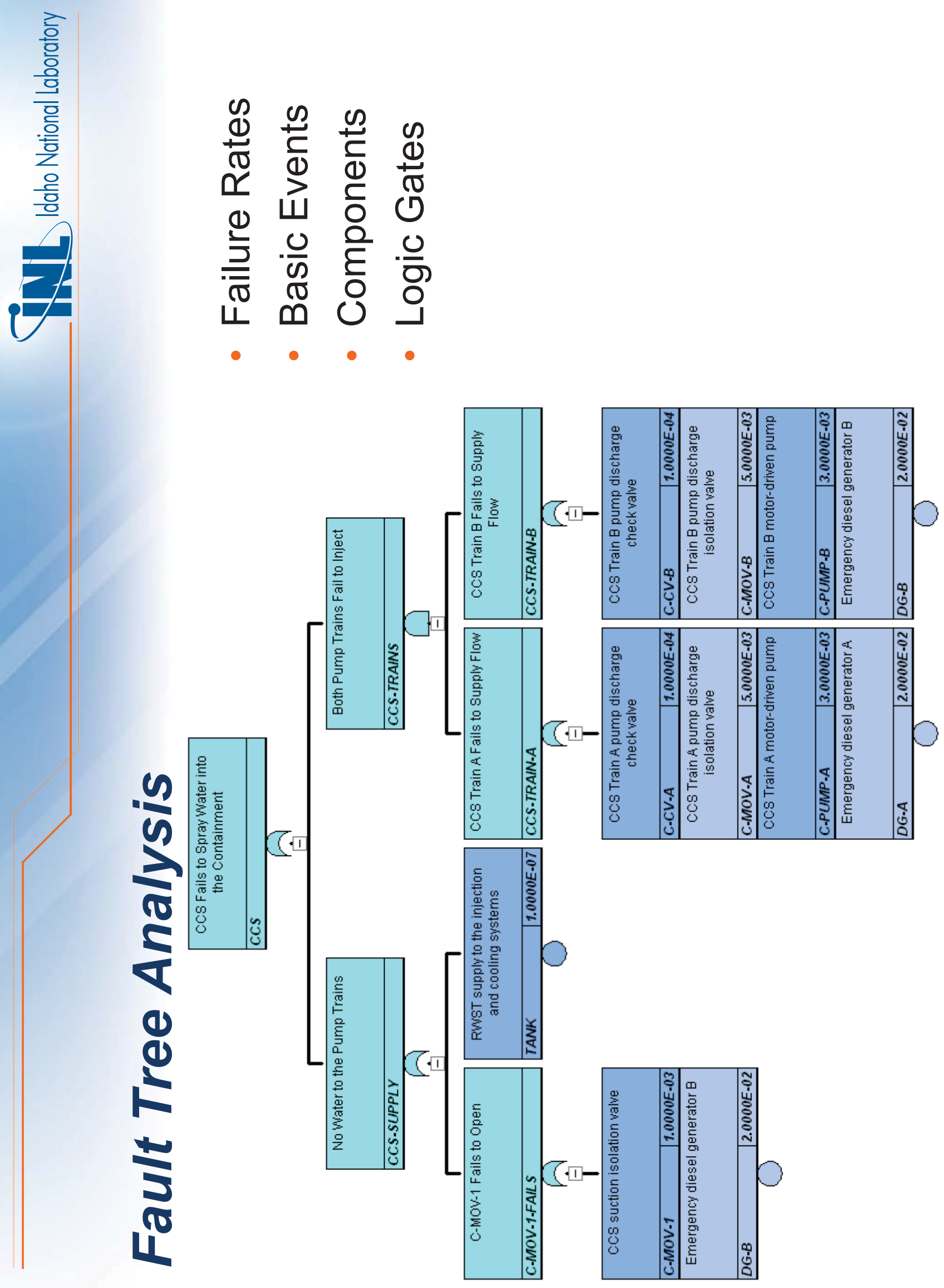


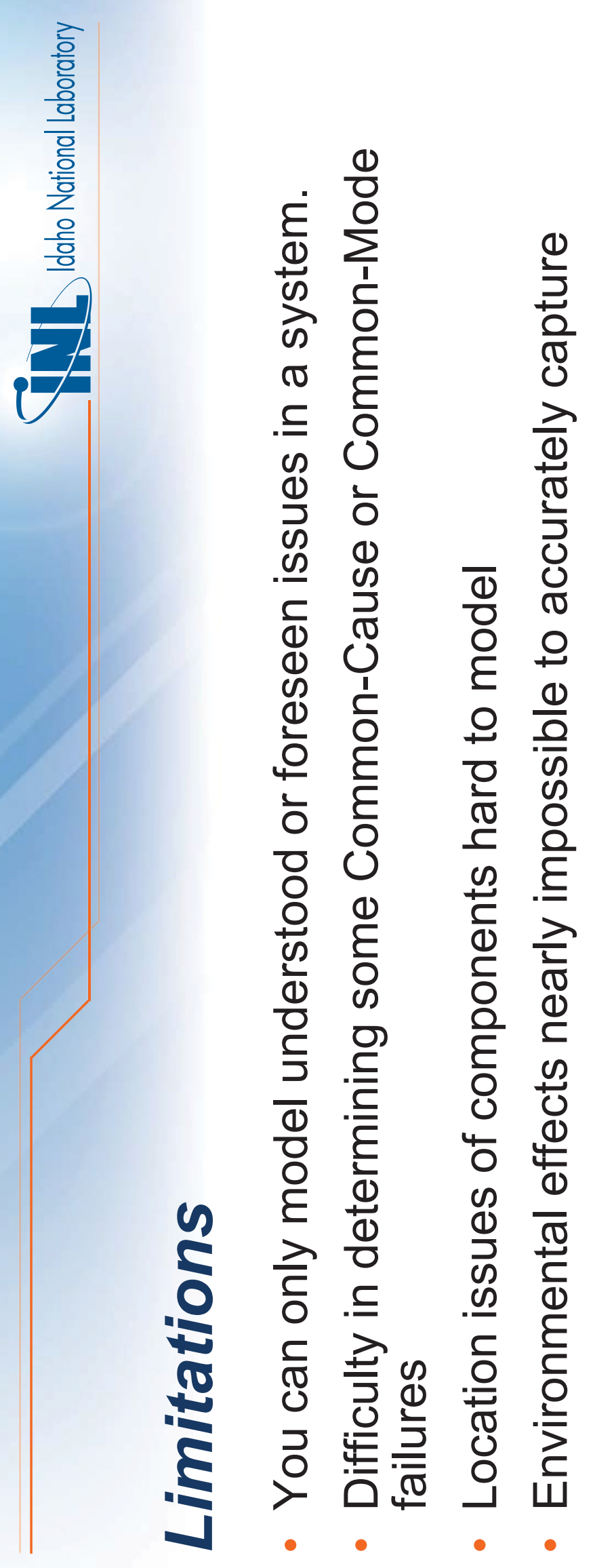




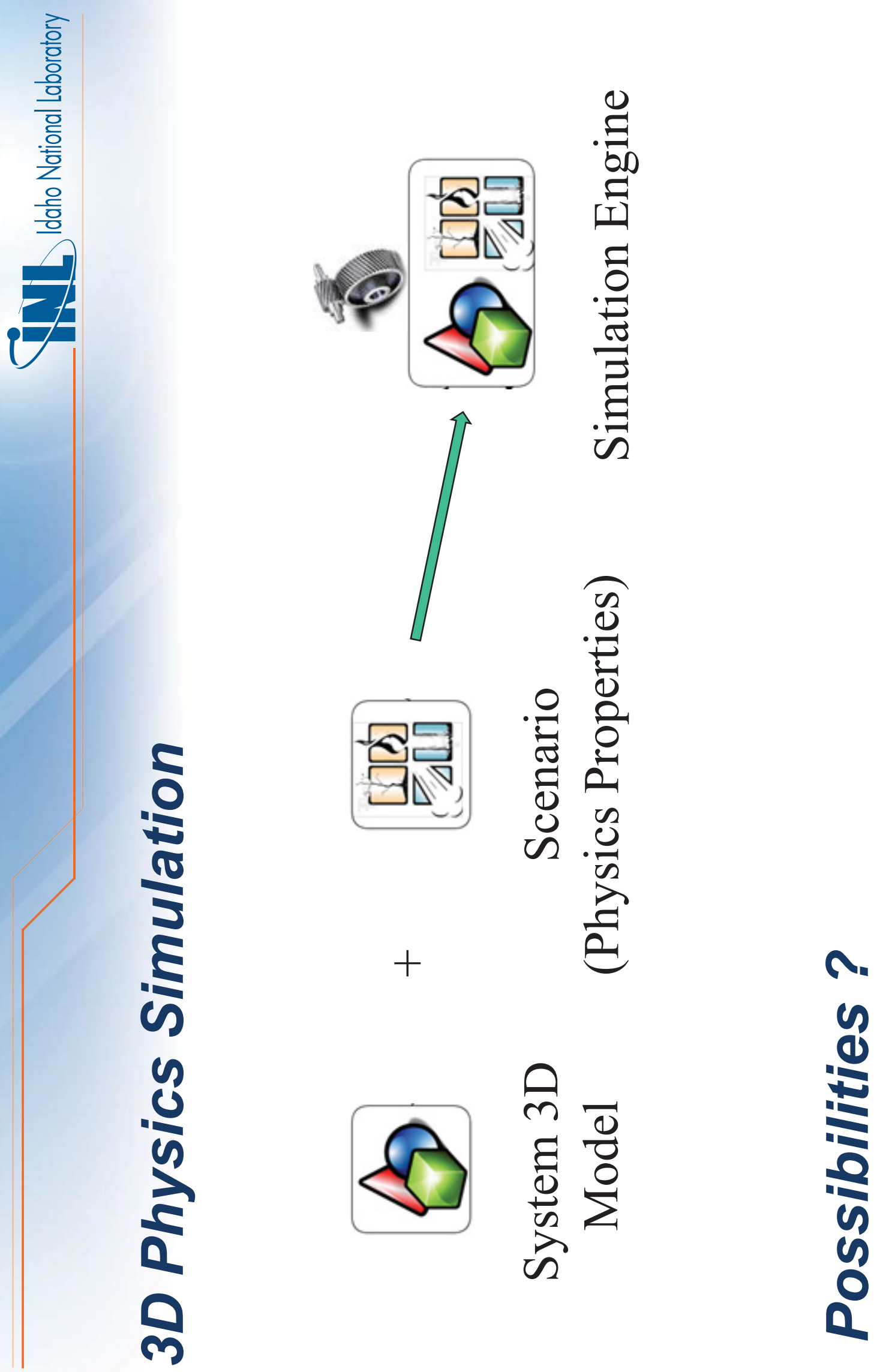




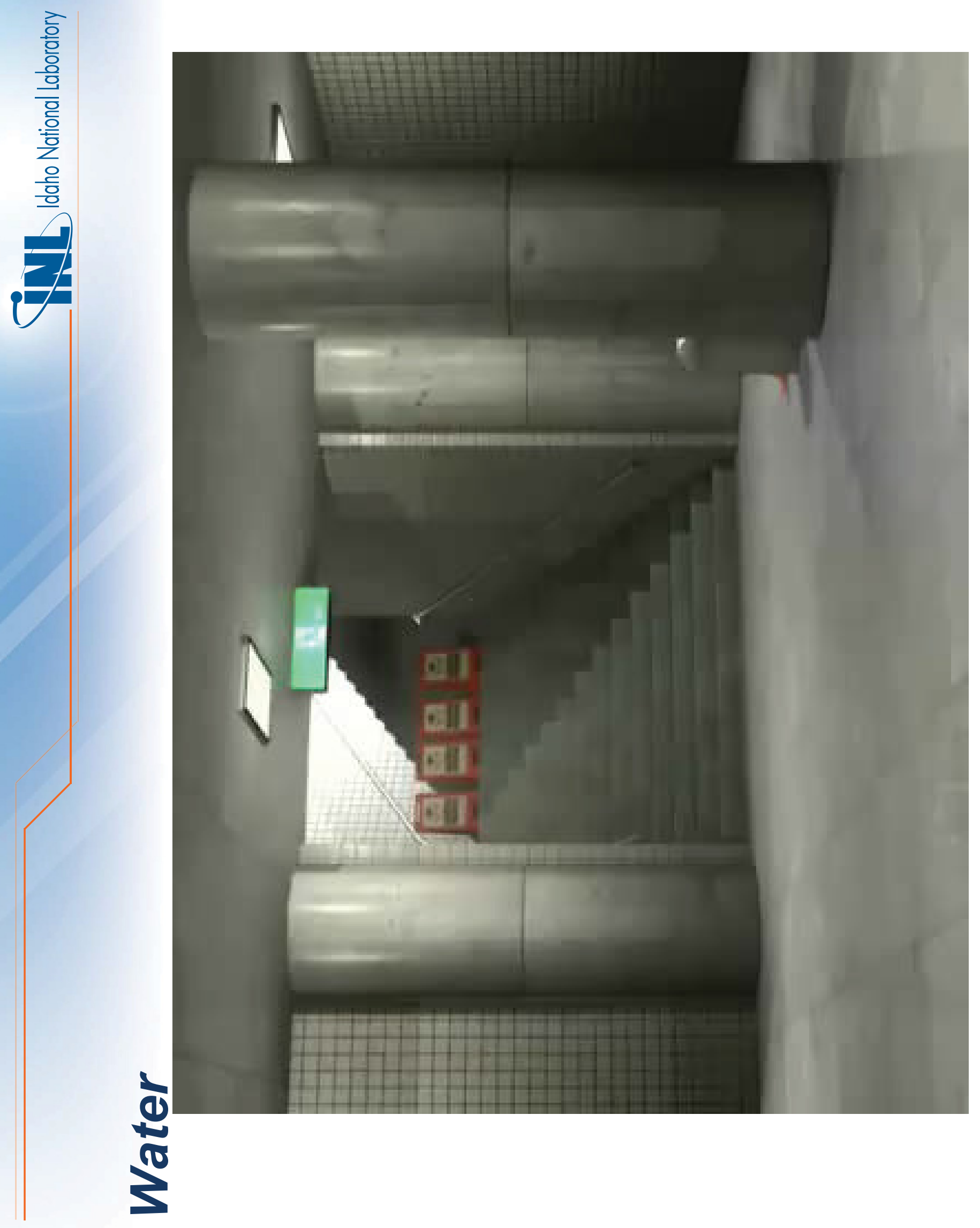




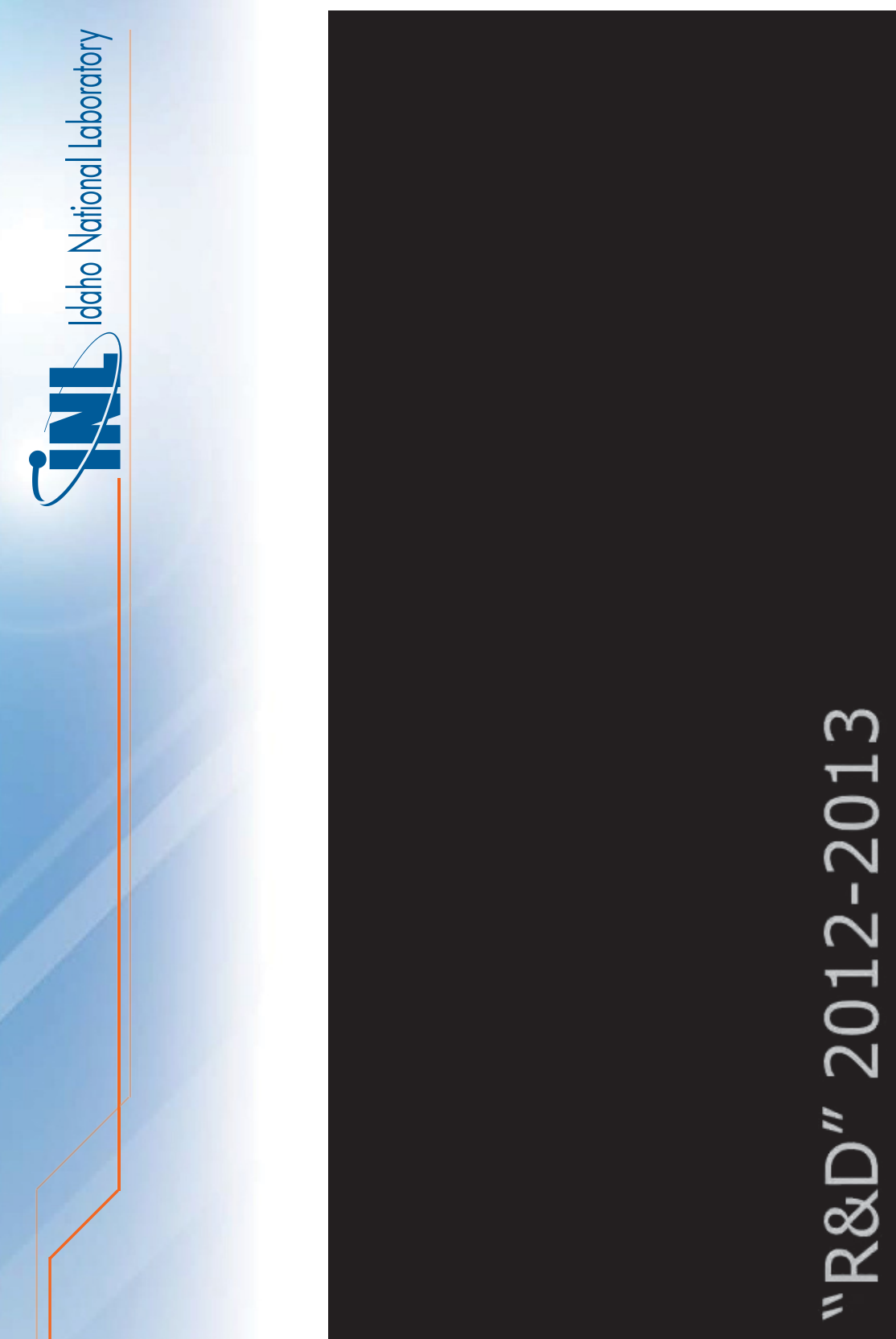

(a)

10 

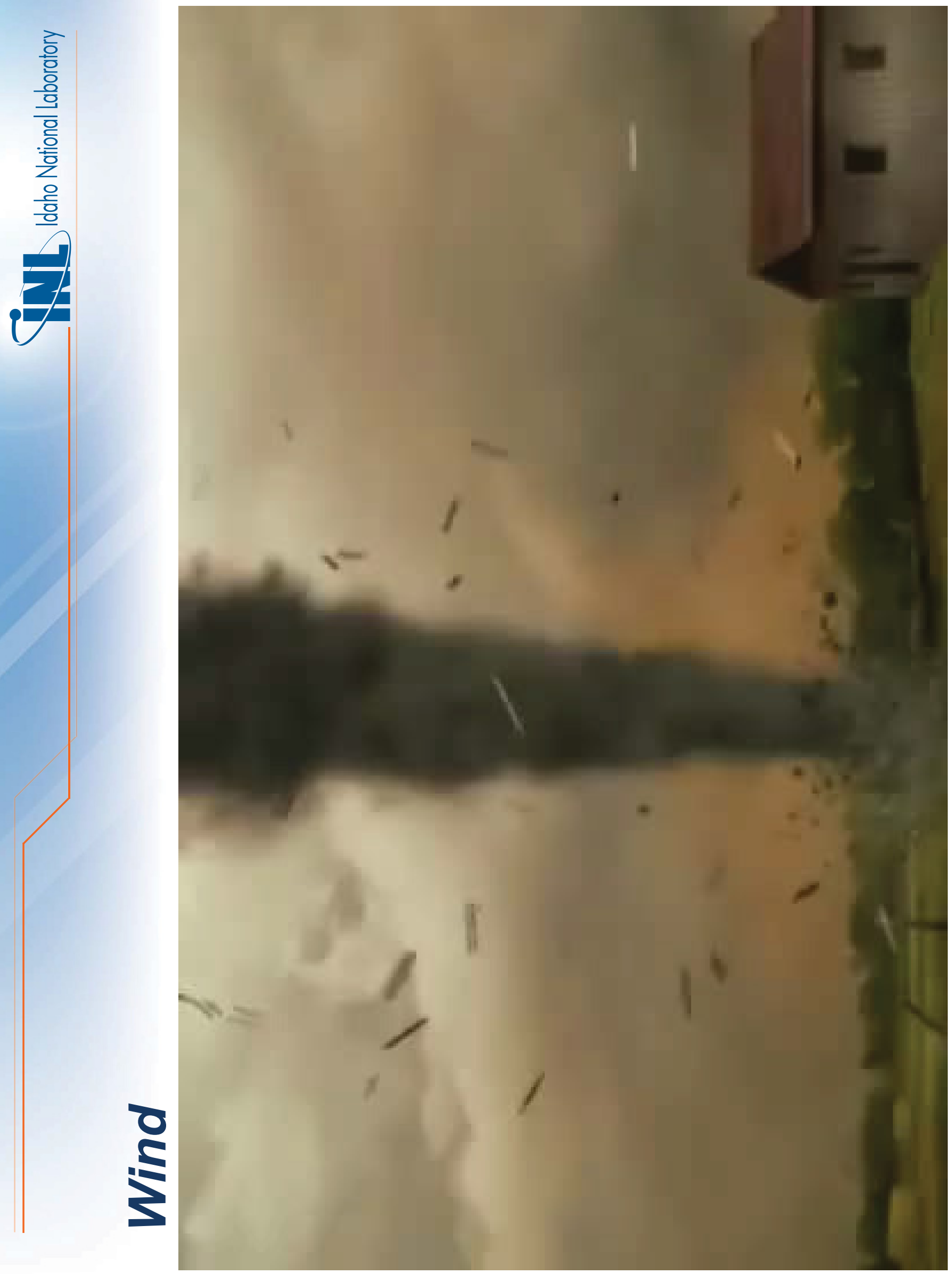


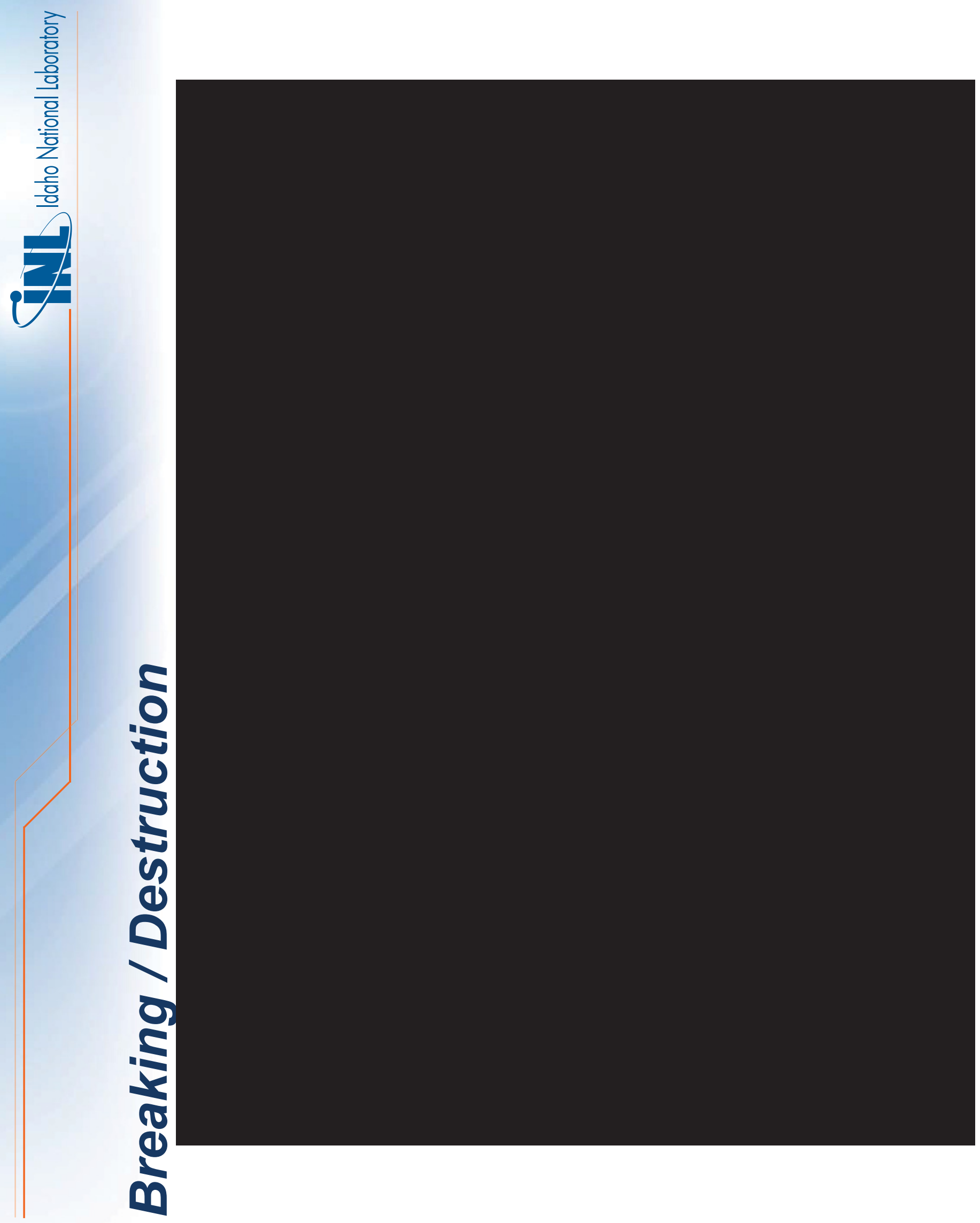




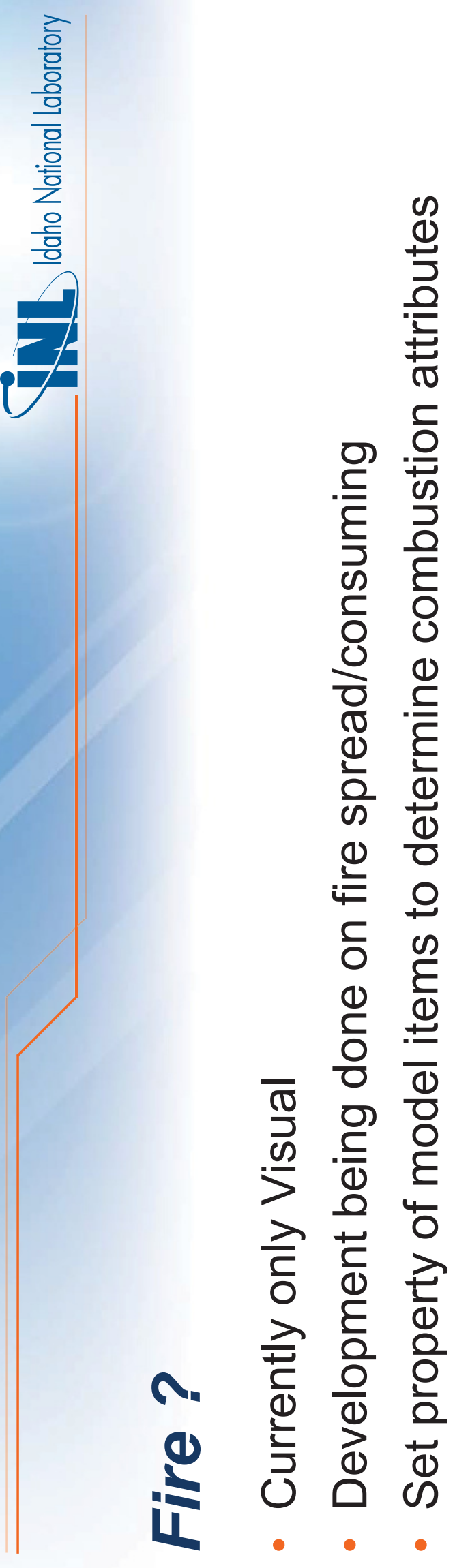




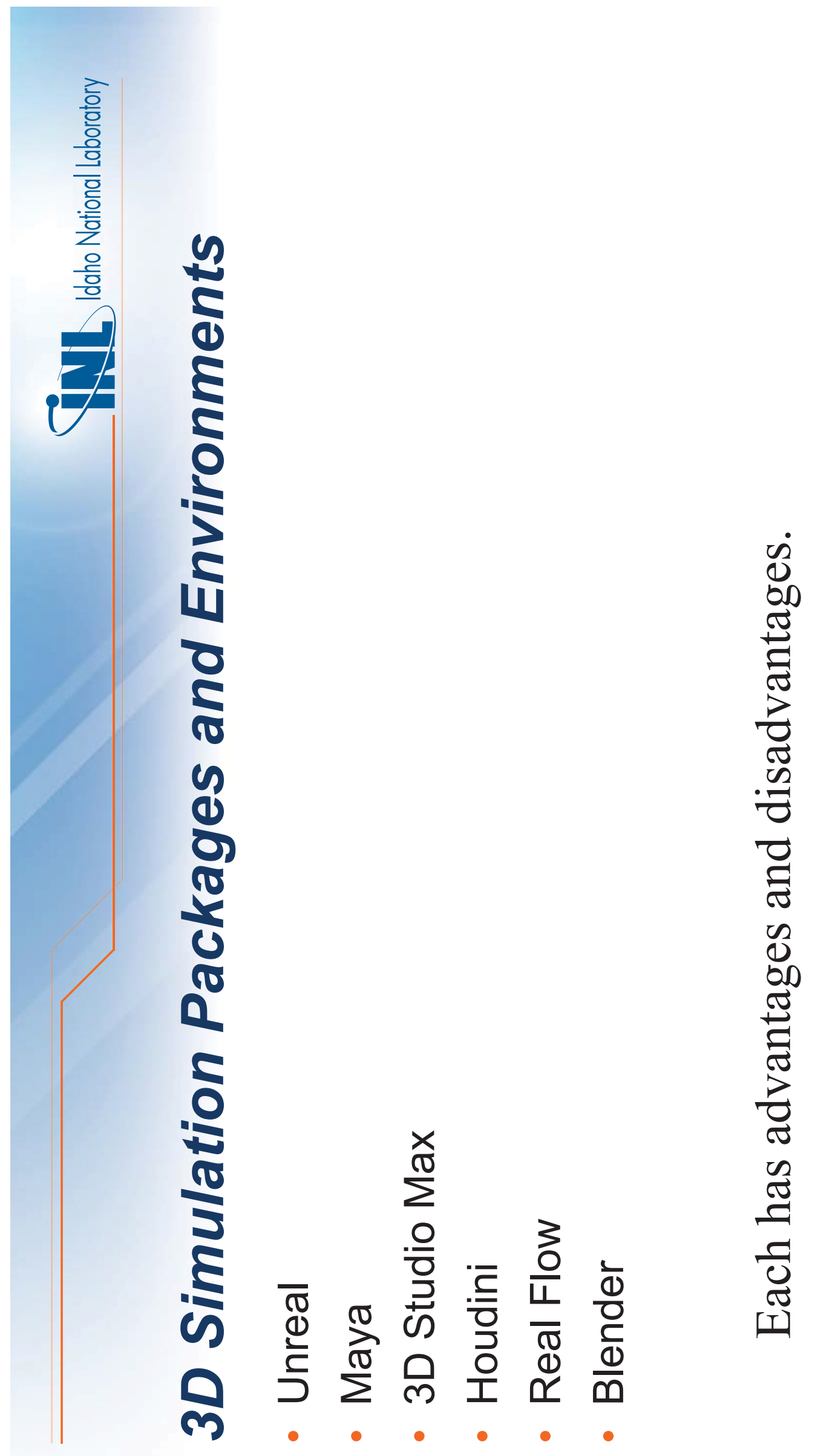




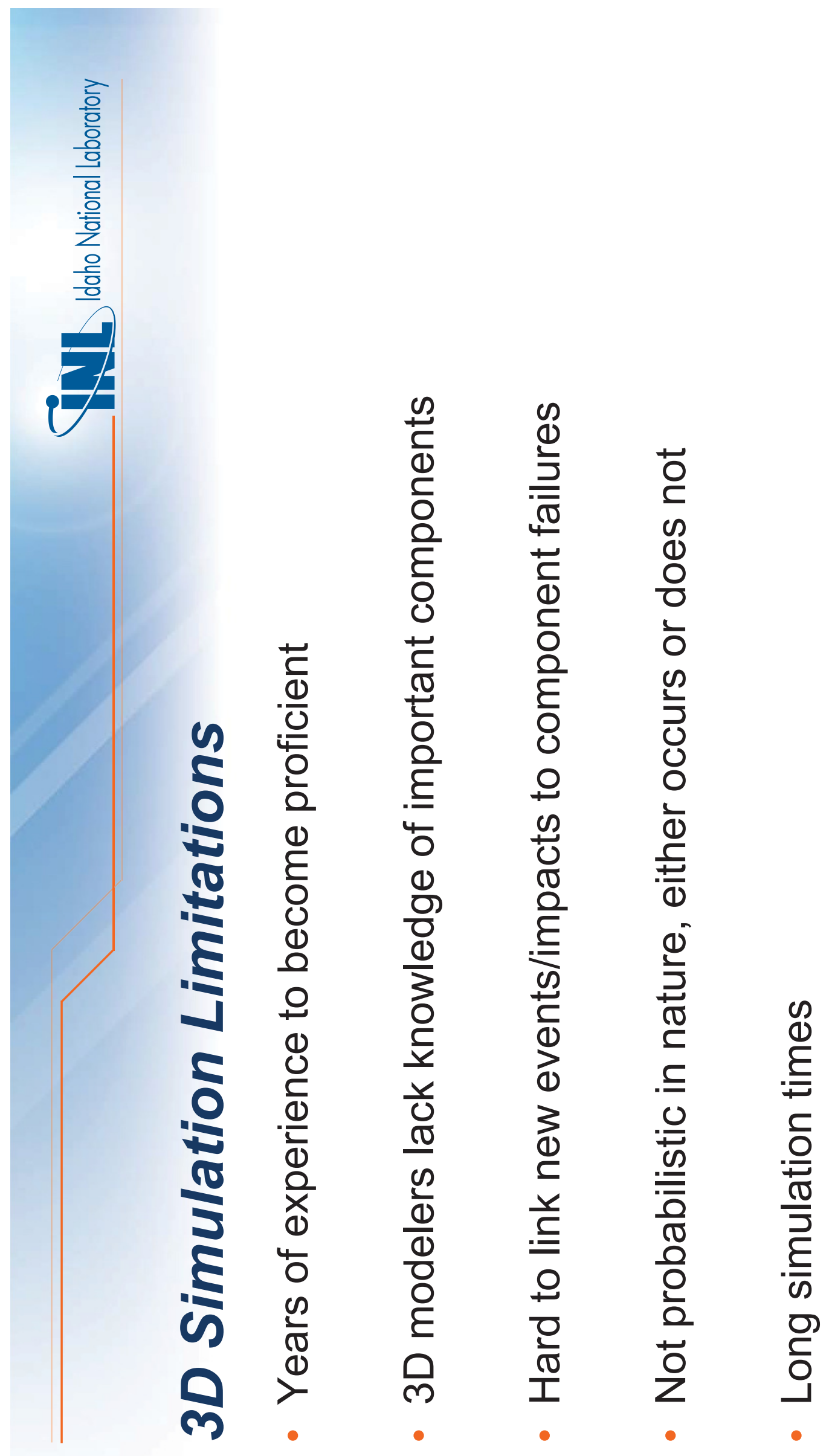




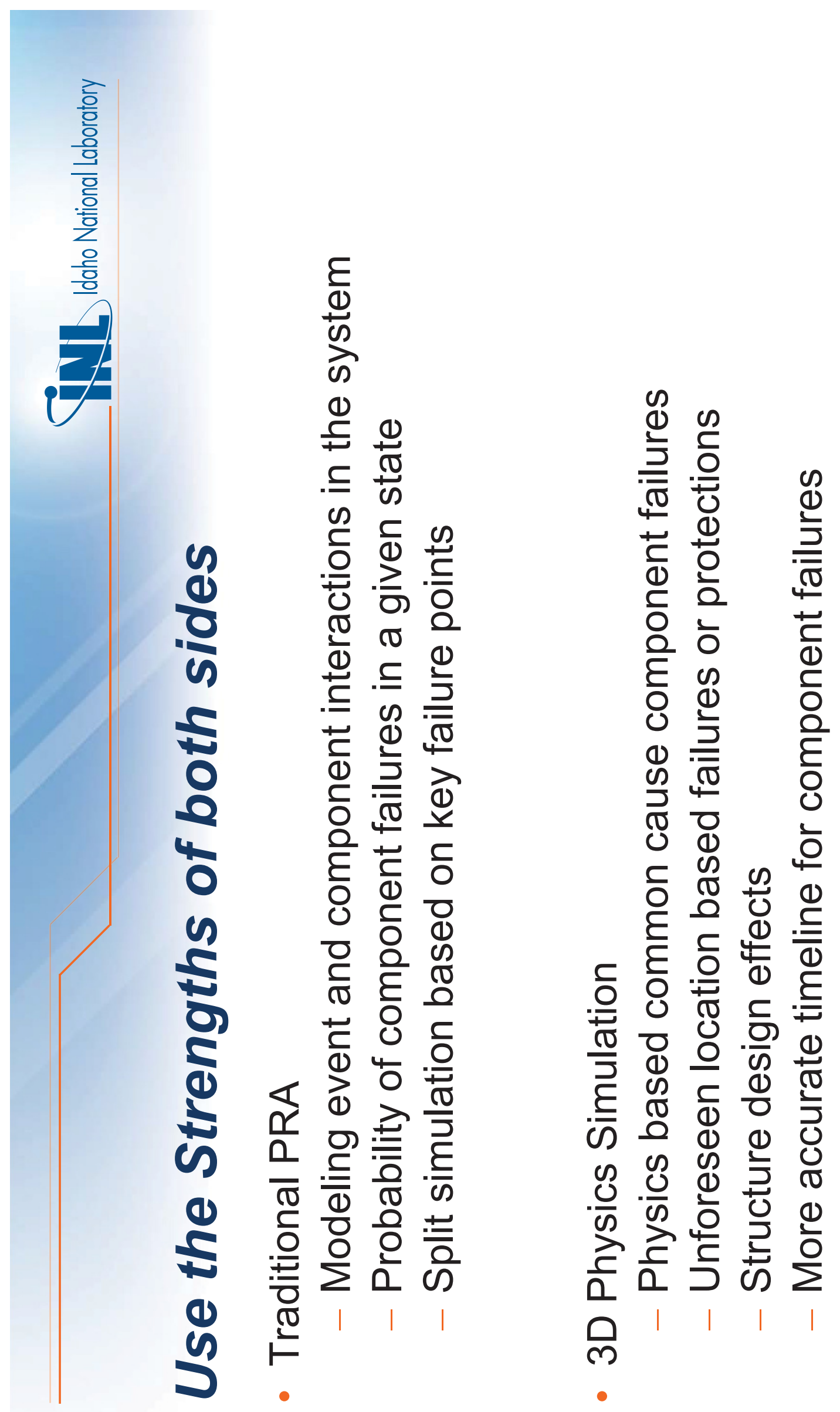




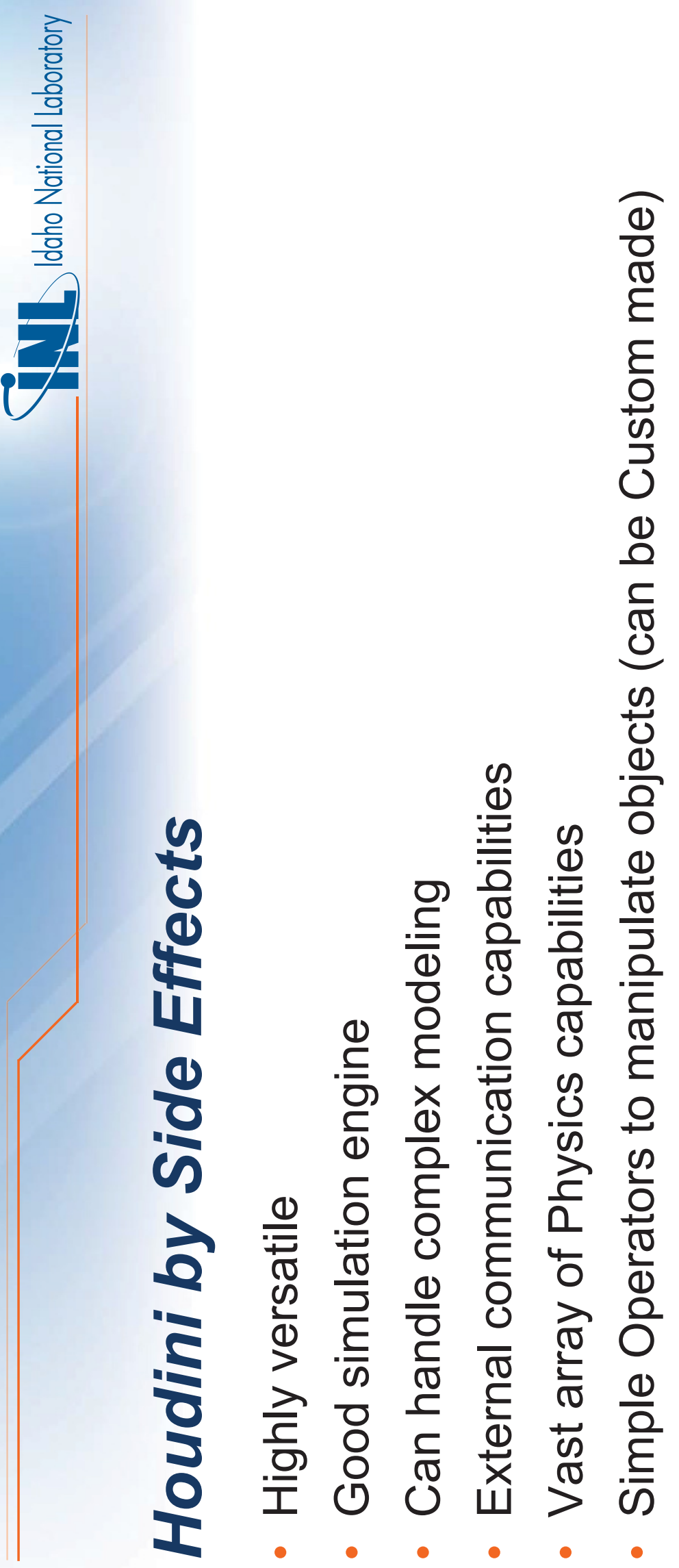




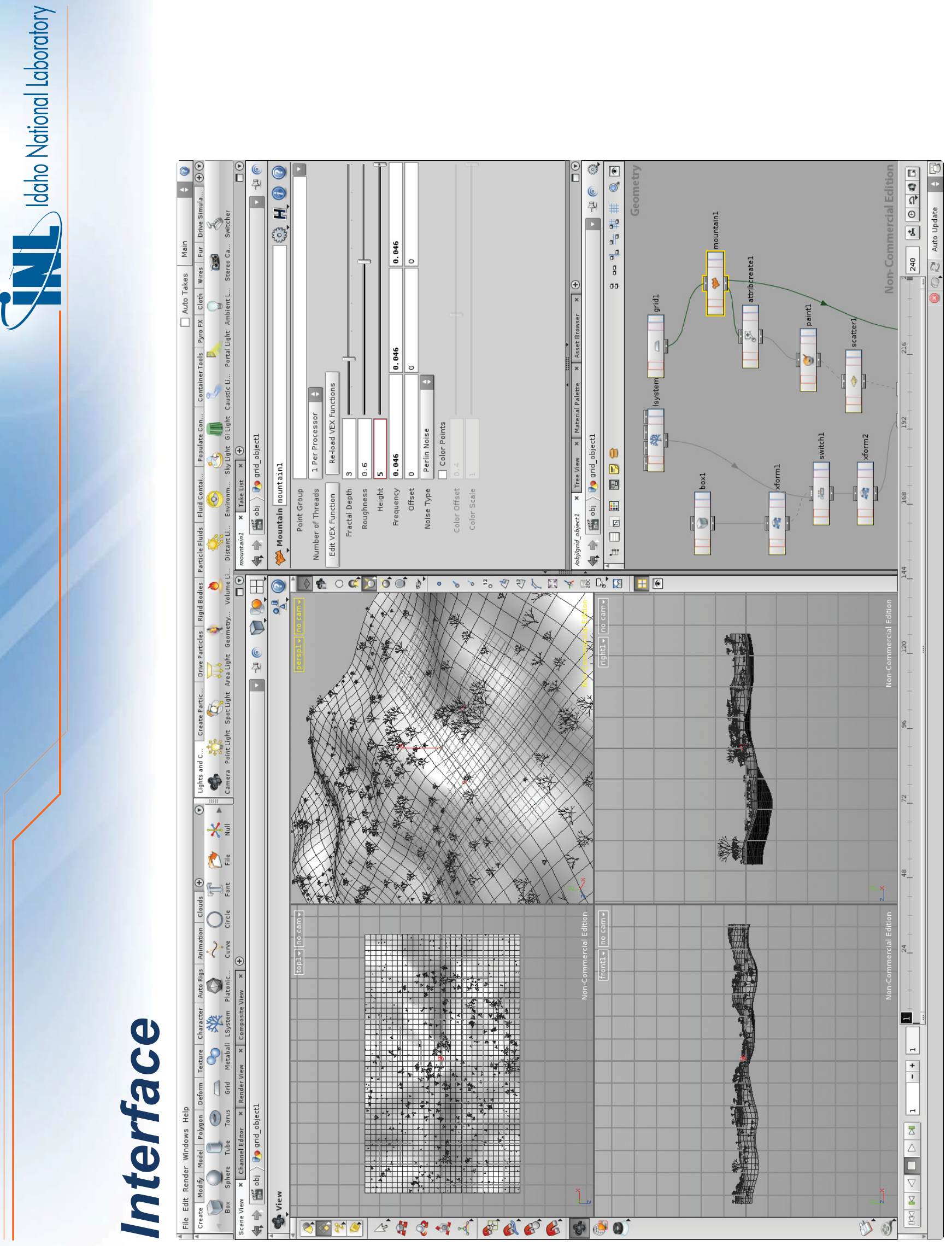




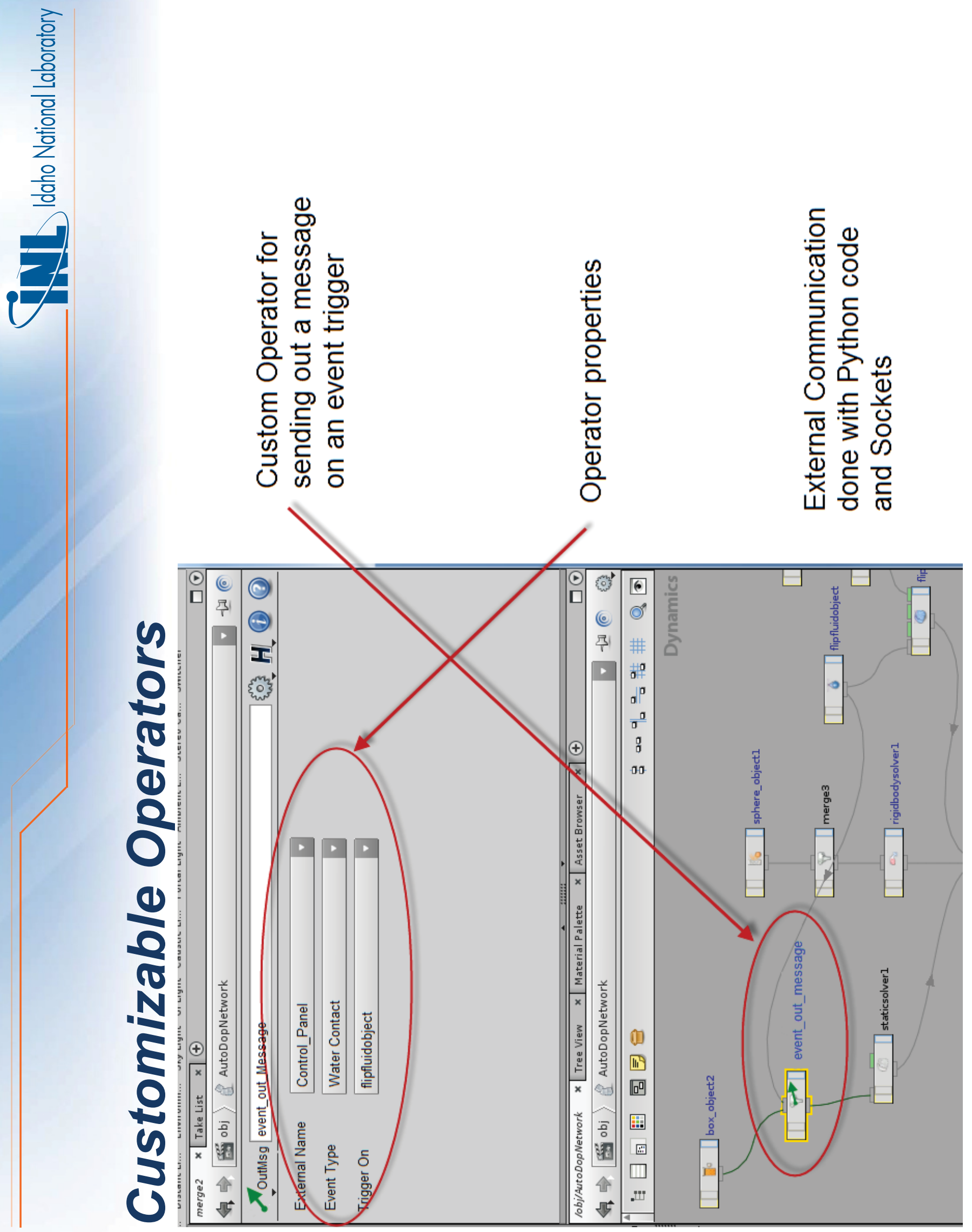



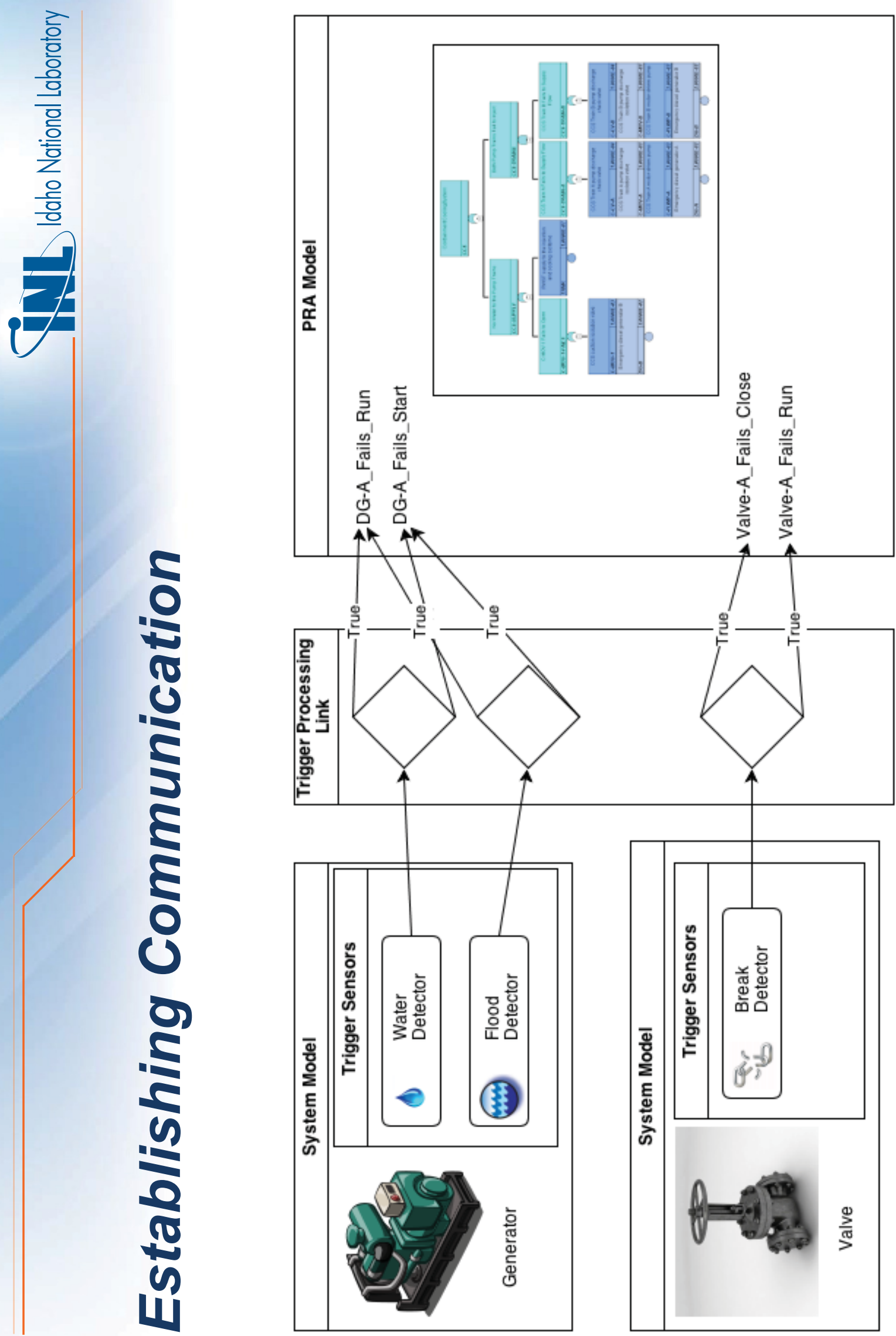


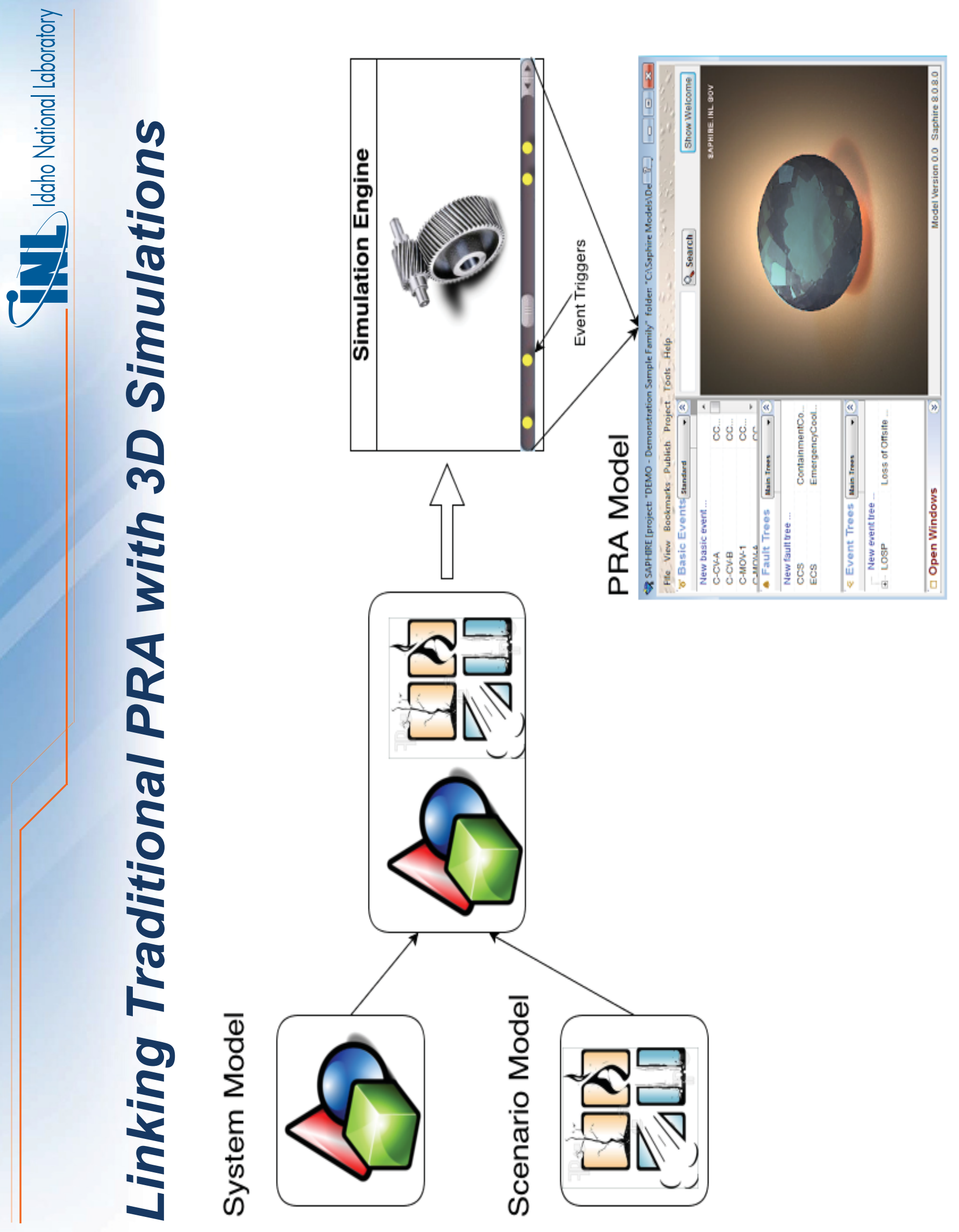




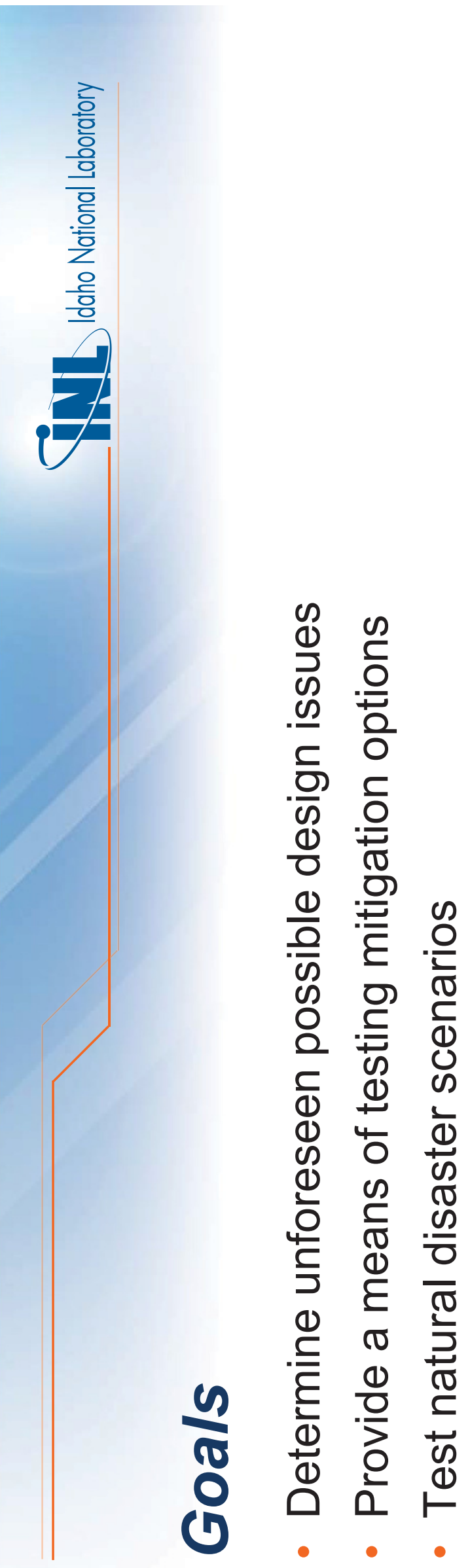




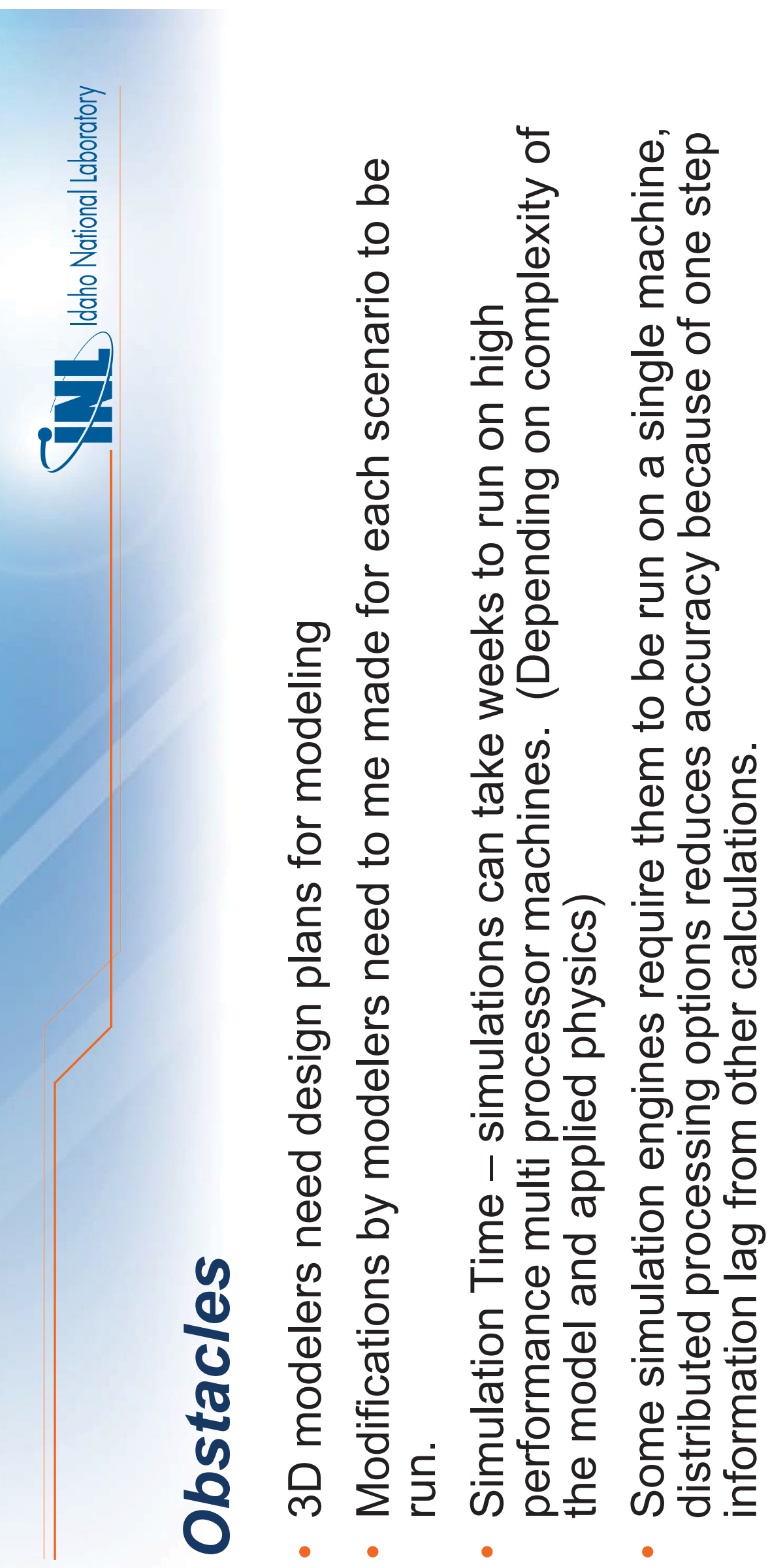



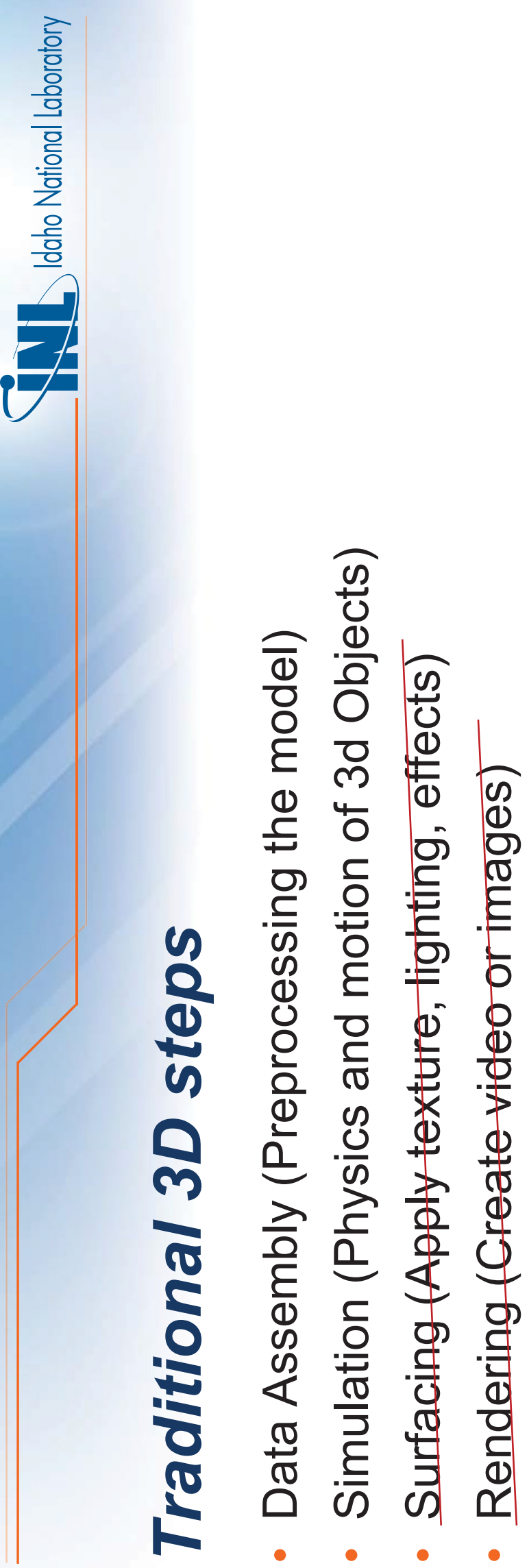


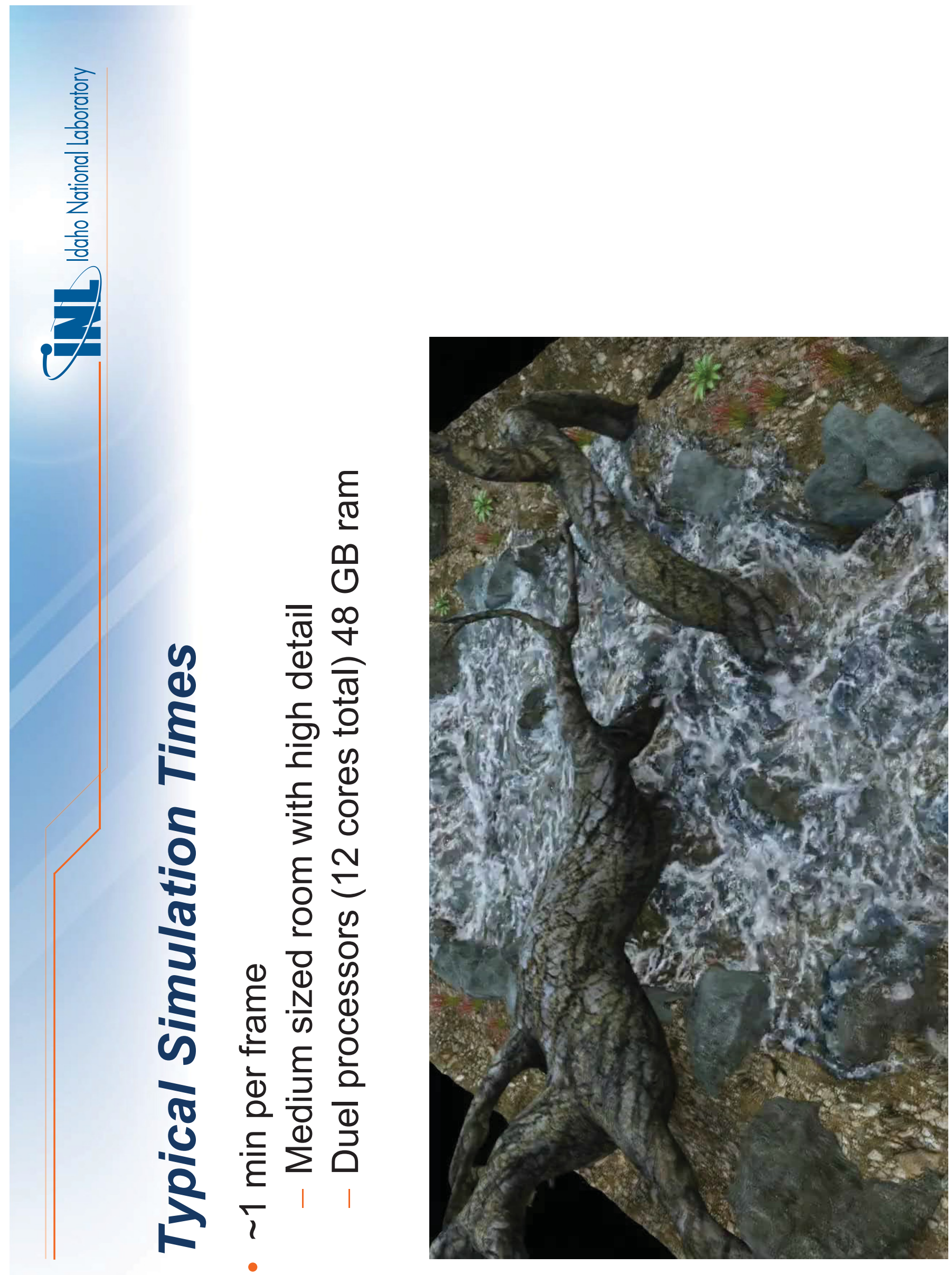




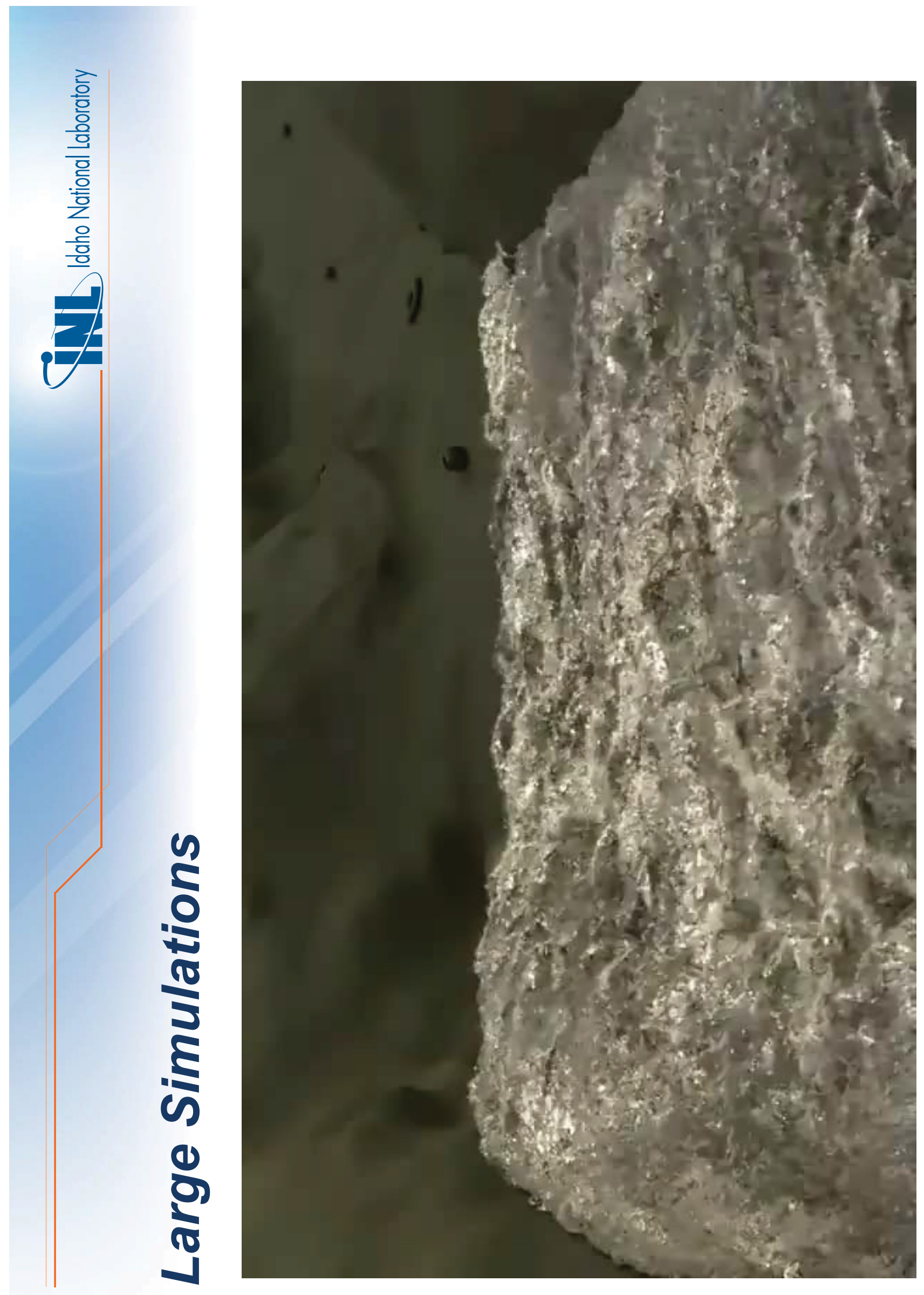



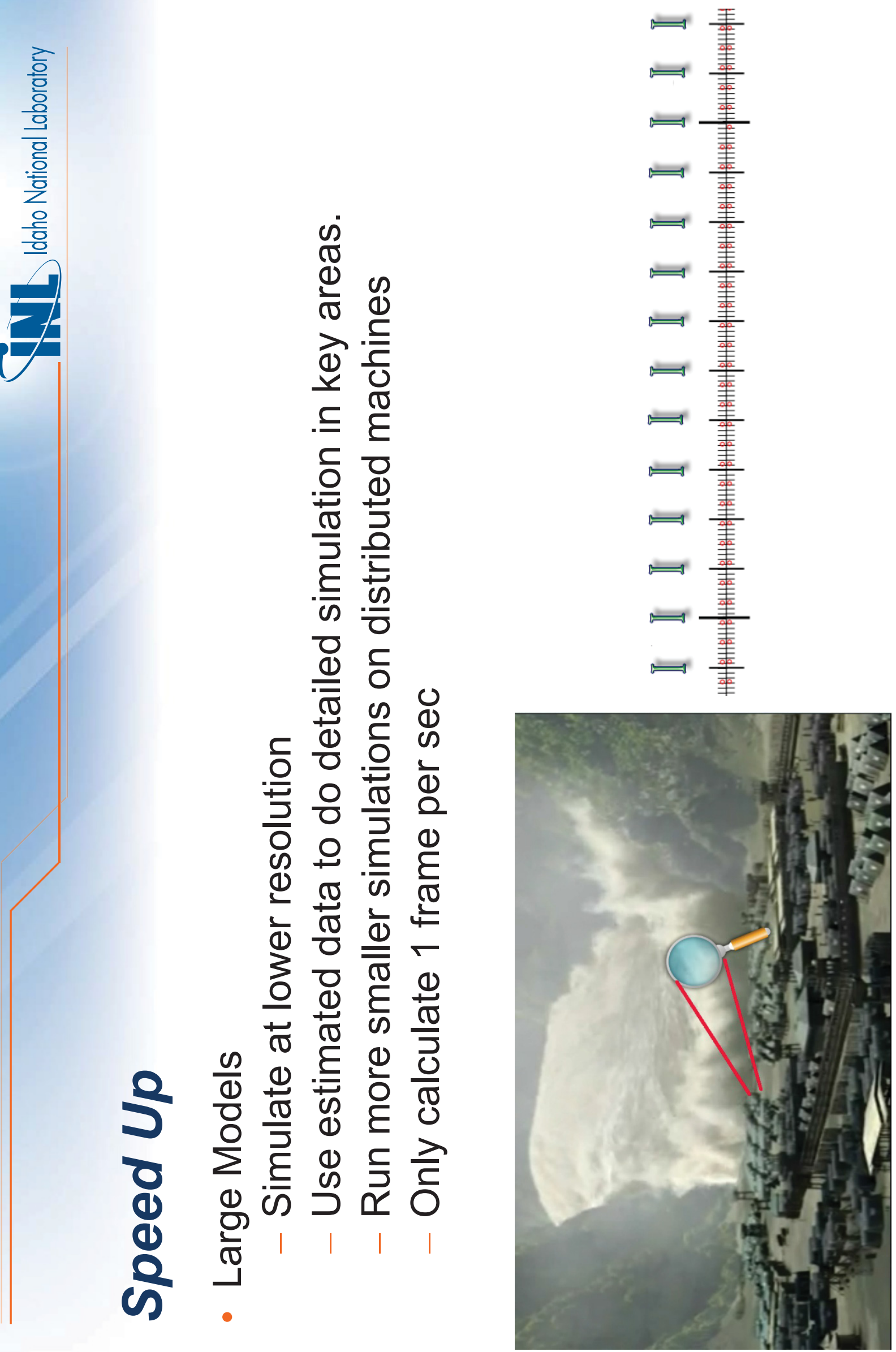


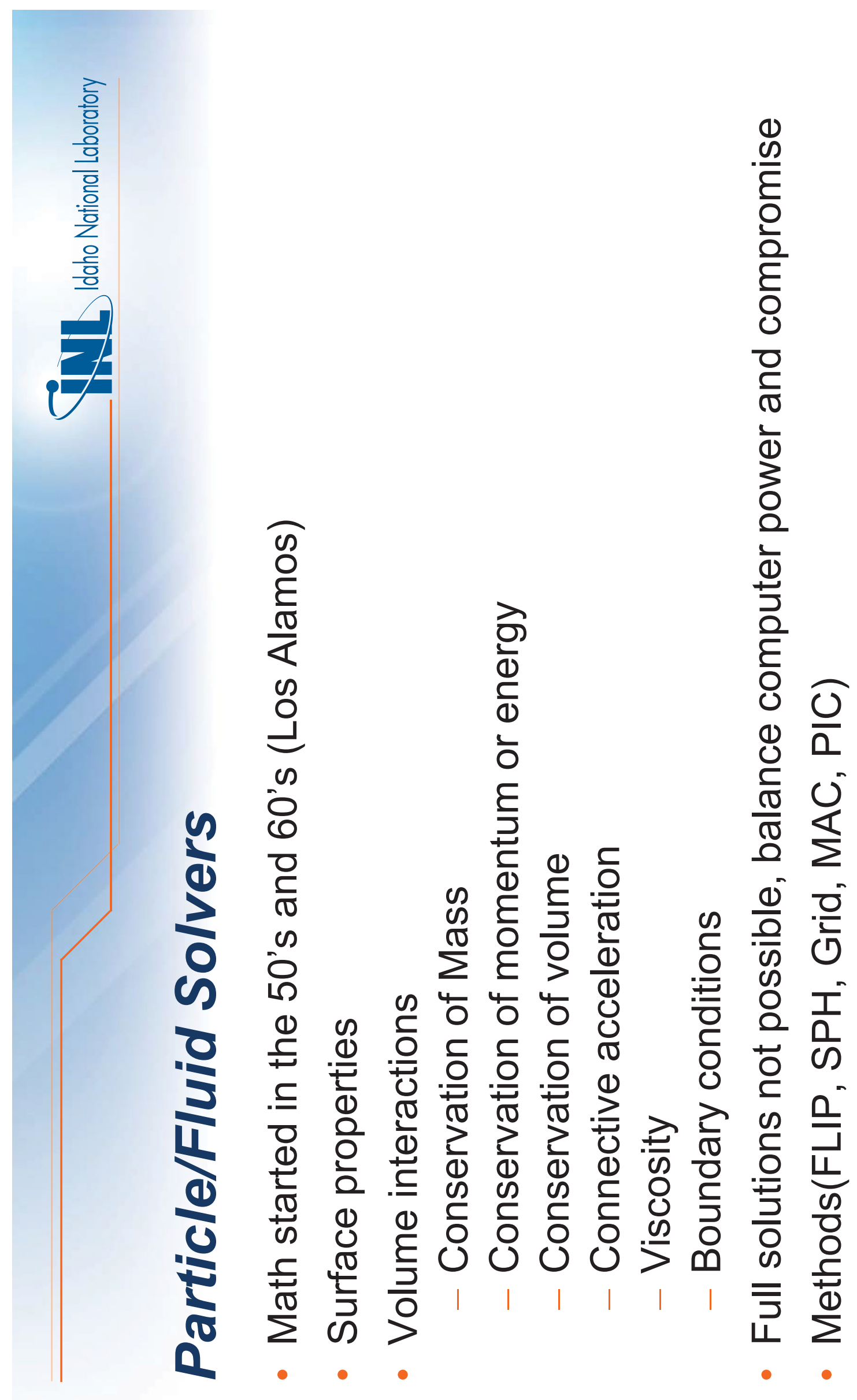




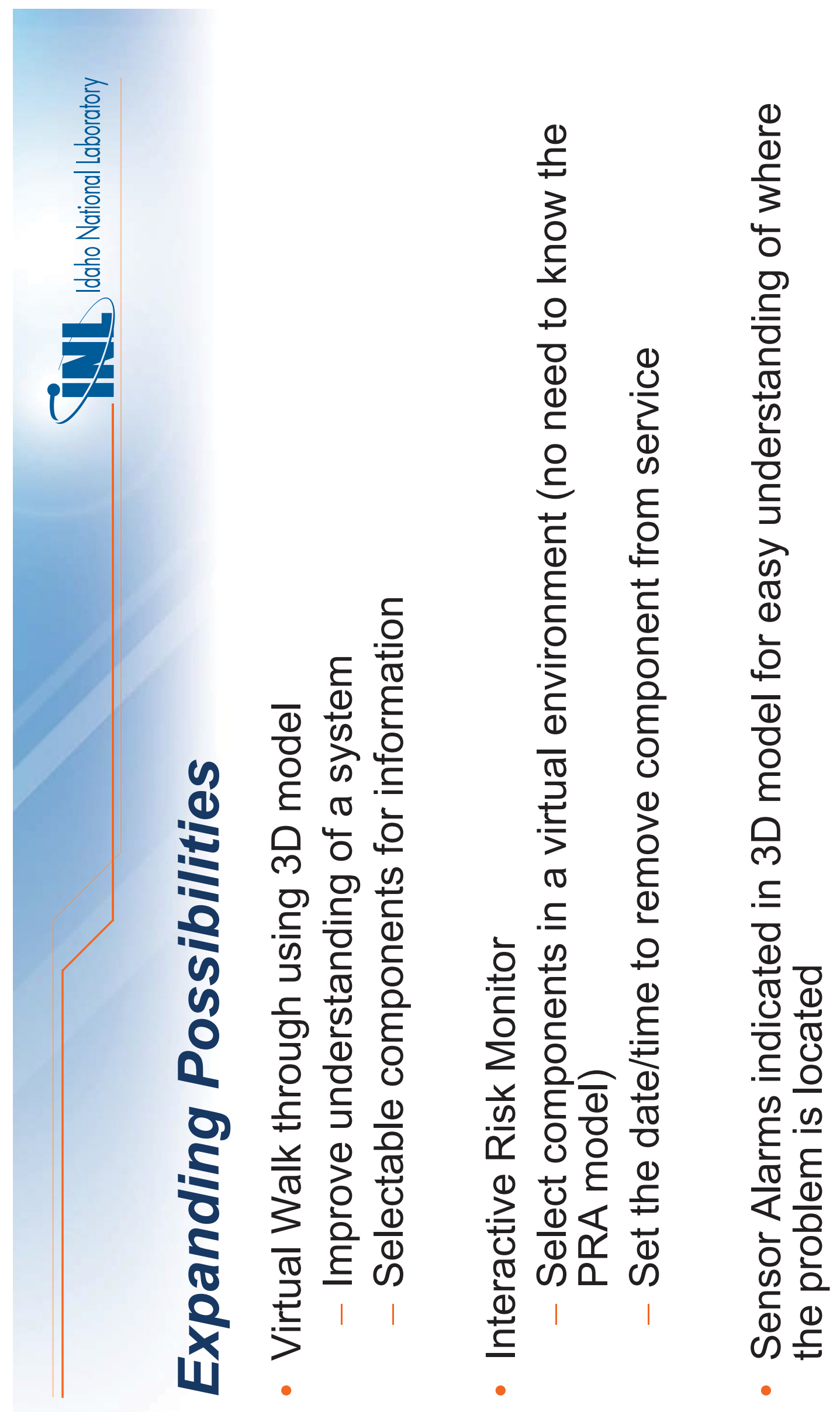




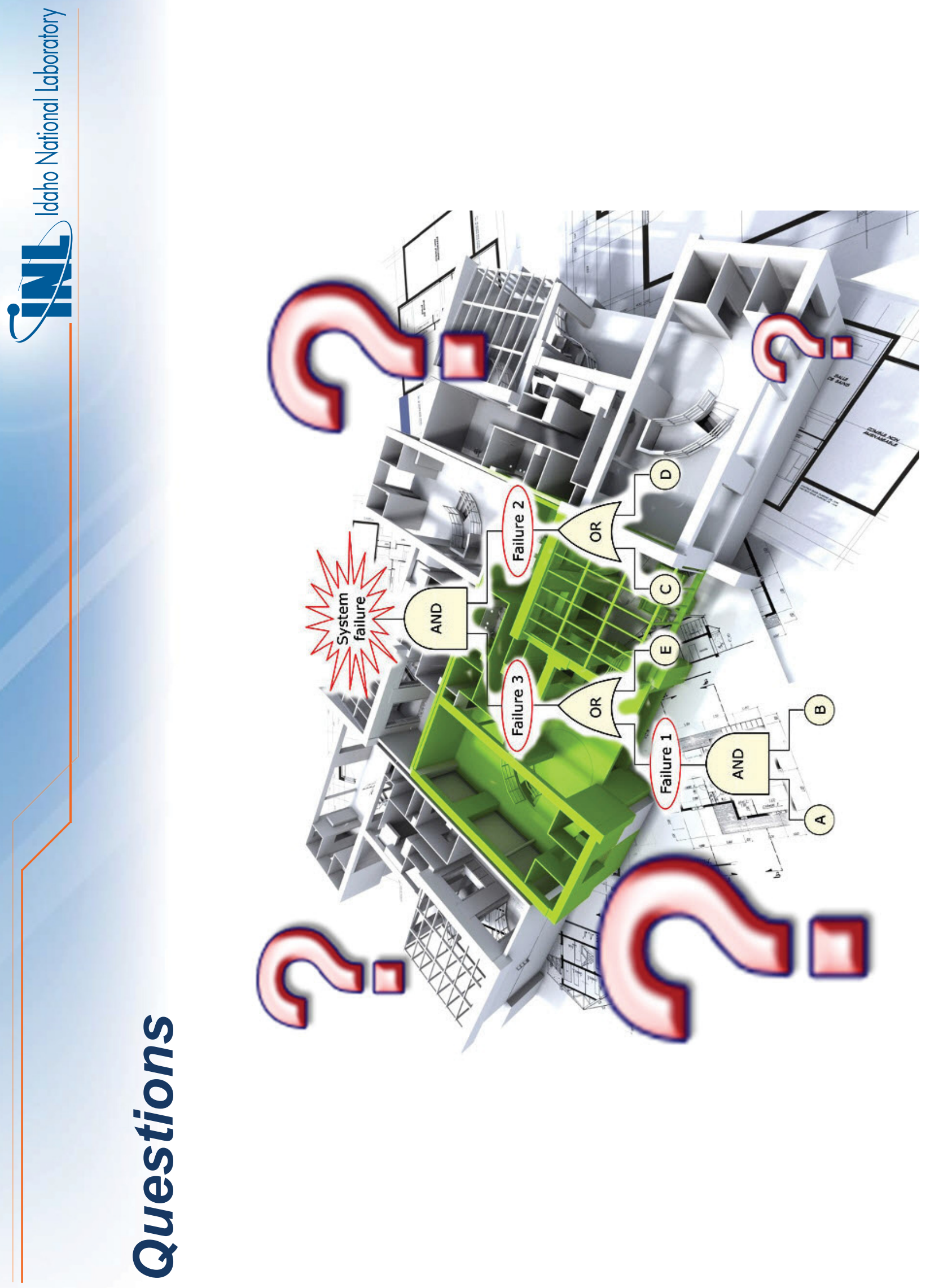

